

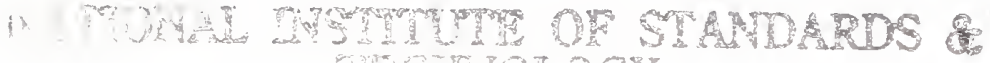

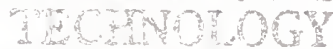

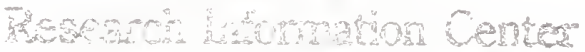

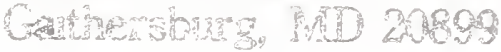


NIST Special Publication 777, 1992 Edition

\section{NIST Serial Holdings 1992}

Susan A. Sanders

Editor

Office of Information Services

National Institute of Standards and Technology

Gaithersburg, MD 20899

April 1992

Supersedes NIST Special Publication 777, 1991 Edition

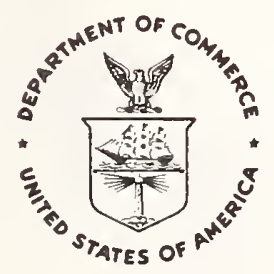

U.S. Department of Commerce

Barbara Hackman Franklin, Secretary

Technology Administration

Robert M. White, Under Secretary for Technology

National Institute of Standards and Technology

John W. Lyons, Director 


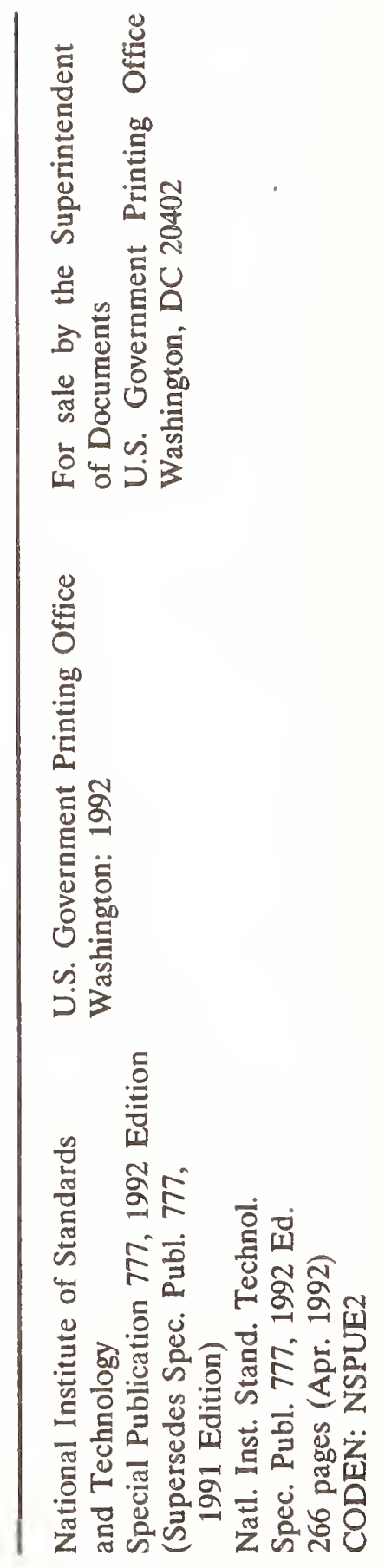




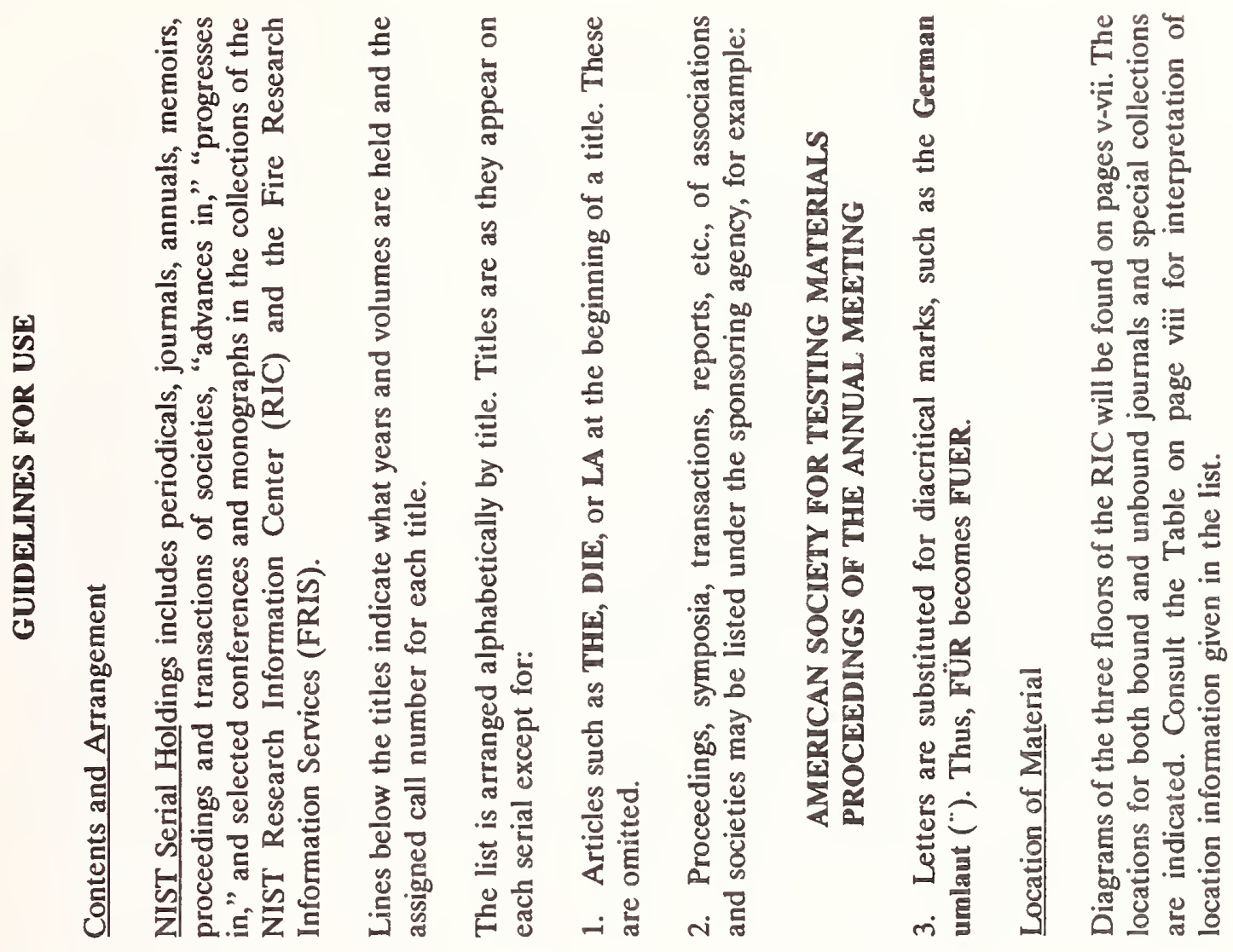

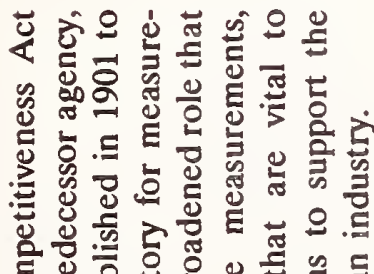

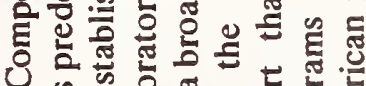

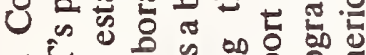

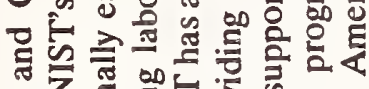

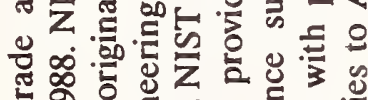

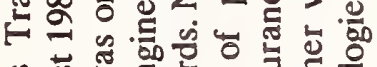

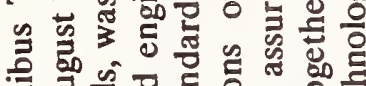

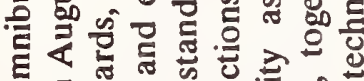

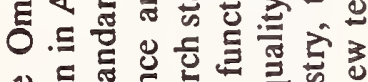

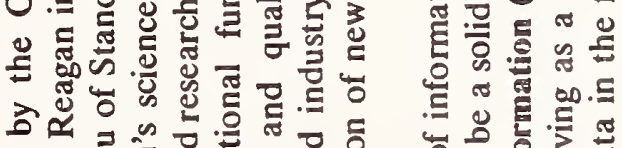

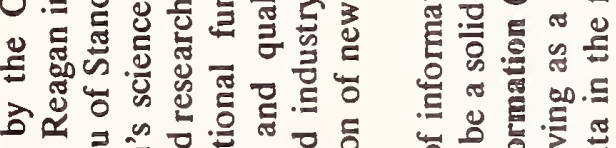
ว

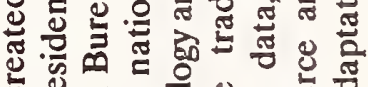

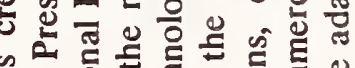

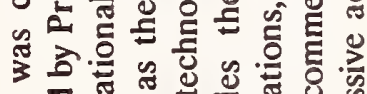

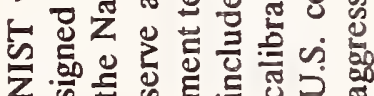

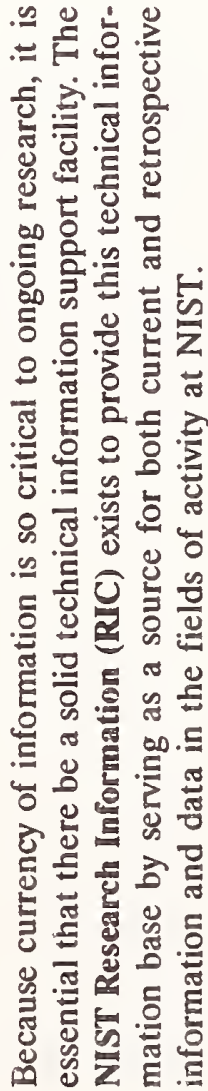

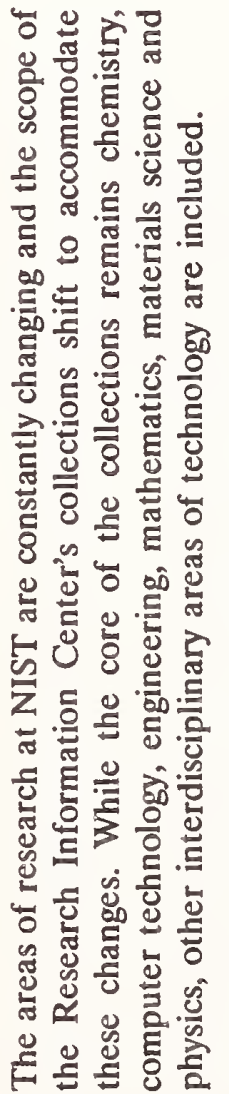

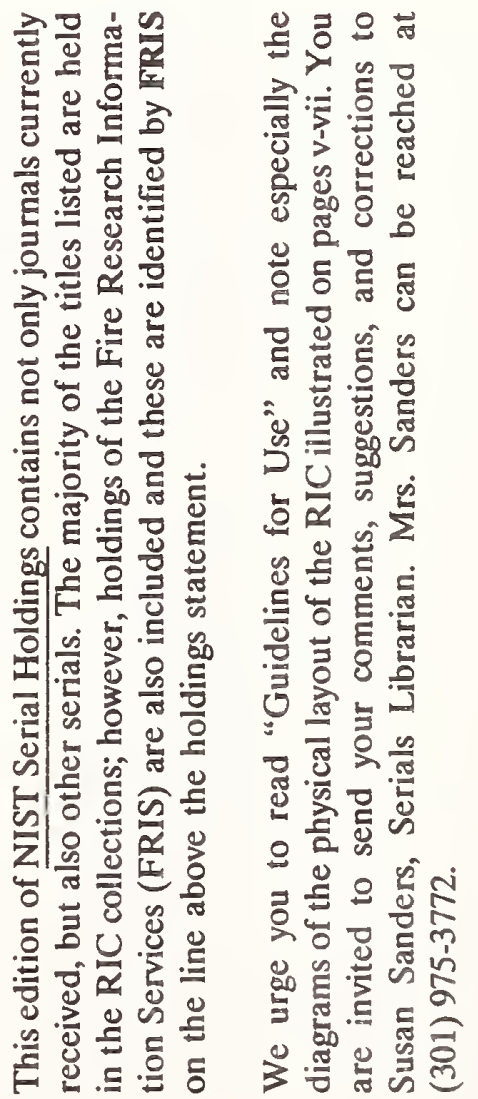




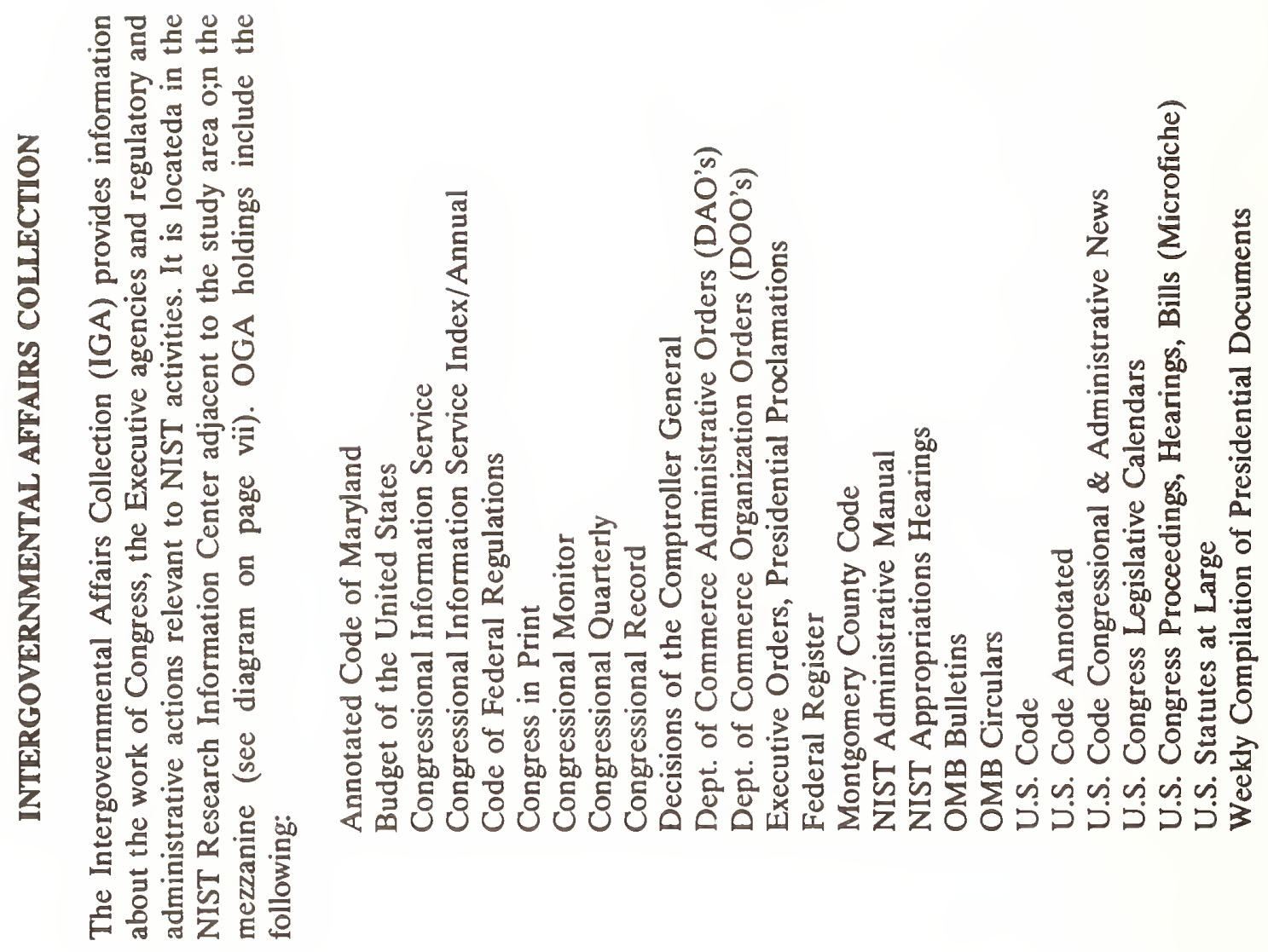

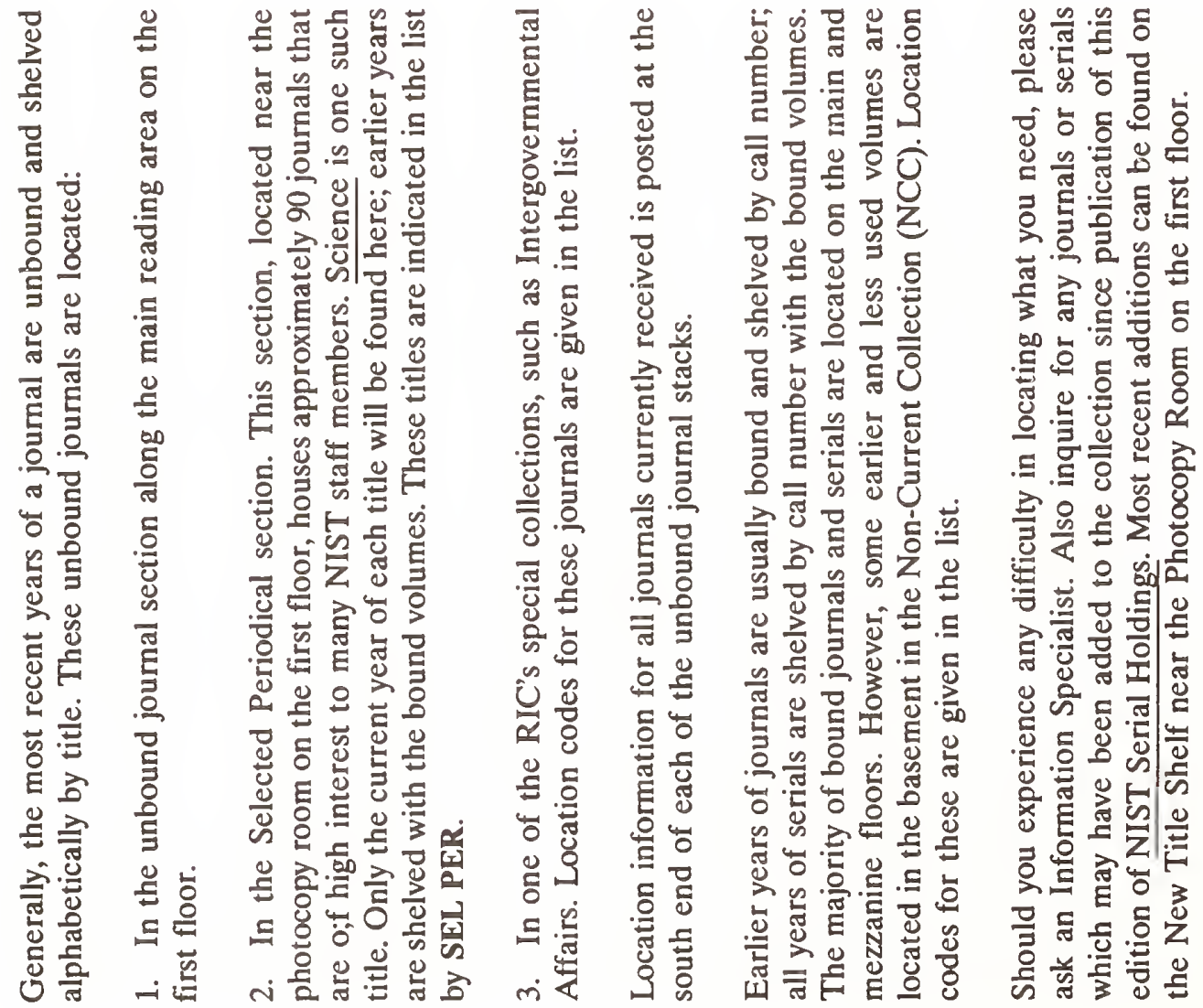




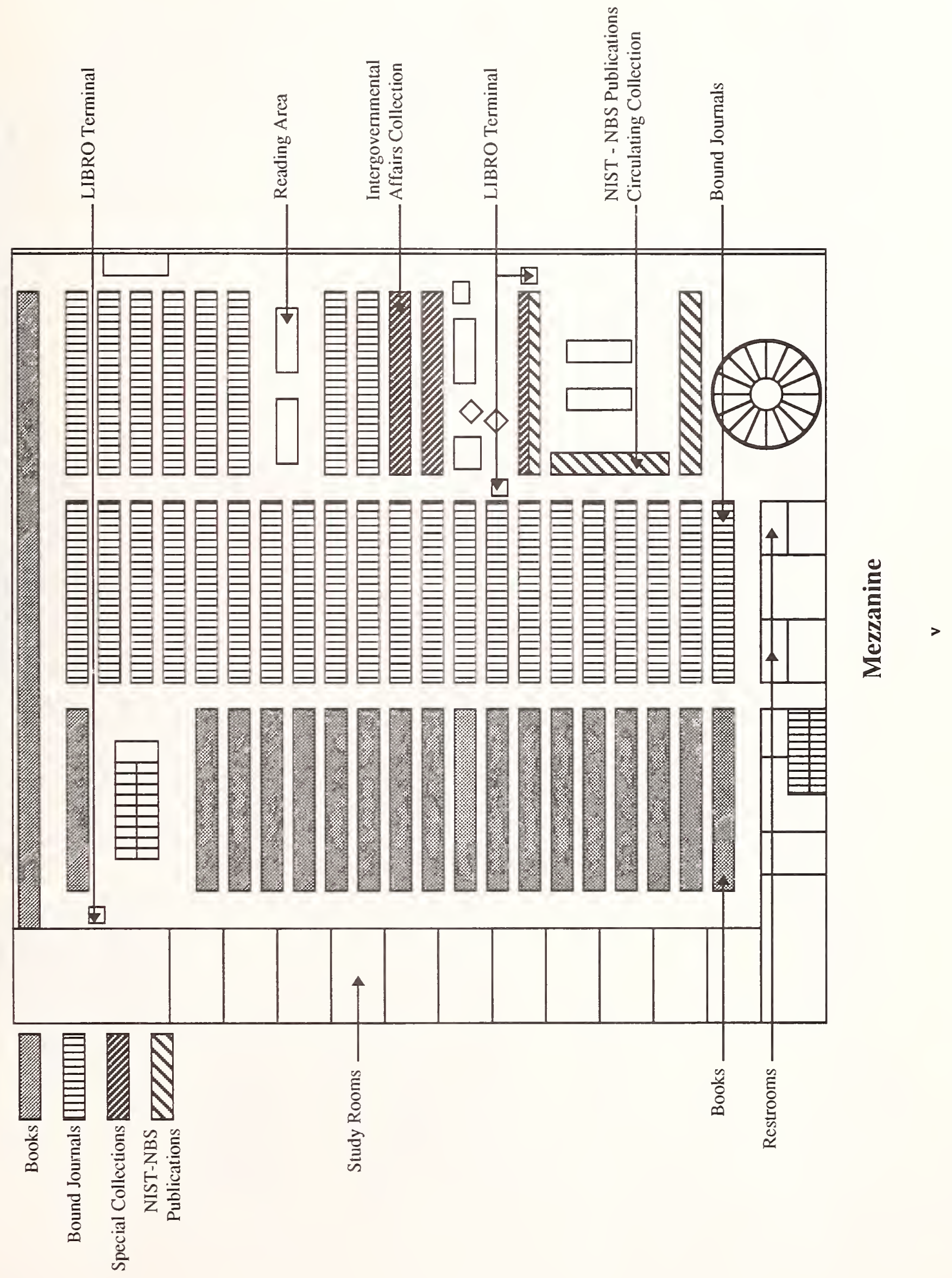




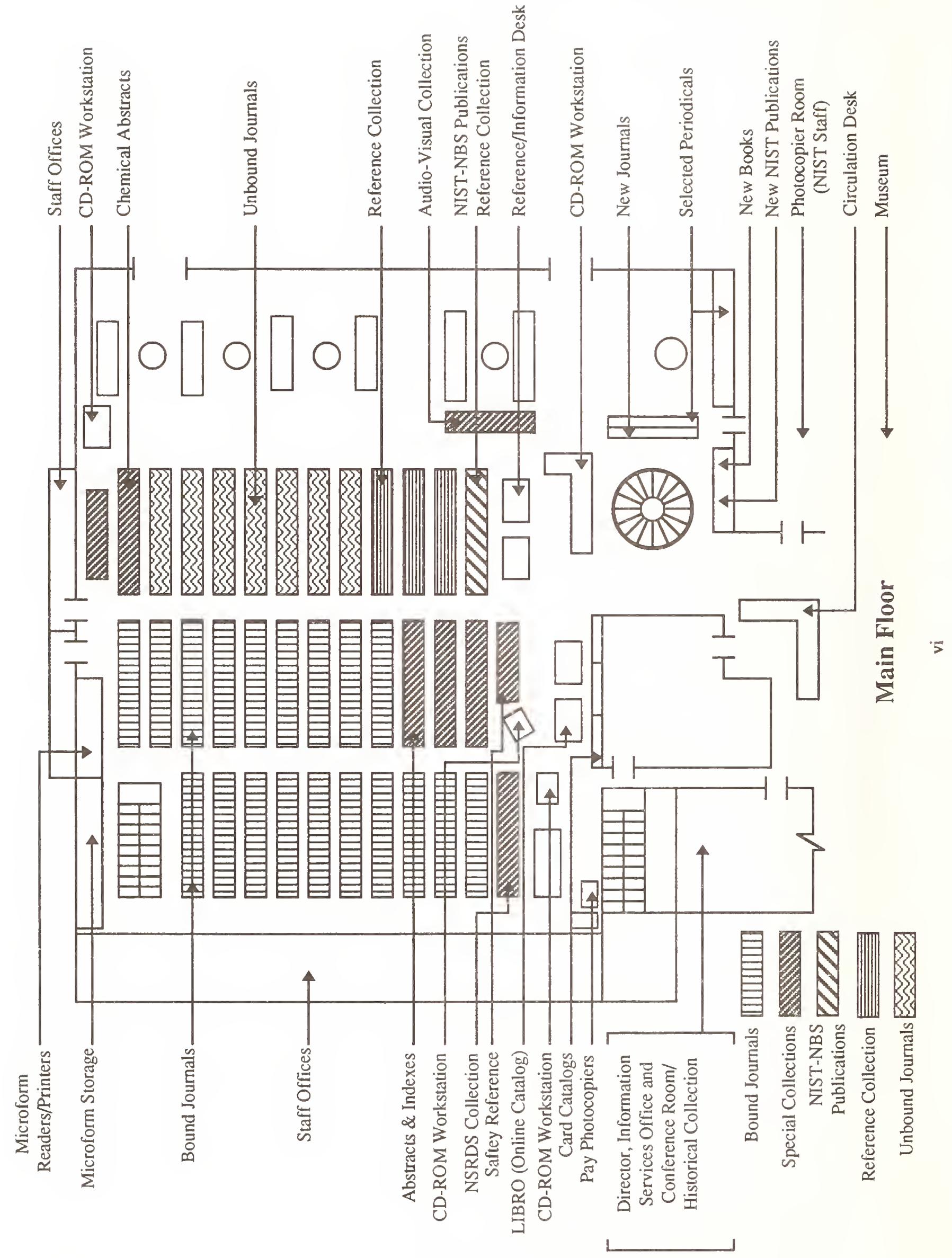




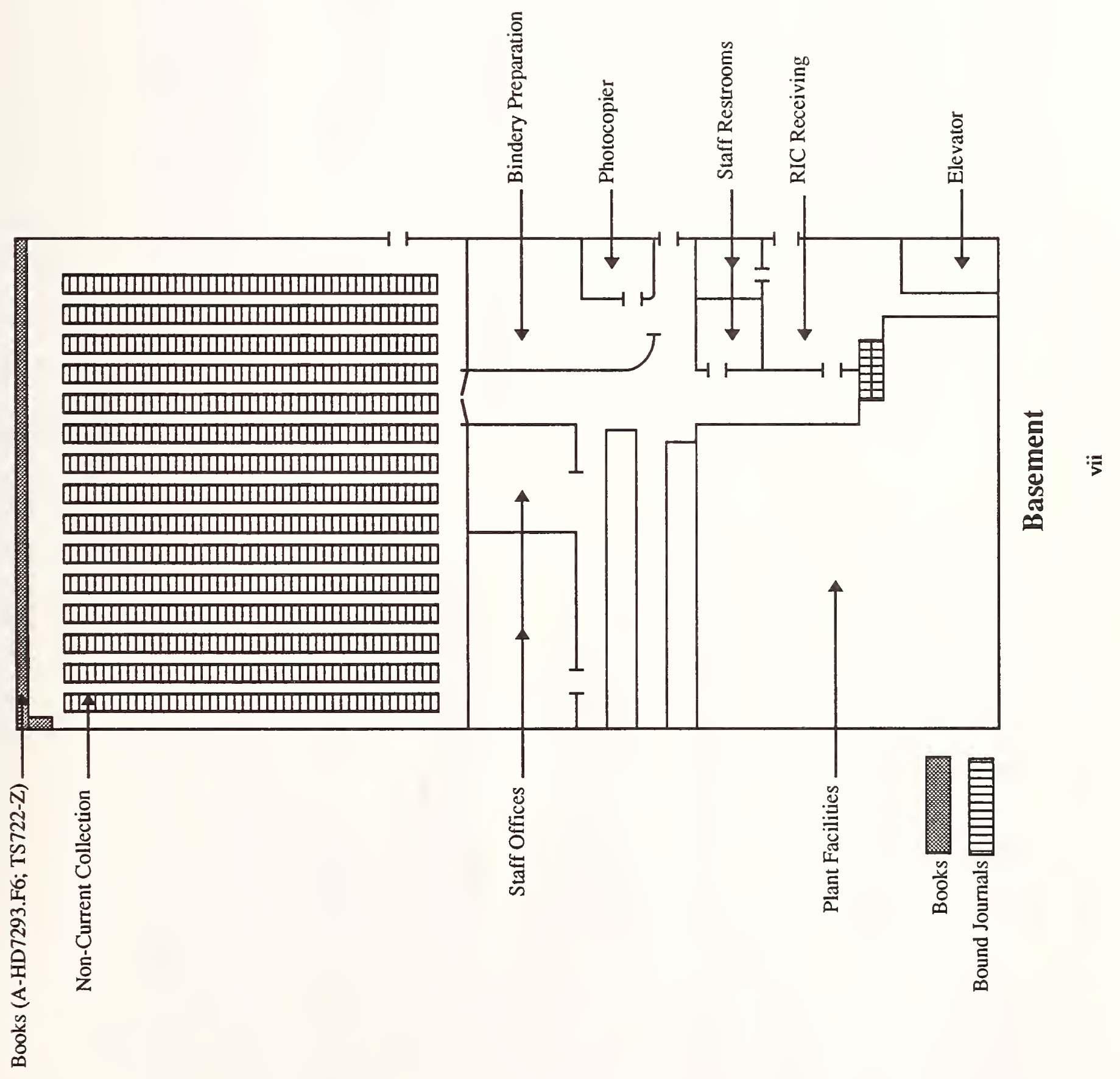




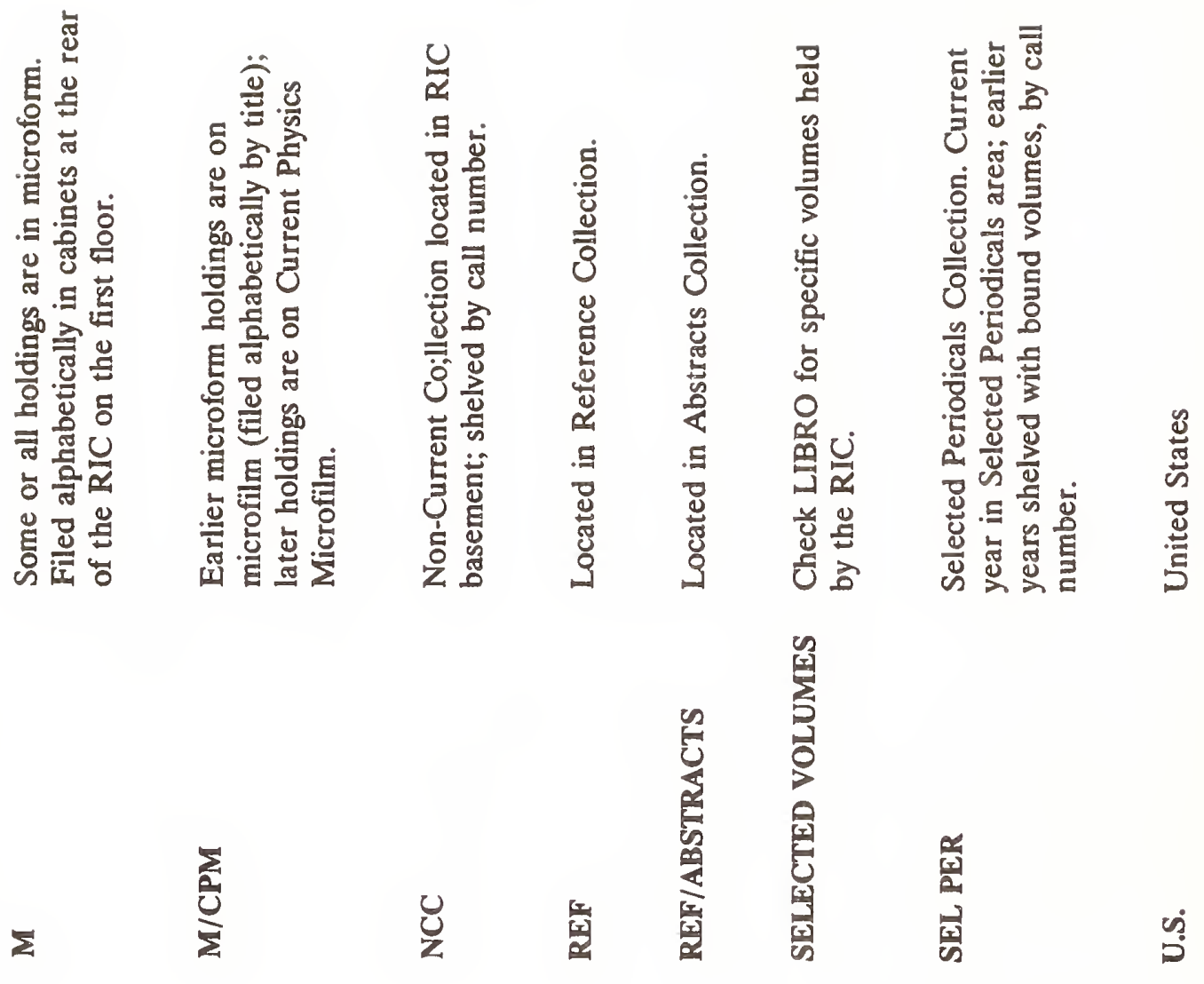

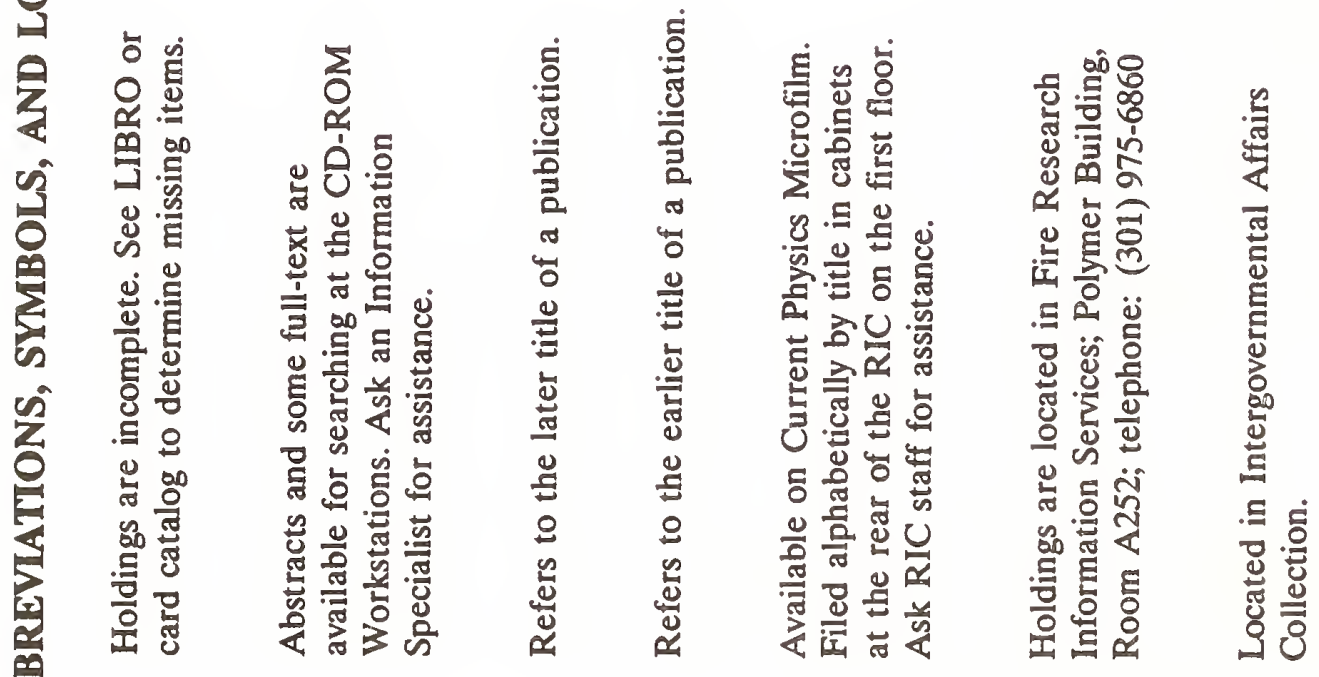

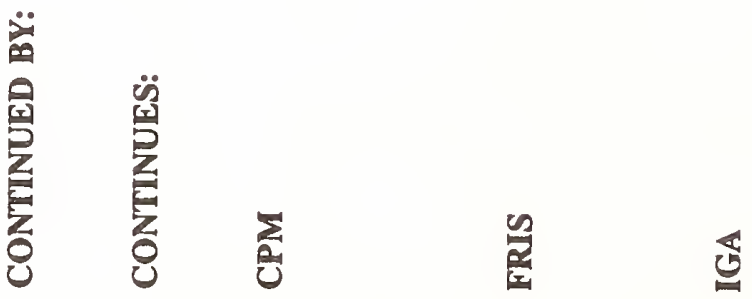



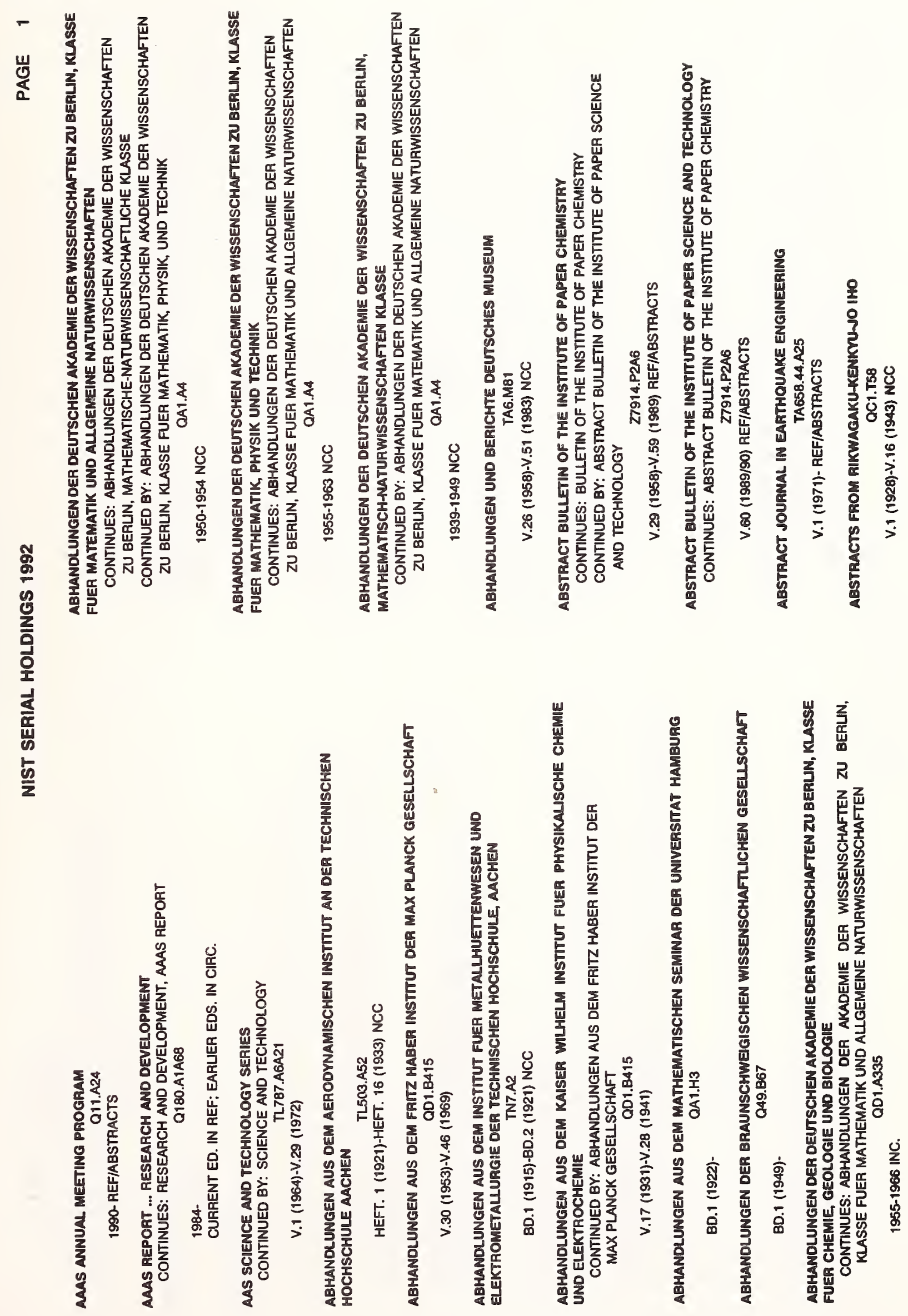


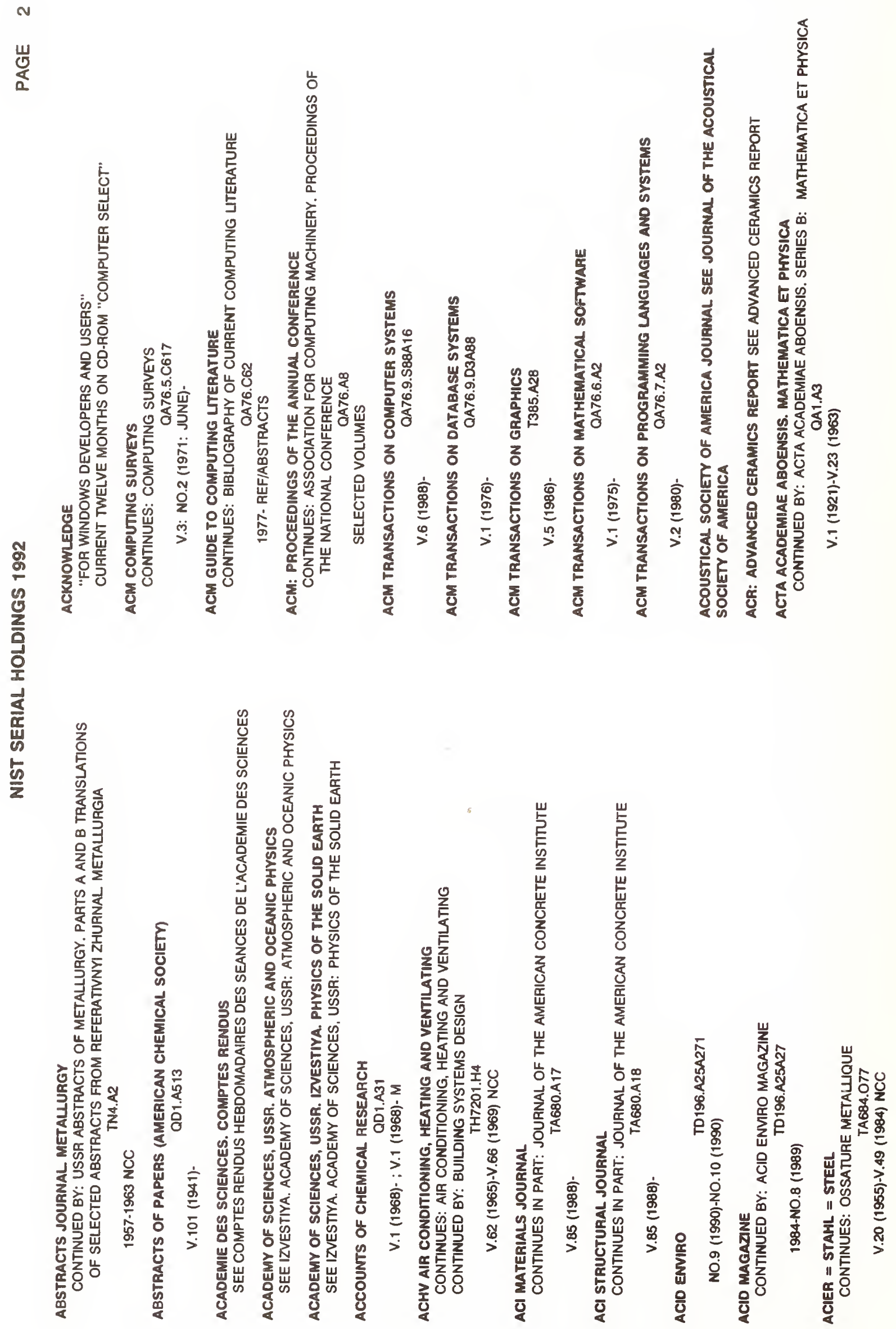



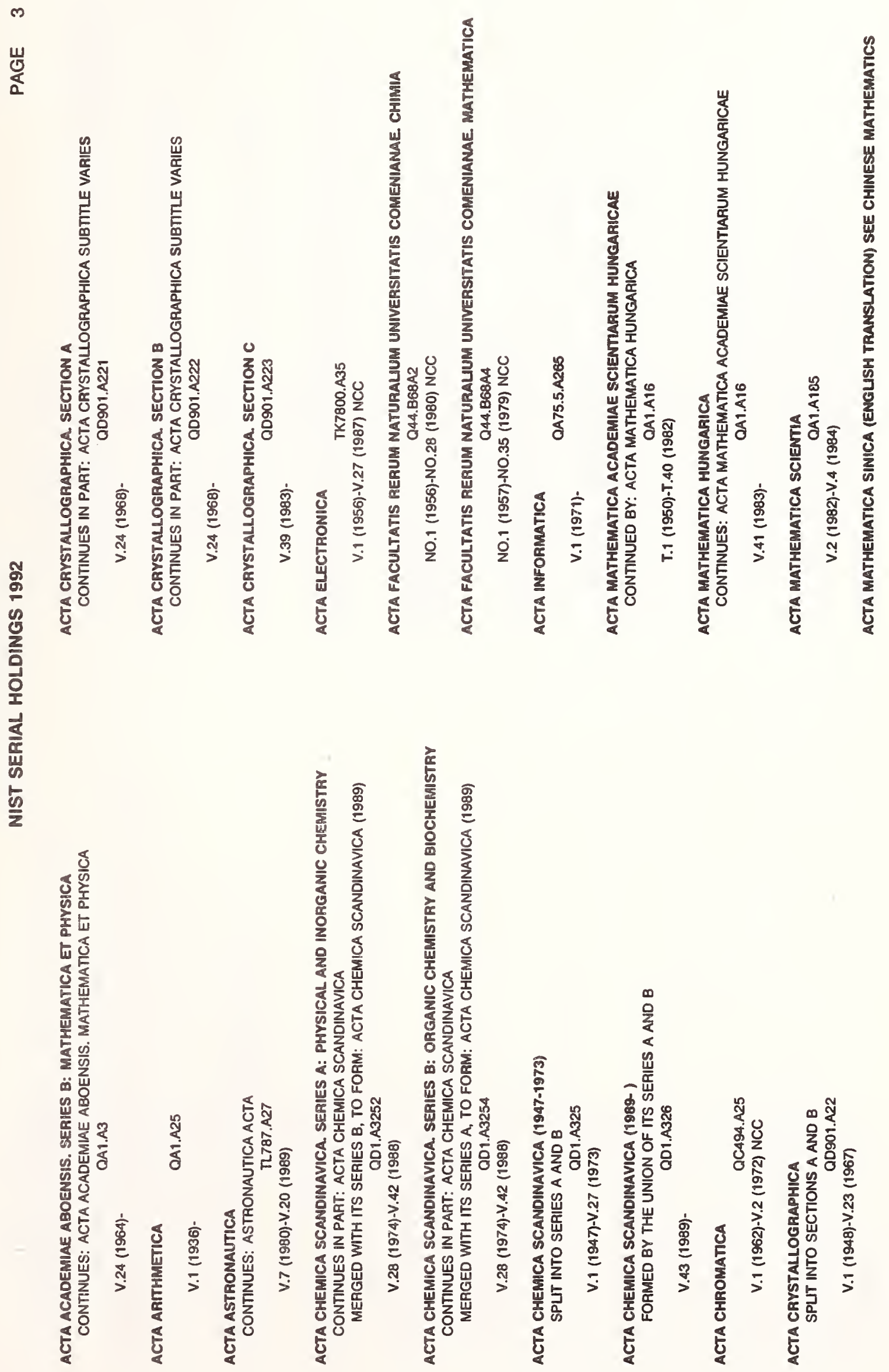

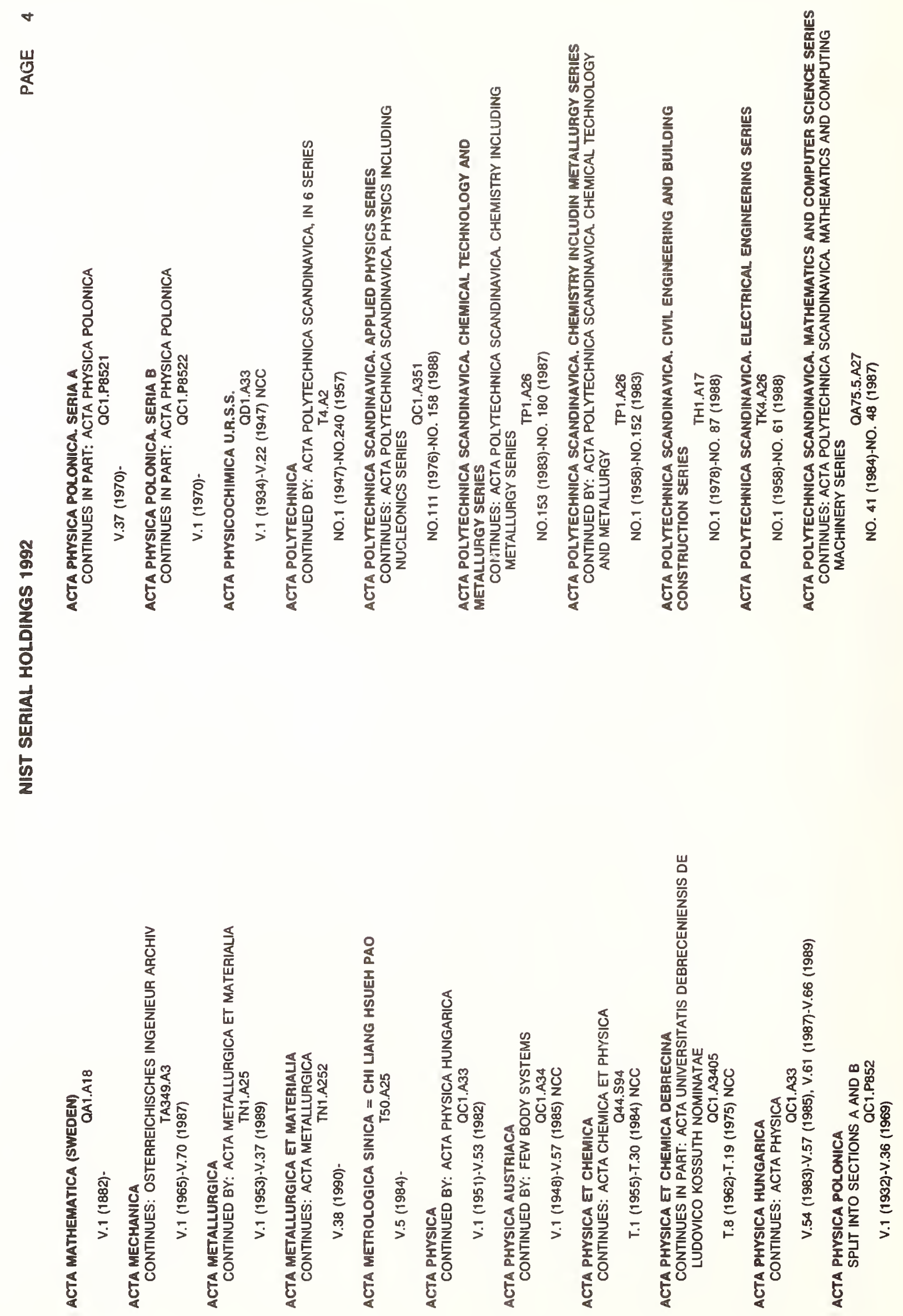


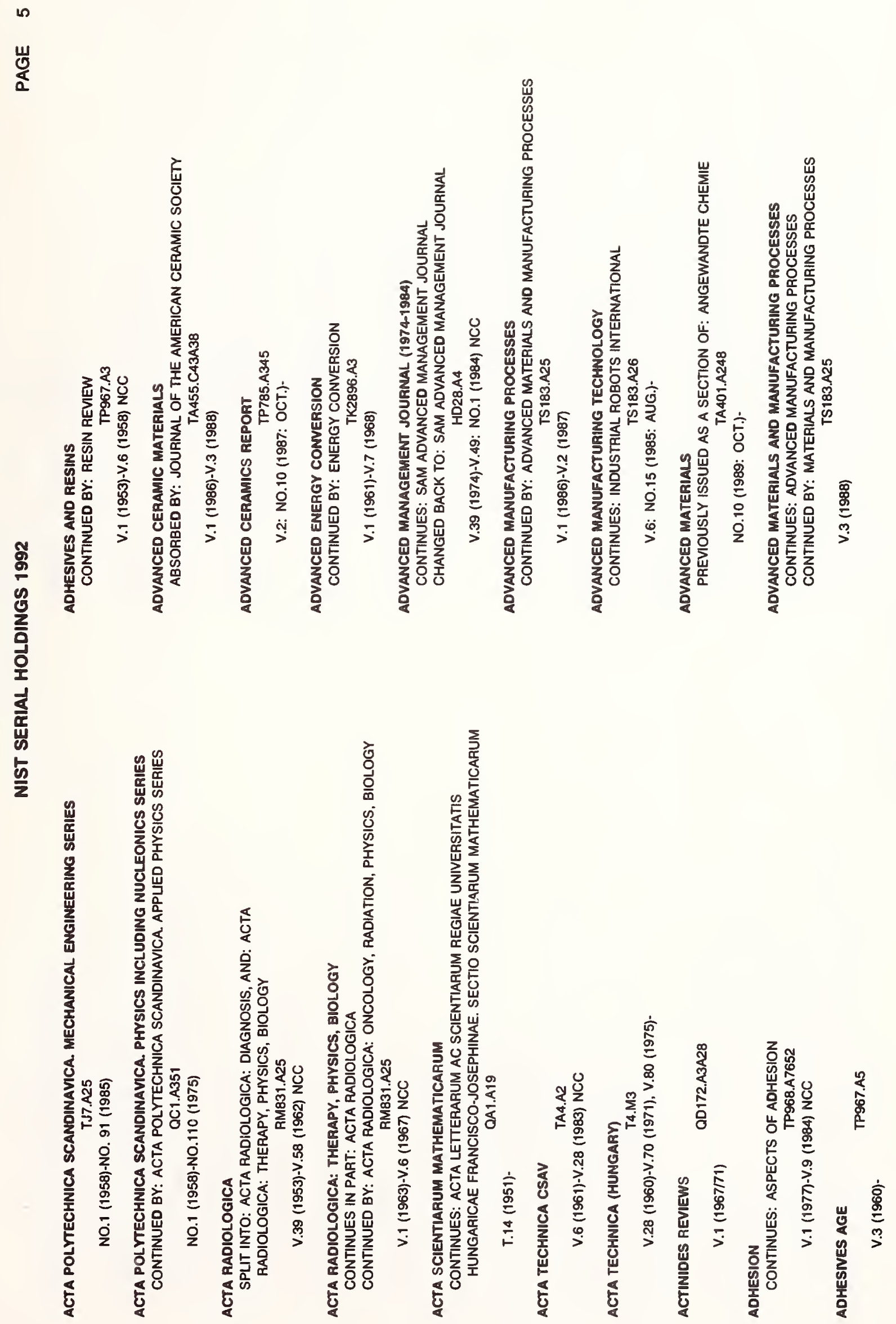



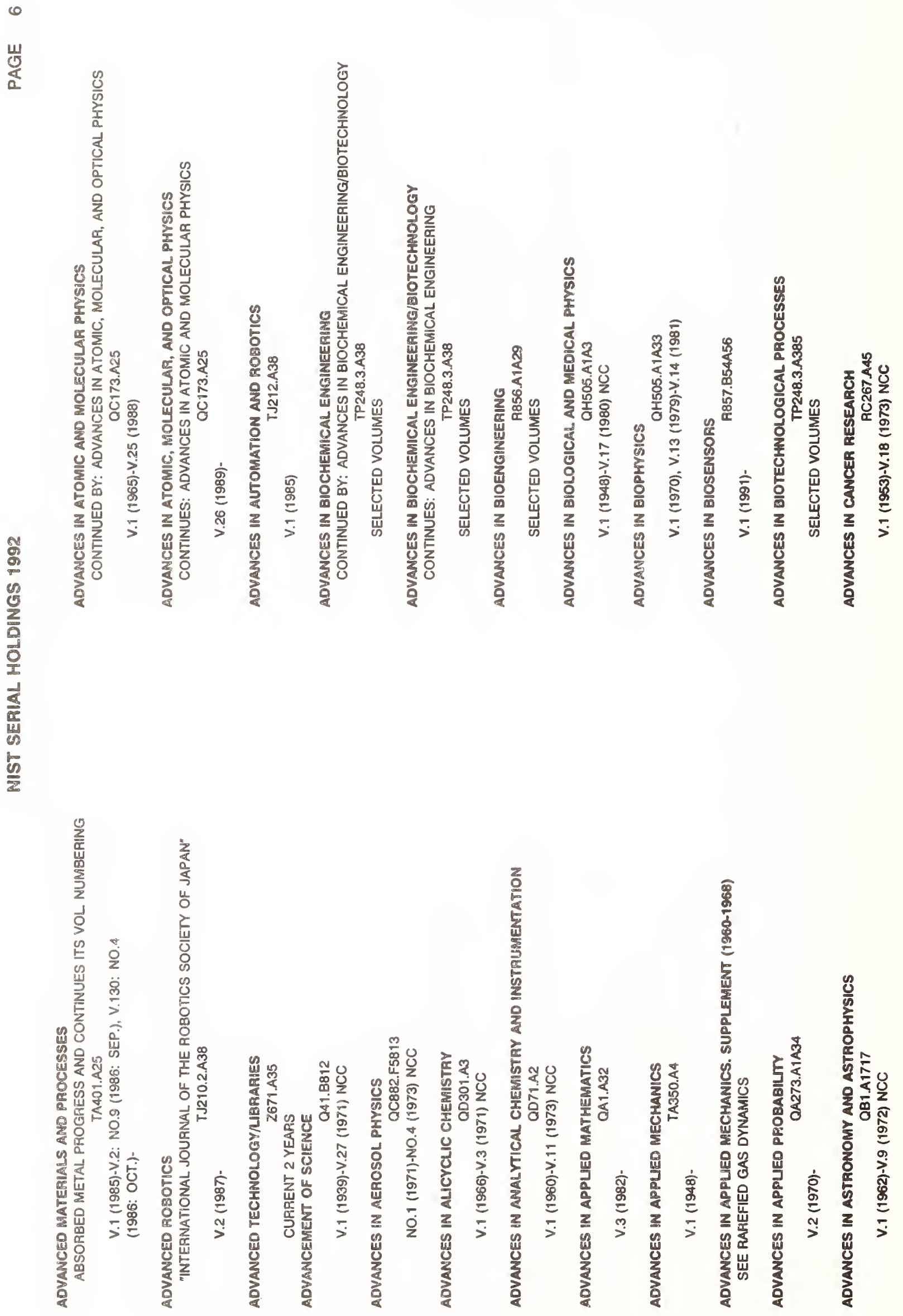
器

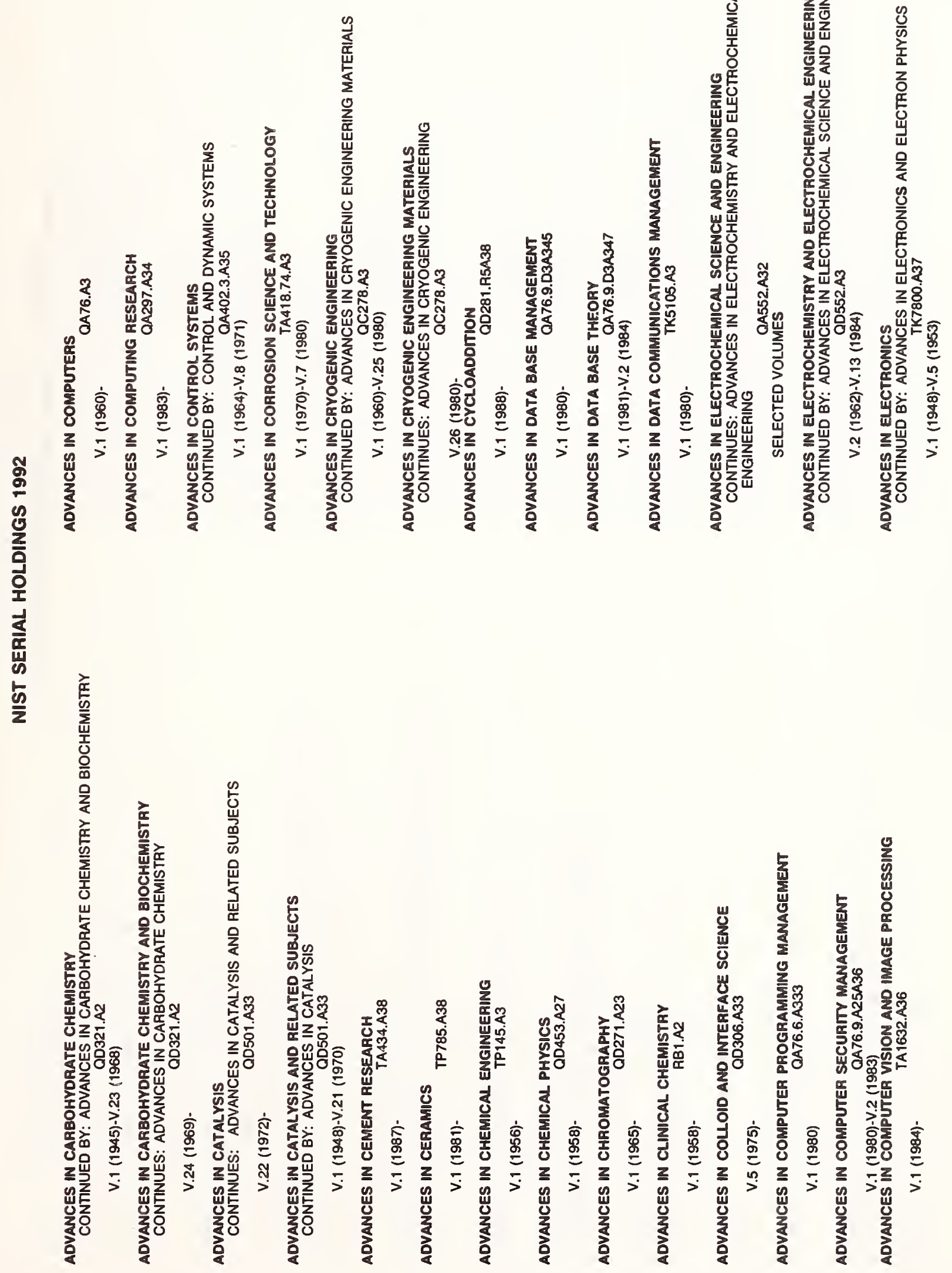


遂

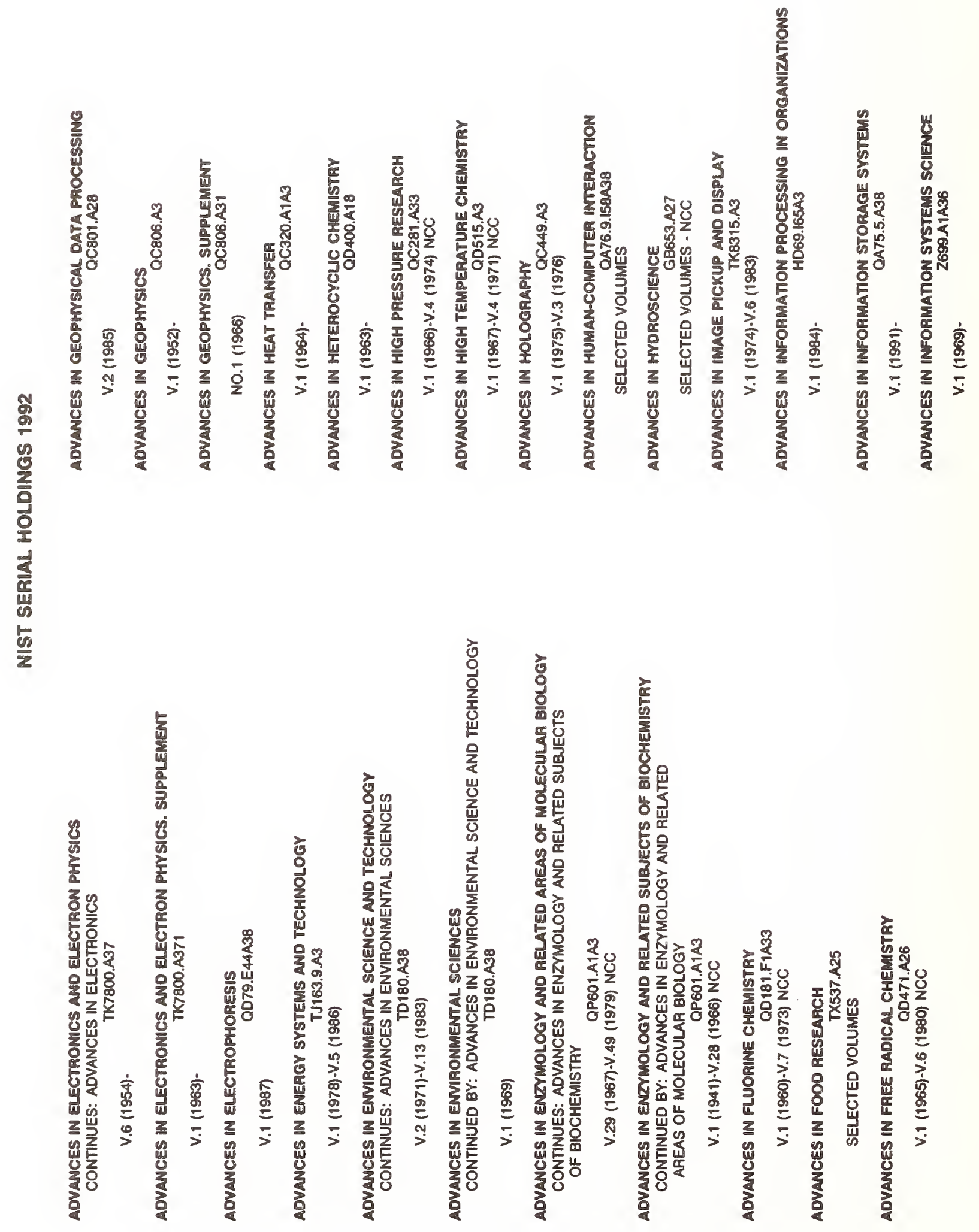




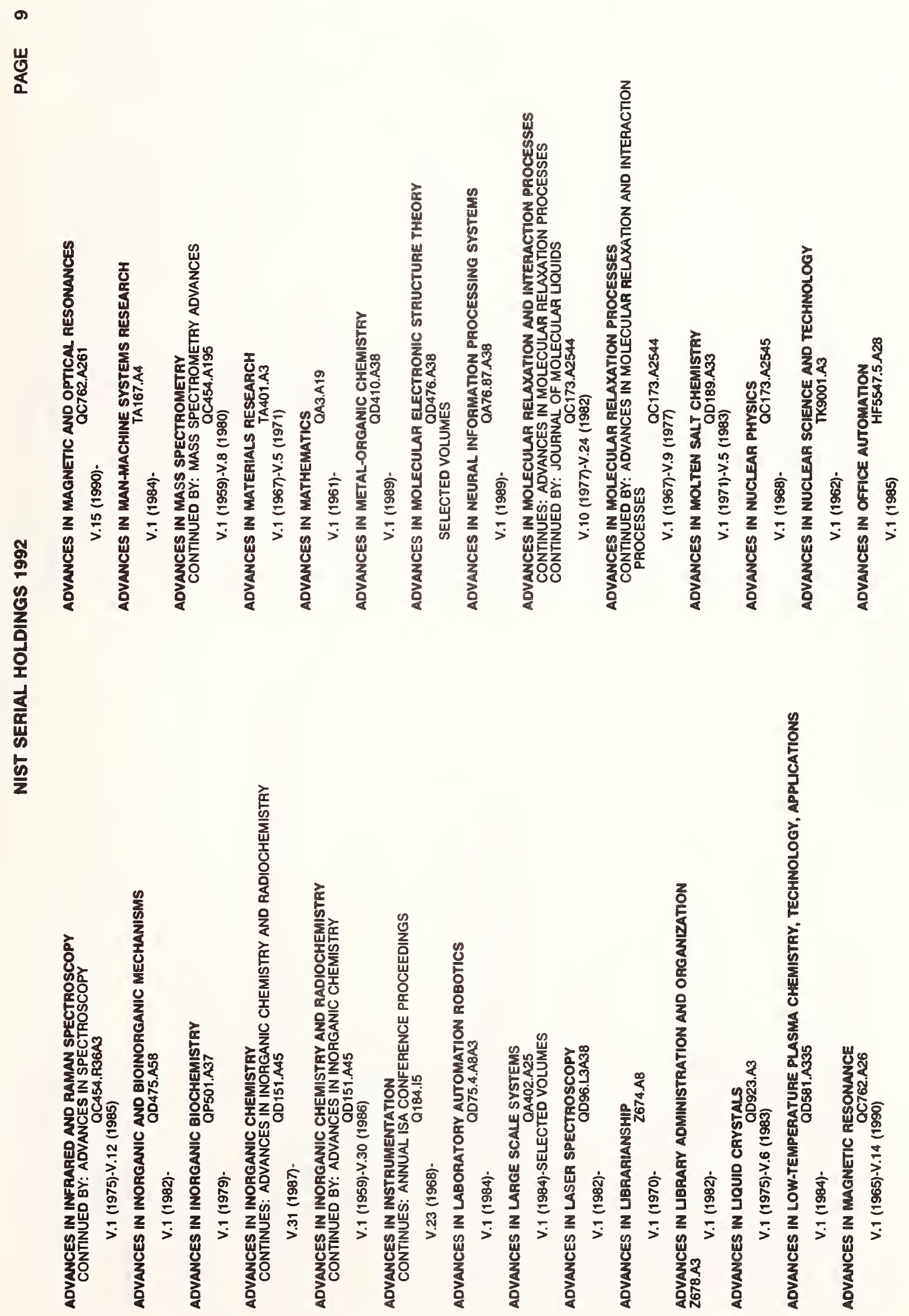


웅

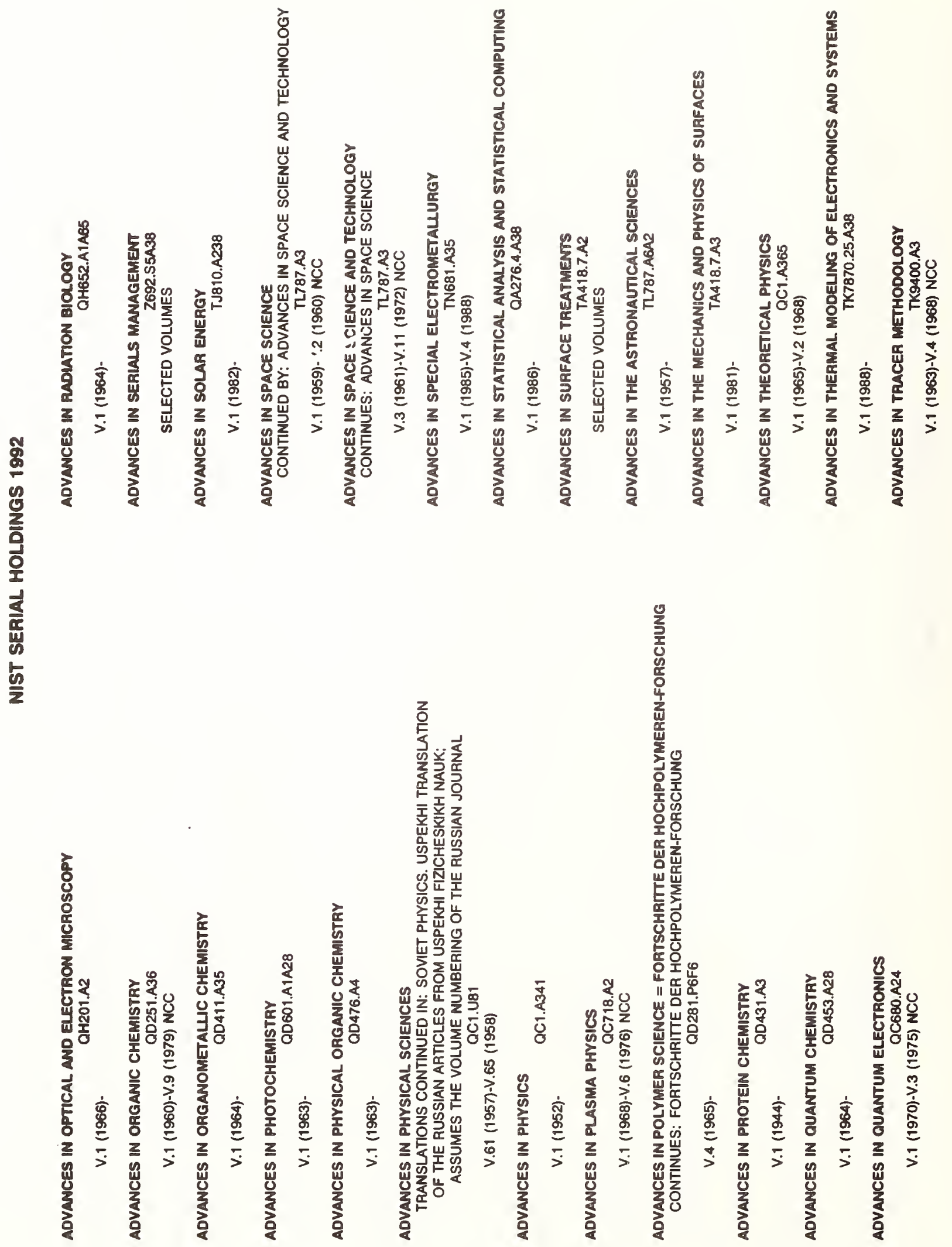




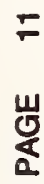

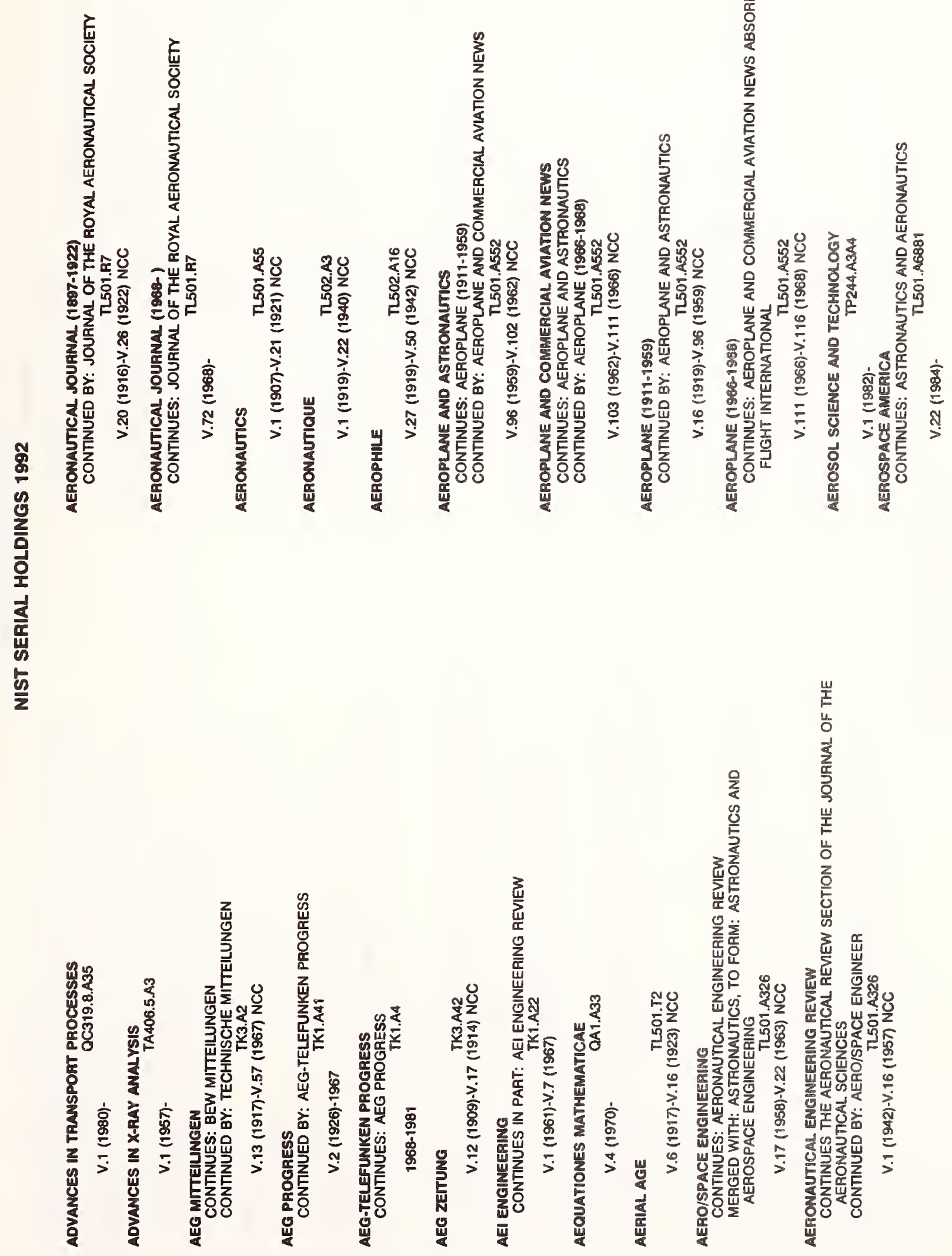


嵌
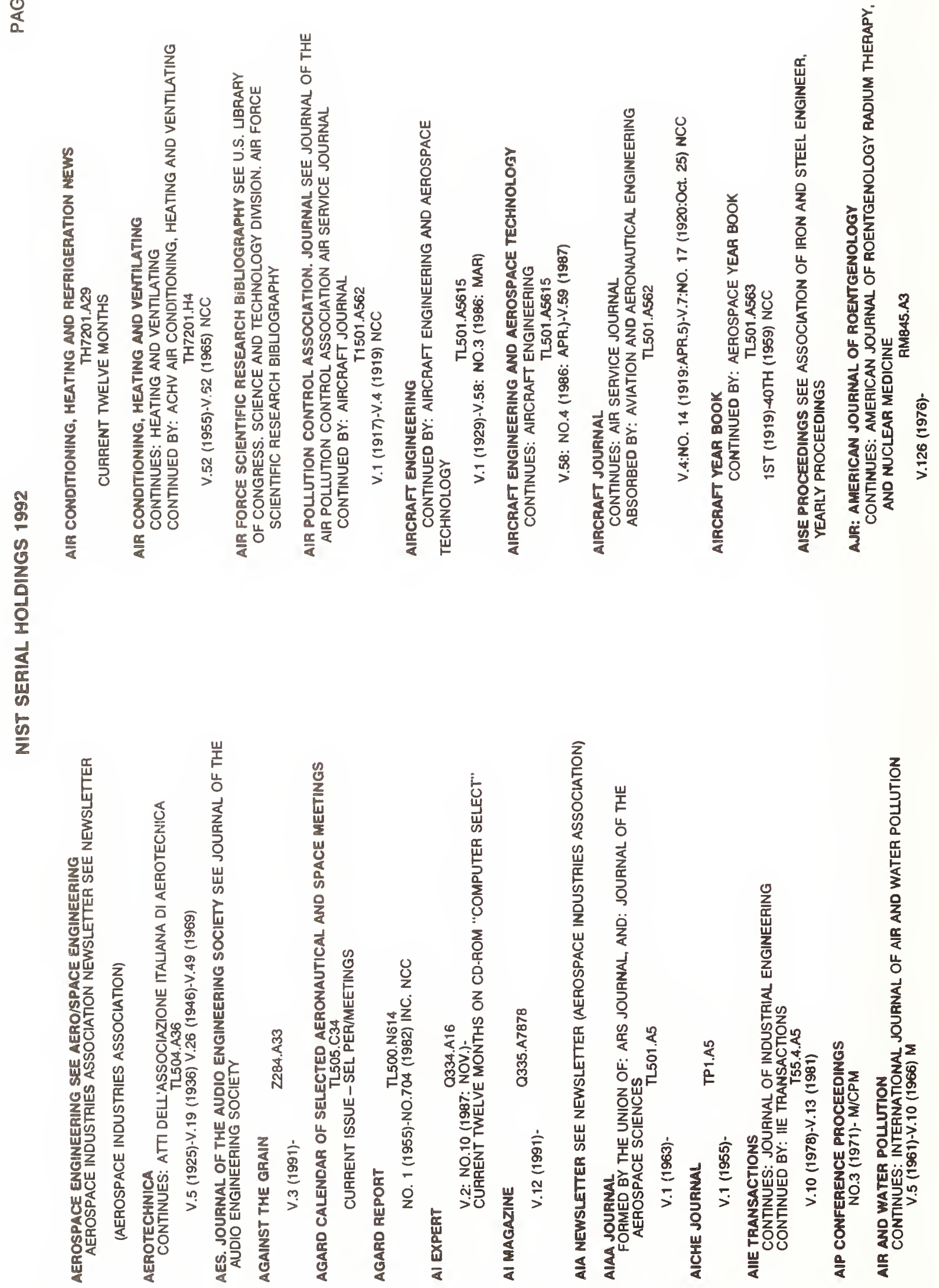
容

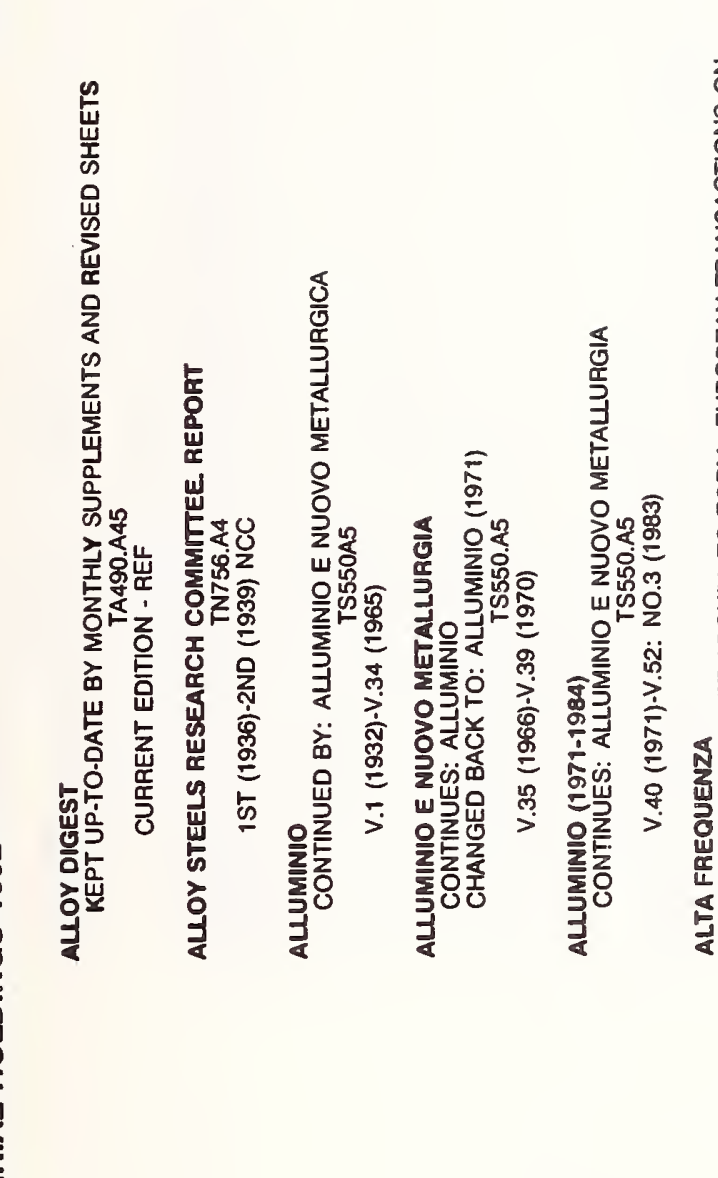

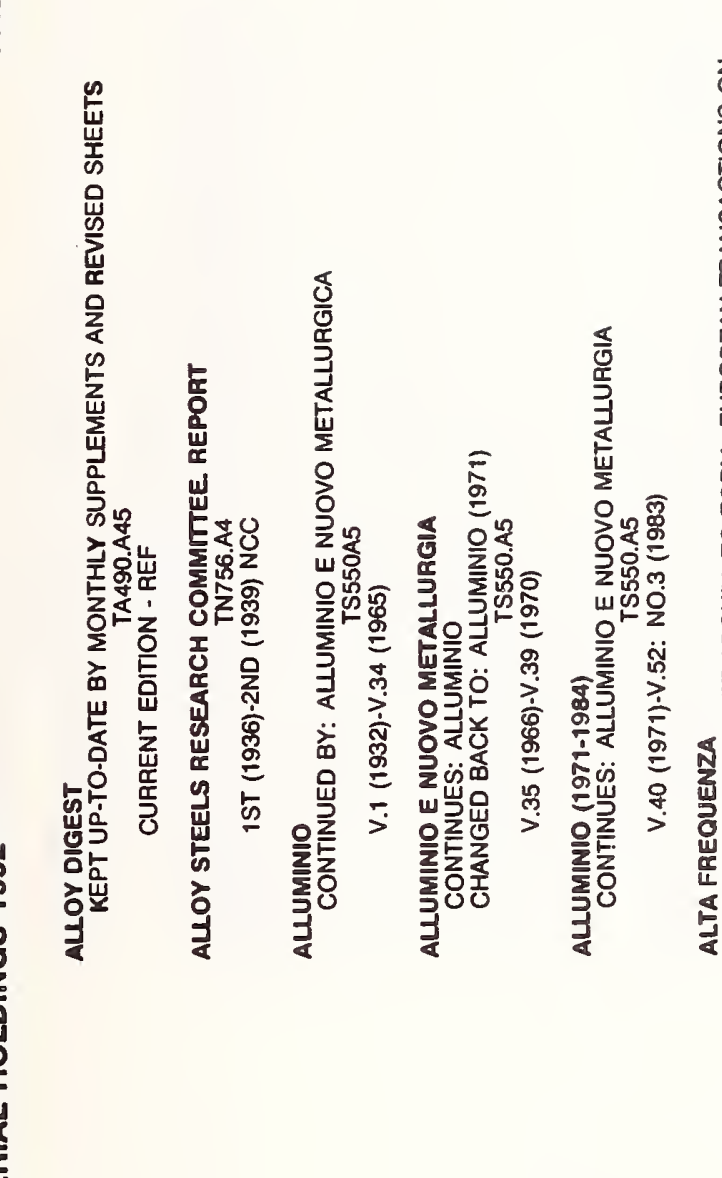

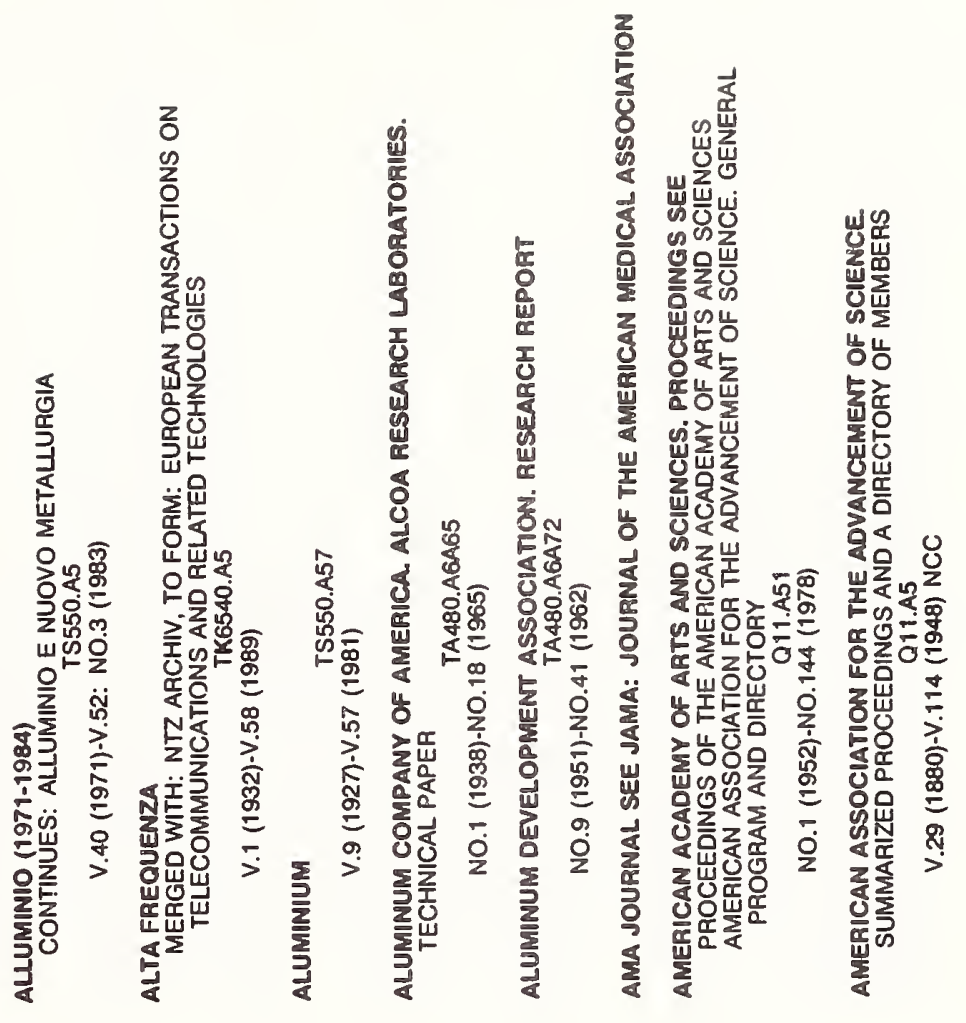

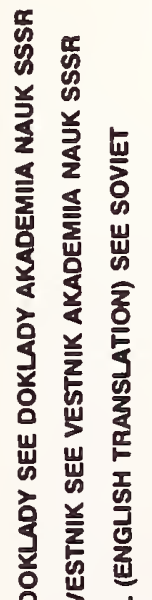

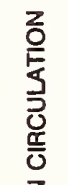

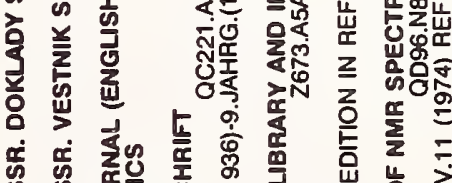

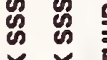

I

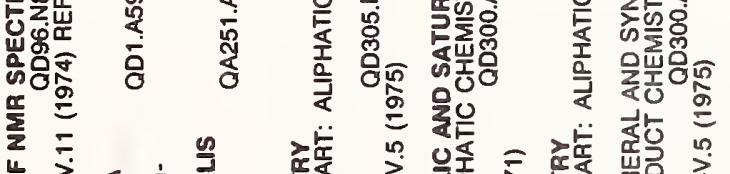

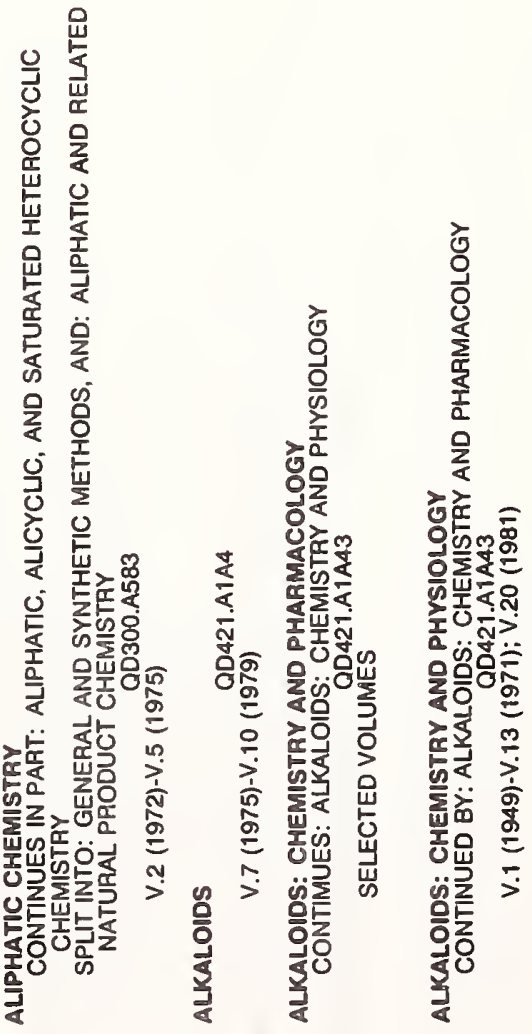




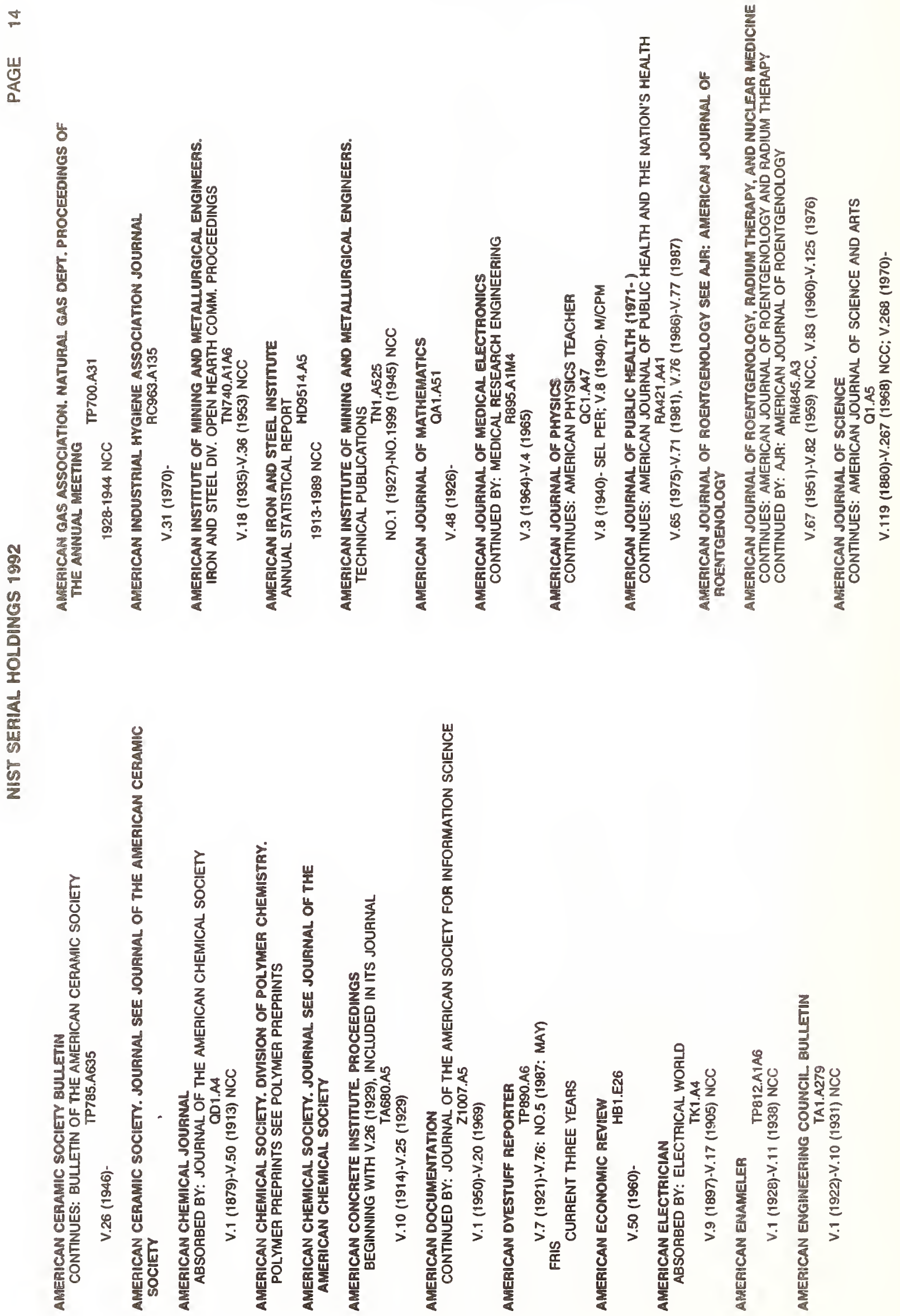



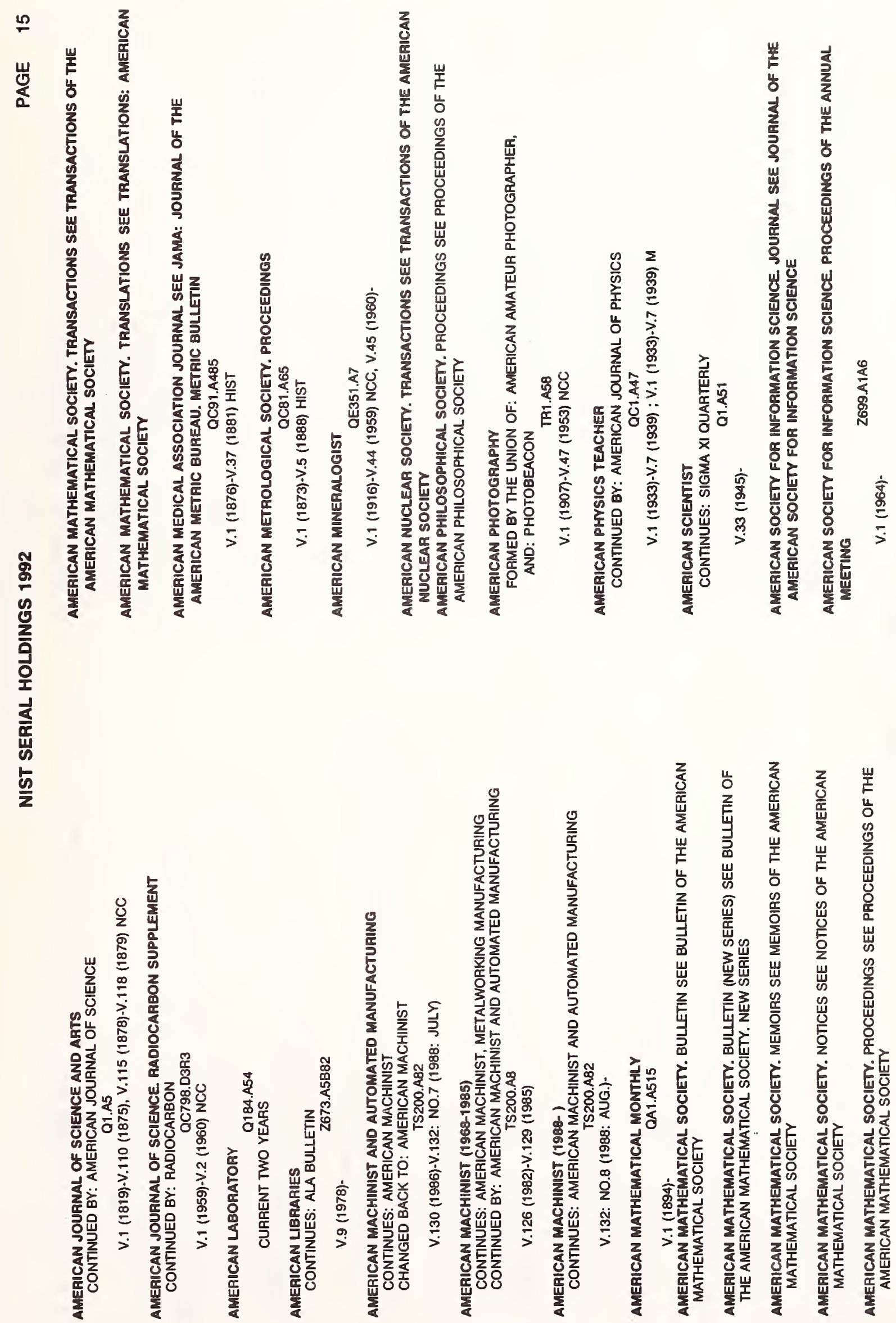


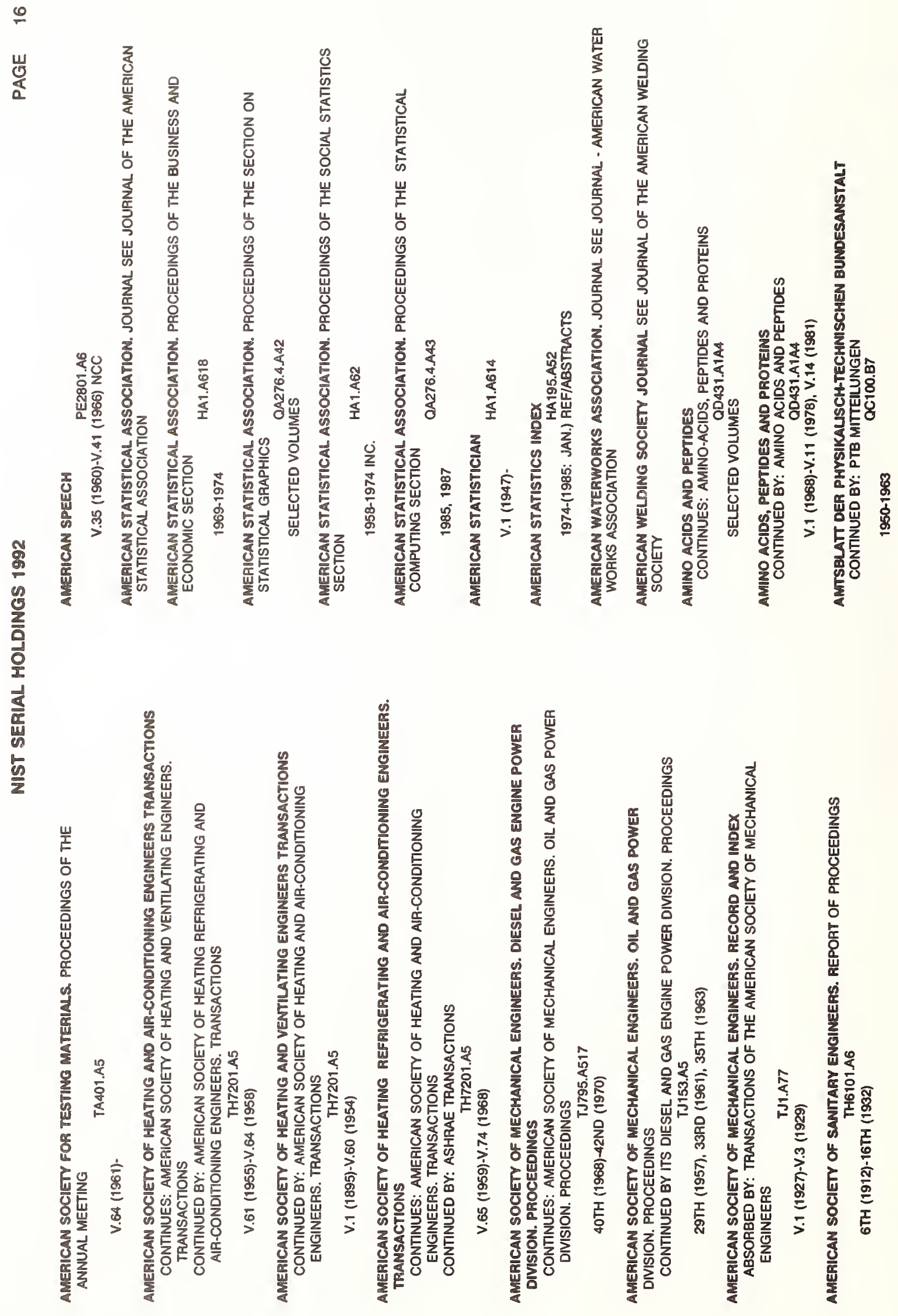




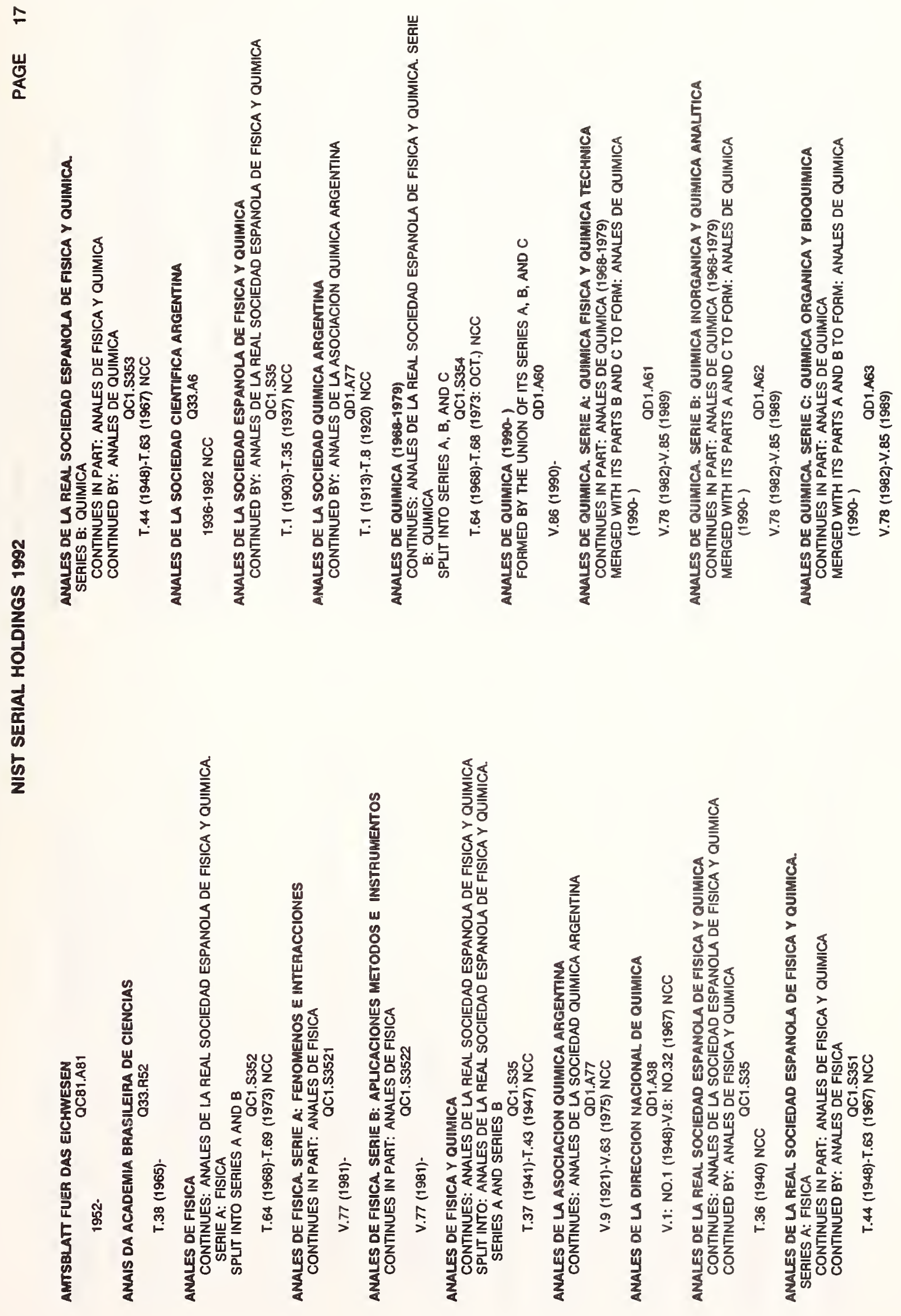




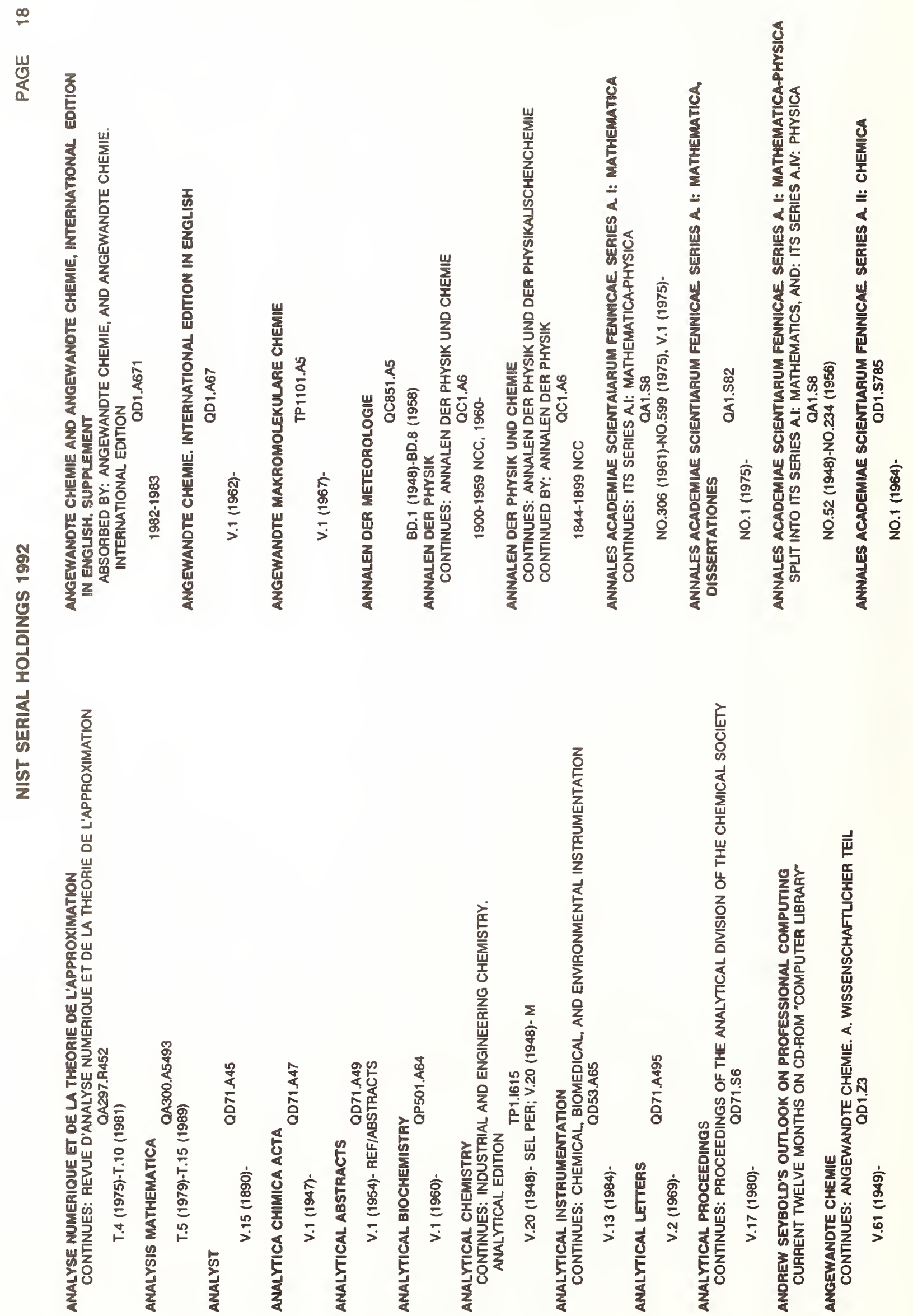



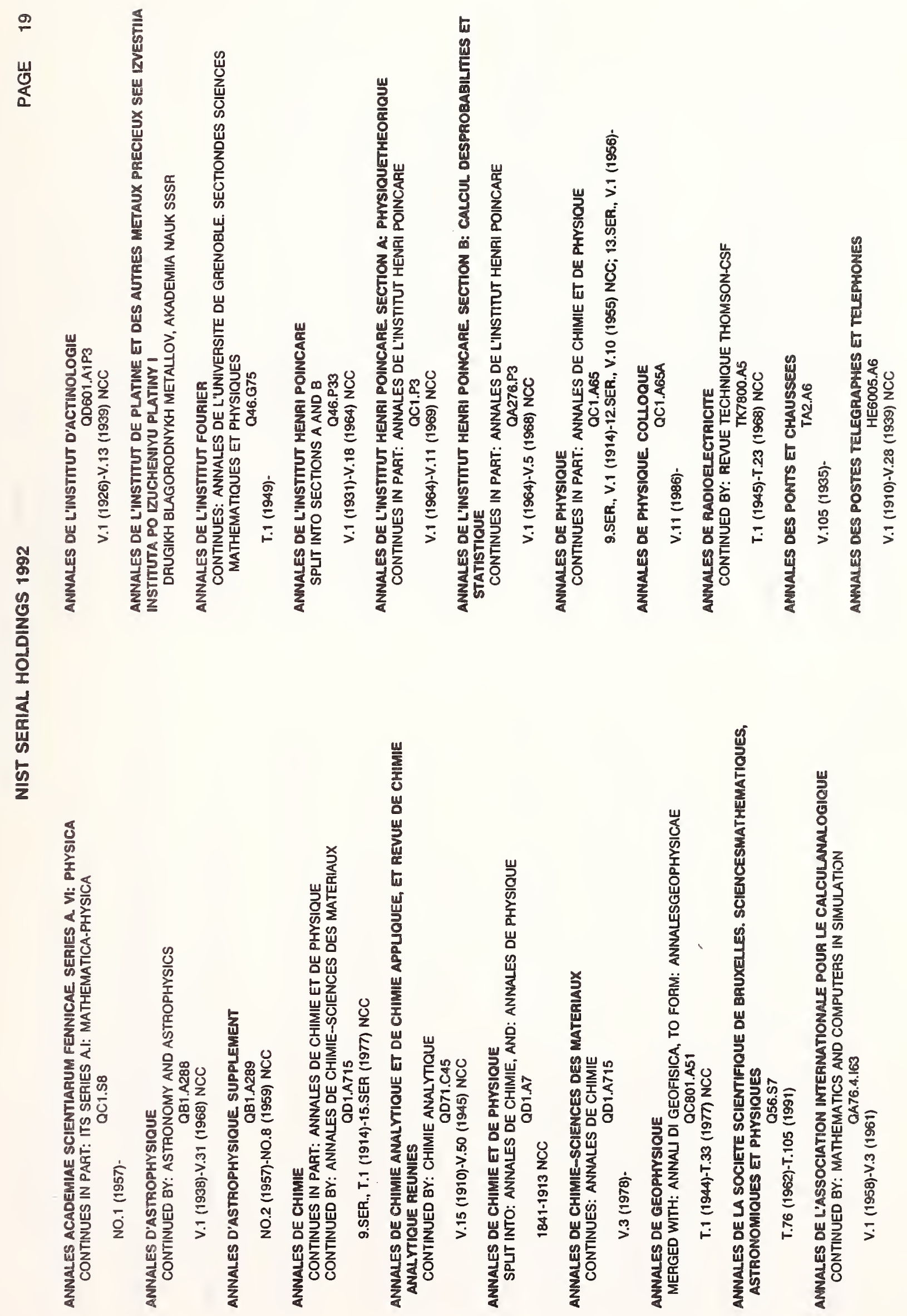


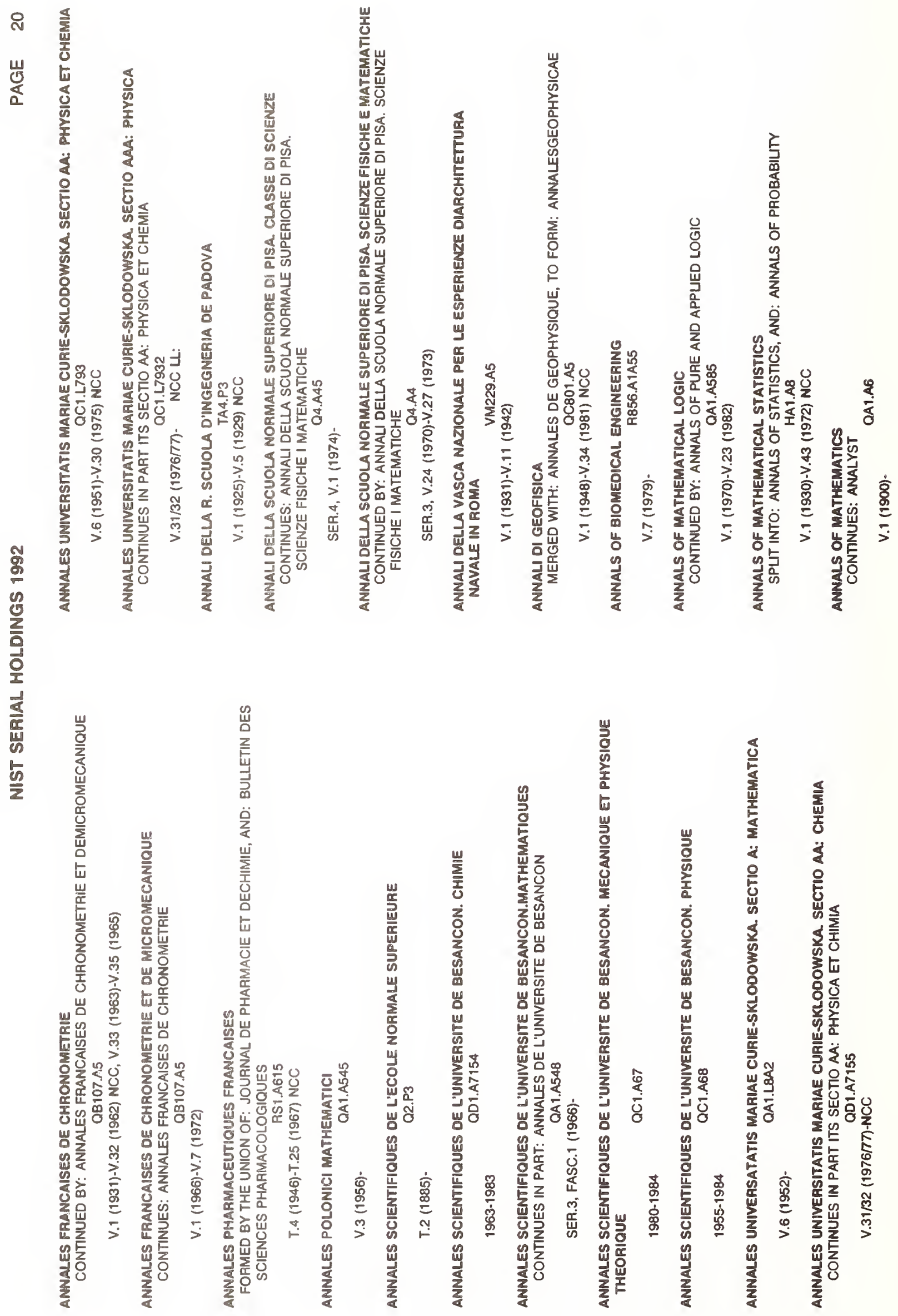




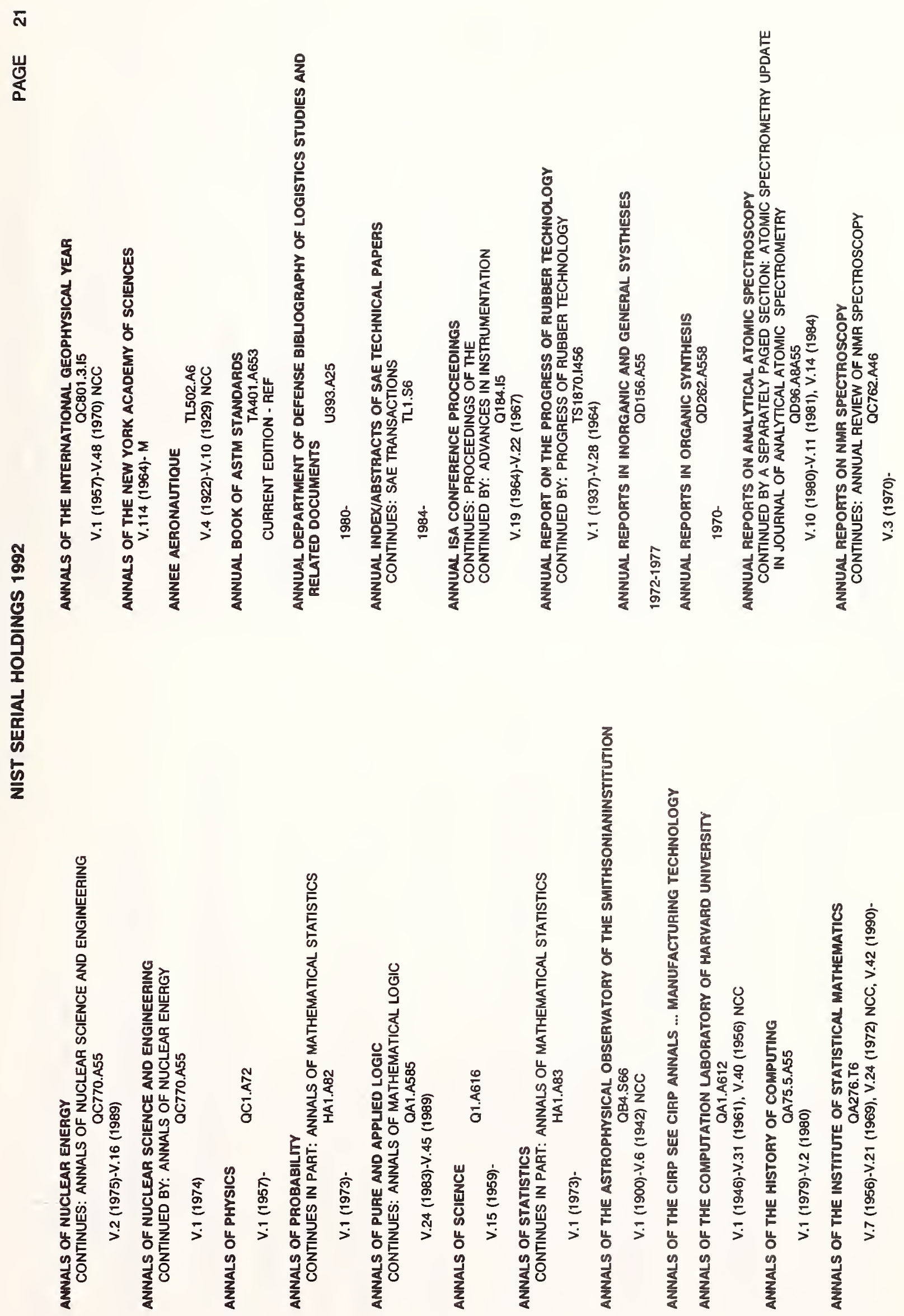


ส

$\frac{u}{\frac{1}{0}}$
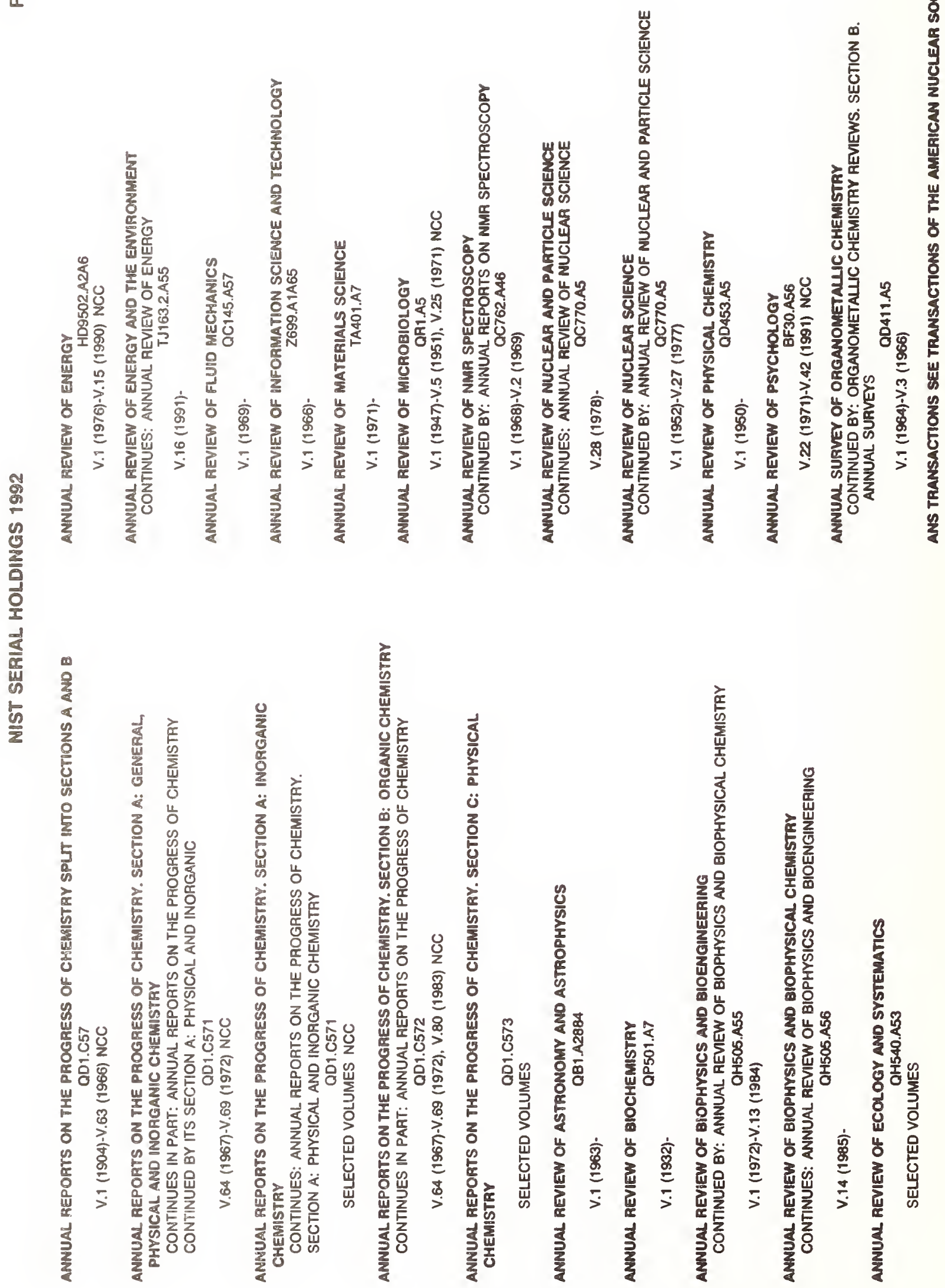

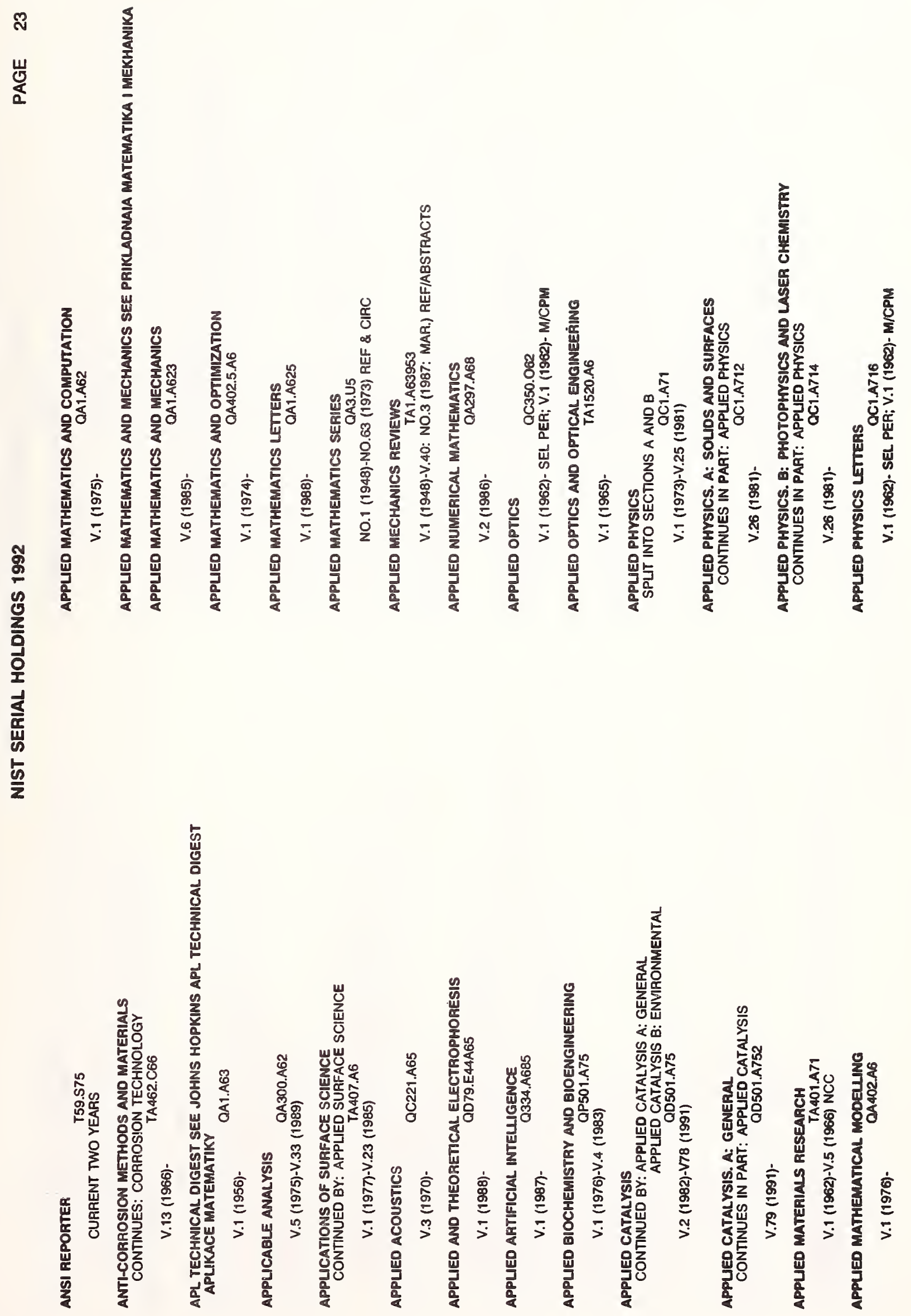
I

뼐

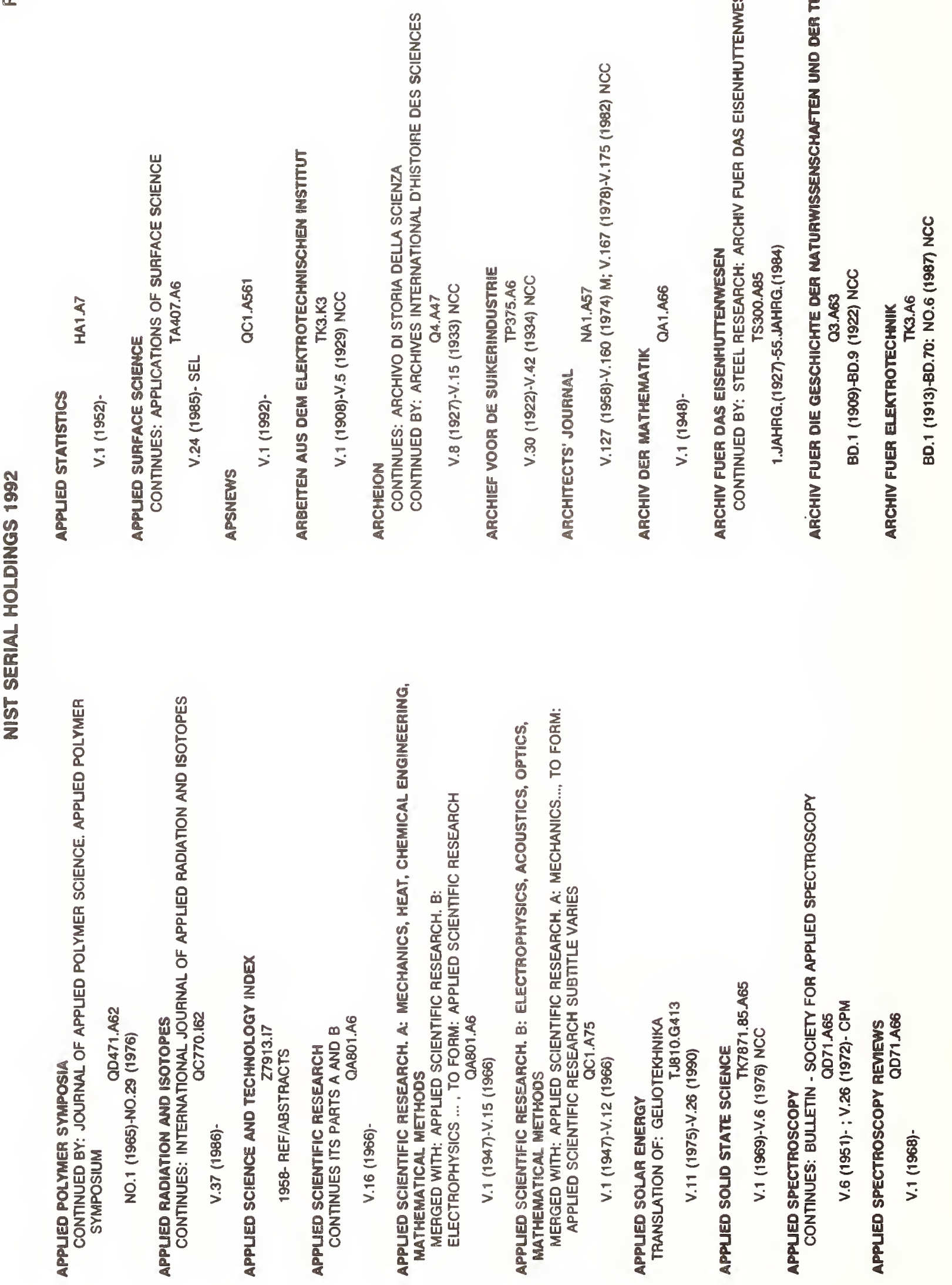


น
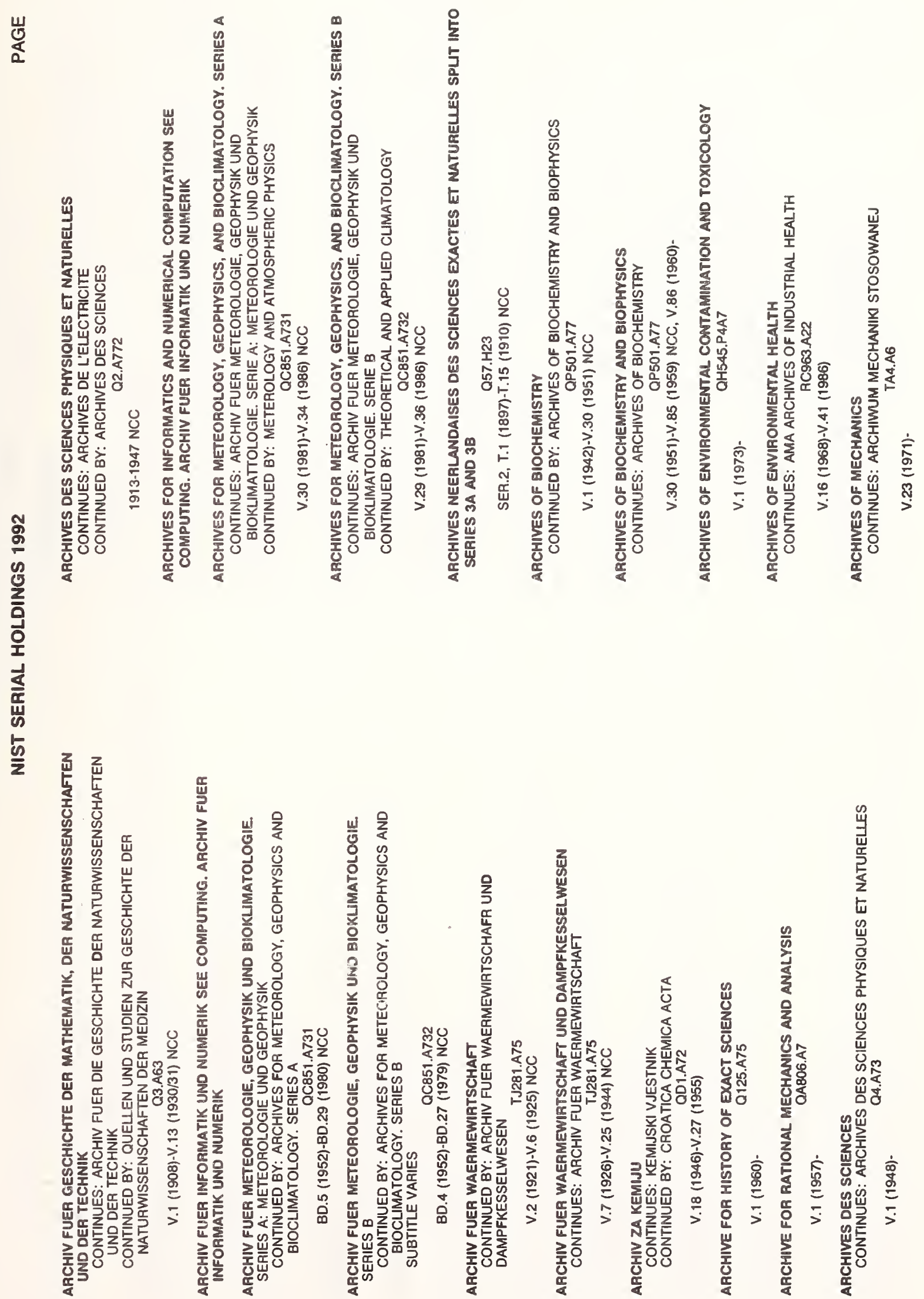
岁

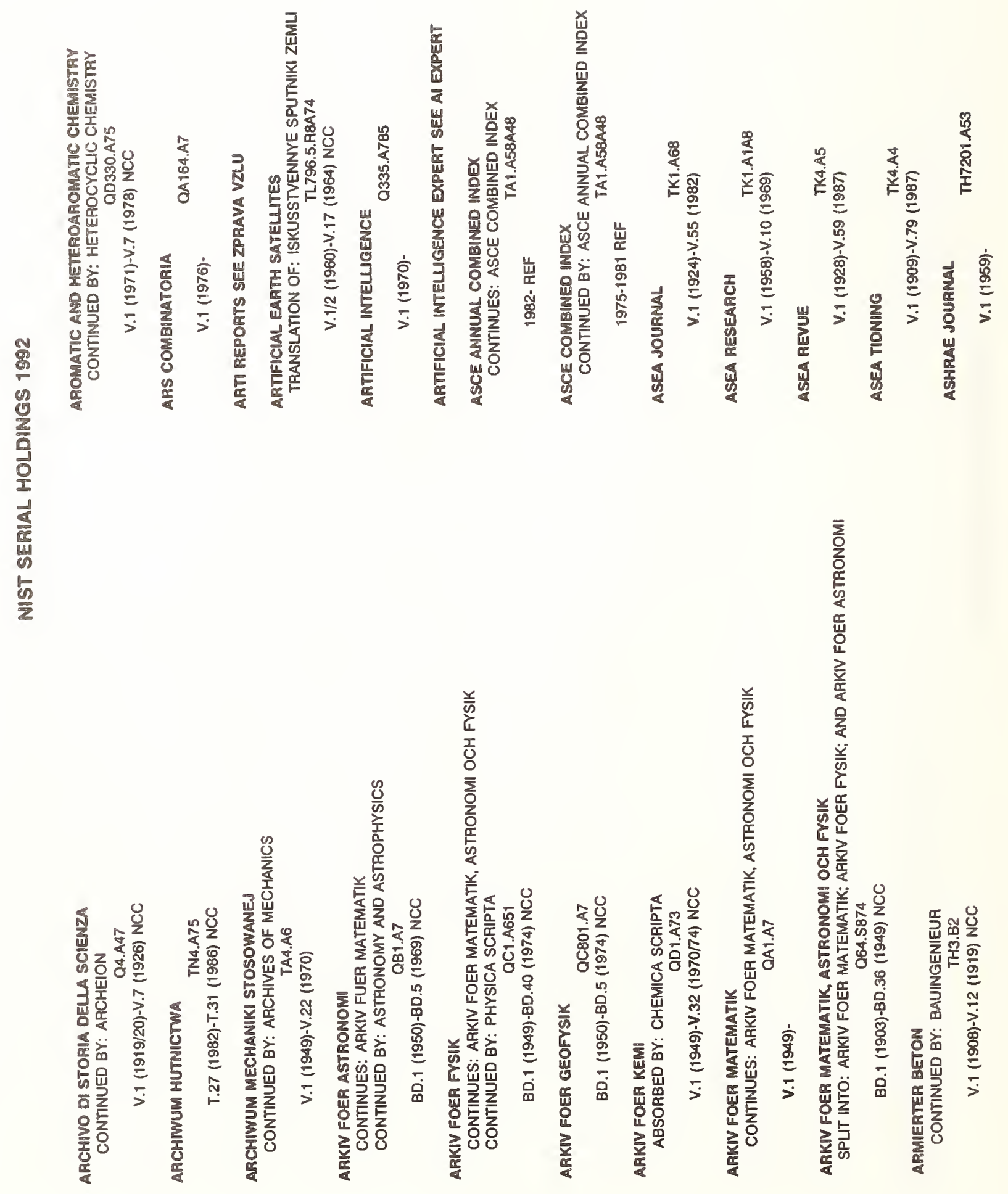



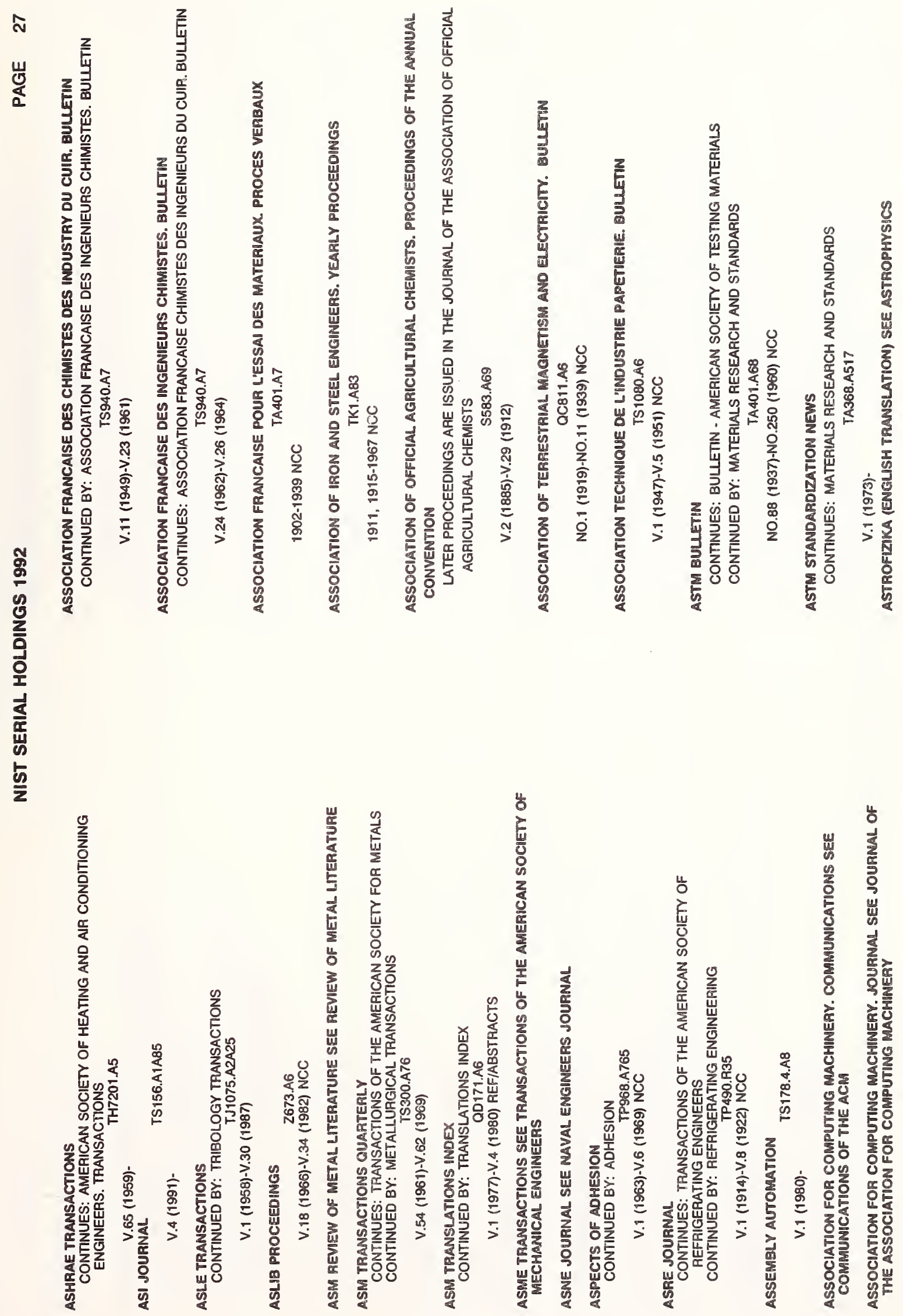
๙
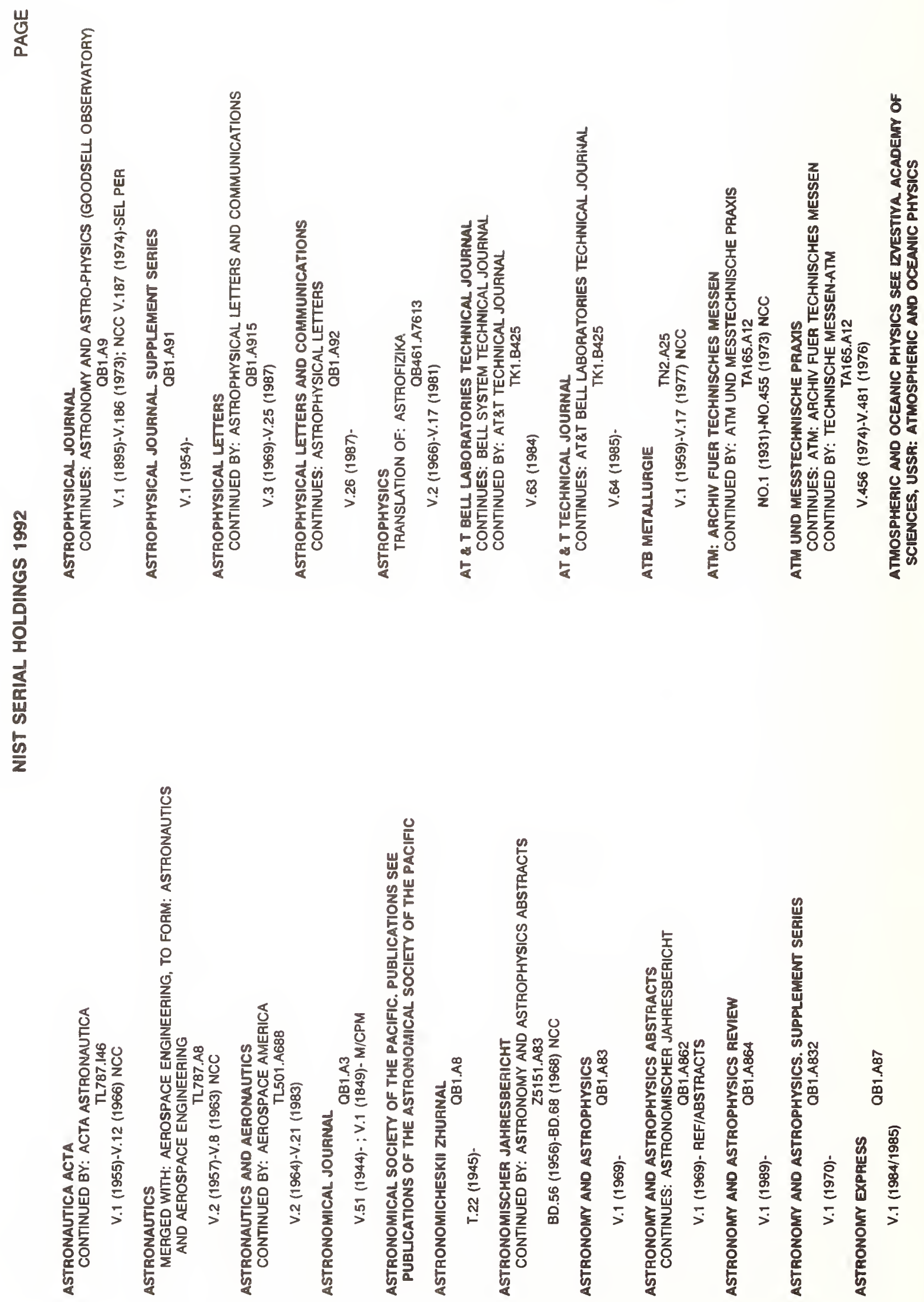
\%

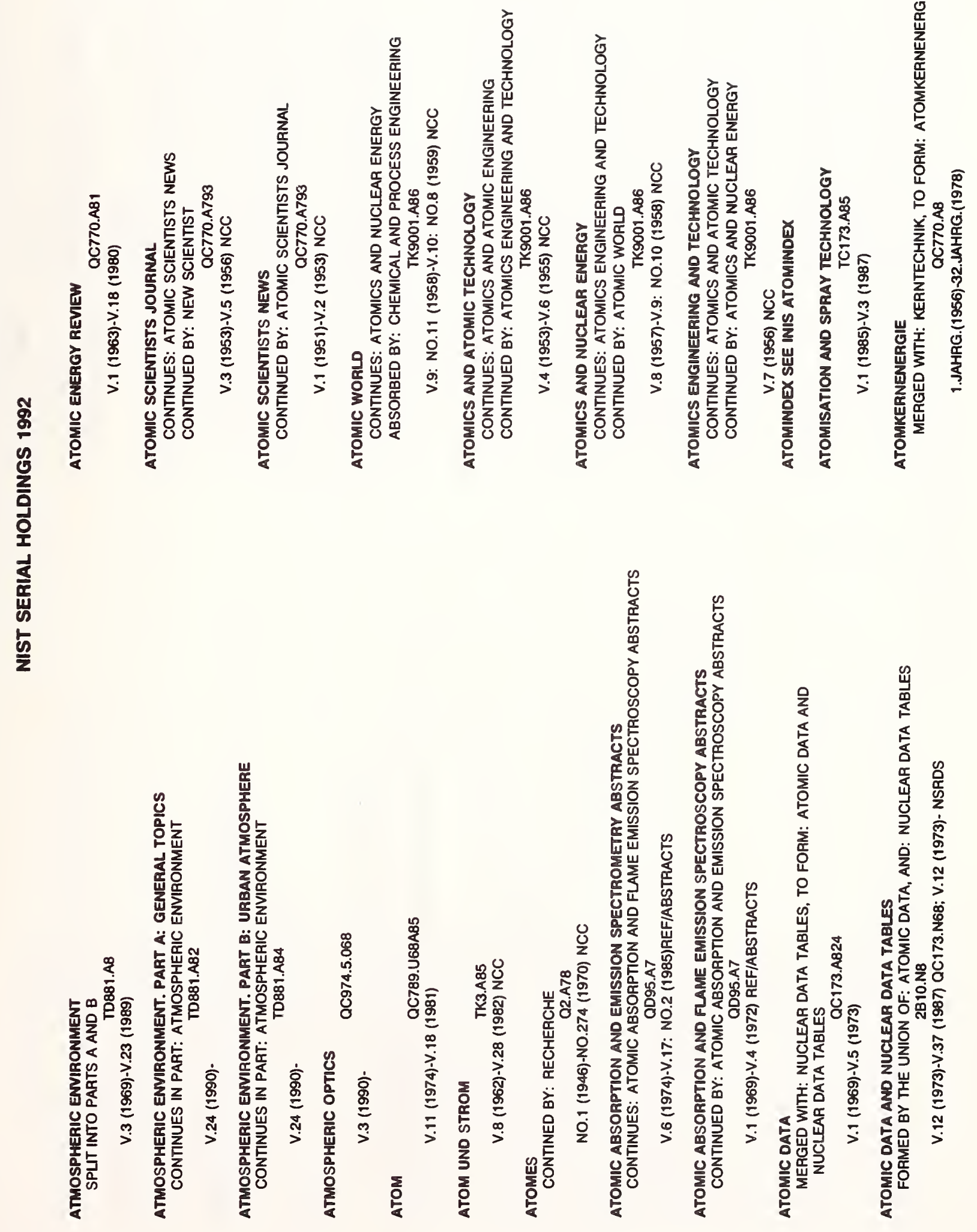




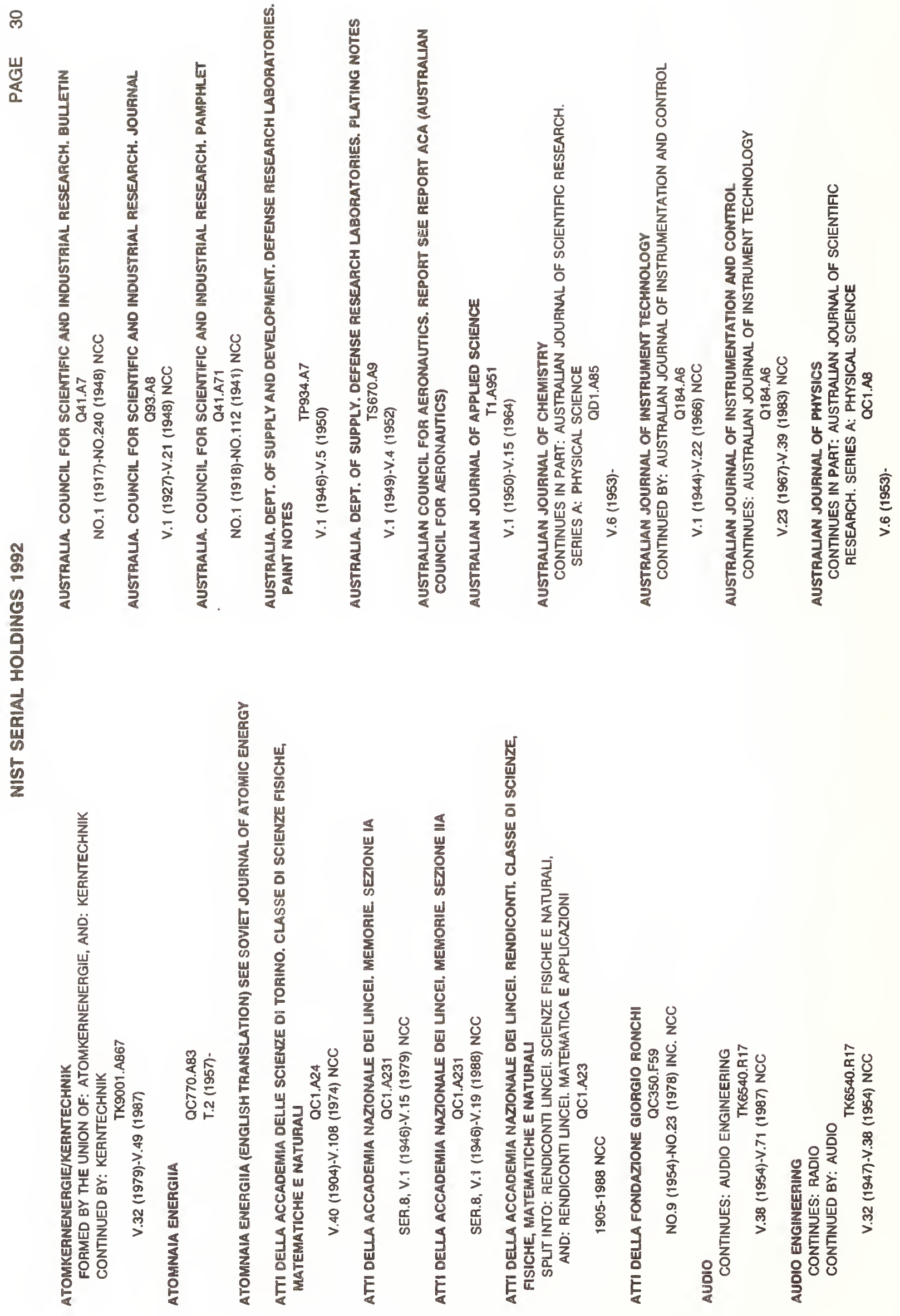


穴

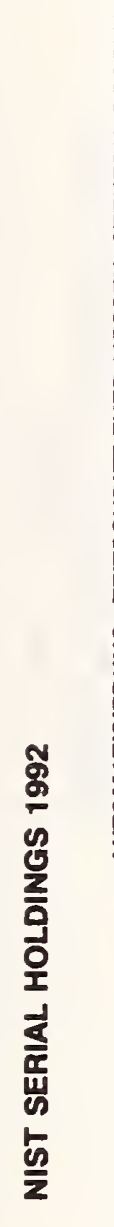

逽

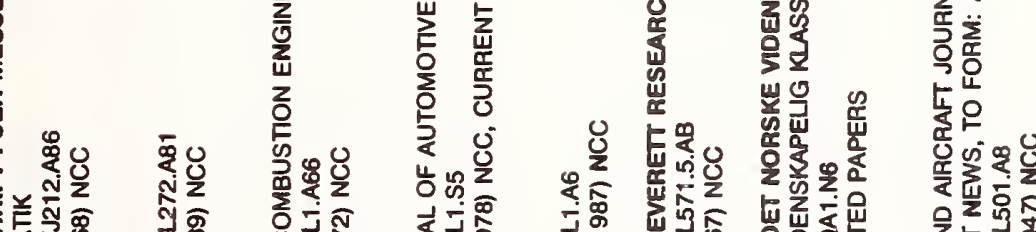

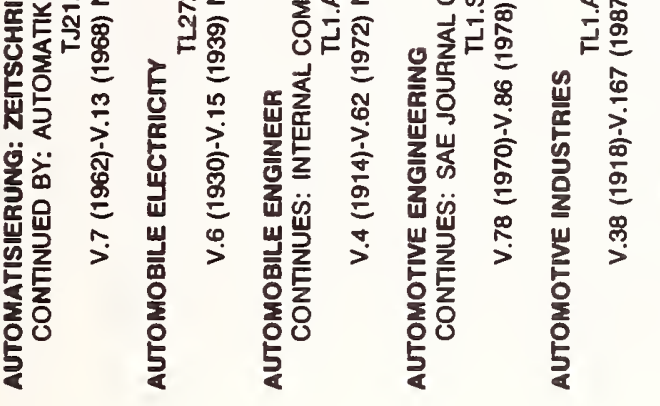

西了约

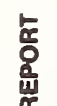

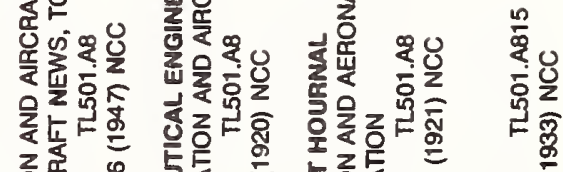

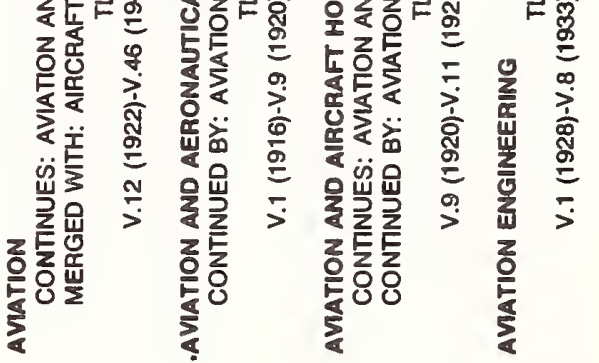

曽

营

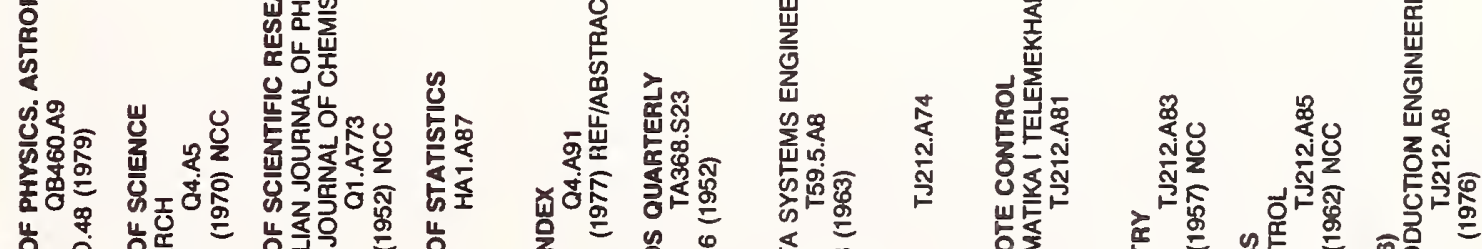
o

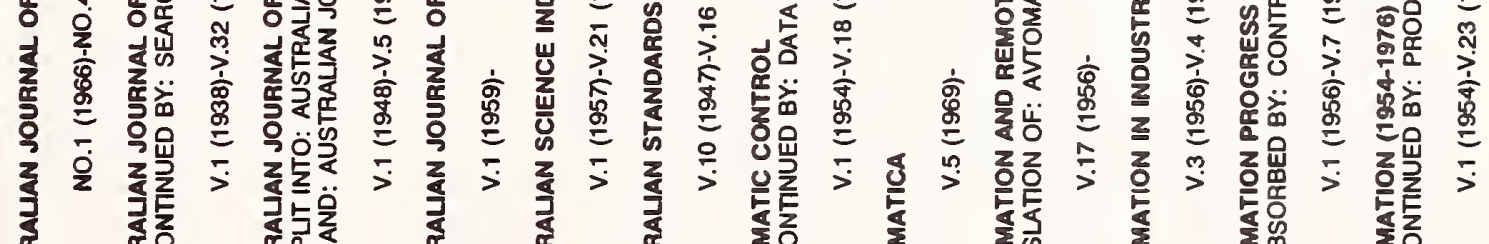

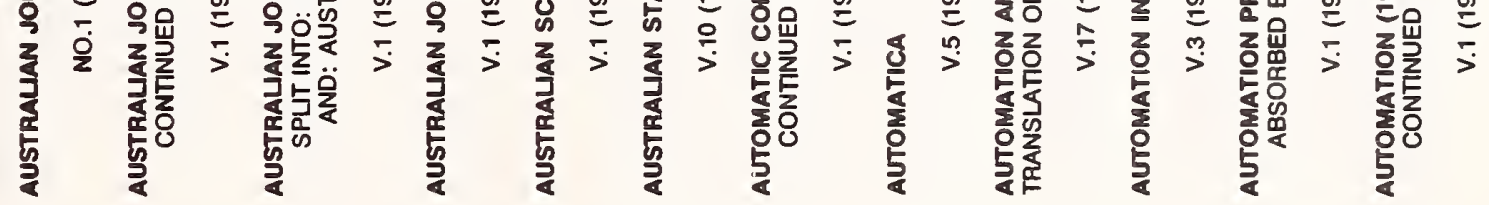




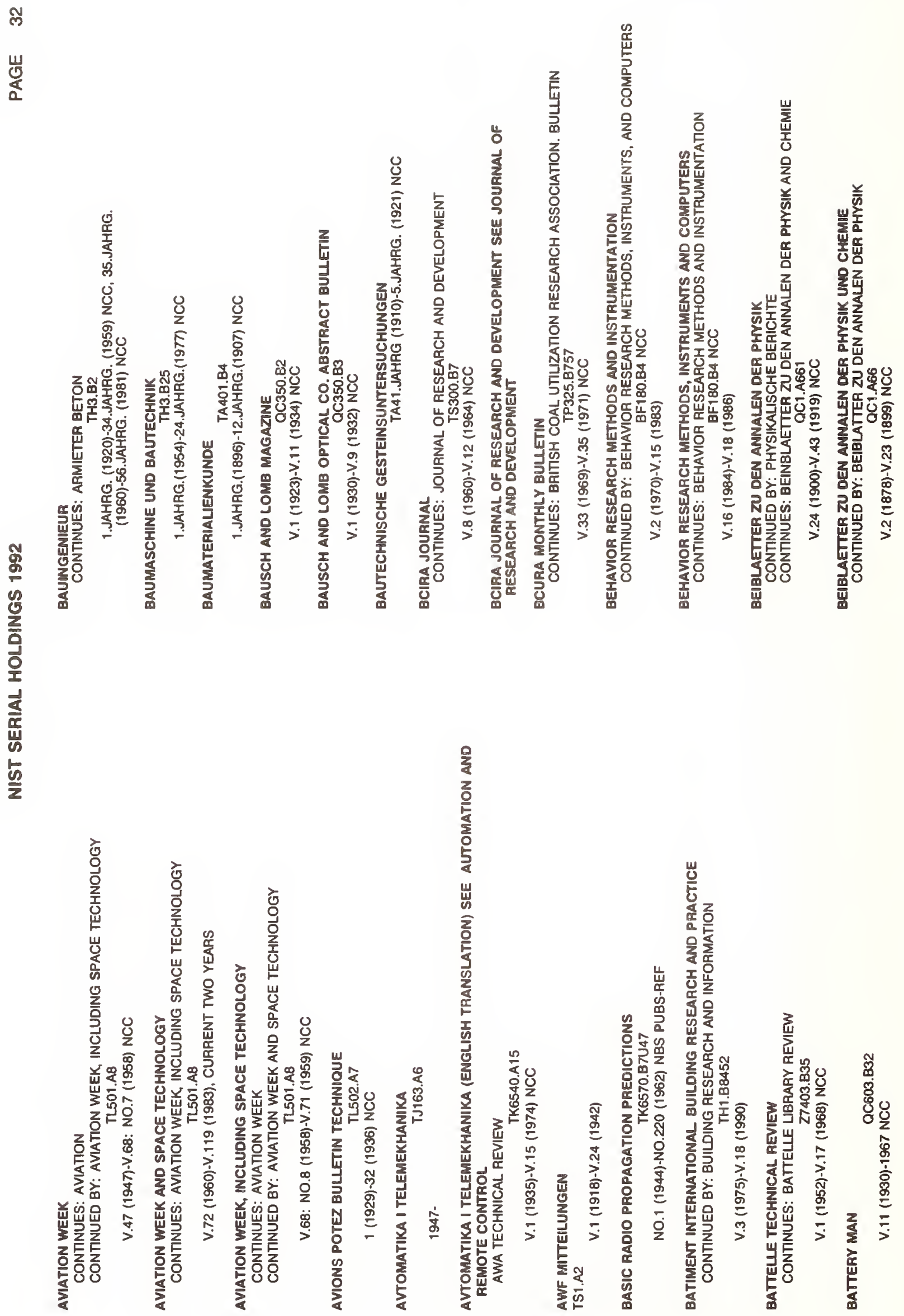




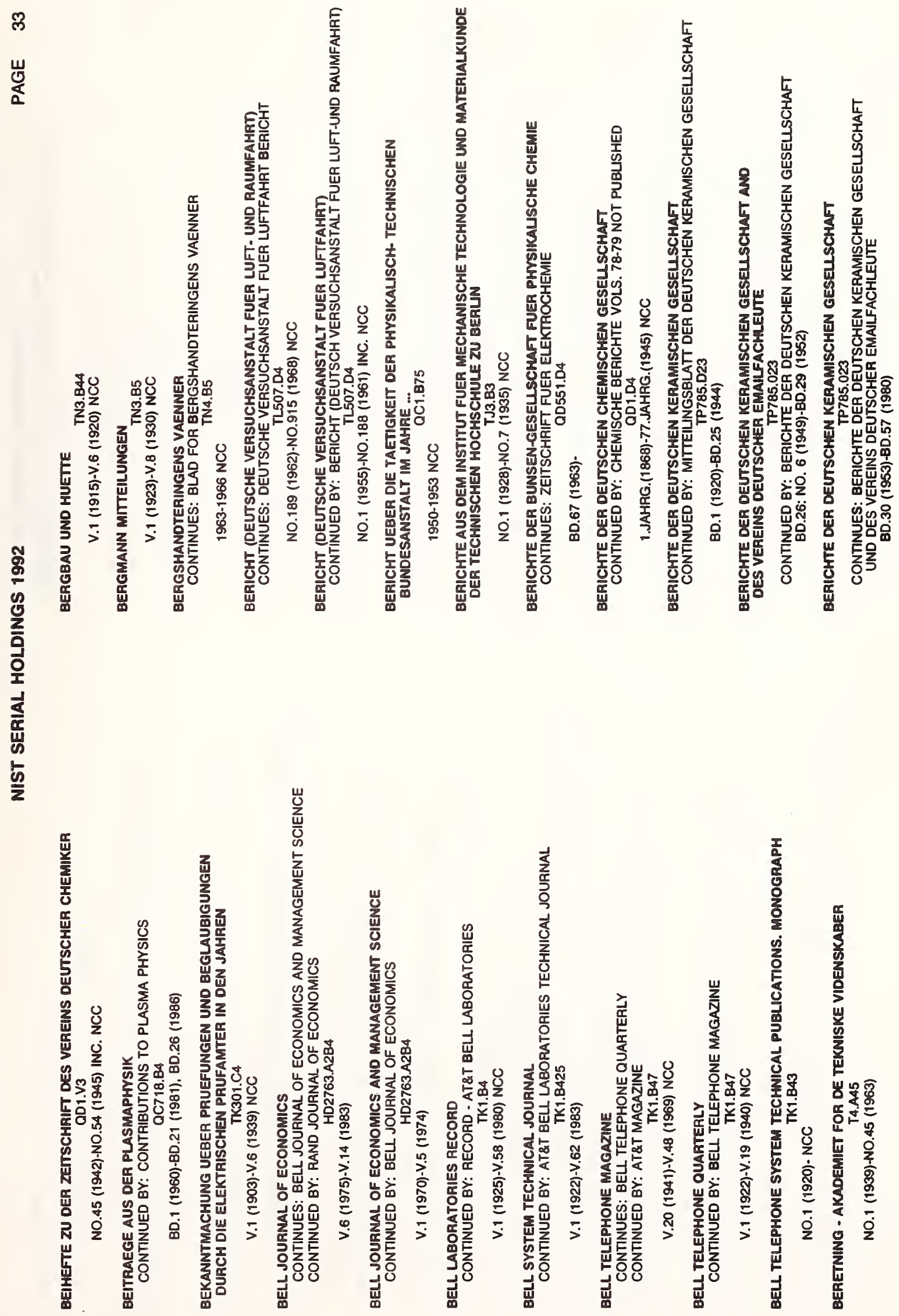


ले

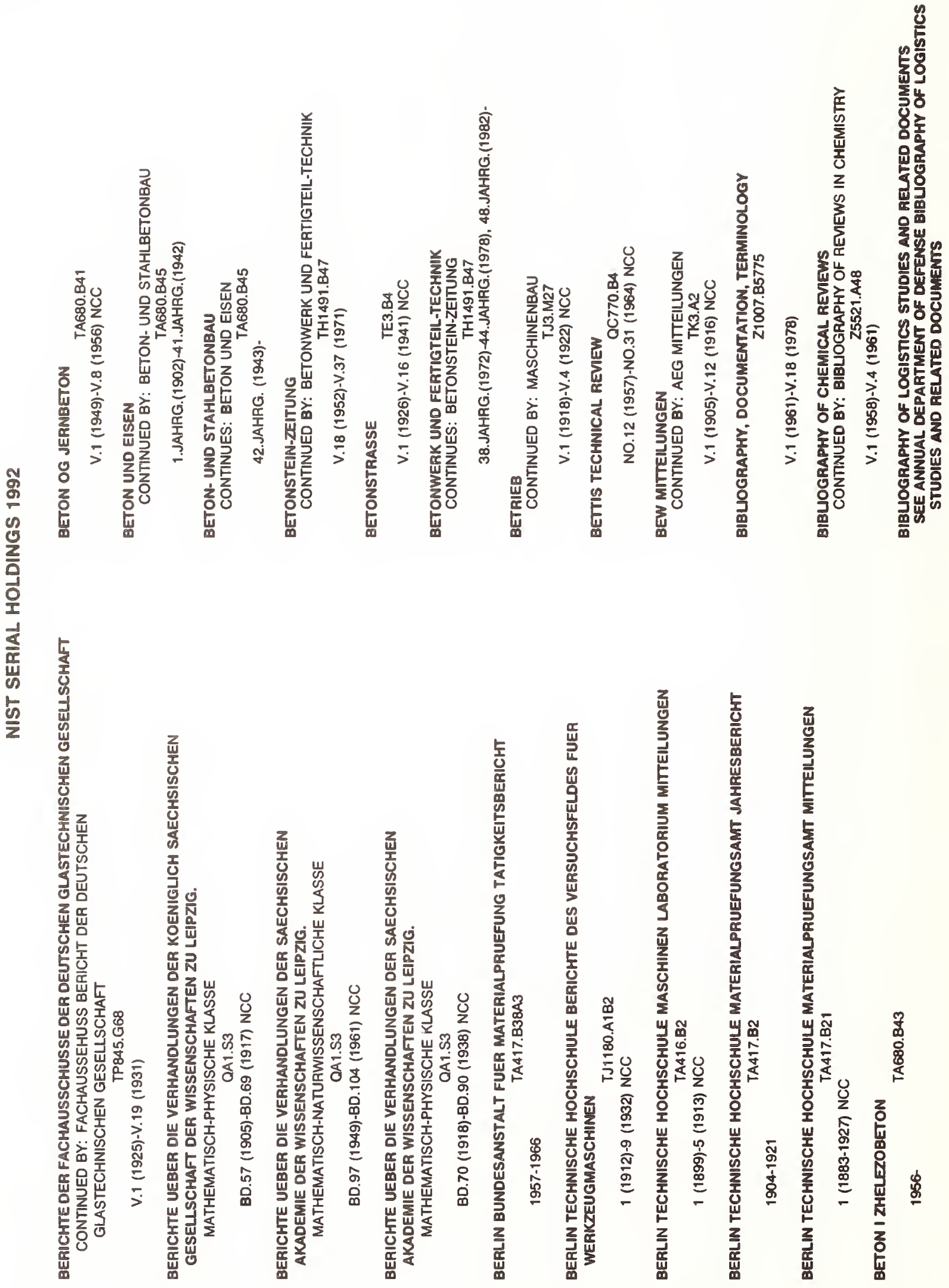




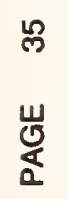
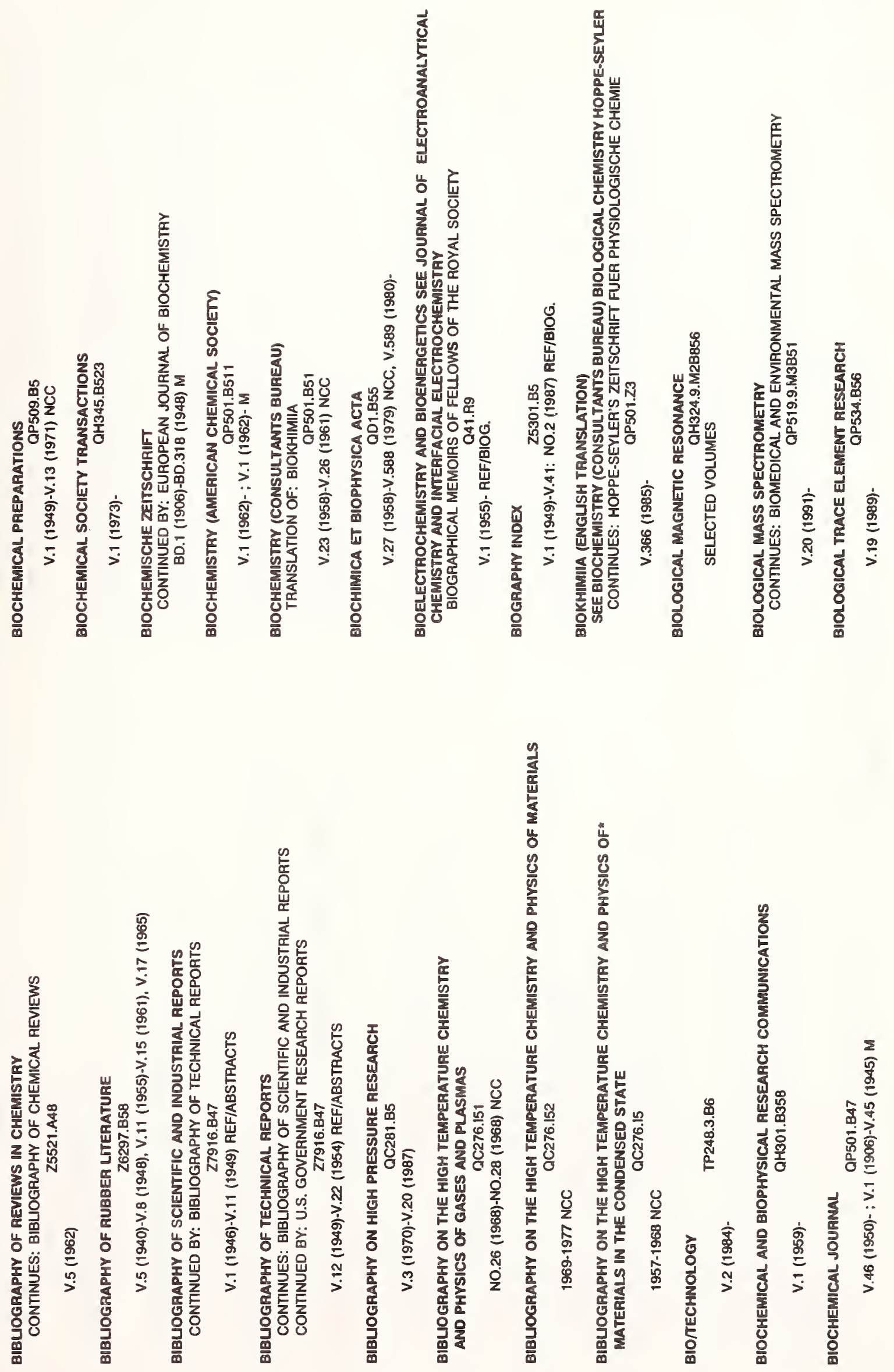
郭

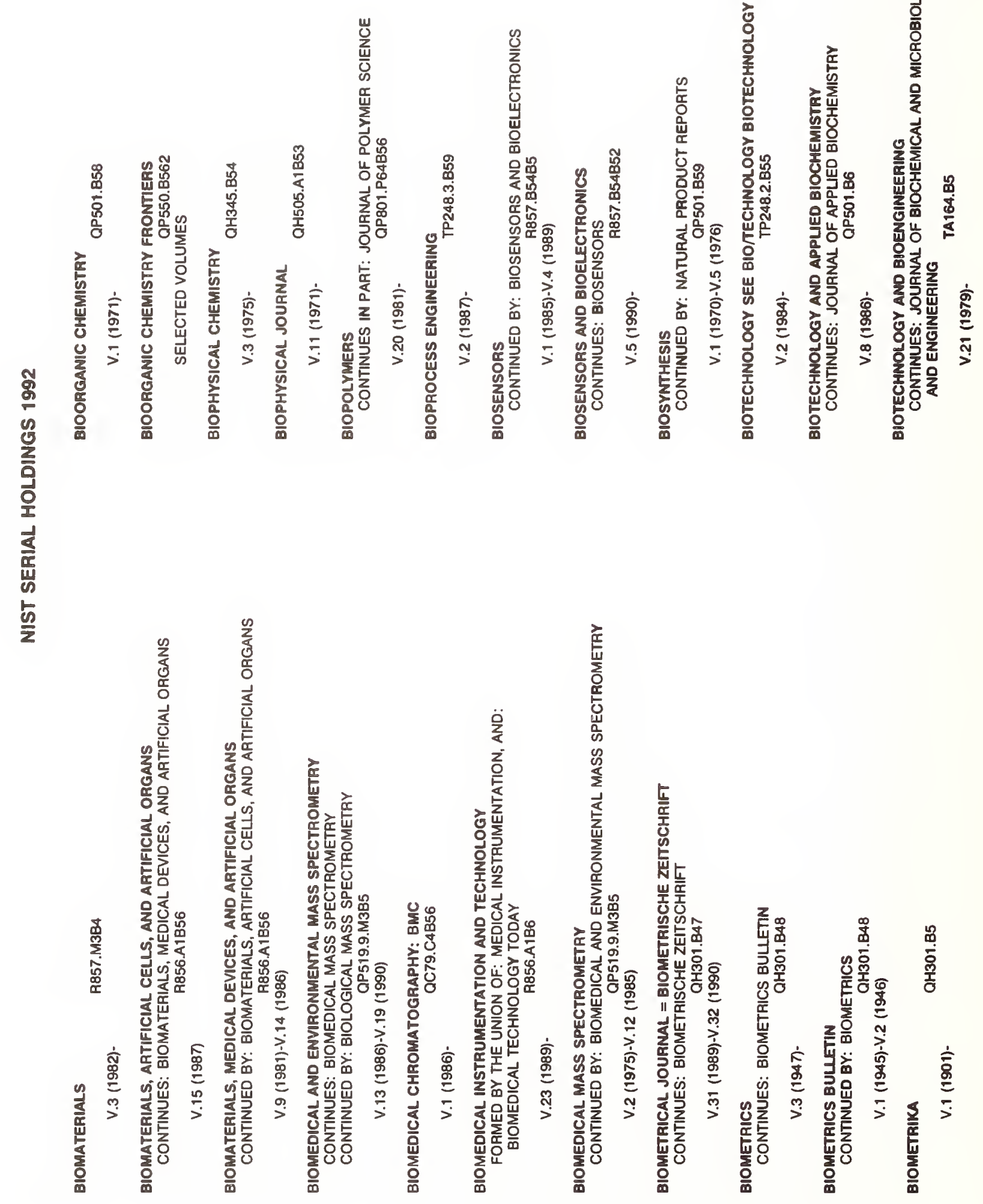


ڤ్

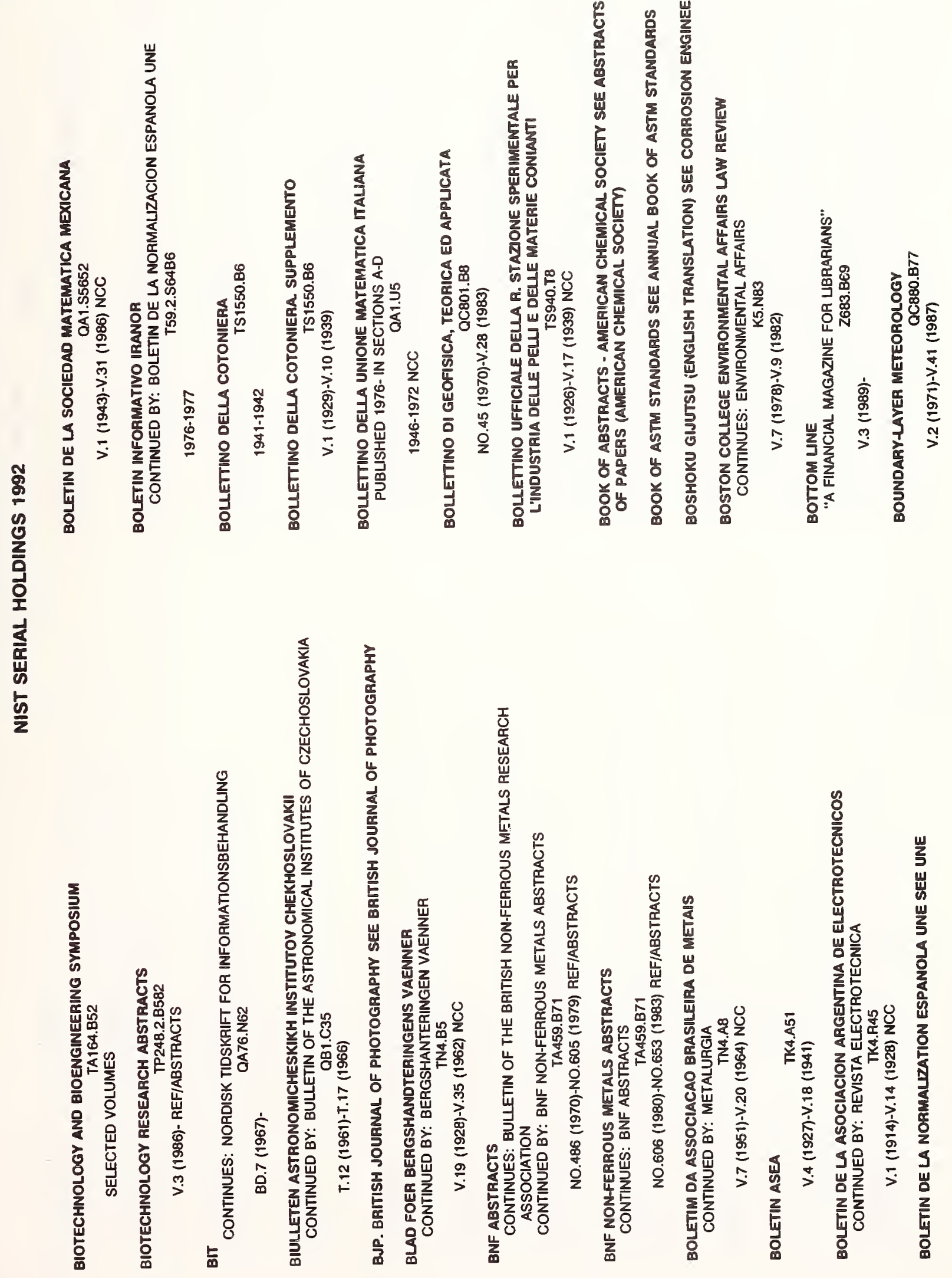




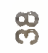

岕
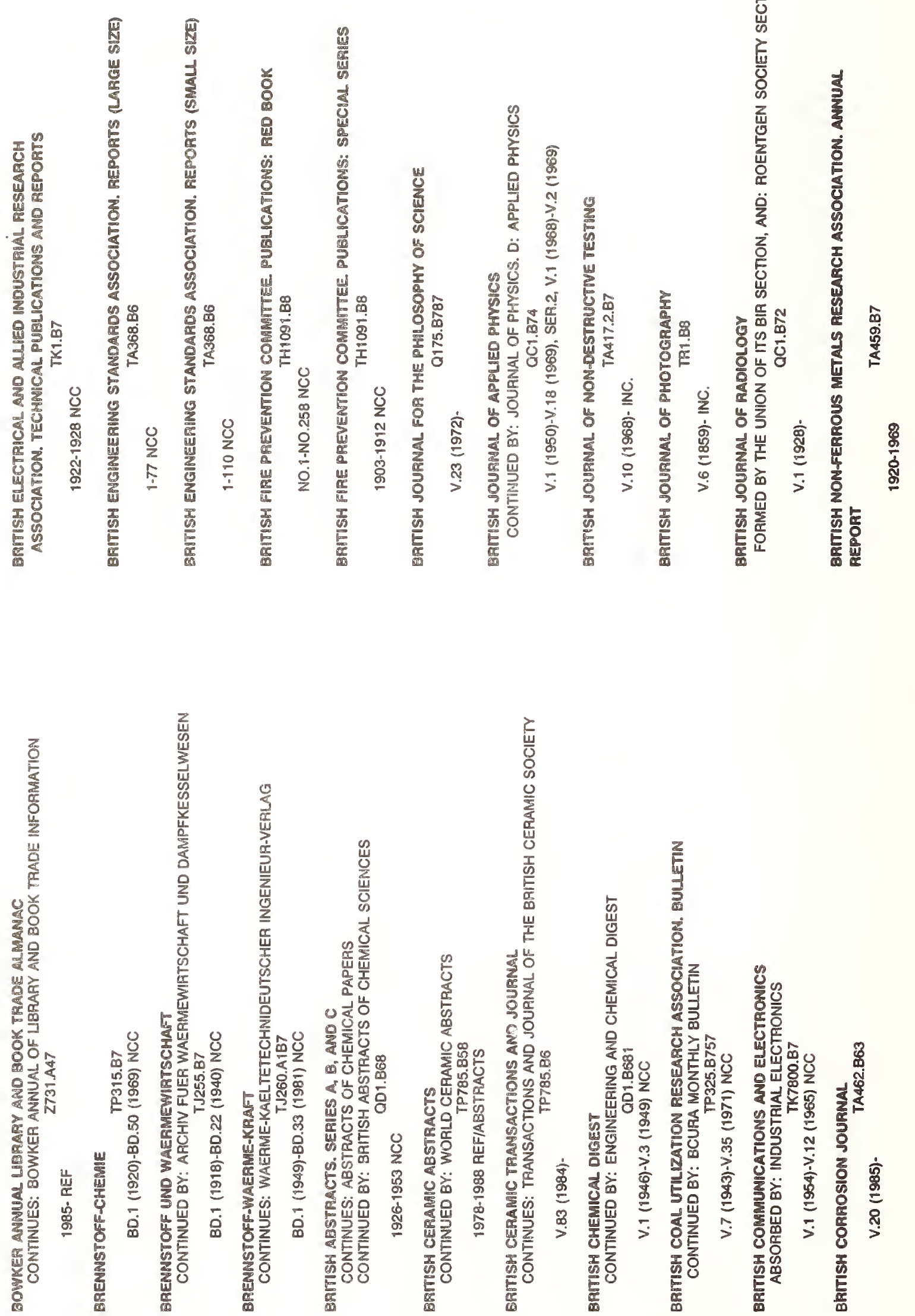
$\frac{1}{2}$

ํํำ
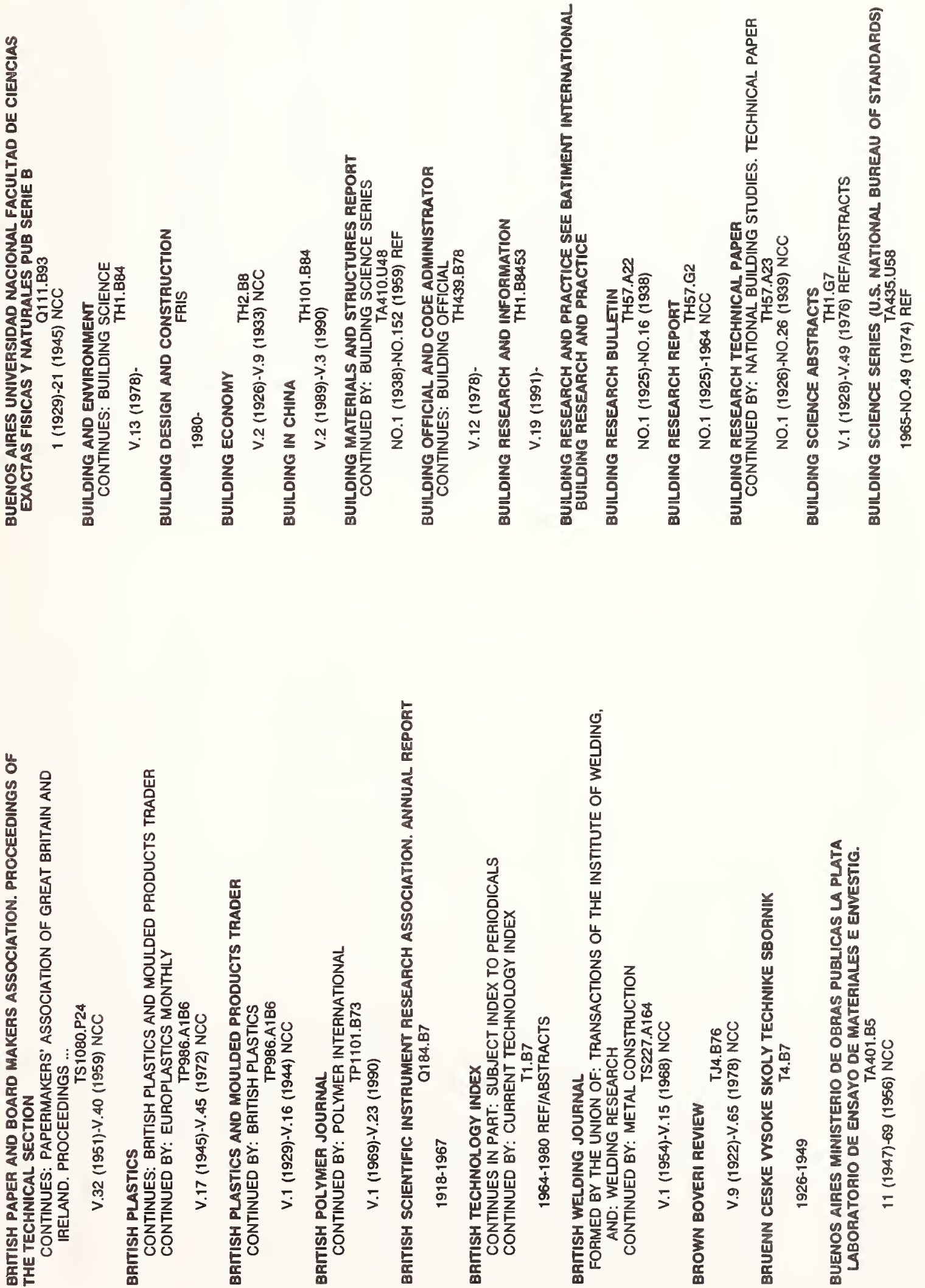

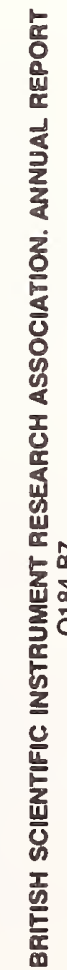

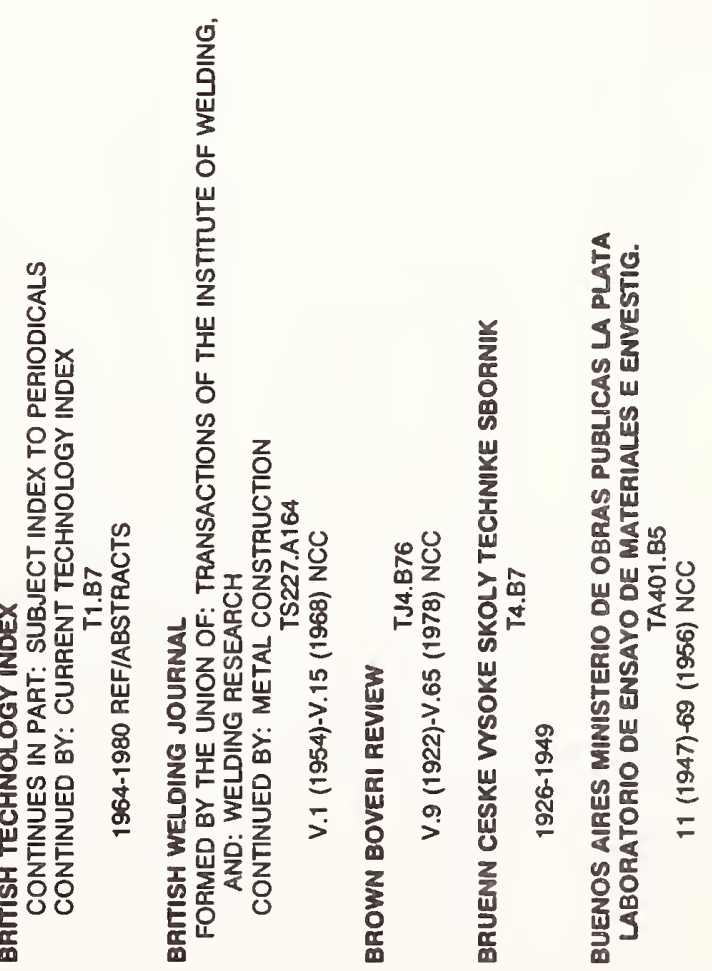




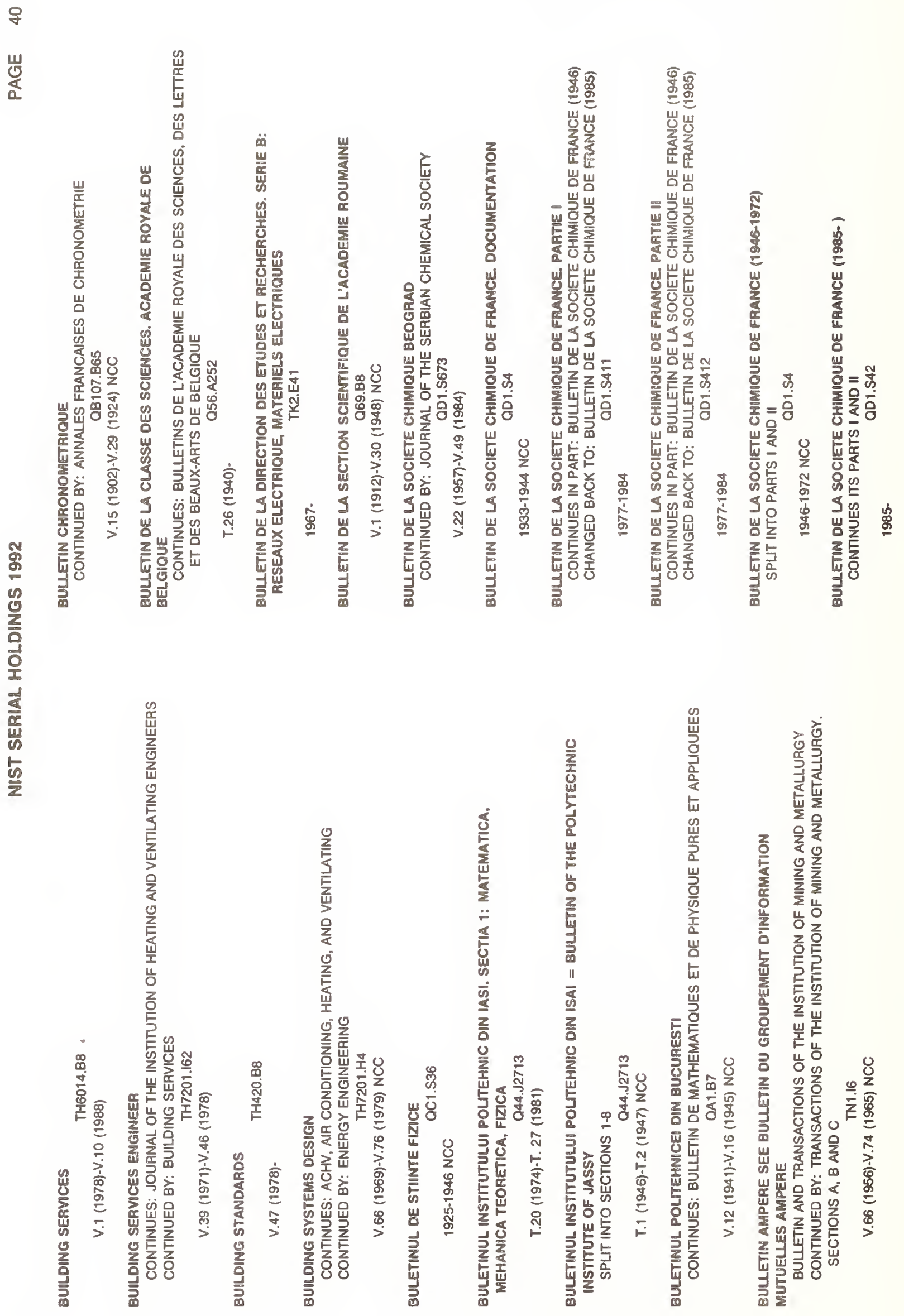



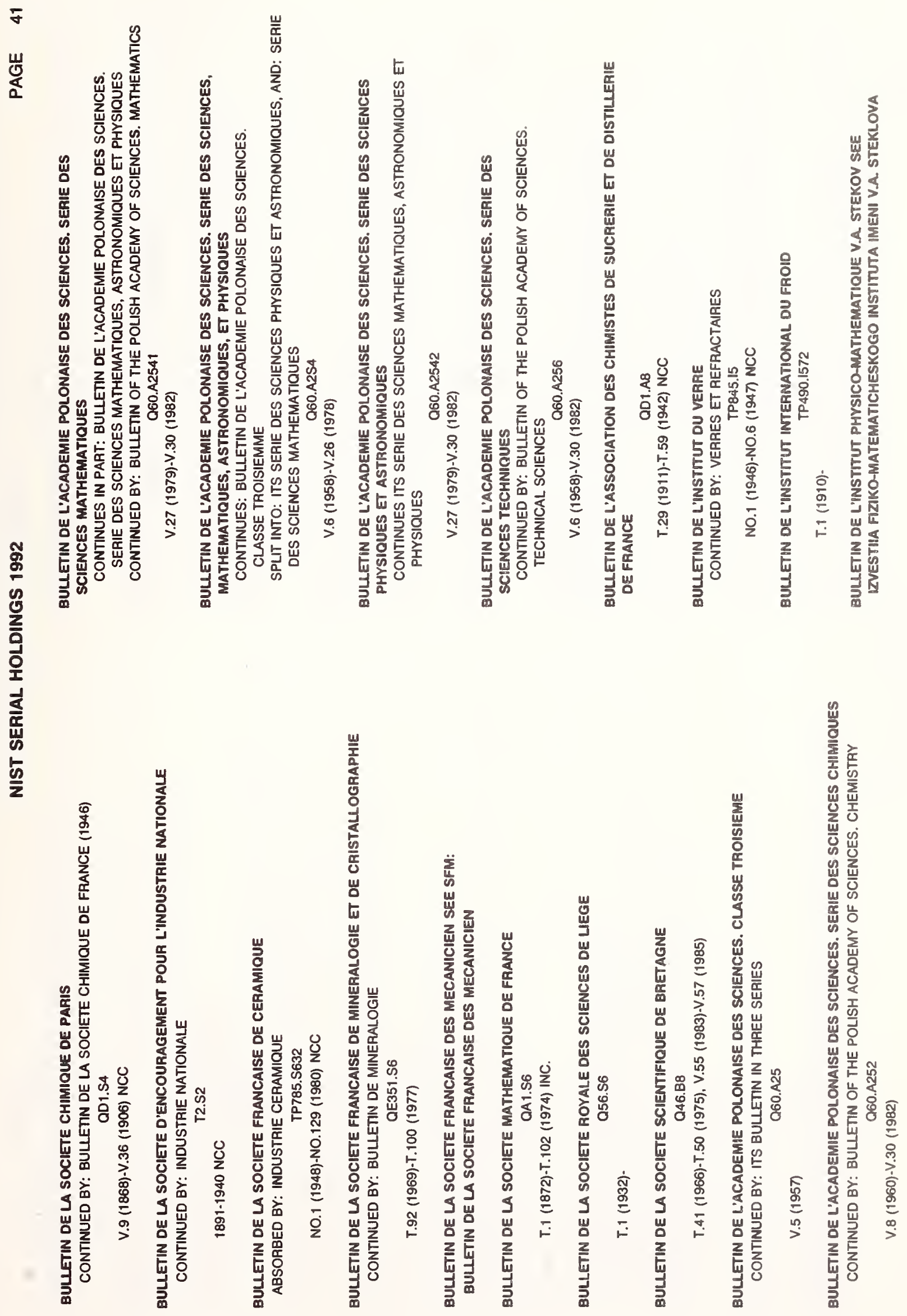


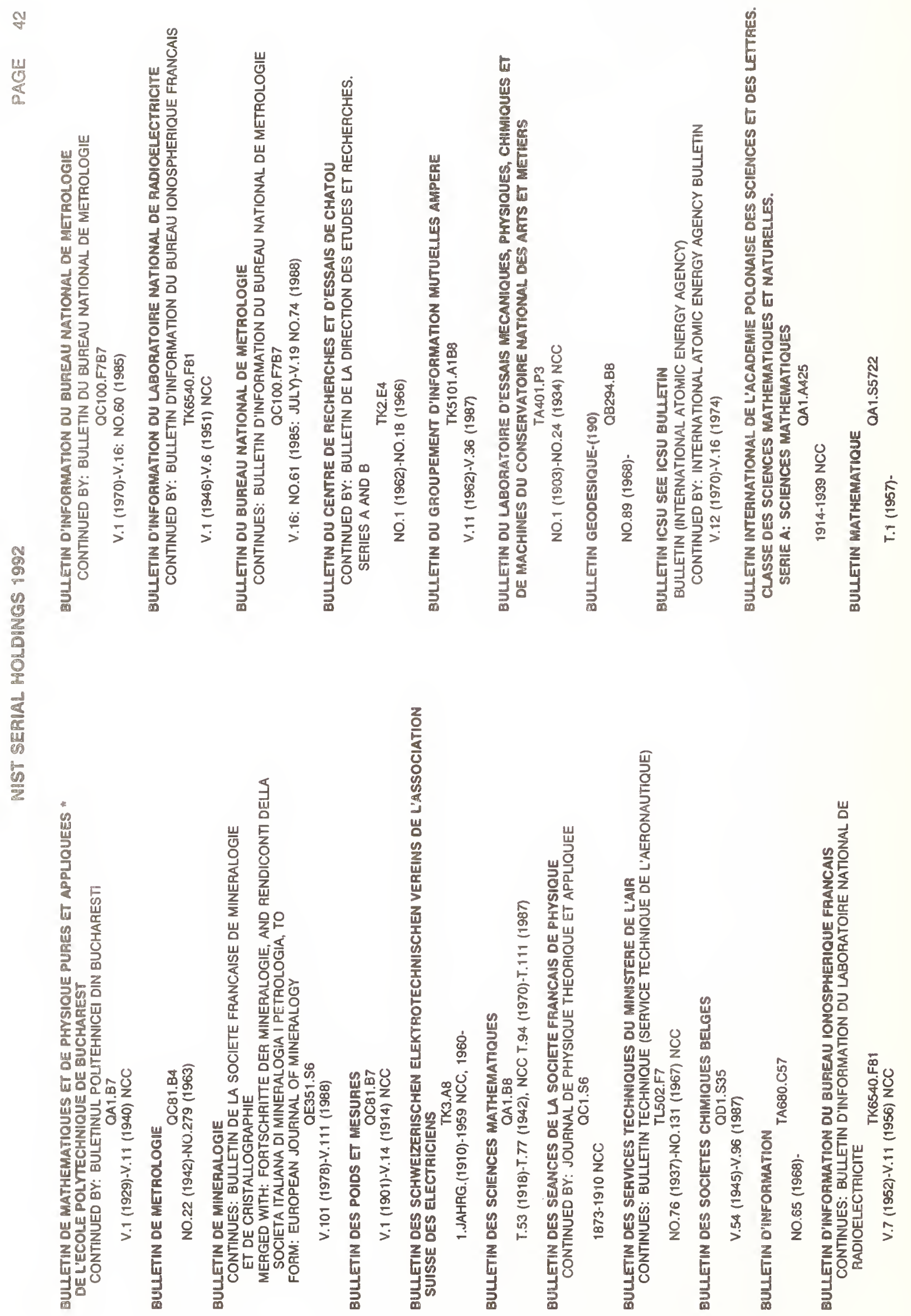


岁

证

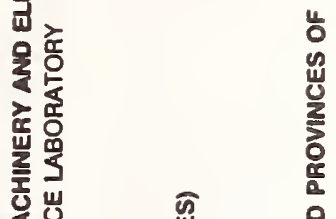

孪岂

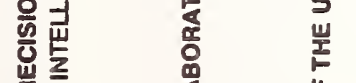

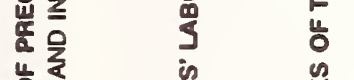

岁交㹂

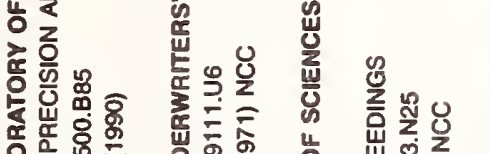

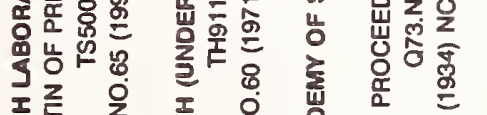

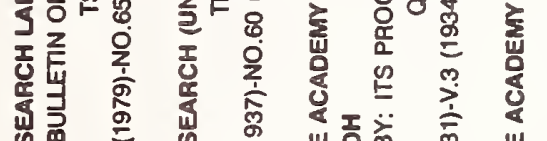

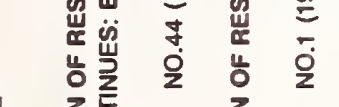

รั

क्ष

호을

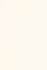

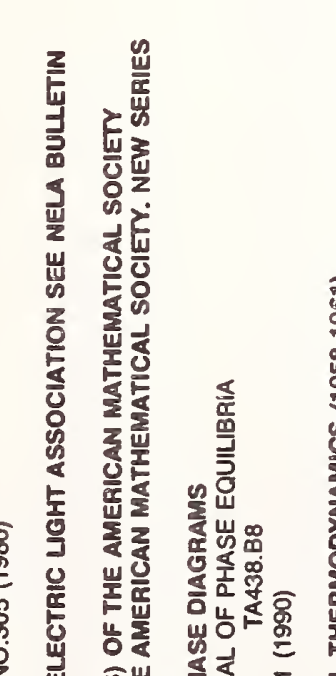

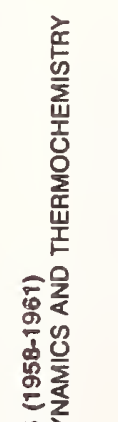

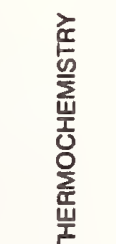

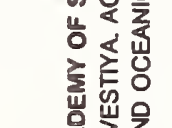

岩岩是 宛 岩竞焉

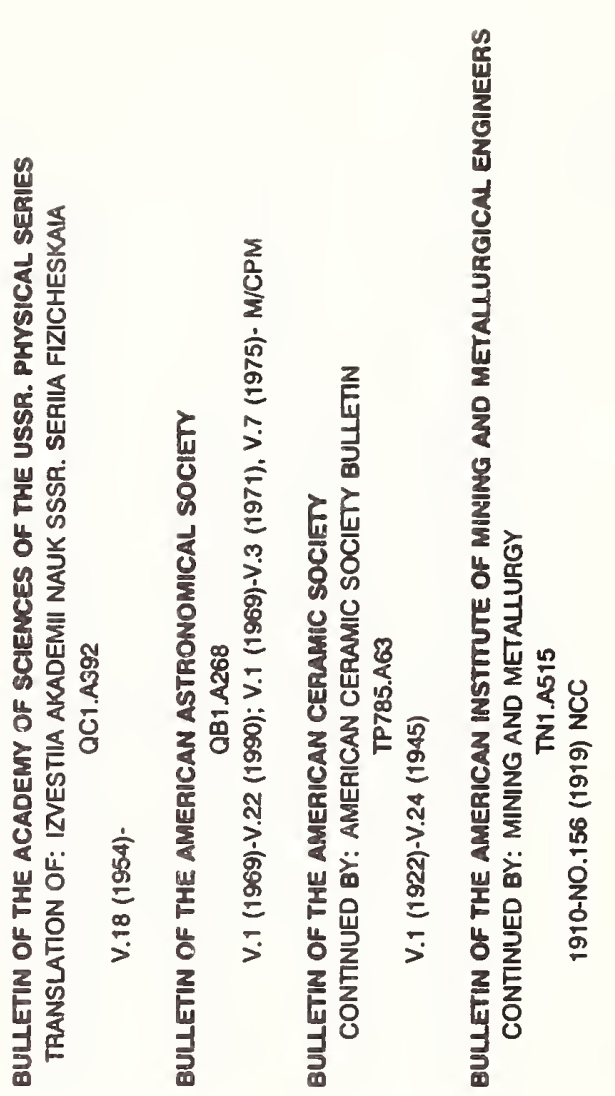




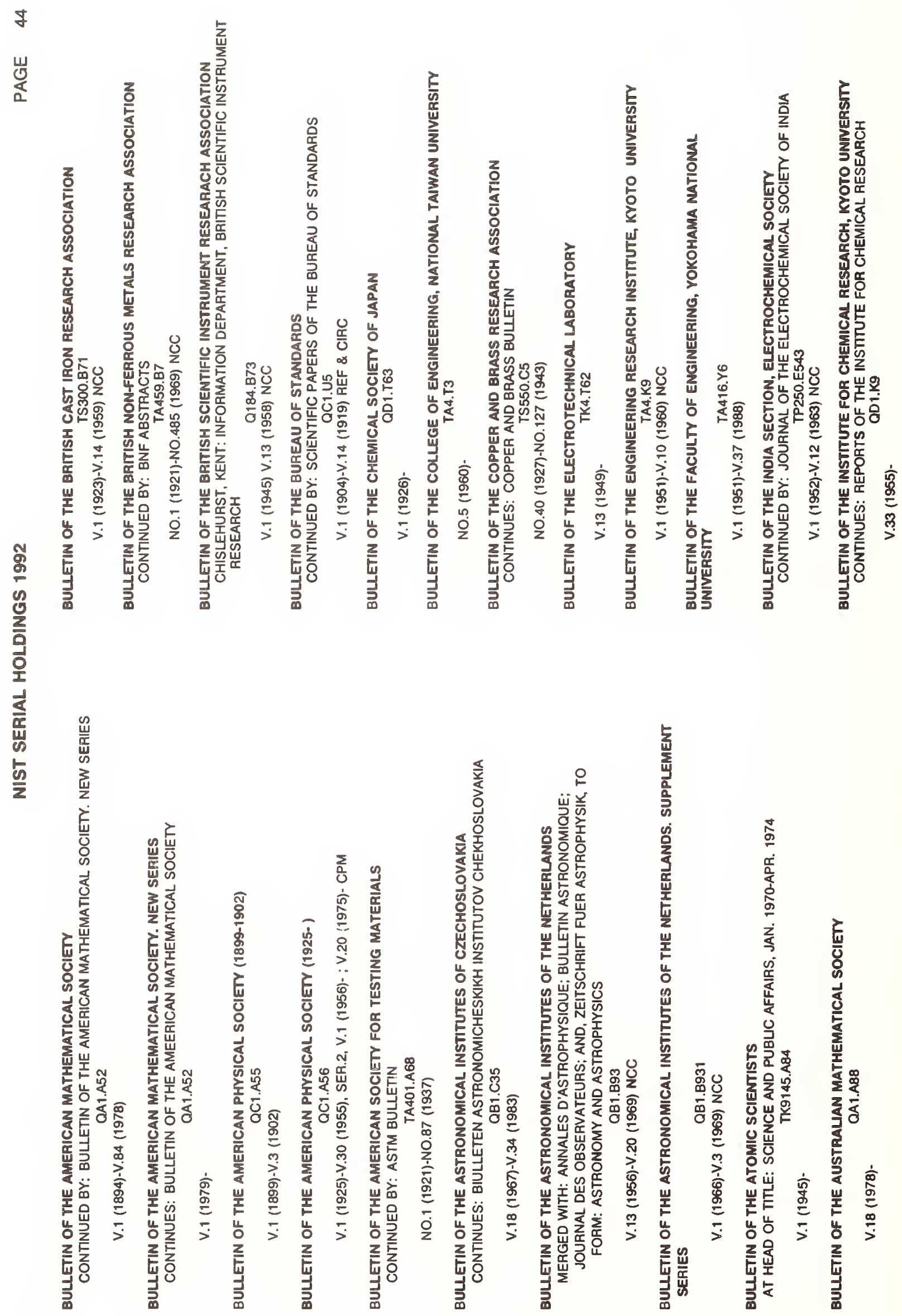



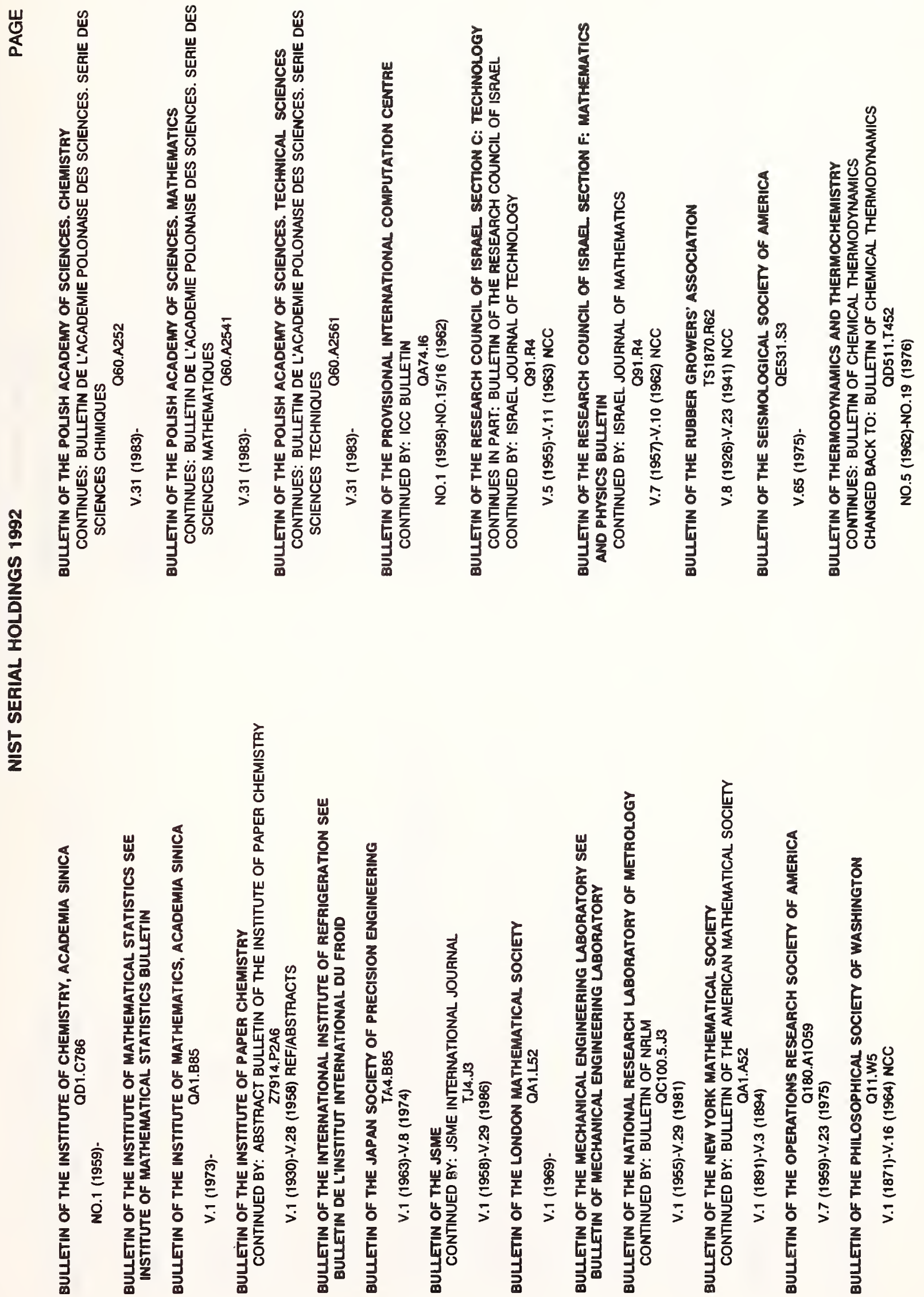
啱
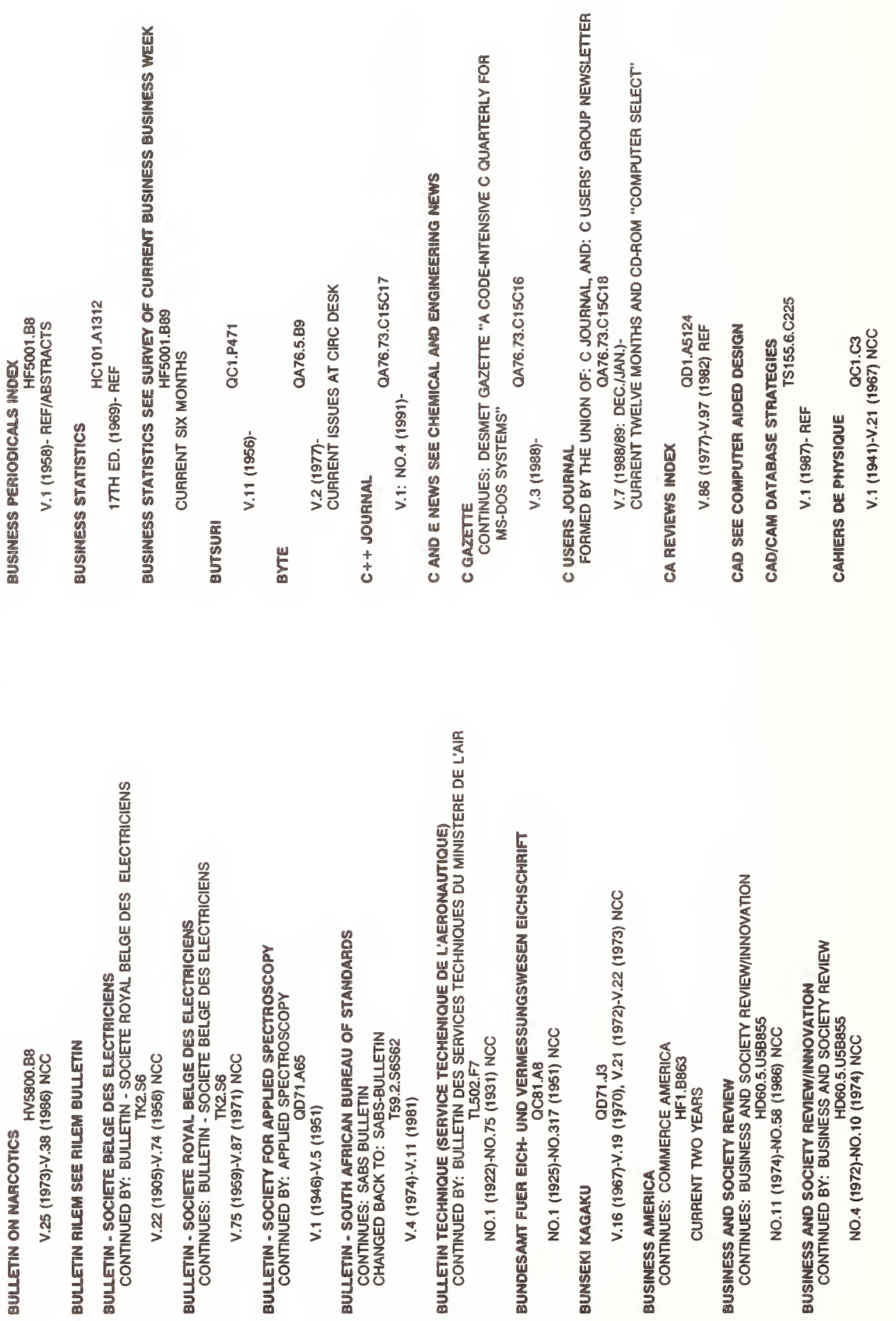

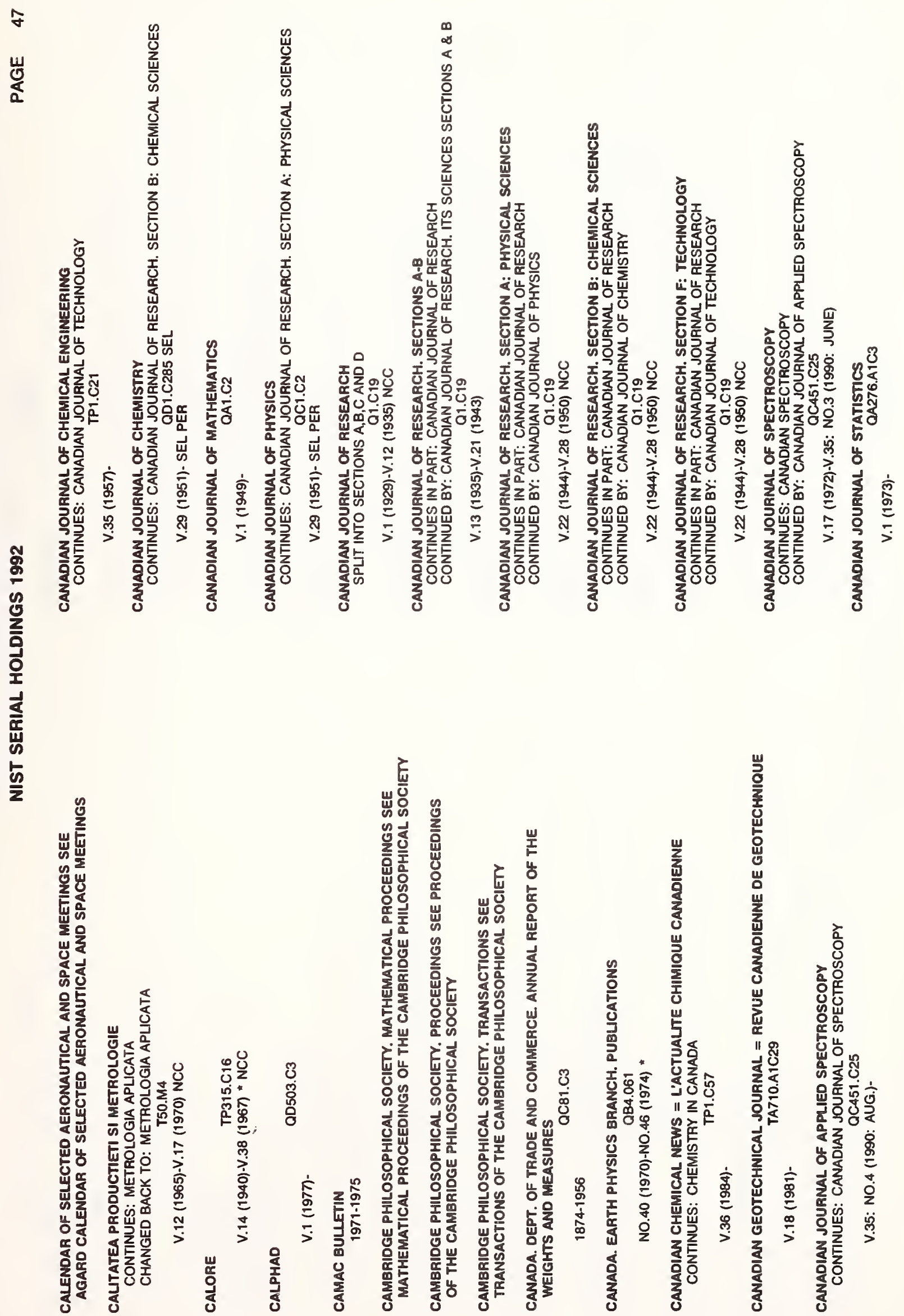


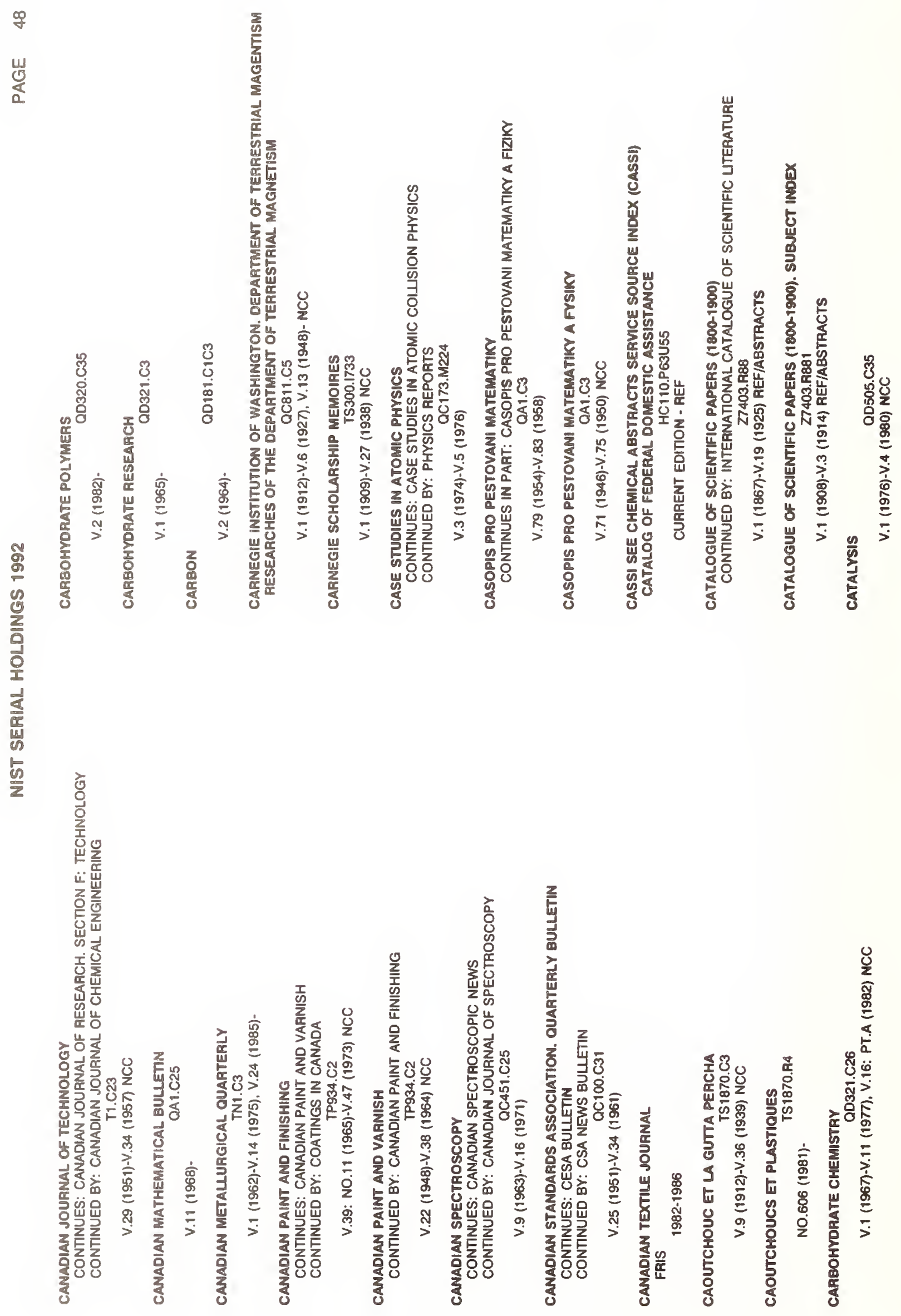




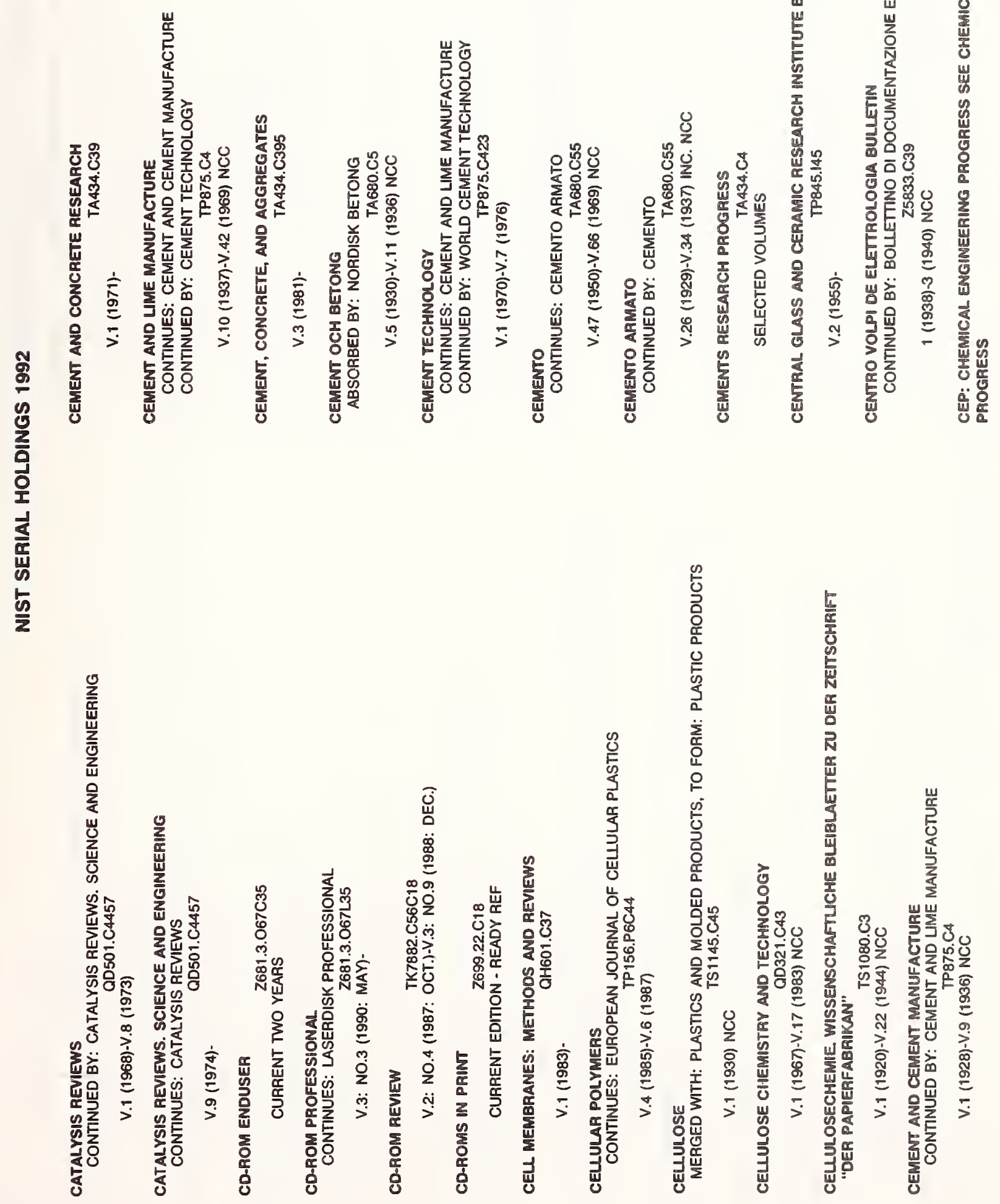



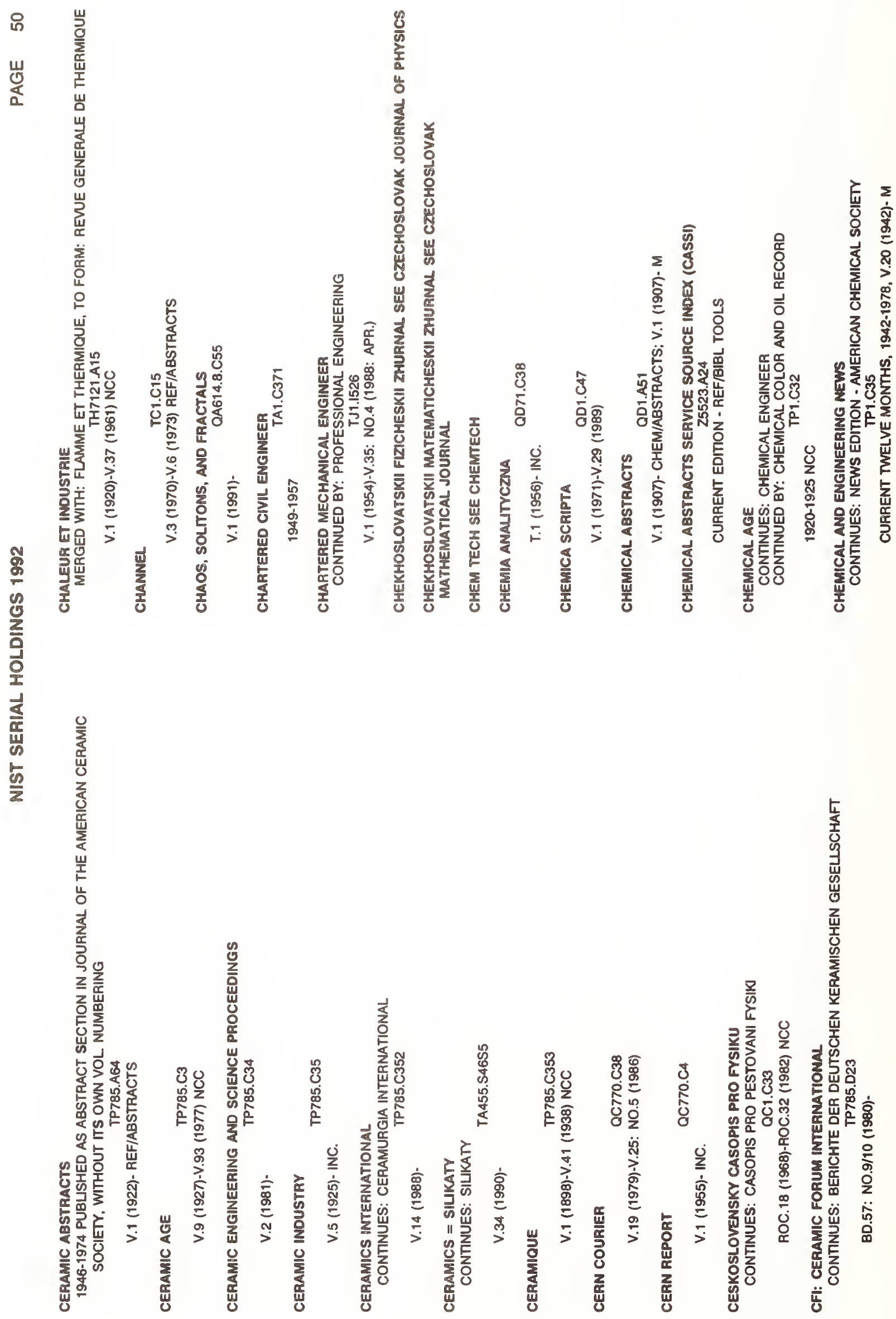


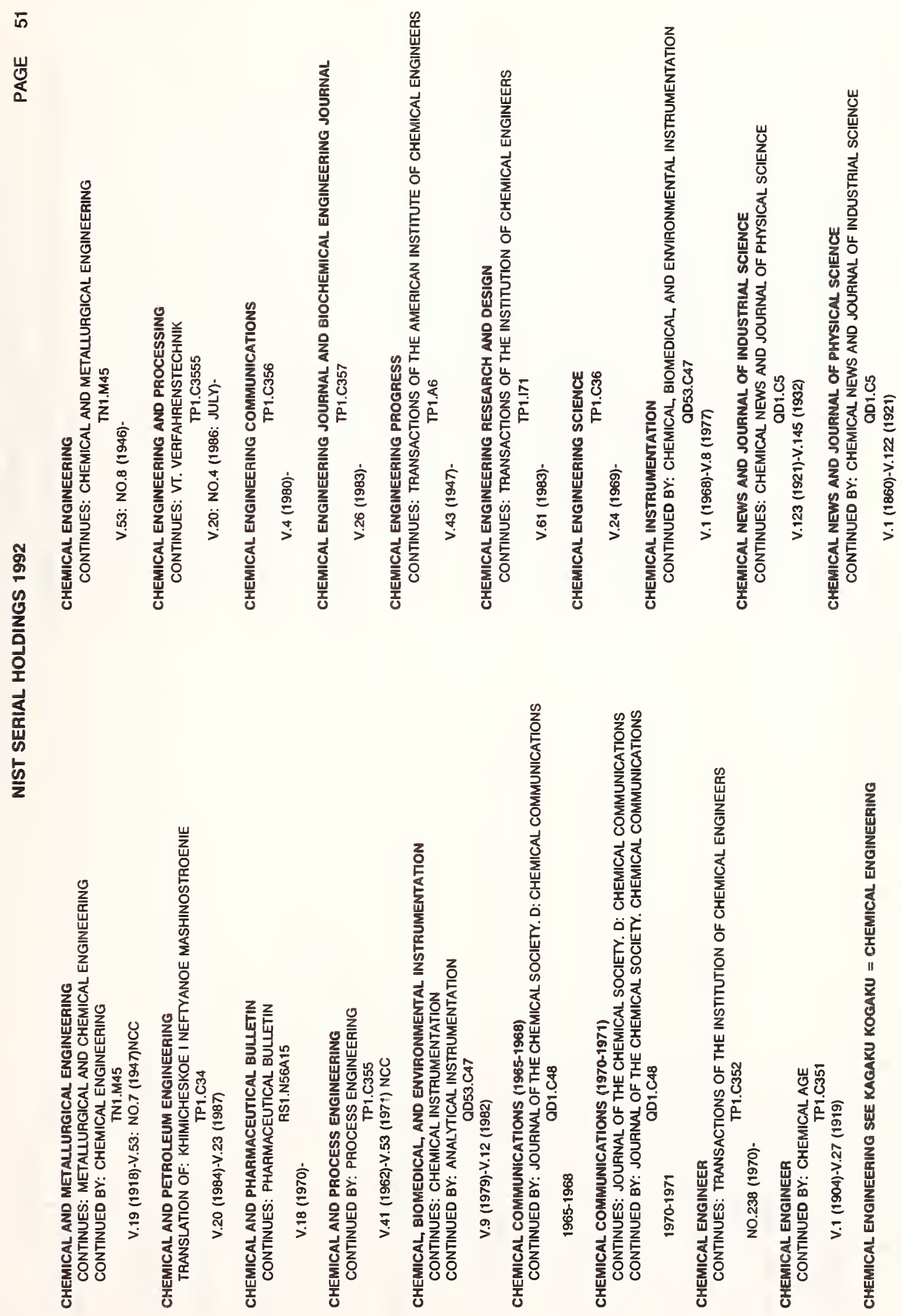


กี

㟧

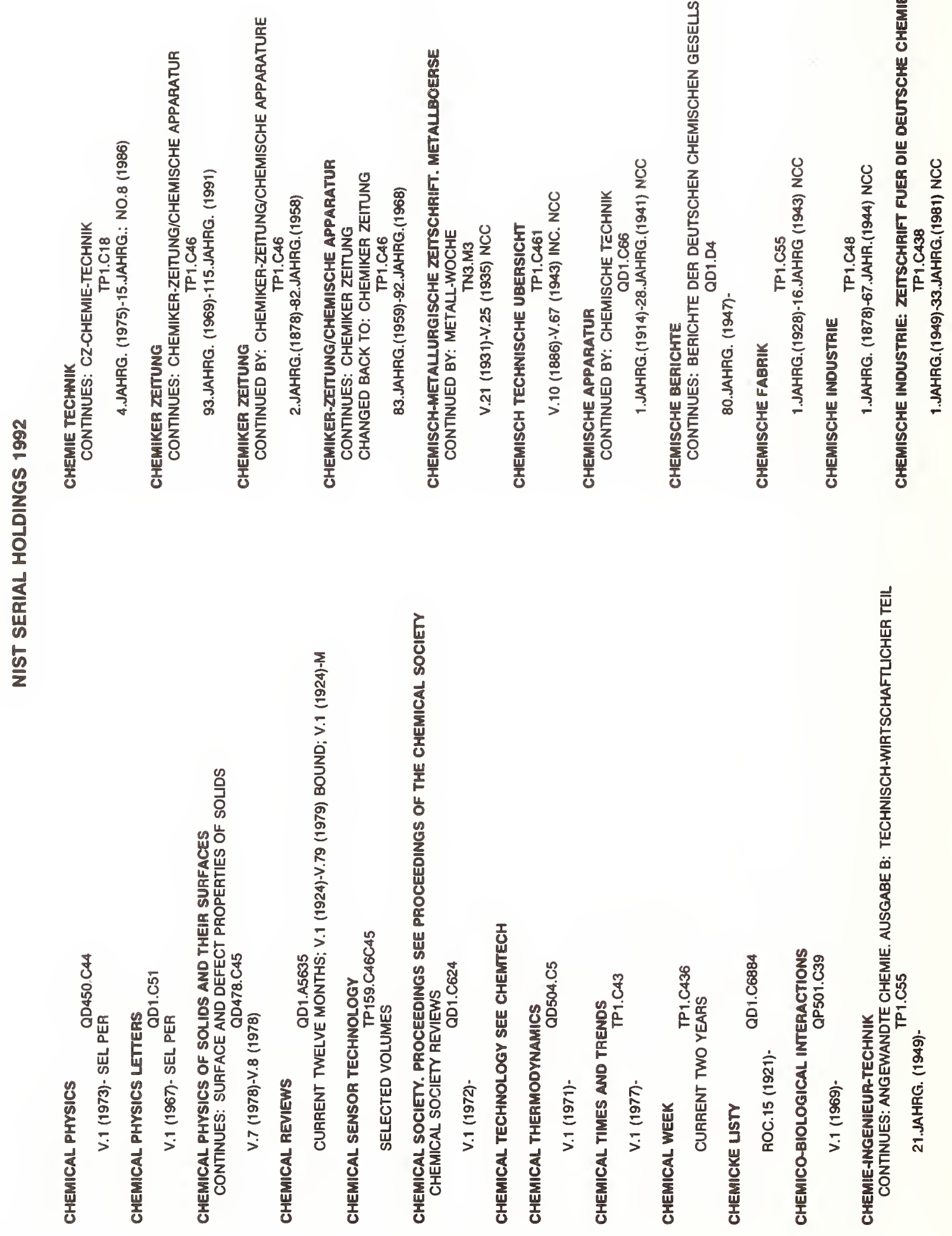


ถึ

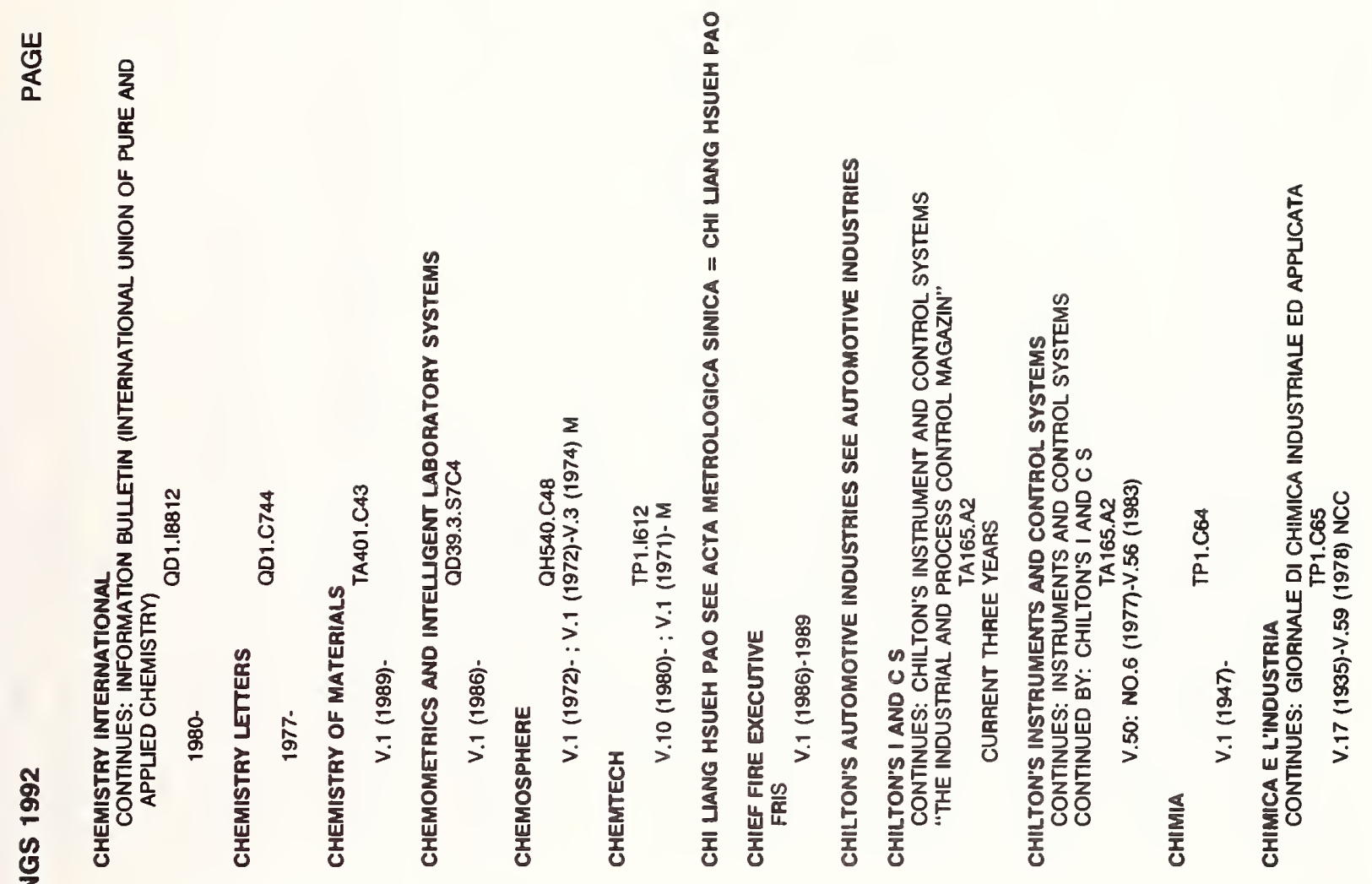

$\frac{5}{2}$

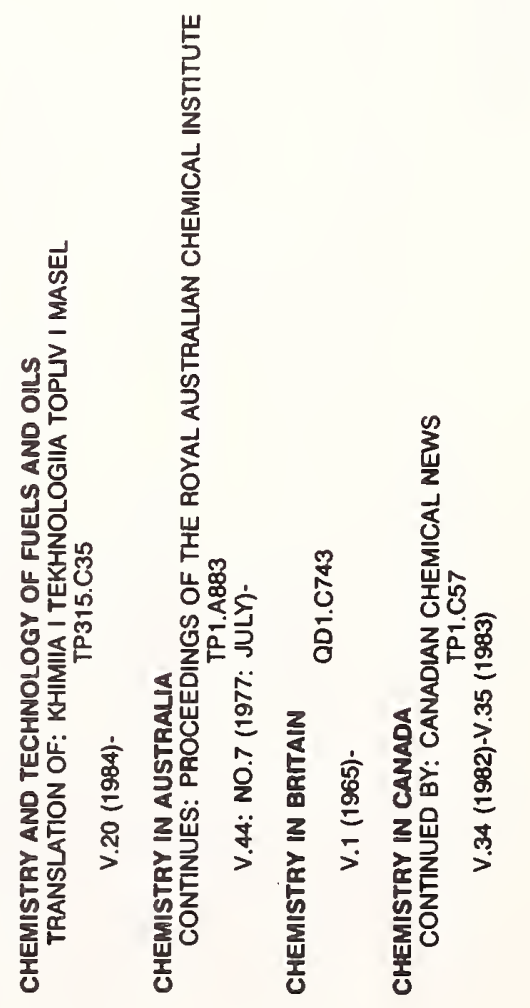


品

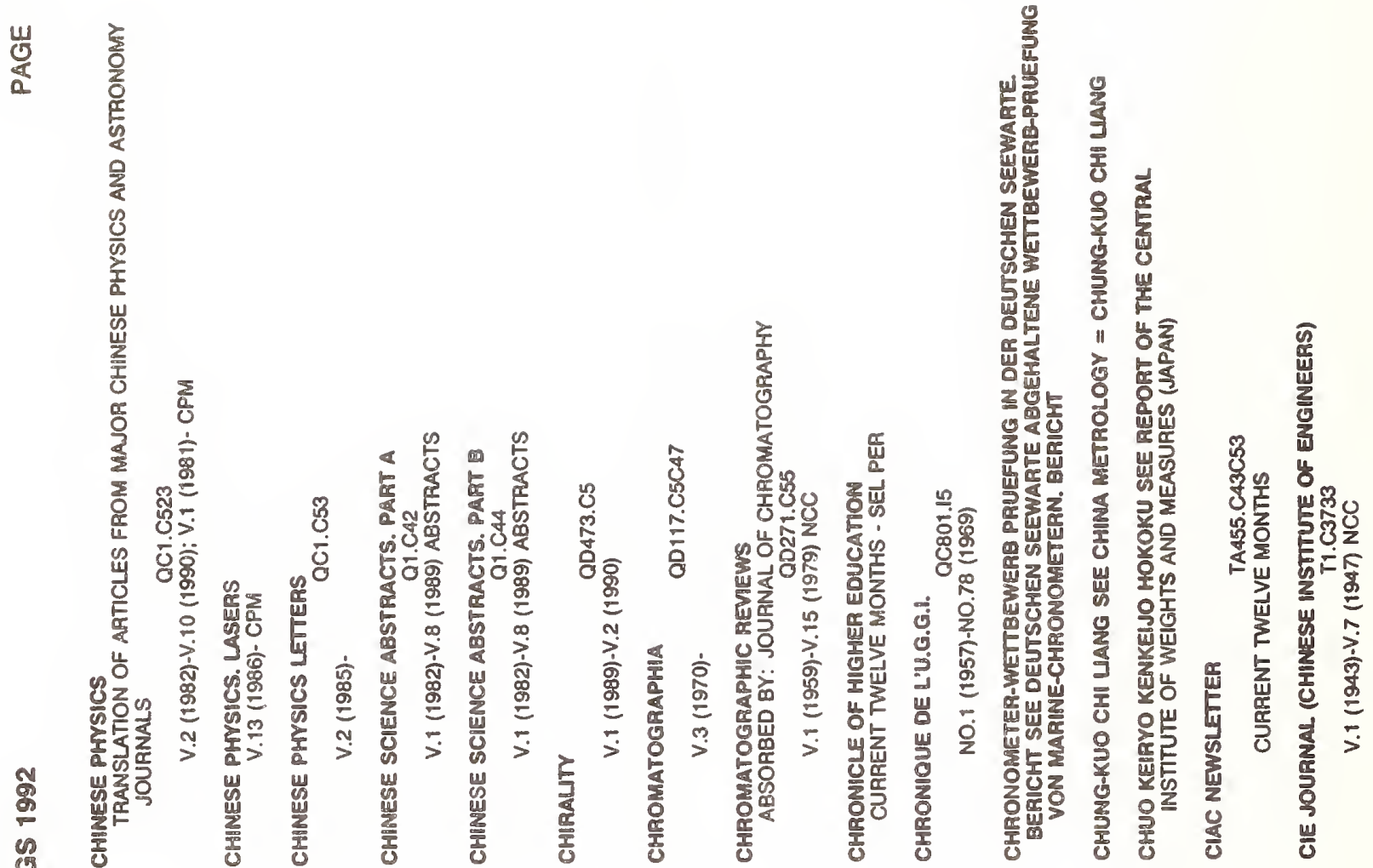

站

喜

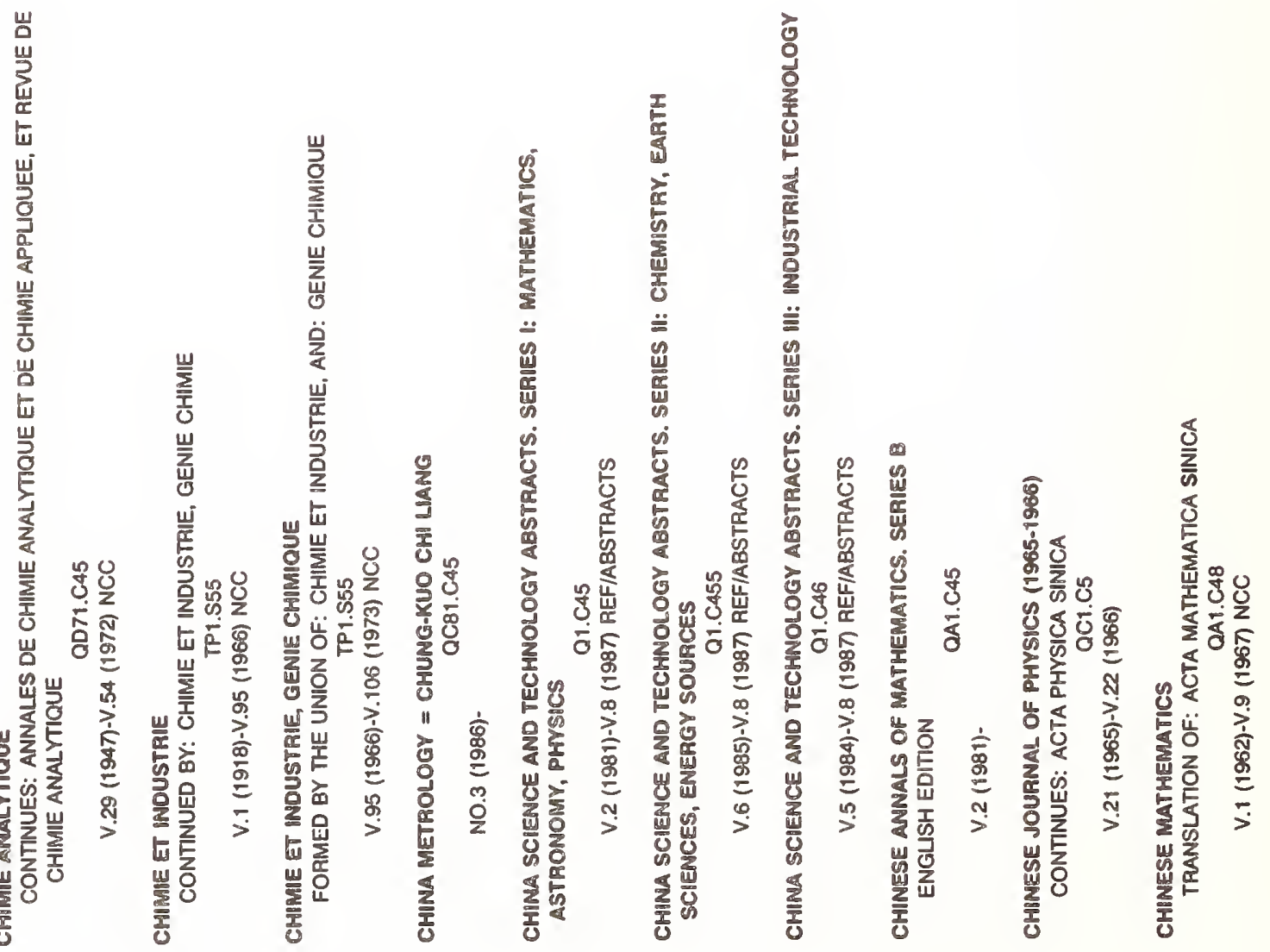


崫

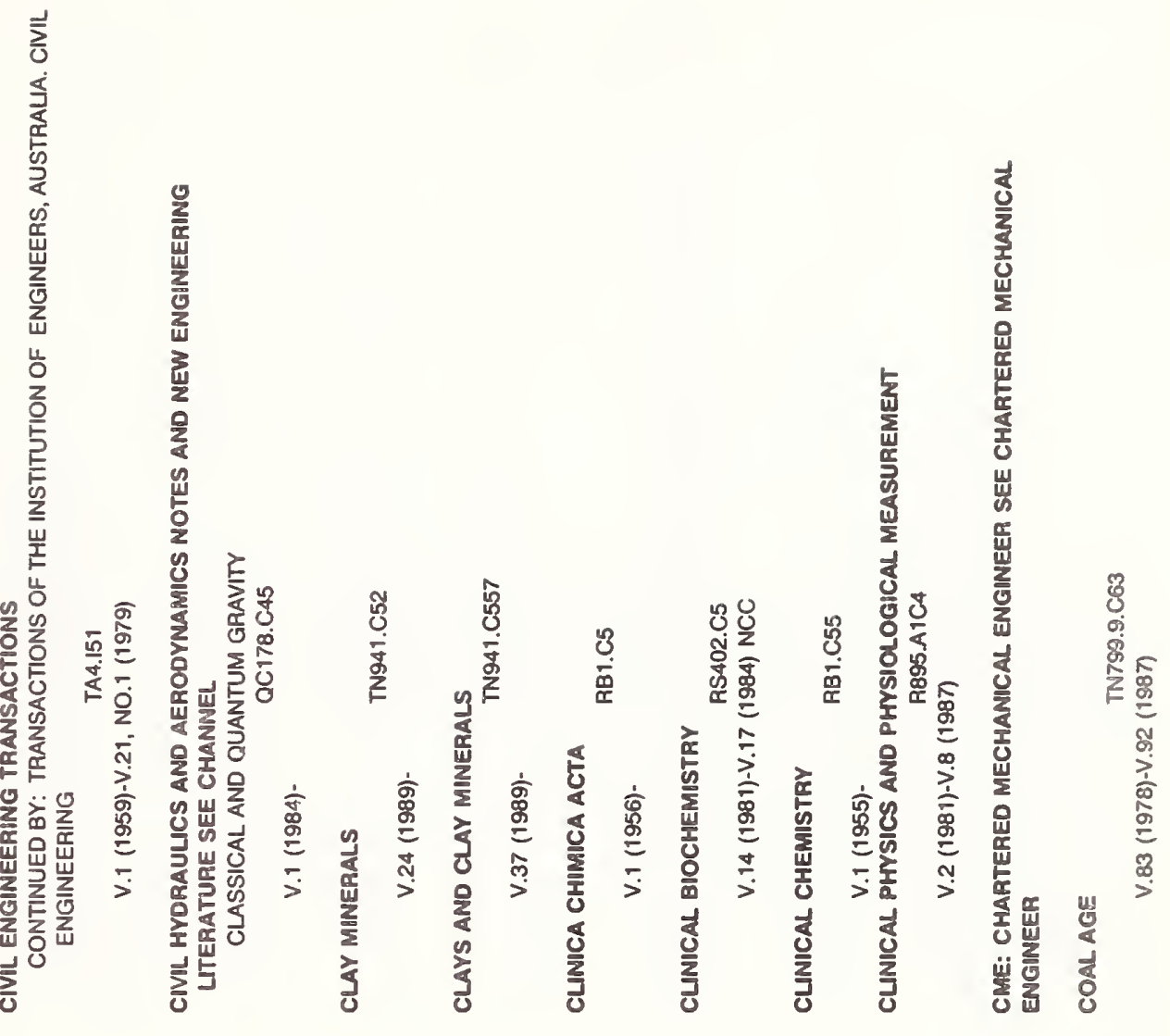

뜸

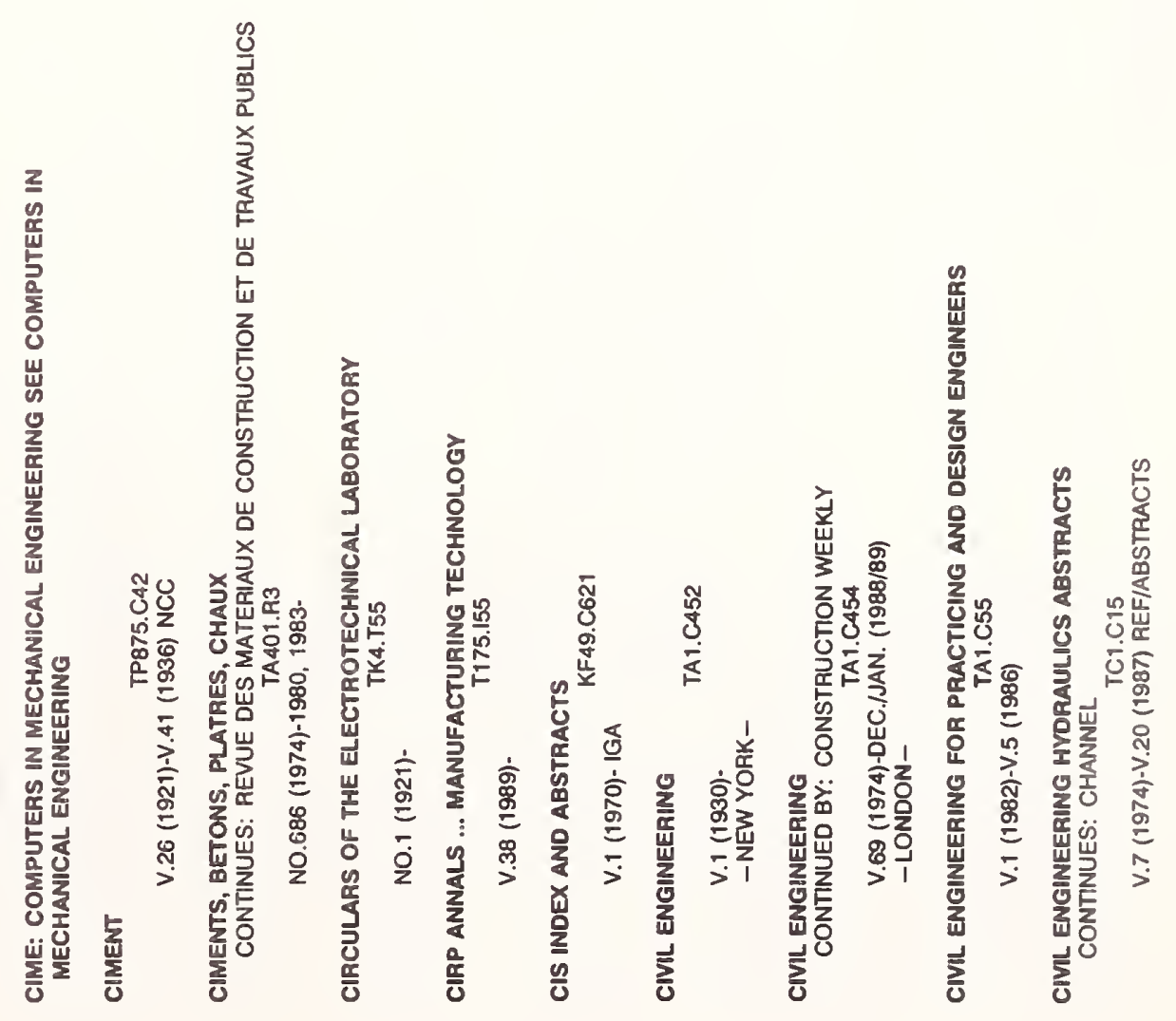




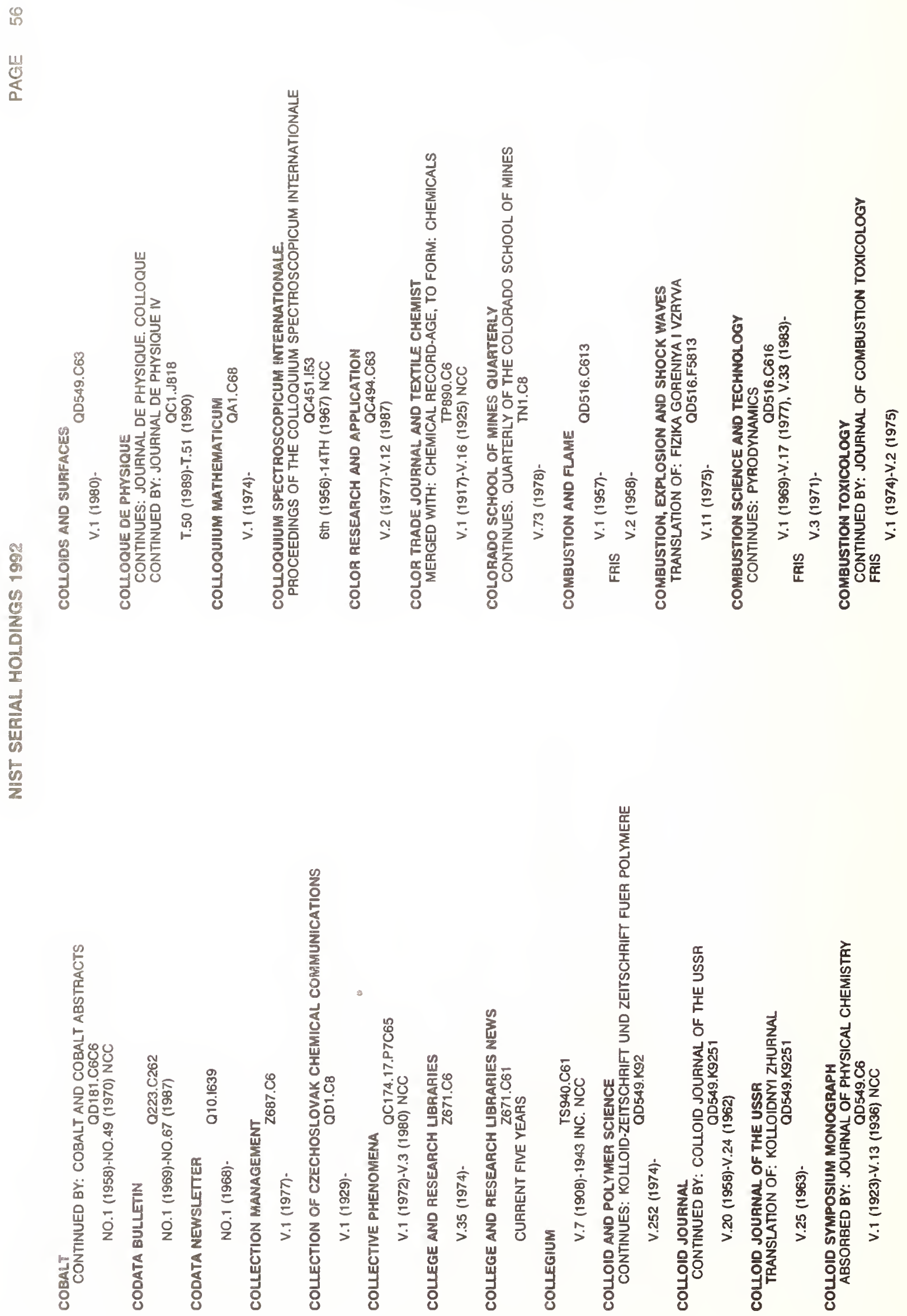


कิ

嵌

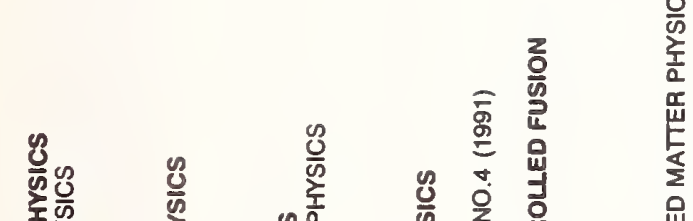

$\frac{\mathscr{U}}{0}$

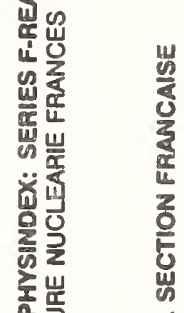

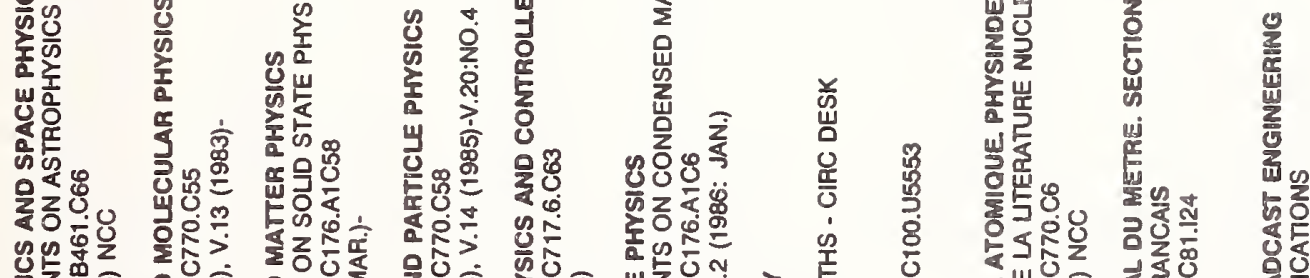

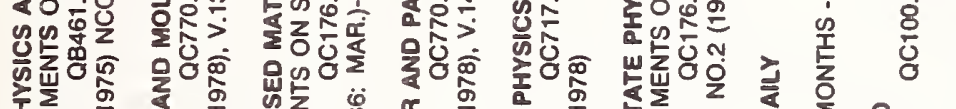

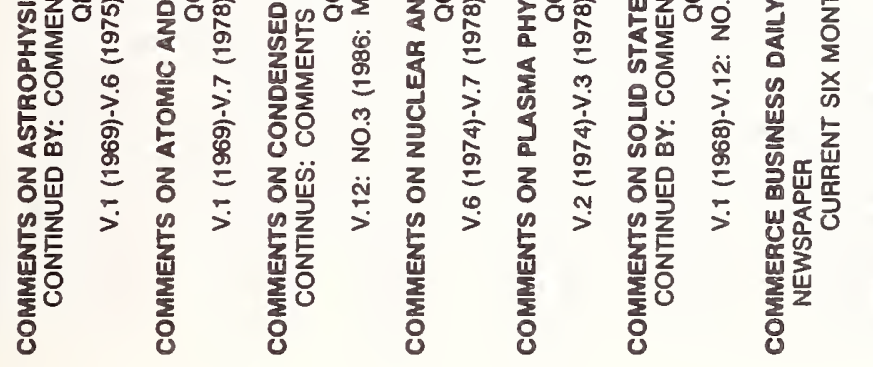

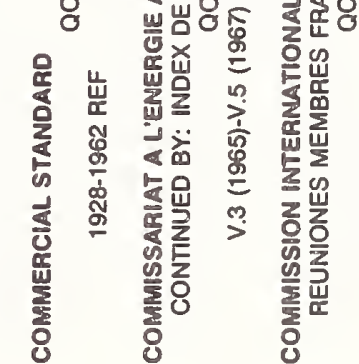

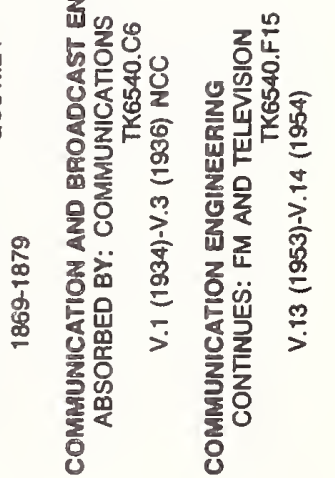

o

夏

$\frac{5}{2}$

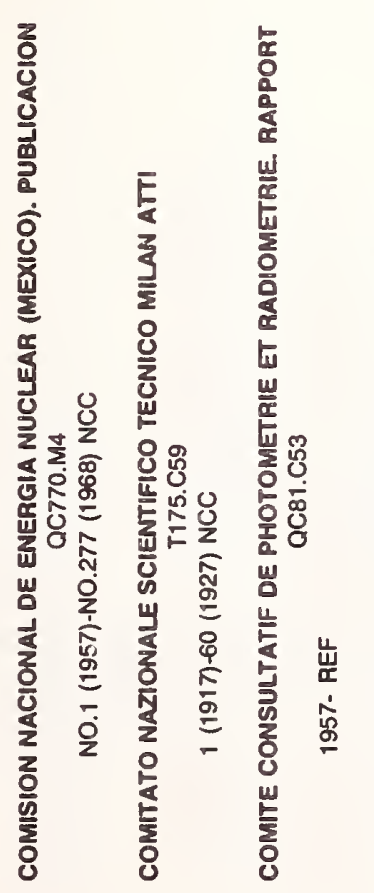

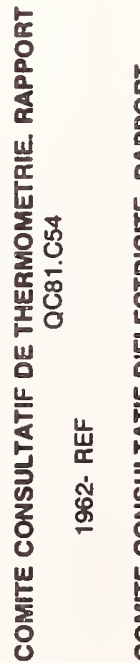

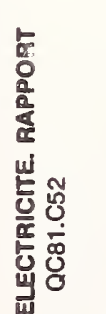

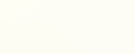

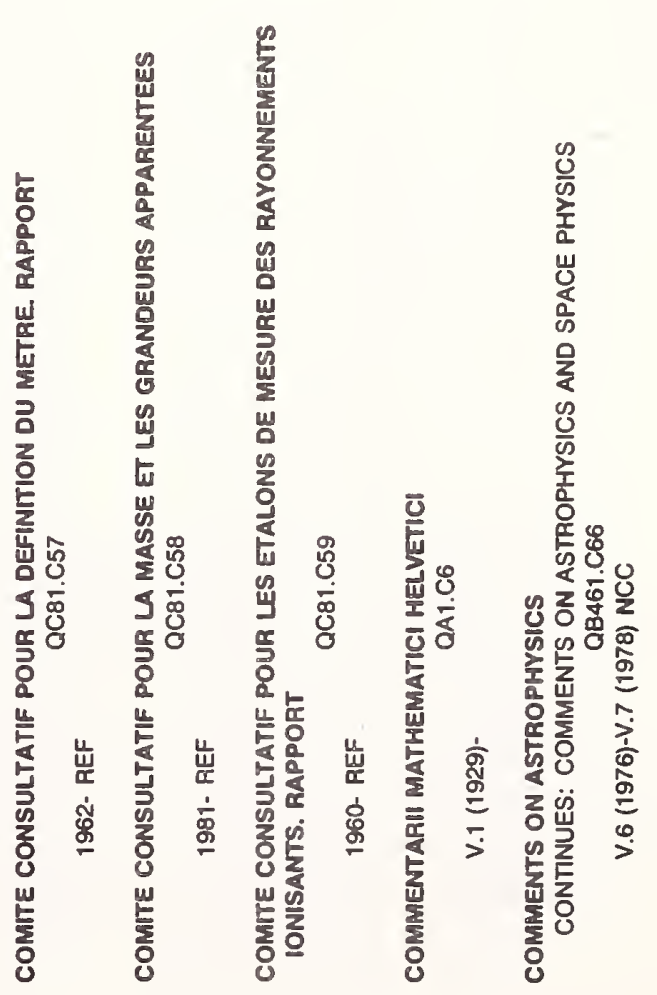




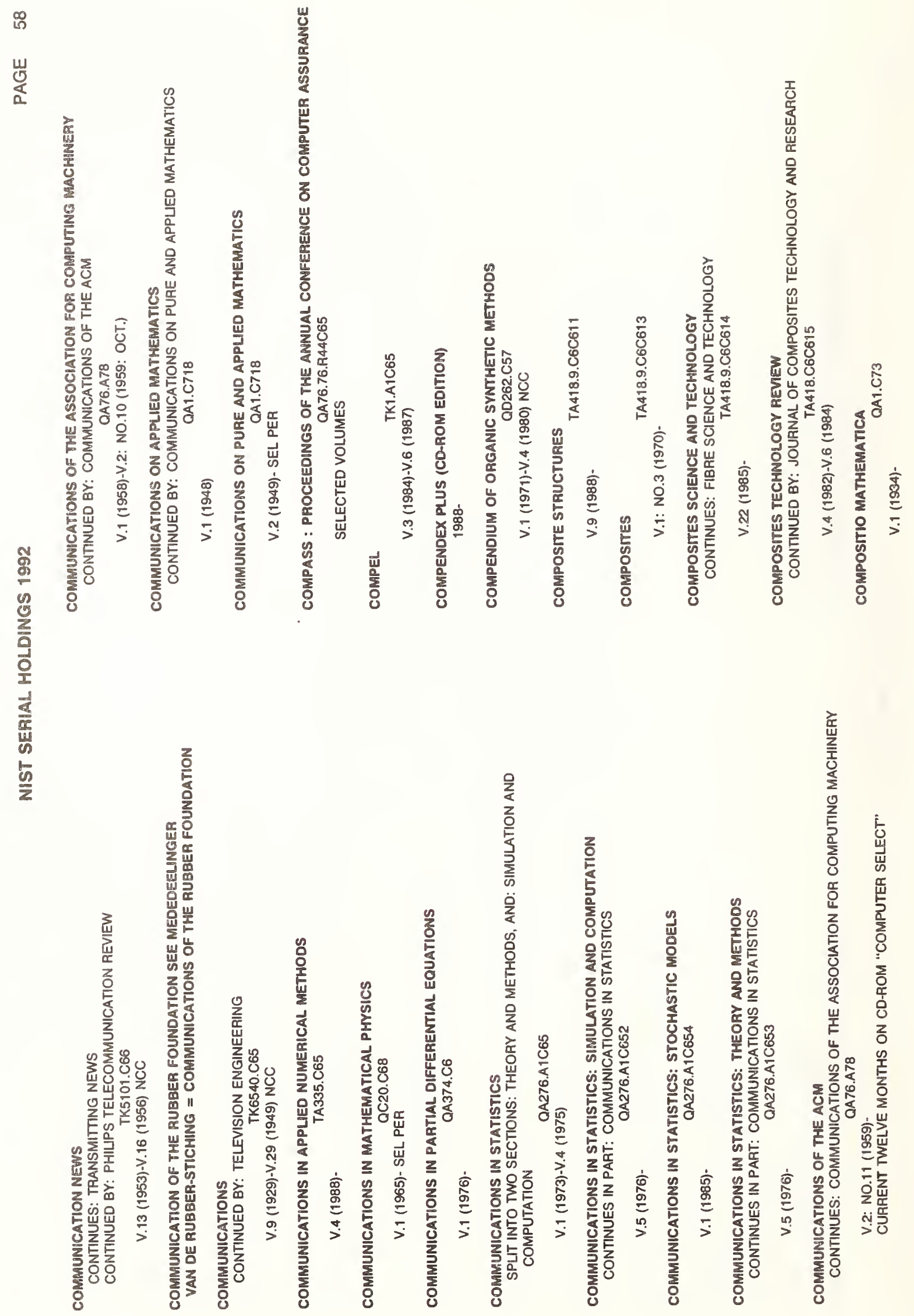



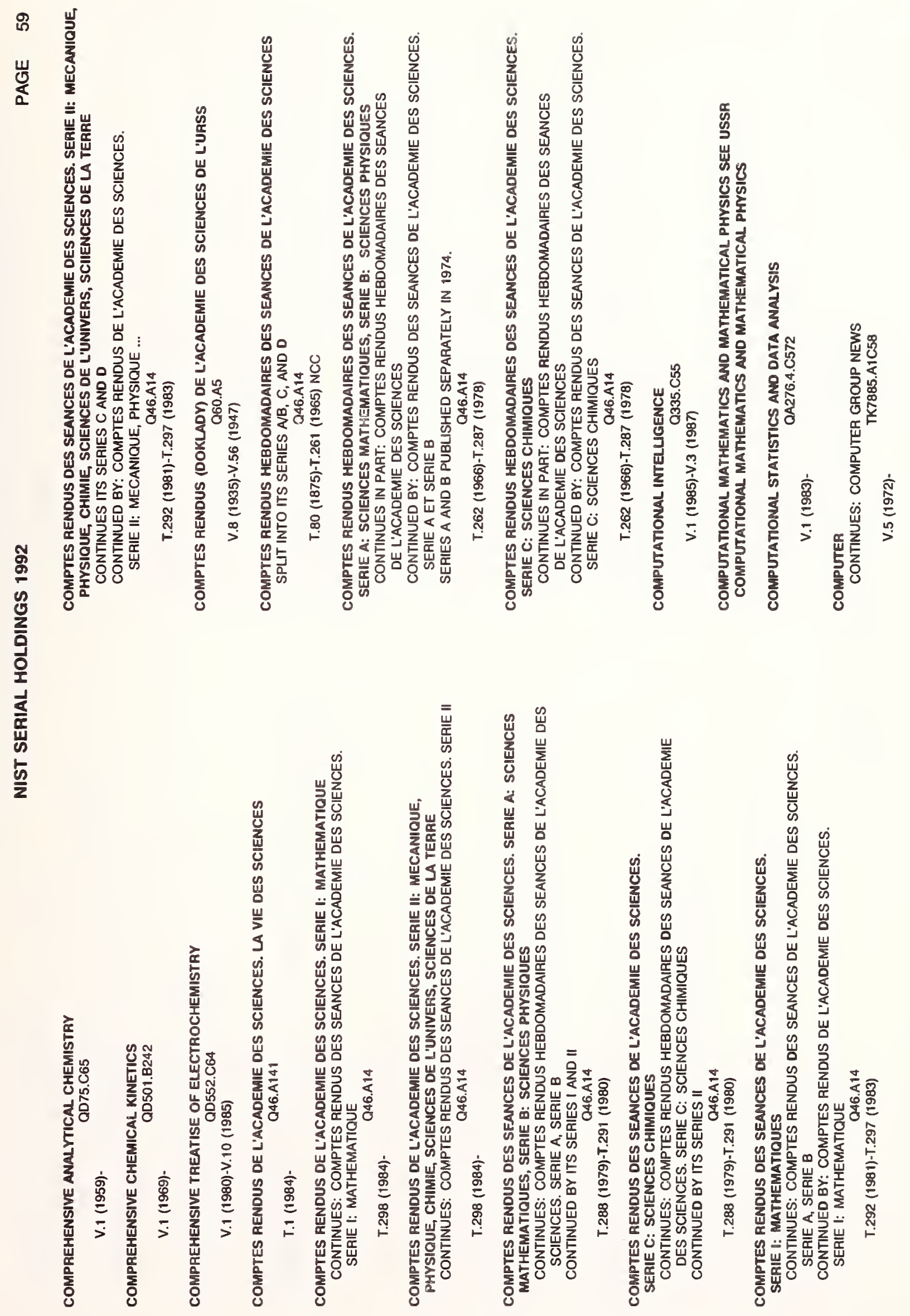


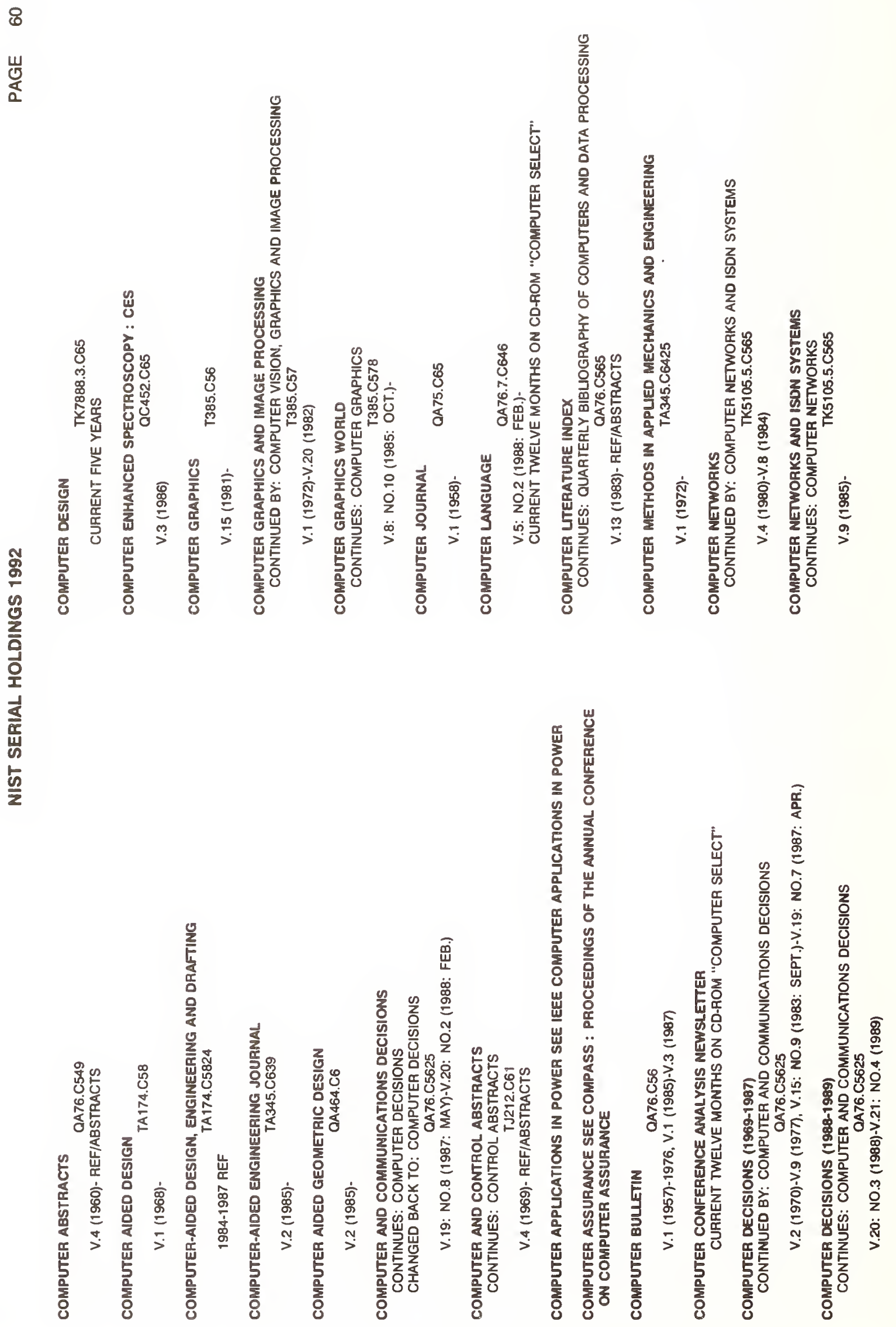


$\frac{0}{0}$

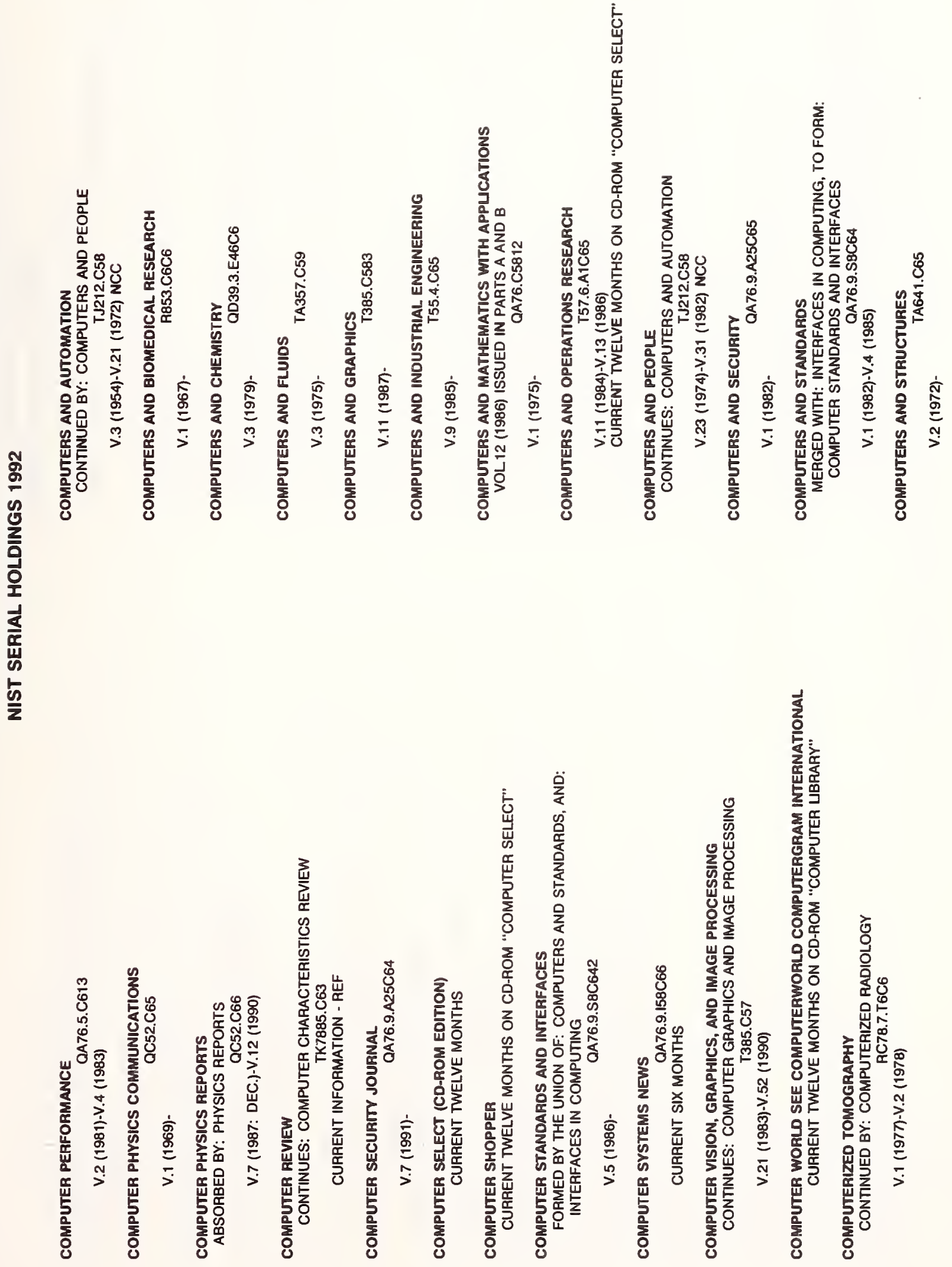



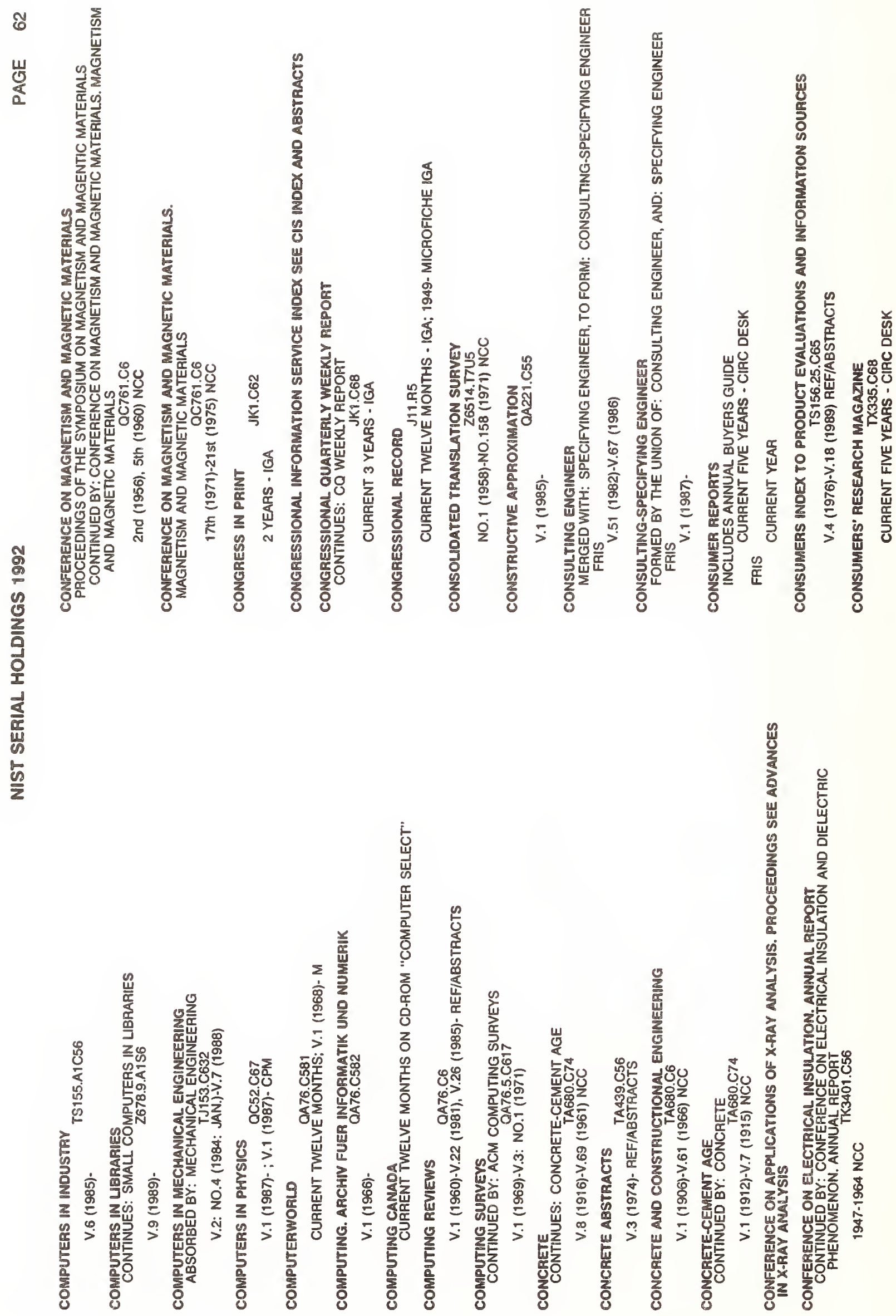


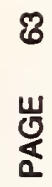
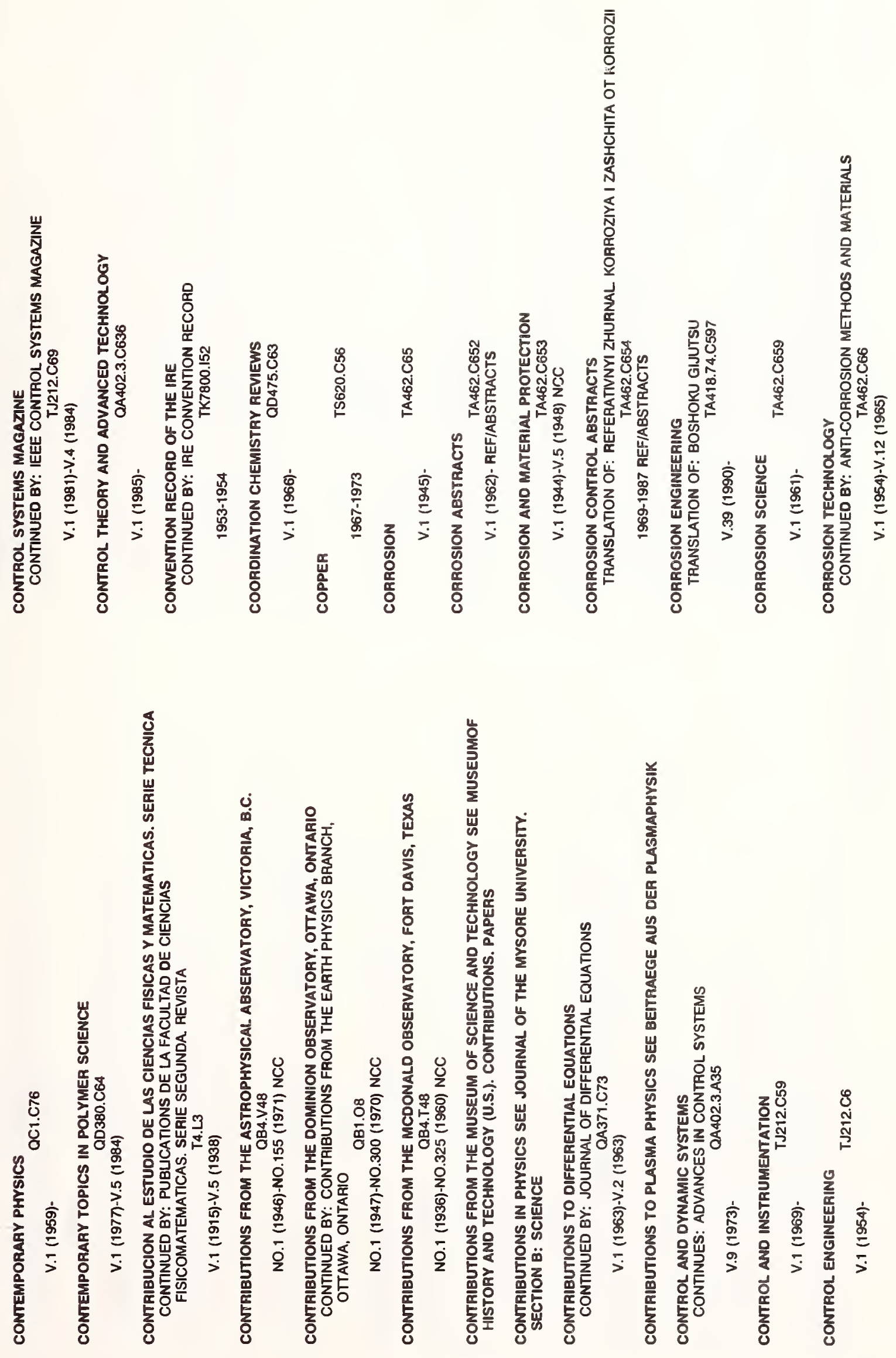


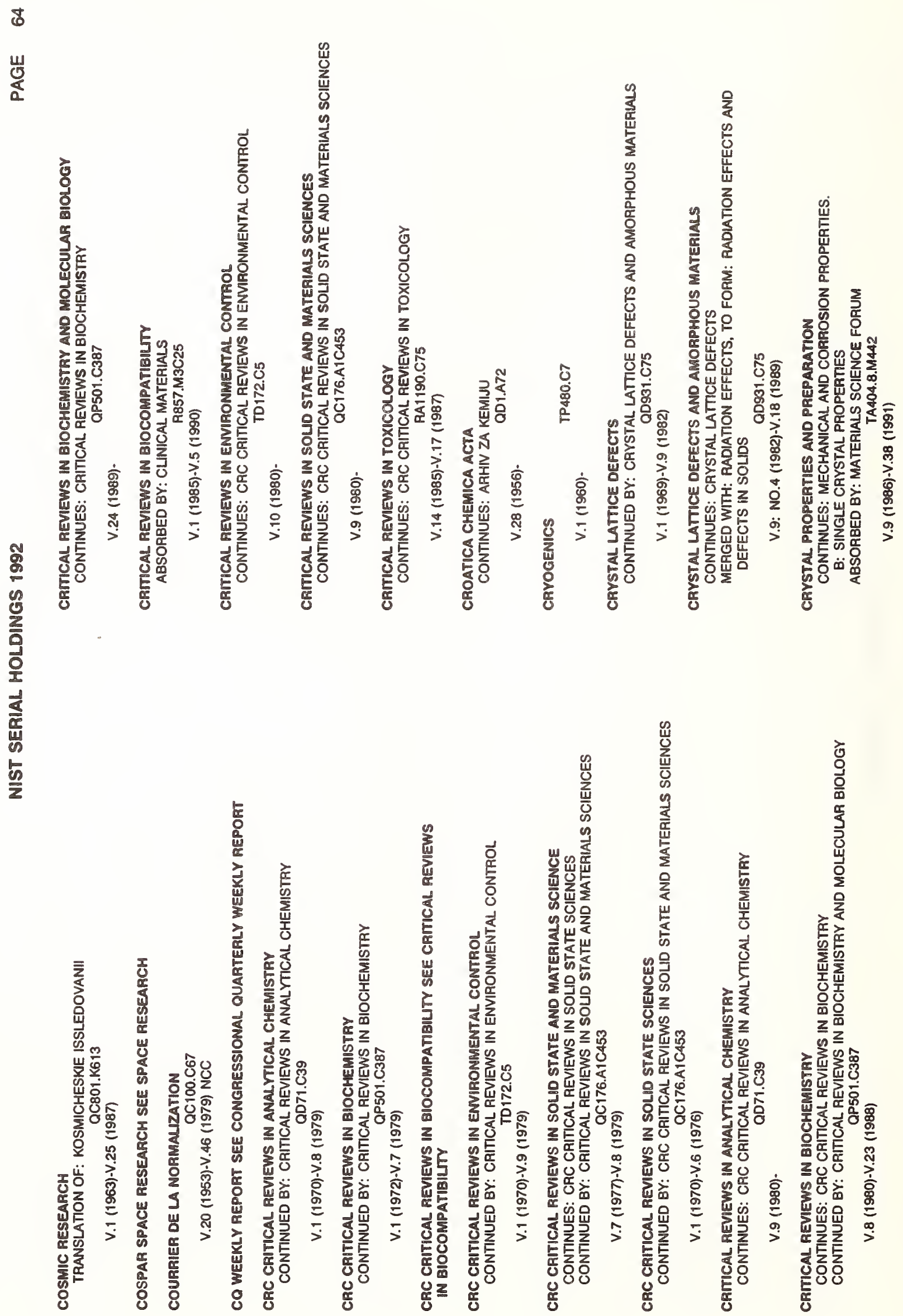


뿔
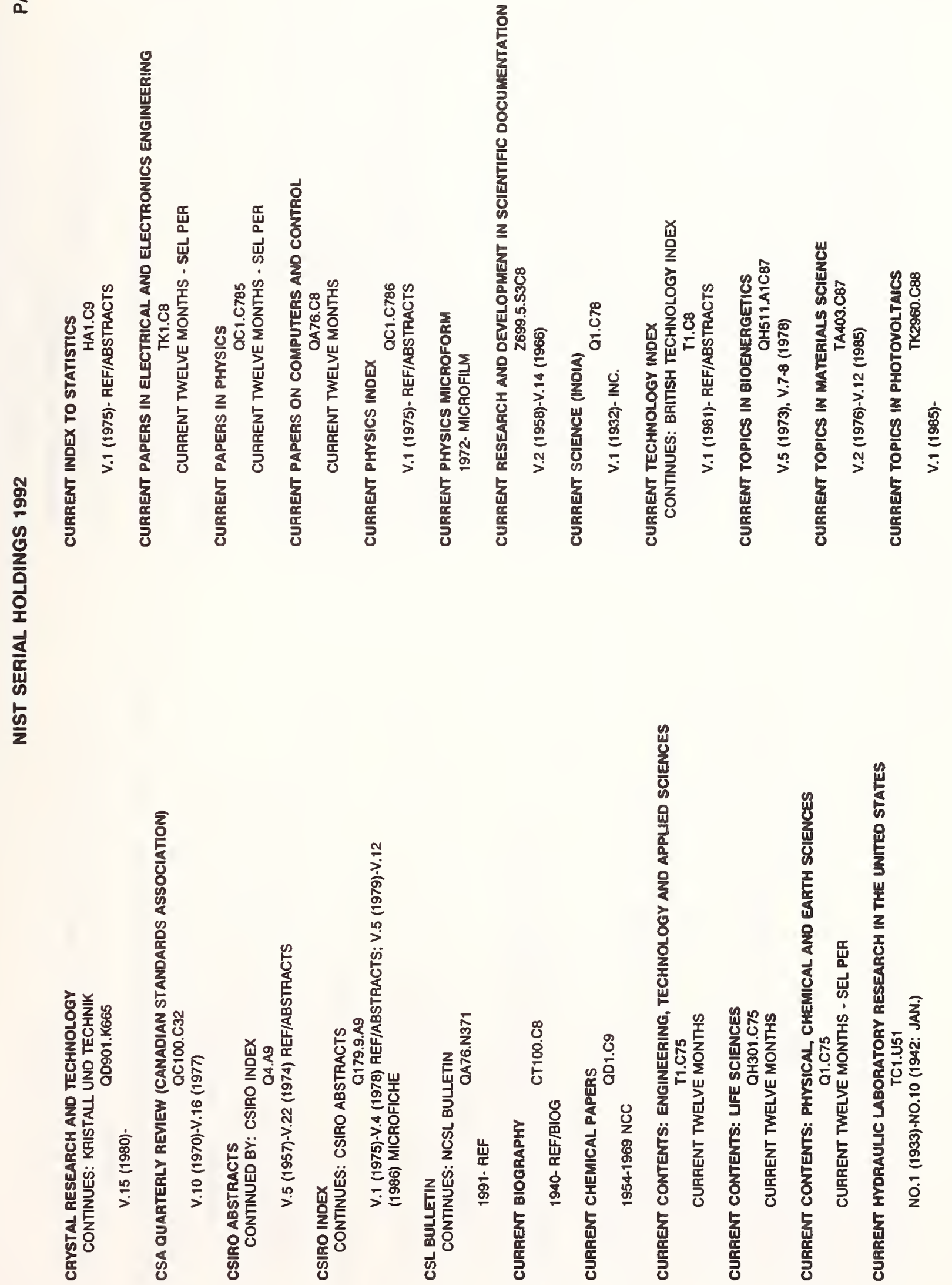
㟧

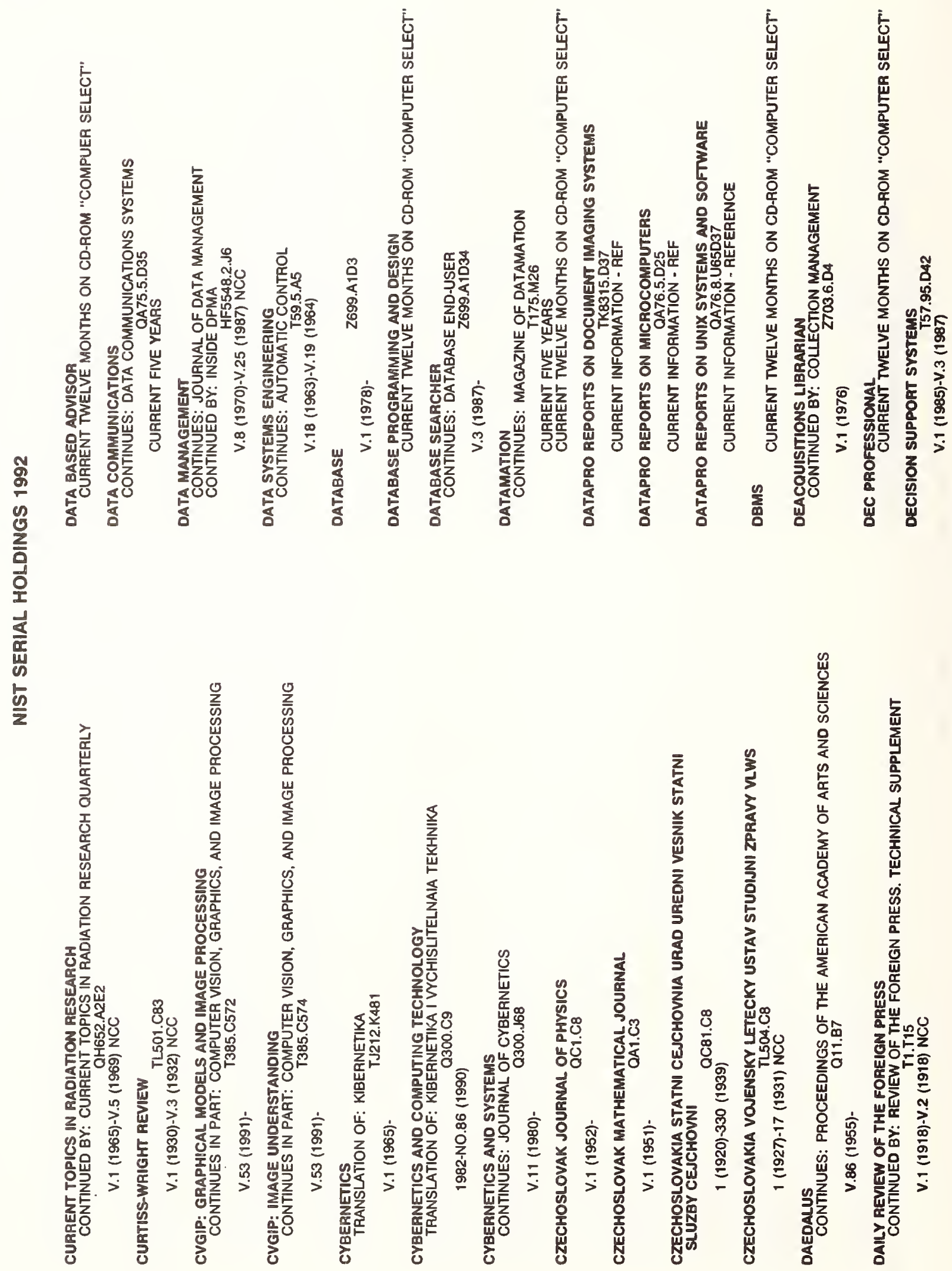


๘ّ

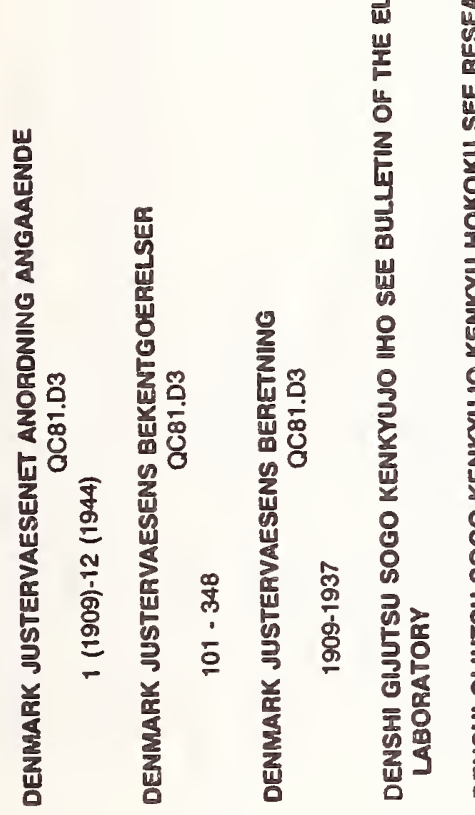

.

2

웅

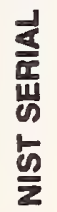
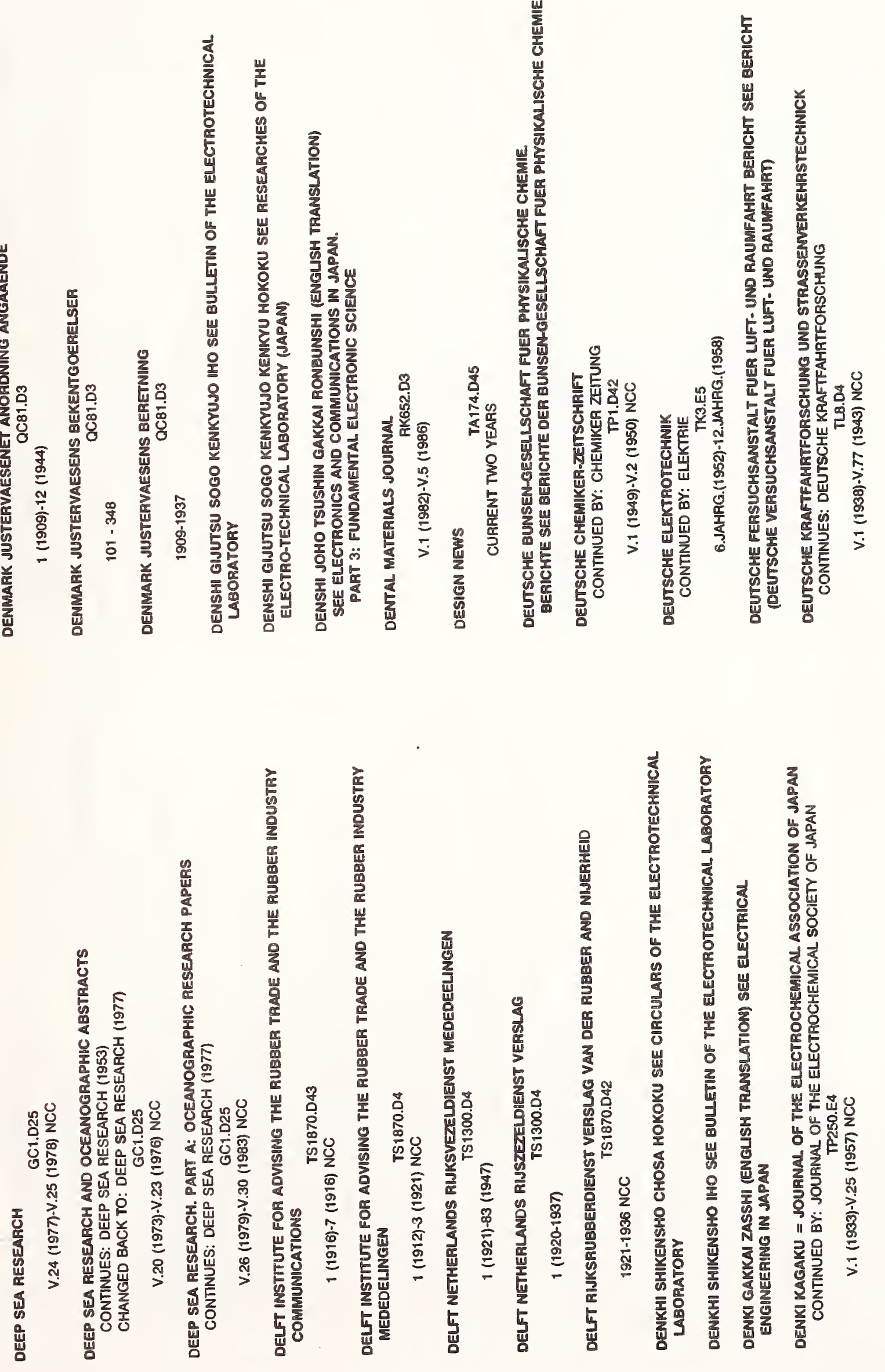
崖

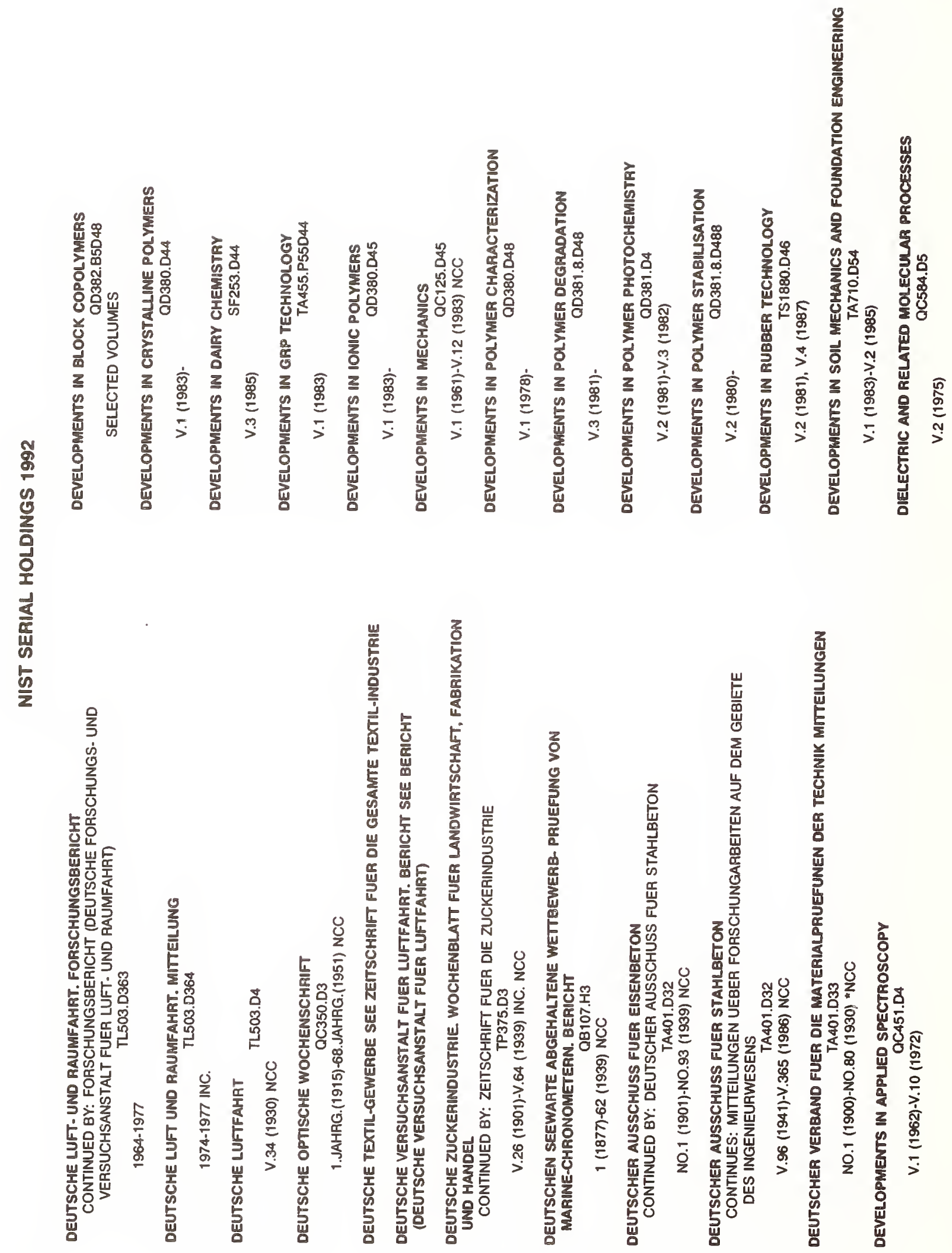




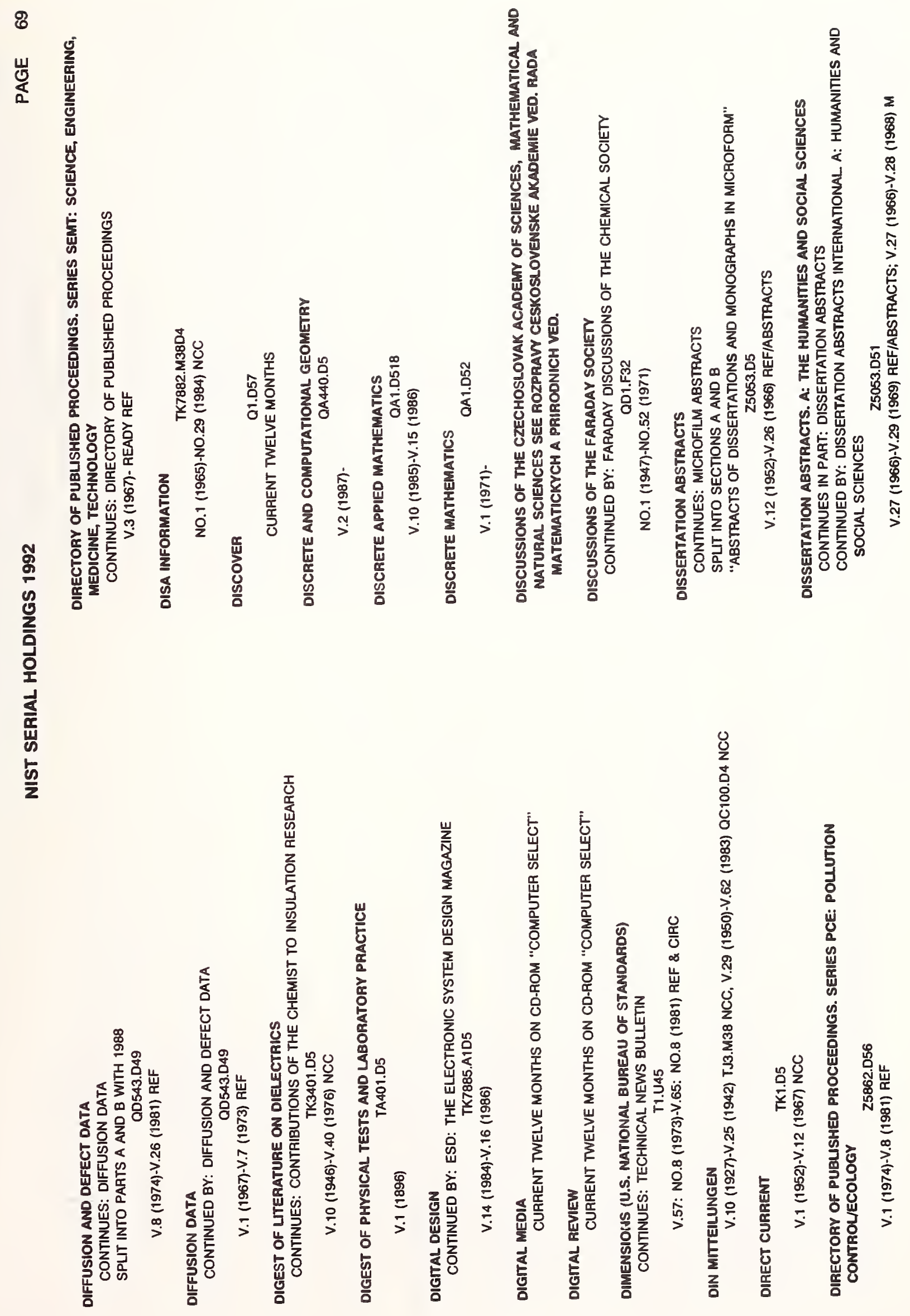


요
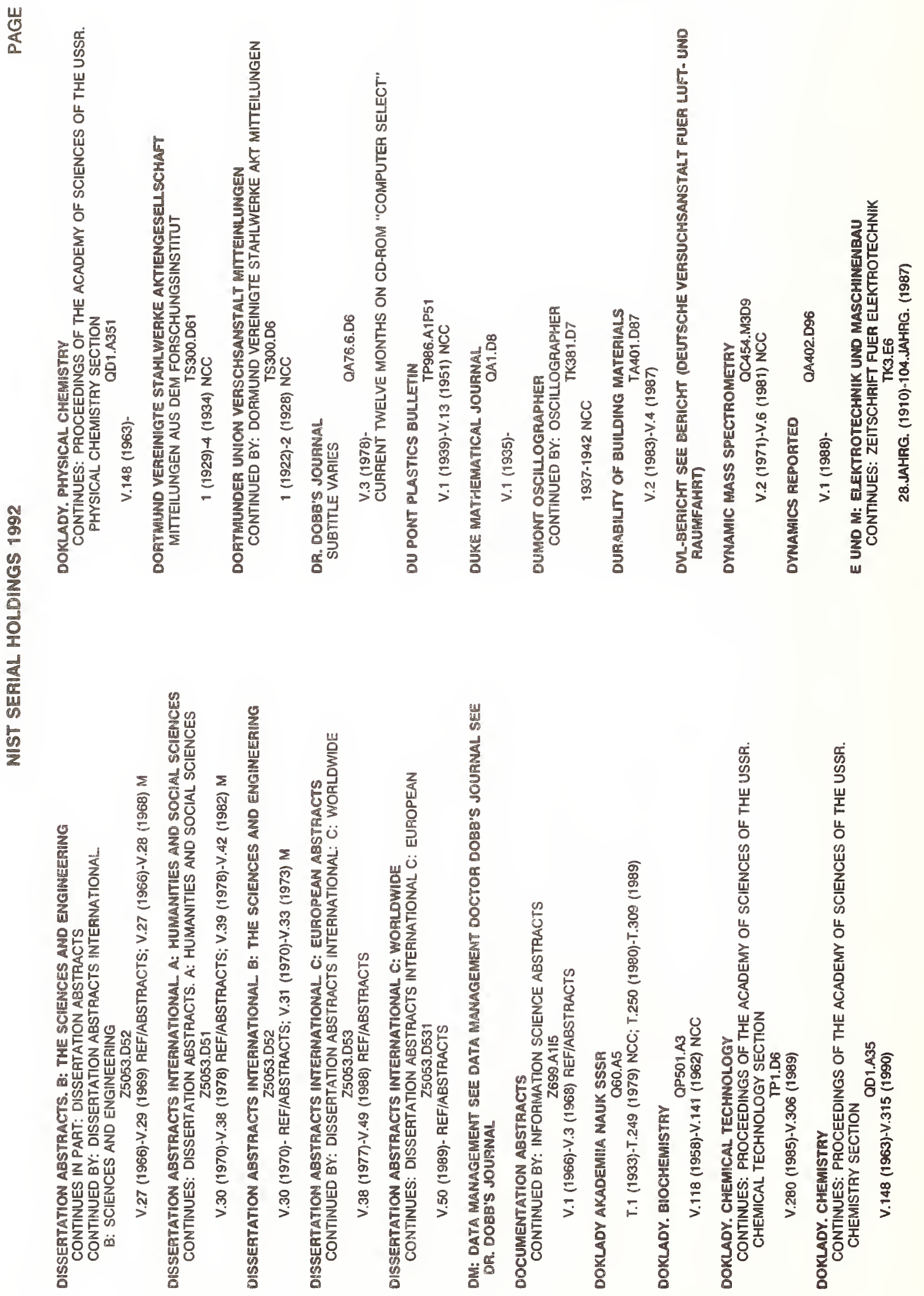

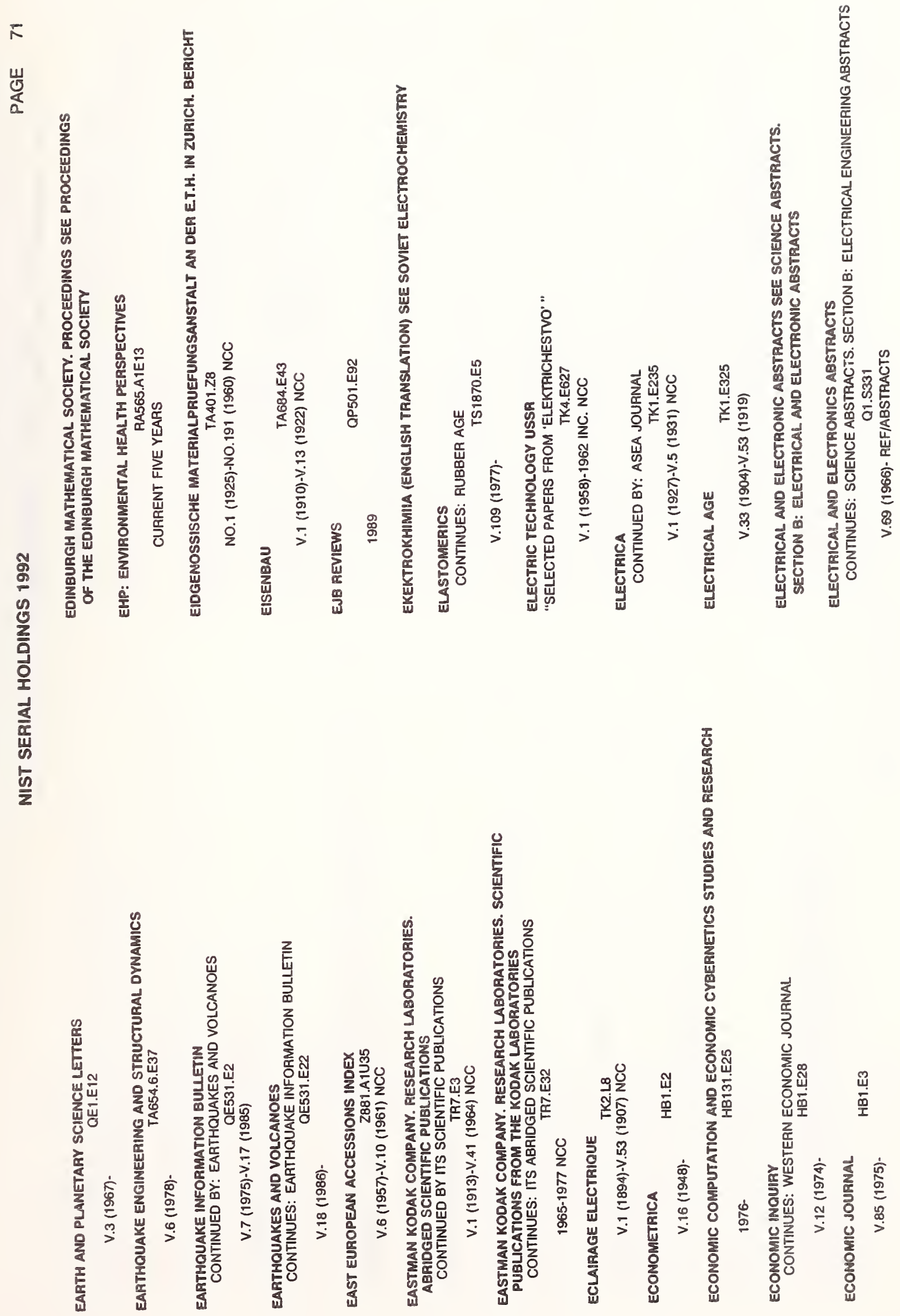
$N$
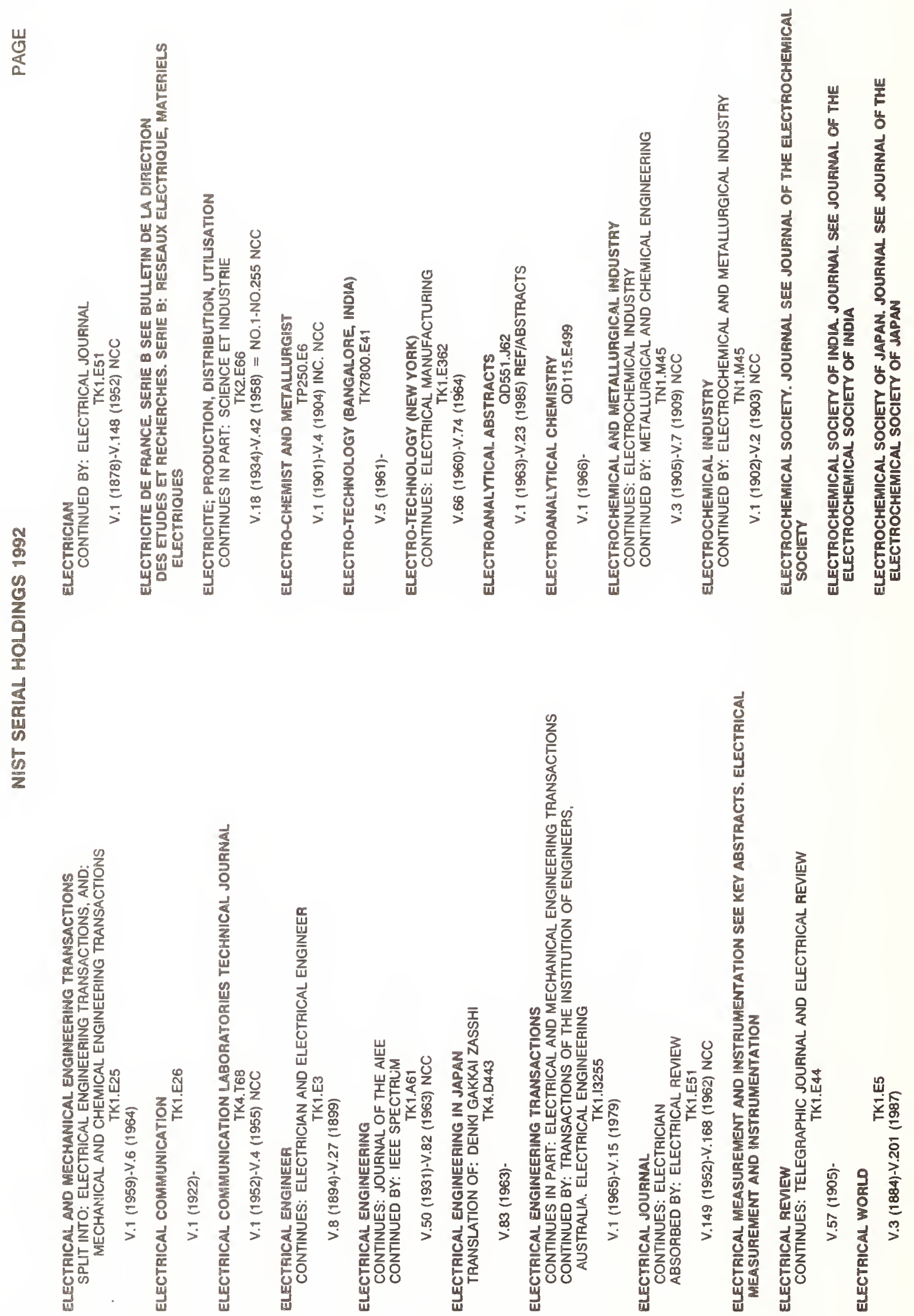


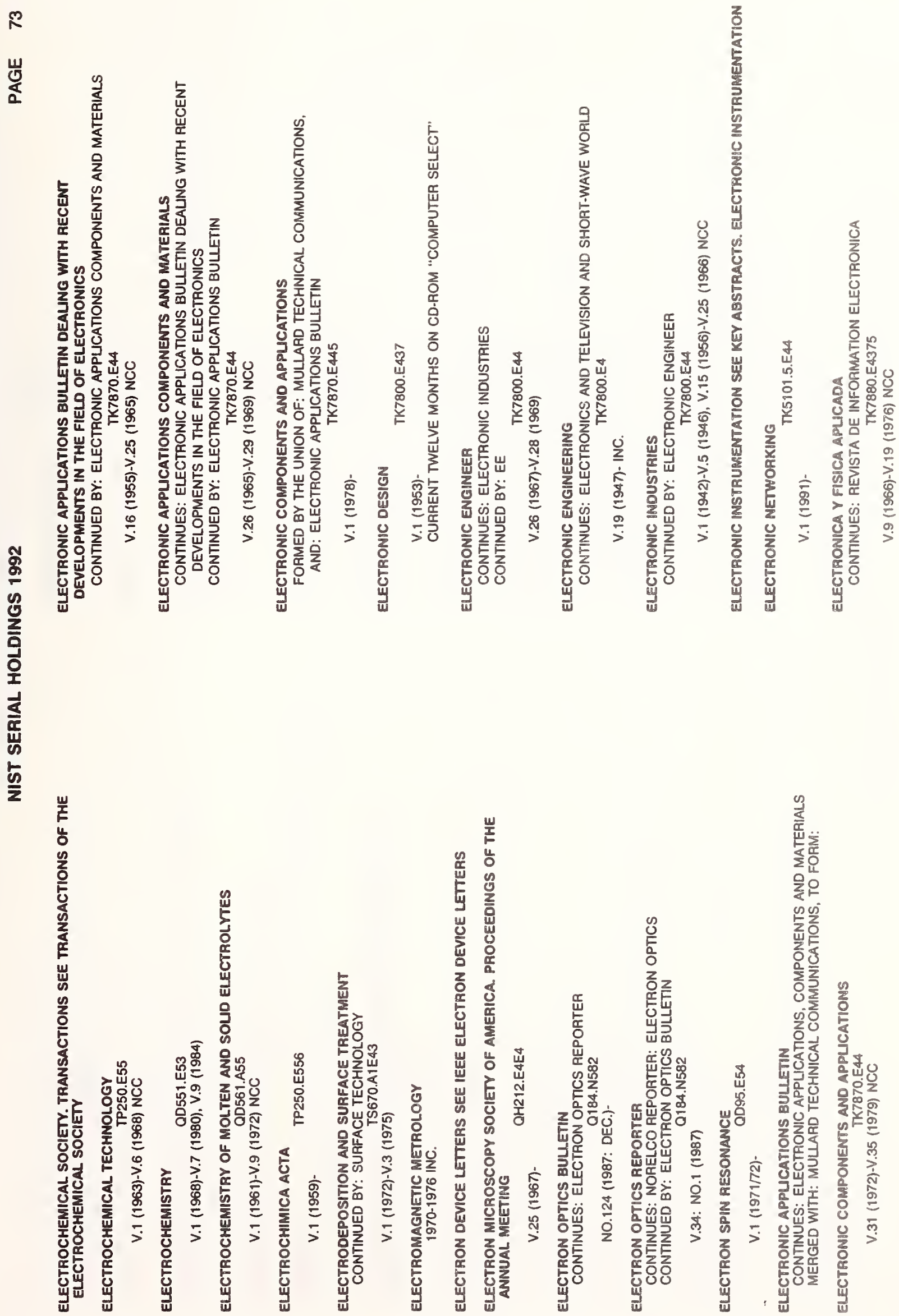


$\frac{1}{\frac{1}{0}}$

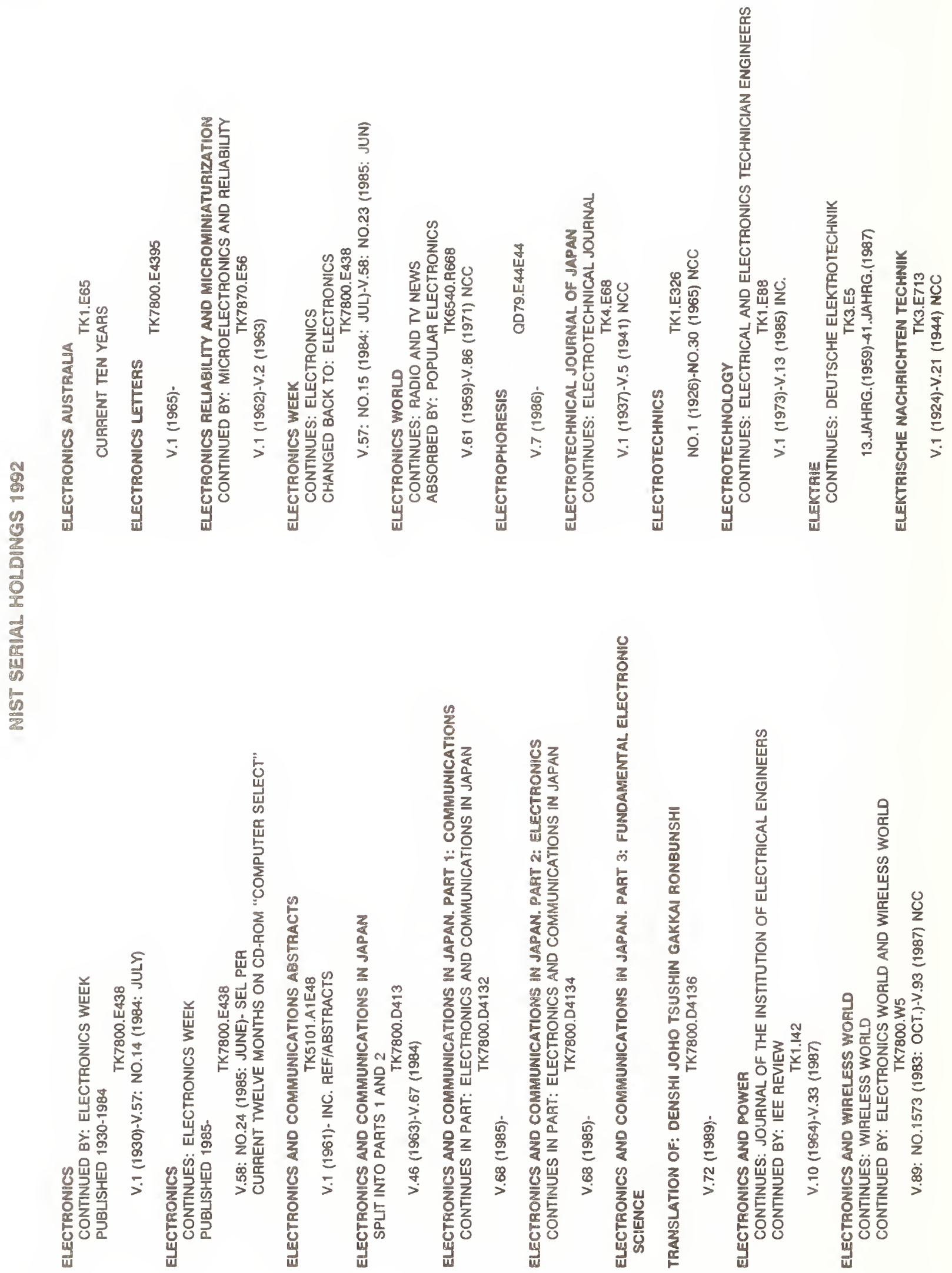




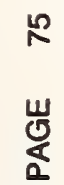

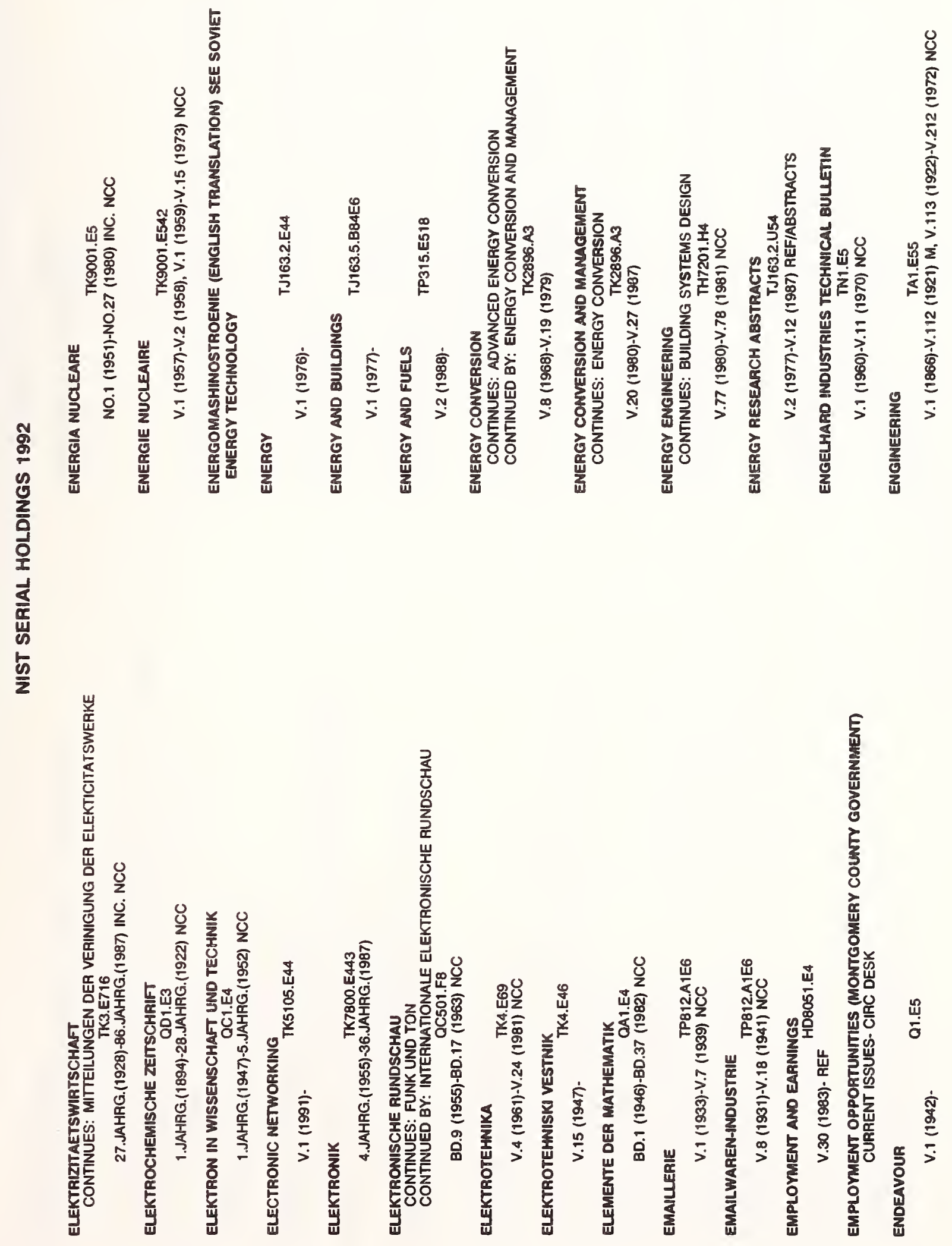




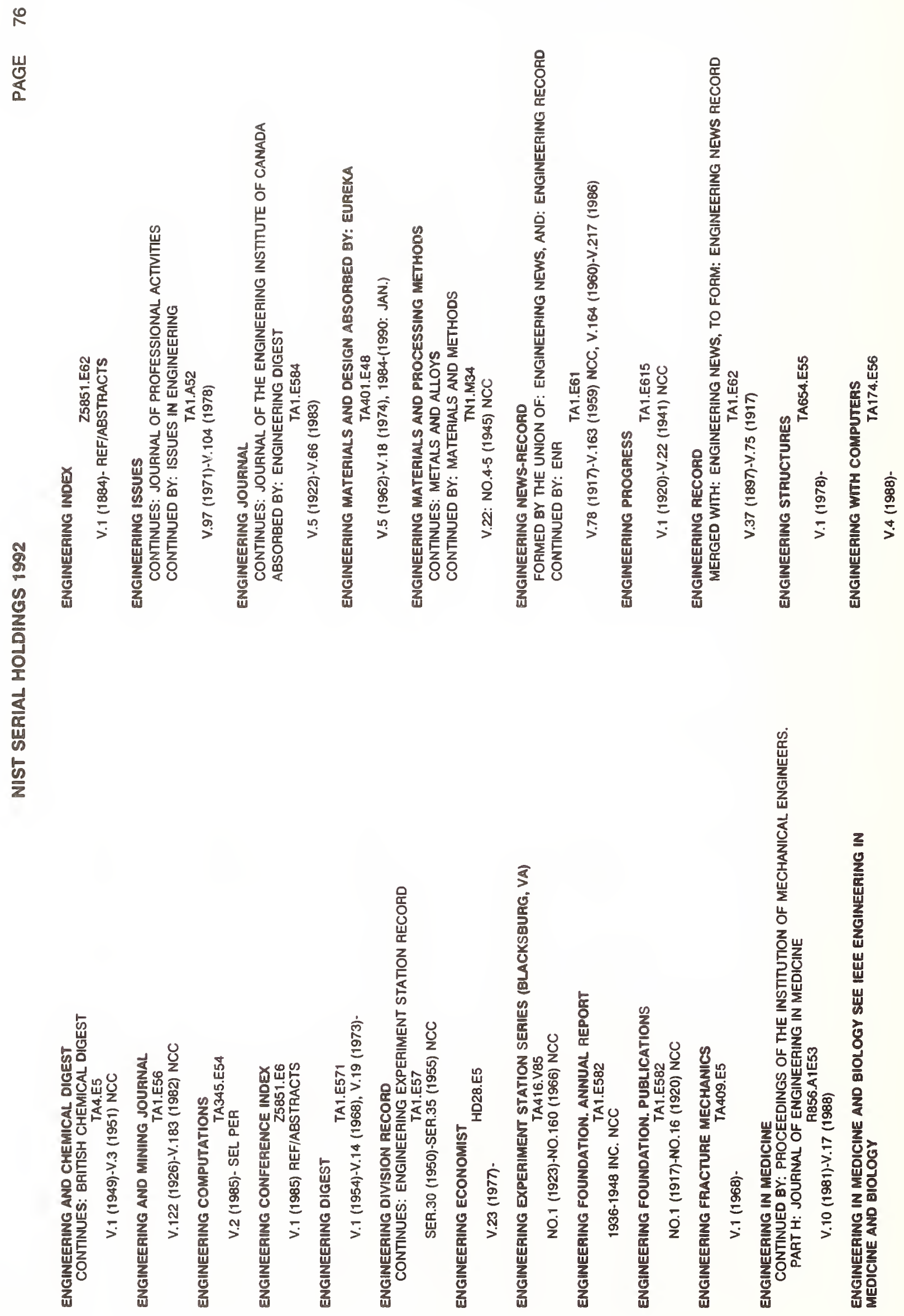


N

器

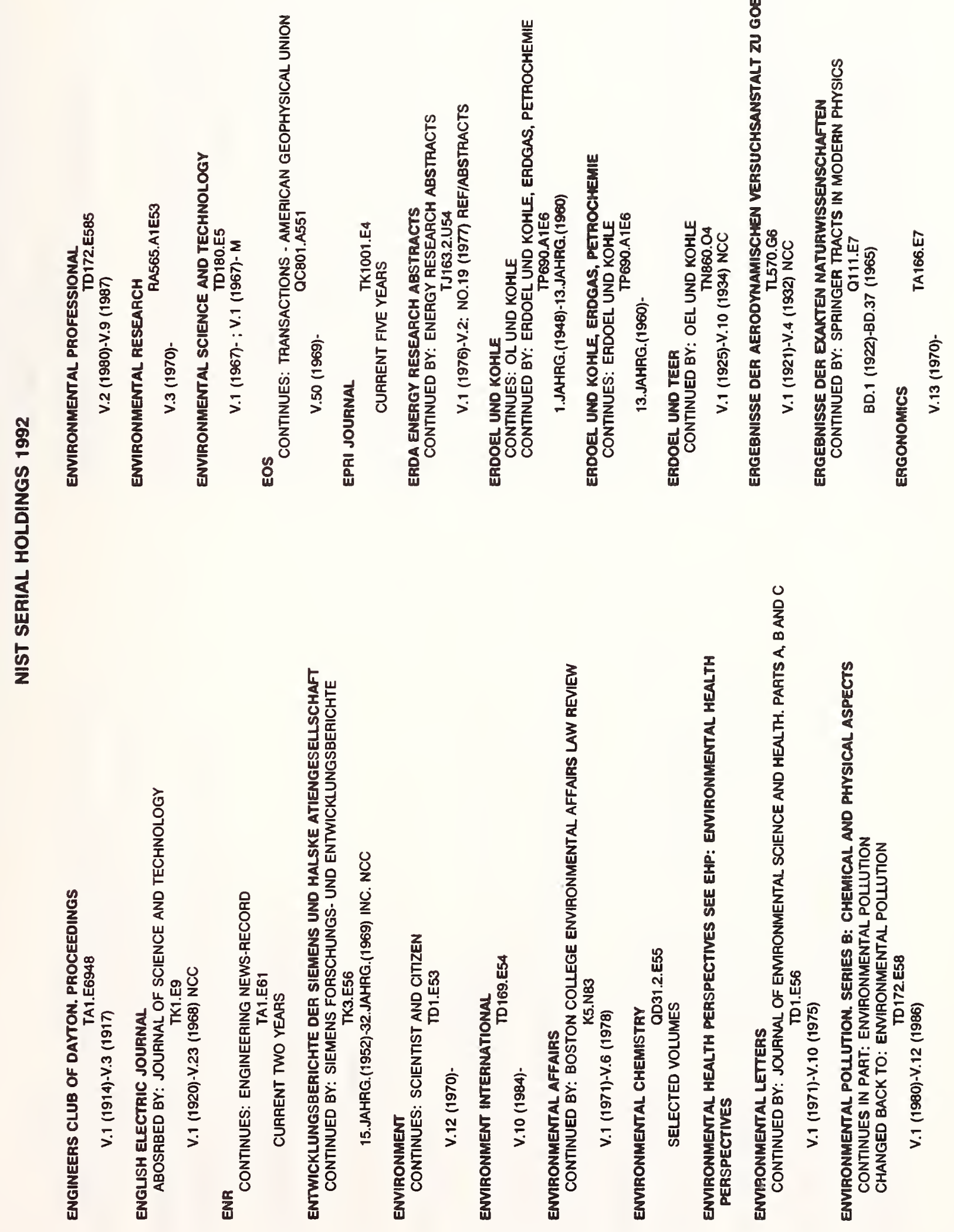




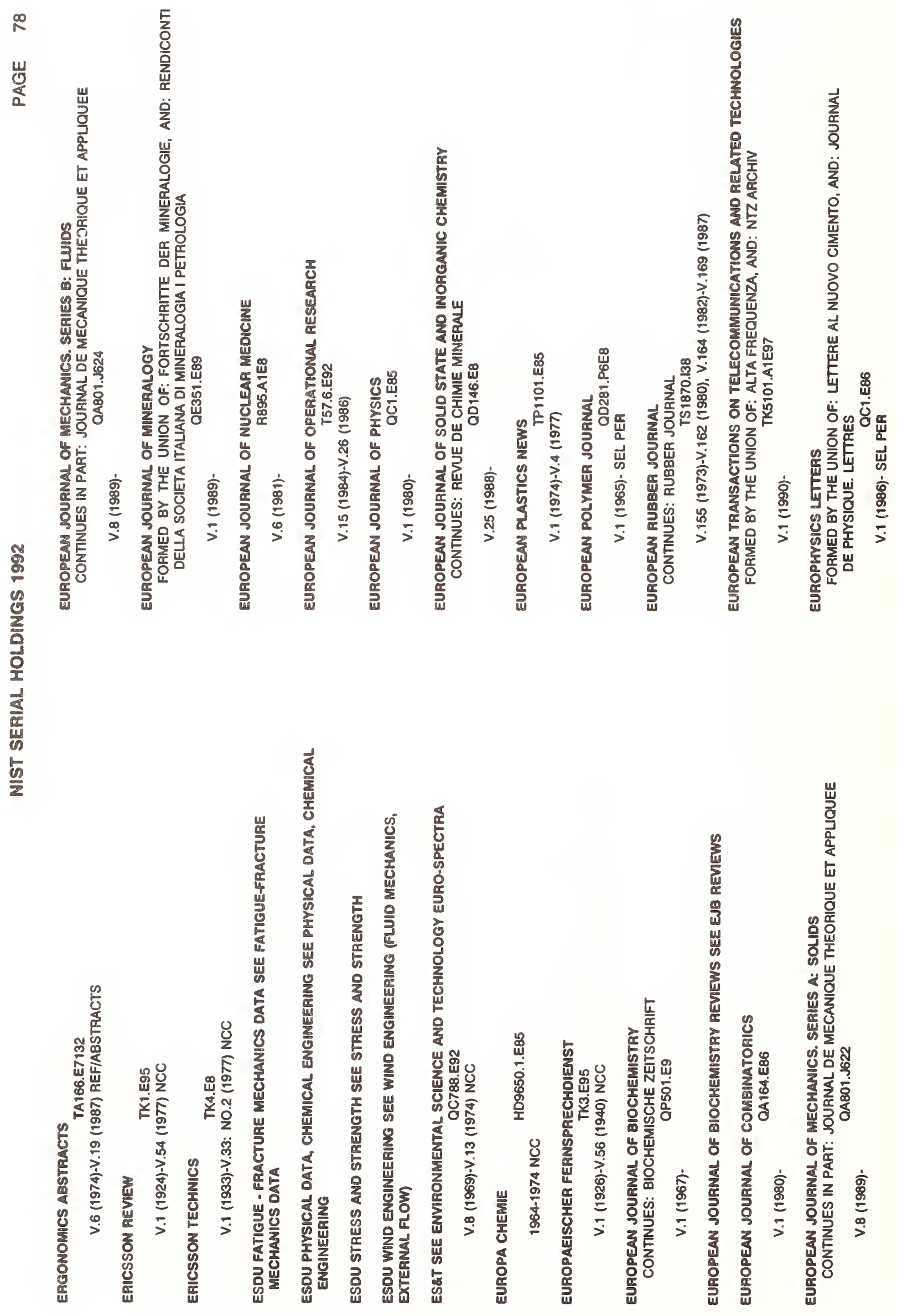




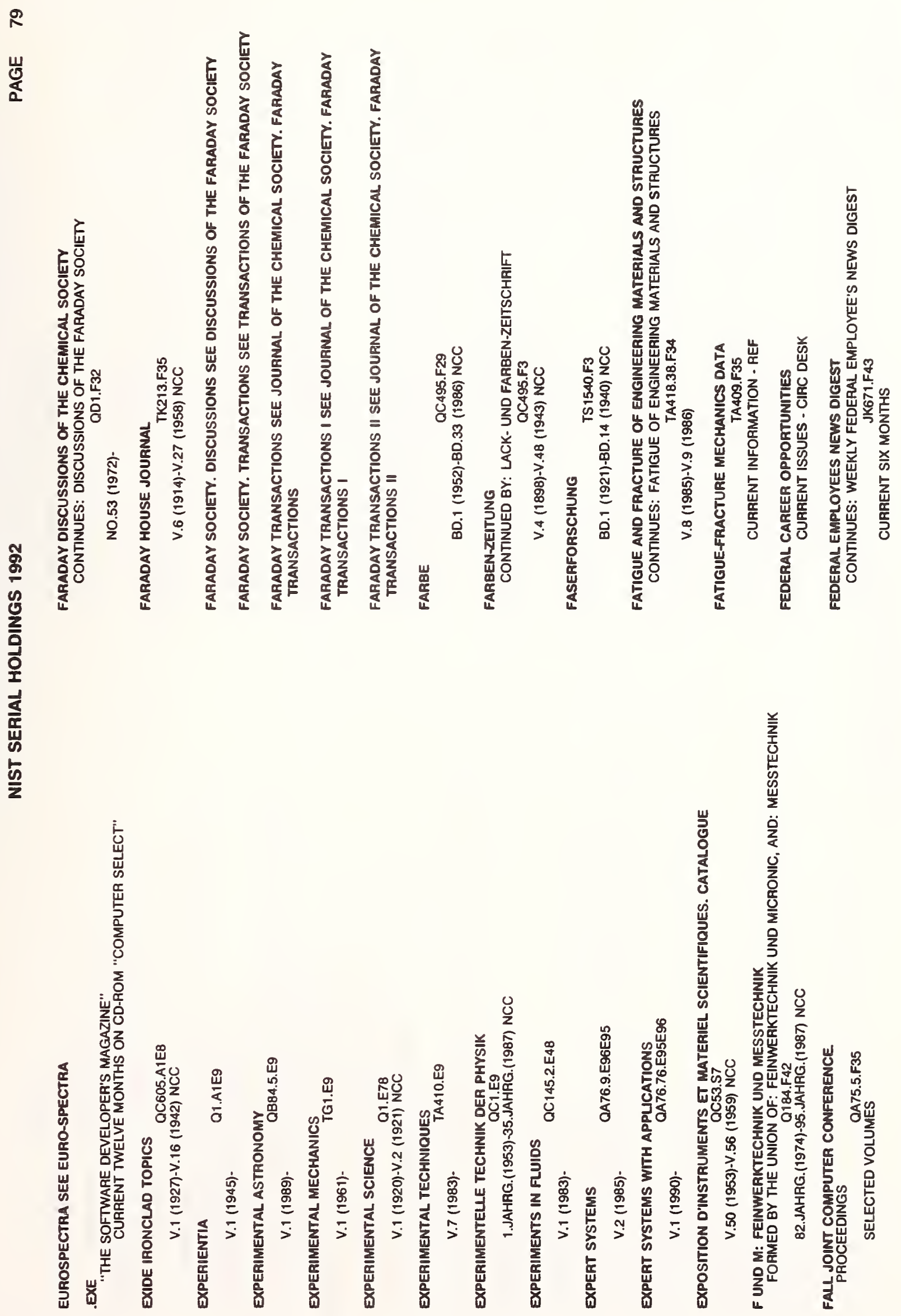


崖

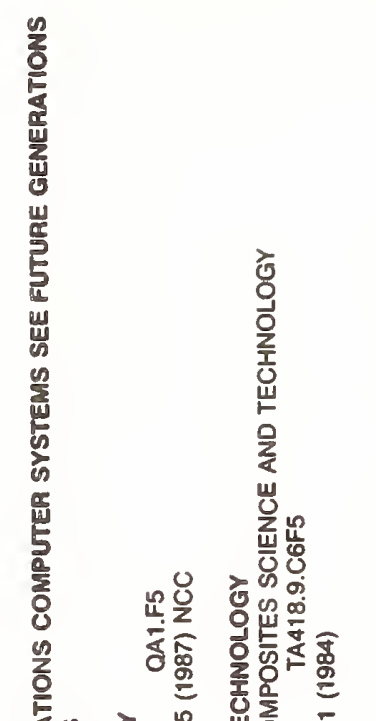

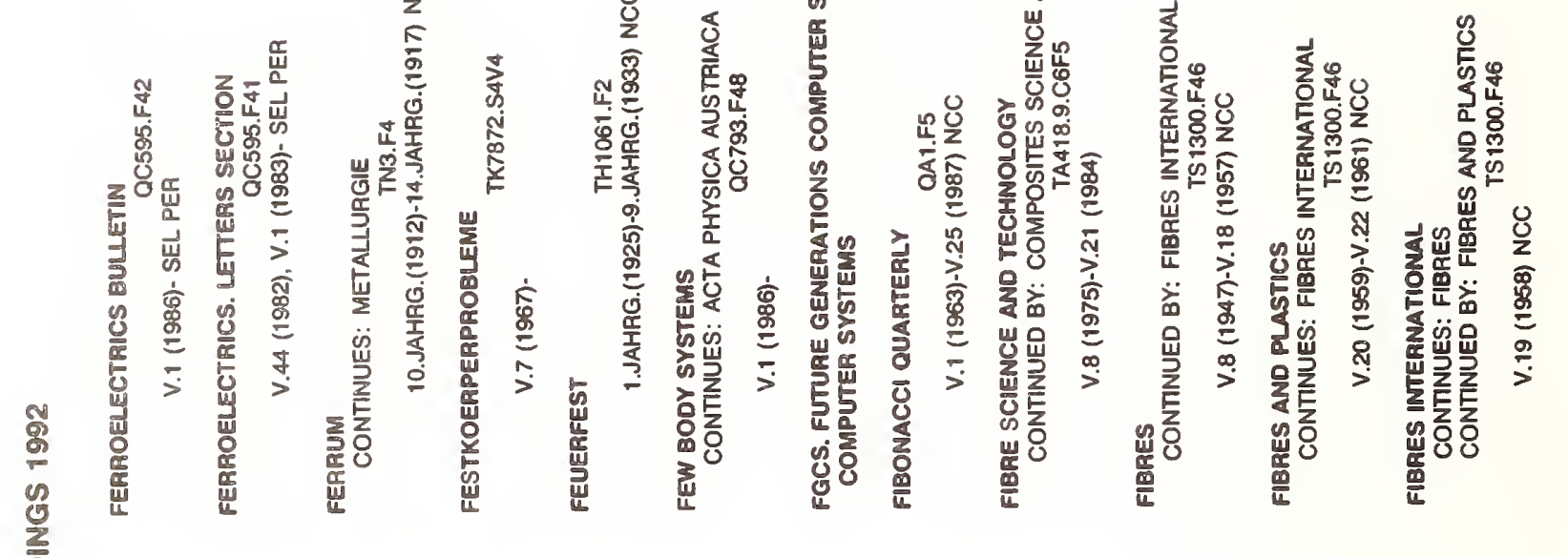

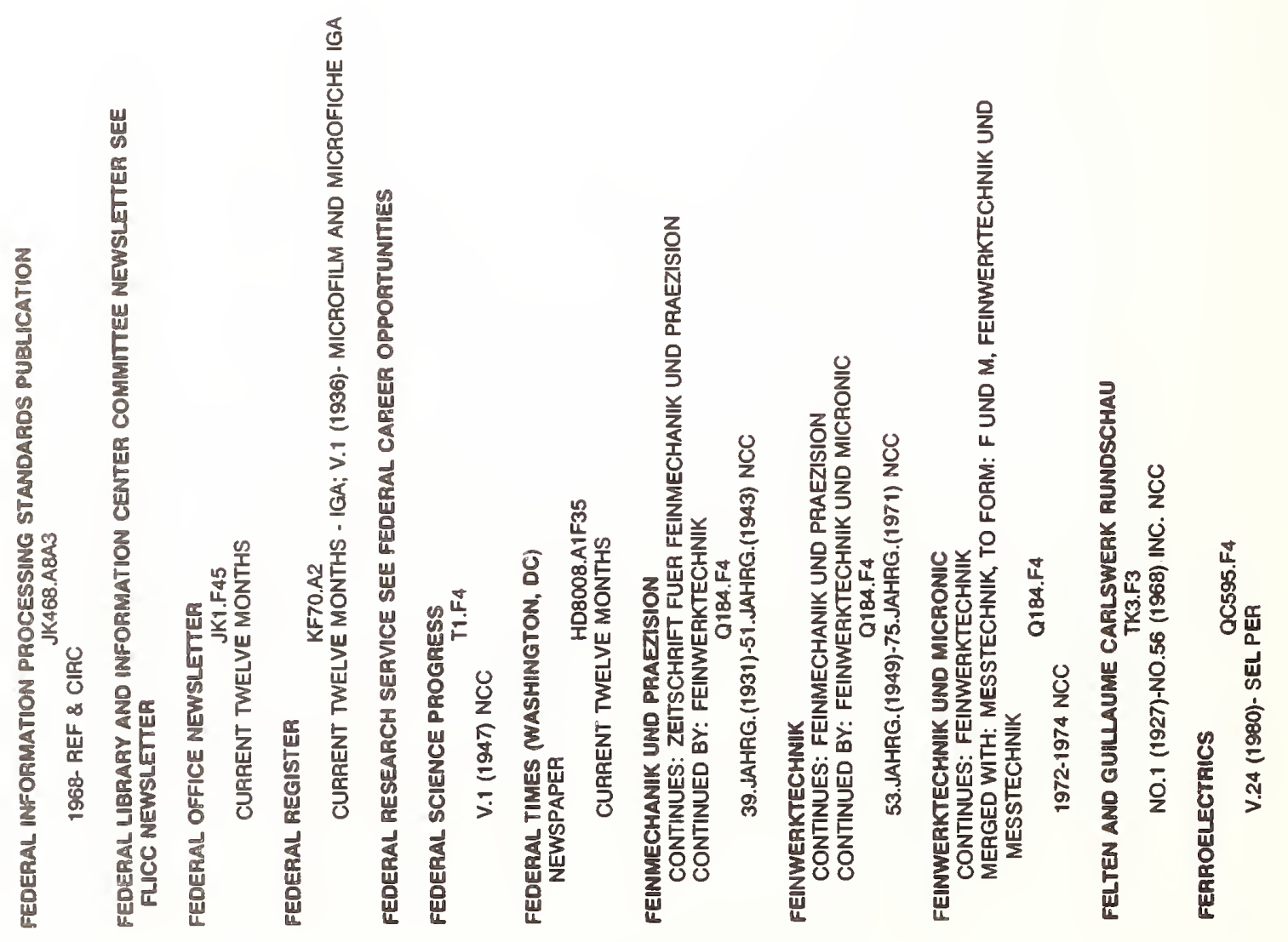




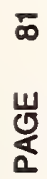

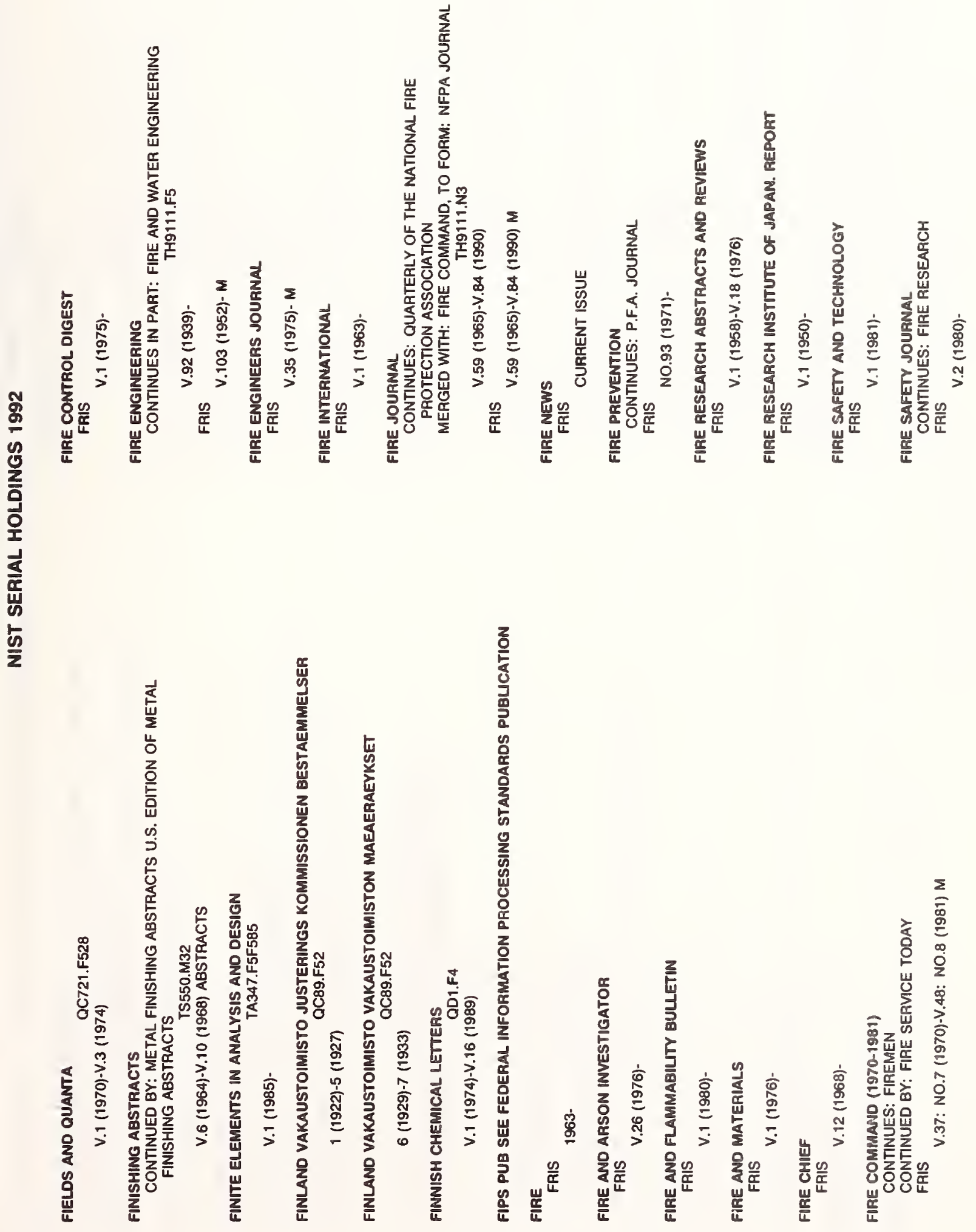



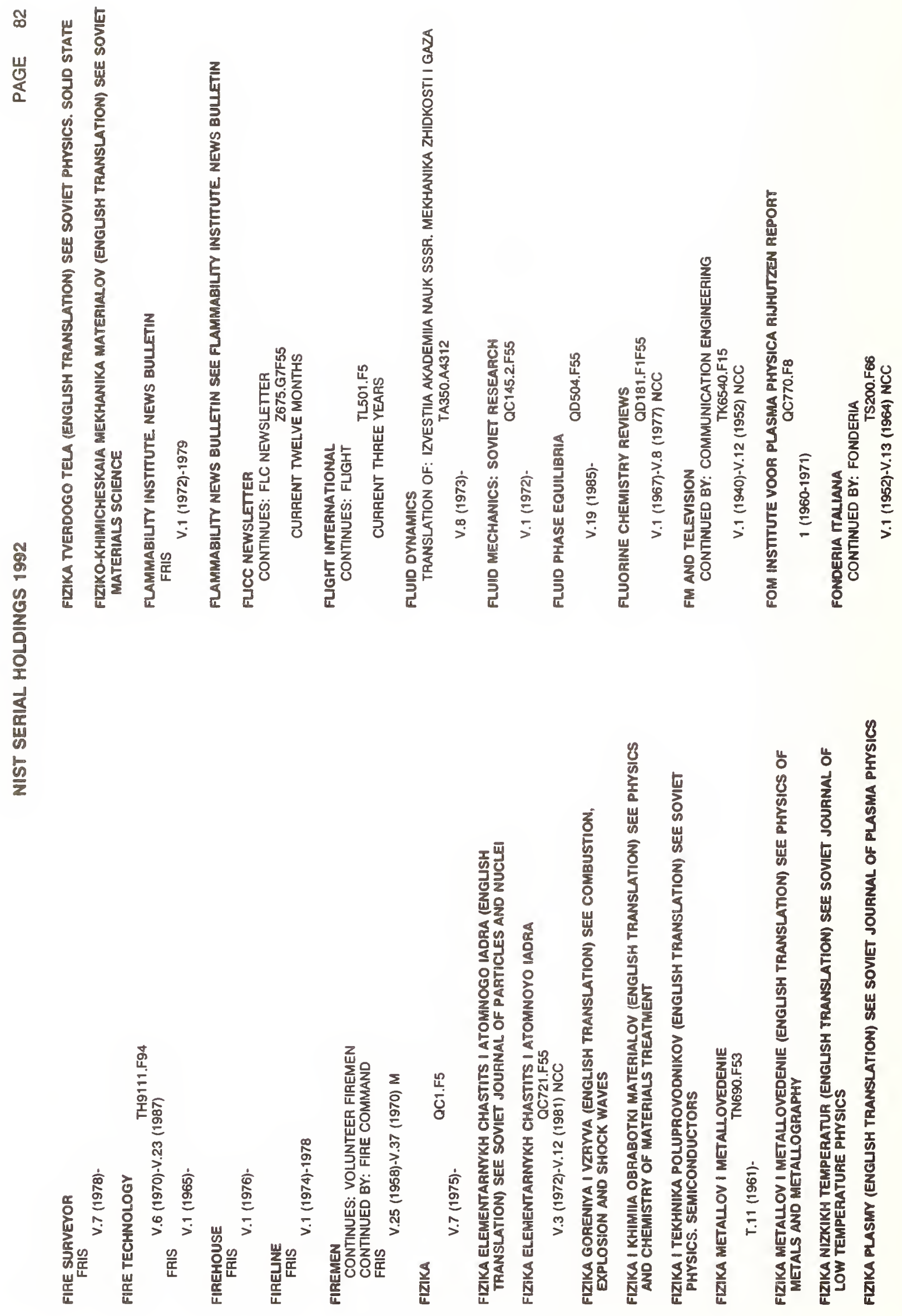
呟
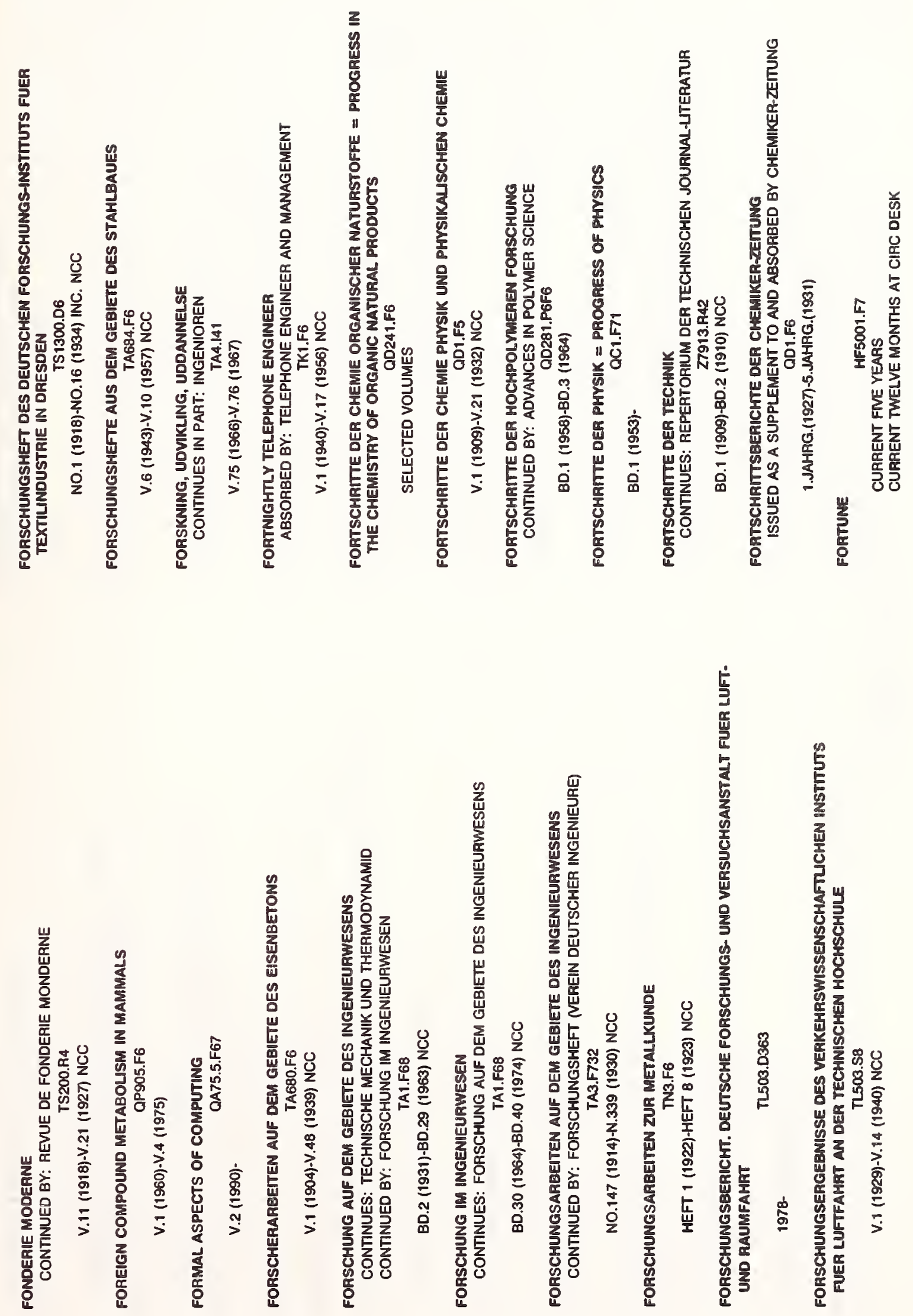
容

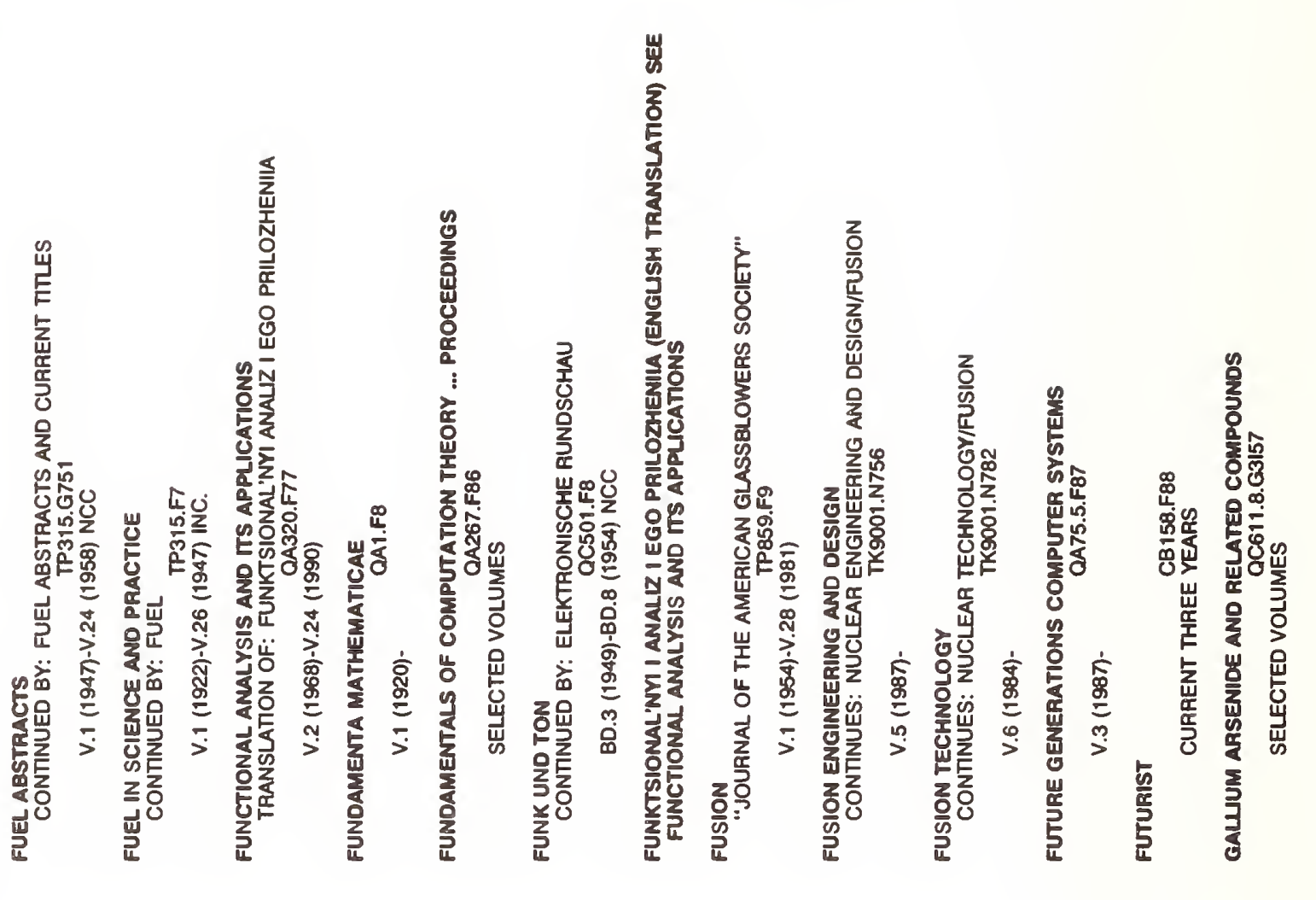

$\frac{5}{2}$

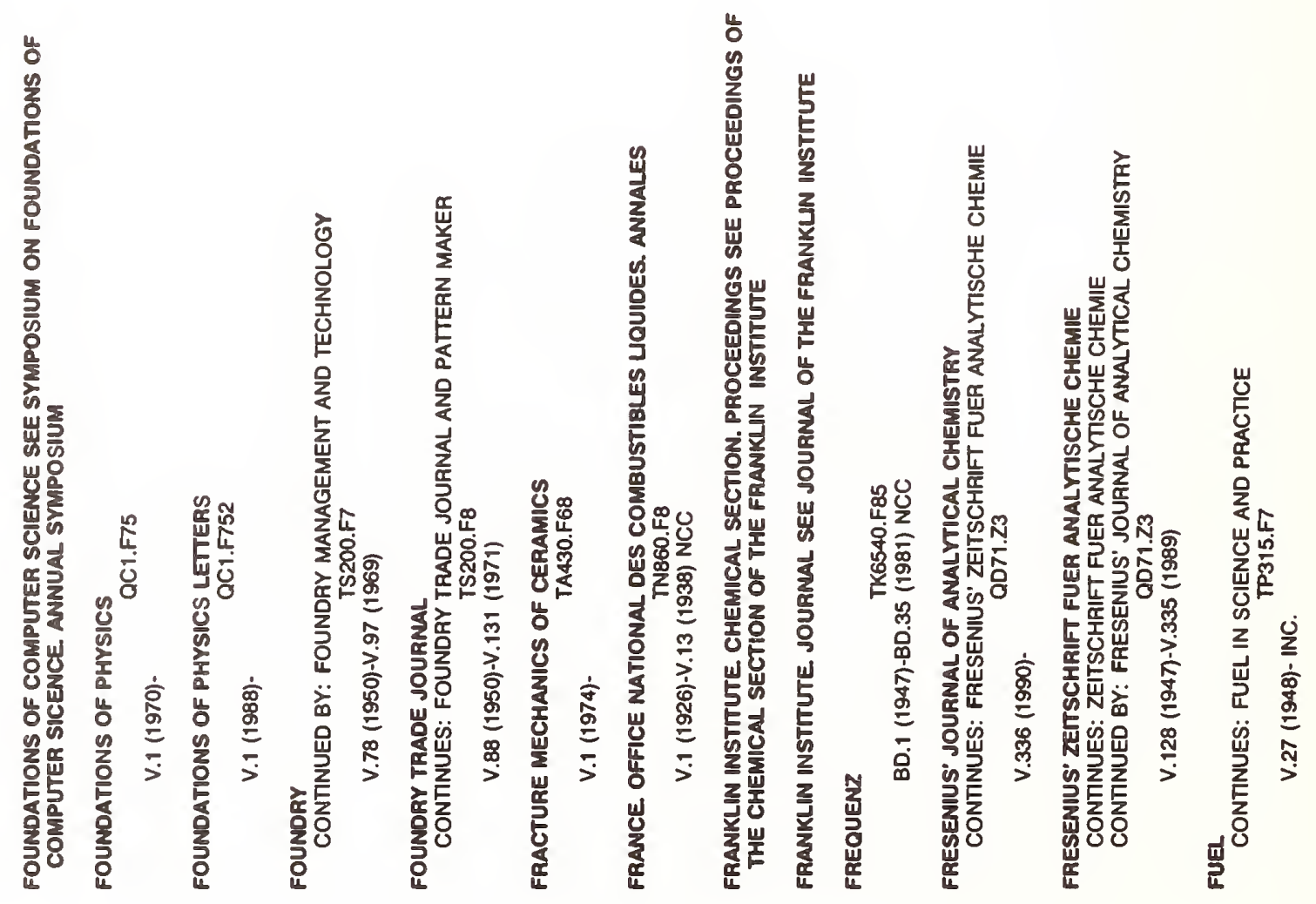



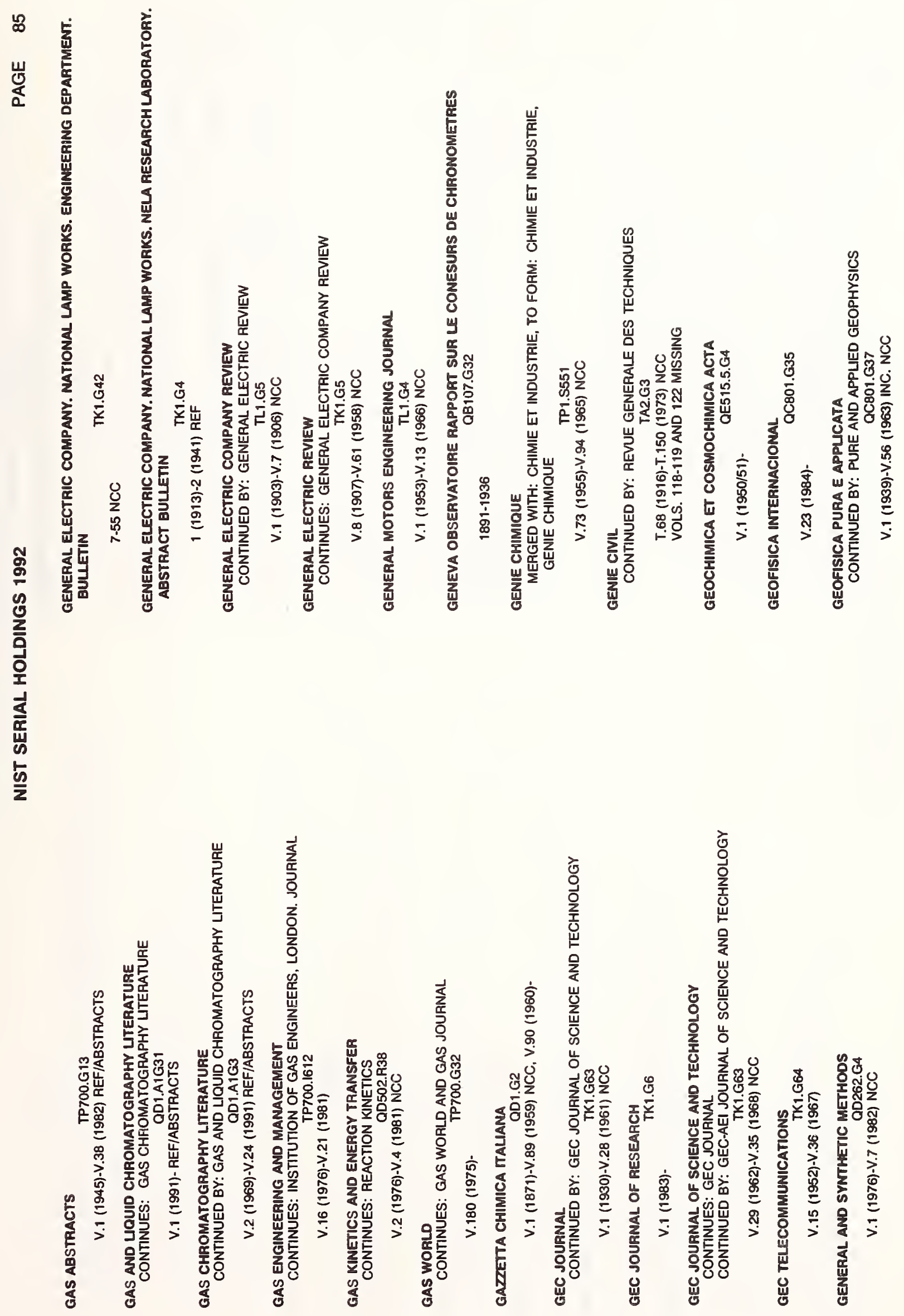


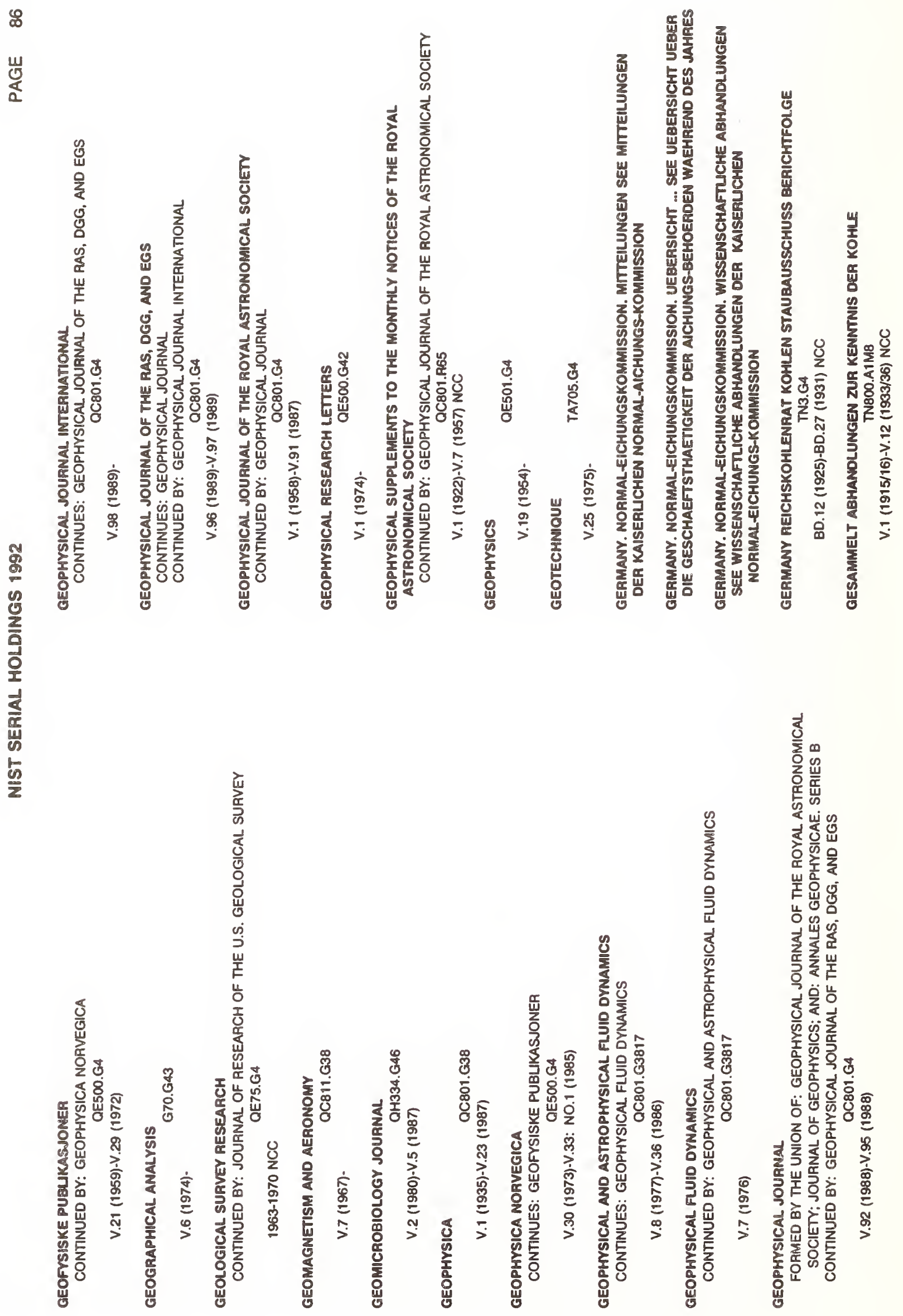


ఏ

郭

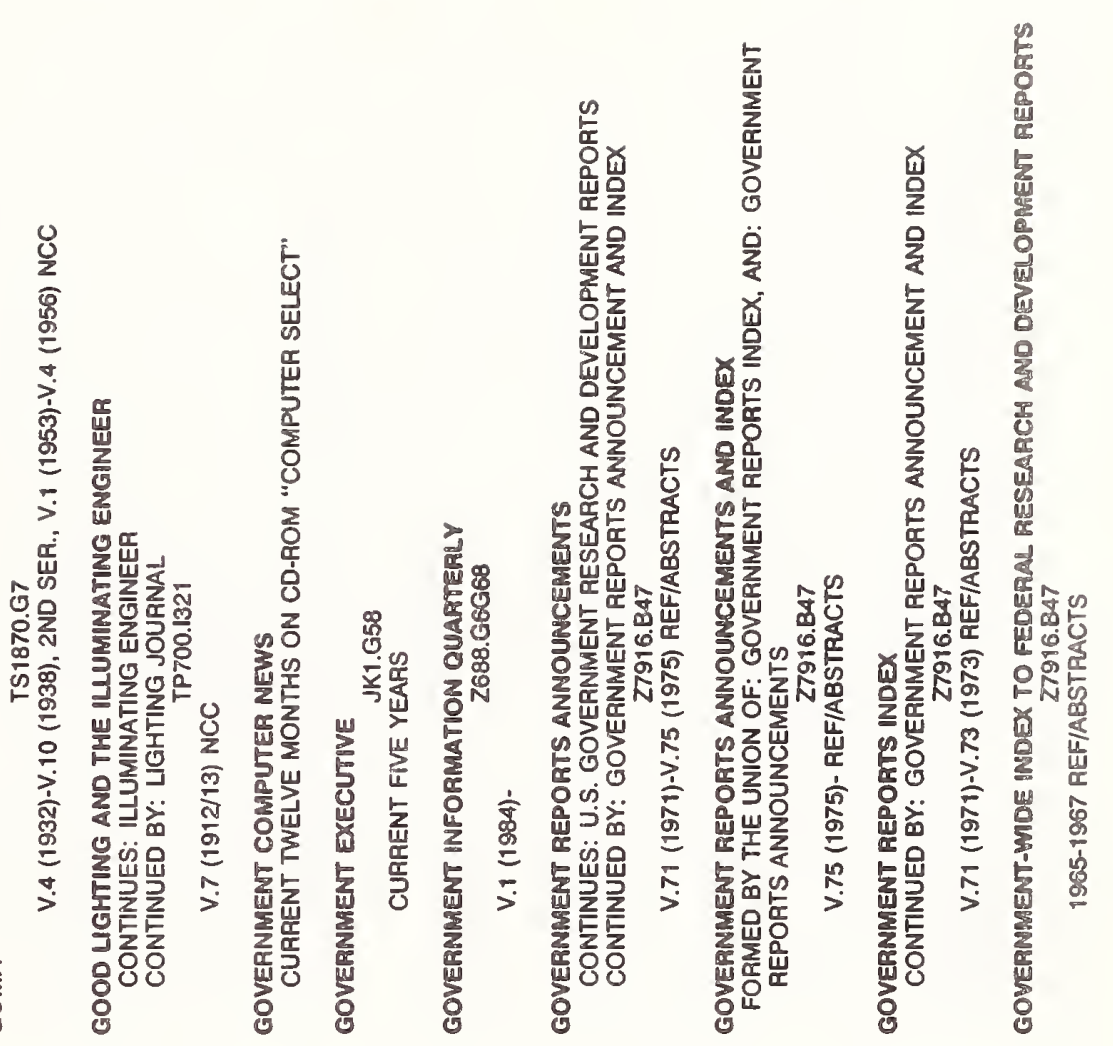

$\frac{5}{2}$

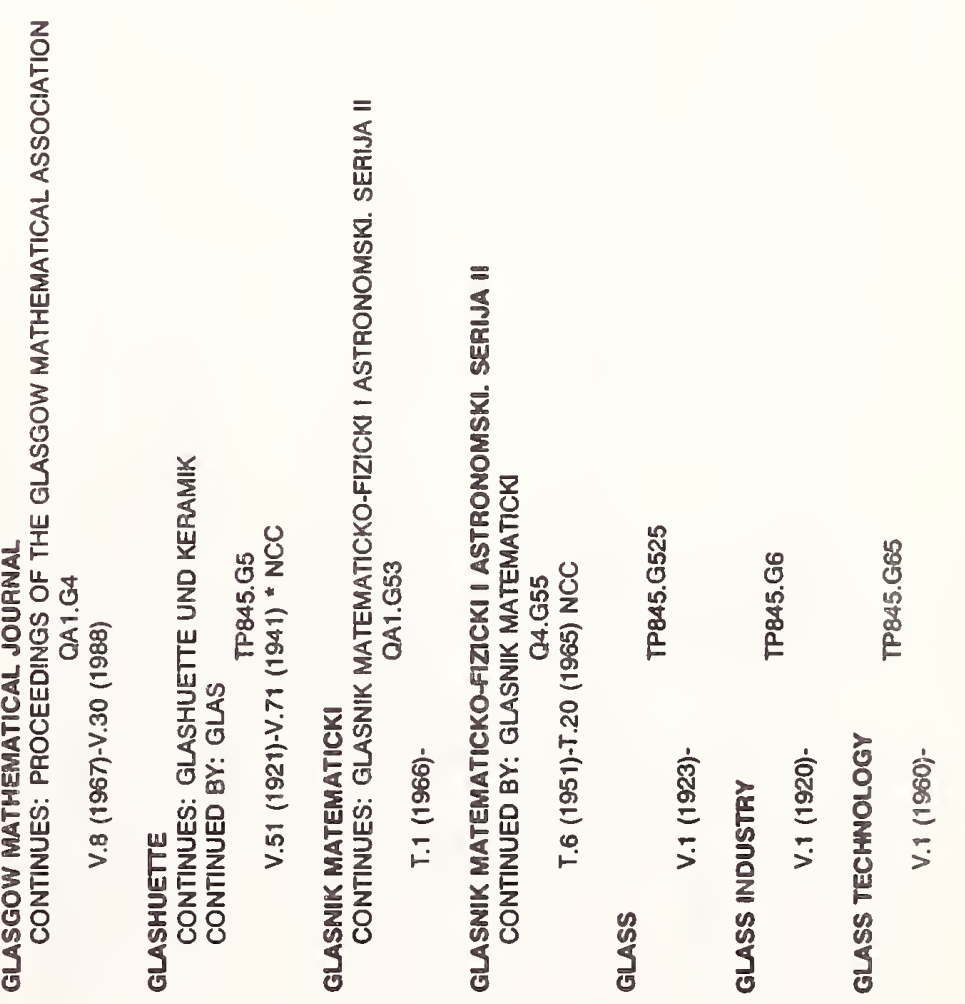




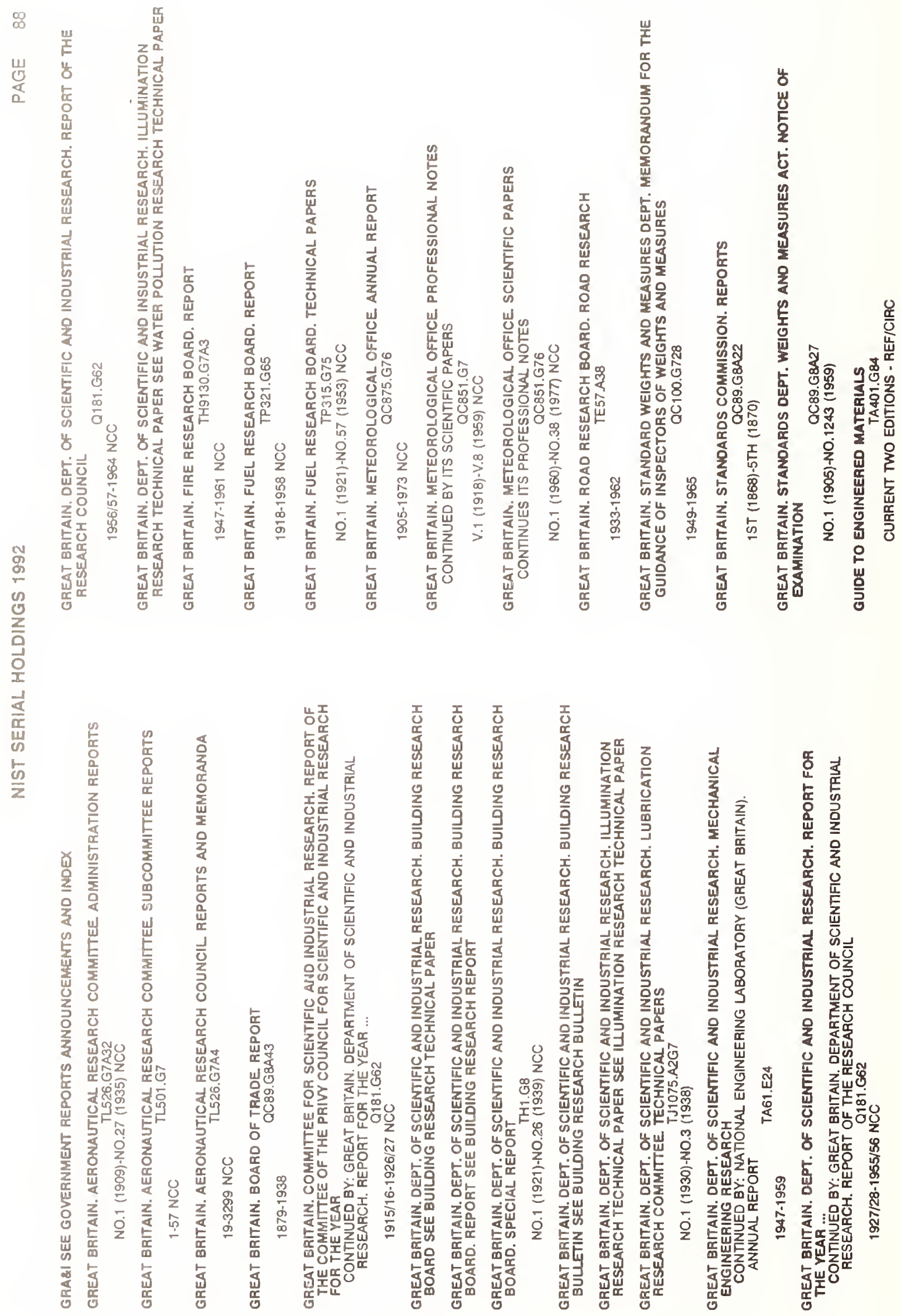


8
$\square$
$\frac{3}{2}$

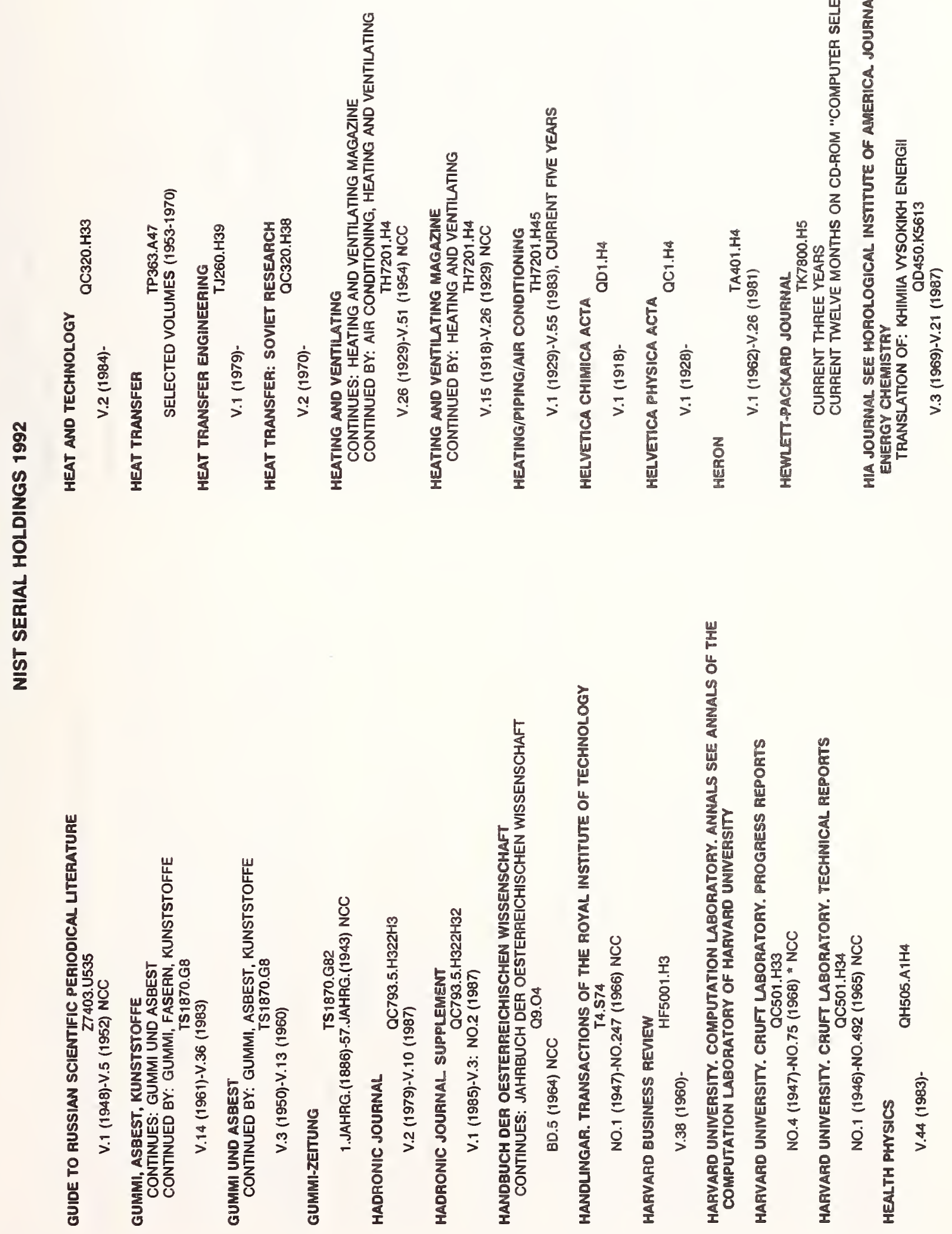


㟧

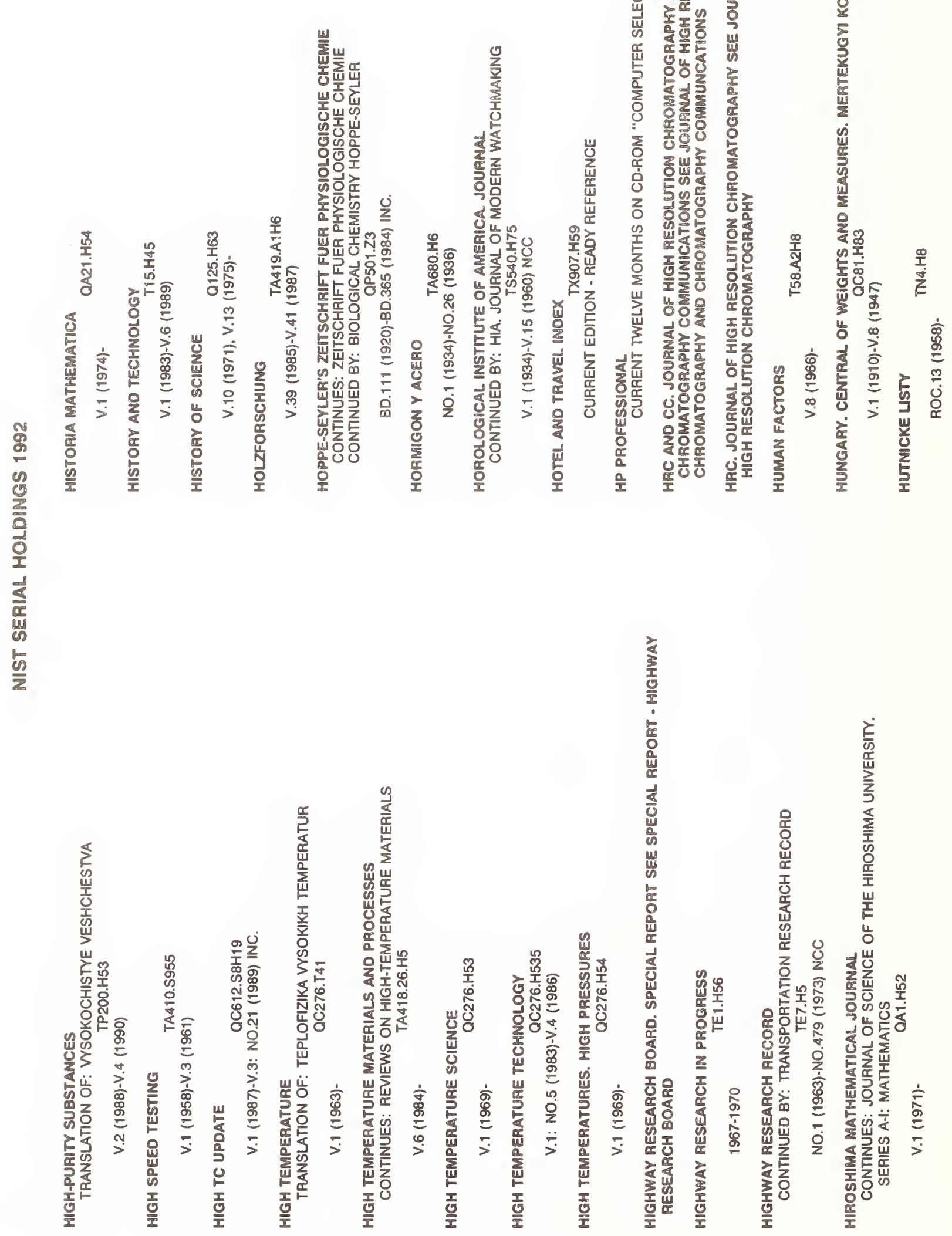




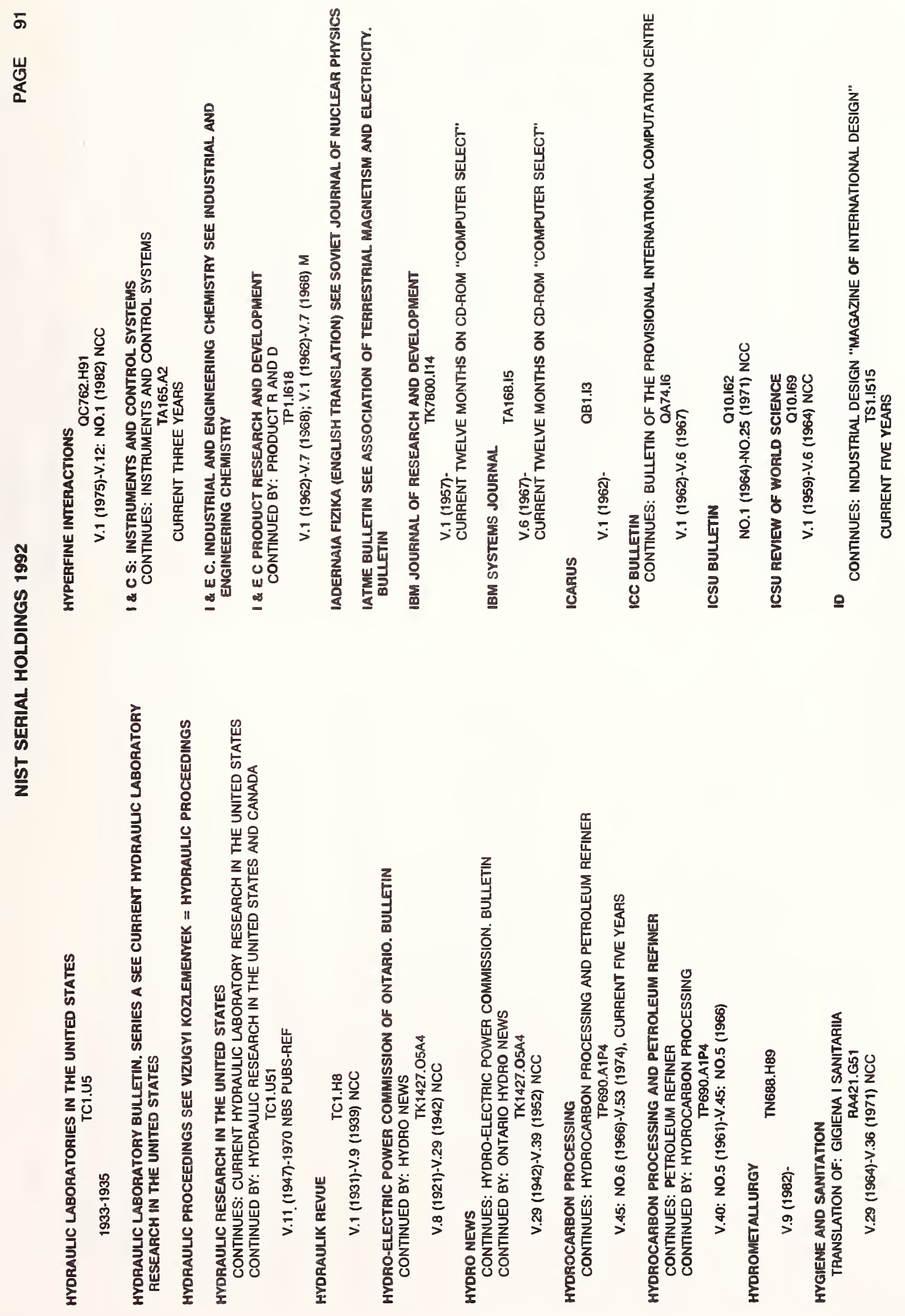




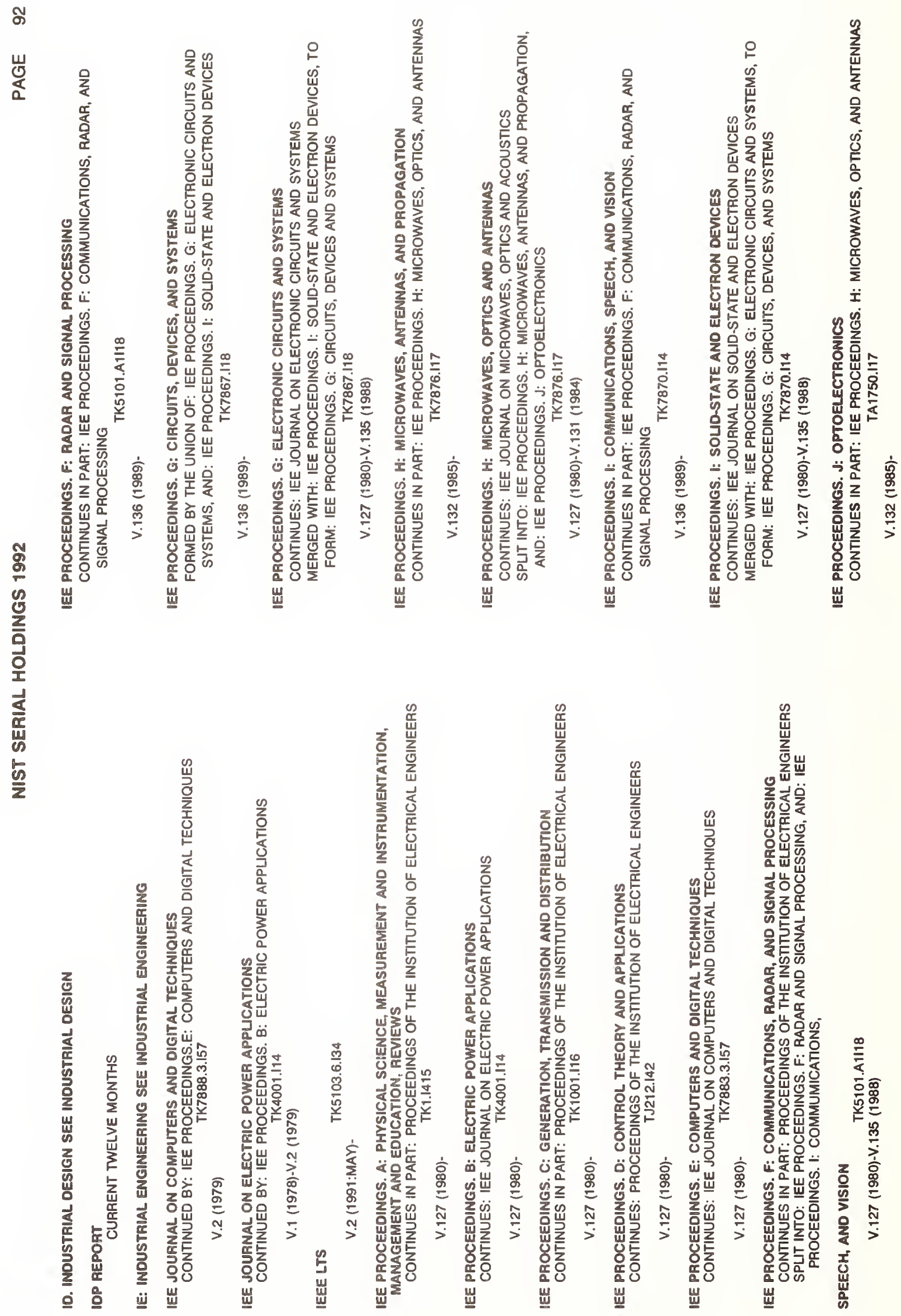


8
$\mathbb{3}$
$\frac{3}{2}$
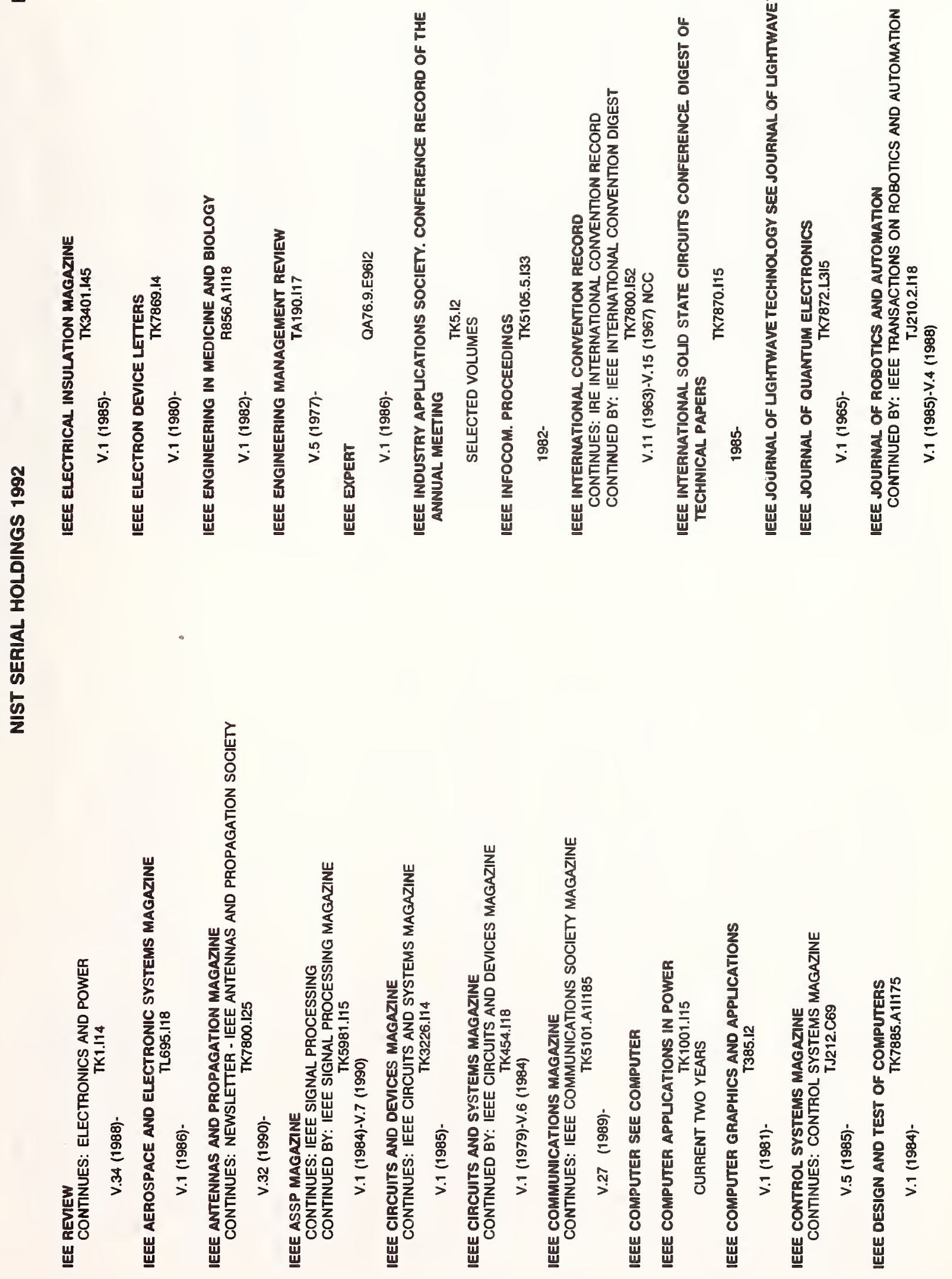


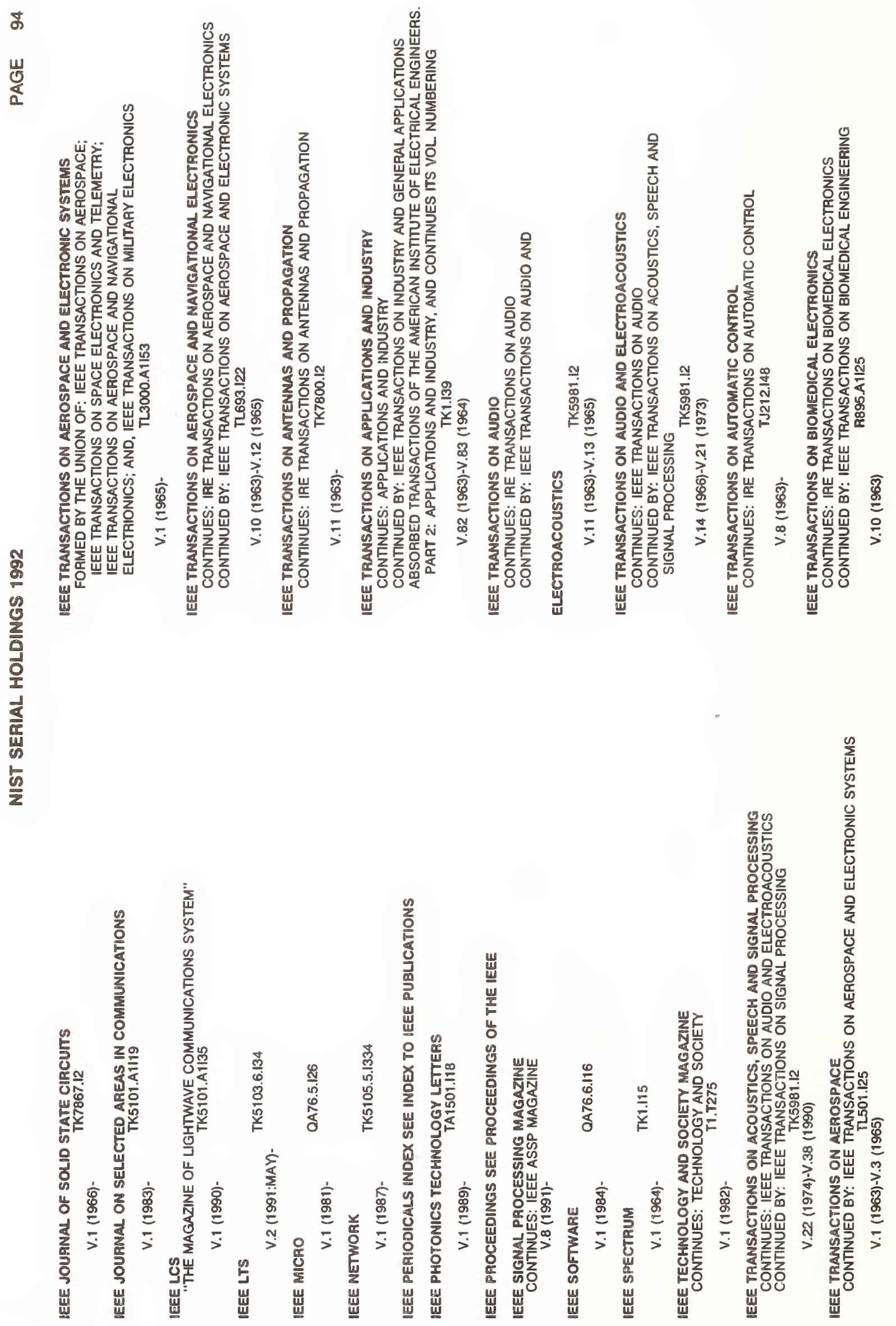




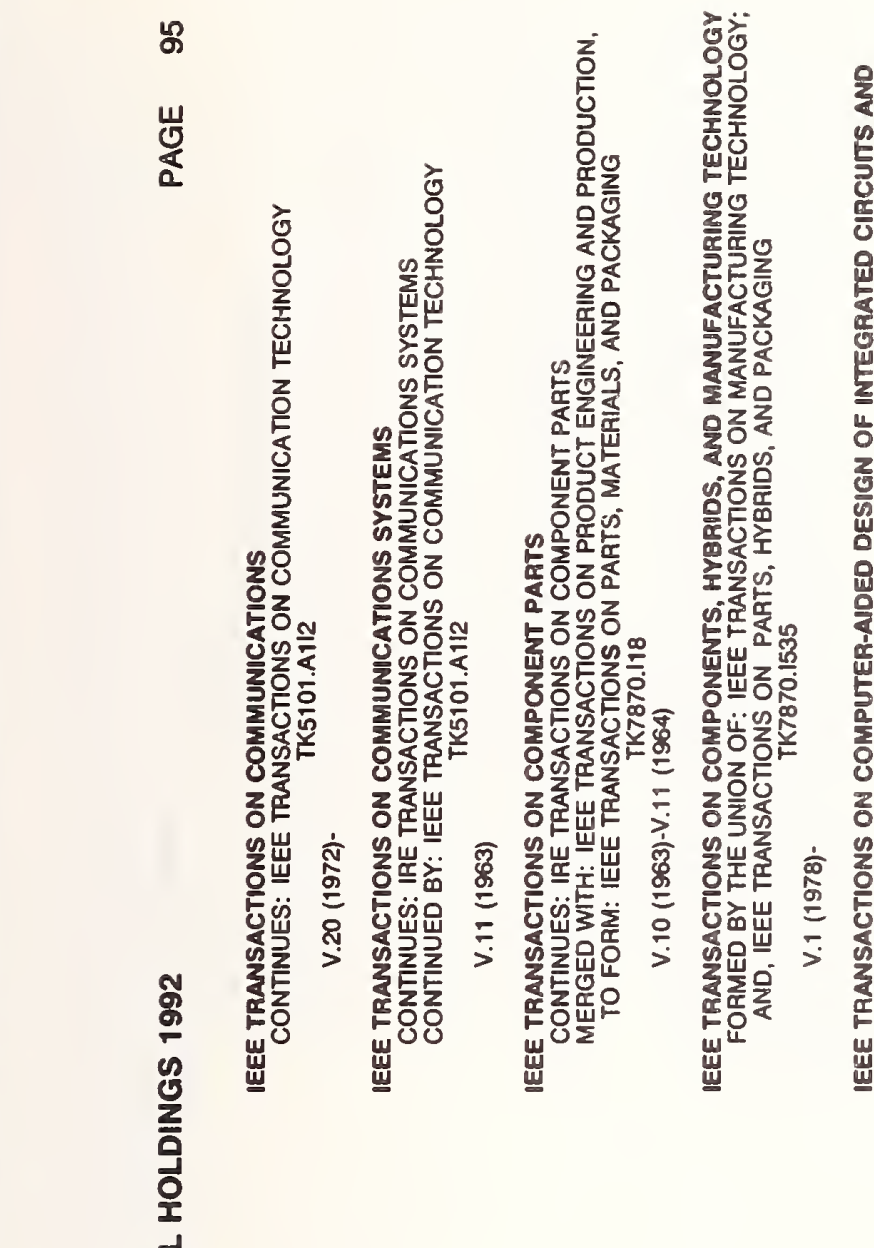
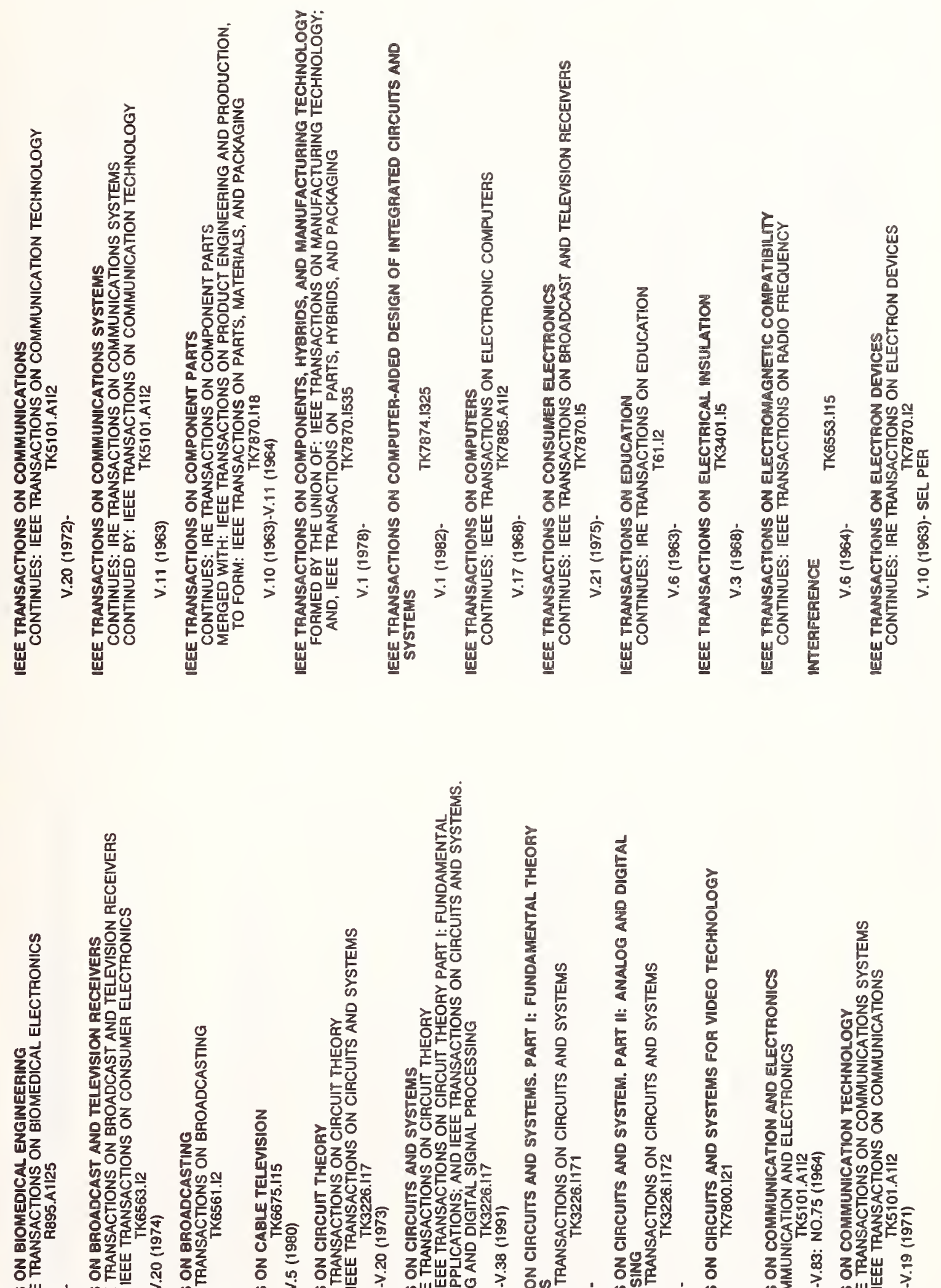

$\frac{1}{5}$
$\frac{5}{5}$
$\frac{5}{2}$

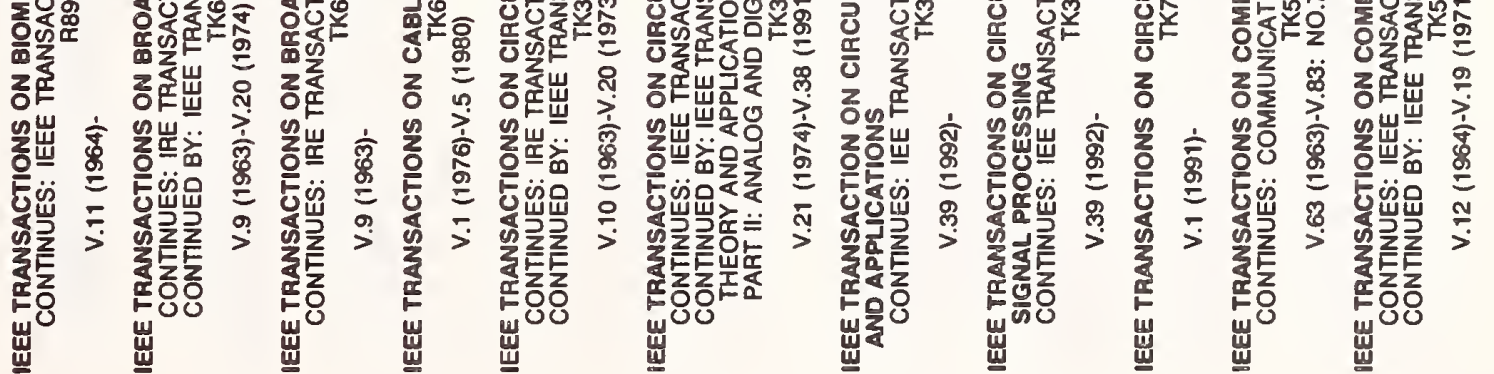




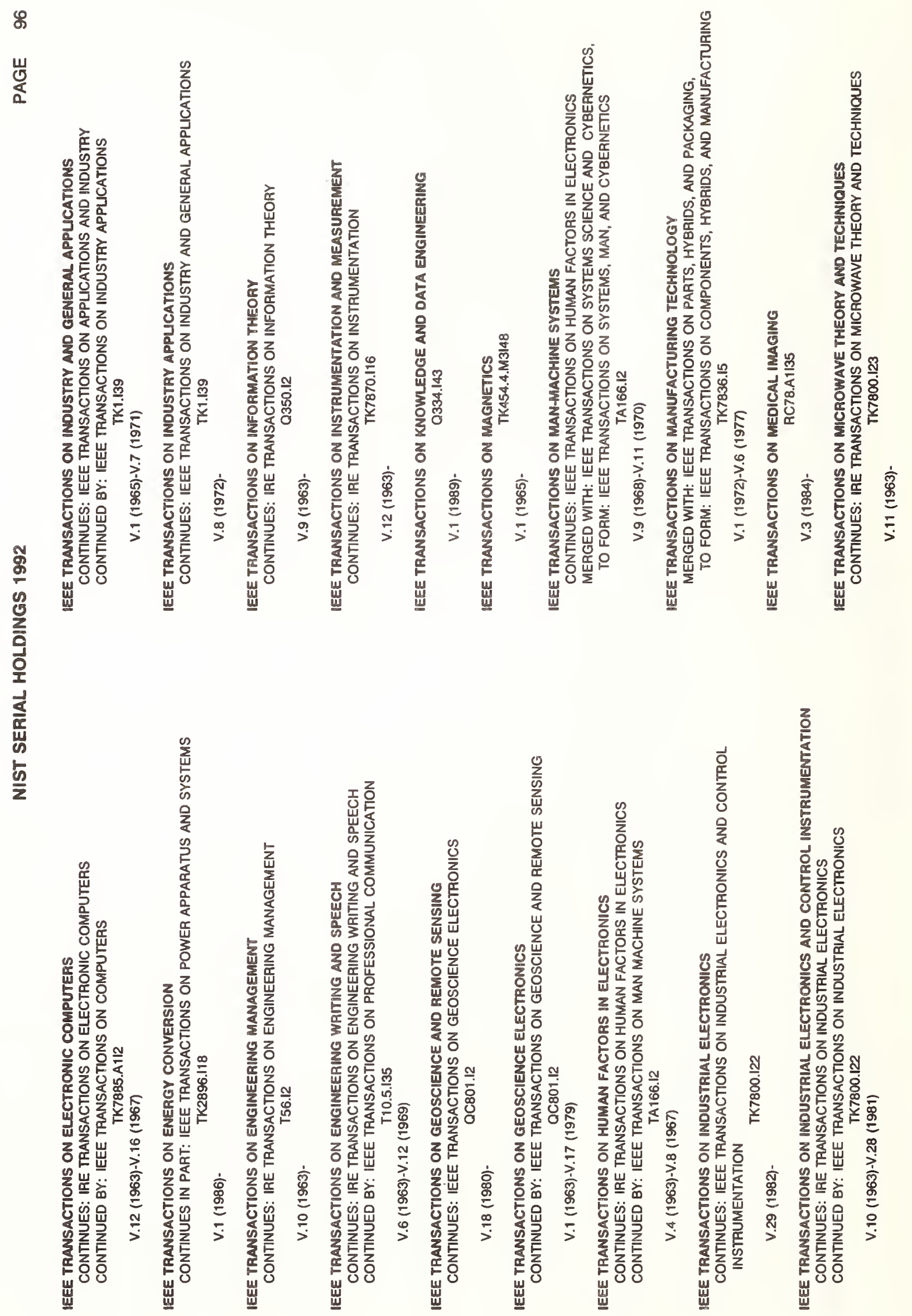




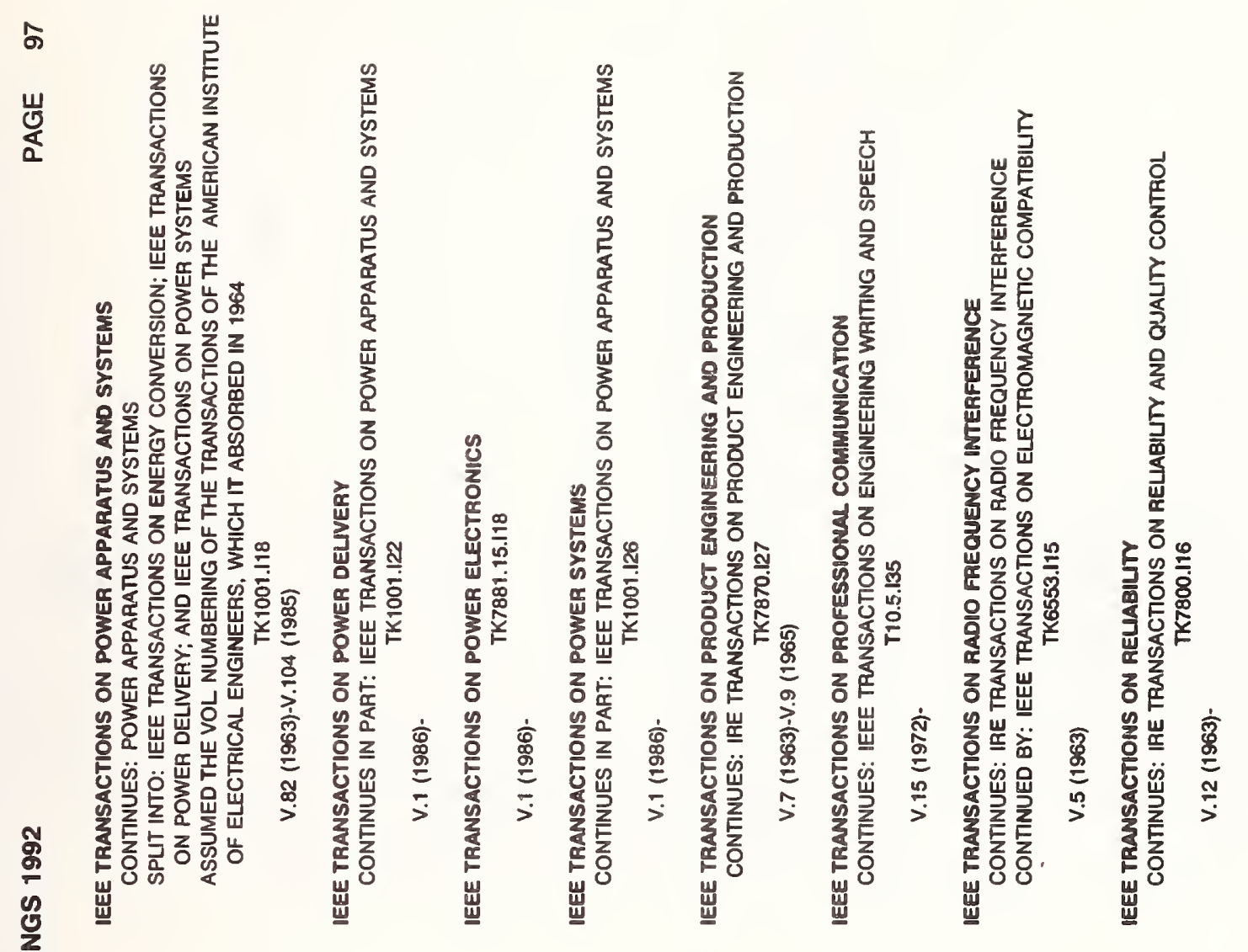


㟧

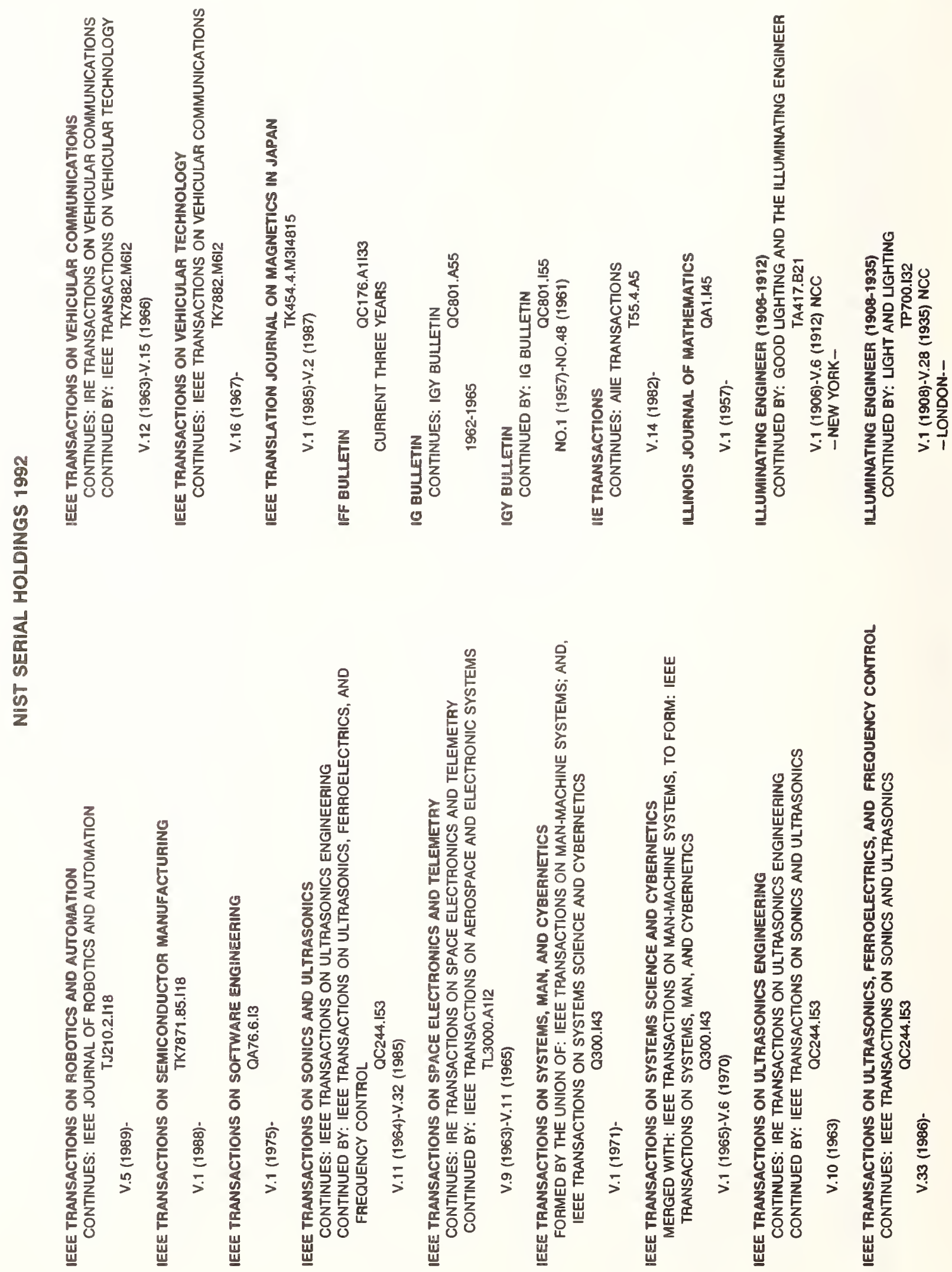




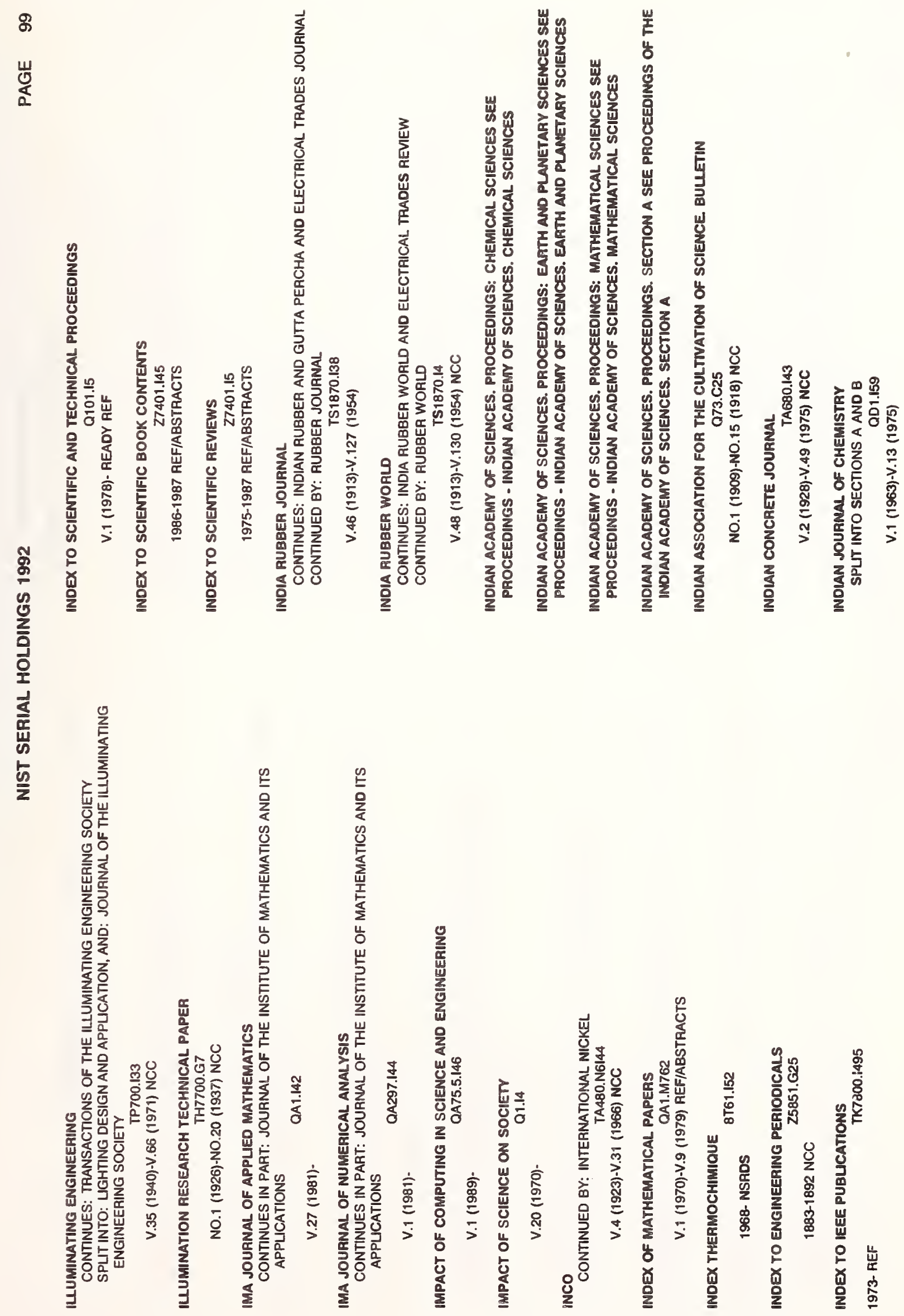


8

崖

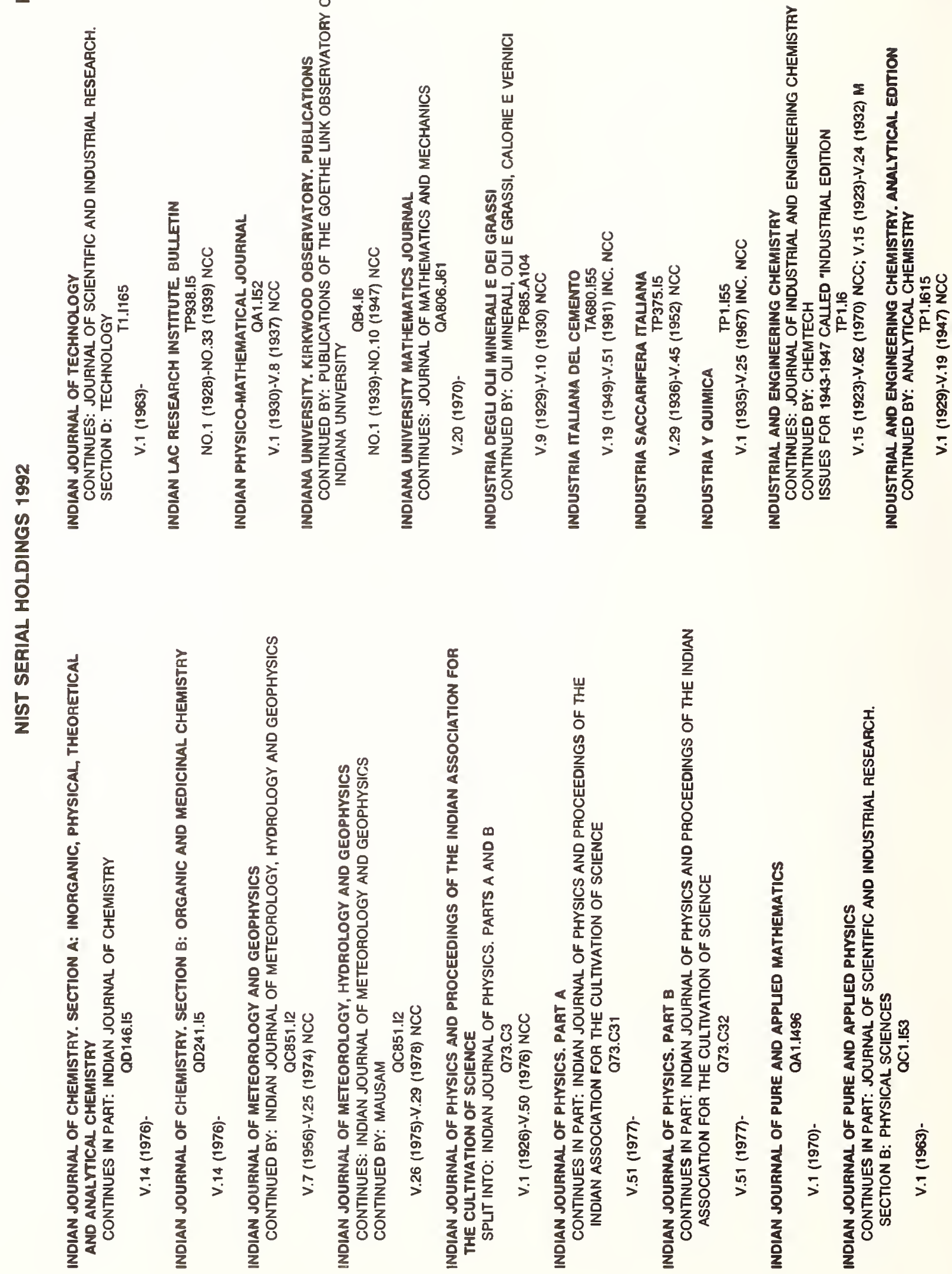


흠

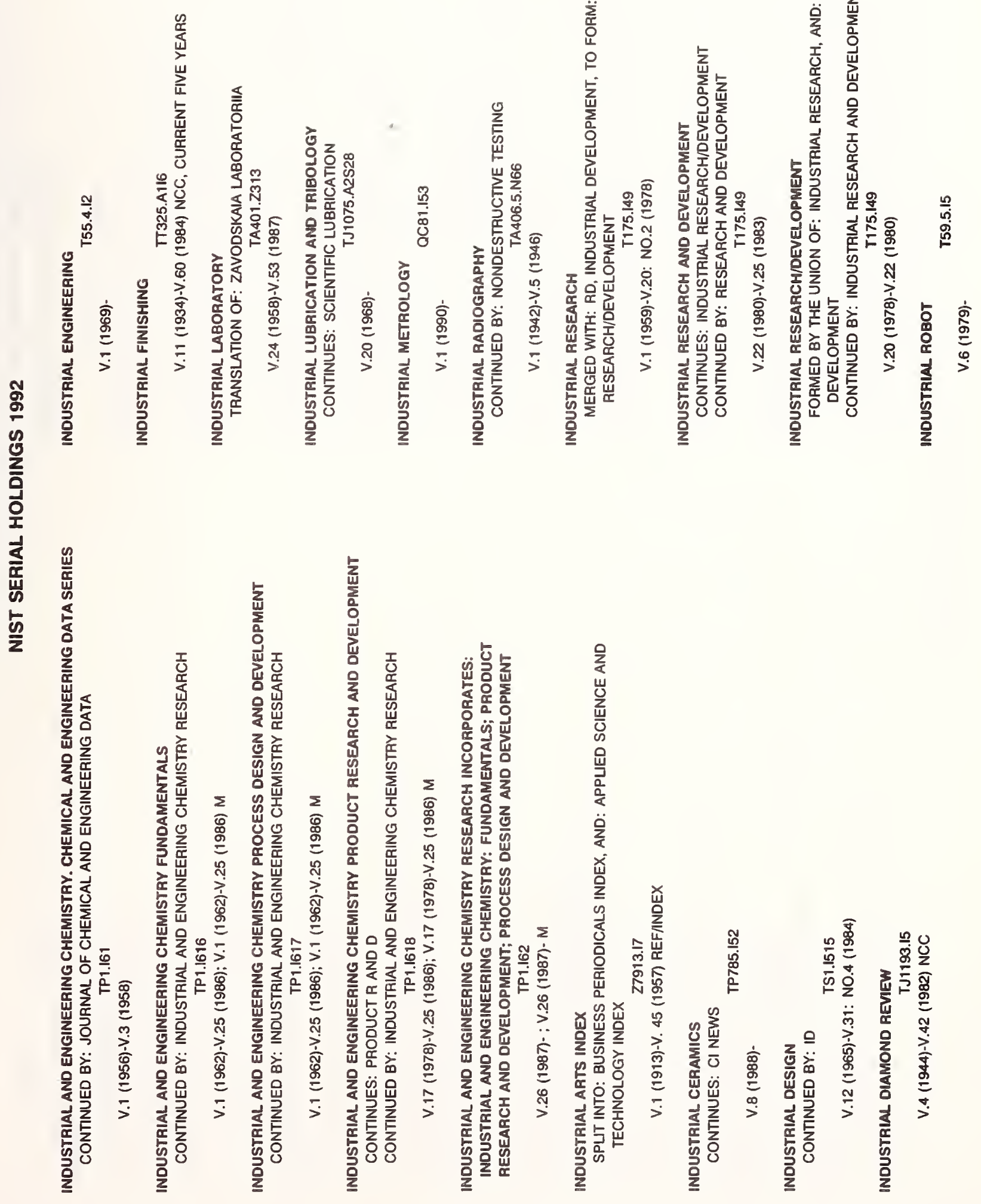


ㅁำ

崖

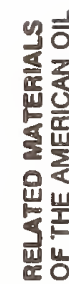

旁紊

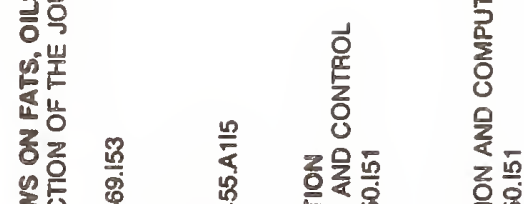

害

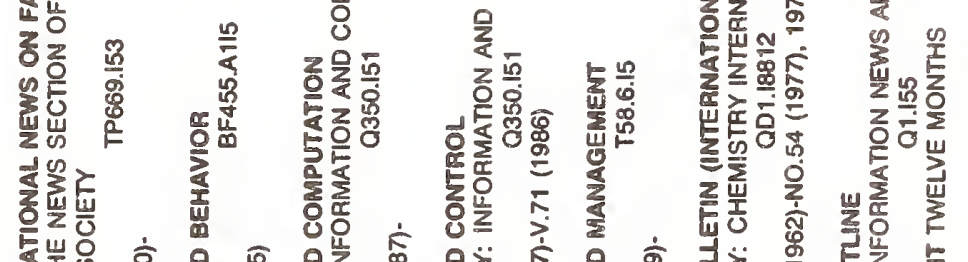

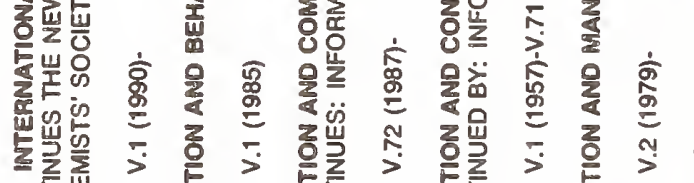

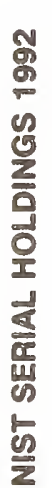

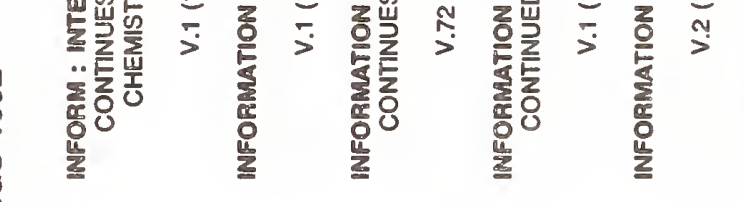

些

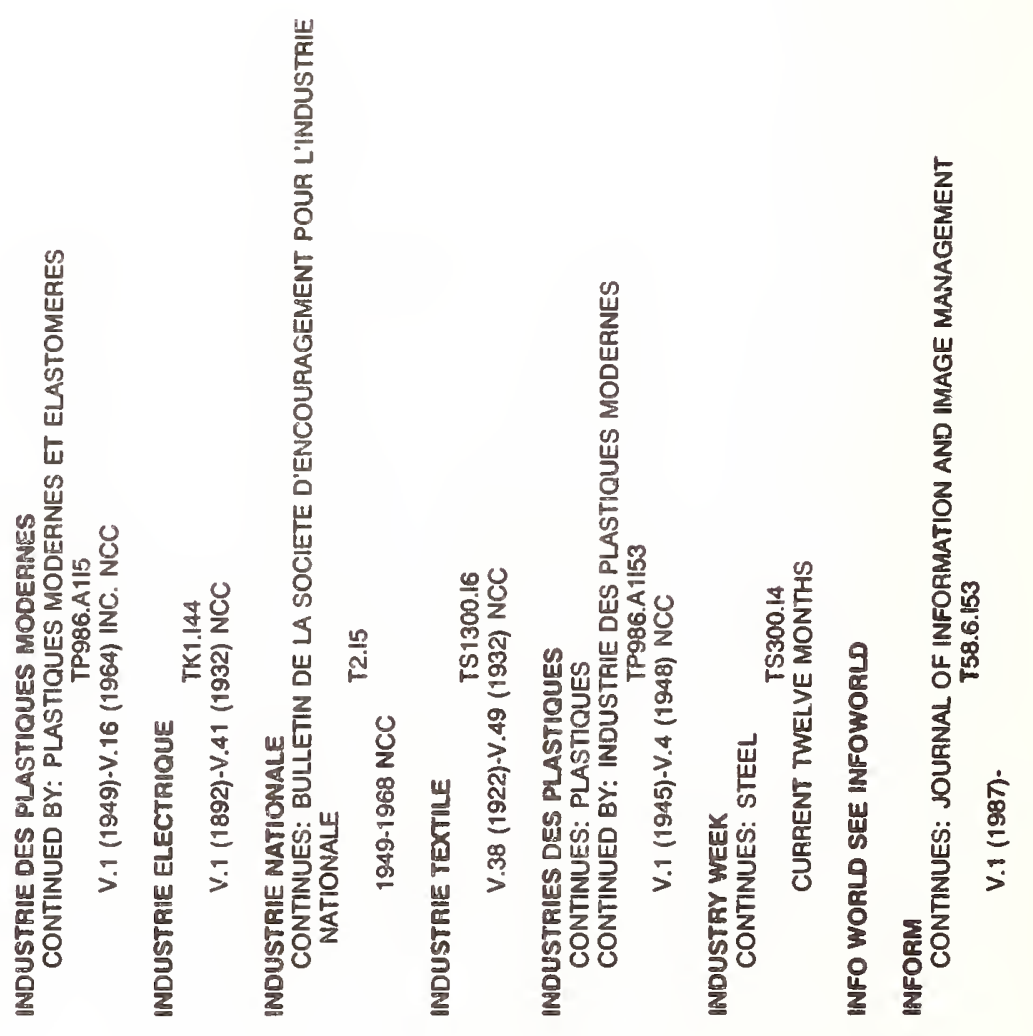


\begin{tabular}{l}
8 \\
\hdashline \\
$\frac{3}{2}$ \\
$\frac{8}{2}$
\end{tabular}
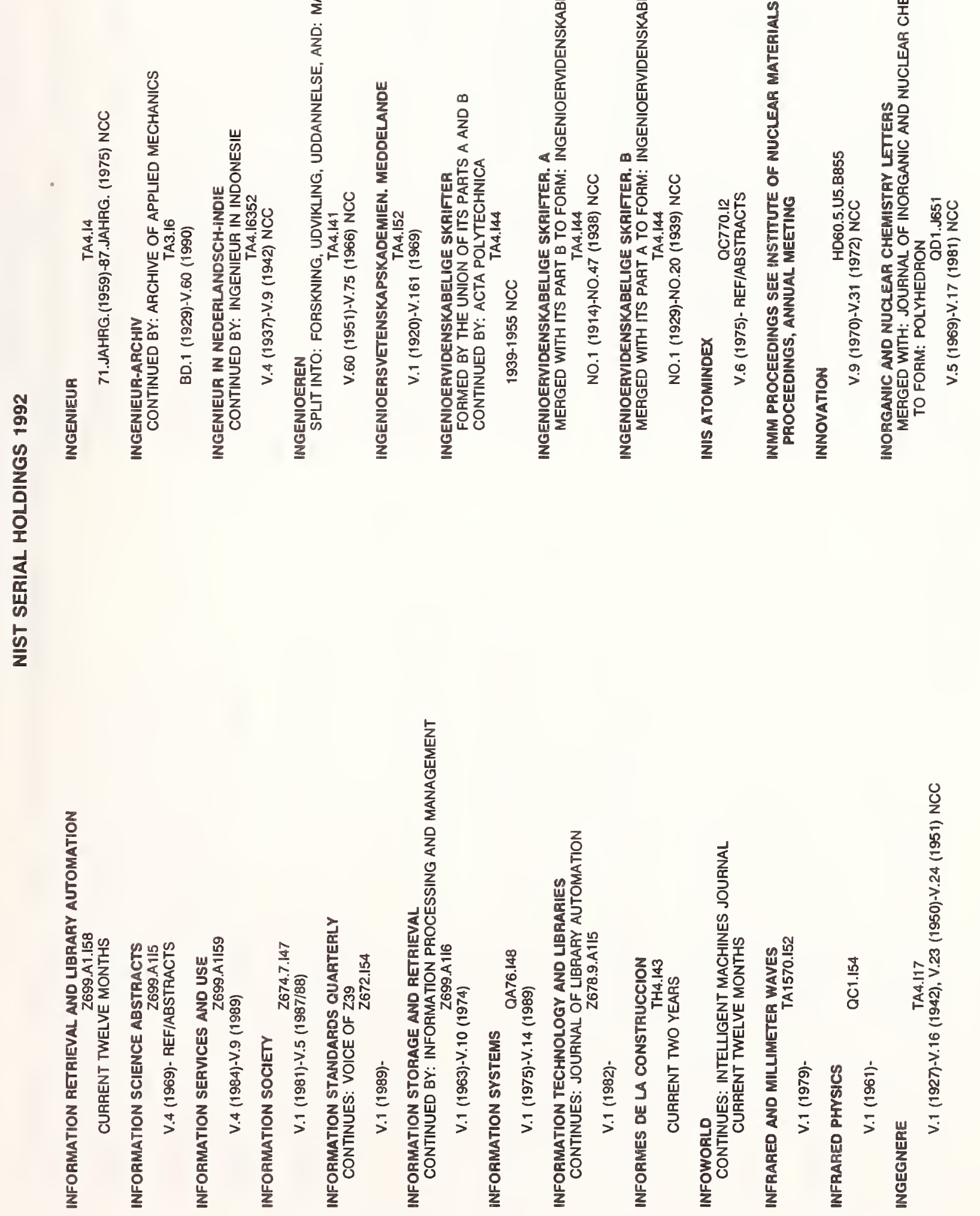

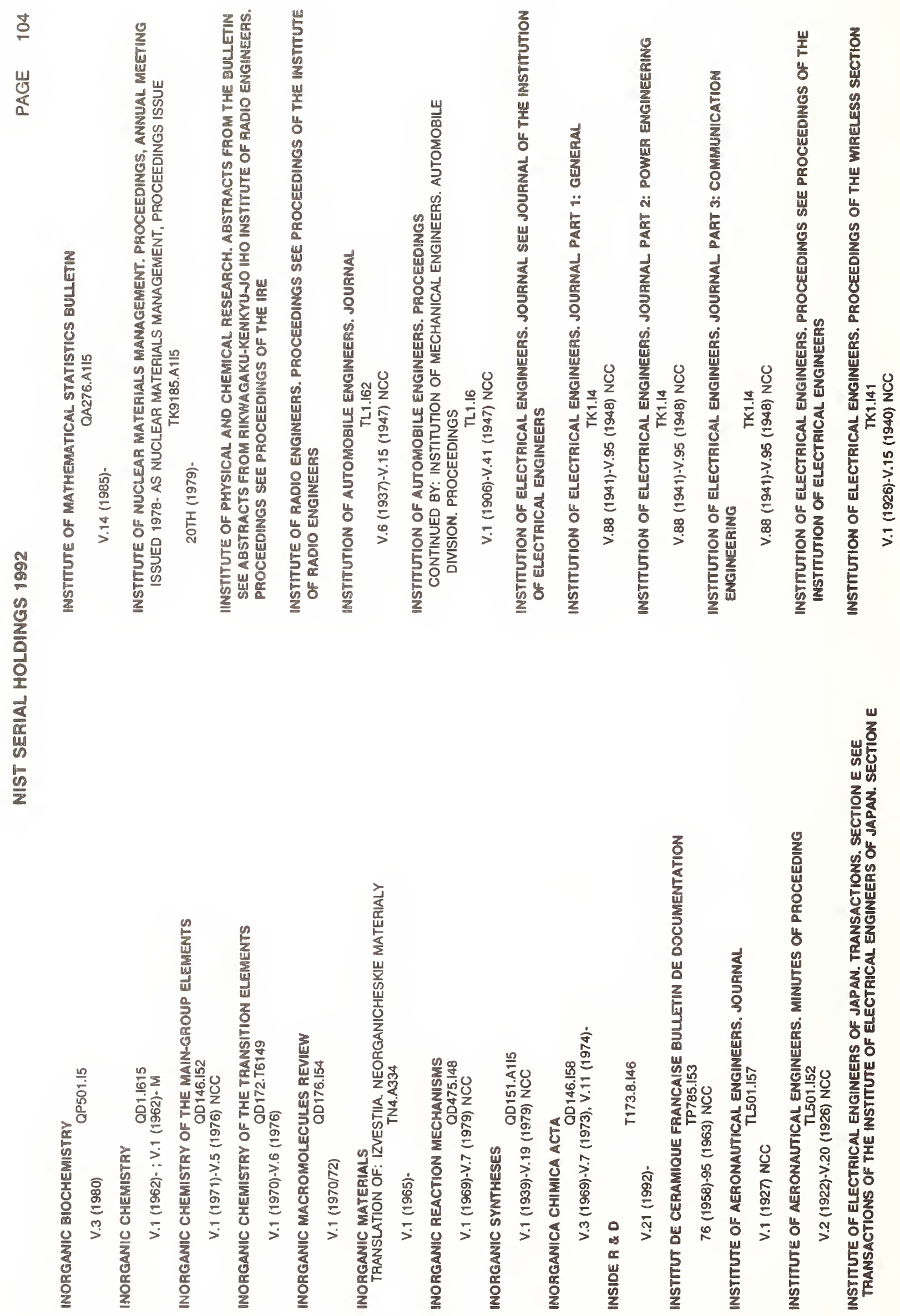


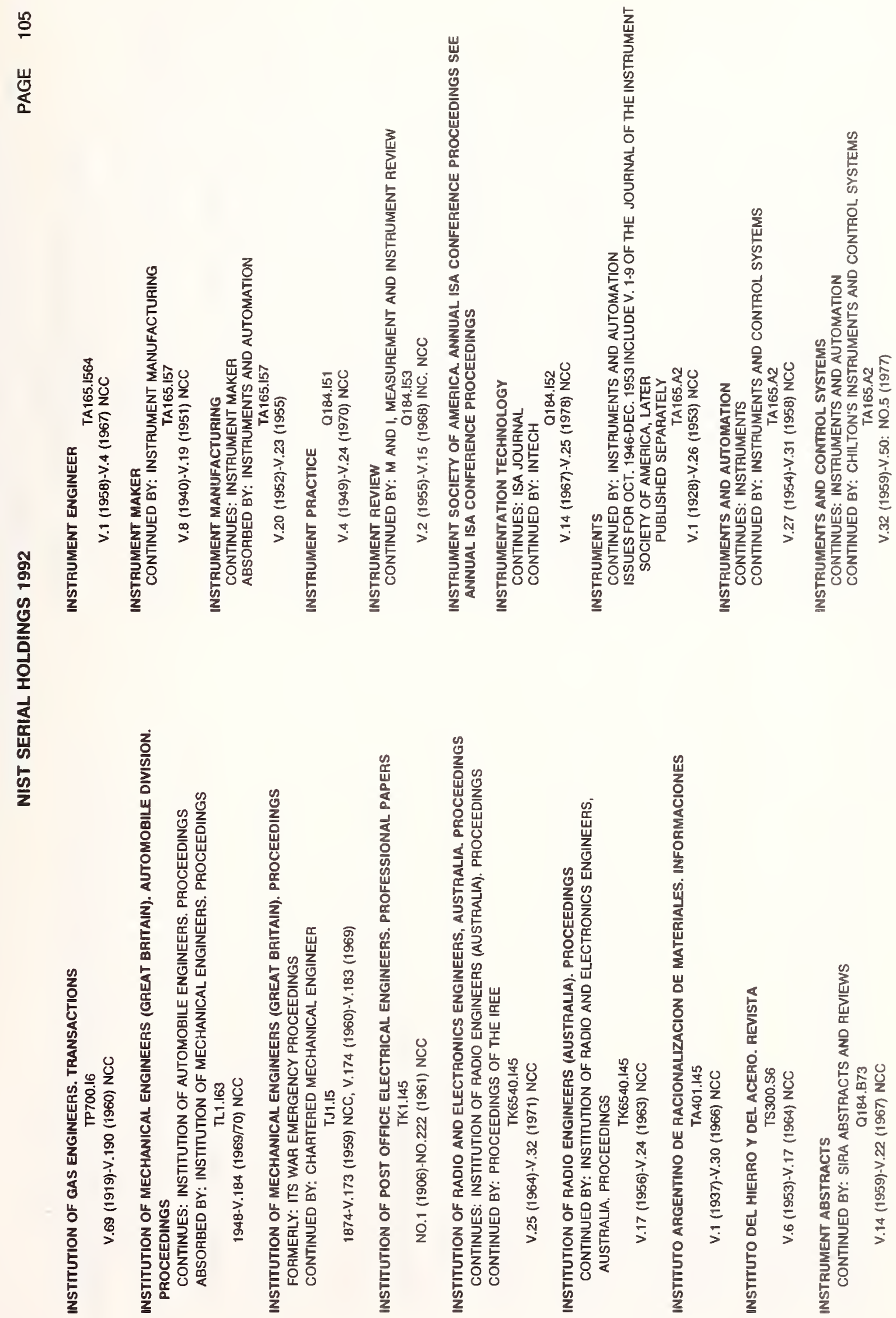




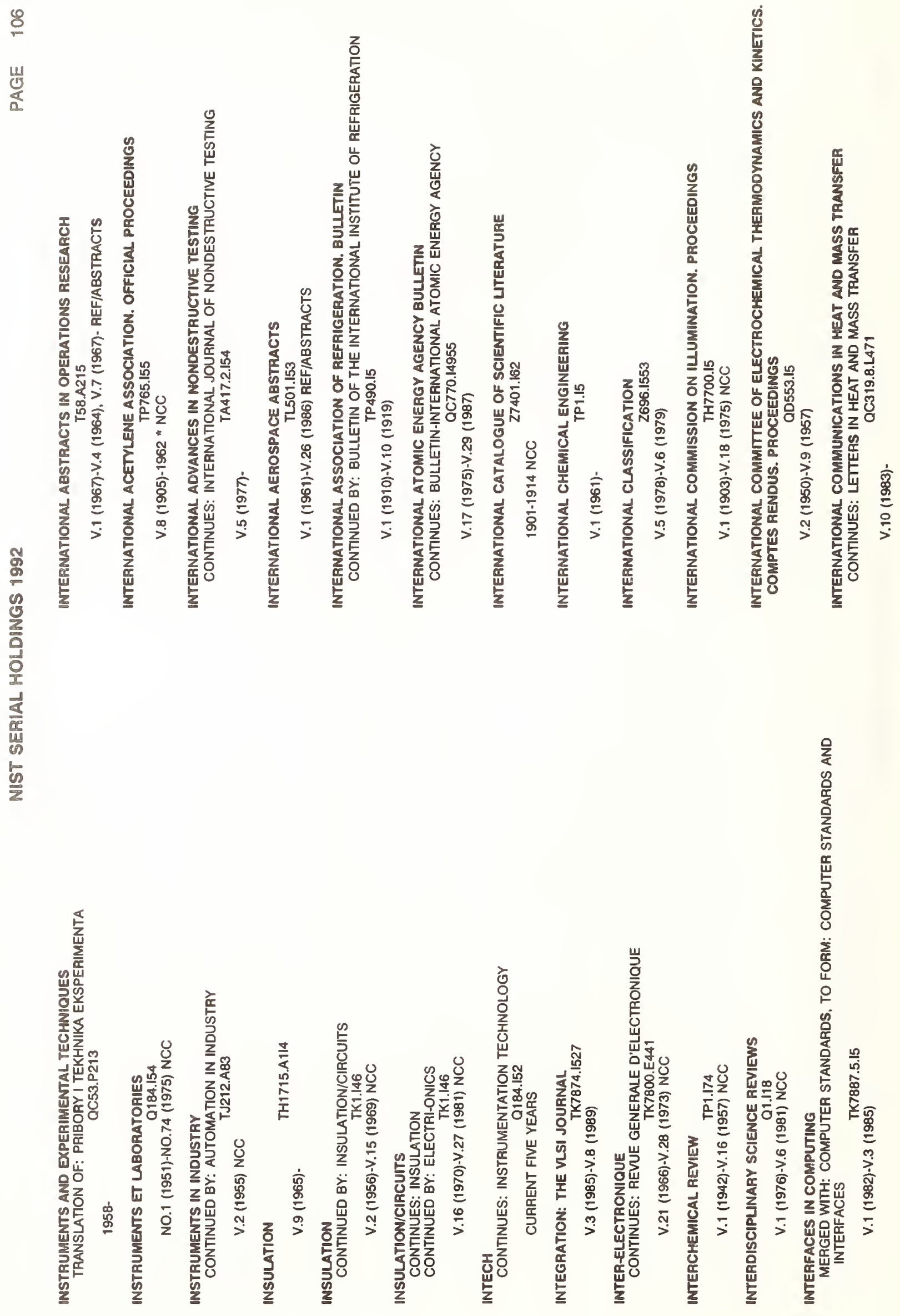


$\underline{0}$

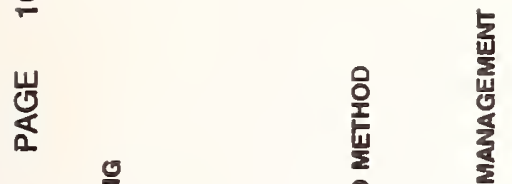

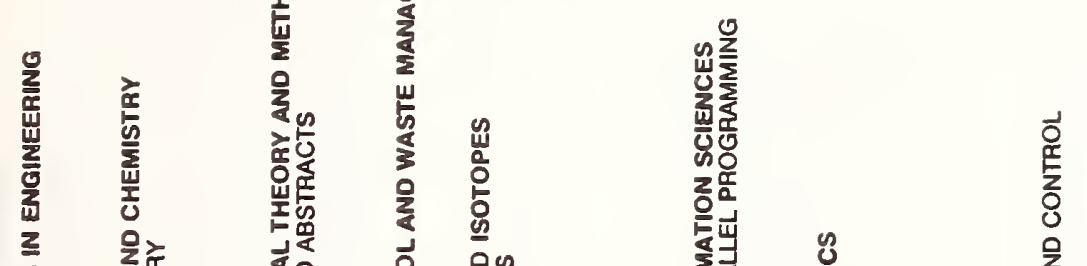

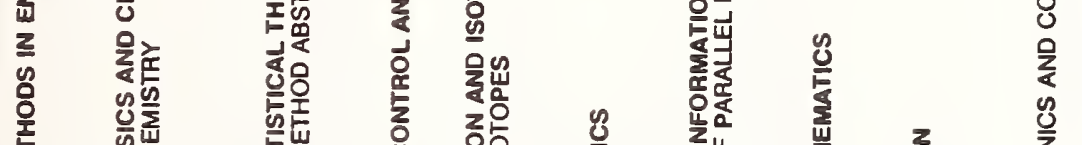

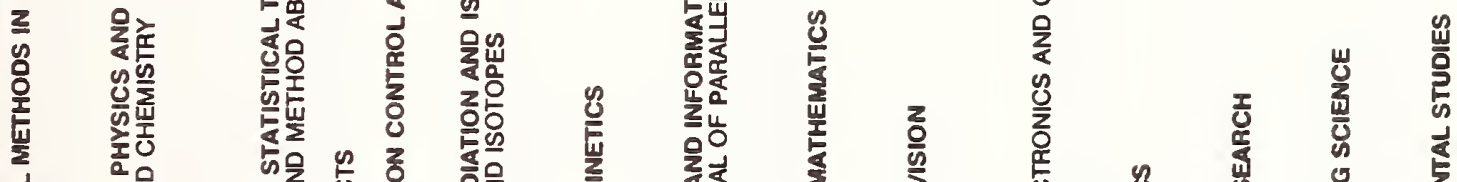

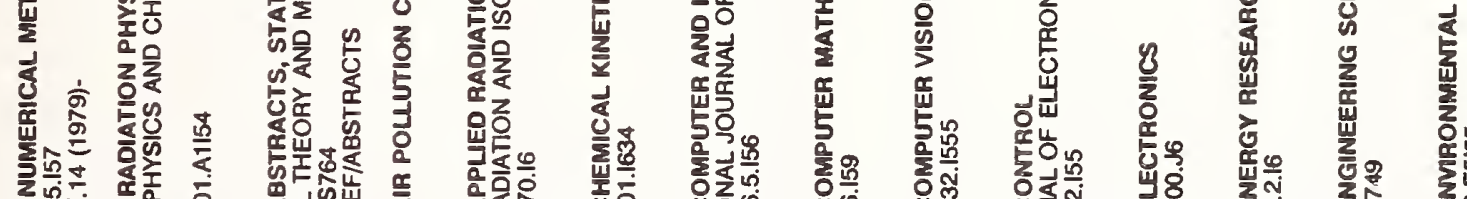

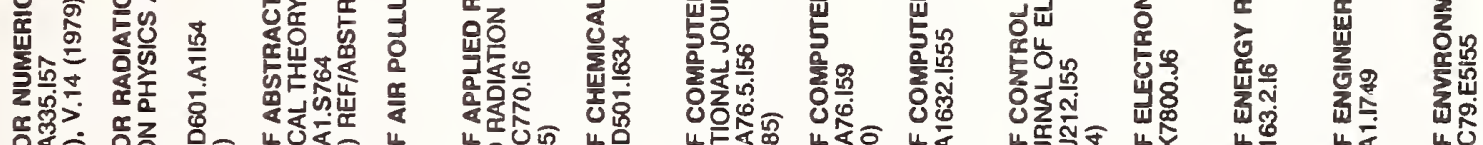

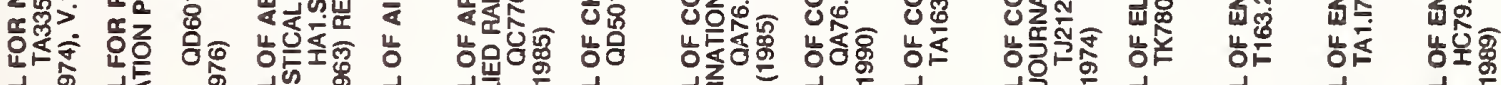

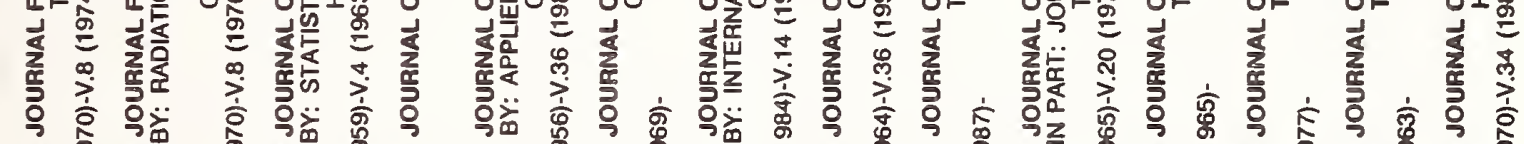
$\begin{array}{lllllllll} & & \\ 0\end{array}$

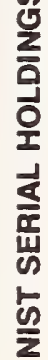

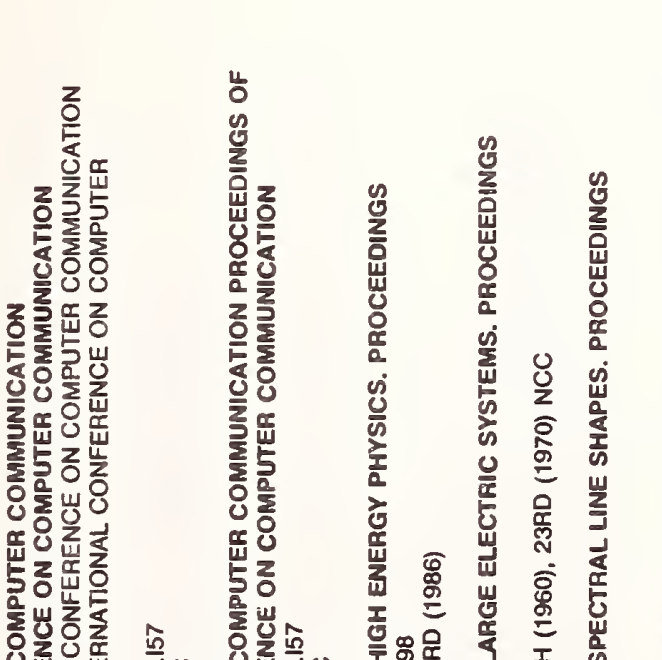

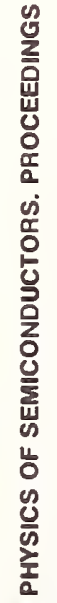

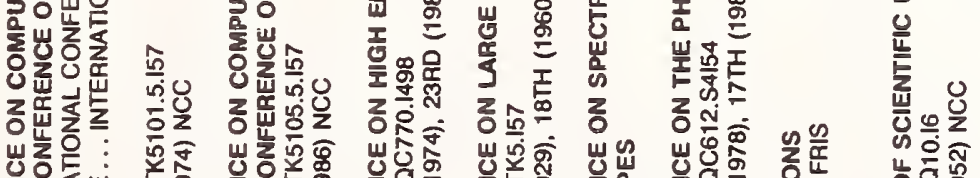

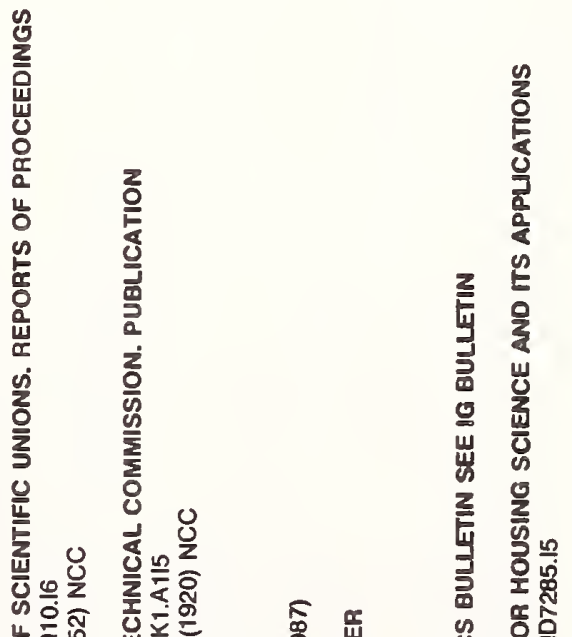

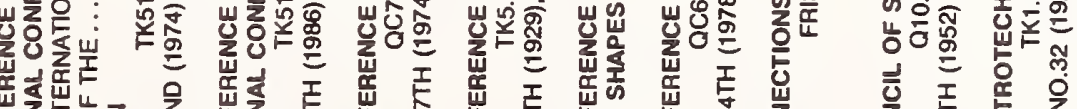

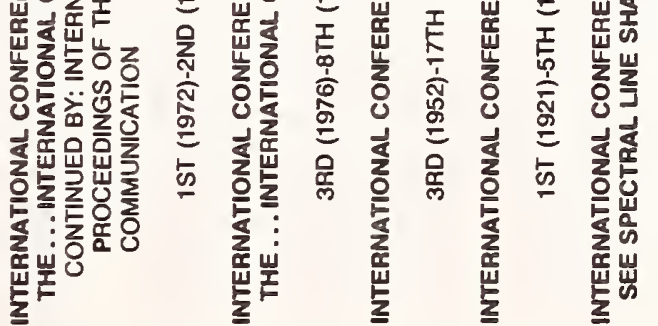

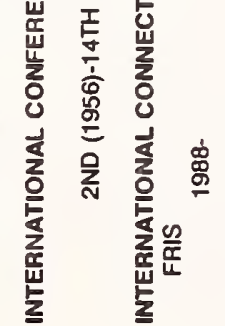

总

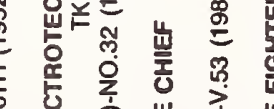

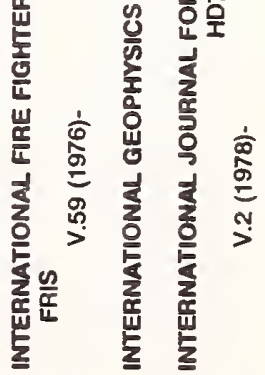


일<smiles>[CH][Co]</smiles>
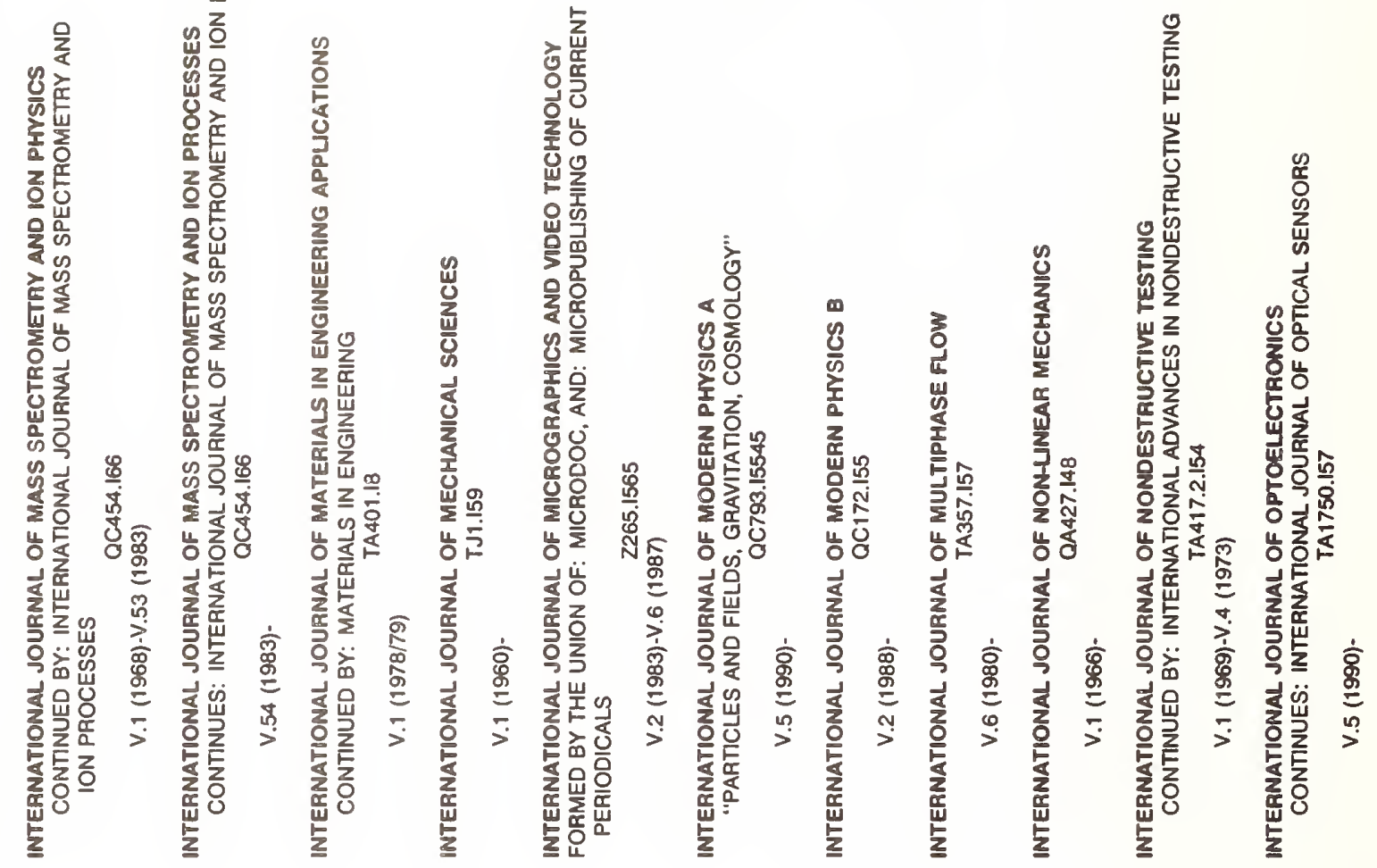

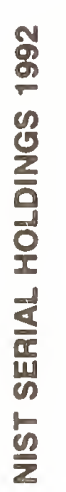

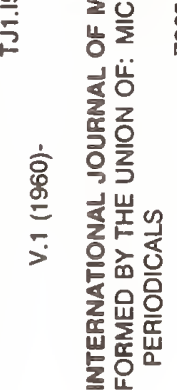

숑
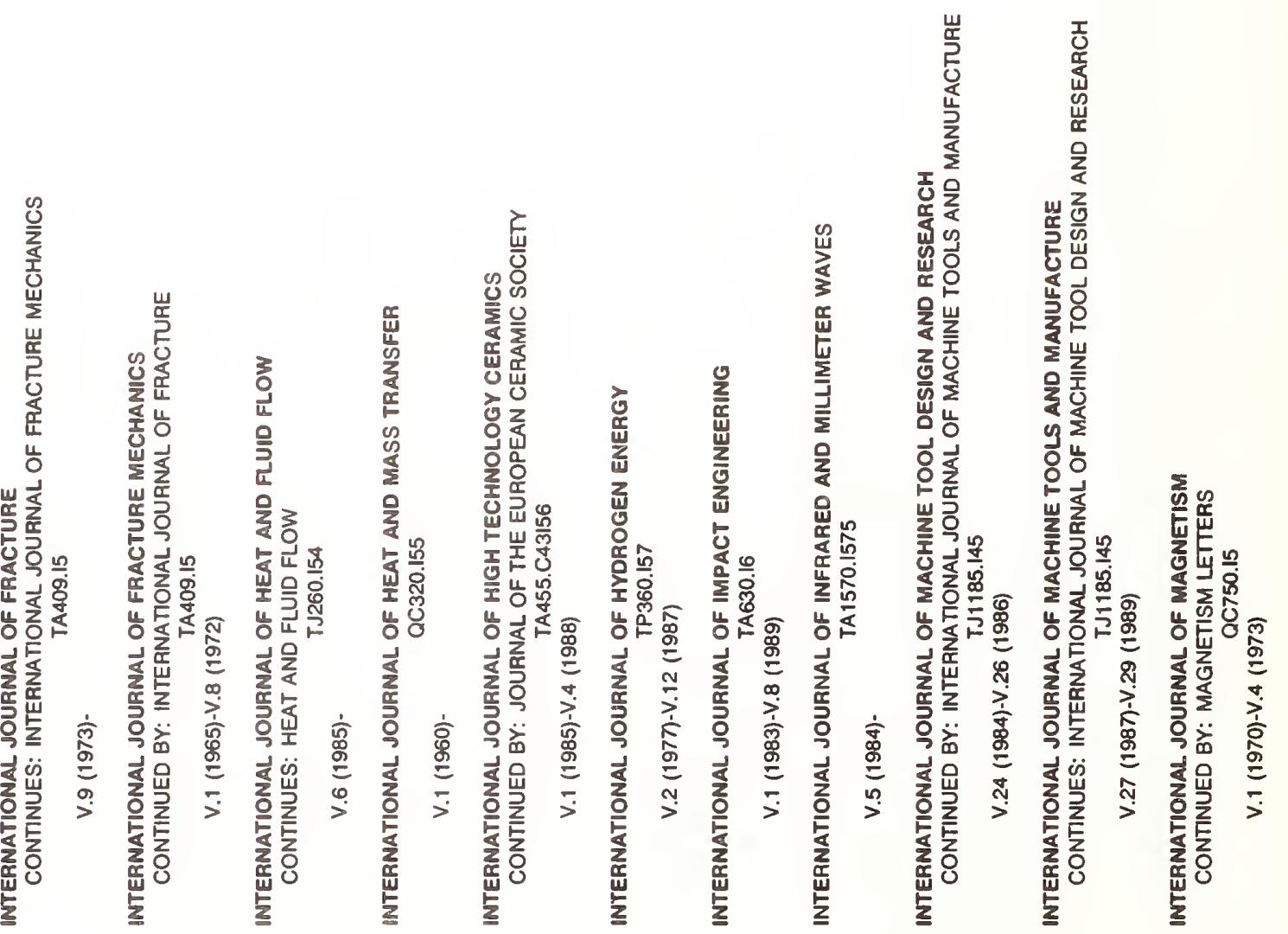
$\stackrel{8}{9}$

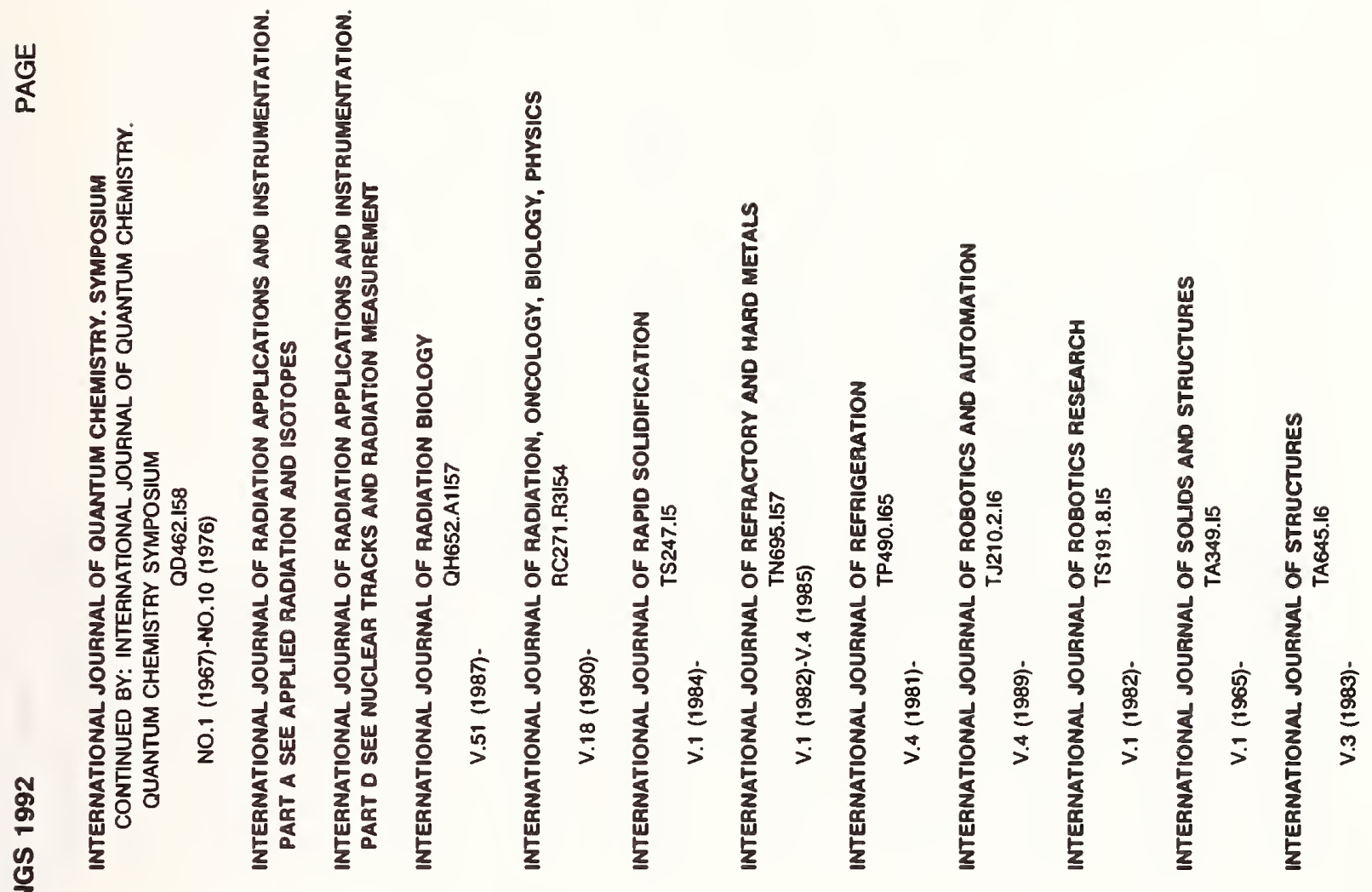

产

毵

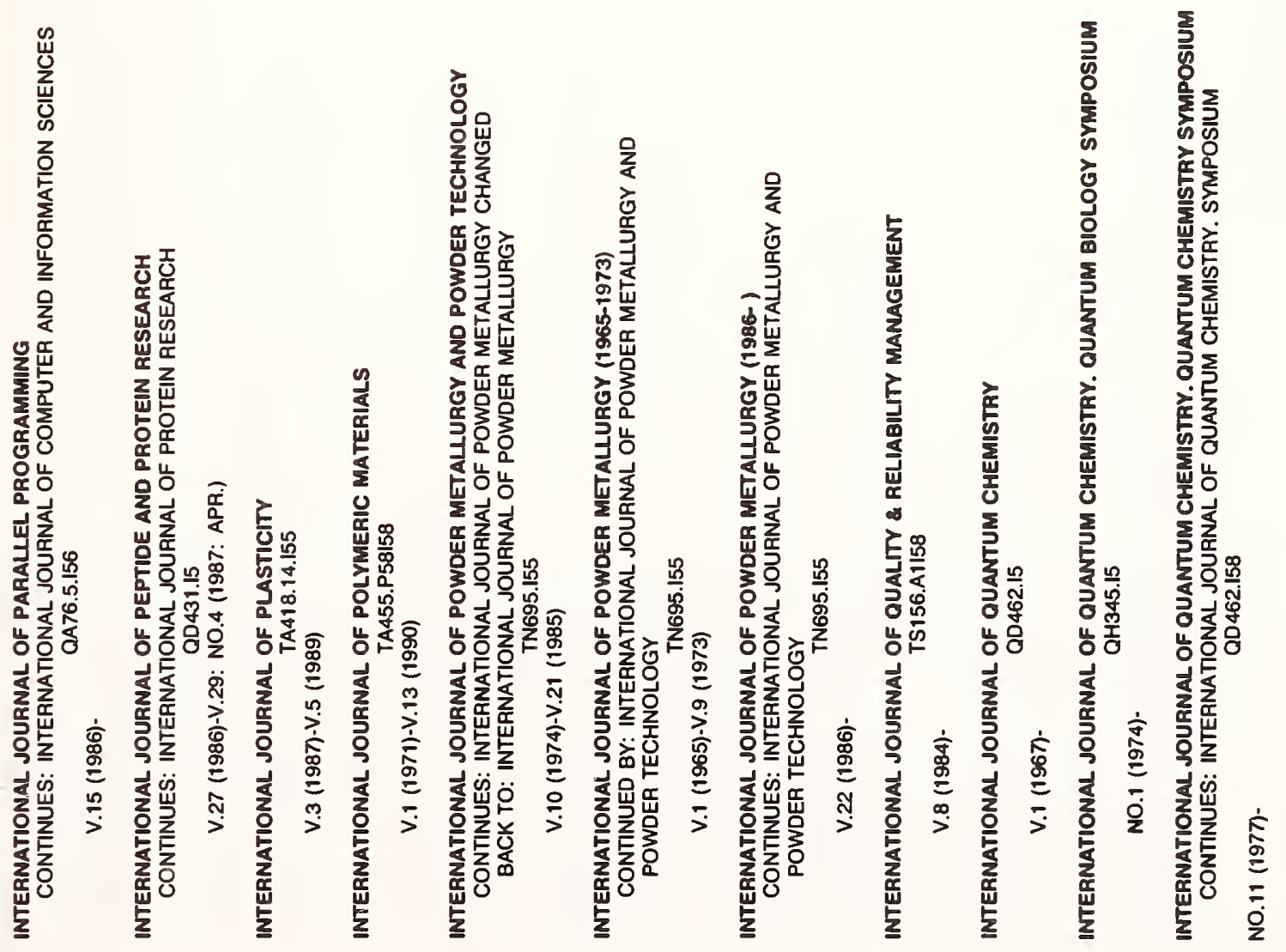




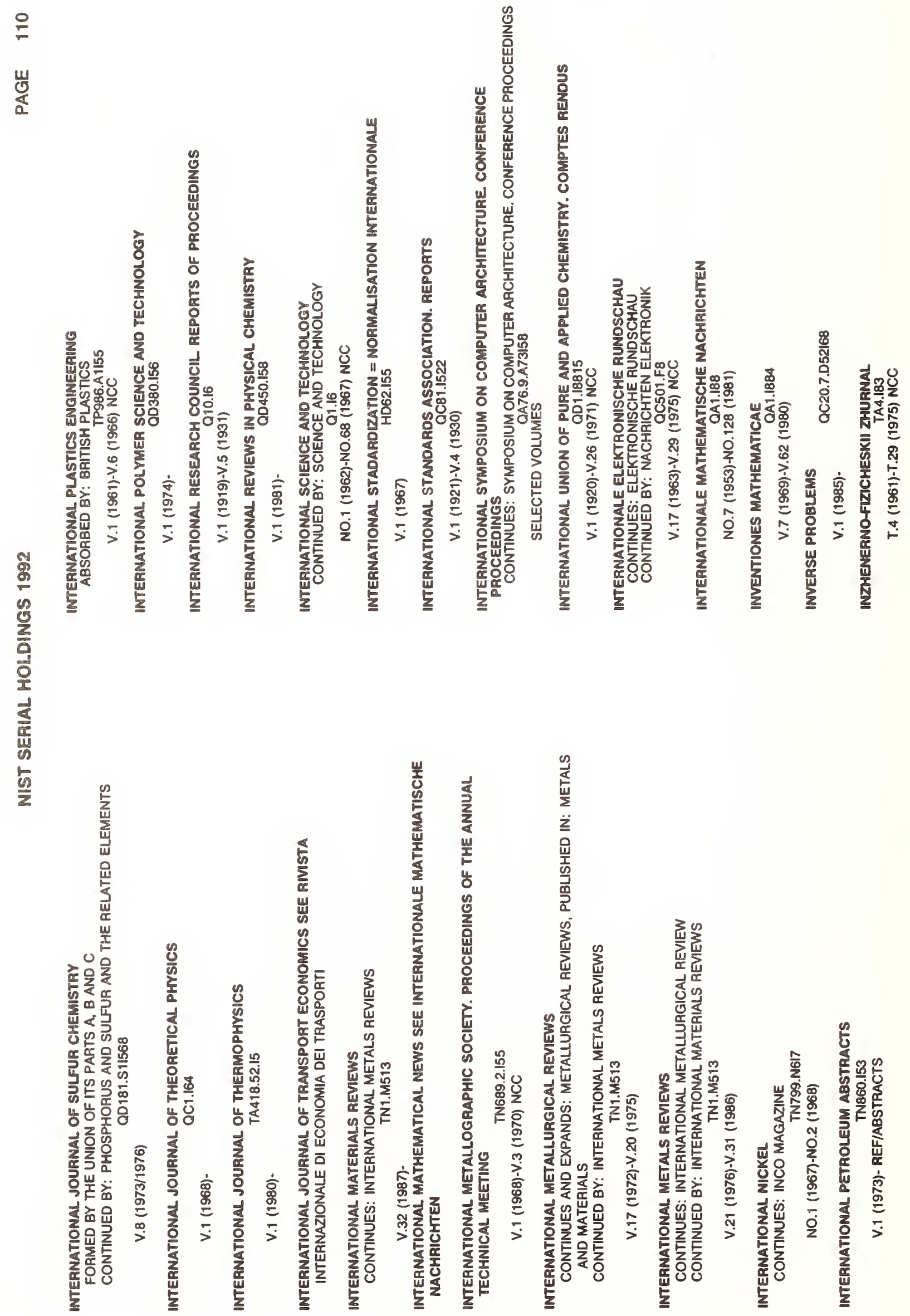




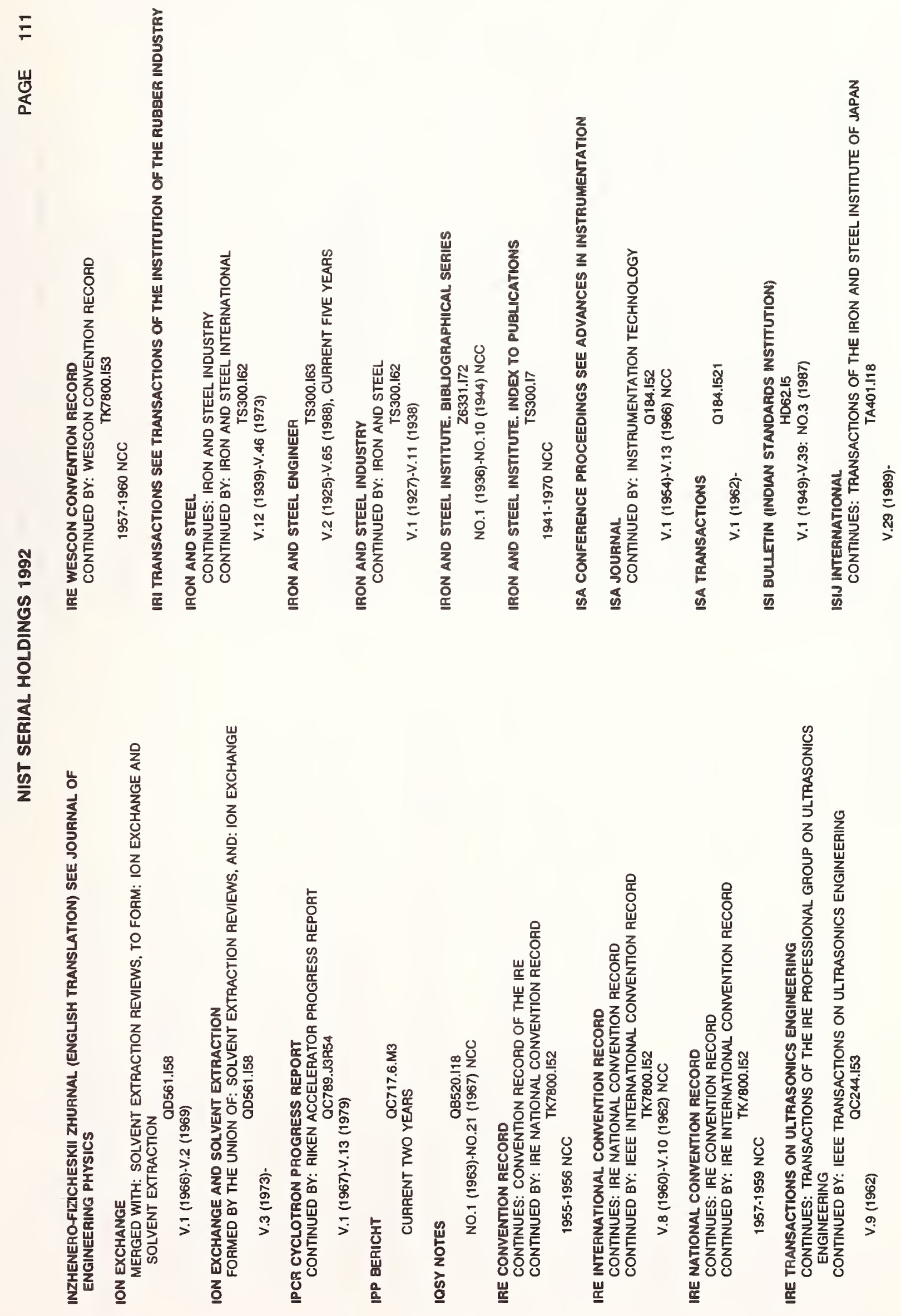



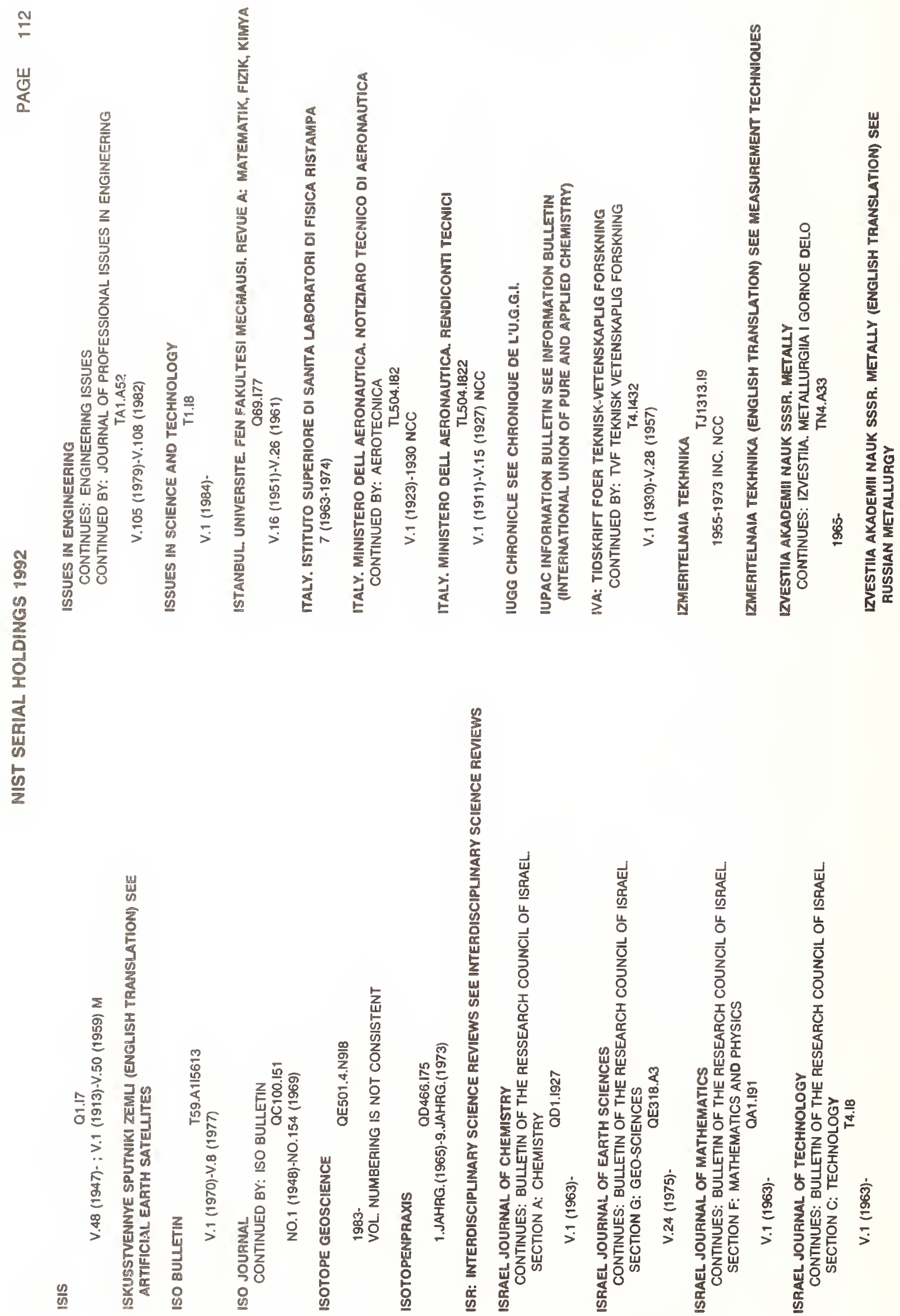


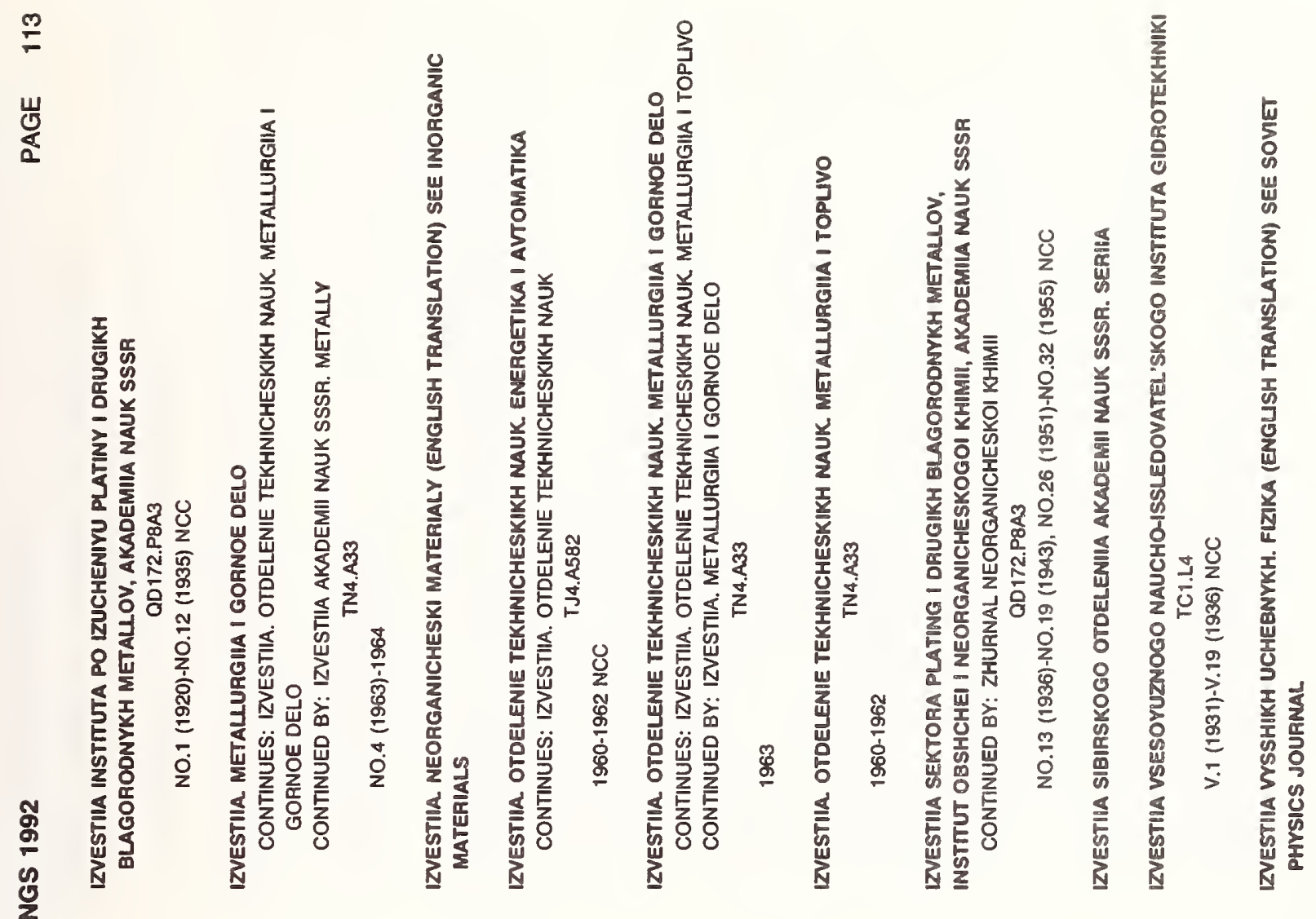

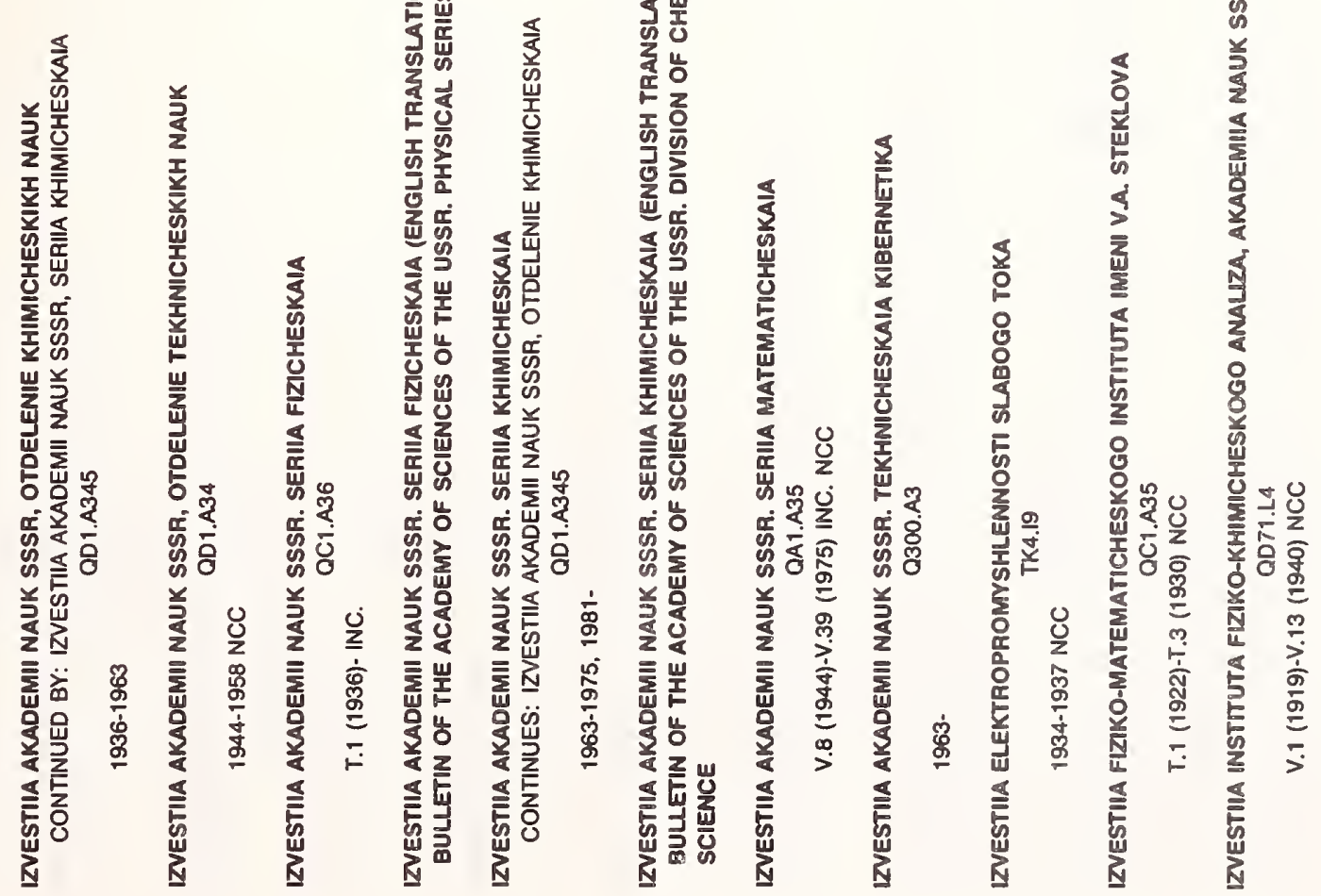



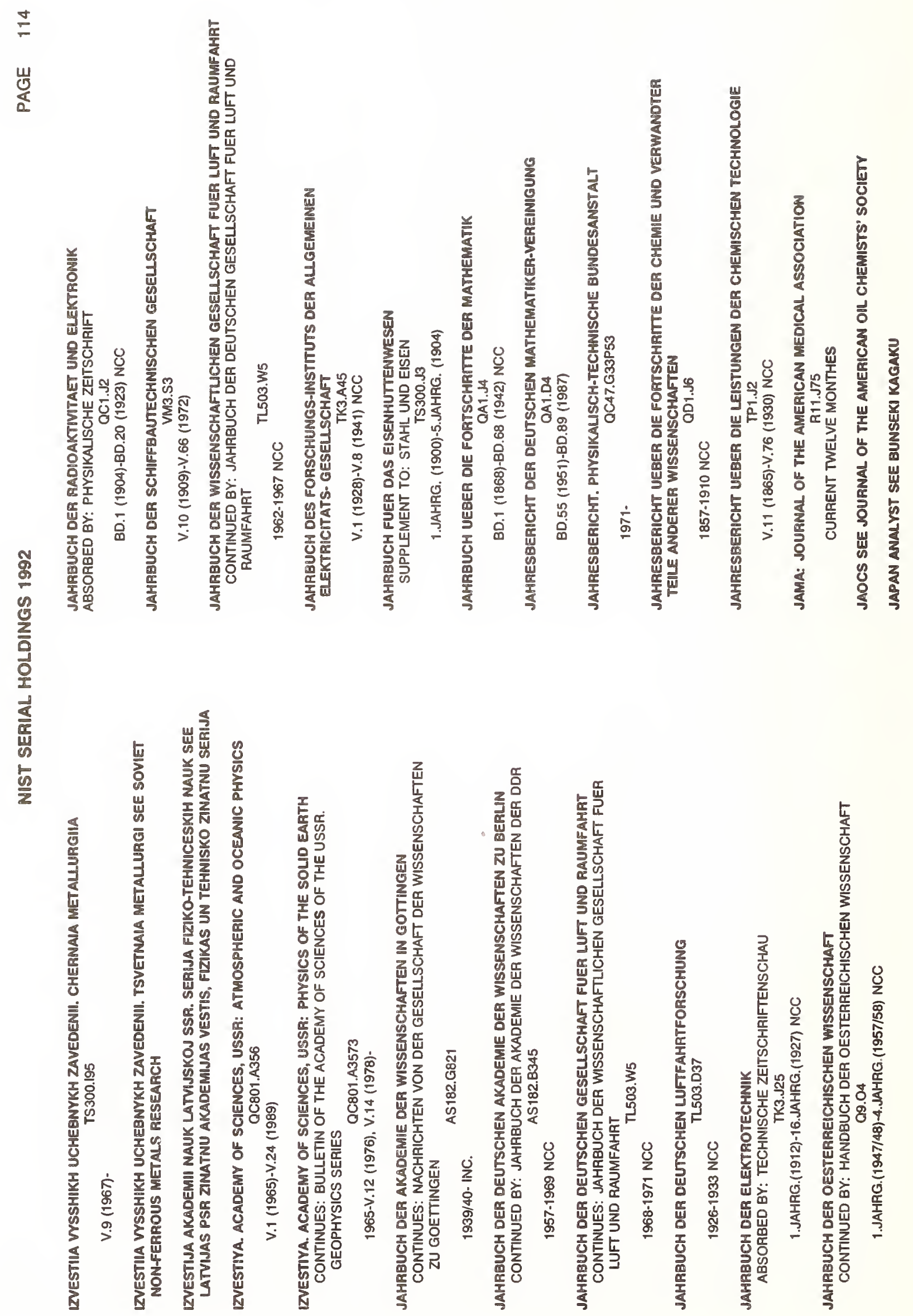


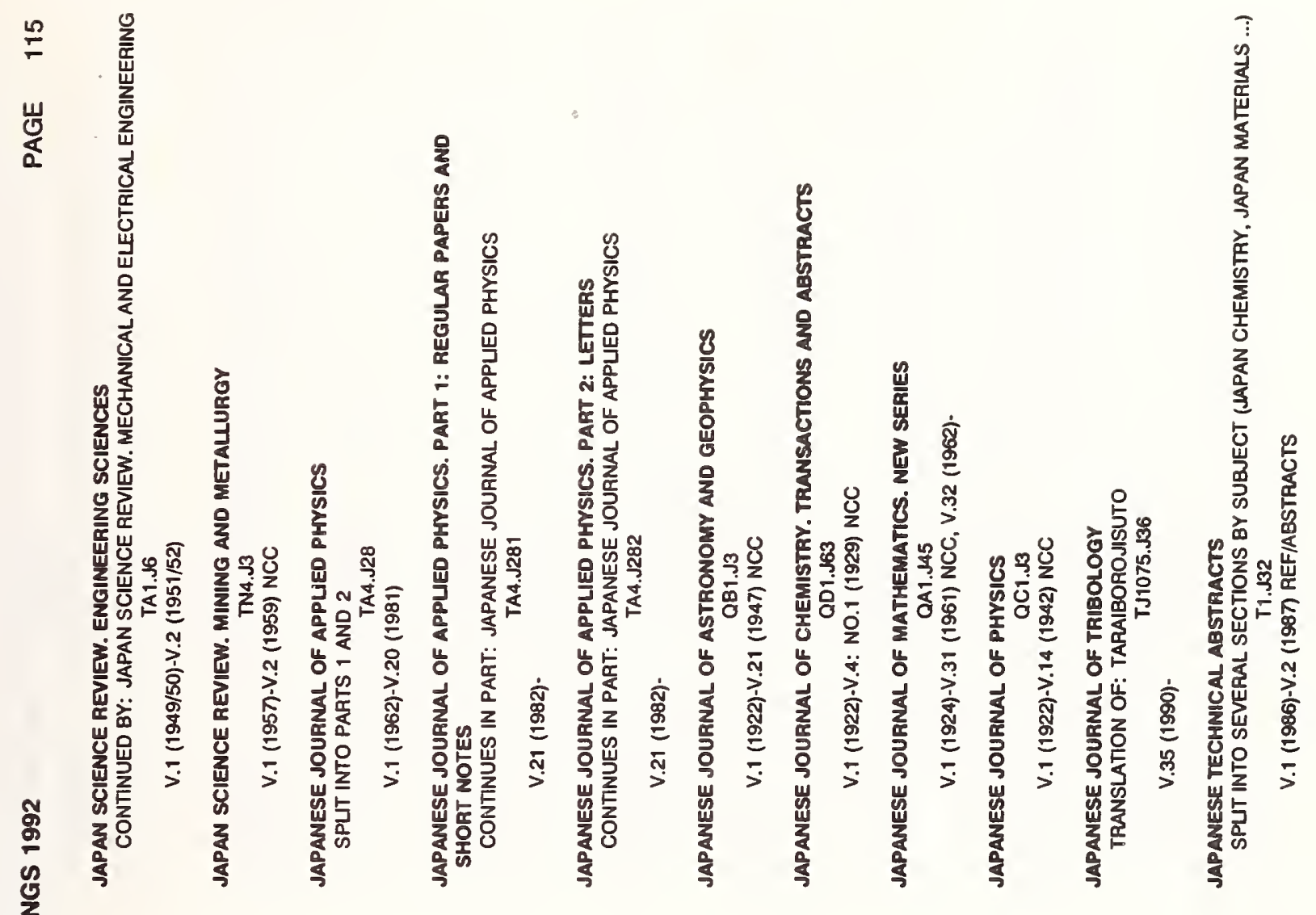



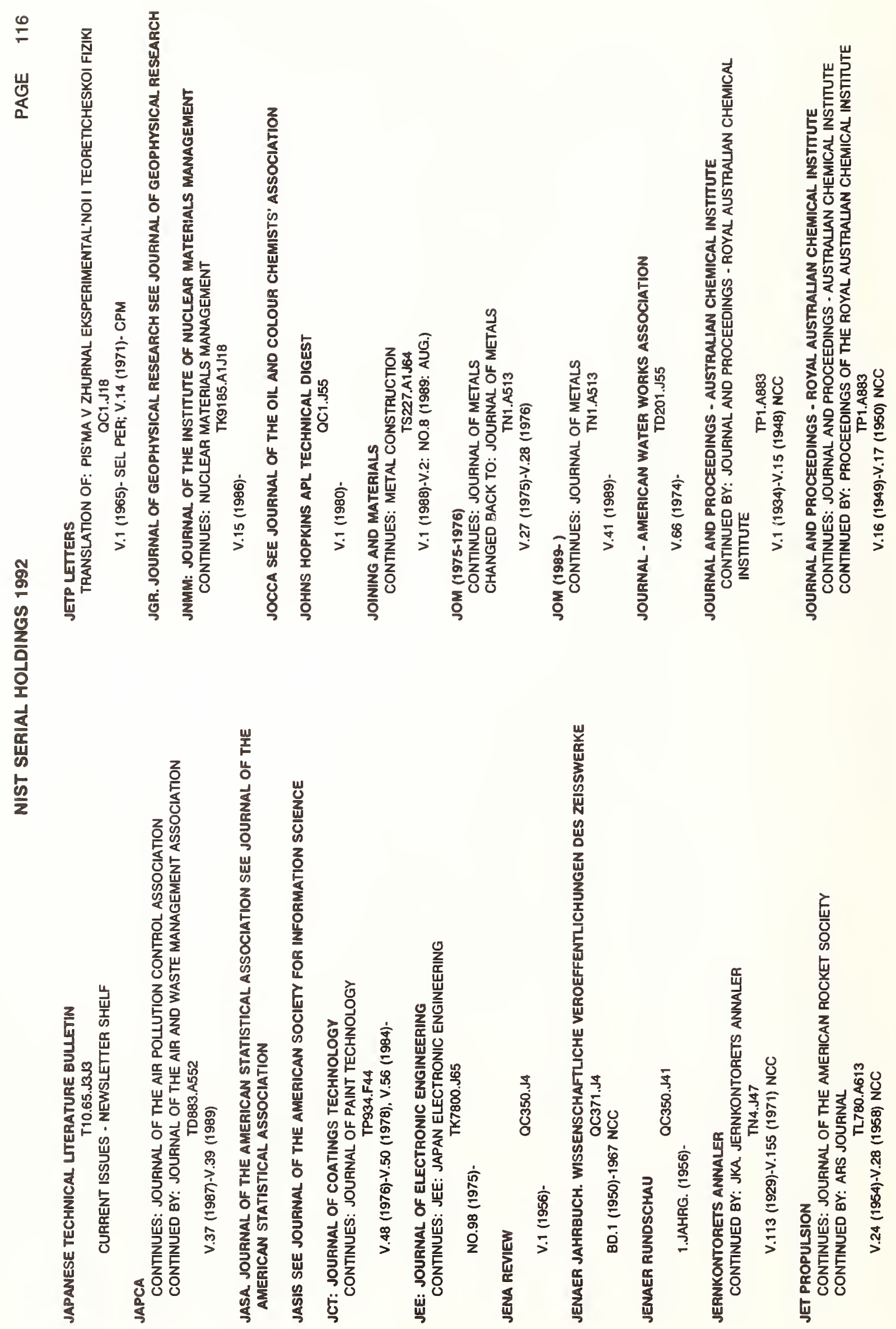
$\stackrel{5}{=}$
$\stackrel{u}{\alpha}$

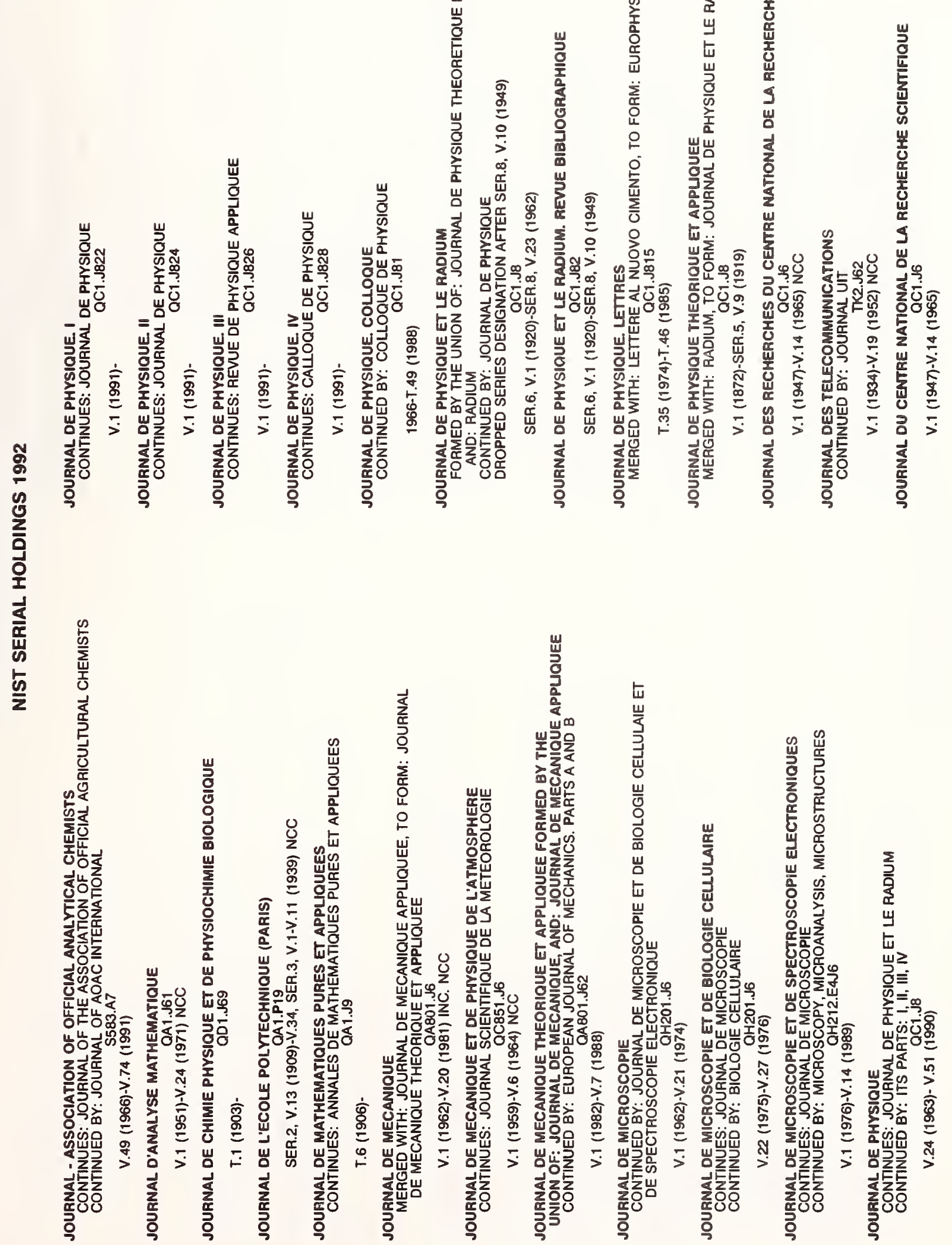


$\stackrel{\infty}{=}$

崖

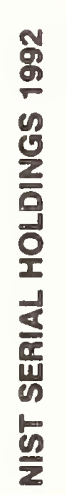
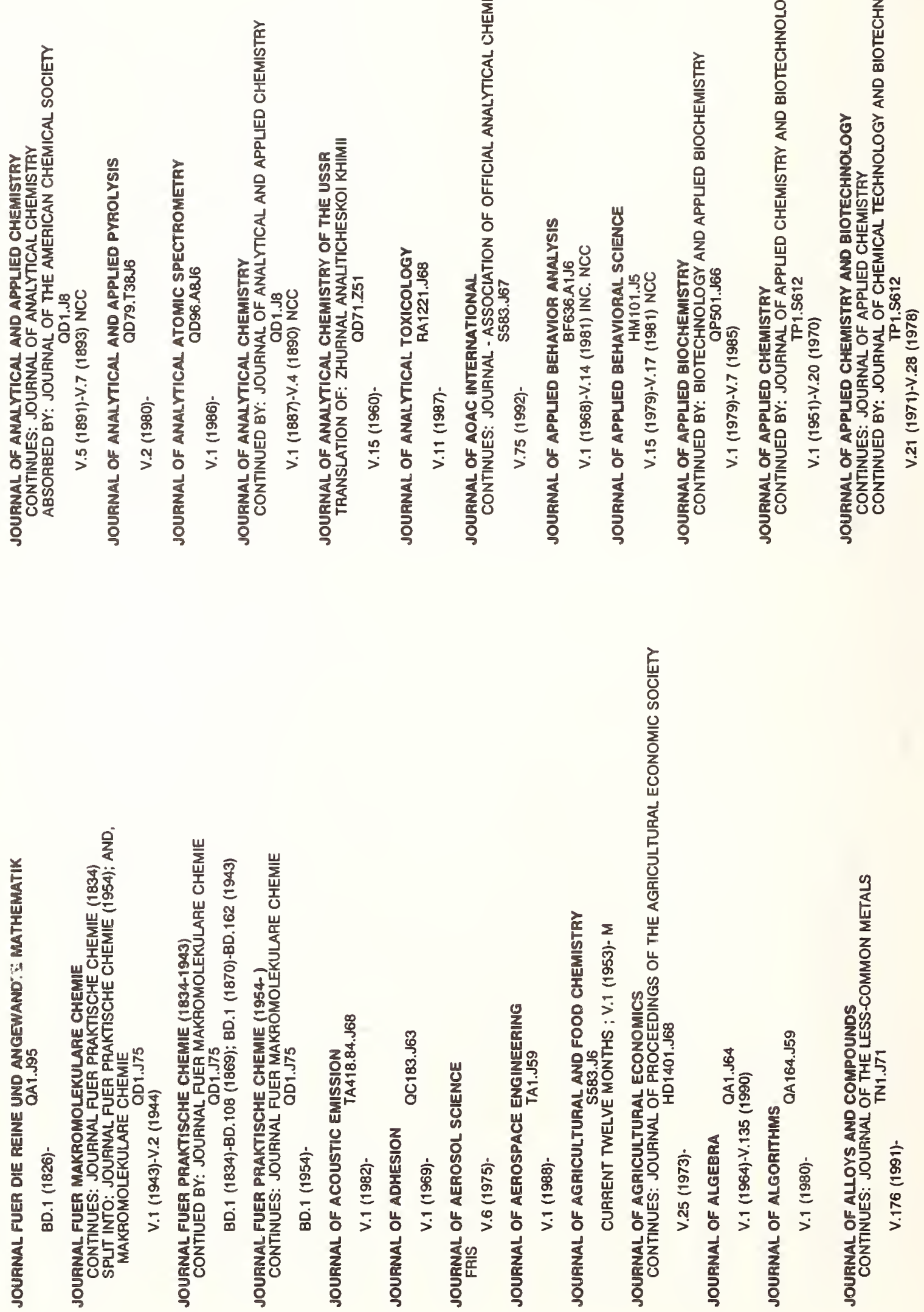
訔
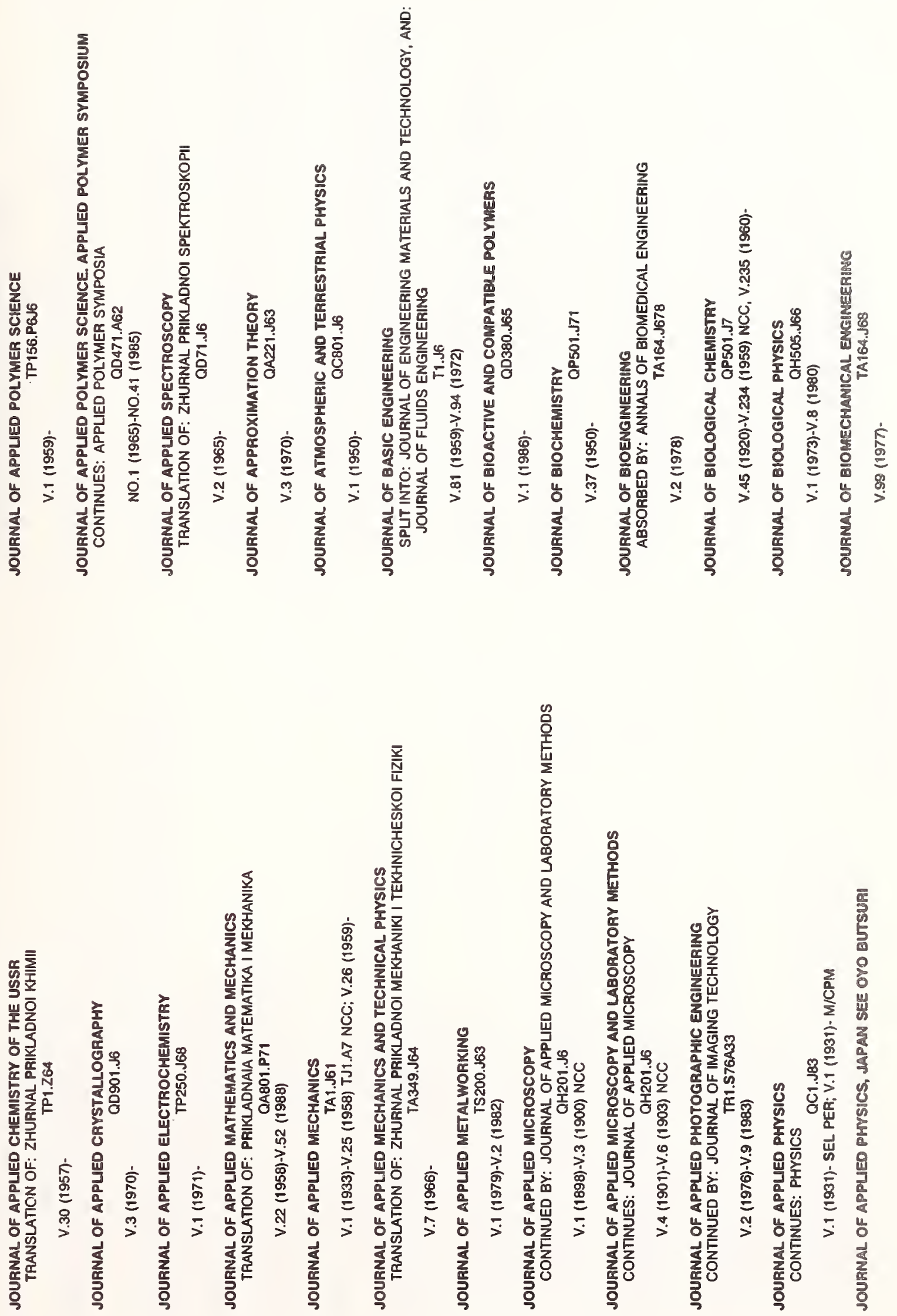


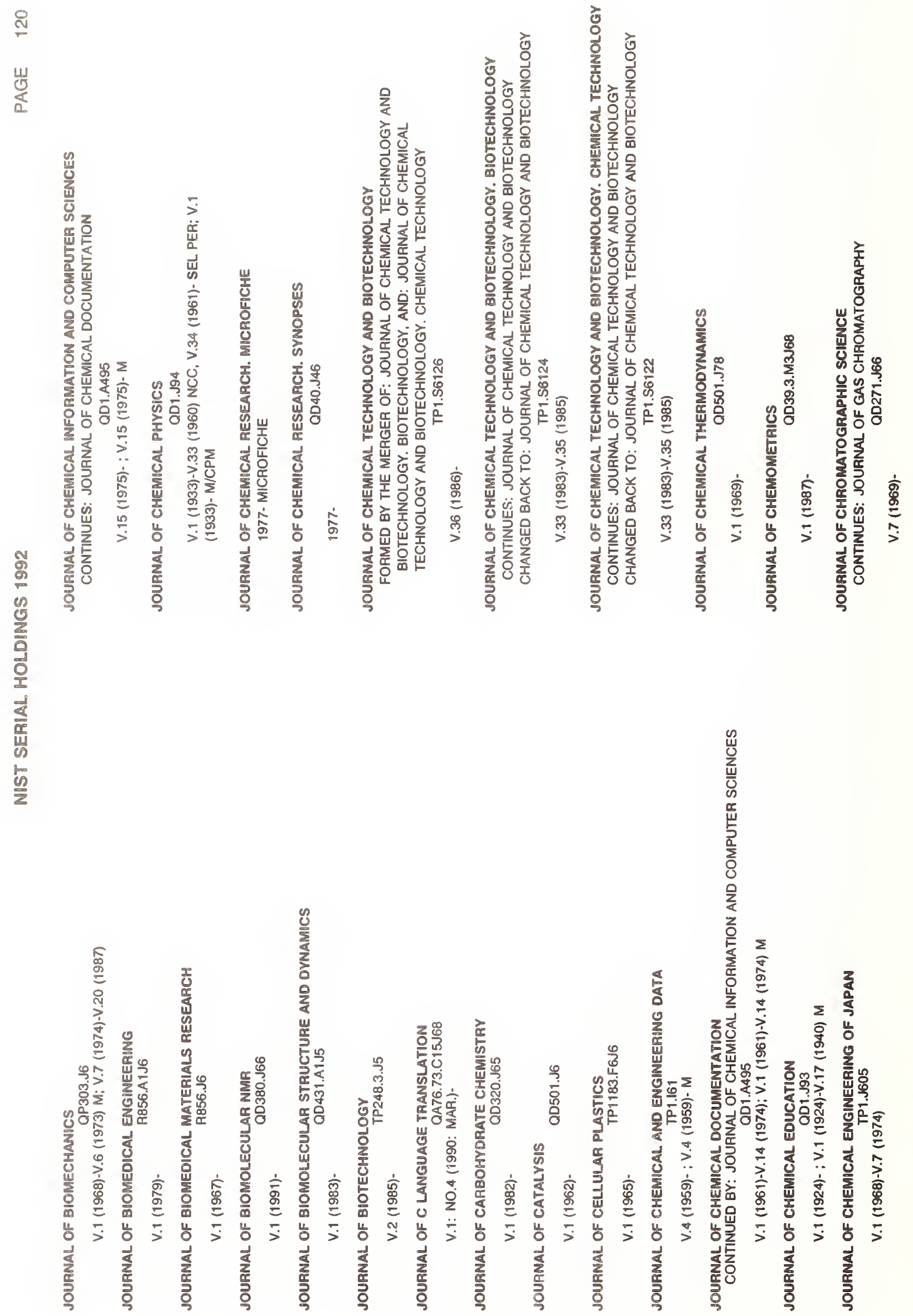




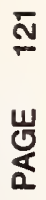

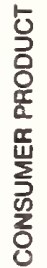

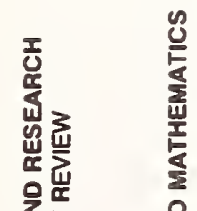

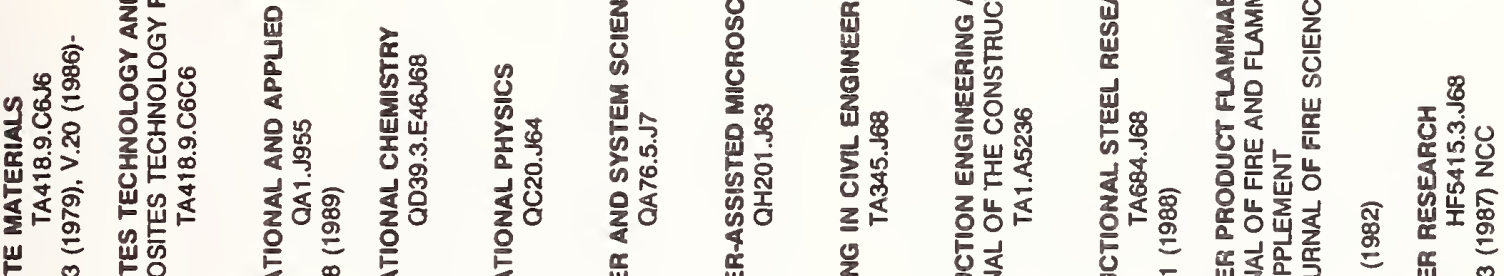

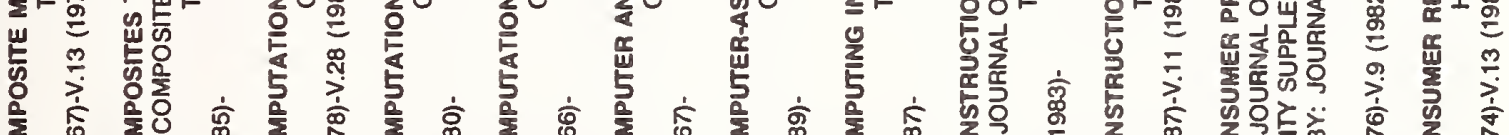

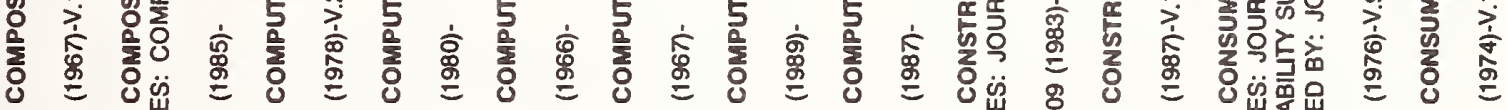

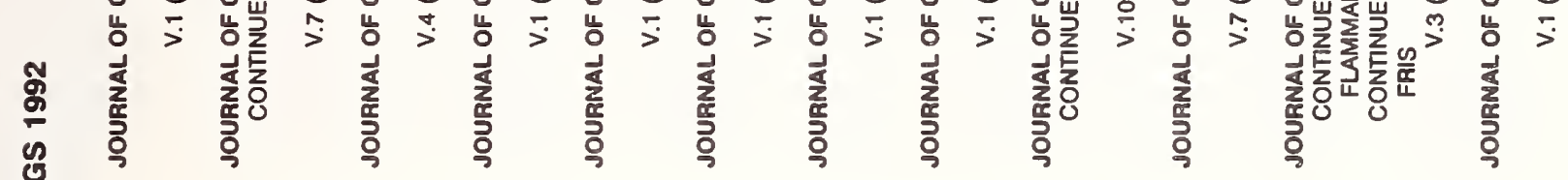

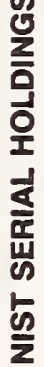

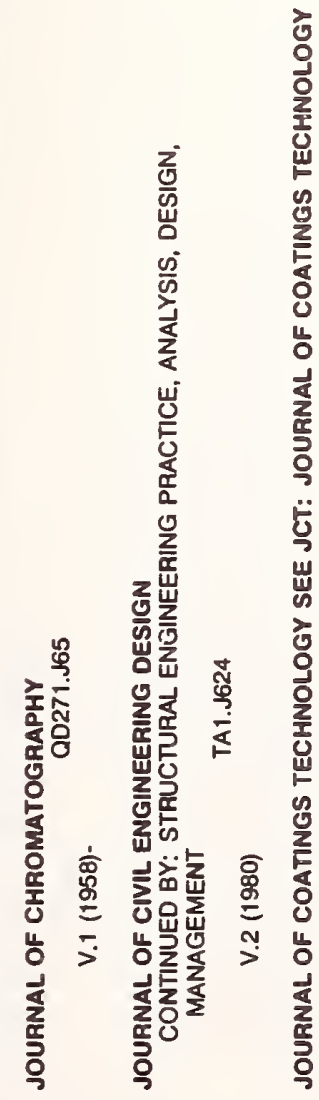

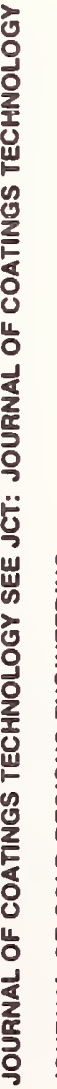

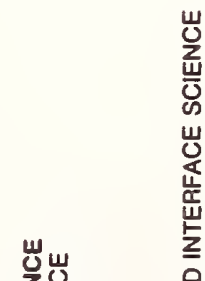

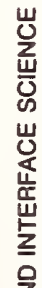

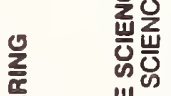

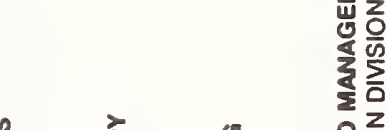

I

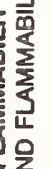

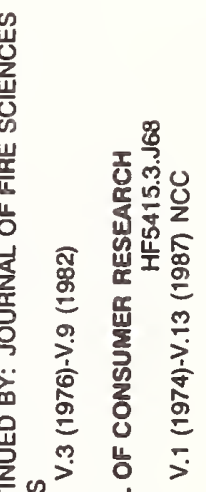

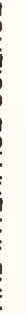

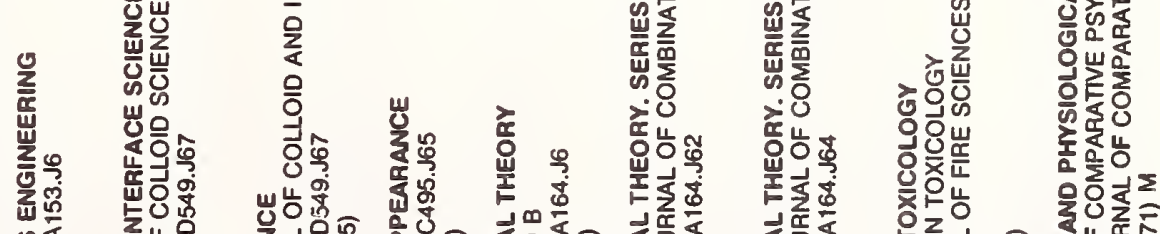

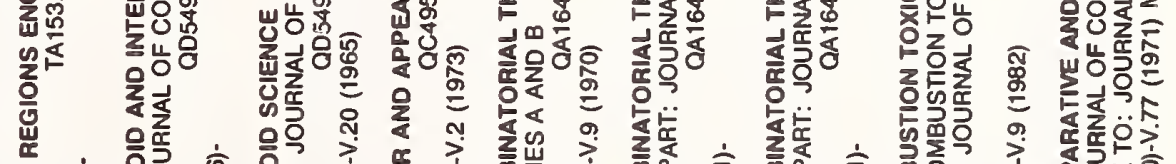

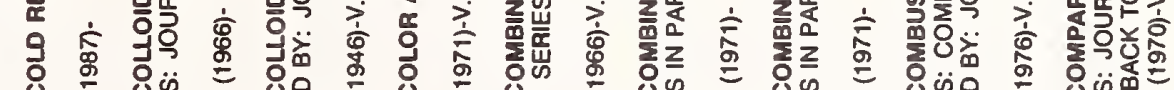

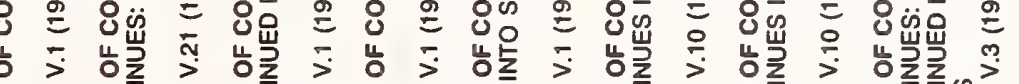




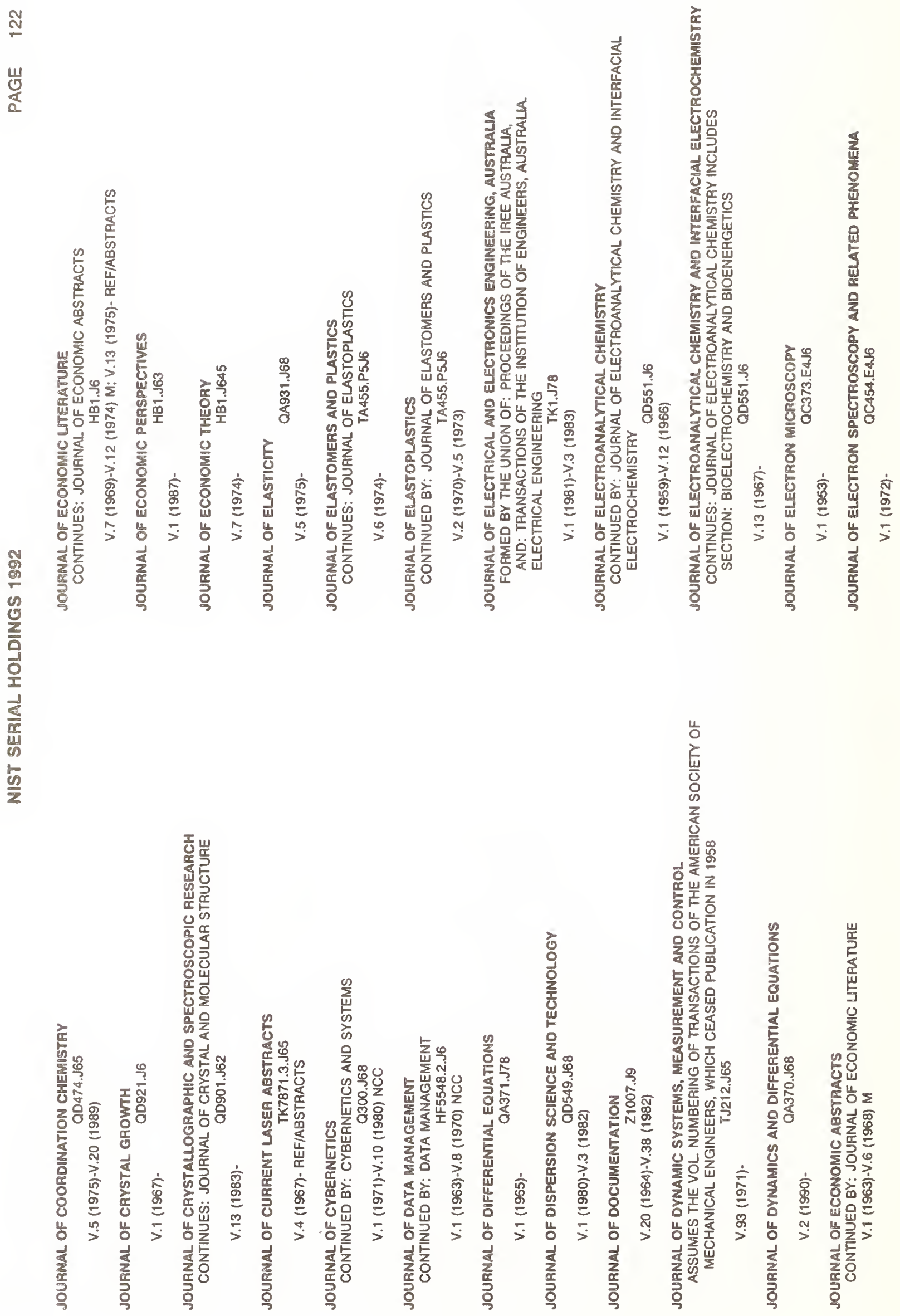


$\cong$

एँ

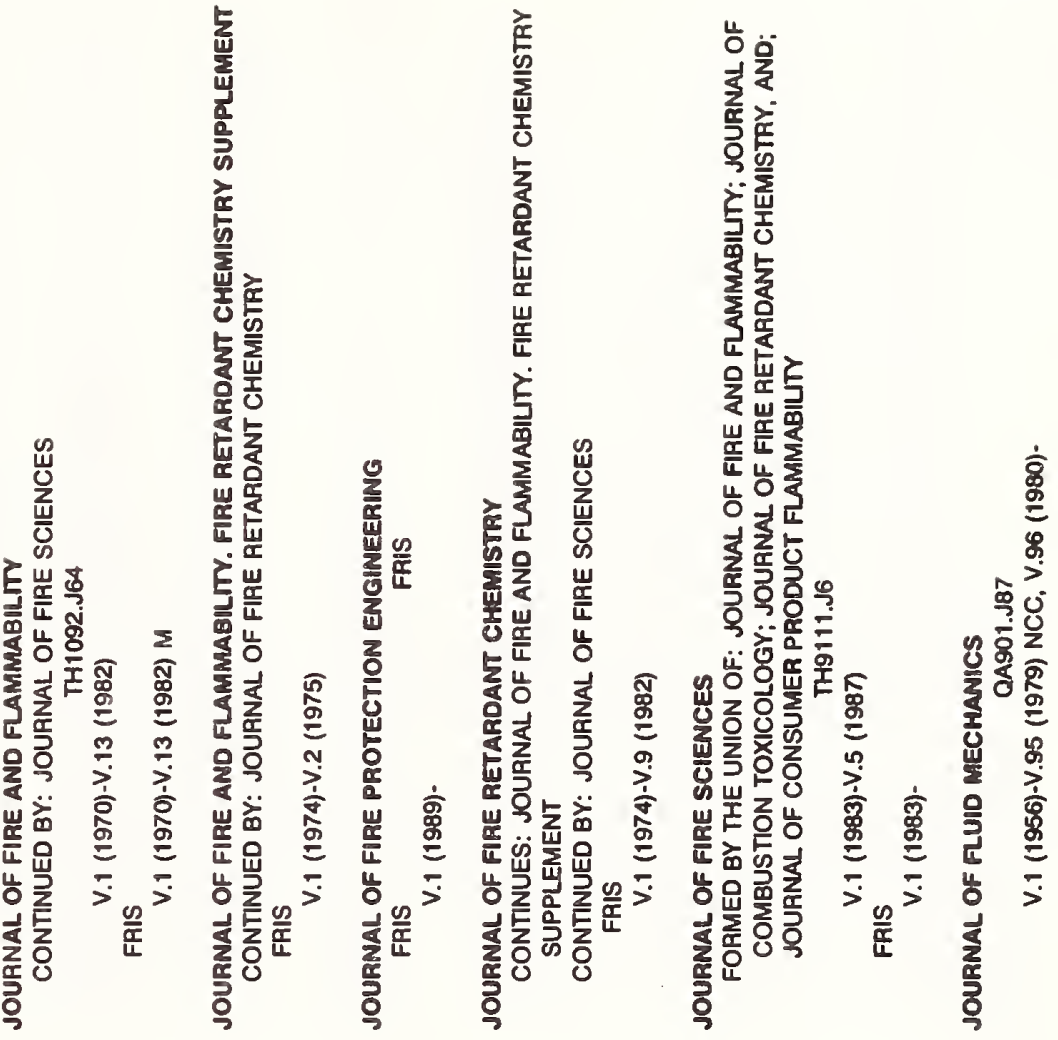

氾

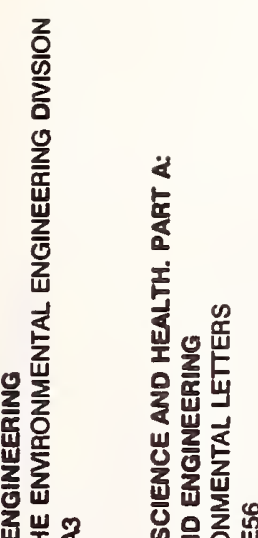

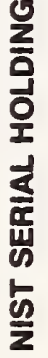

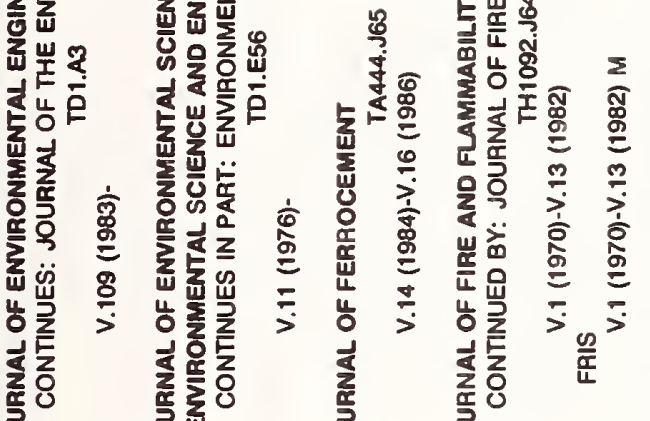

证

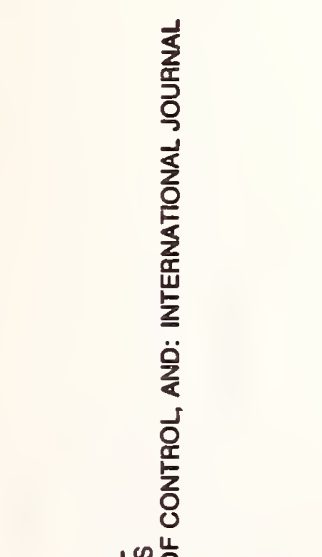

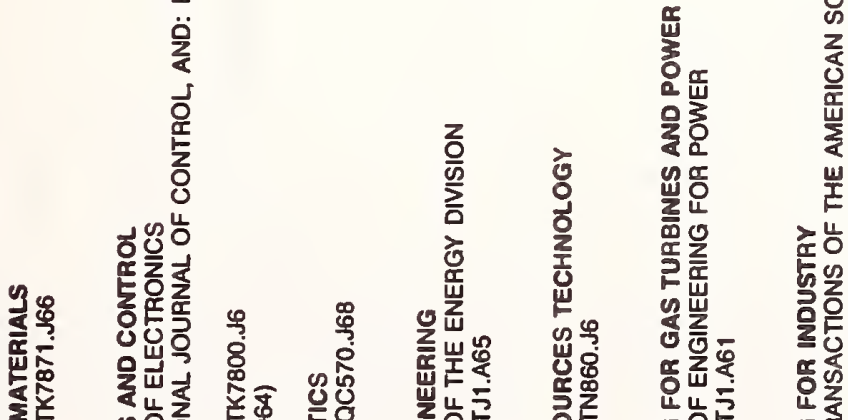

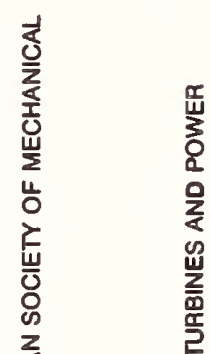

岳

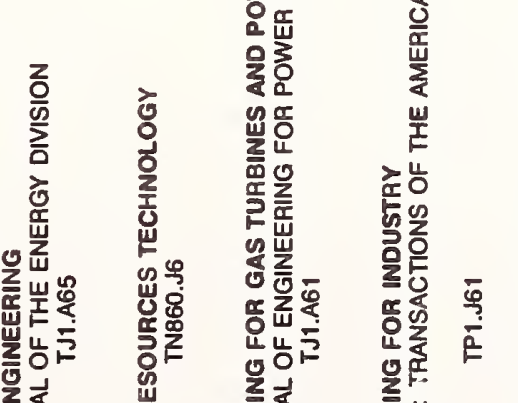

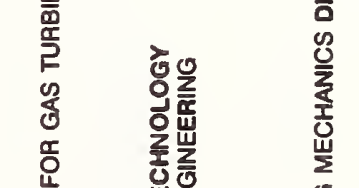

20

永

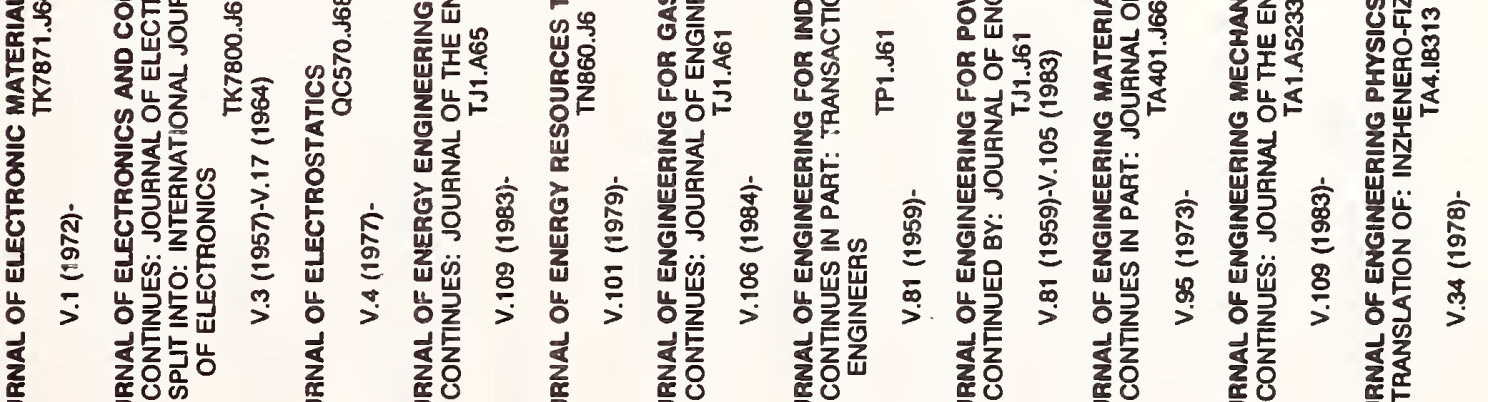

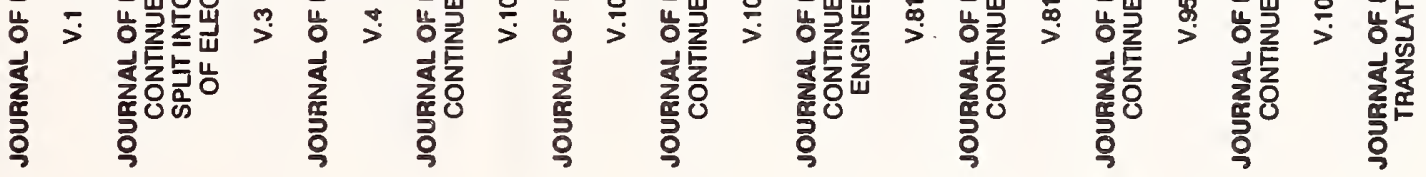




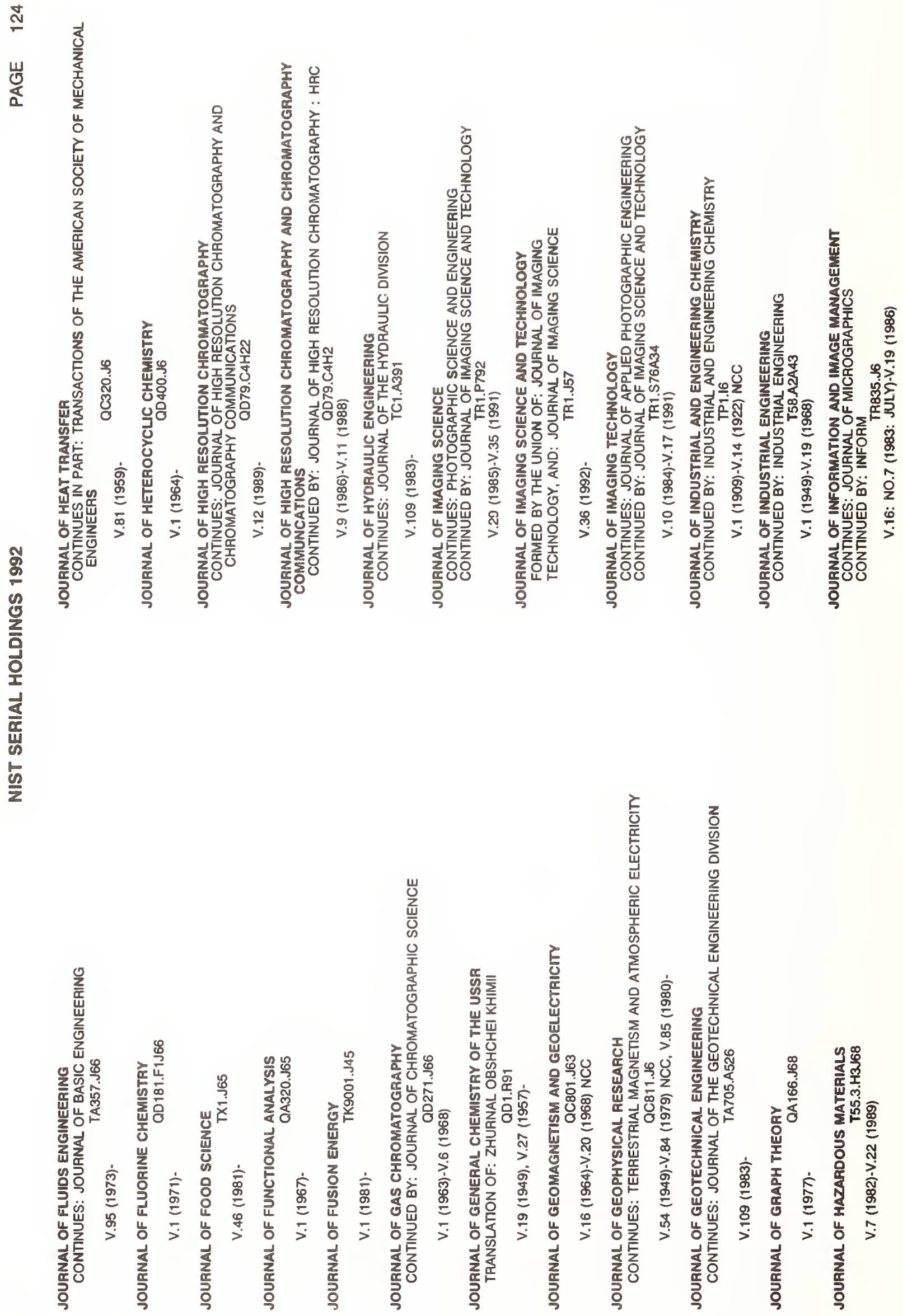



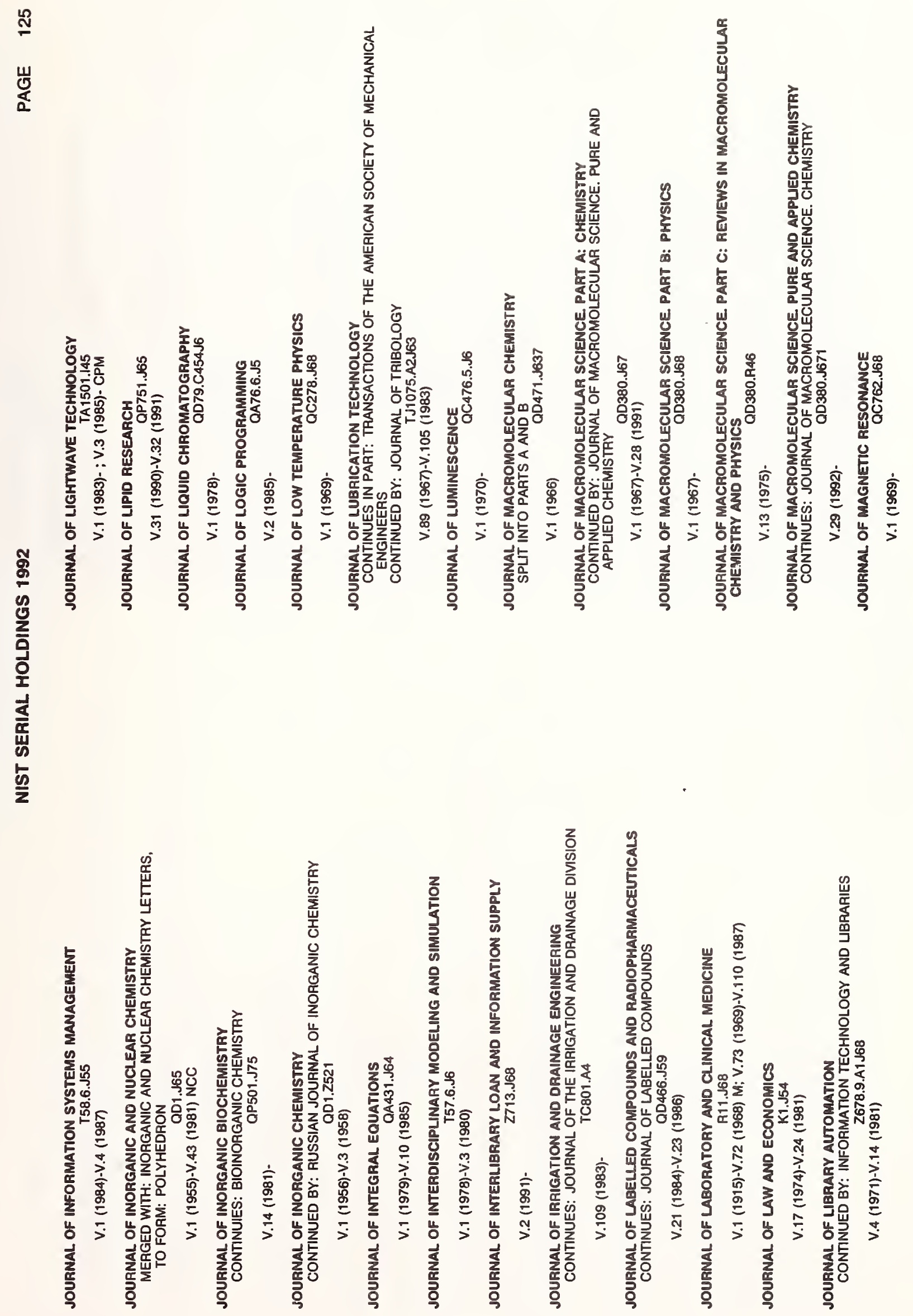


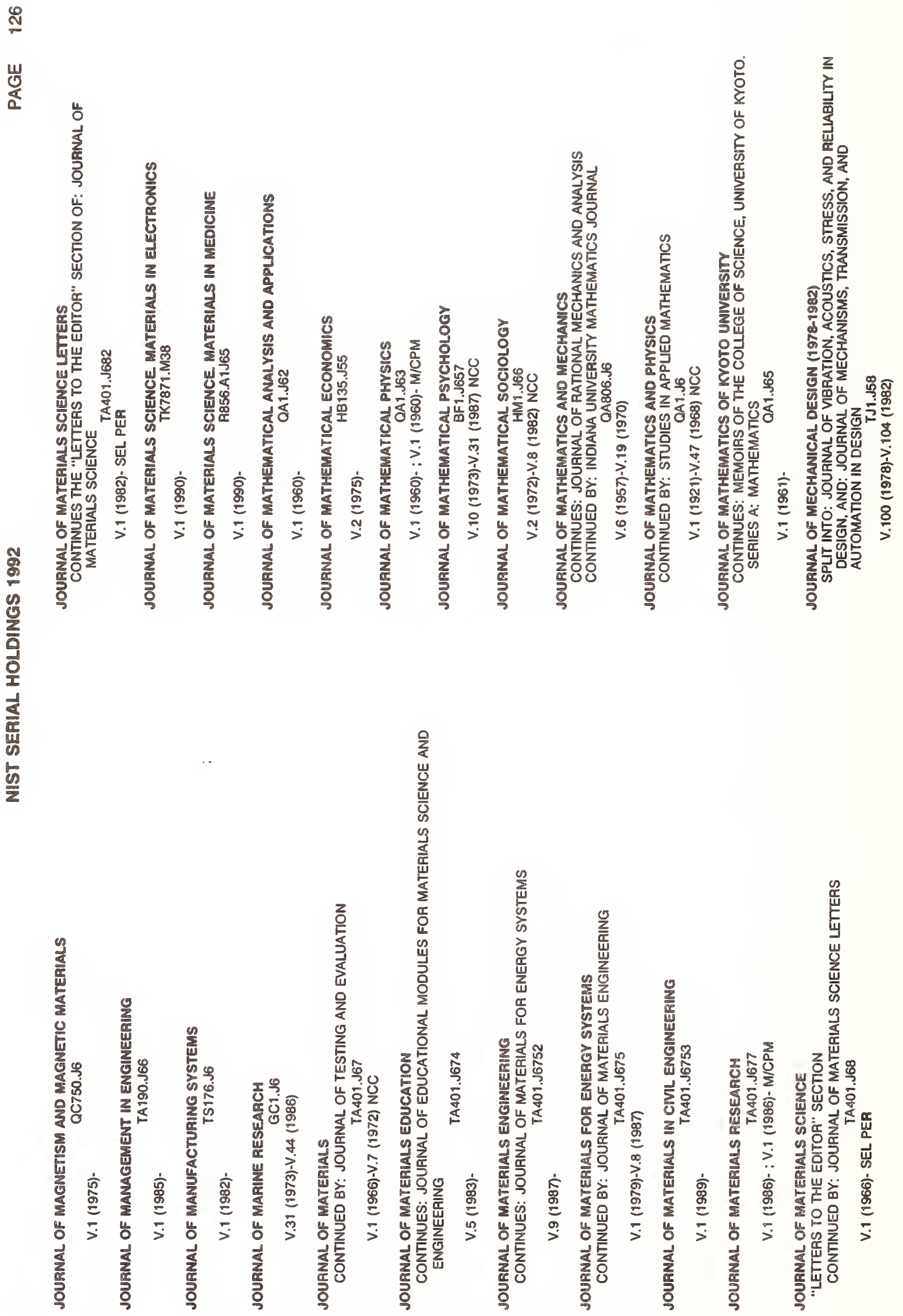


ง

嶉

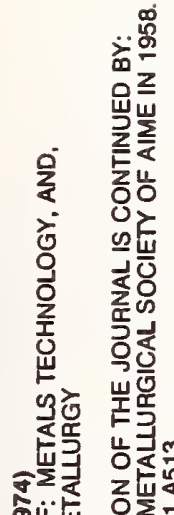

岂

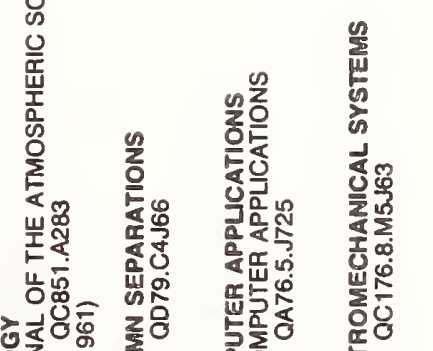

点

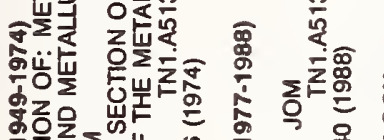

余

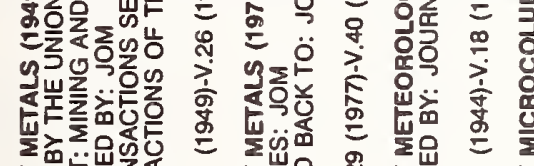
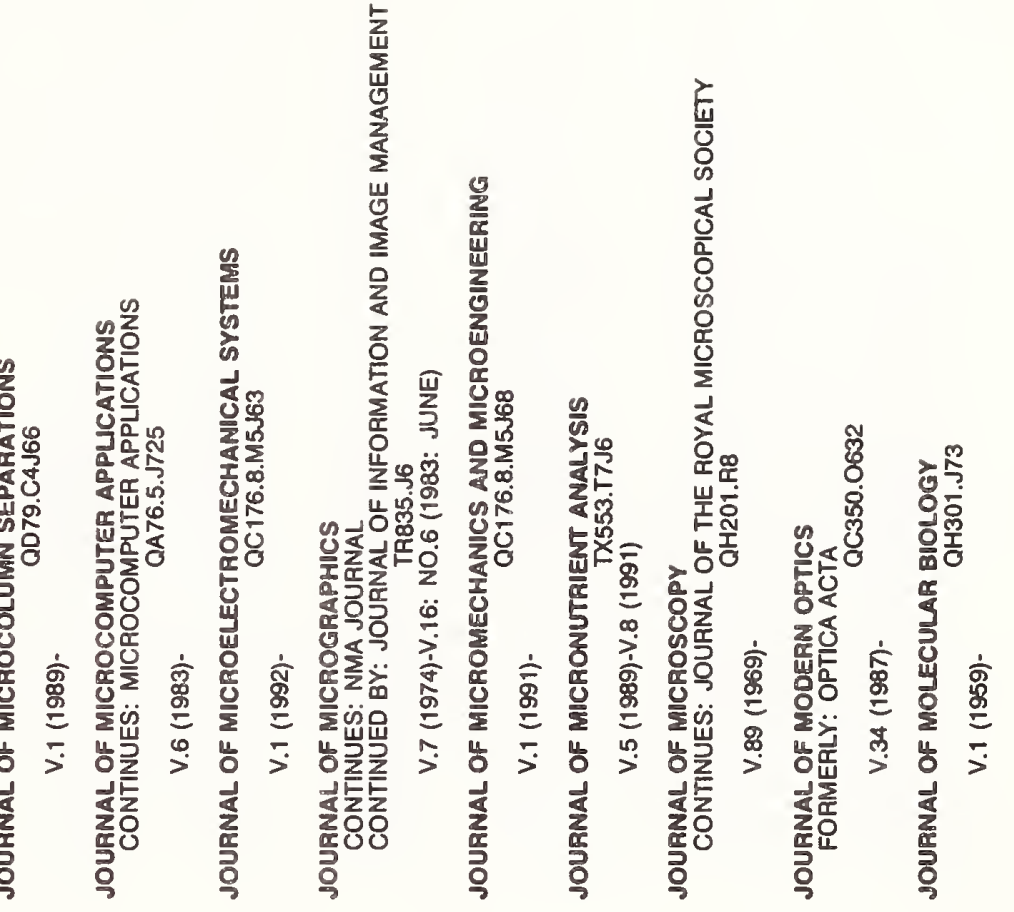

용

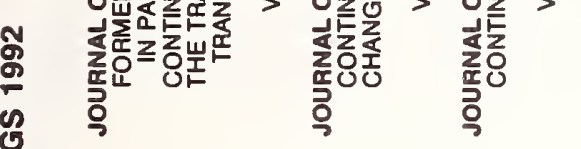

热

咅
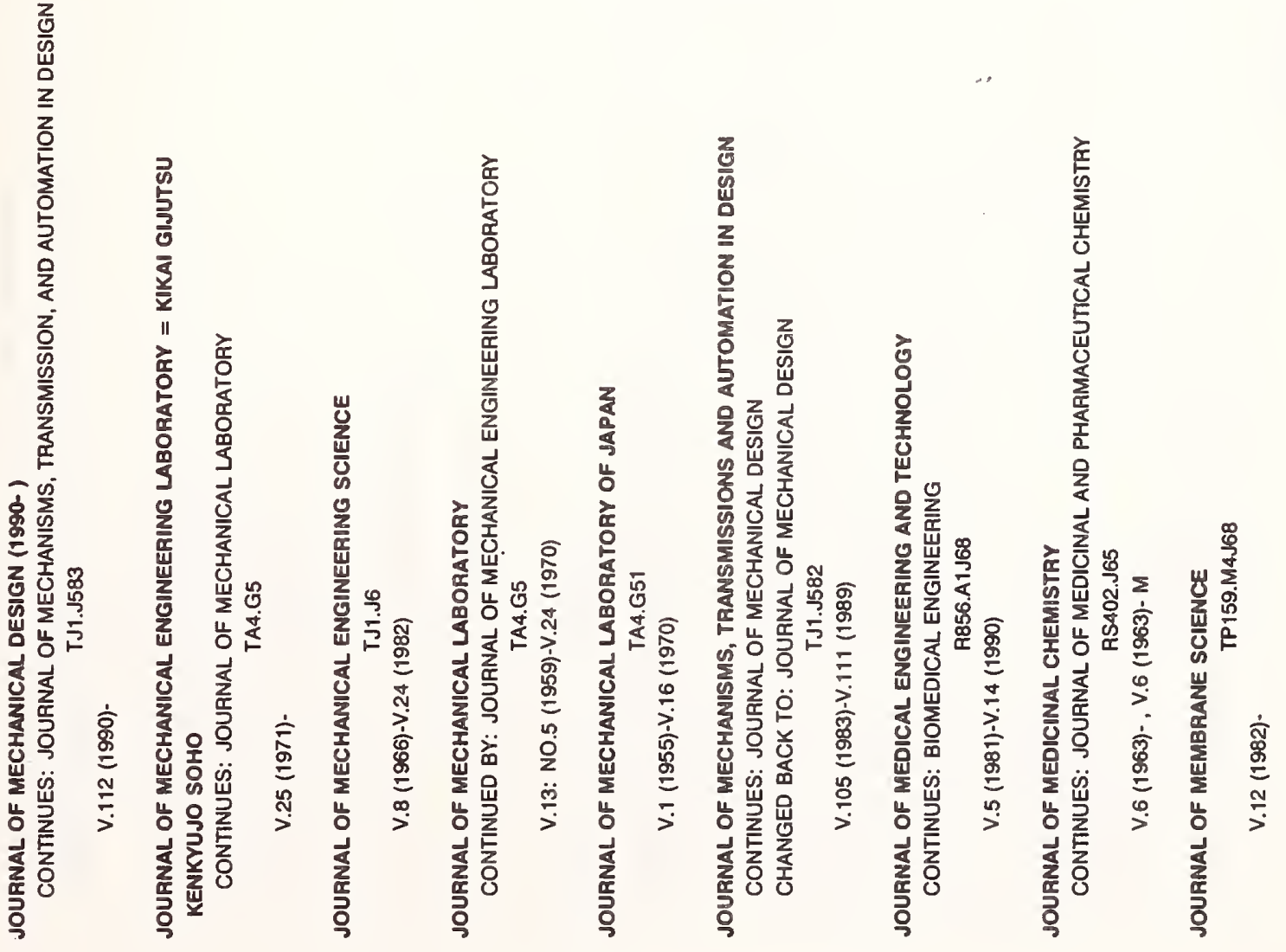


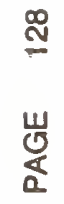

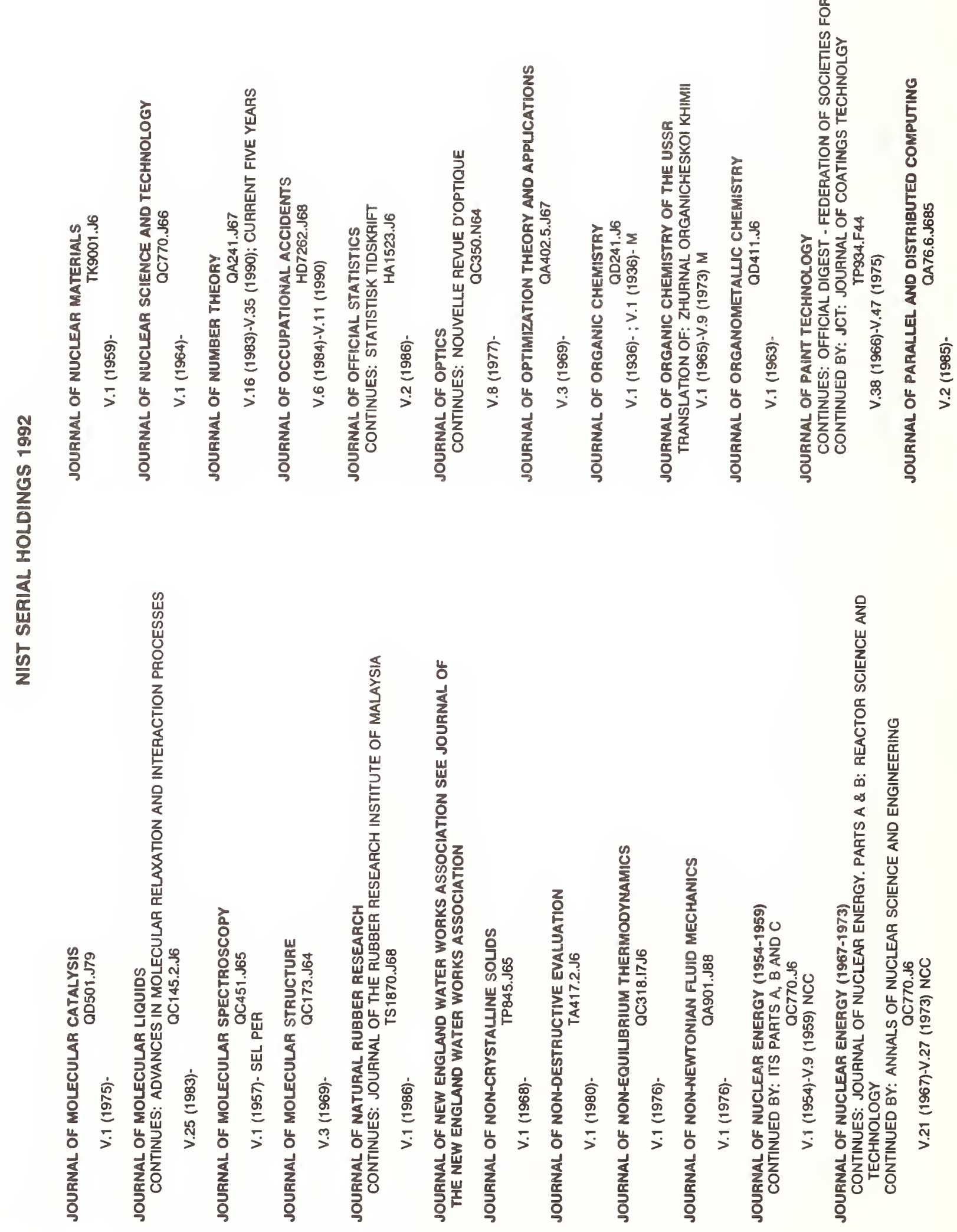


웜
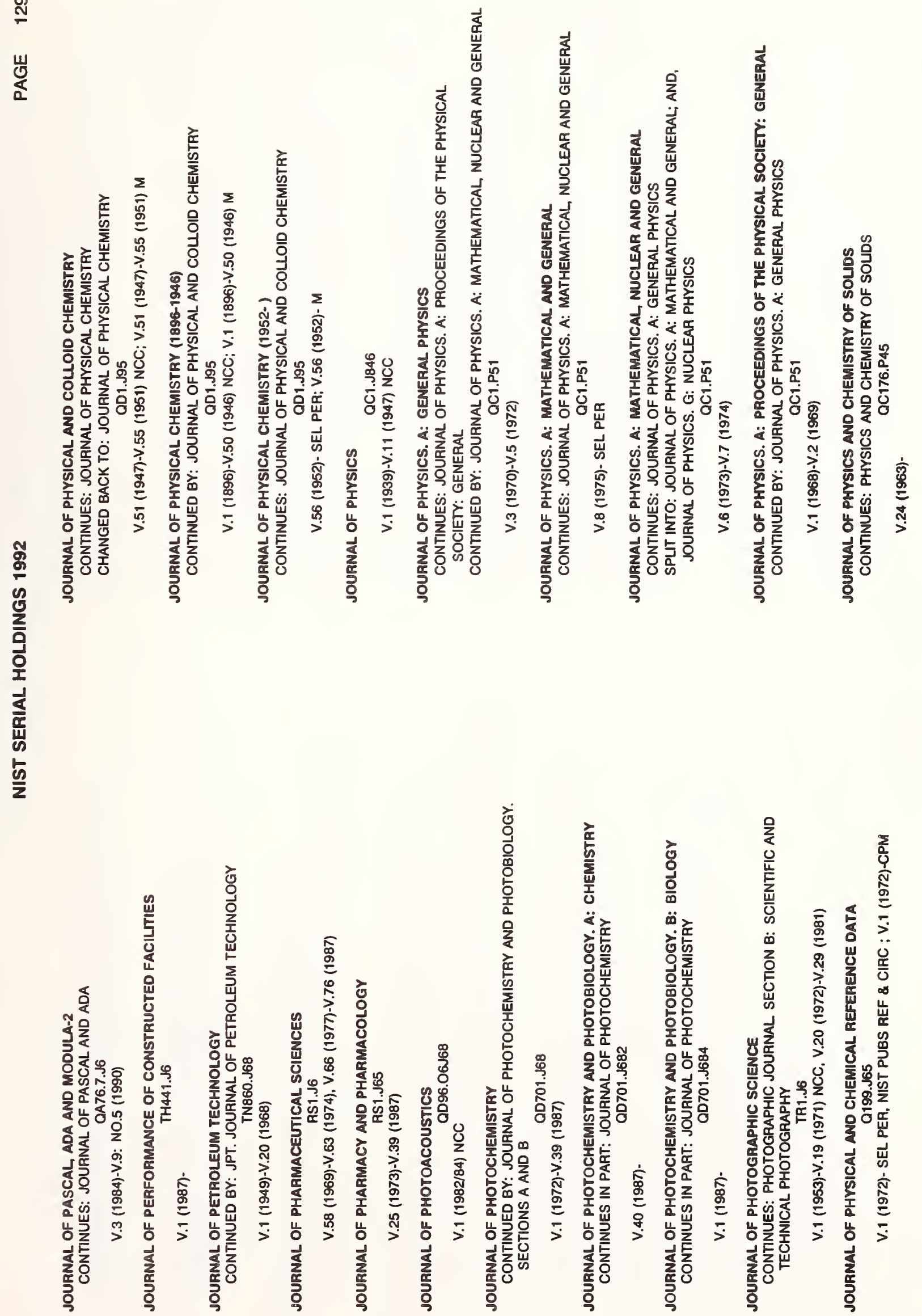


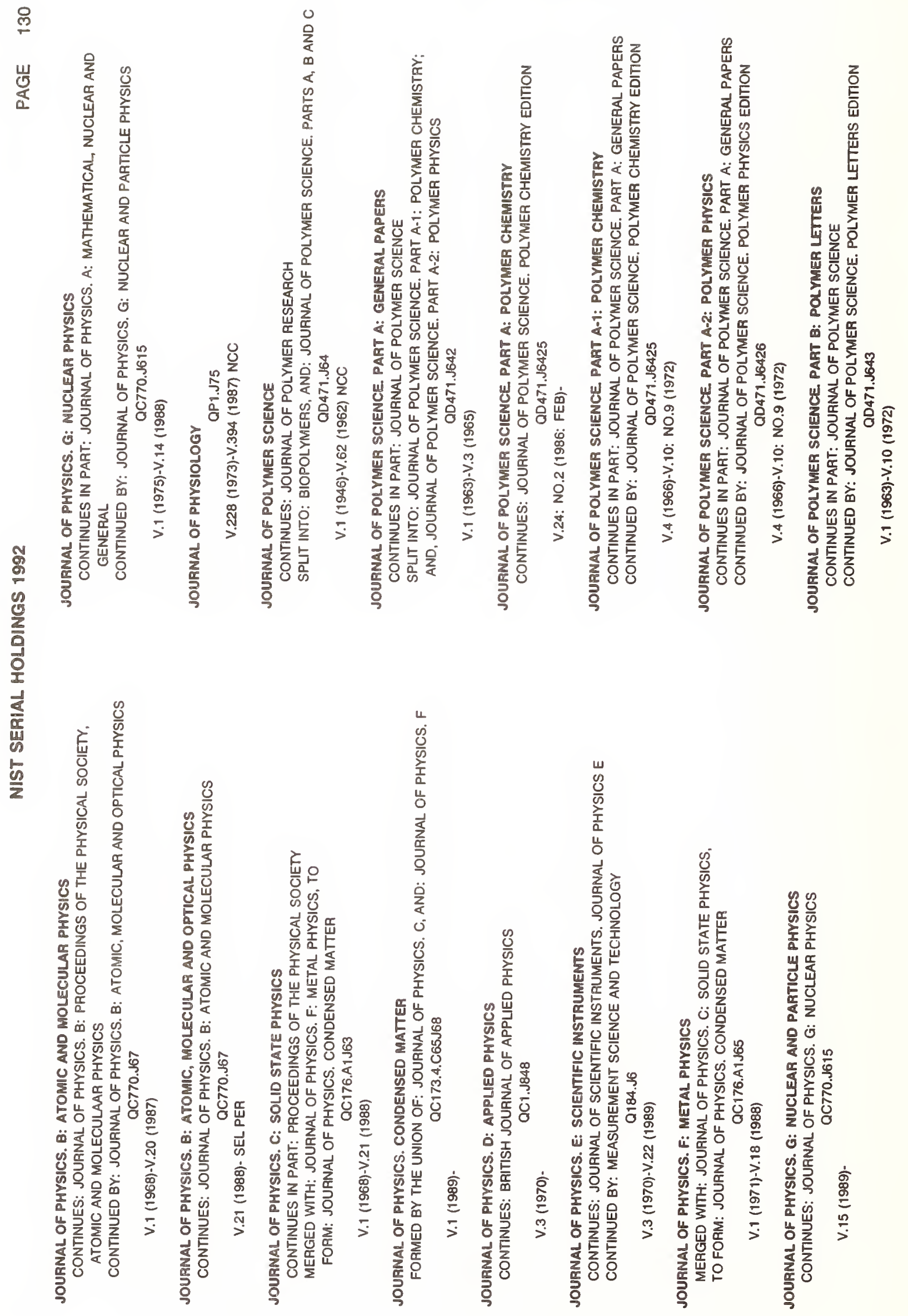



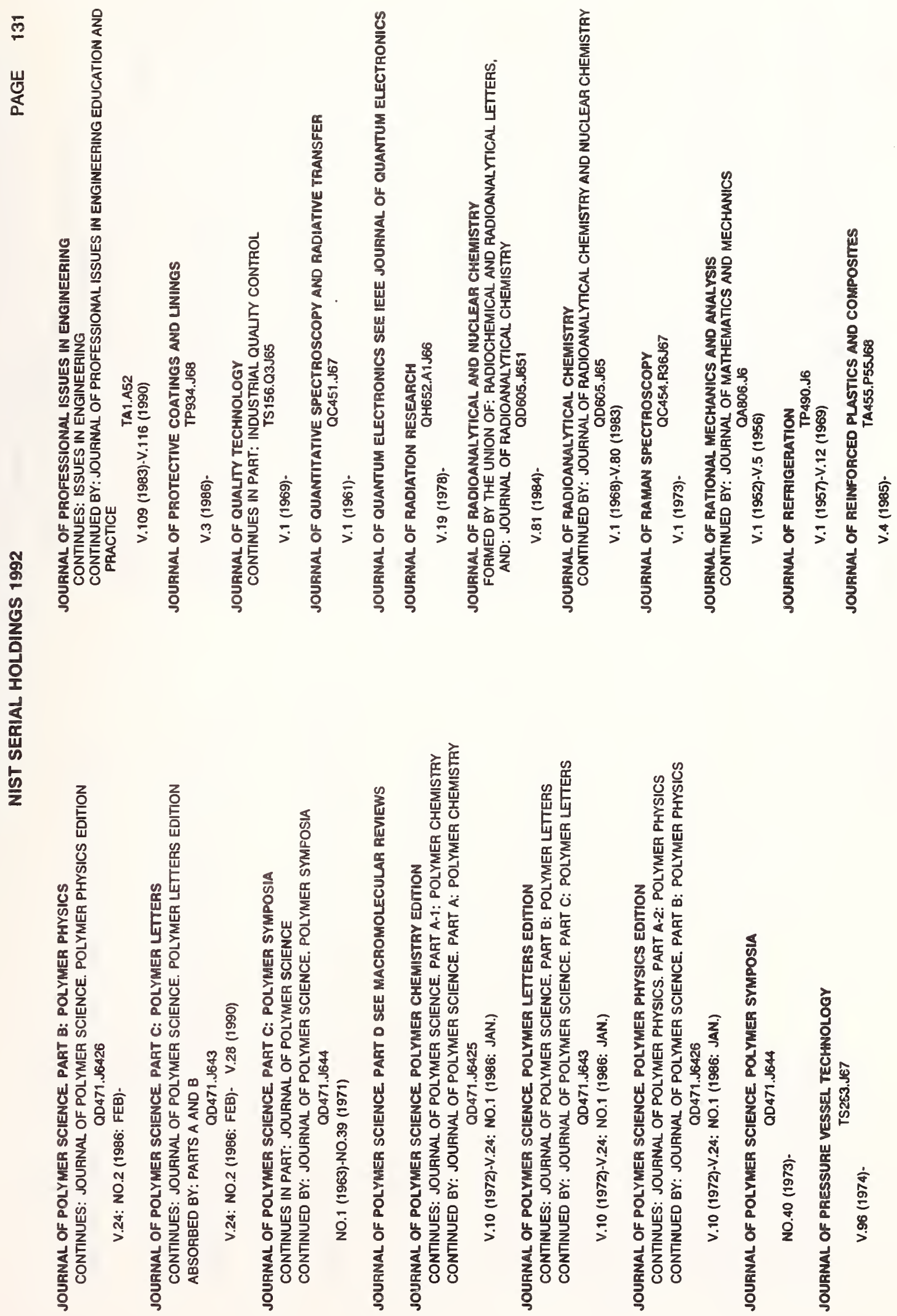


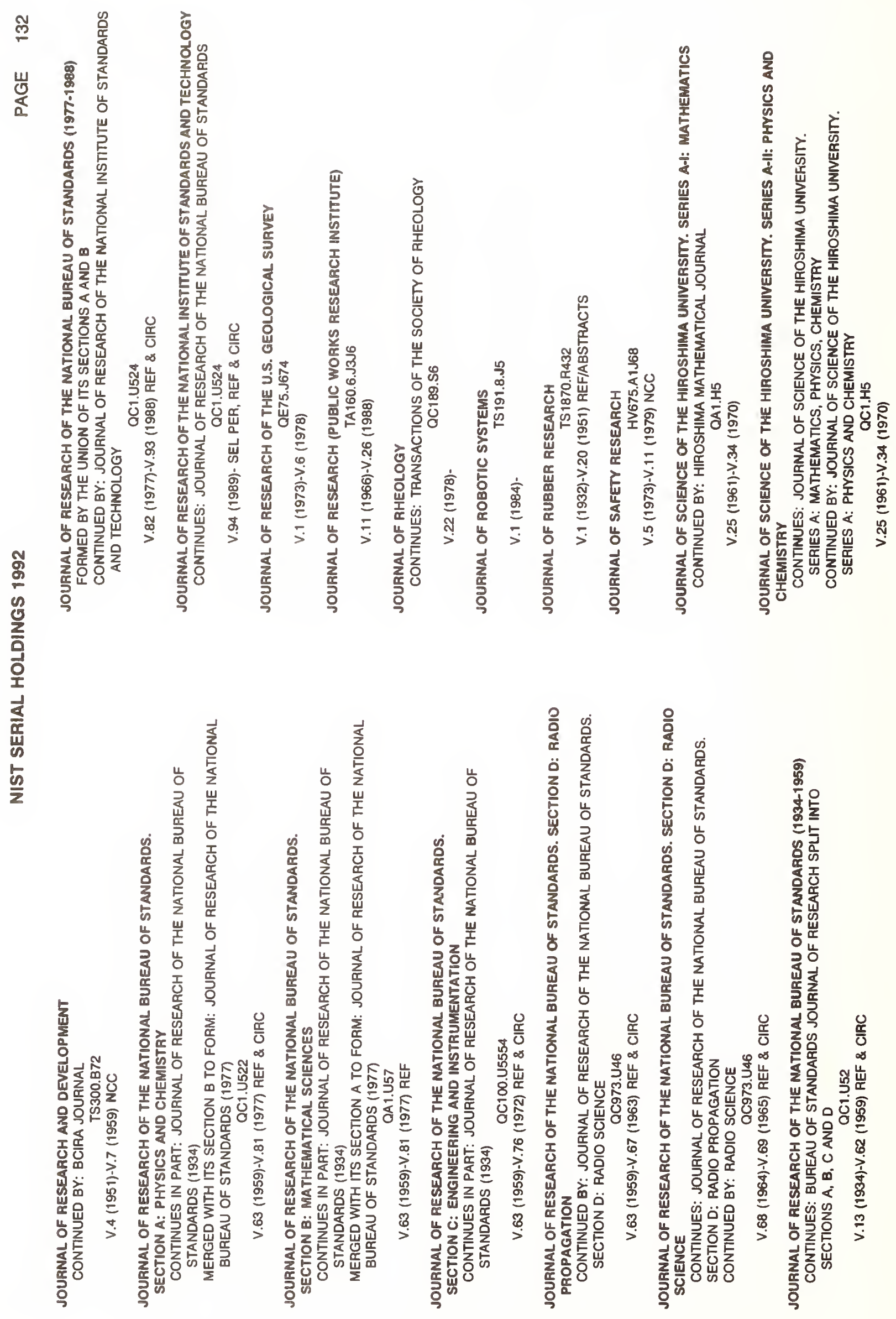


옴

容
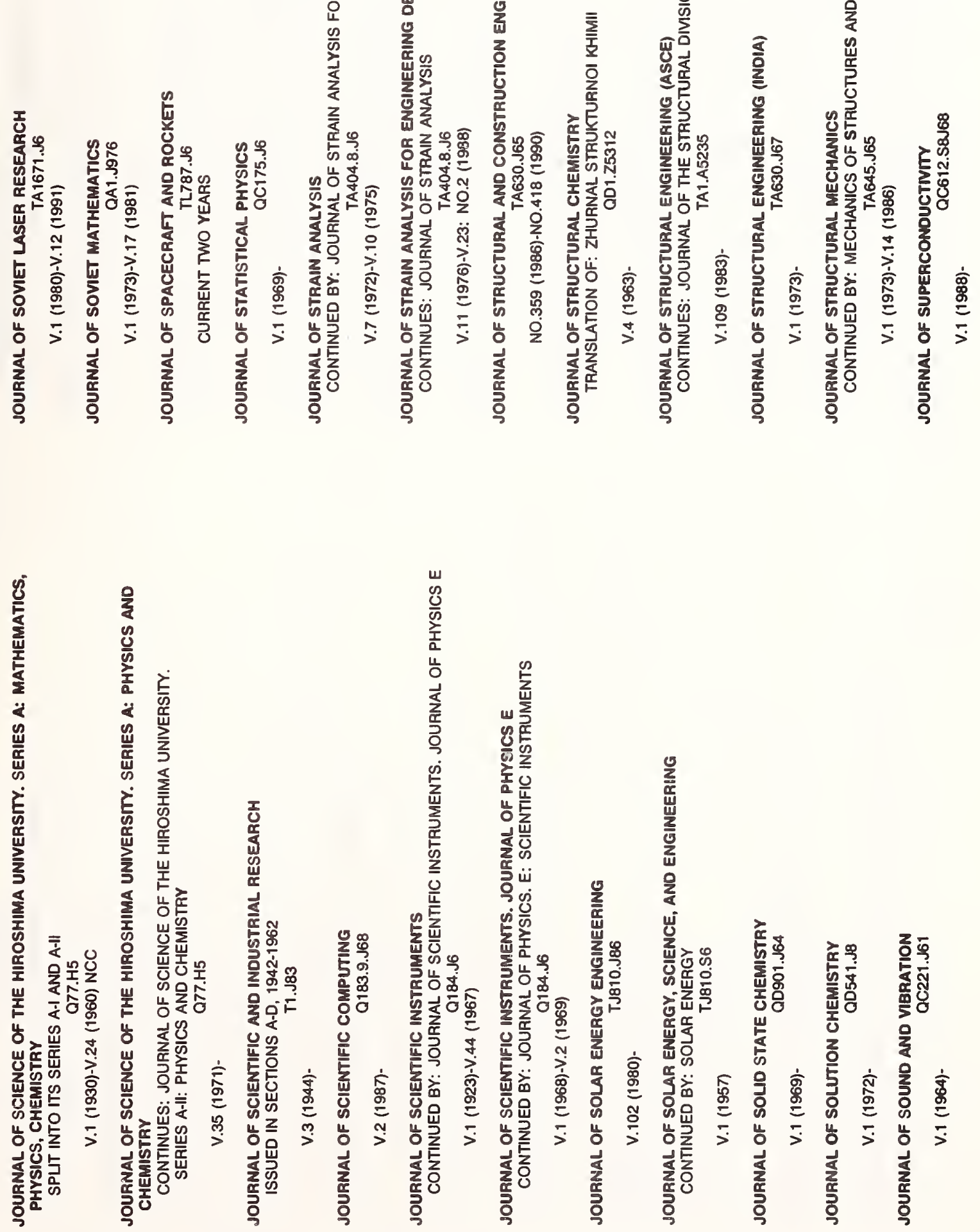
声
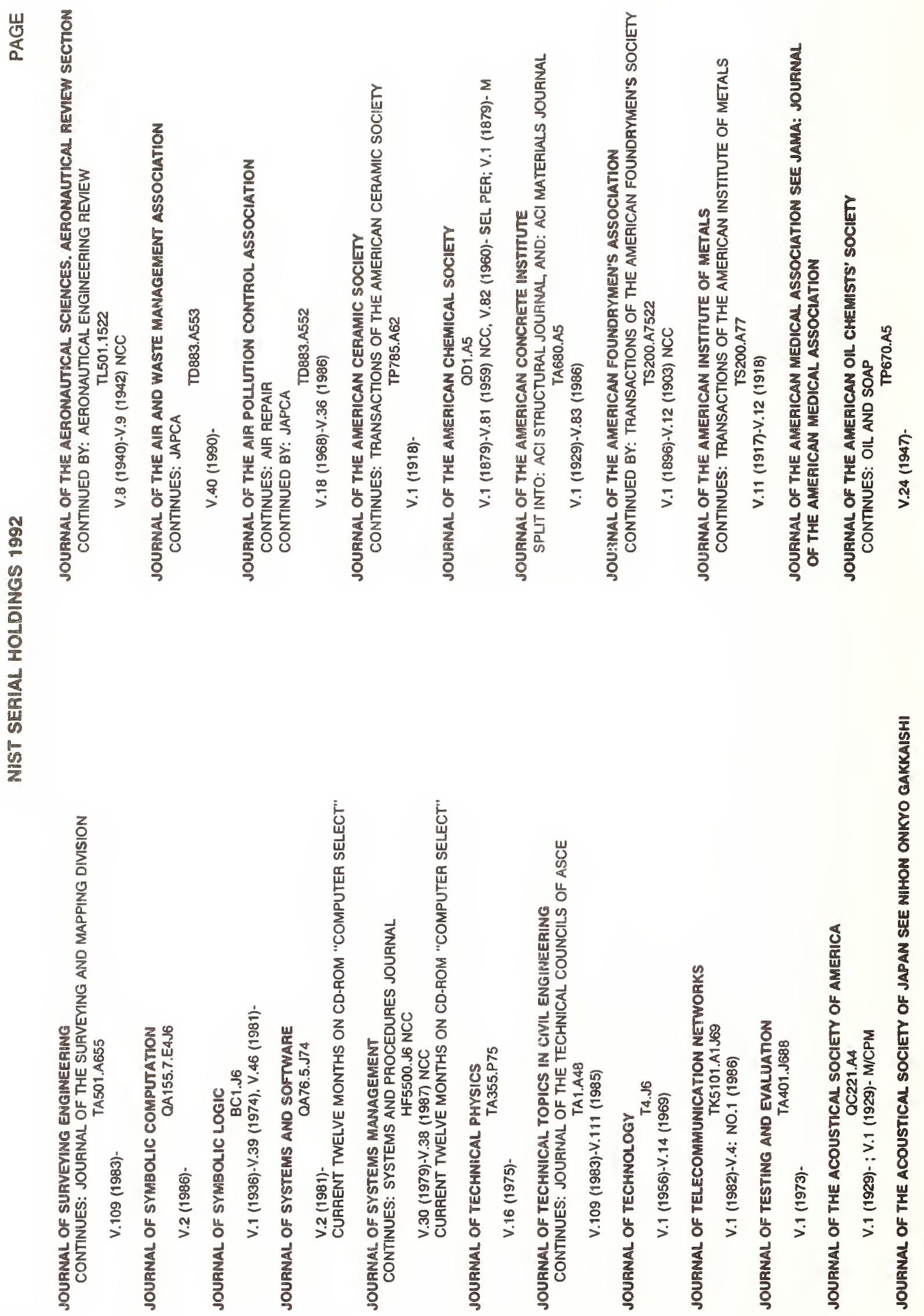


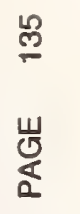



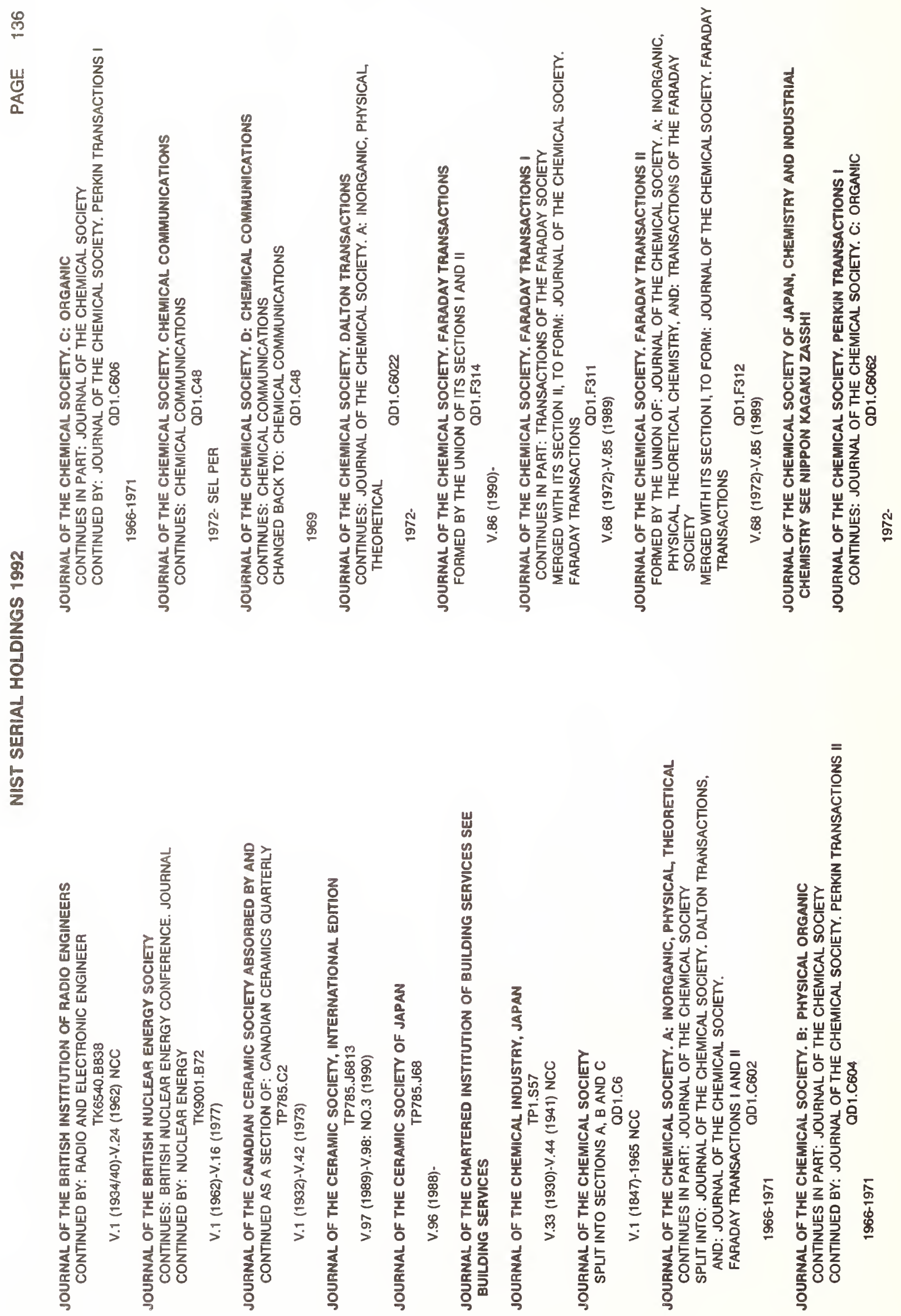


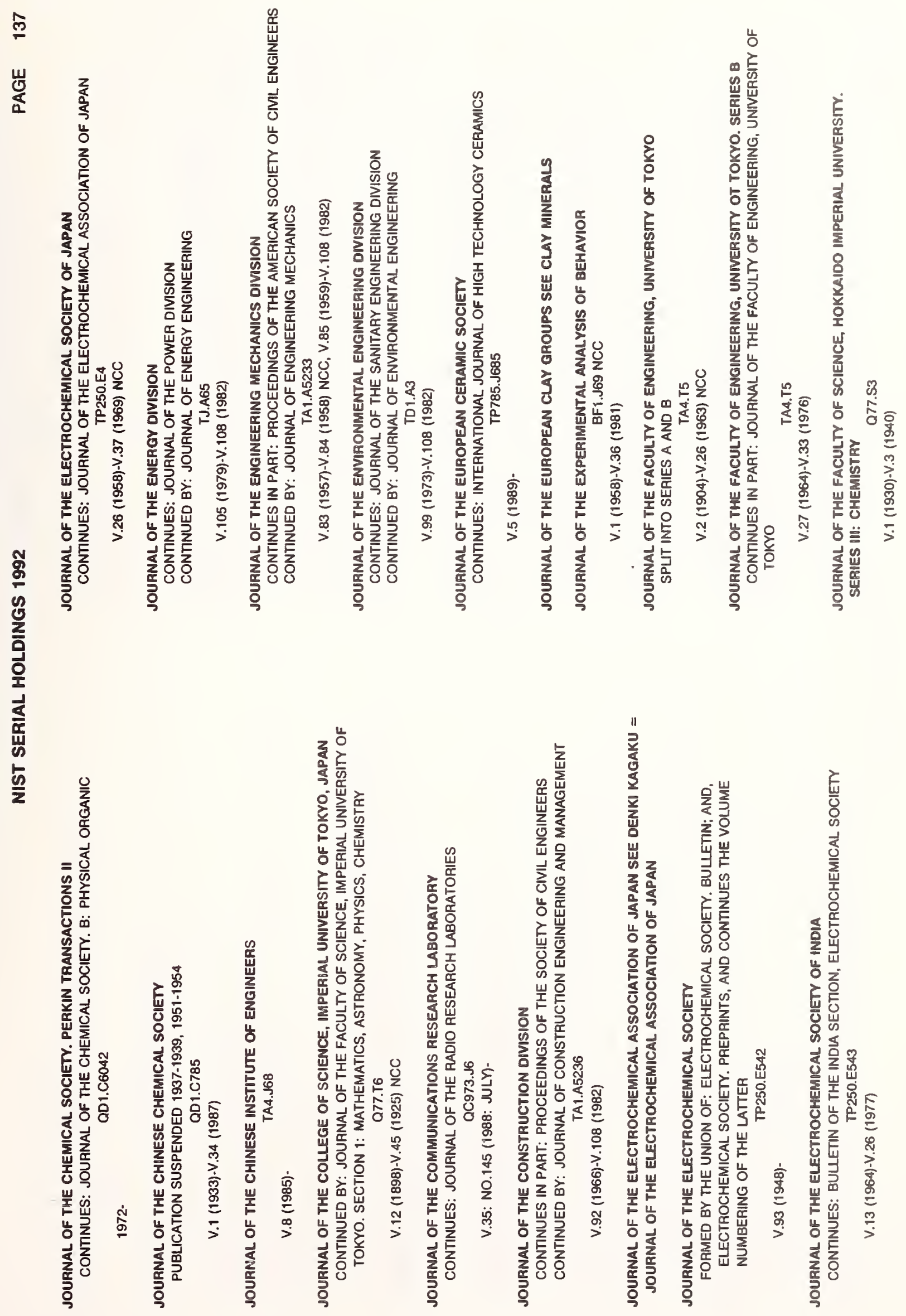




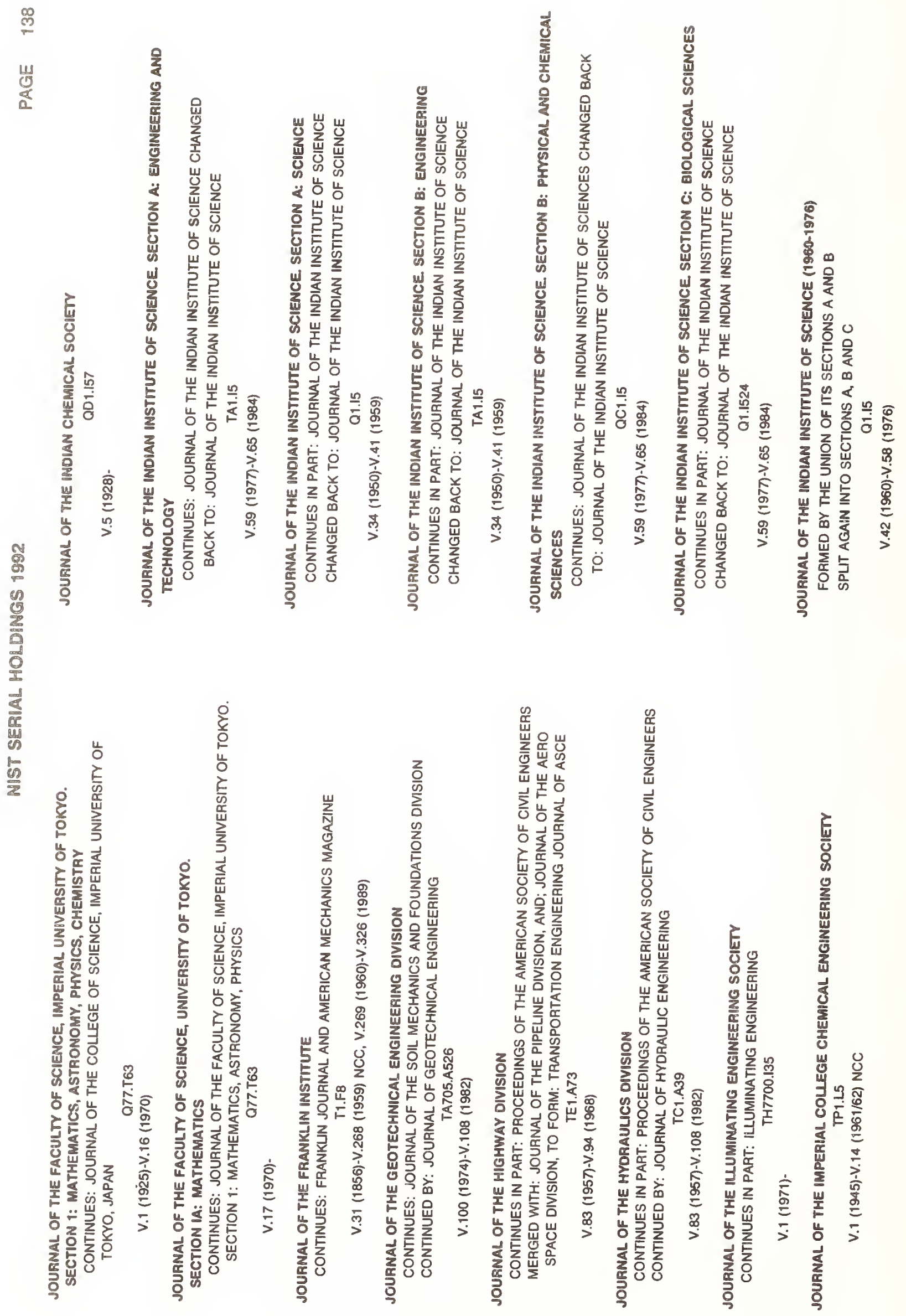



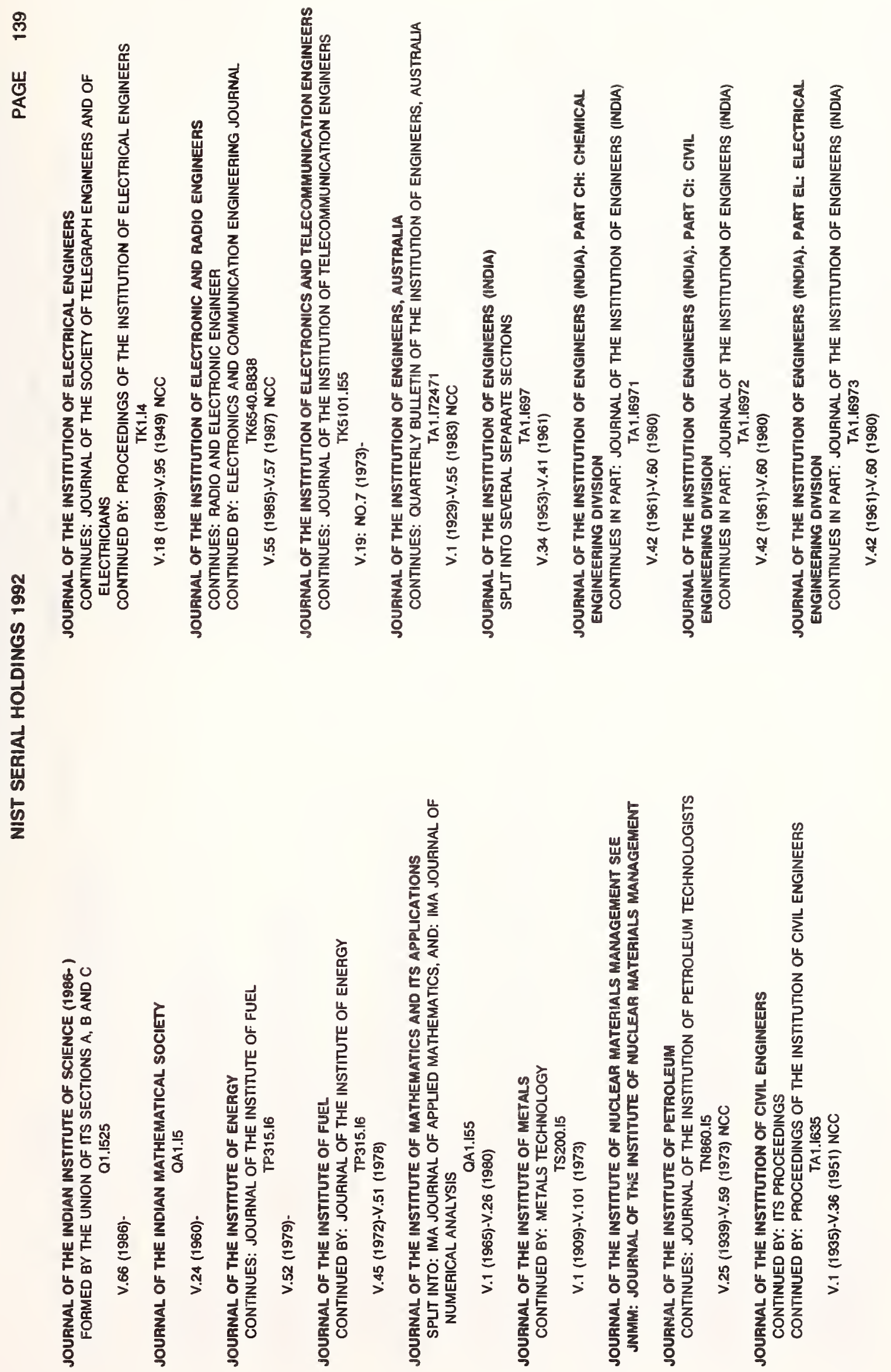


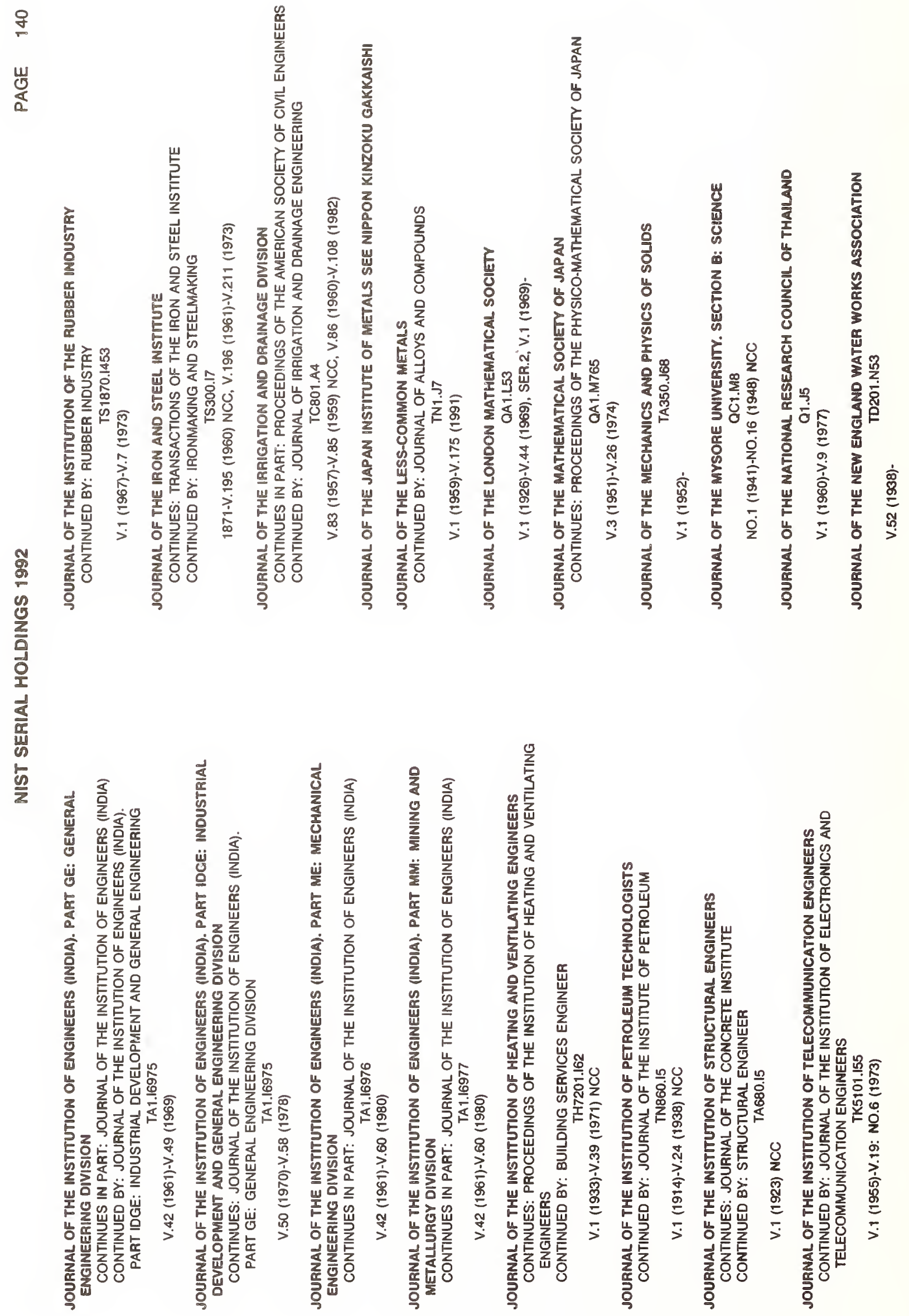



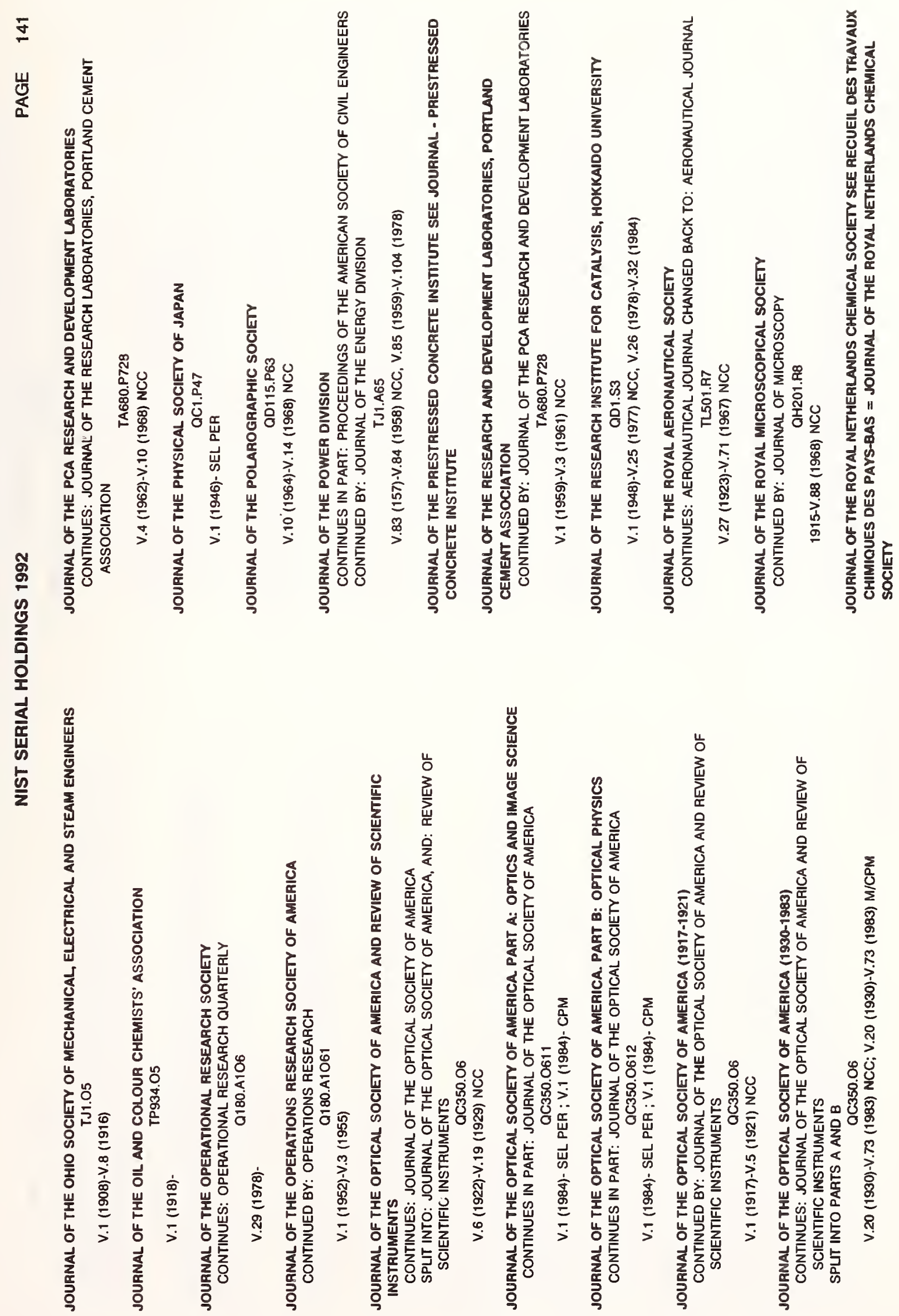


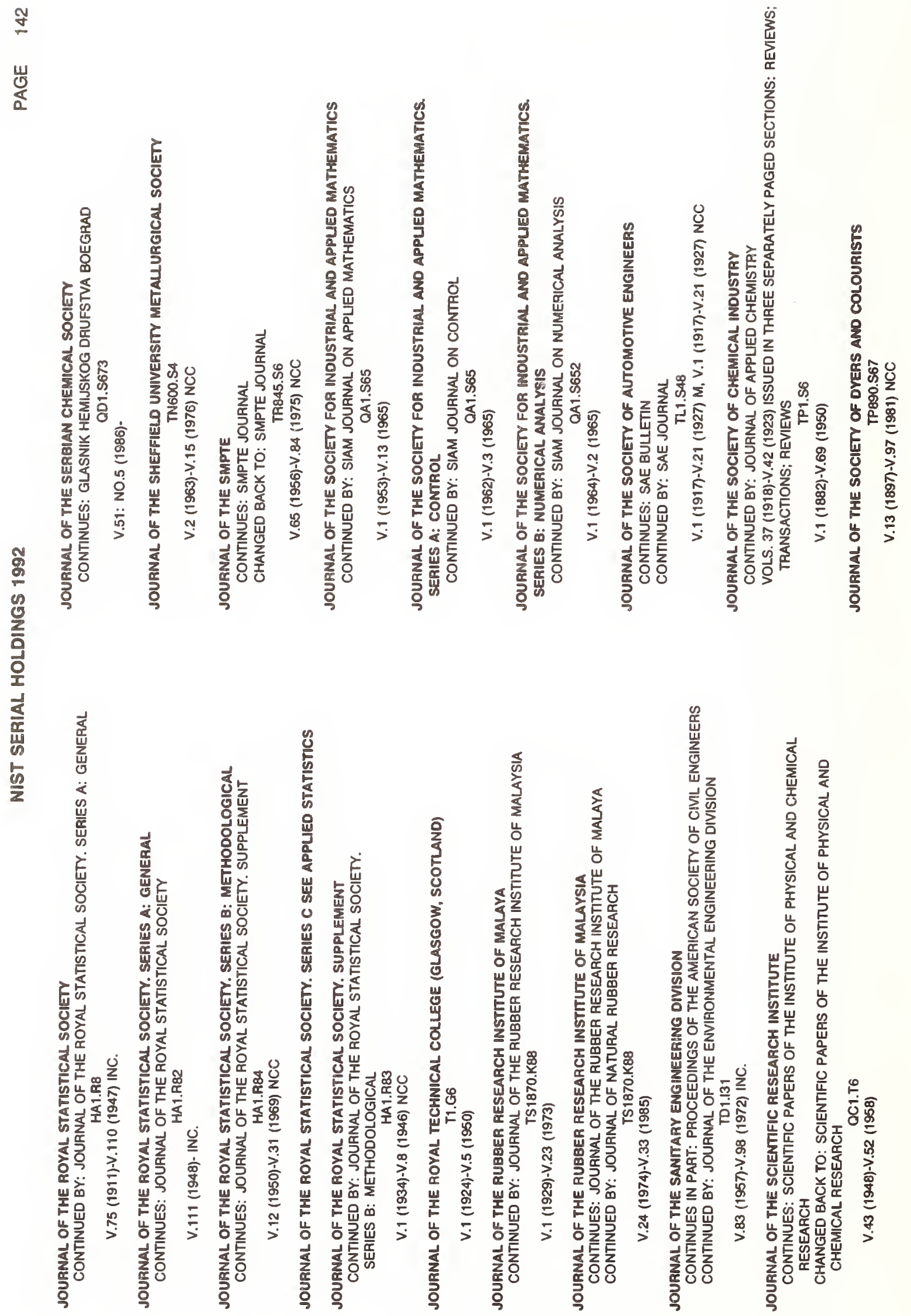



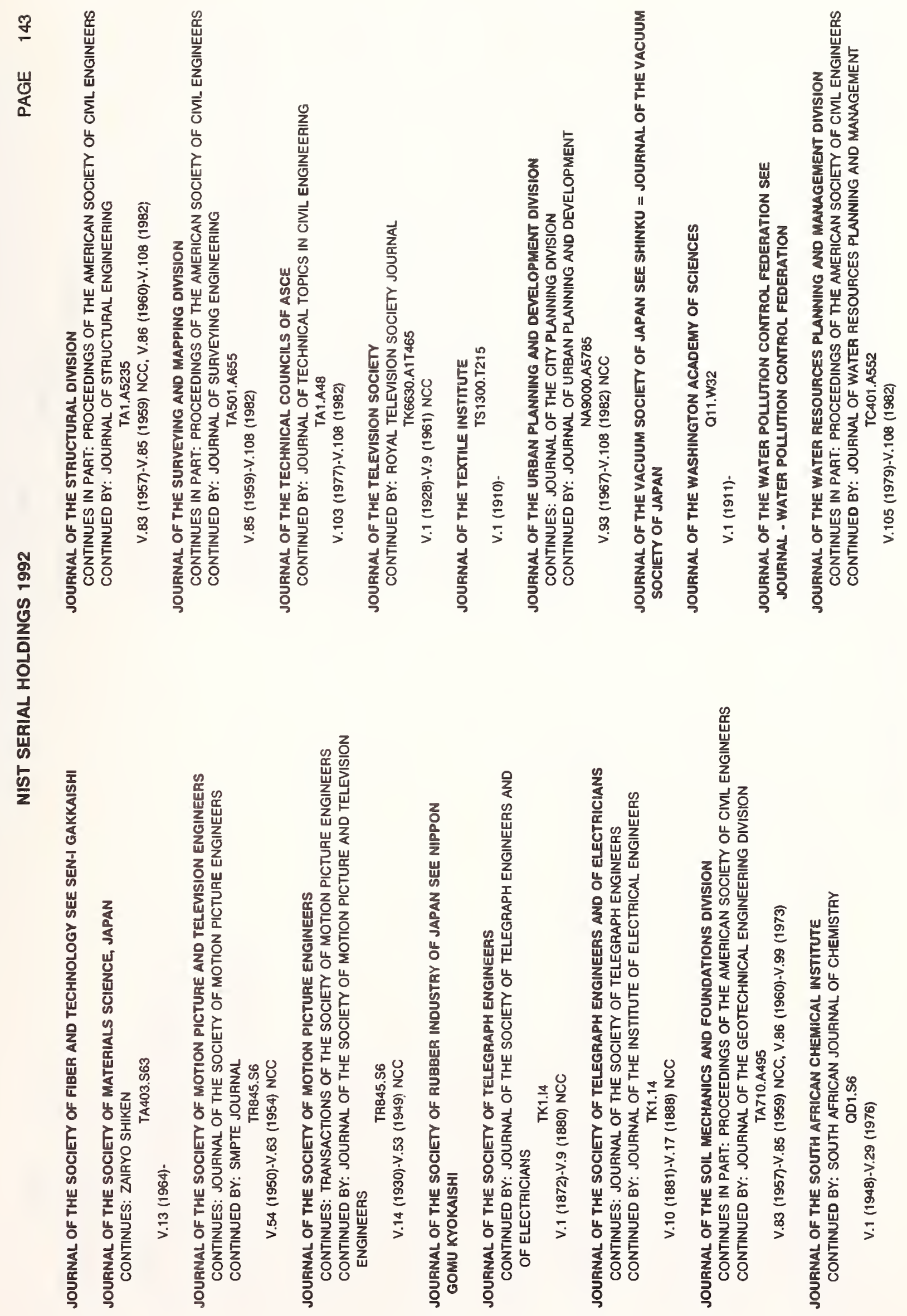


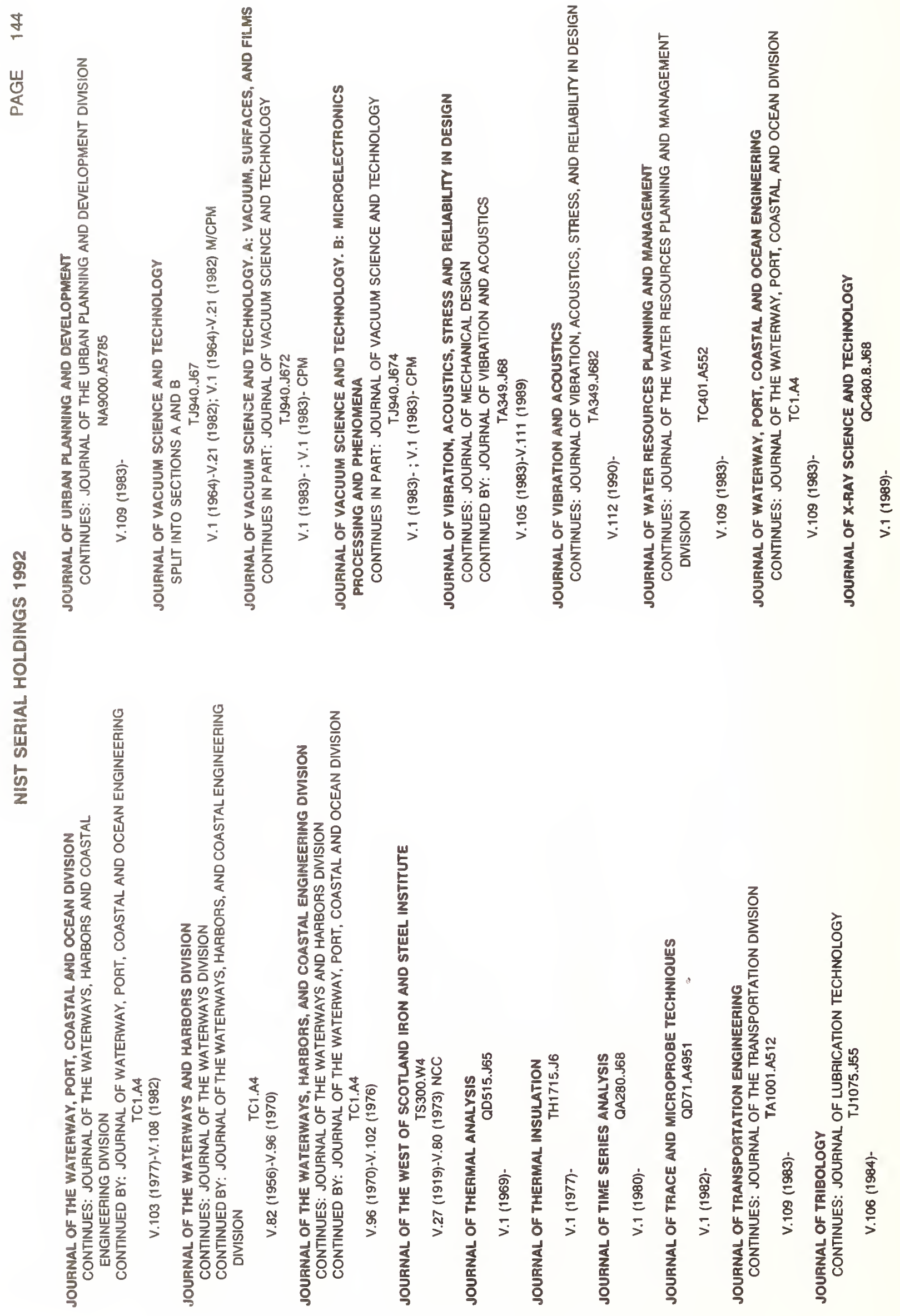



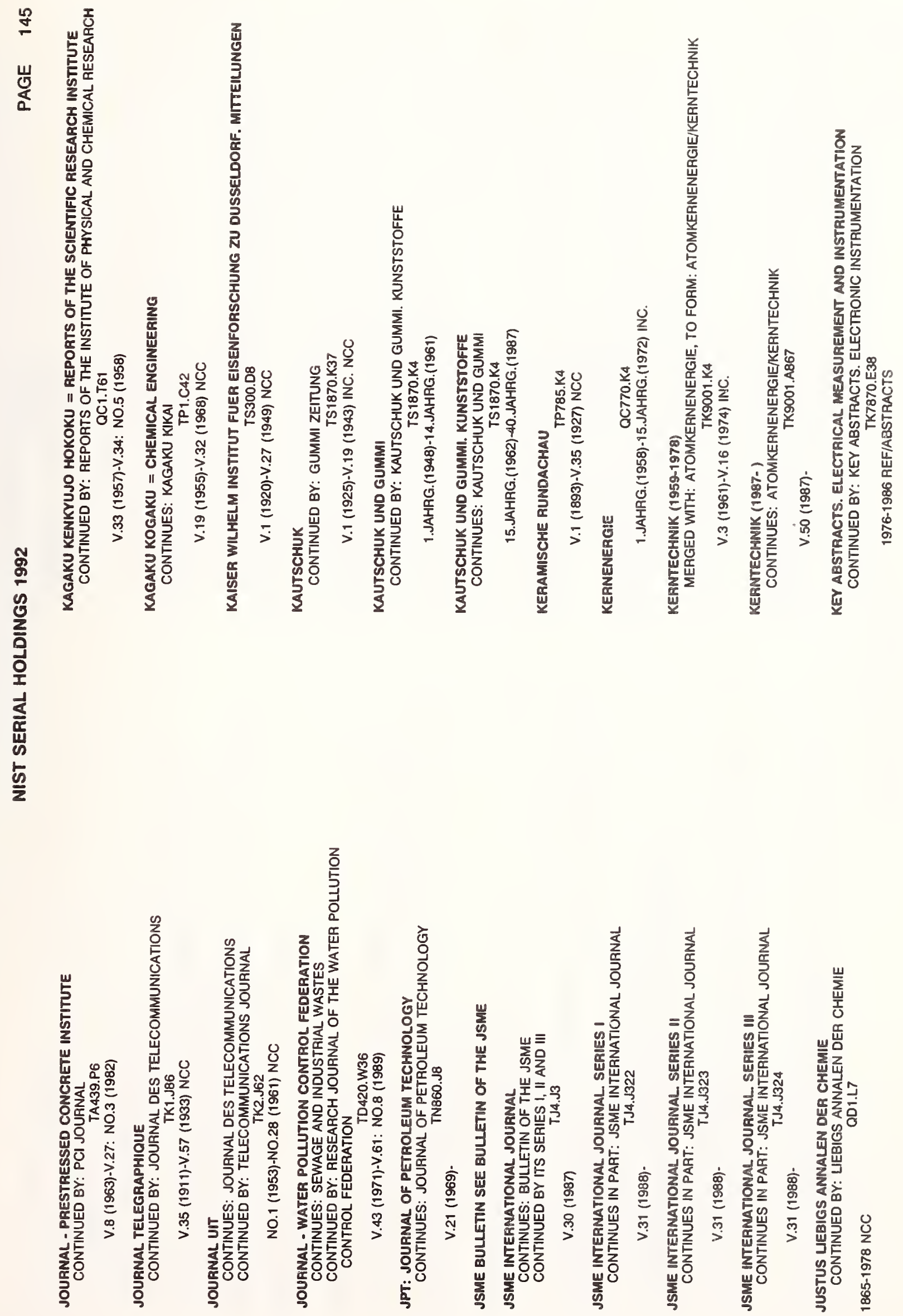


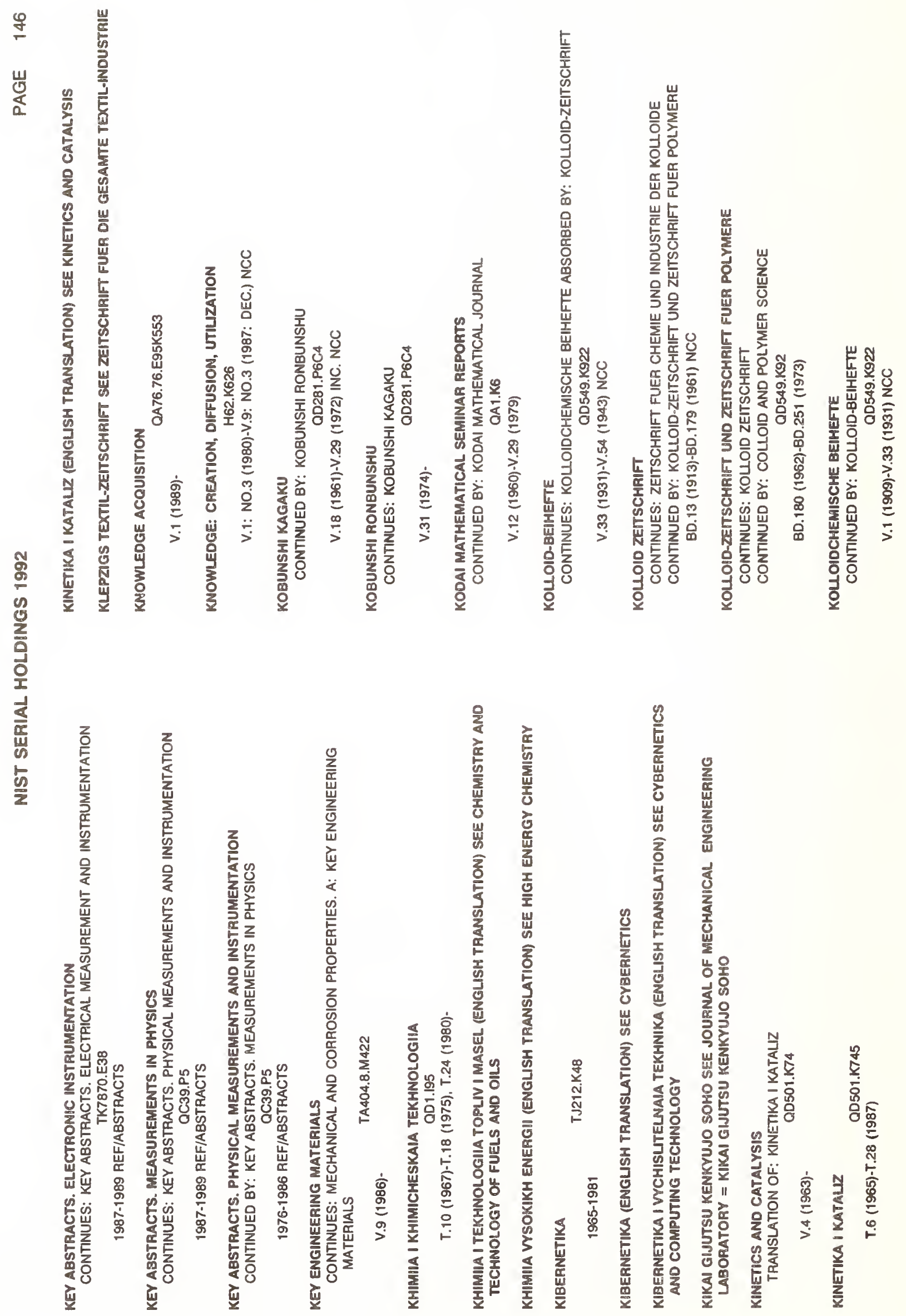




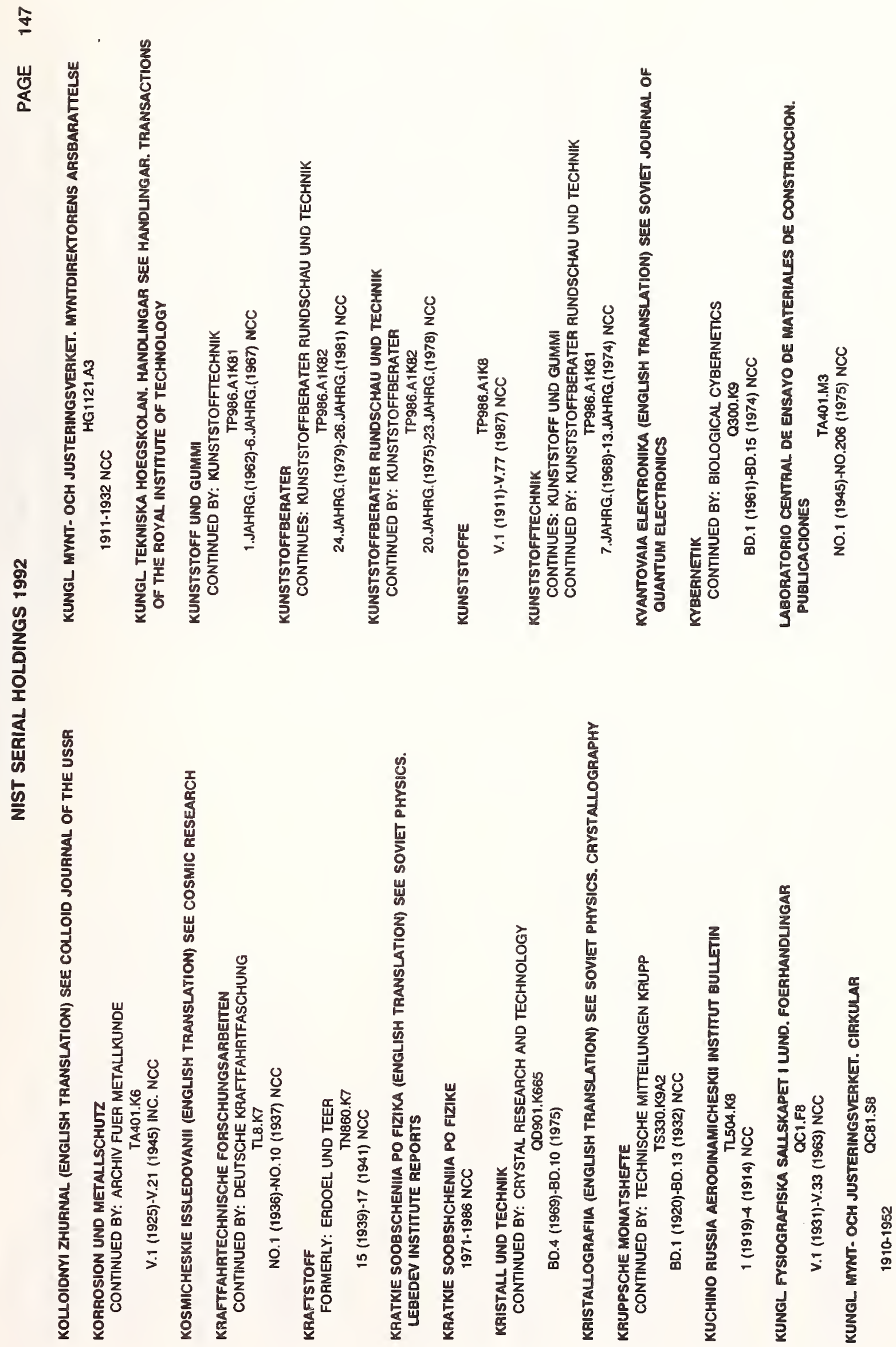


里
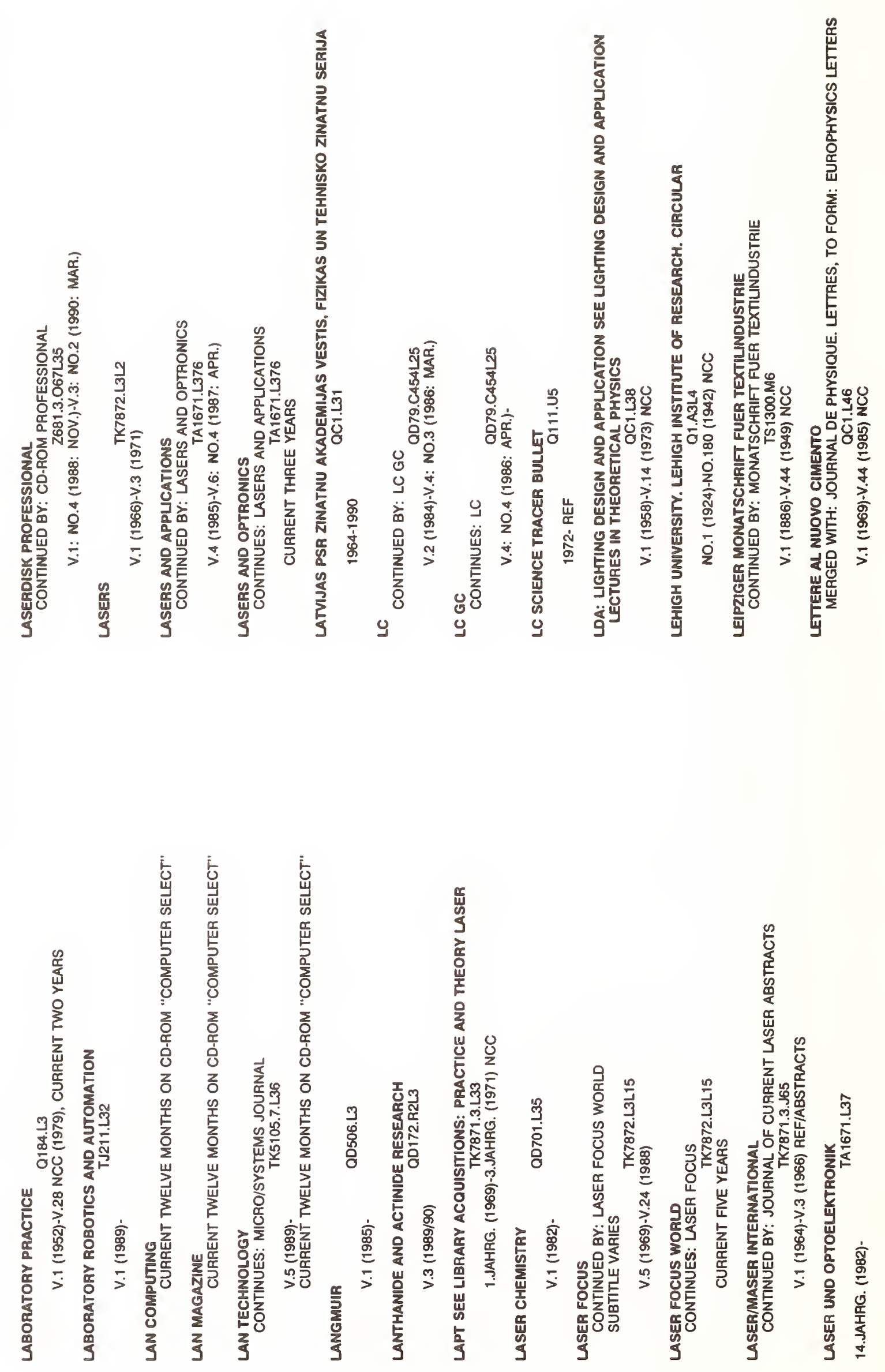
g
땅

高

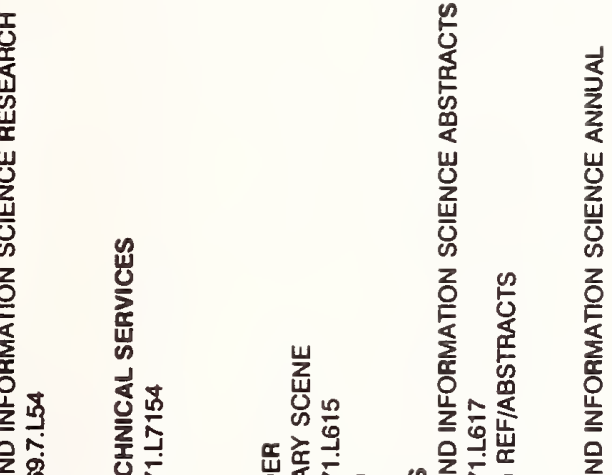

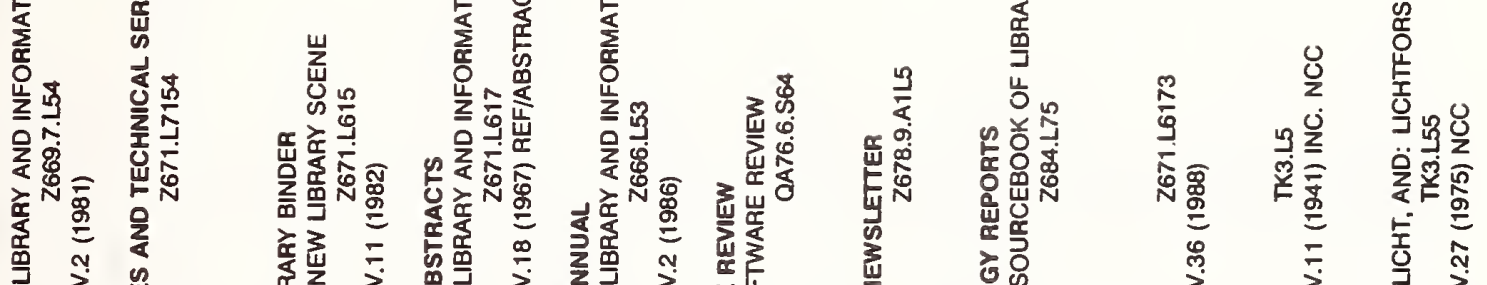

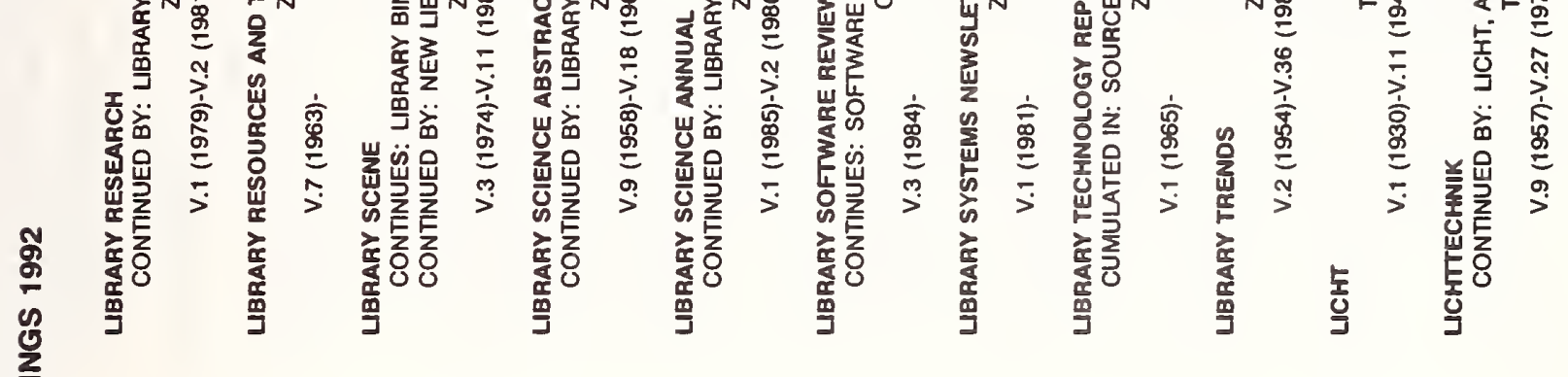

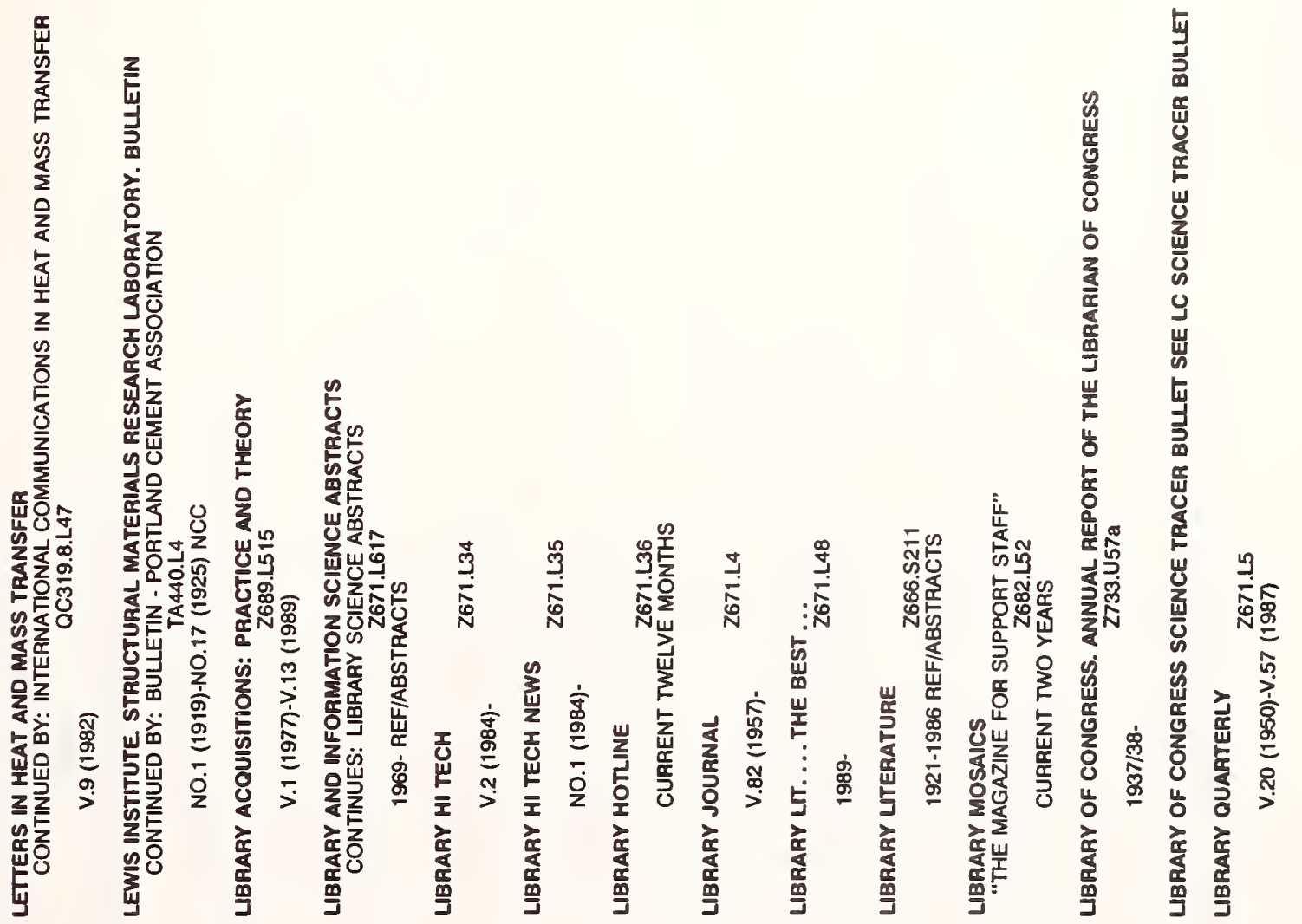




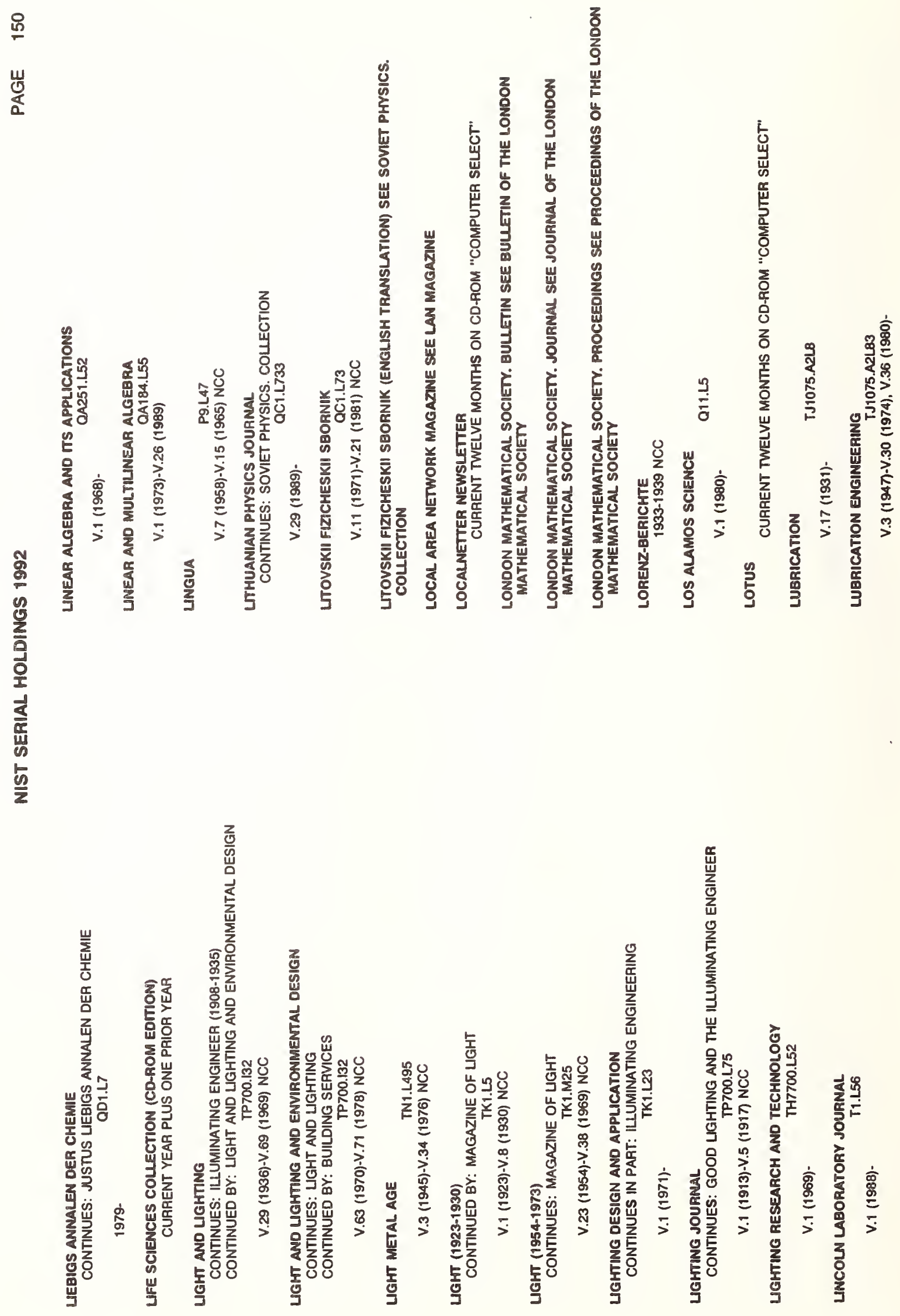



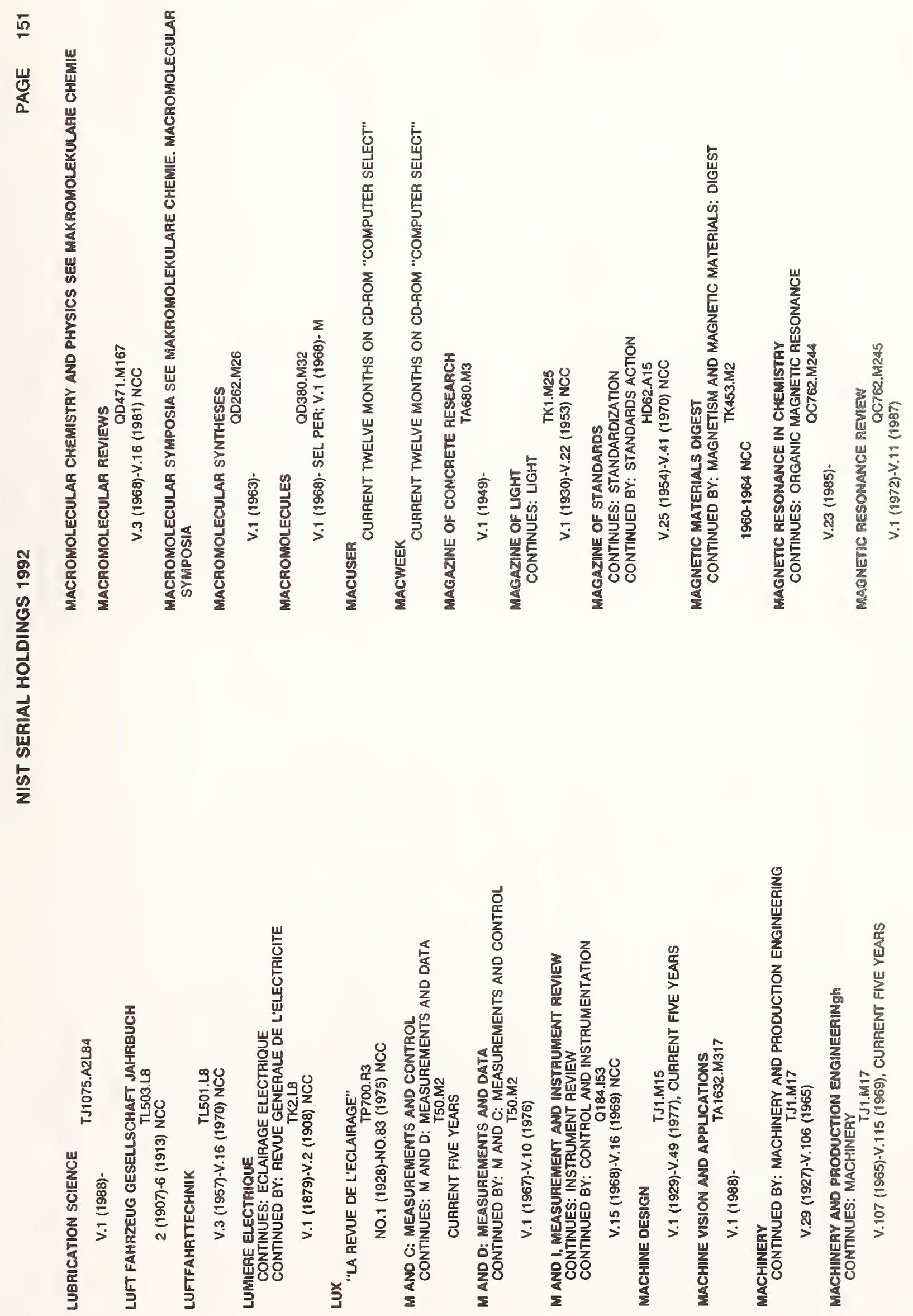


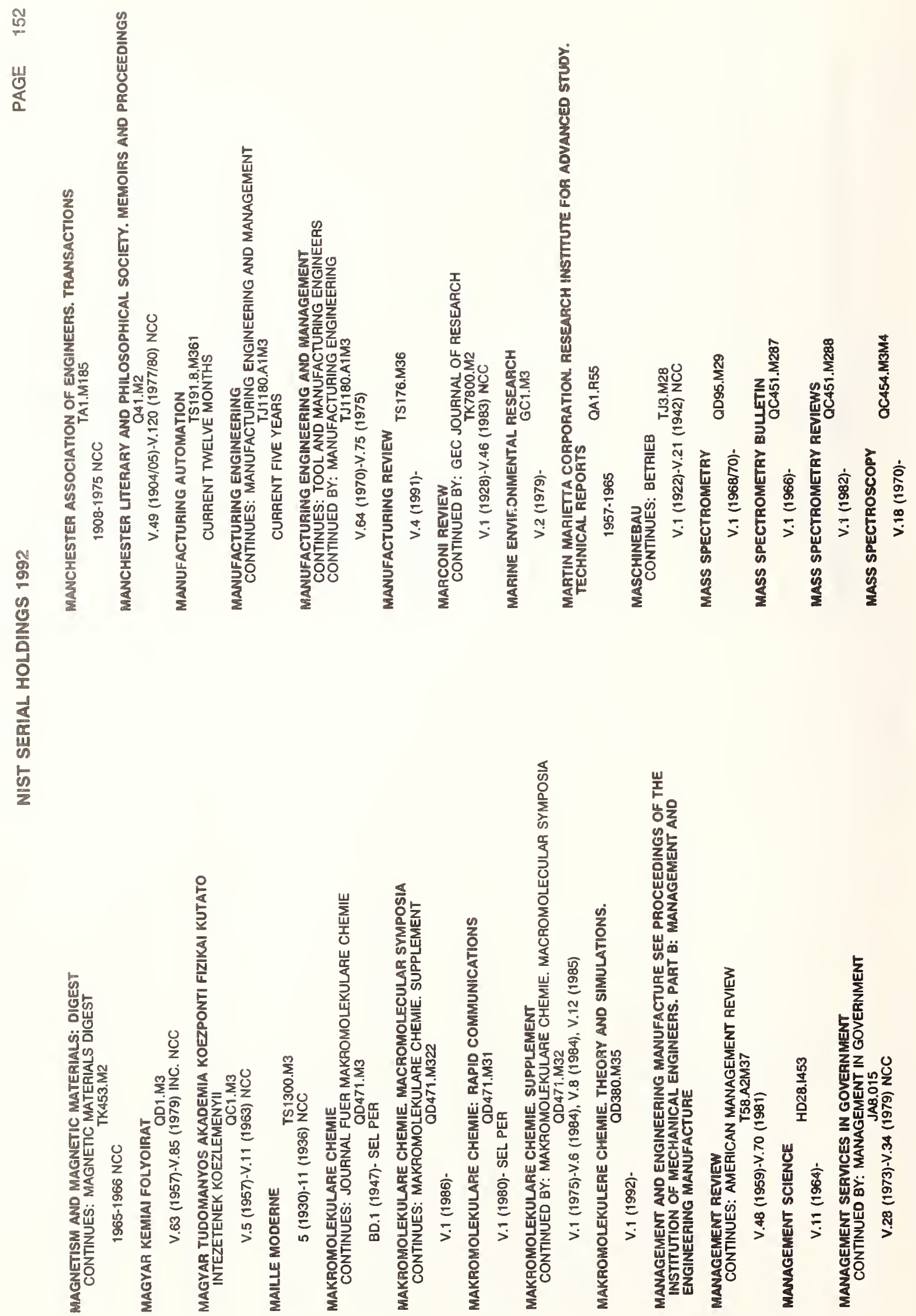



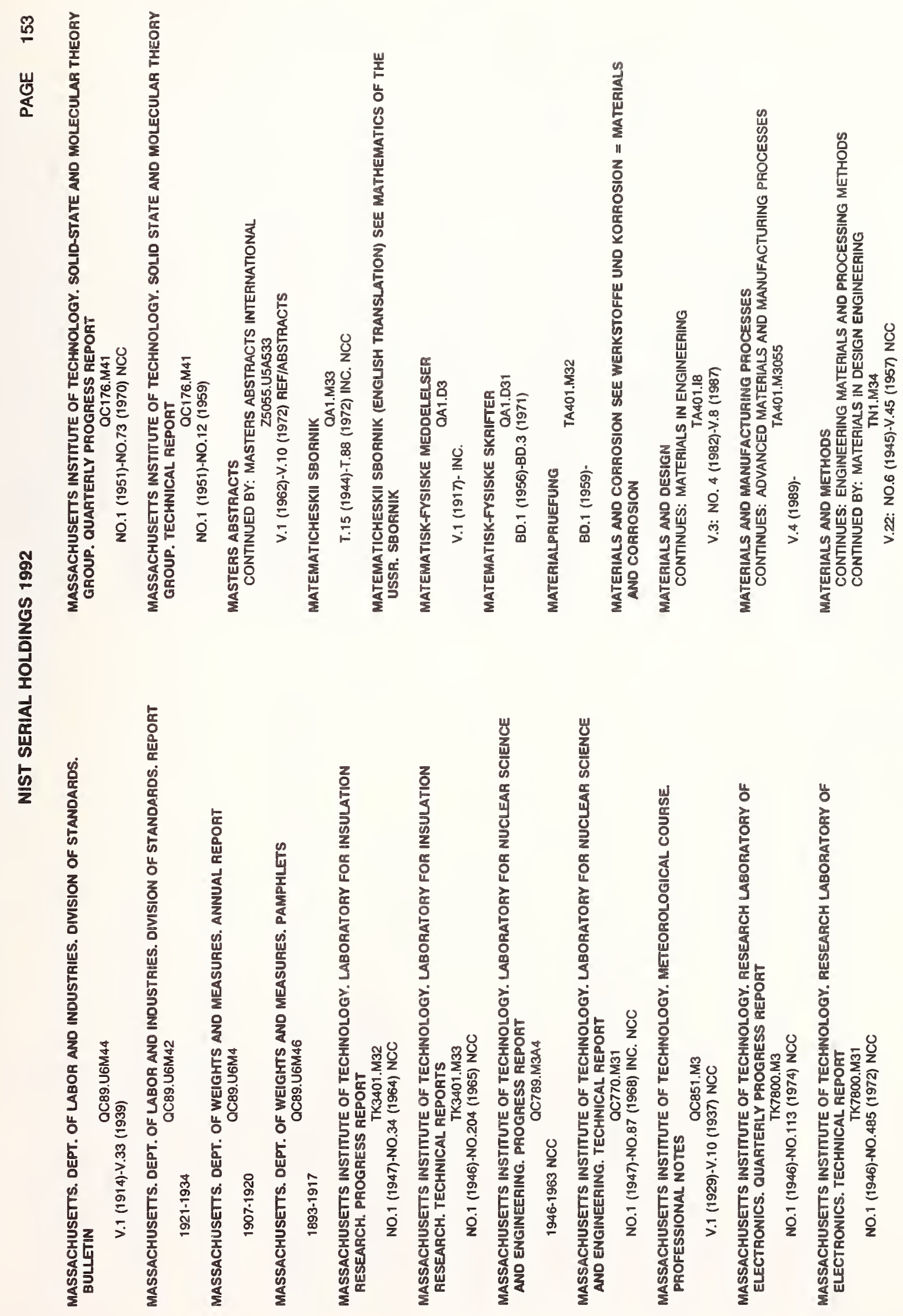


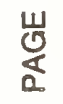

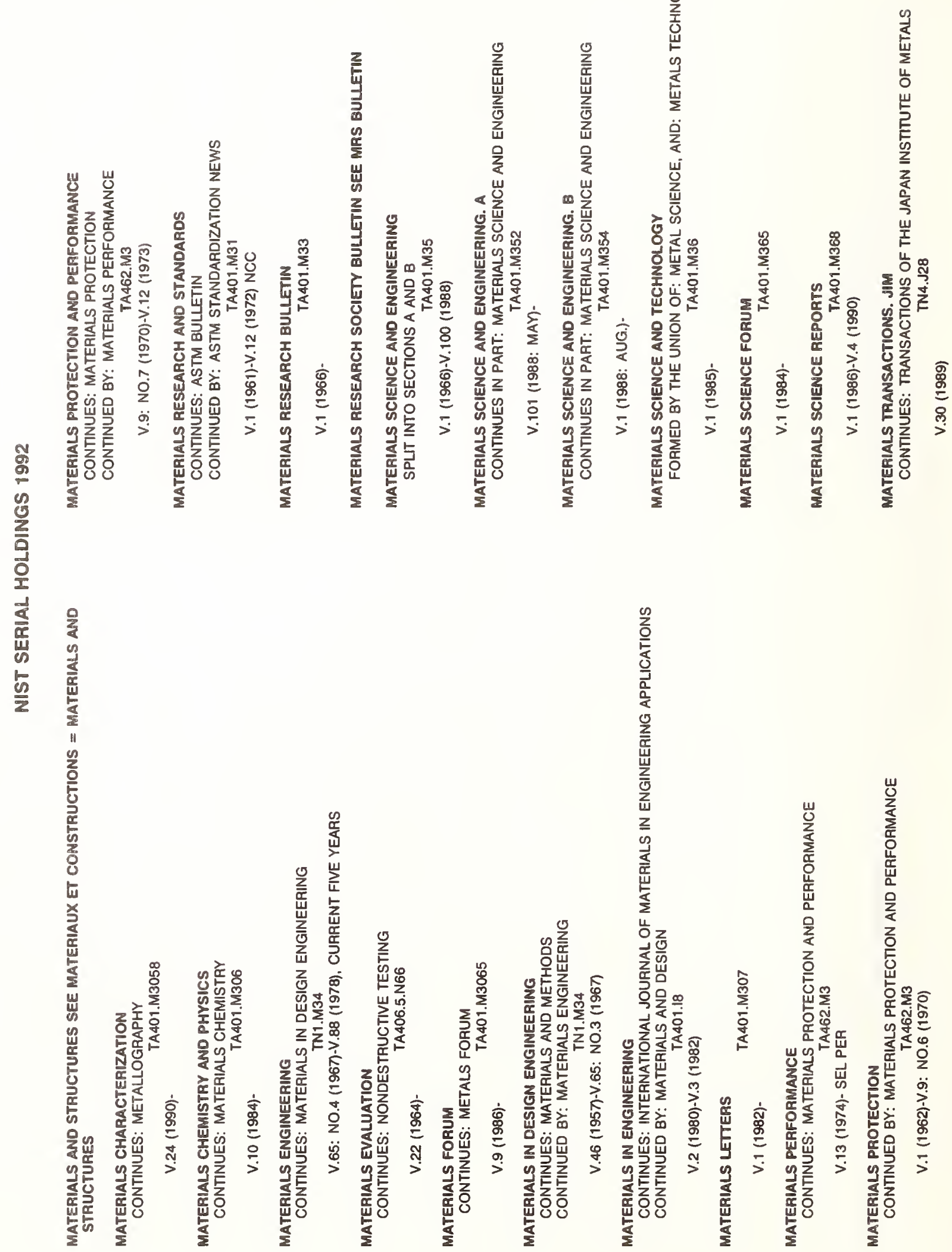




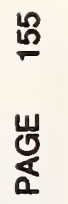

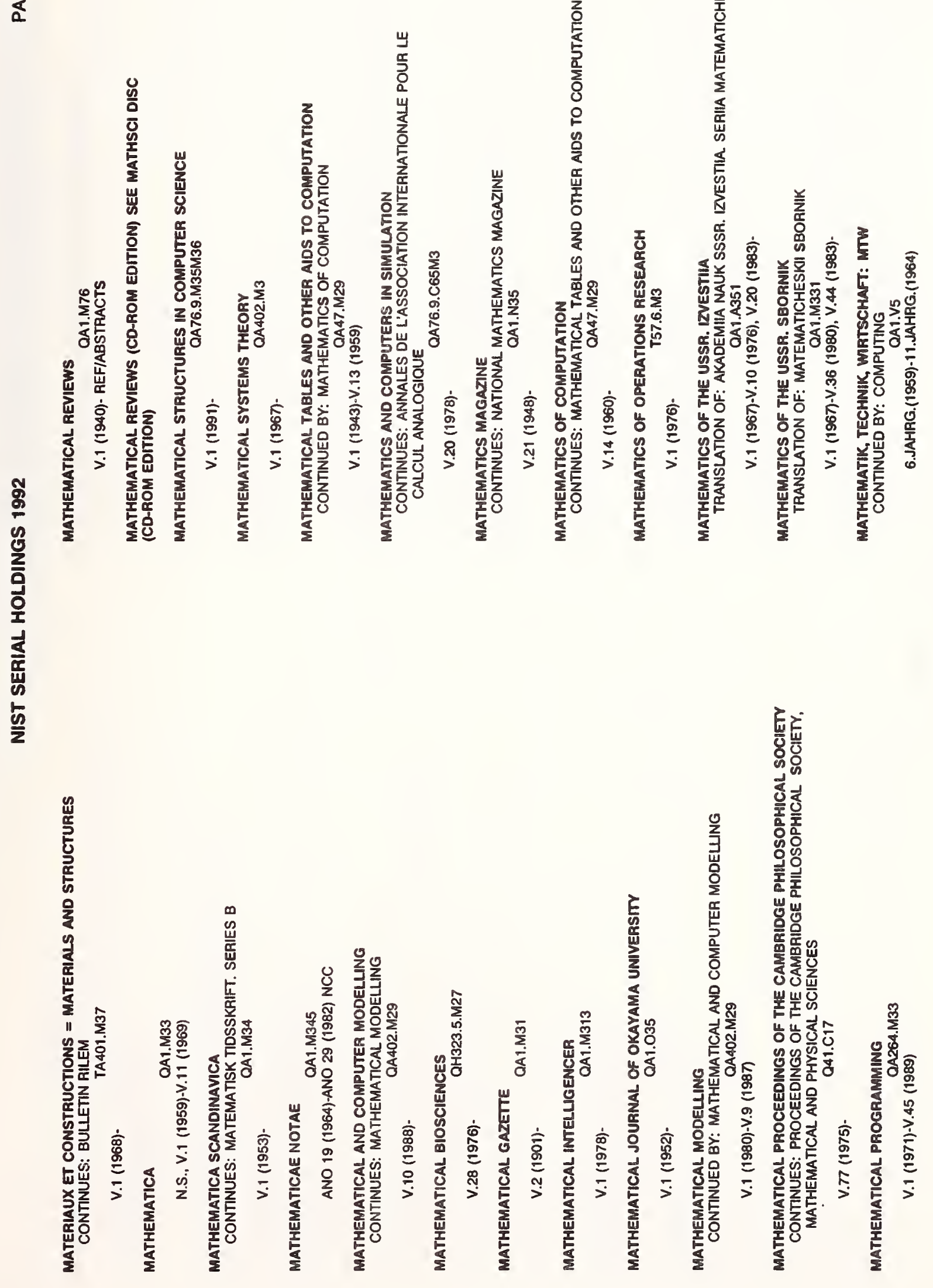




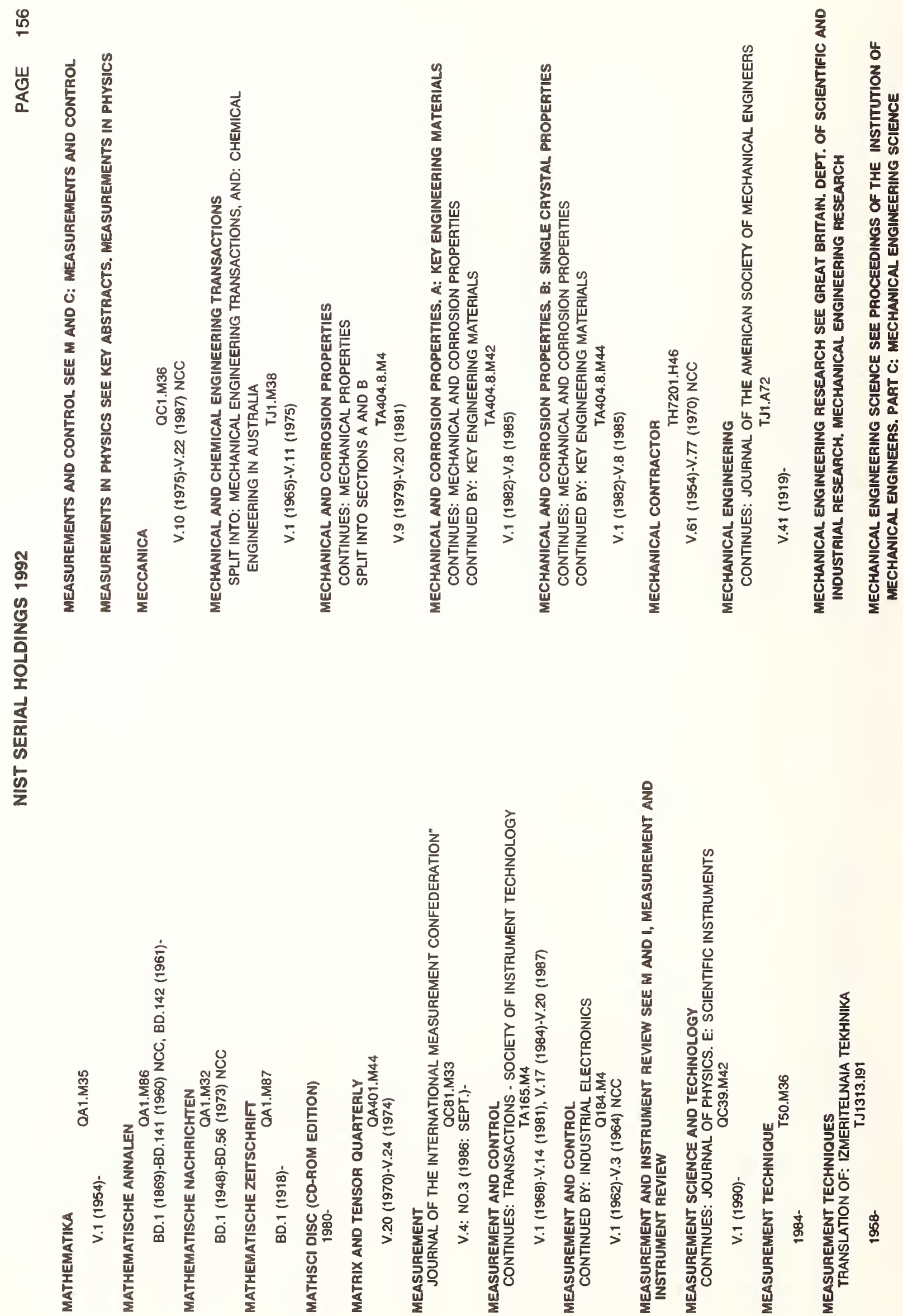




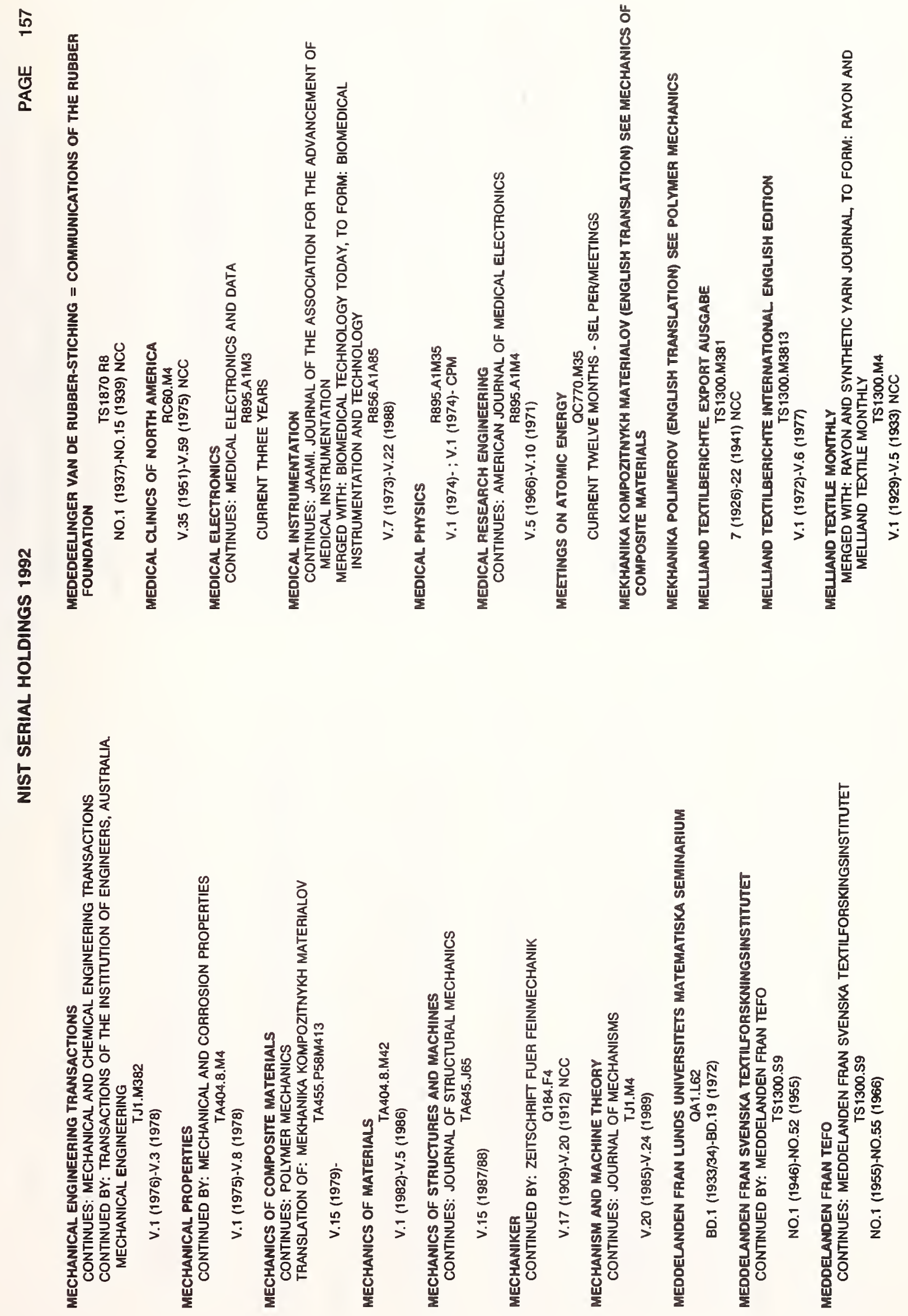




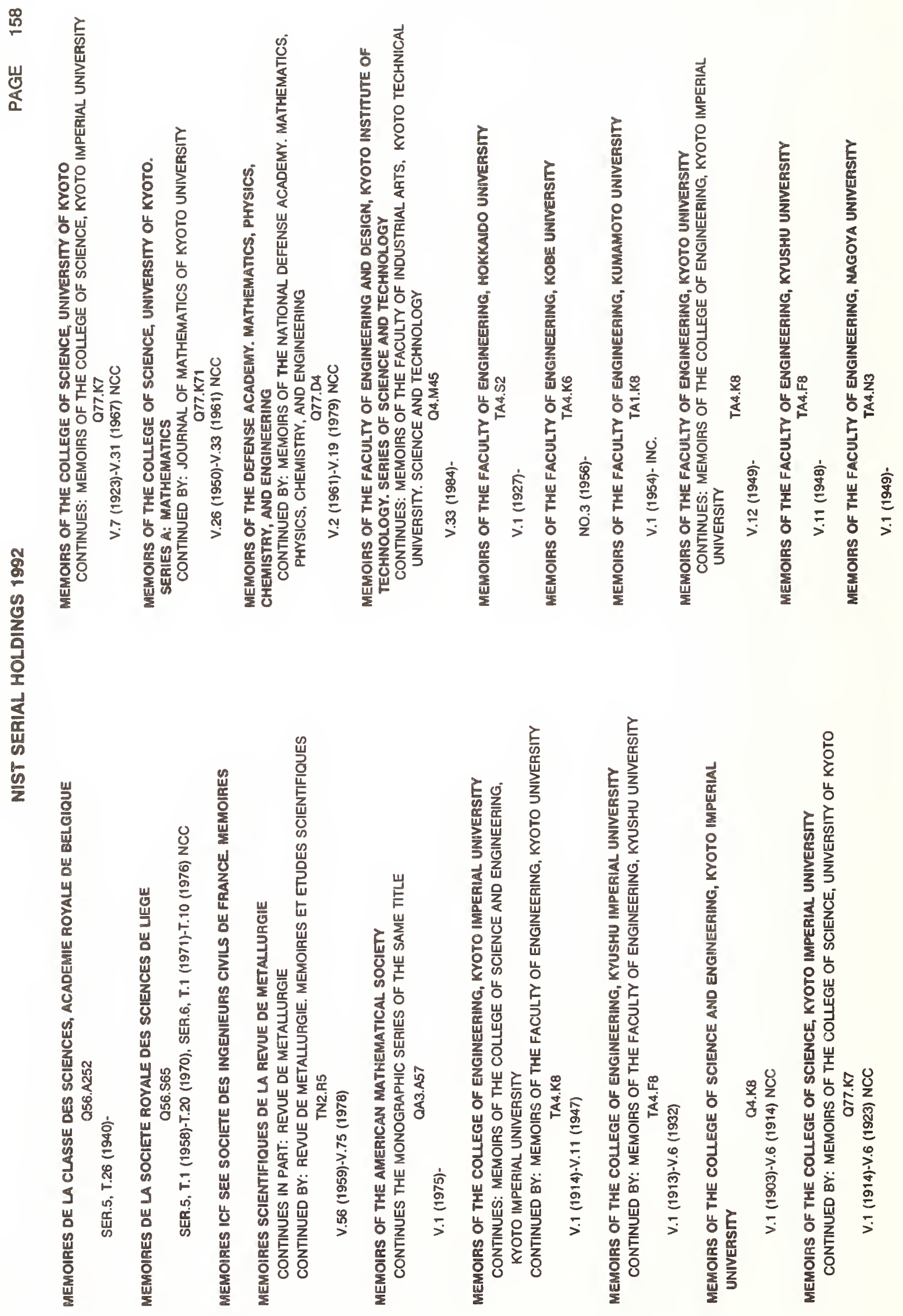




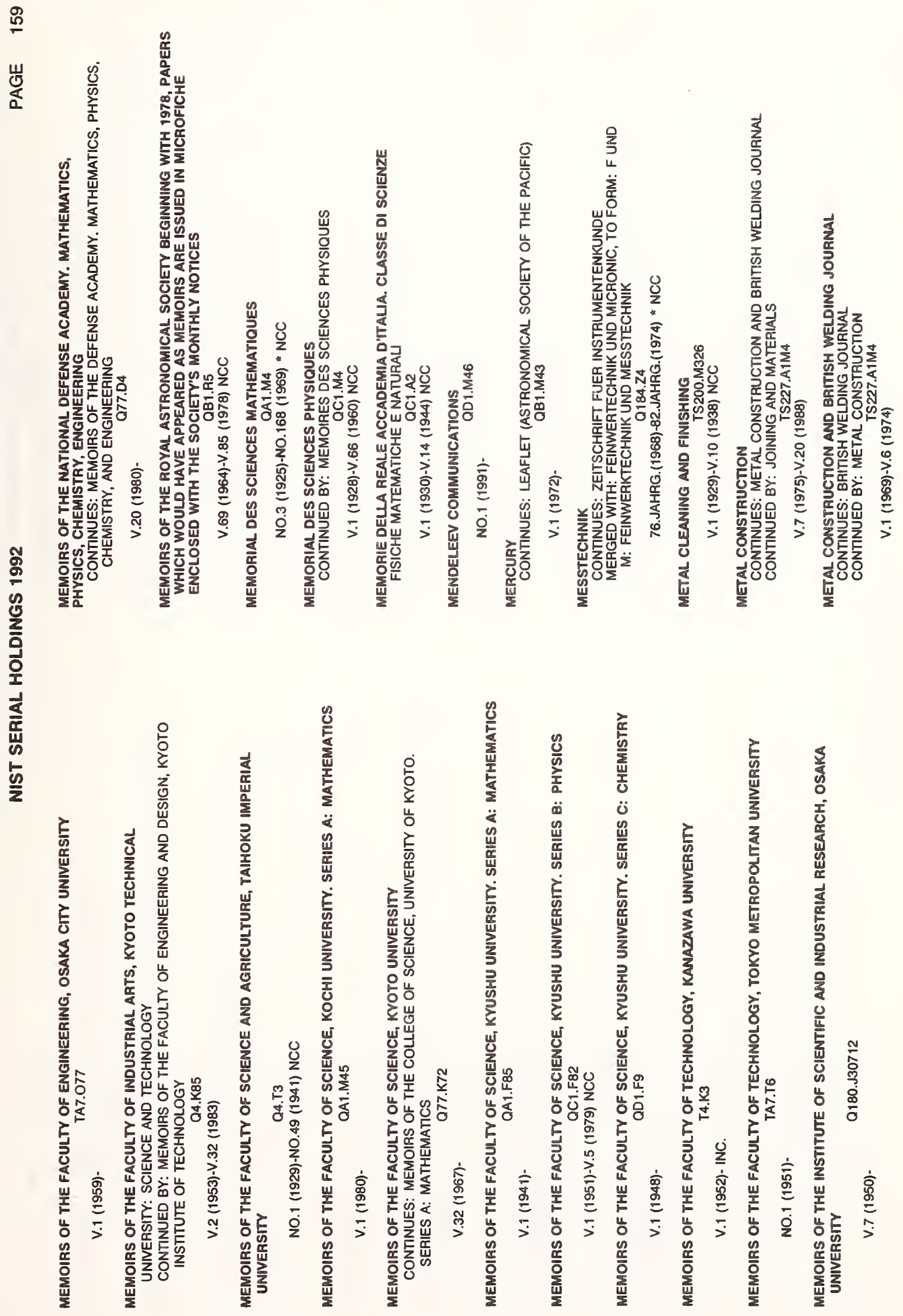




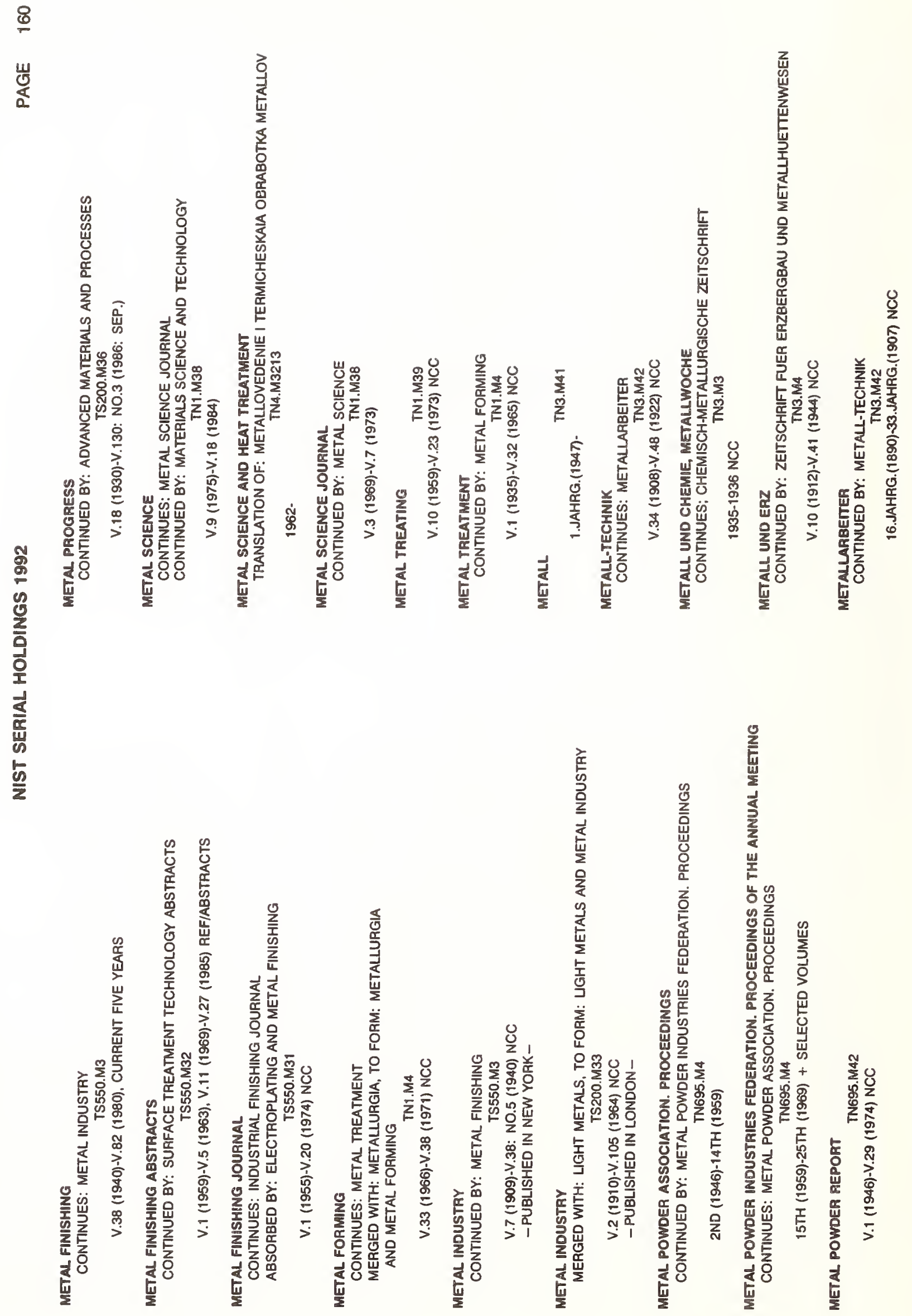



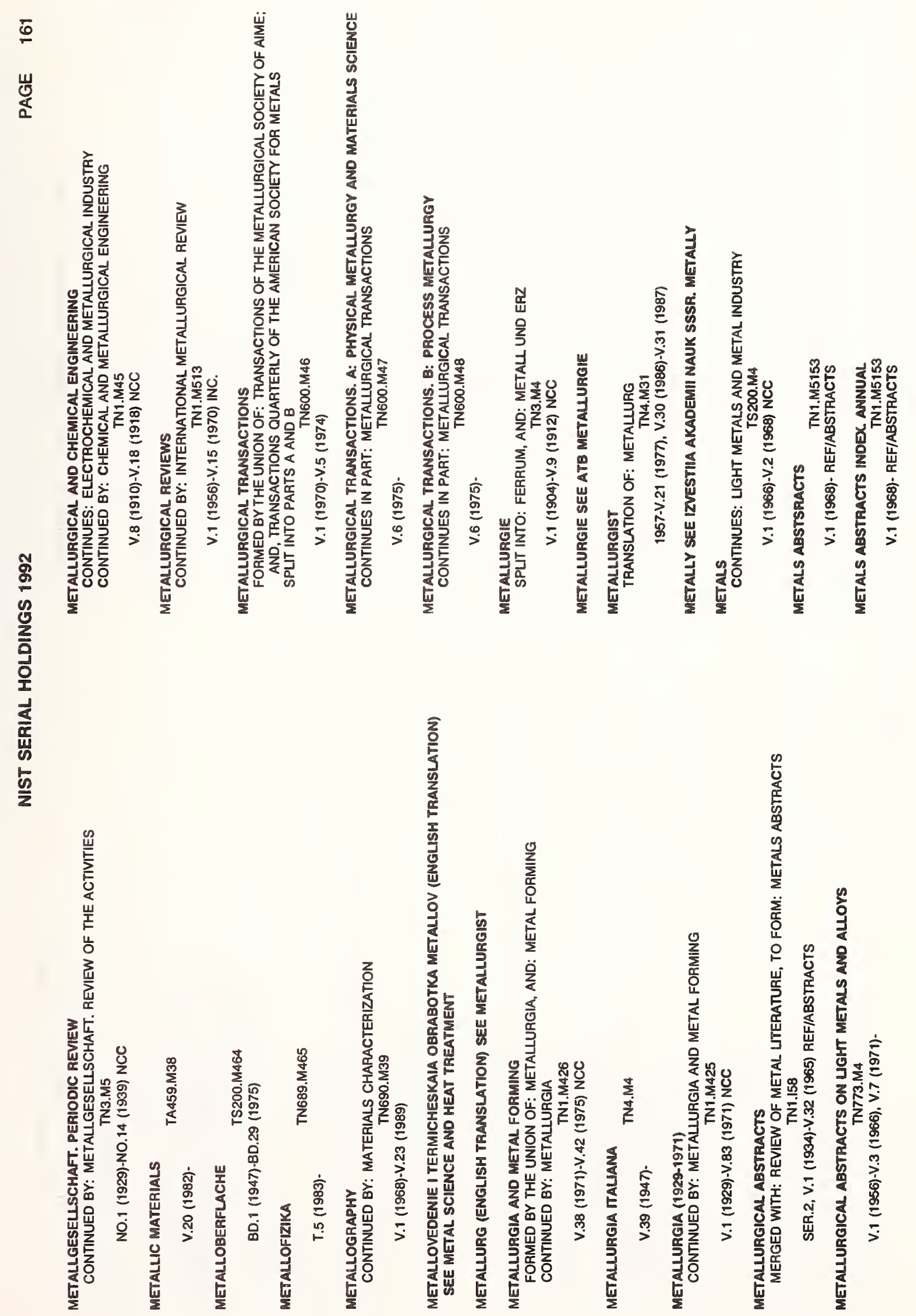
๕

뿡

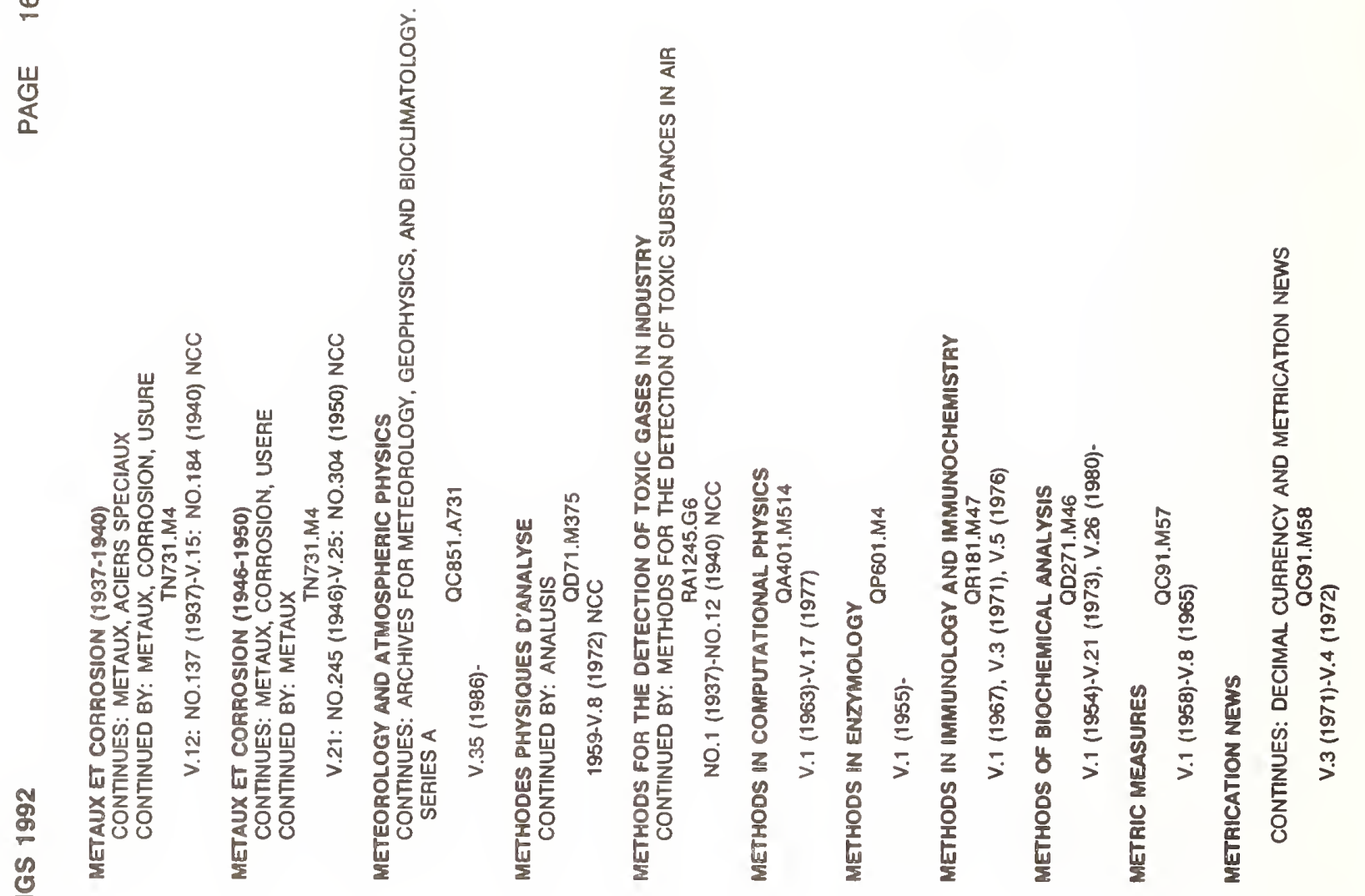

흘
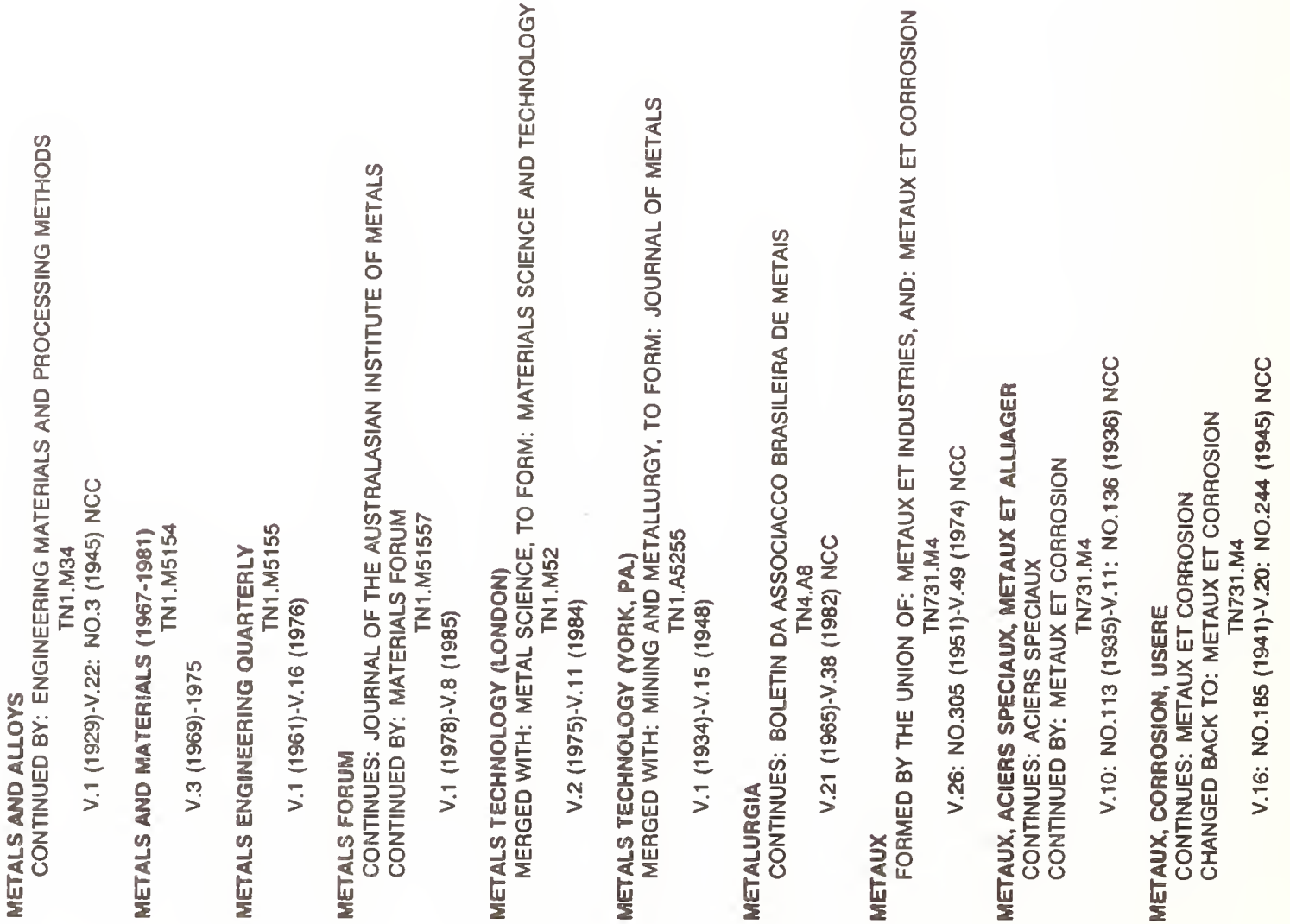
$\stackrel{8}{8}$

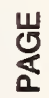
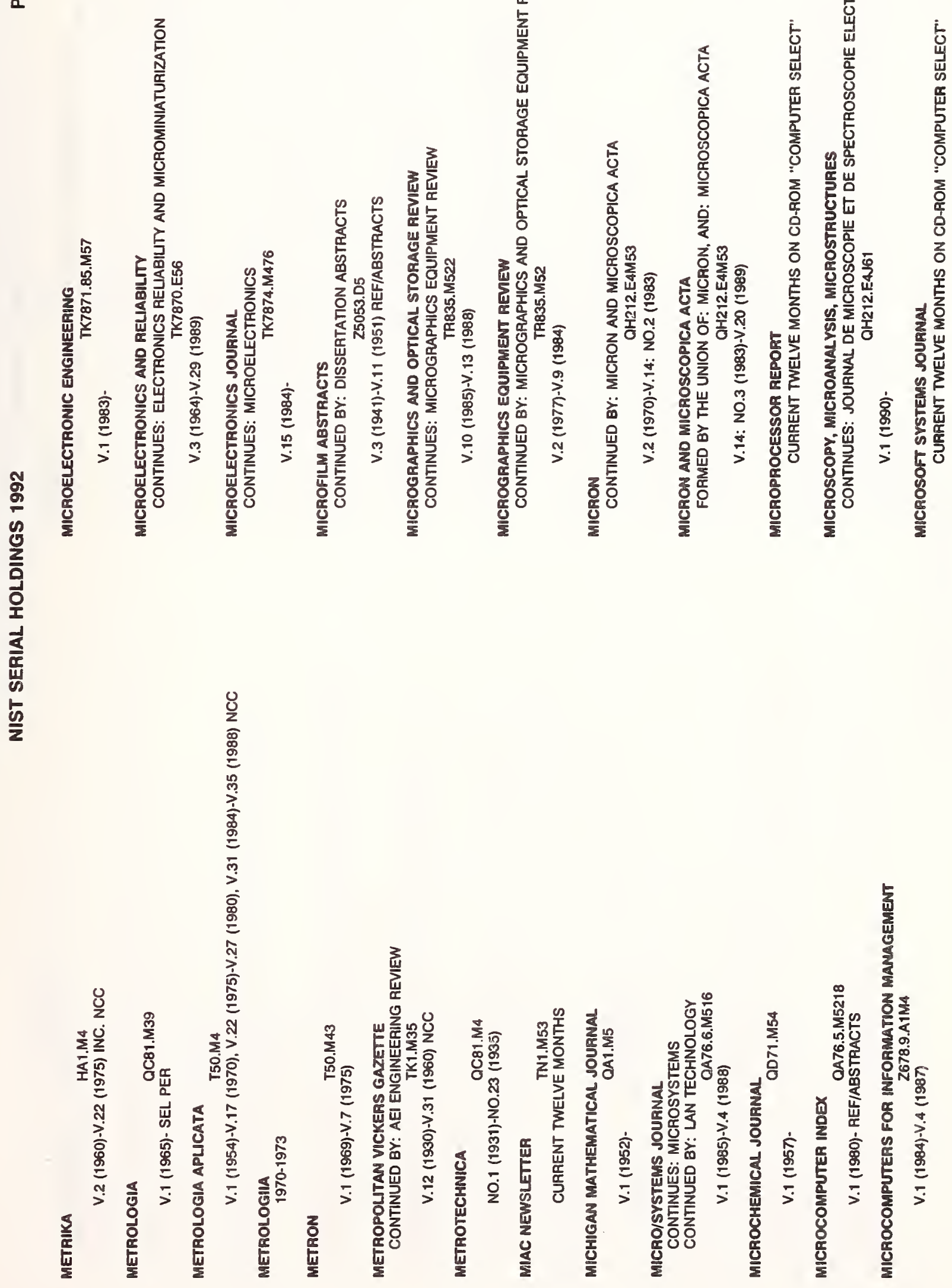

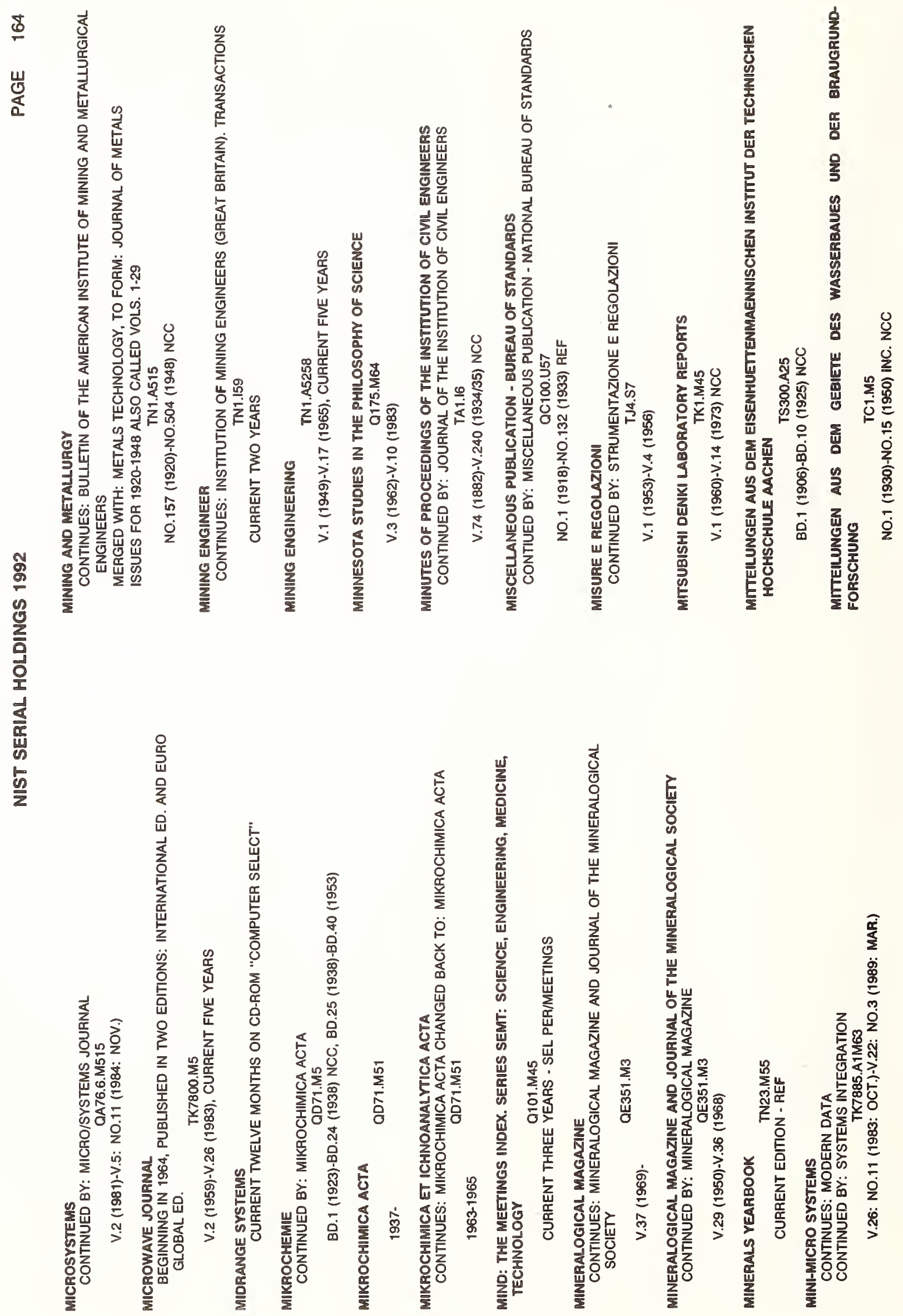
$\stackrel{8}{\circ}$

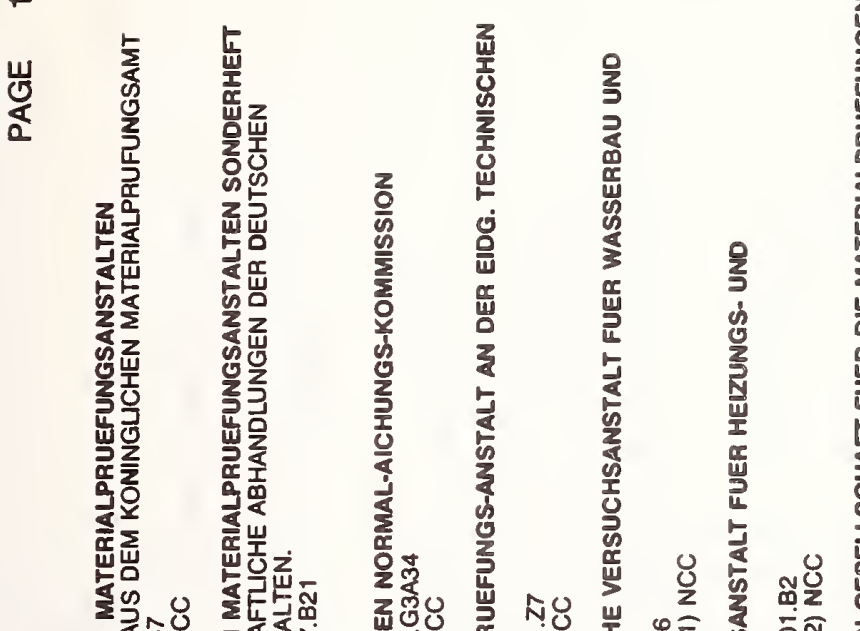

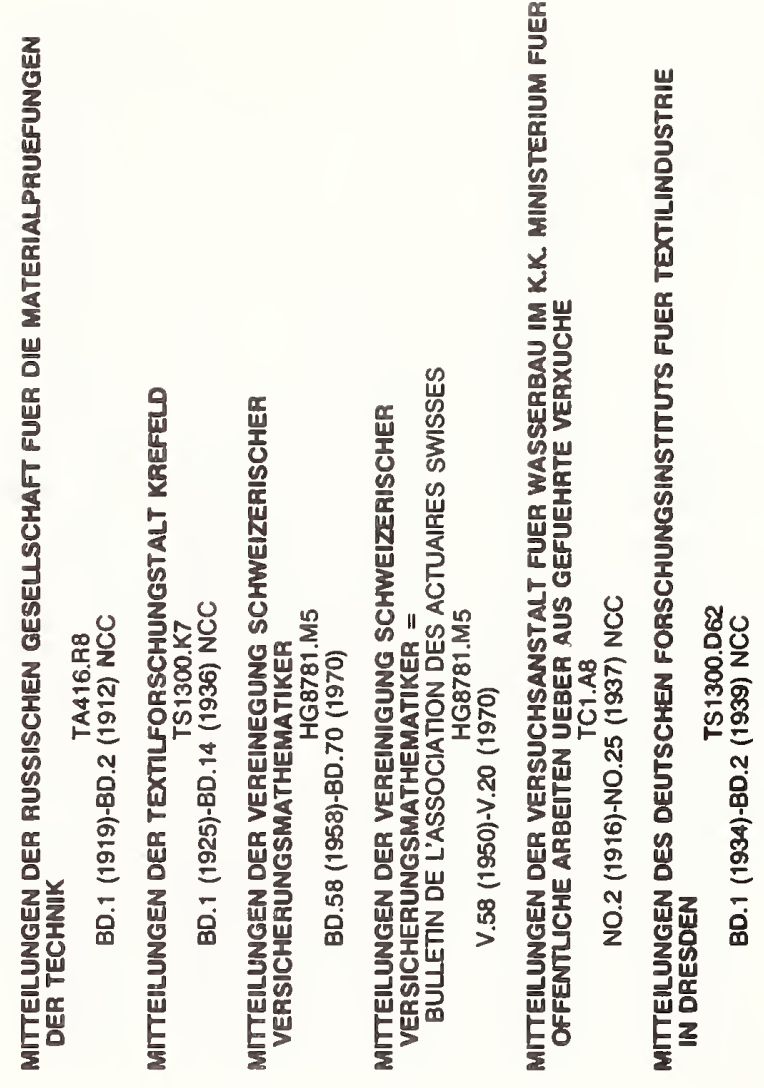

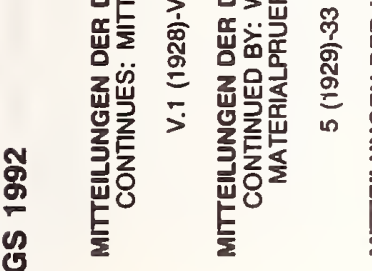

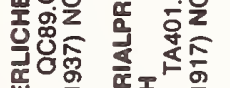

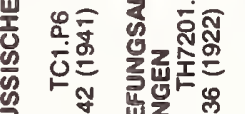

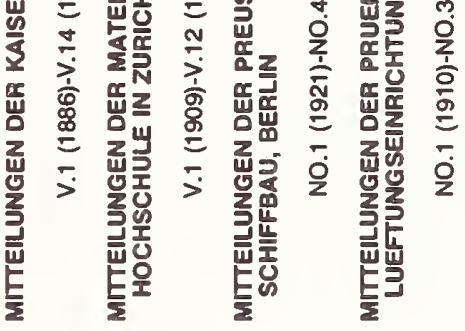

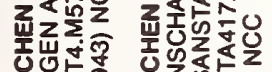

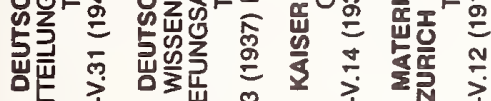

高

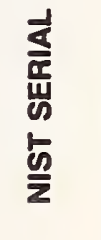

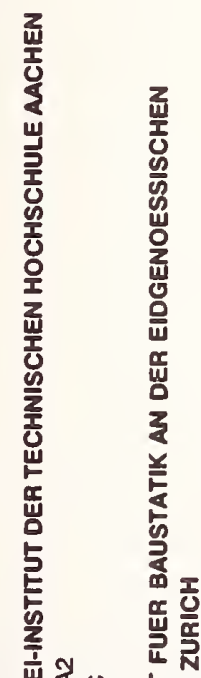

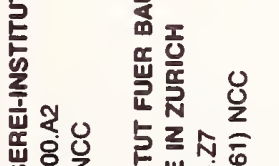

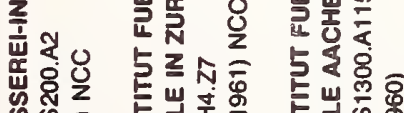

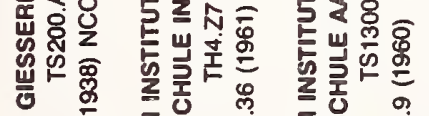

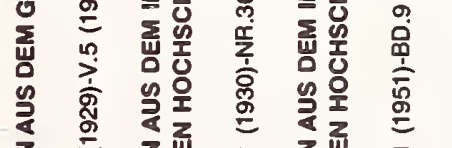

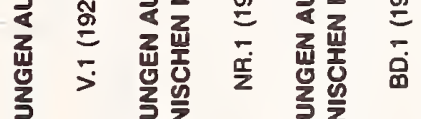

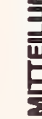

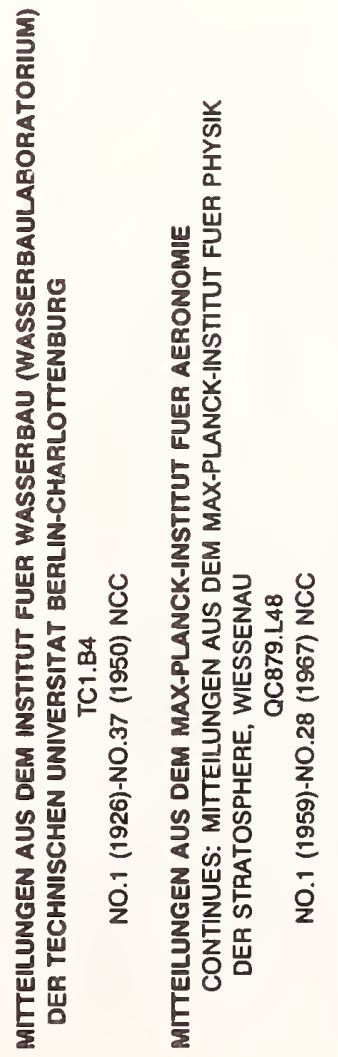

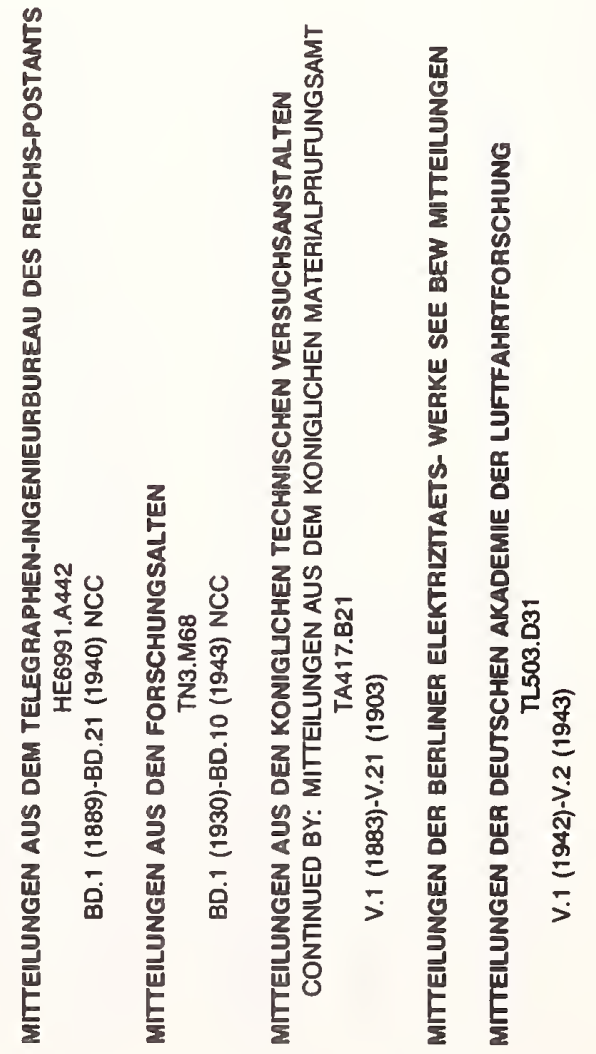


$\frac{8}{\dddot{w}}$

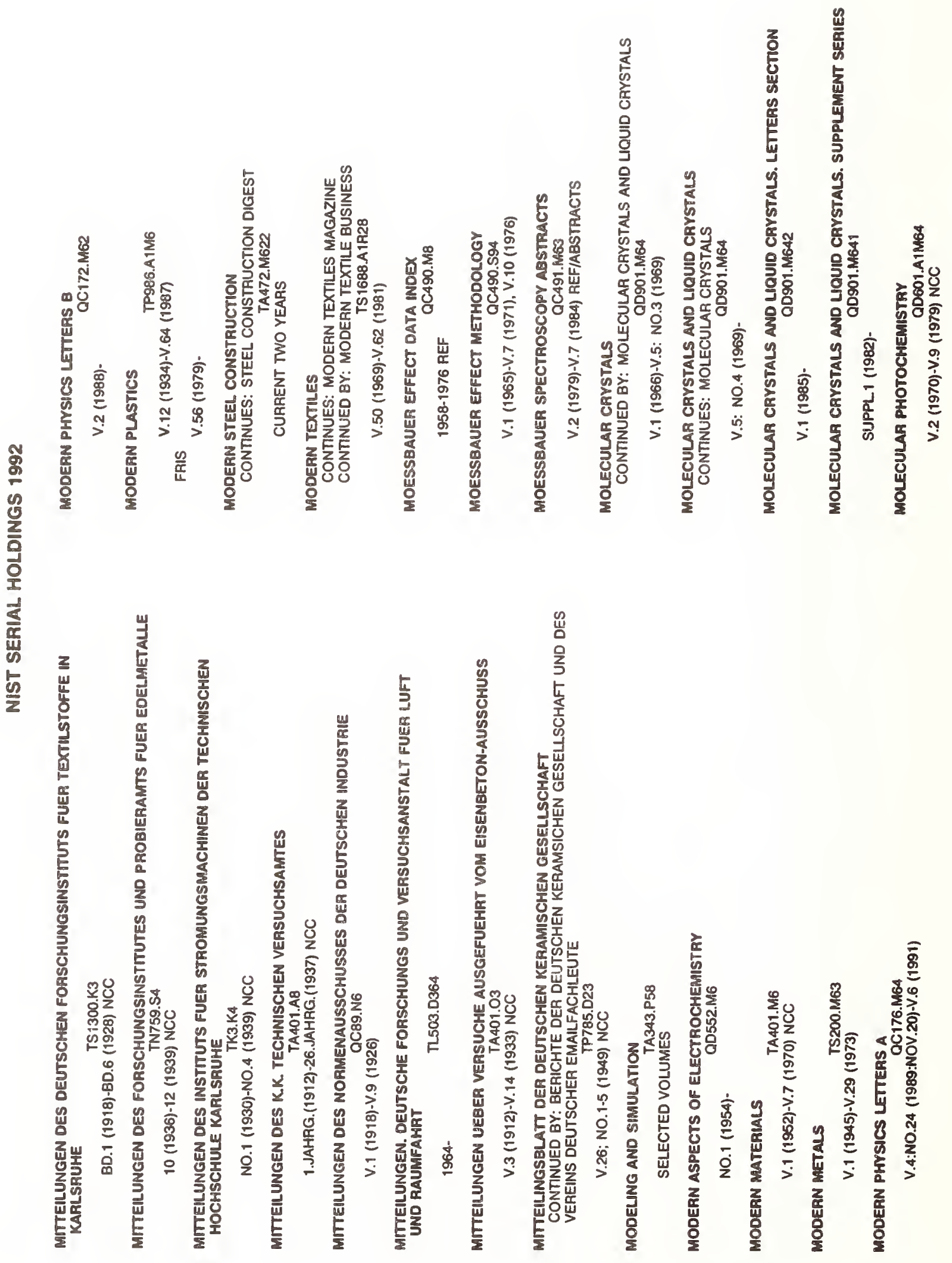



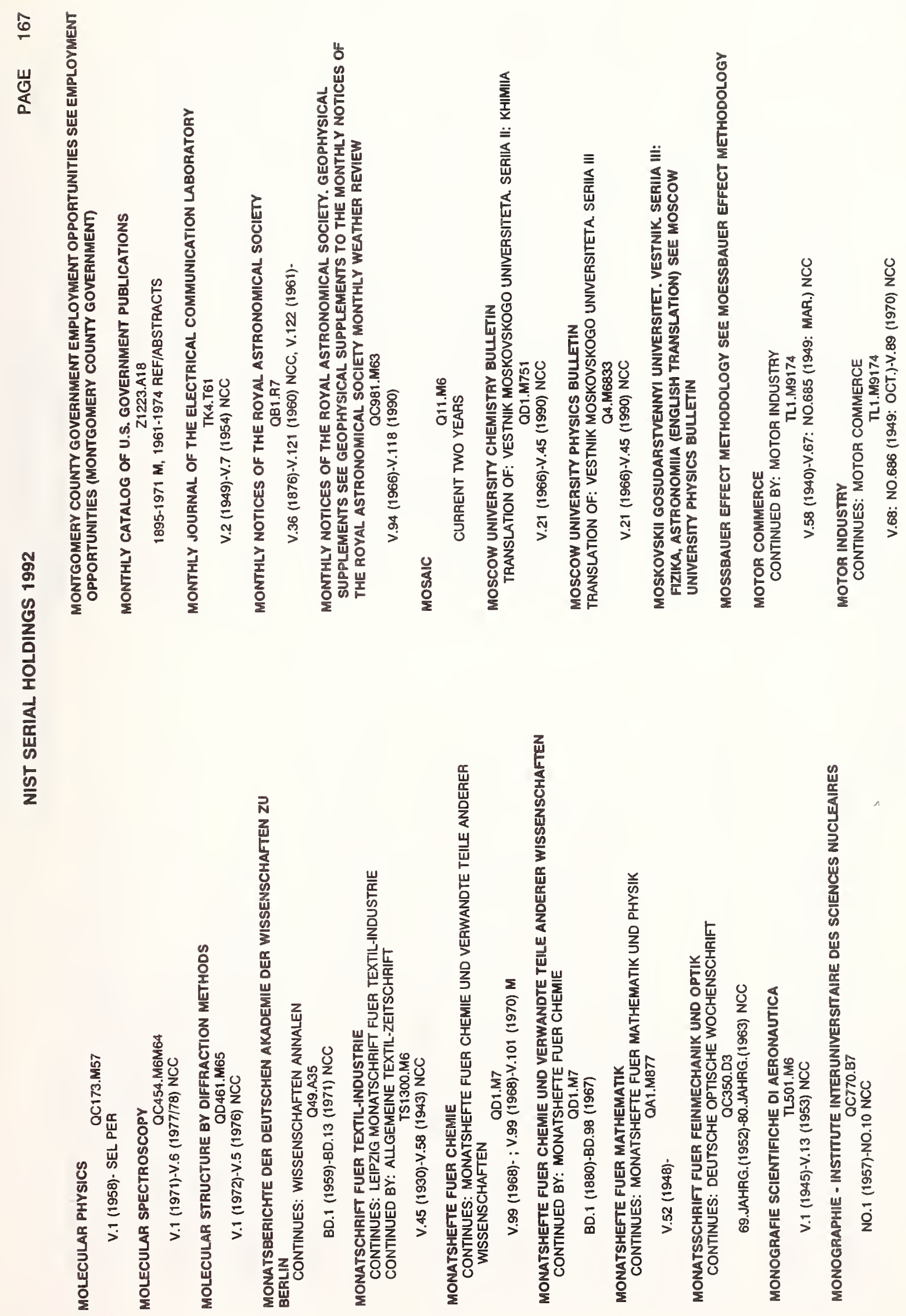
$\mathscr{0}$
$\stackrel{0}{0}$
$\stackrel{0}{0}$
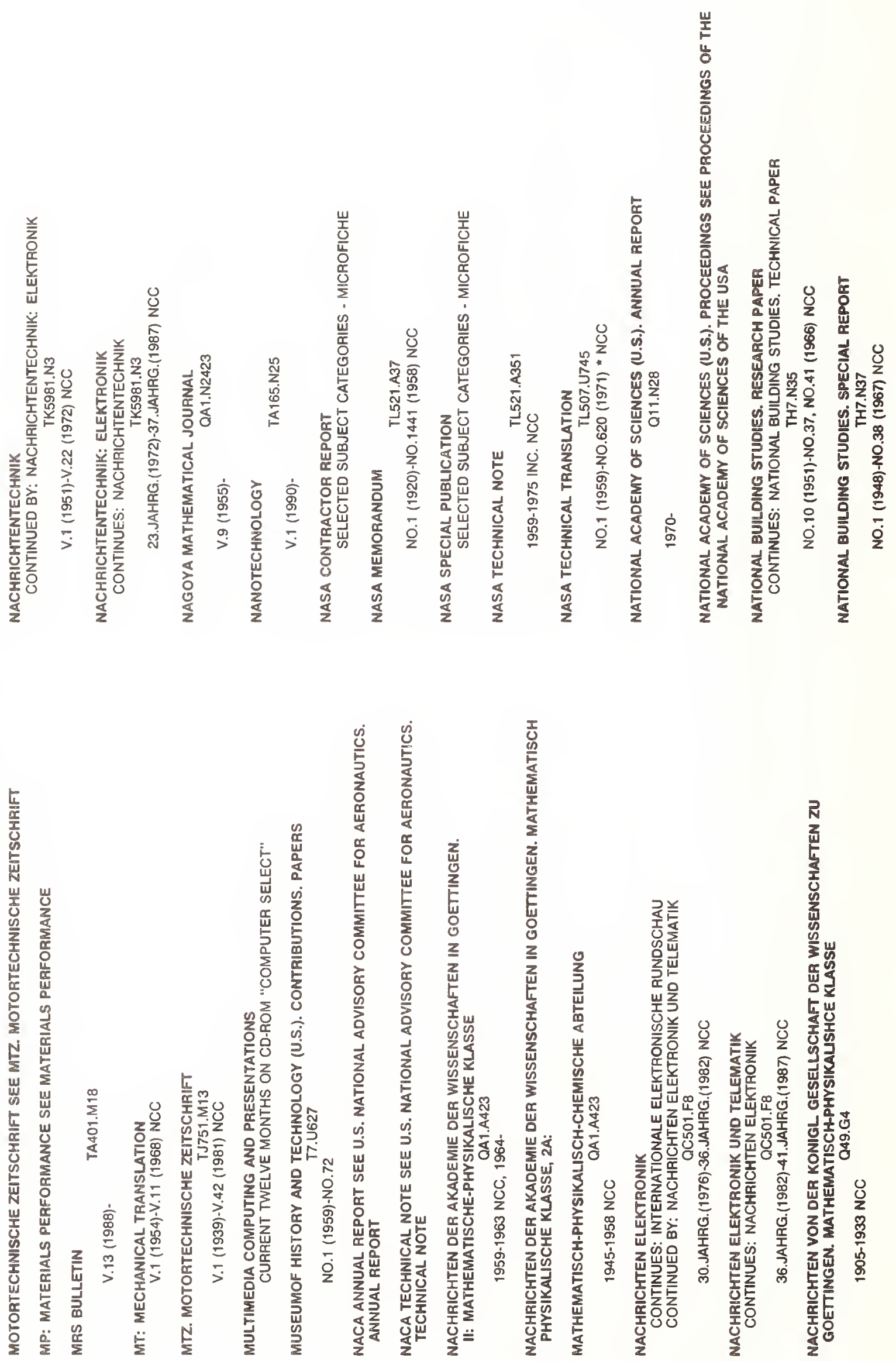

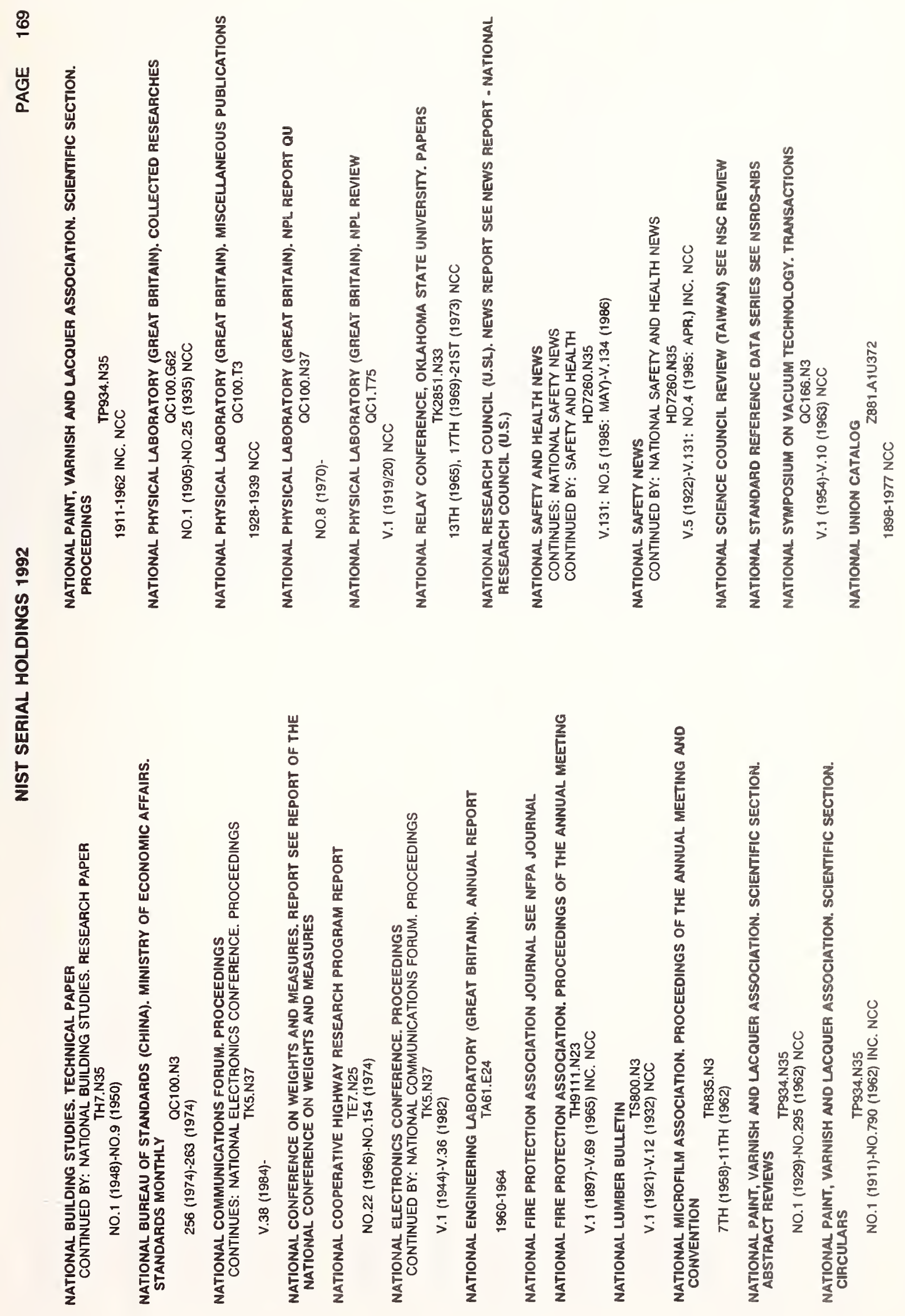
요
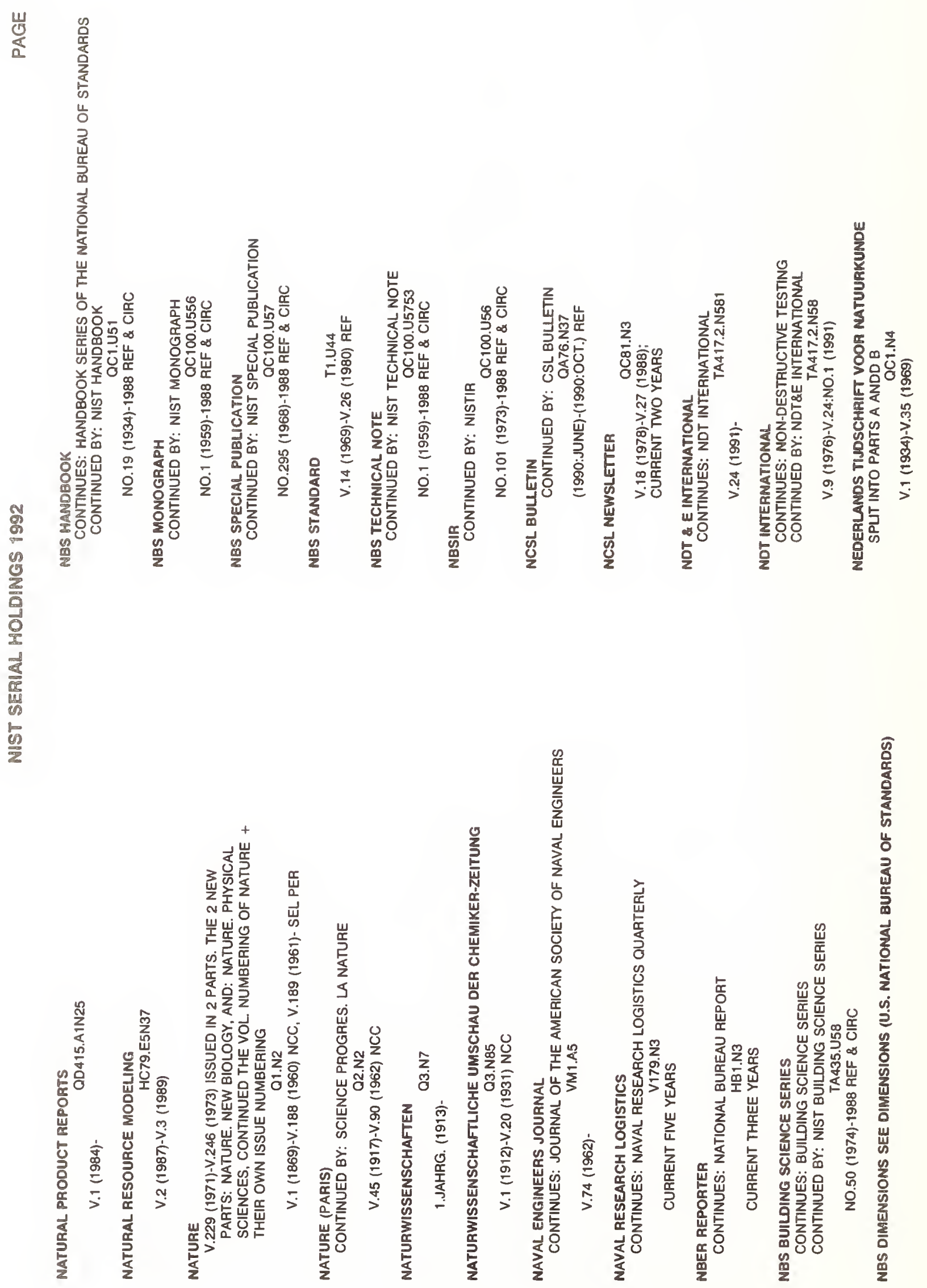

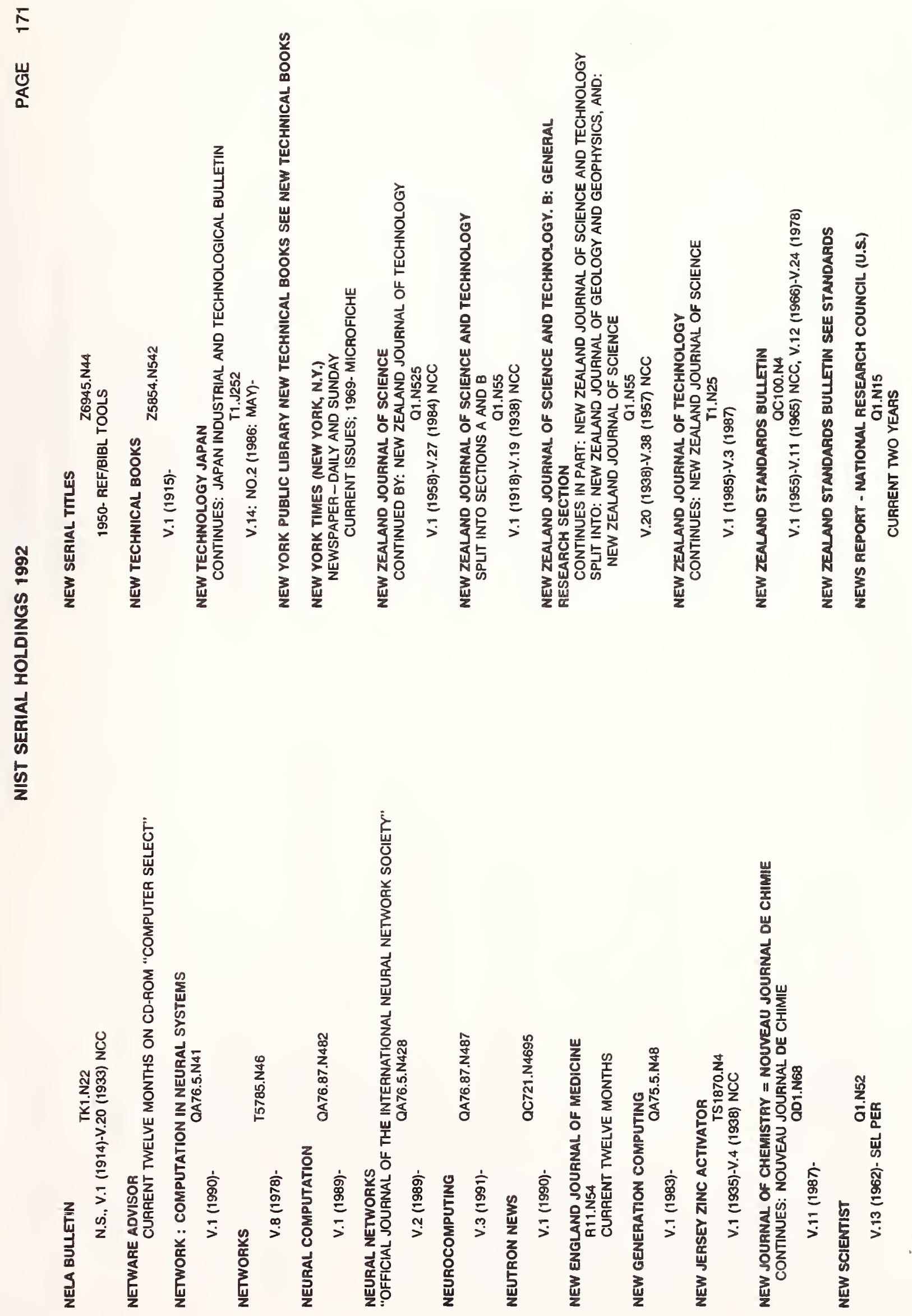


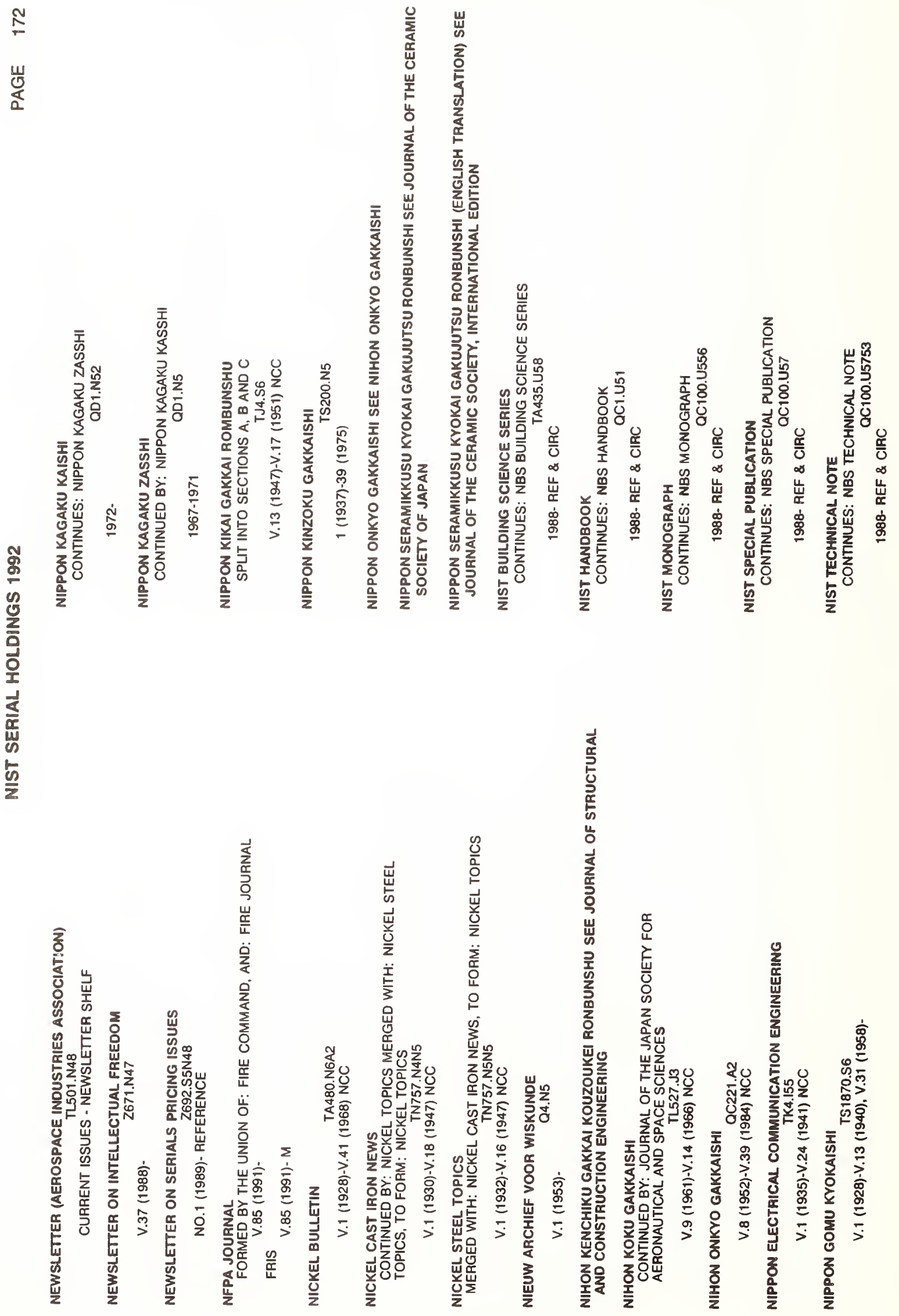




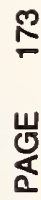

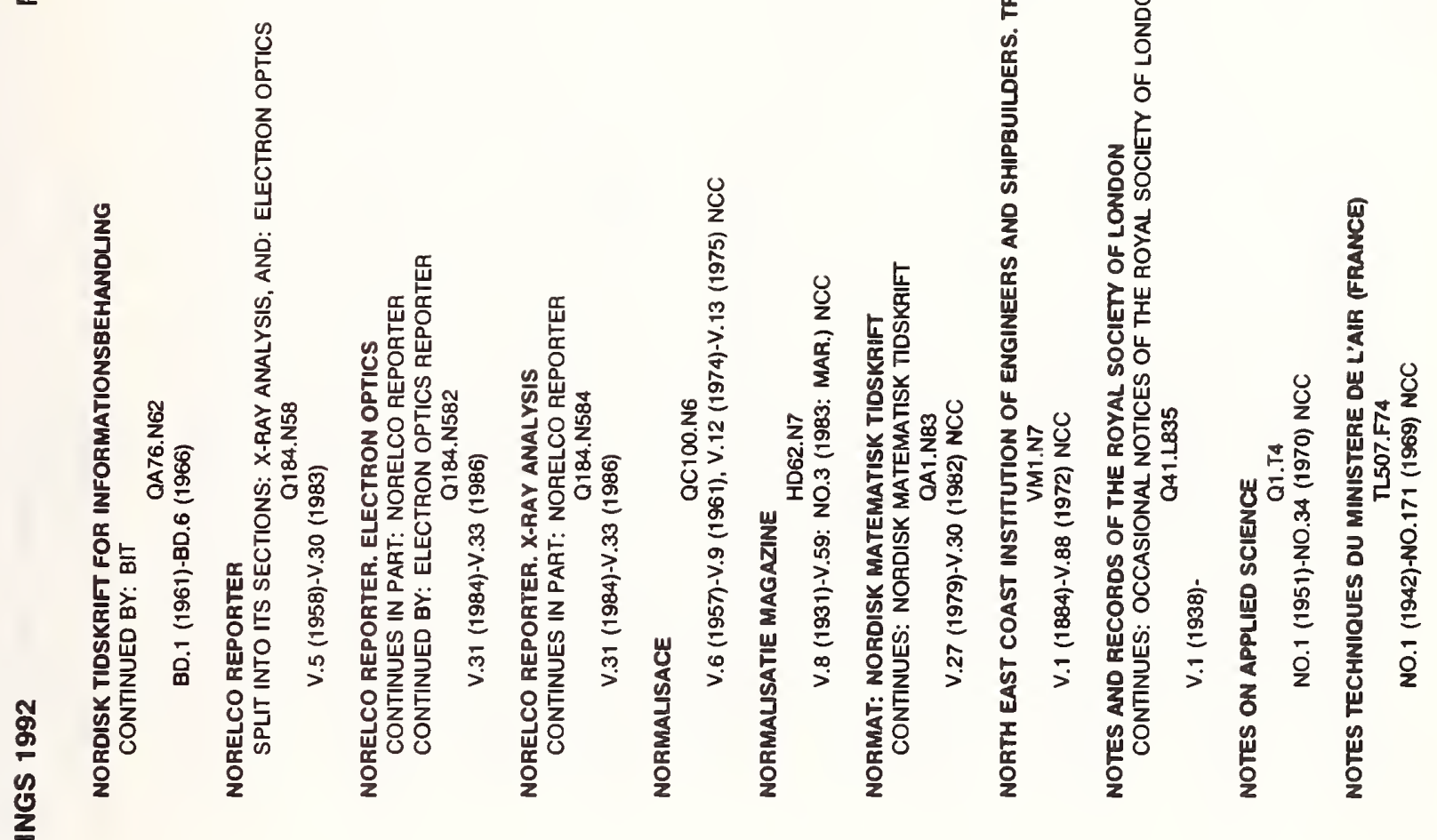




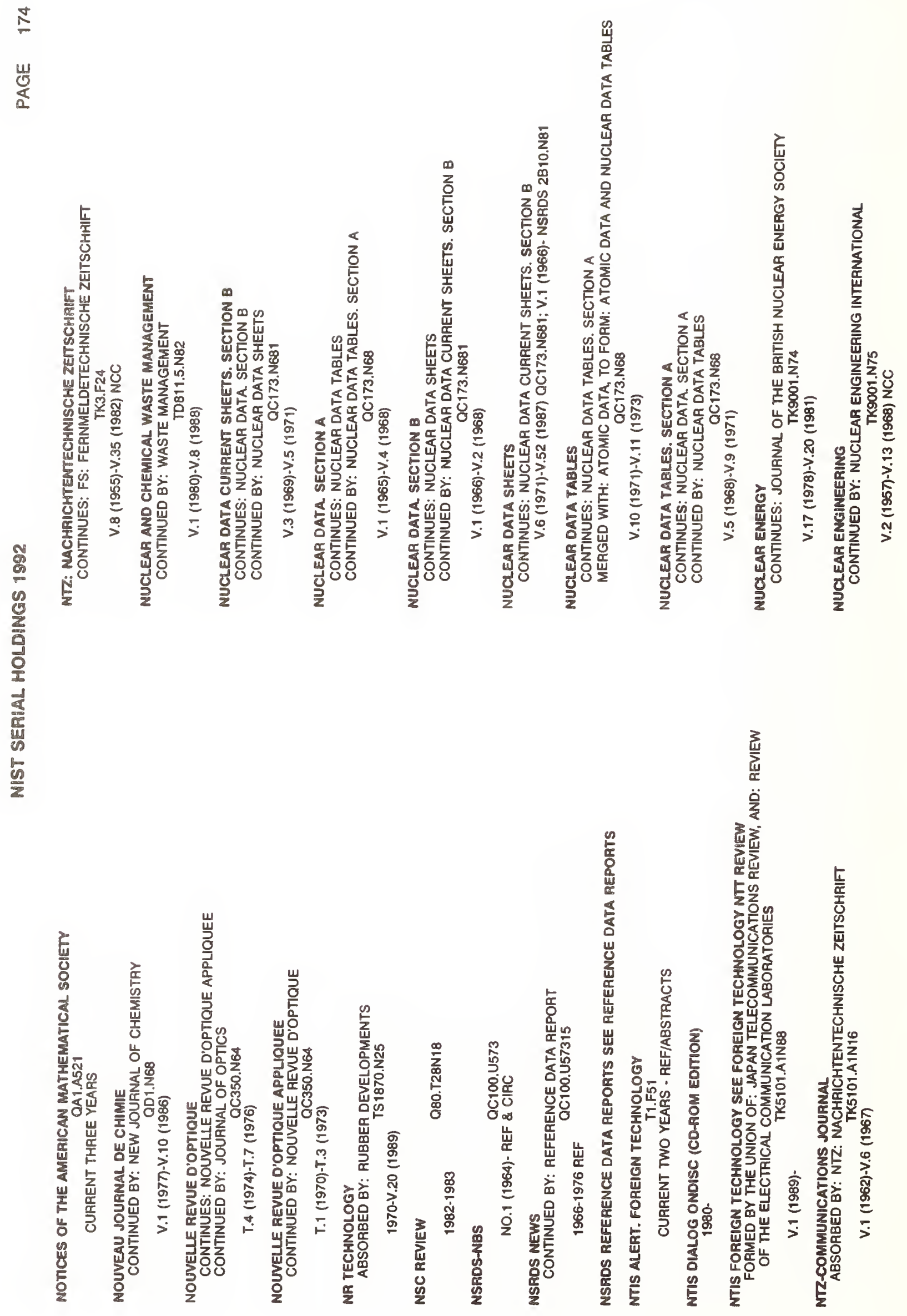


$\stackrel{\wp}{\stackrel{0}{2}}$
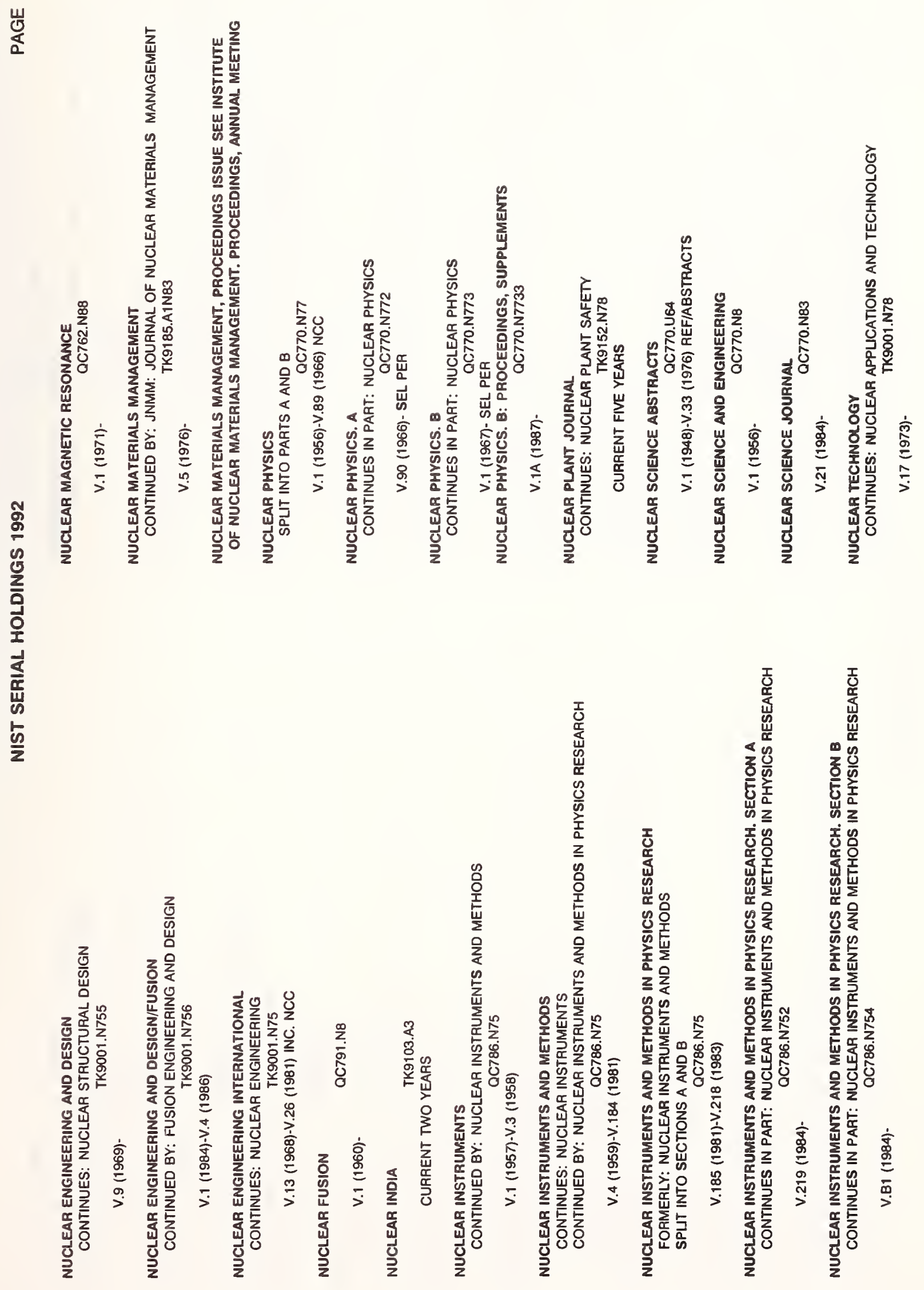


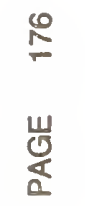

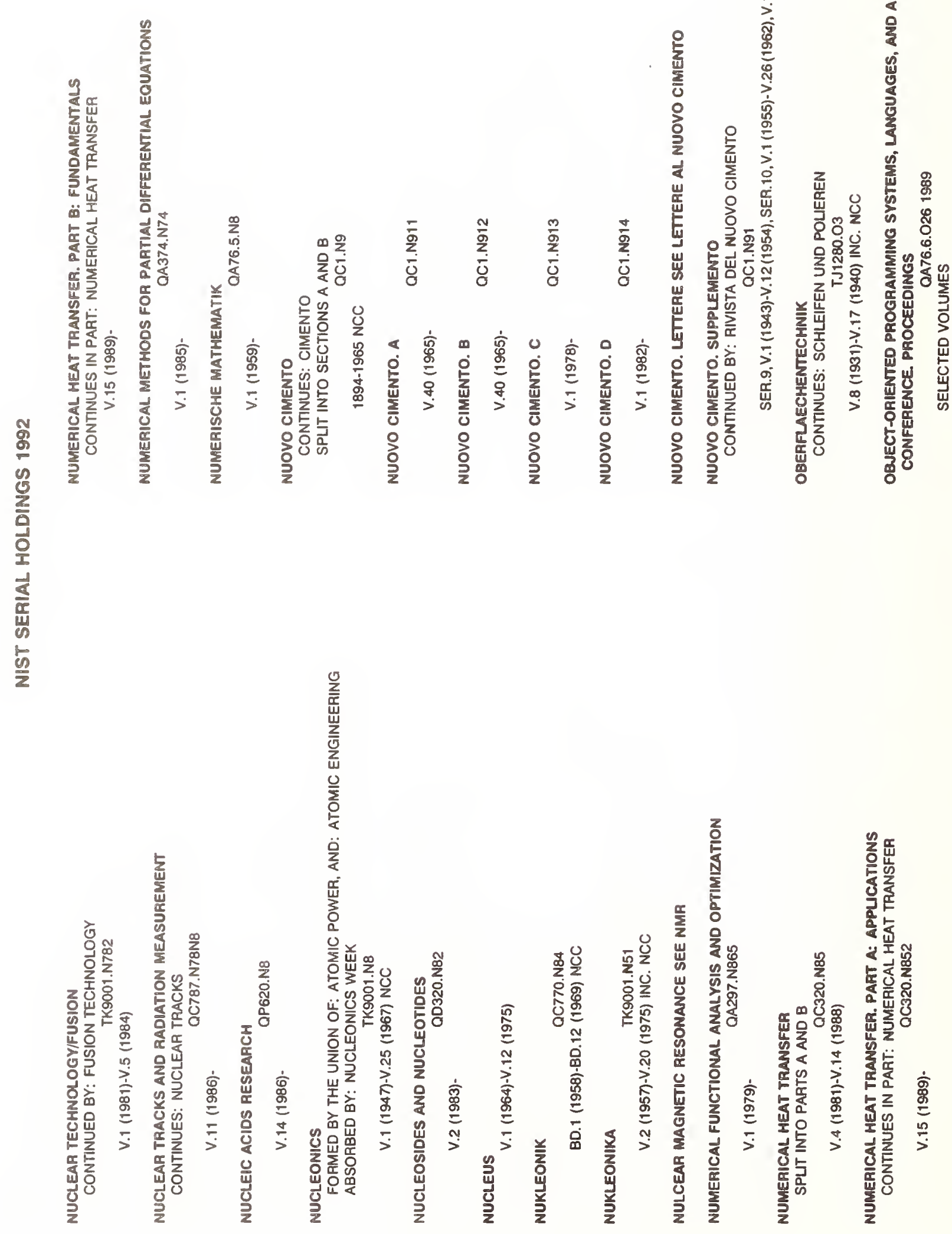



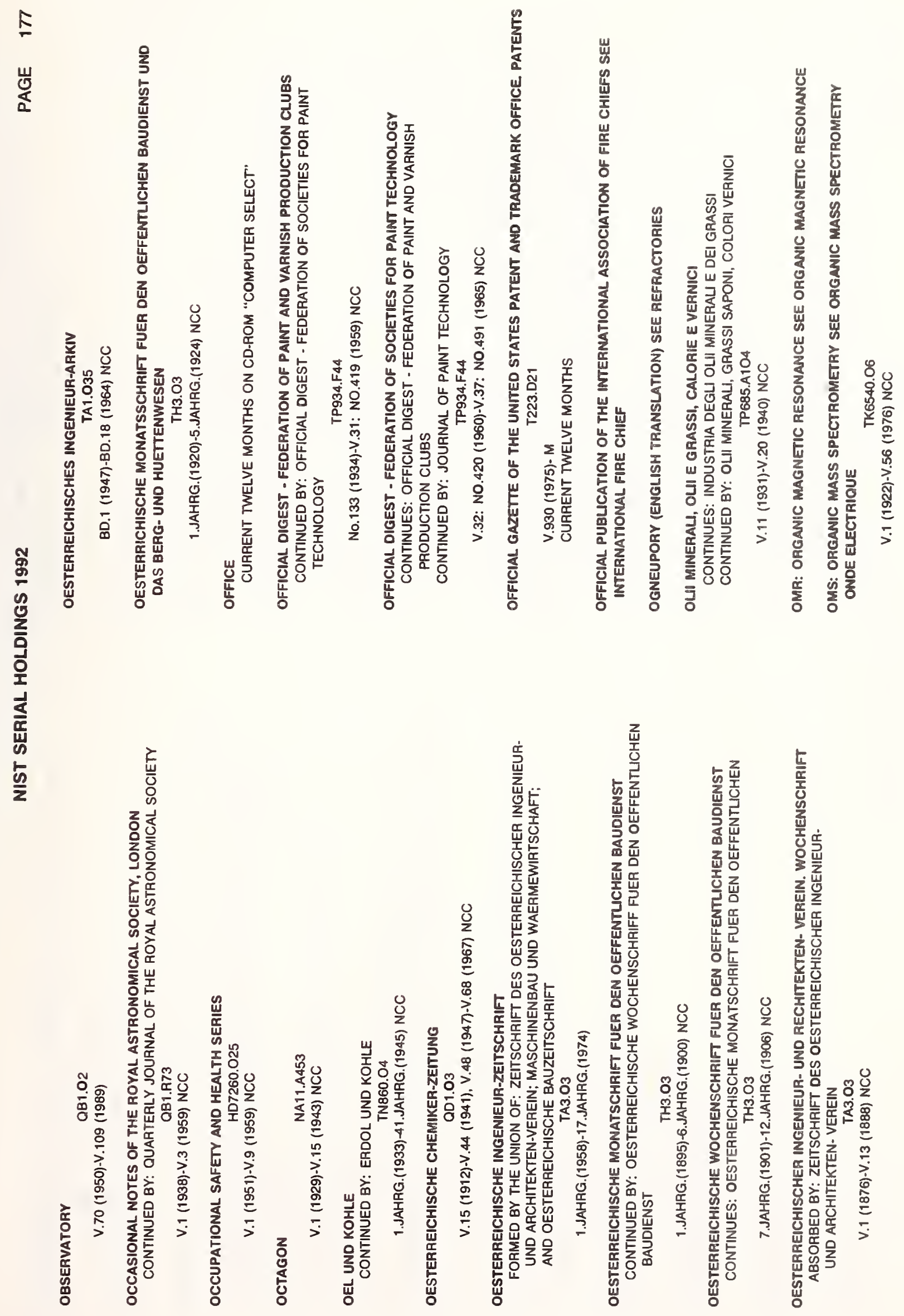


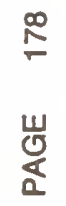
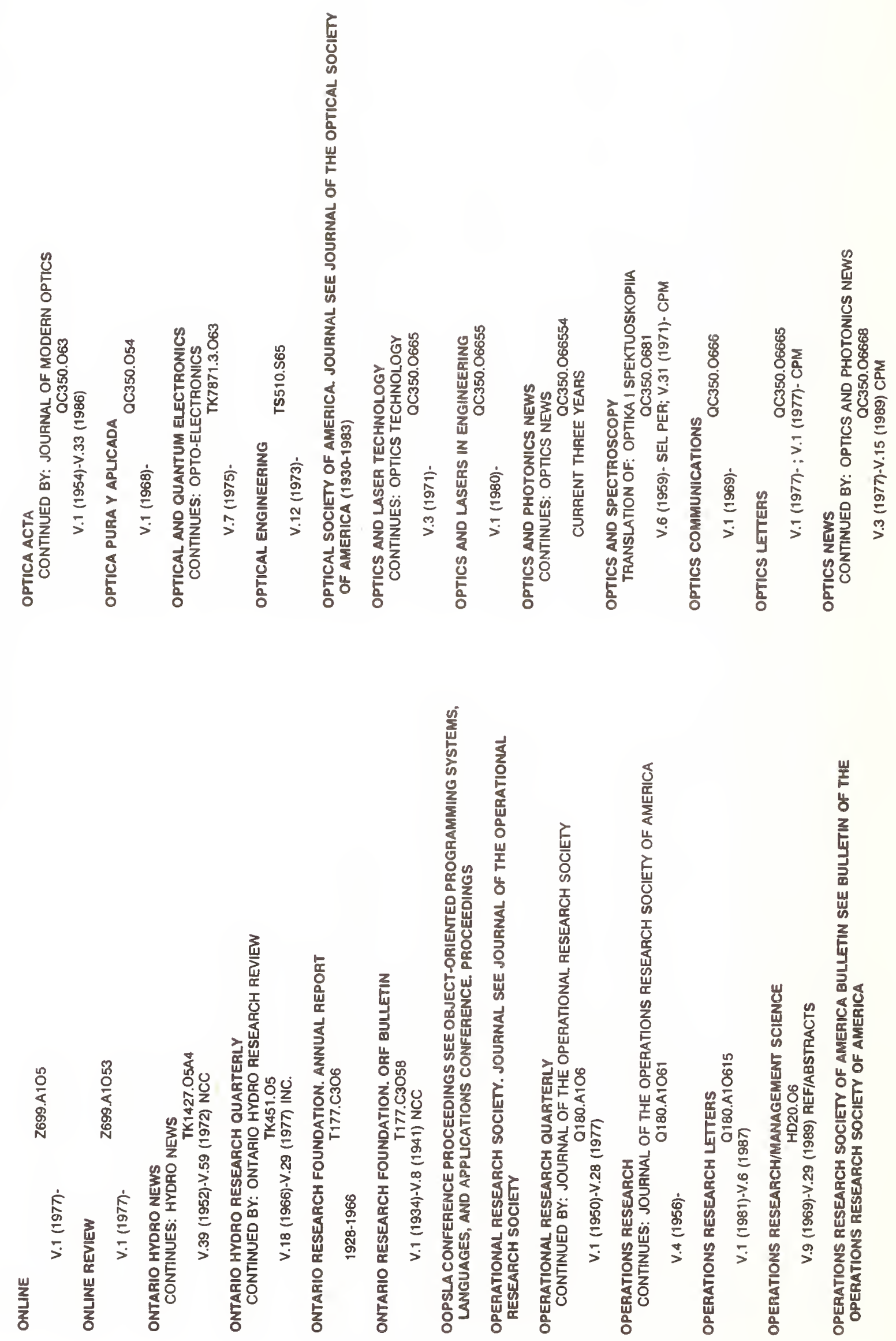


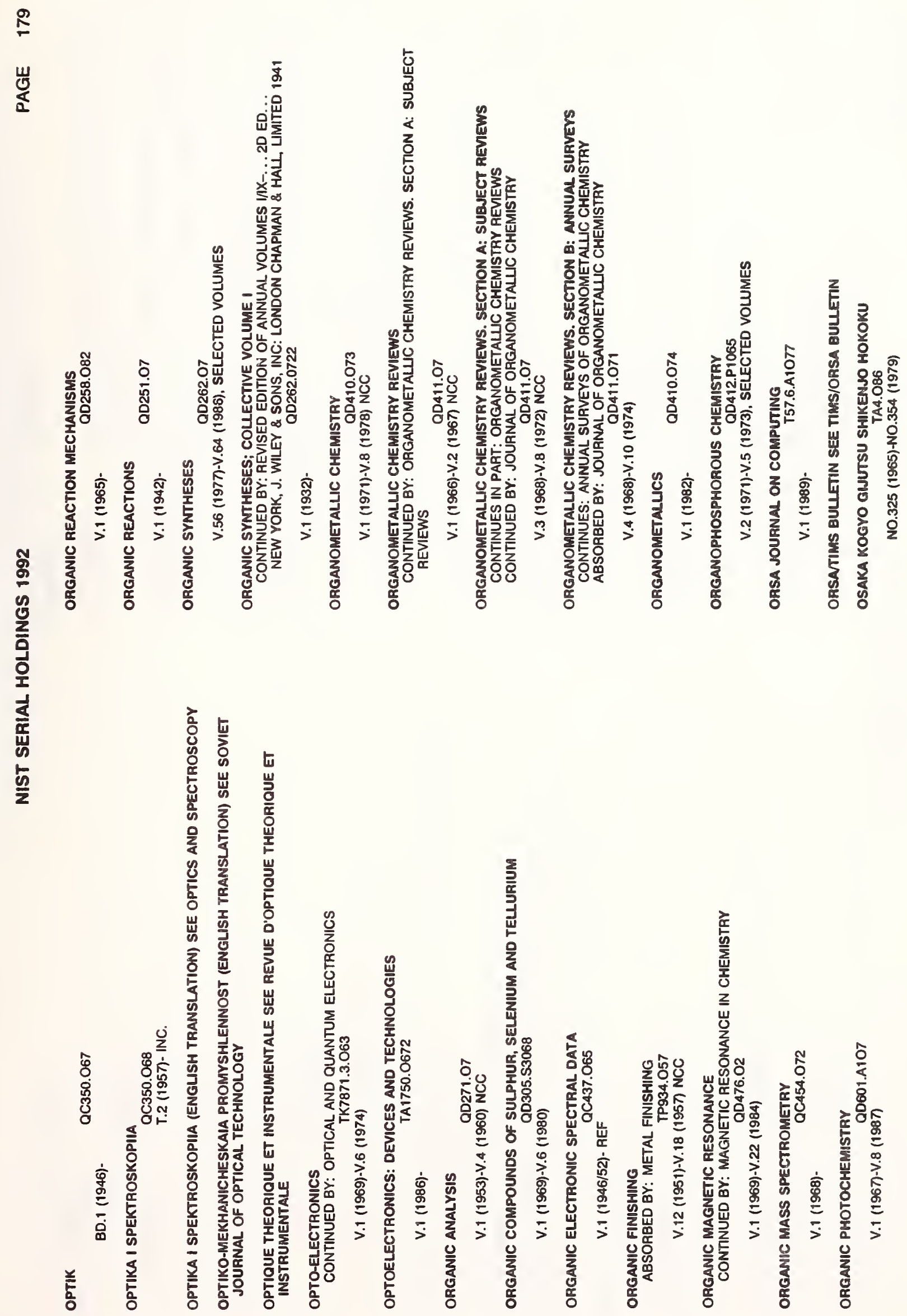




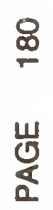
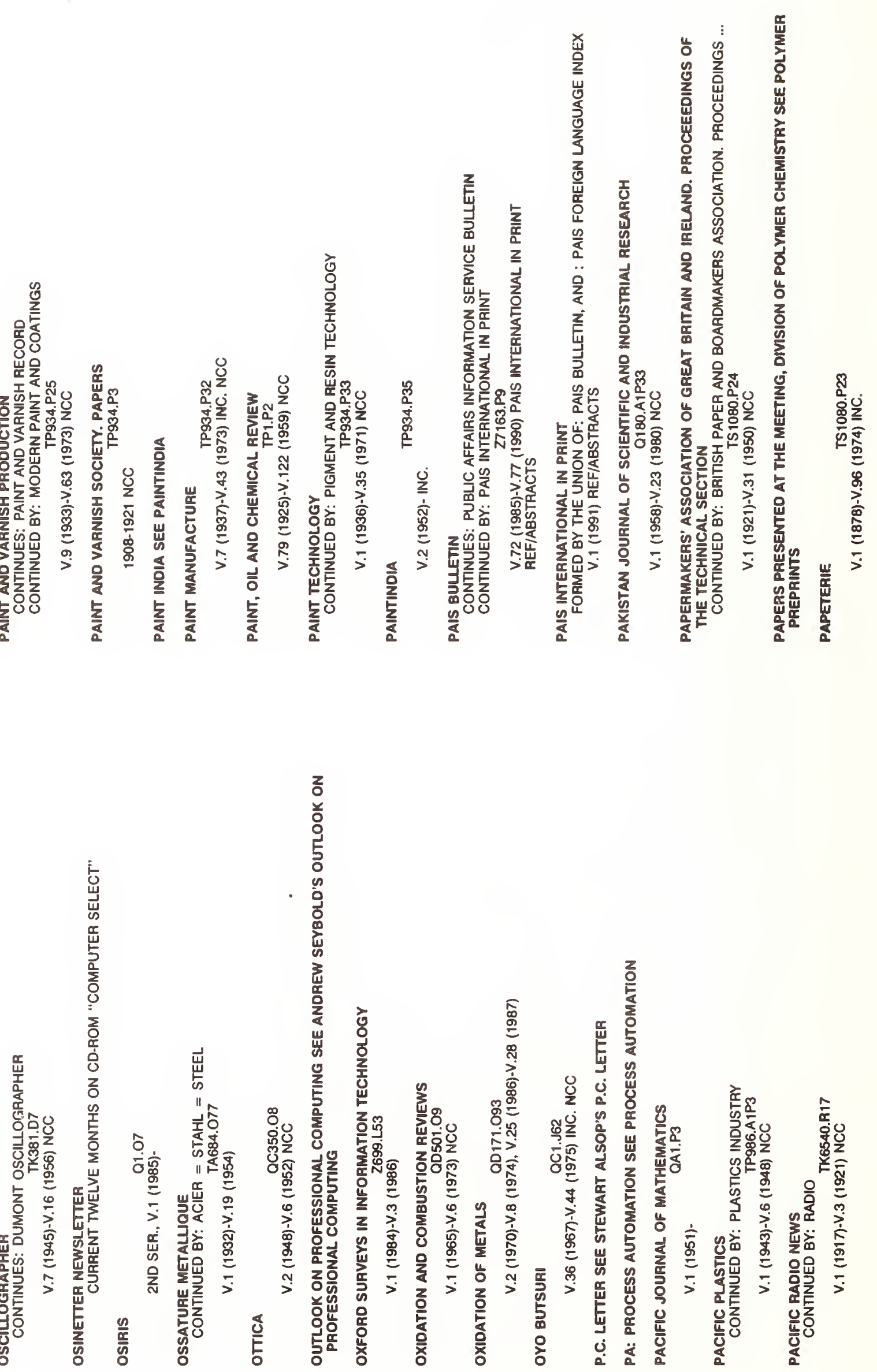
Ф્

嵌

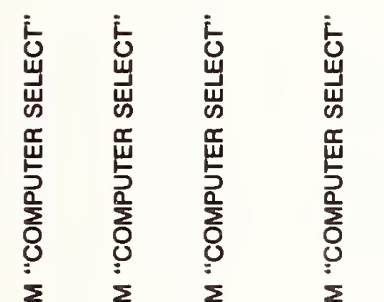

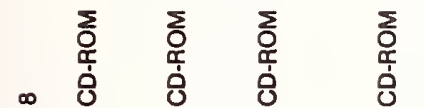

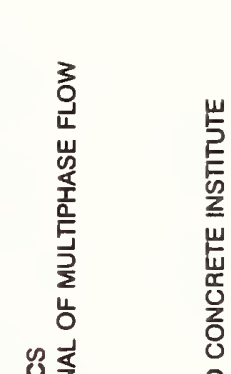

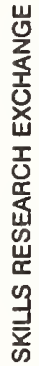

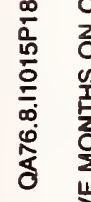

o

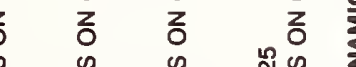

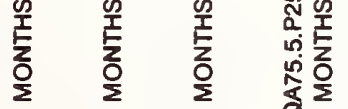

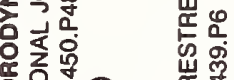

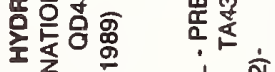

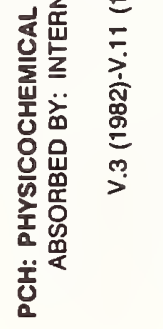

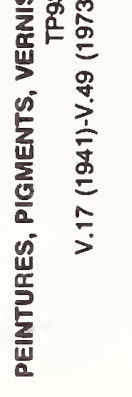

点

意

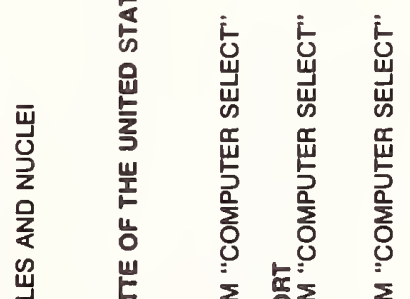

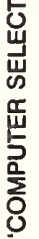

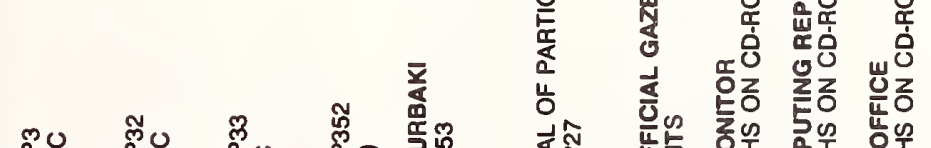

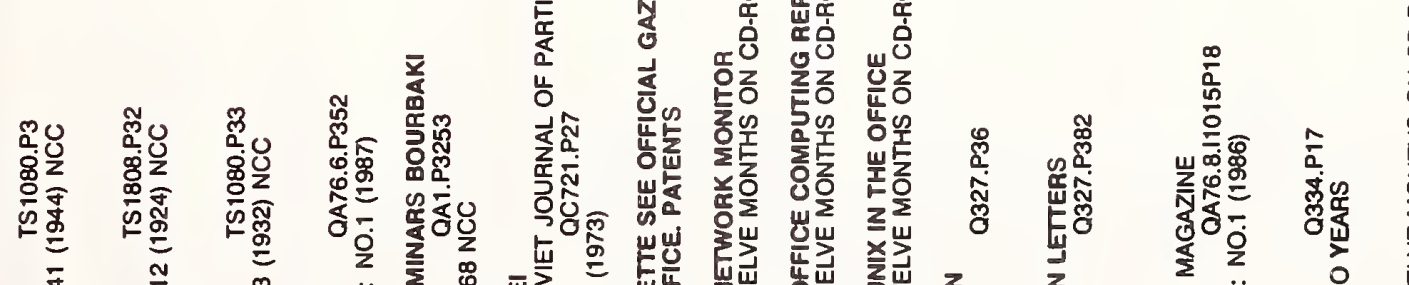

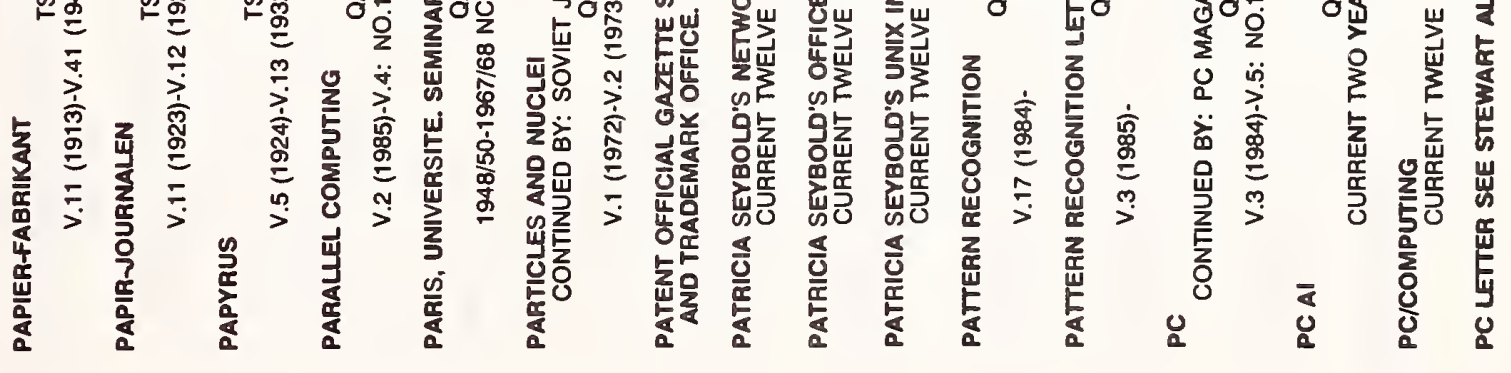


뭉

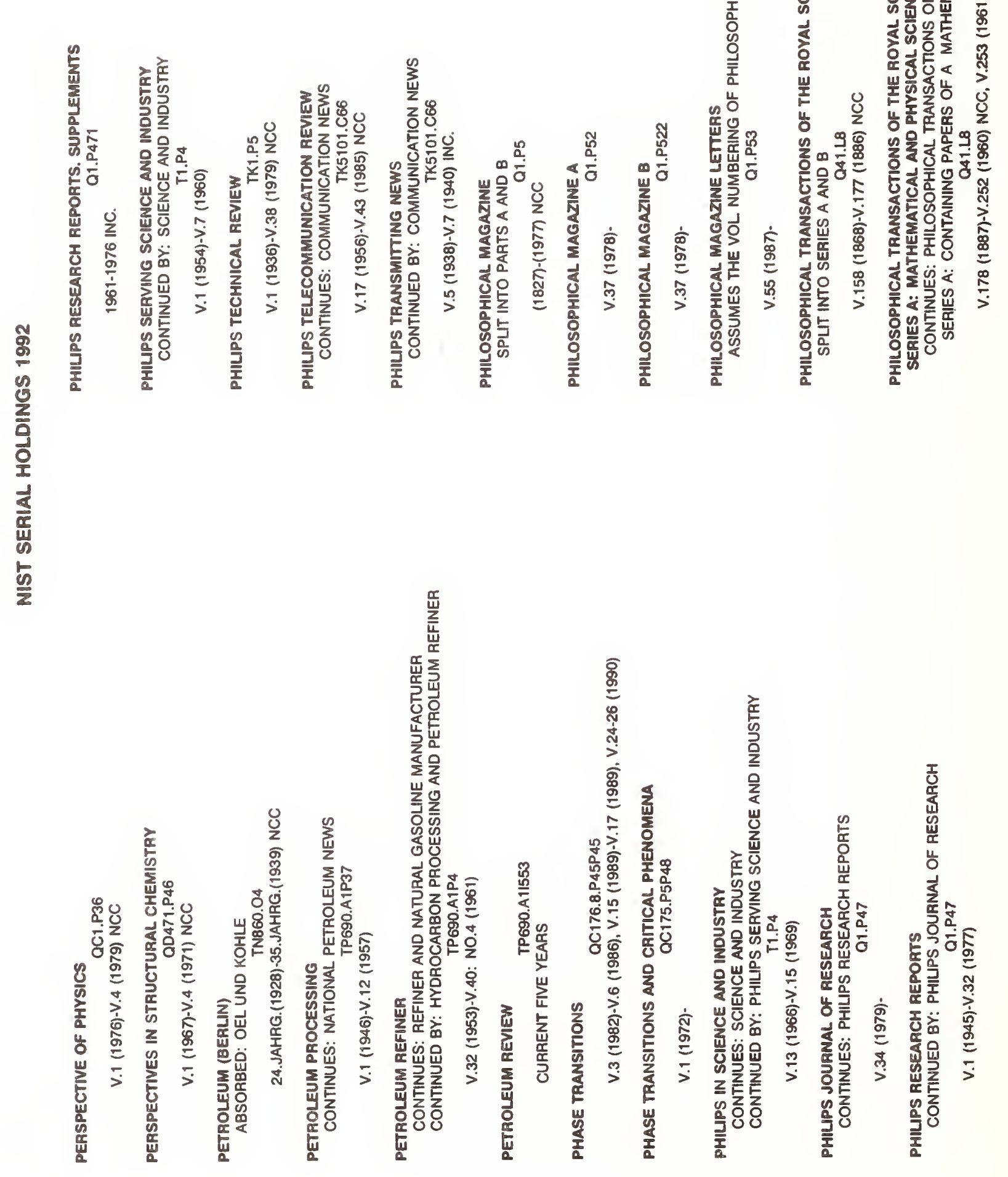




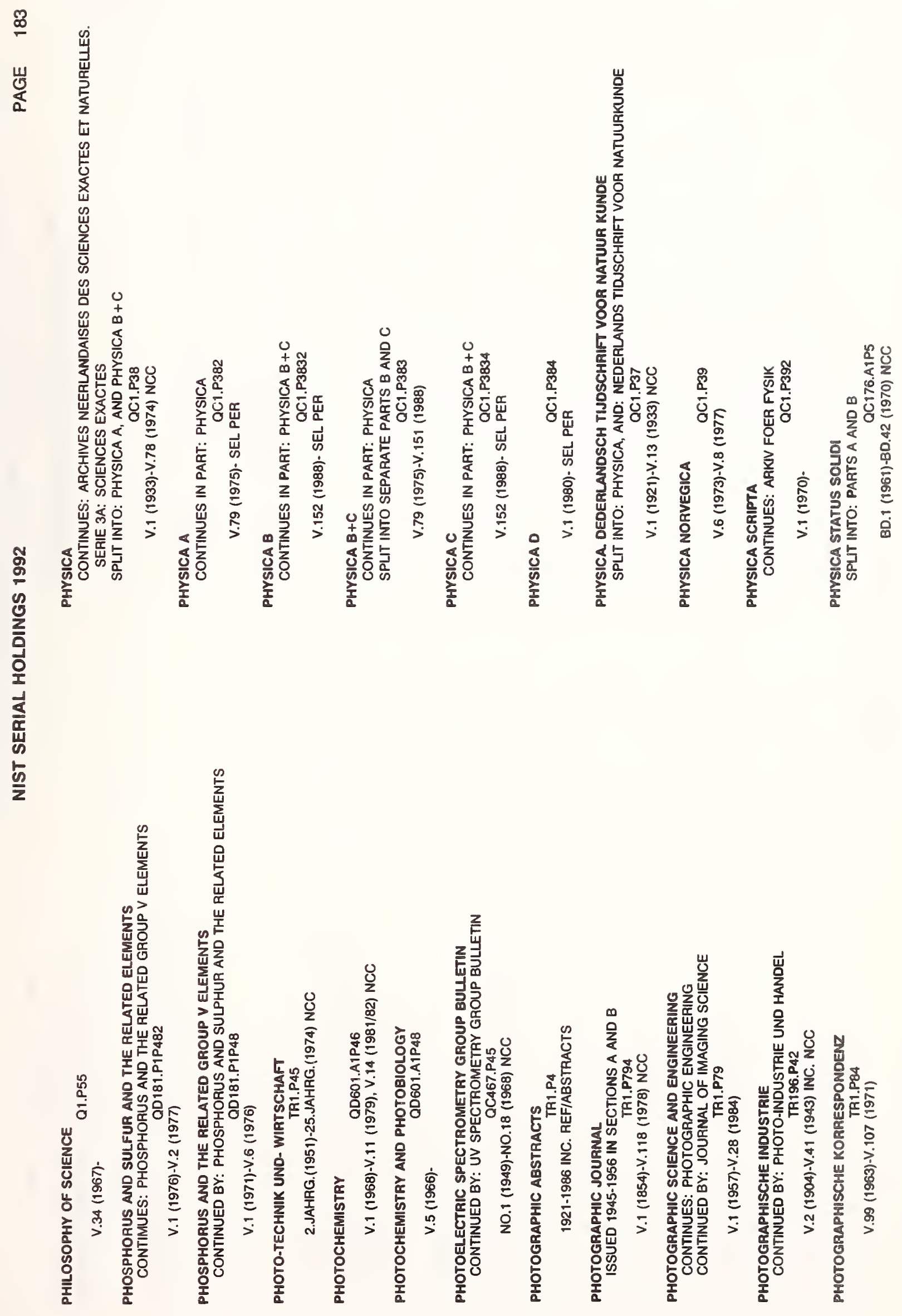




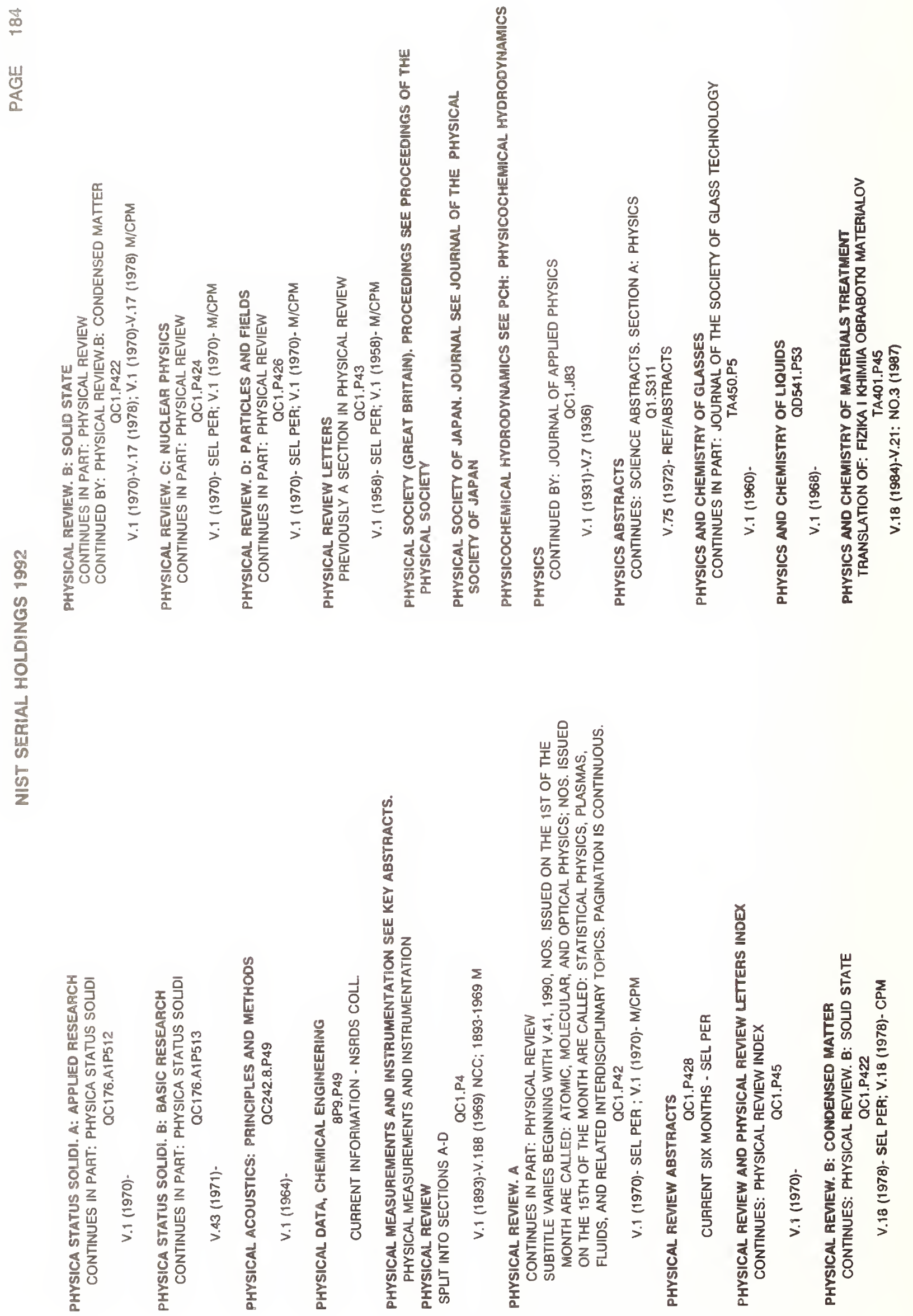




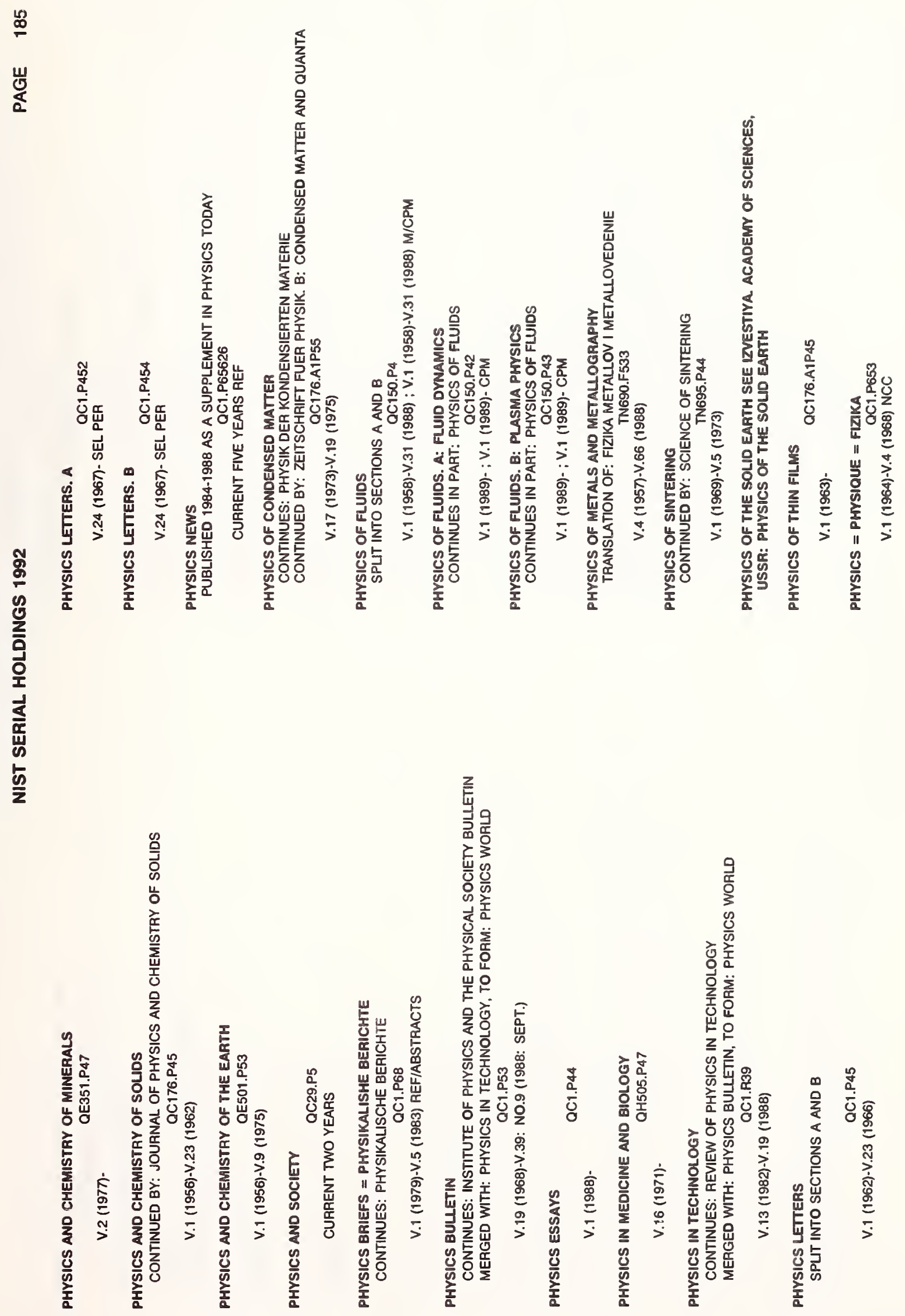




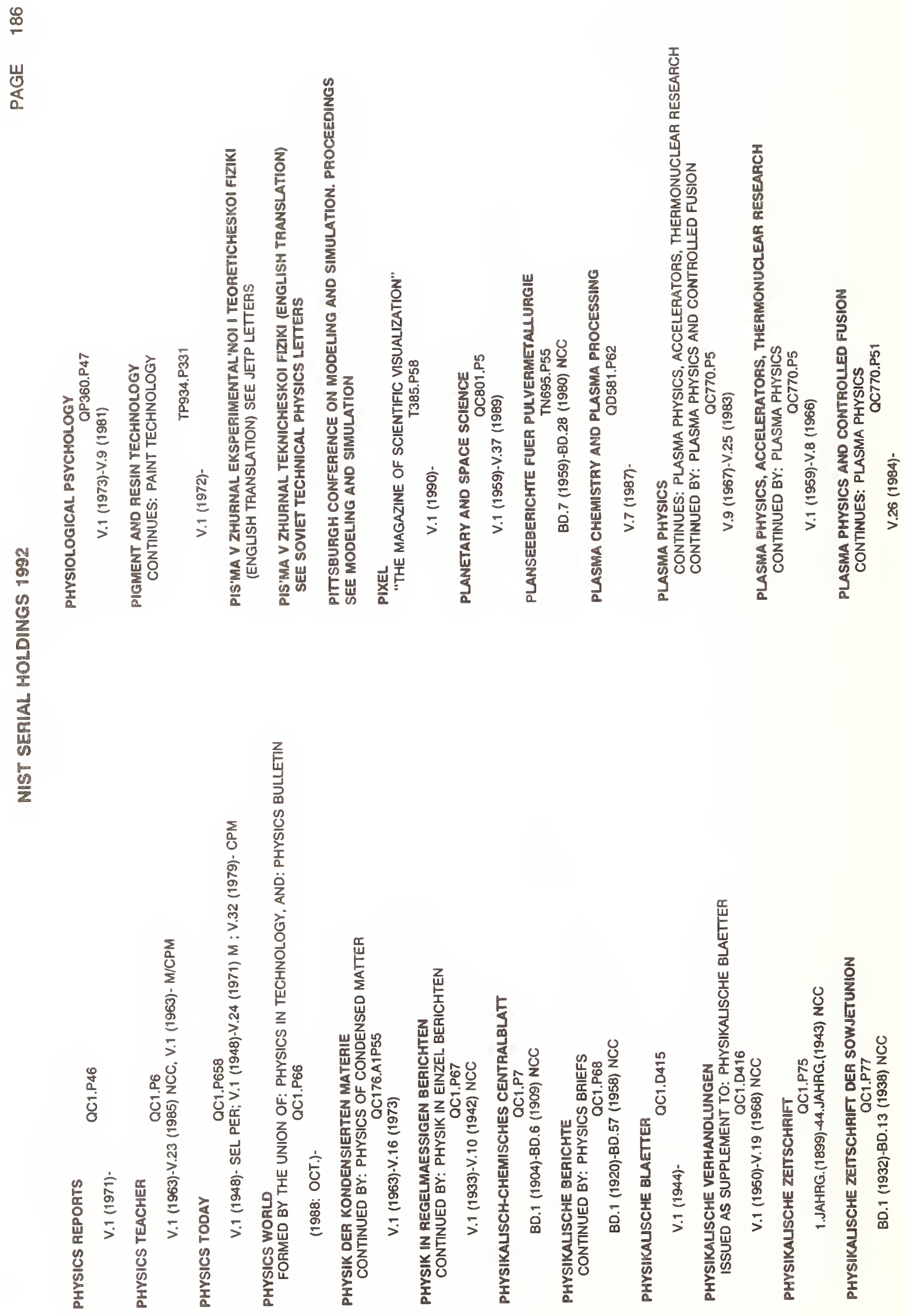




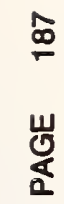

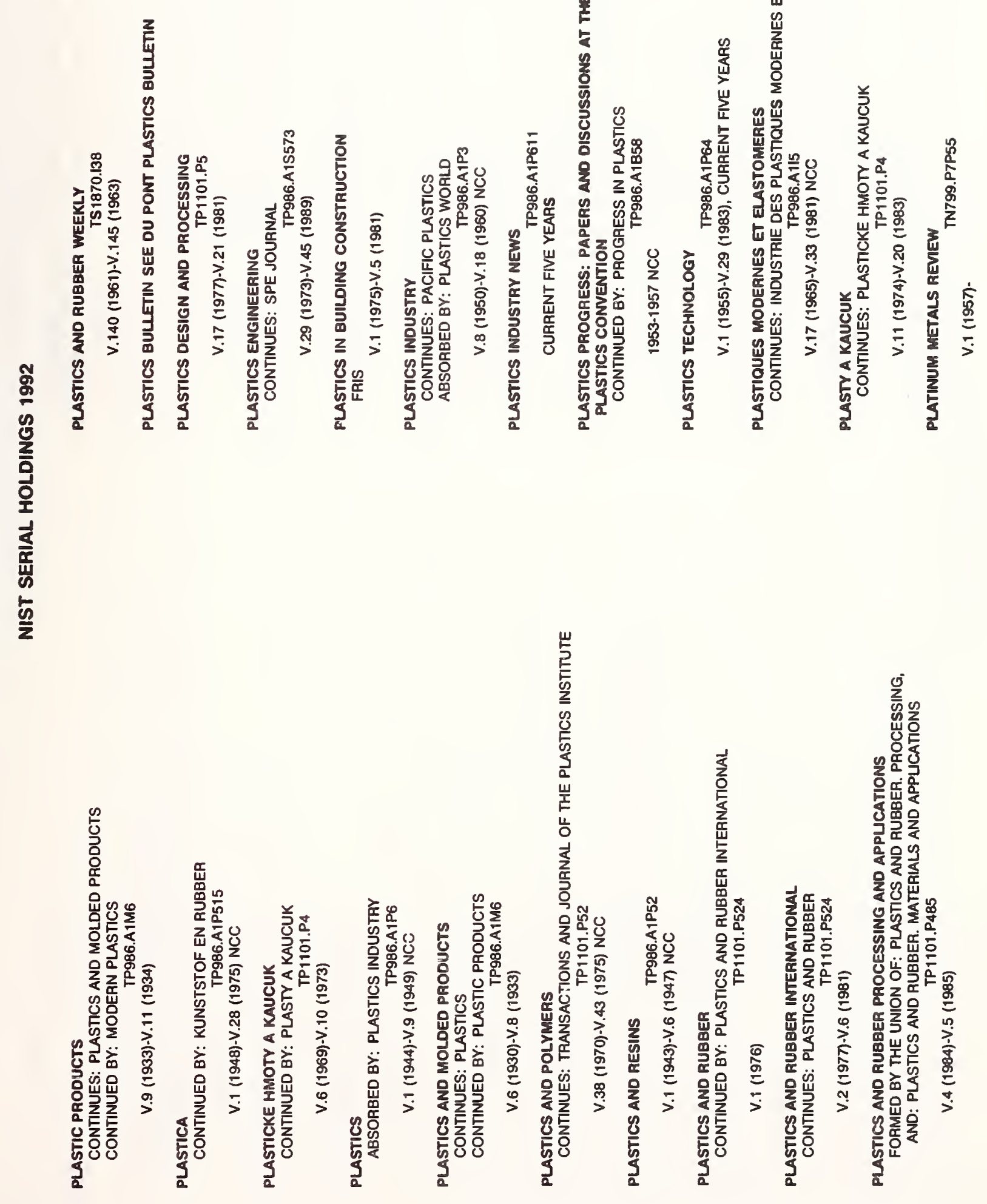


崖

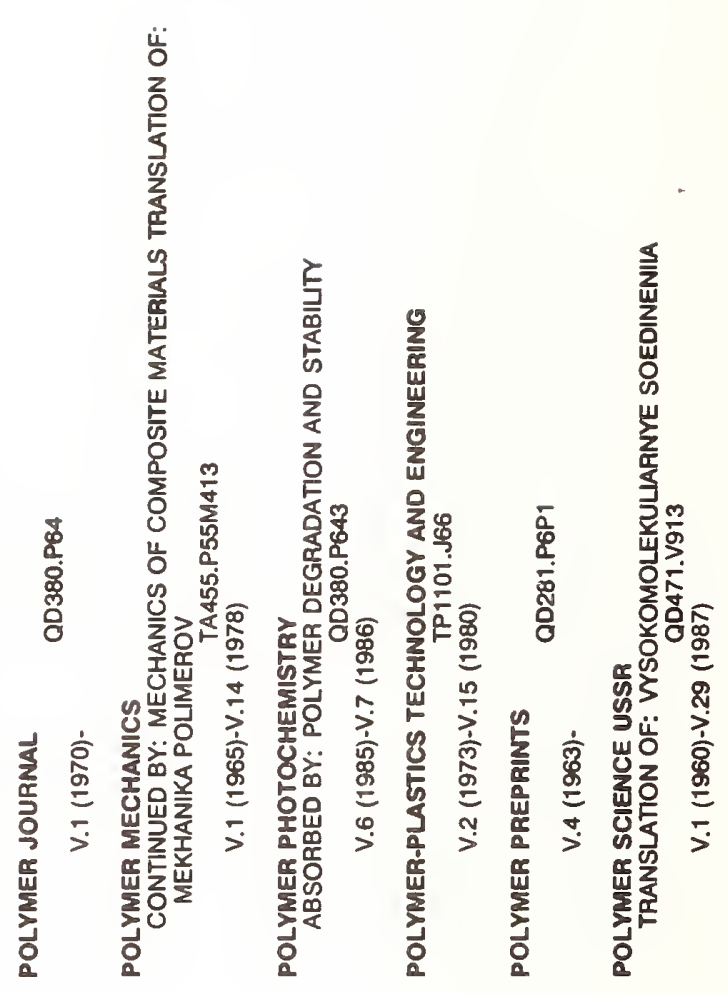

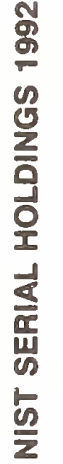

焉

蛋

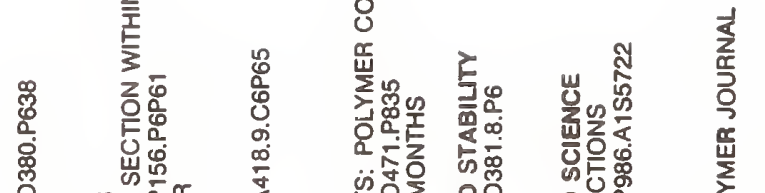

8

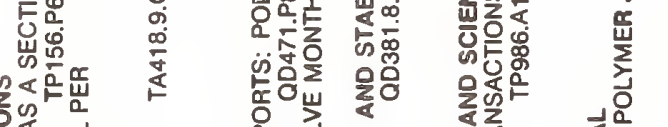

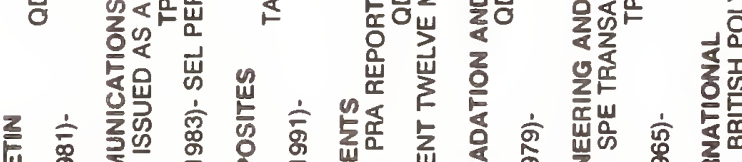

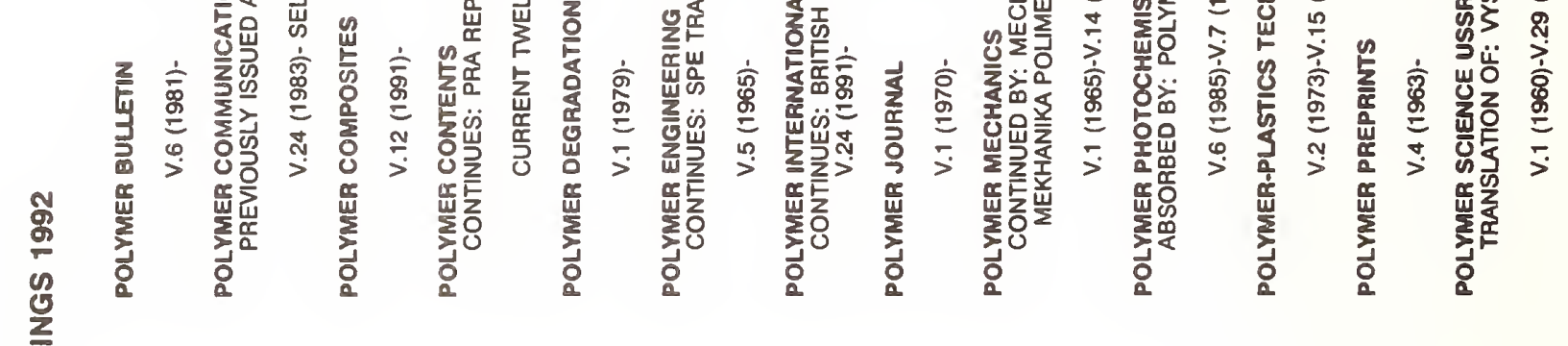

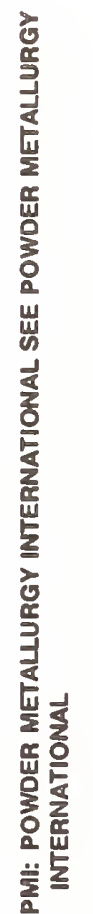

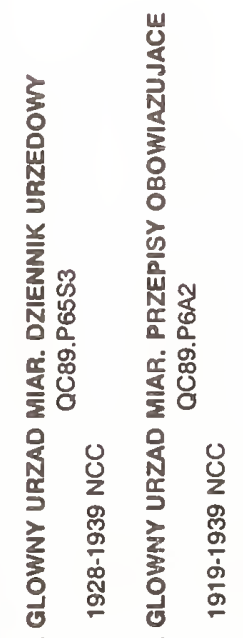

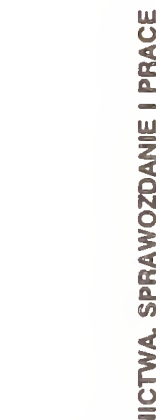

造

은

要

赵 중

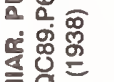

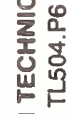

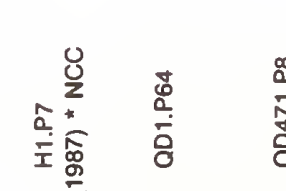

离

章

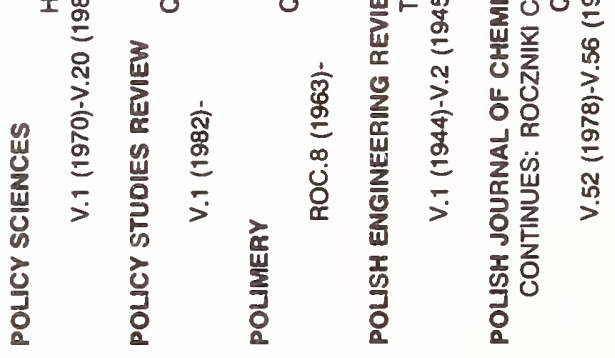

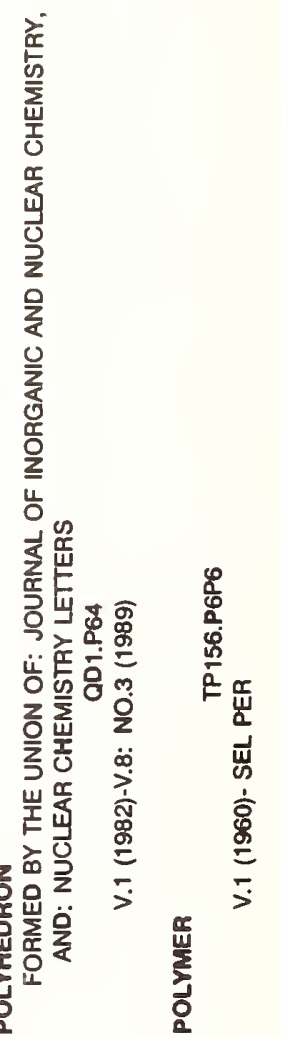




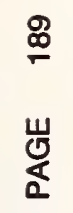
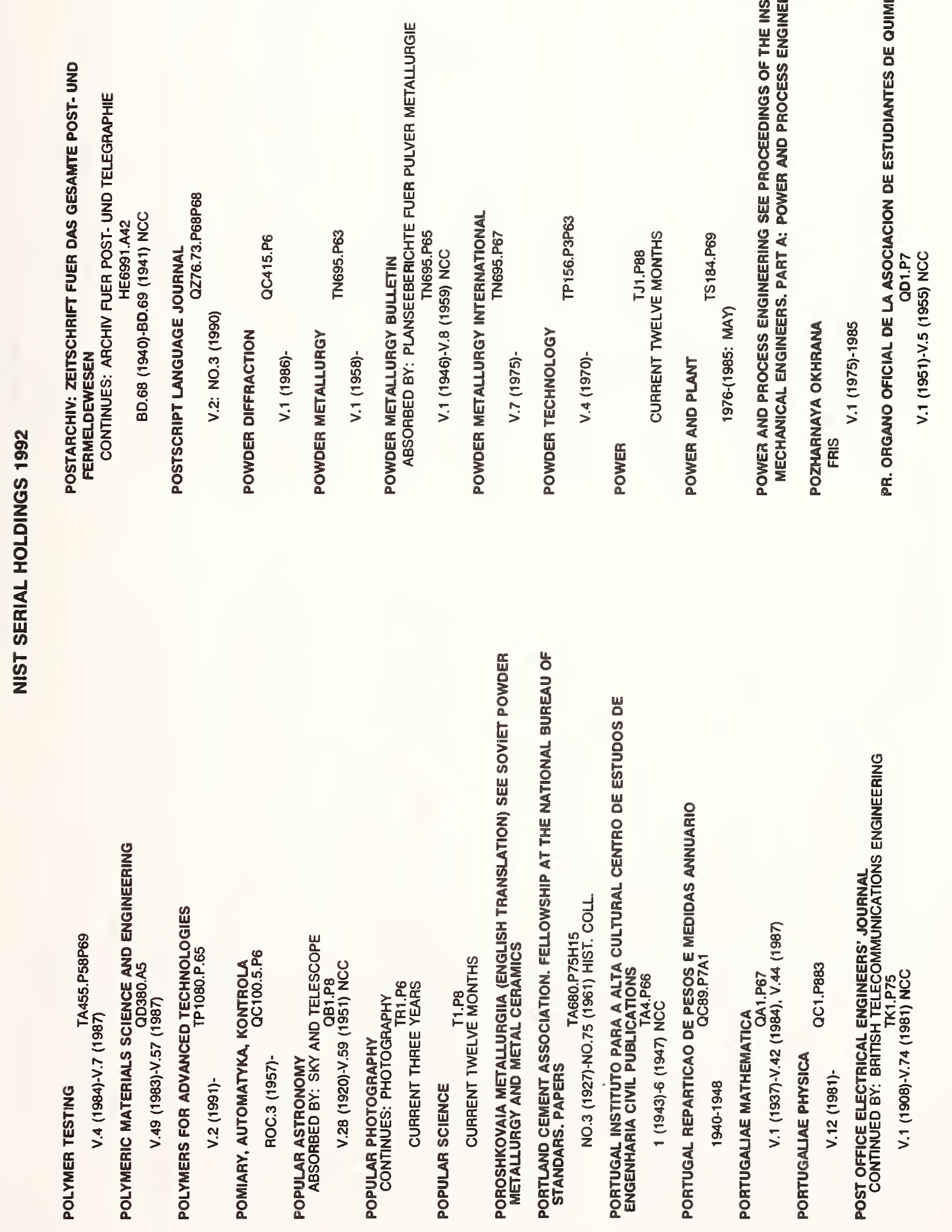


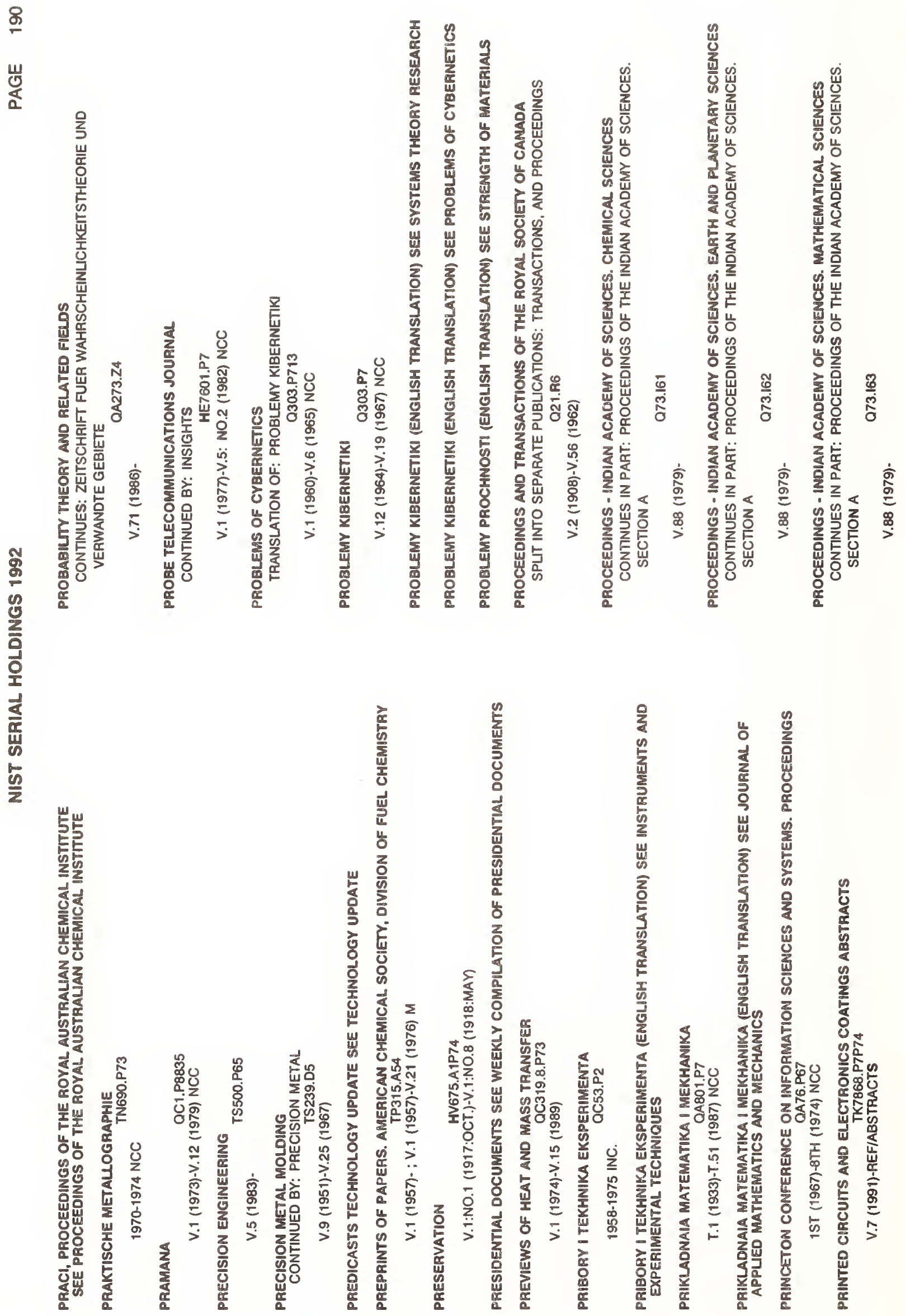




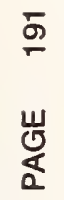

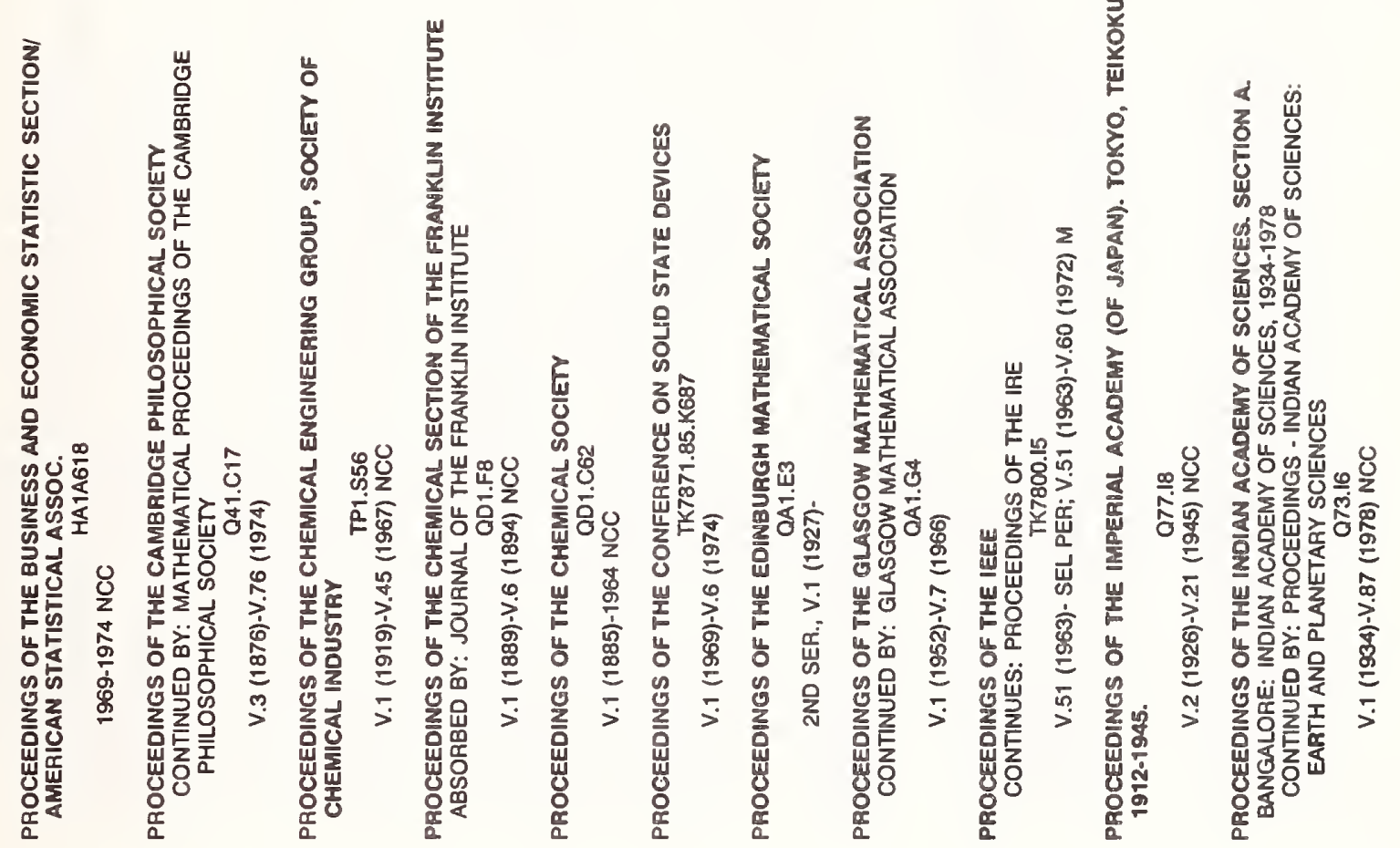

홓

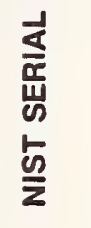
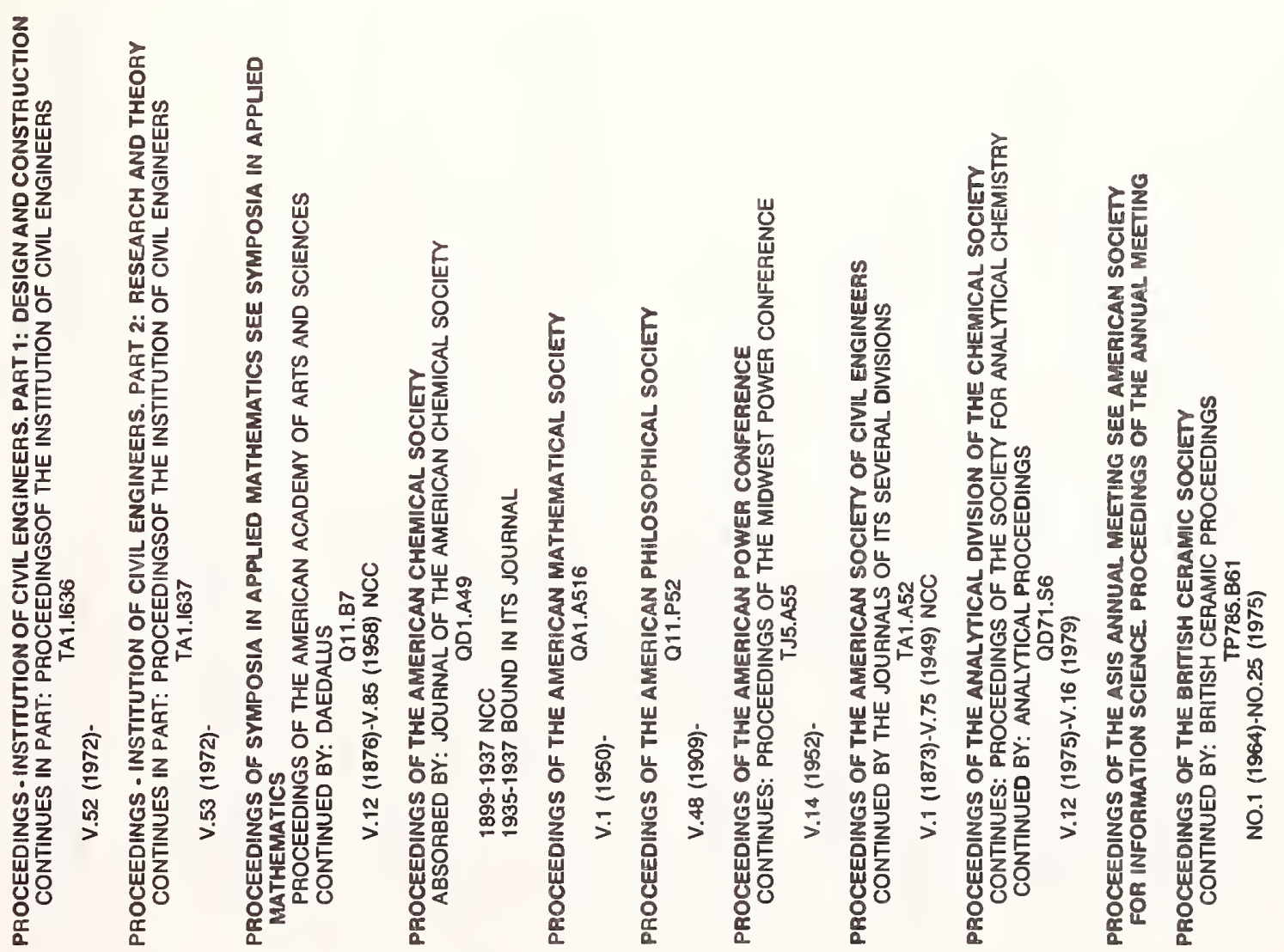


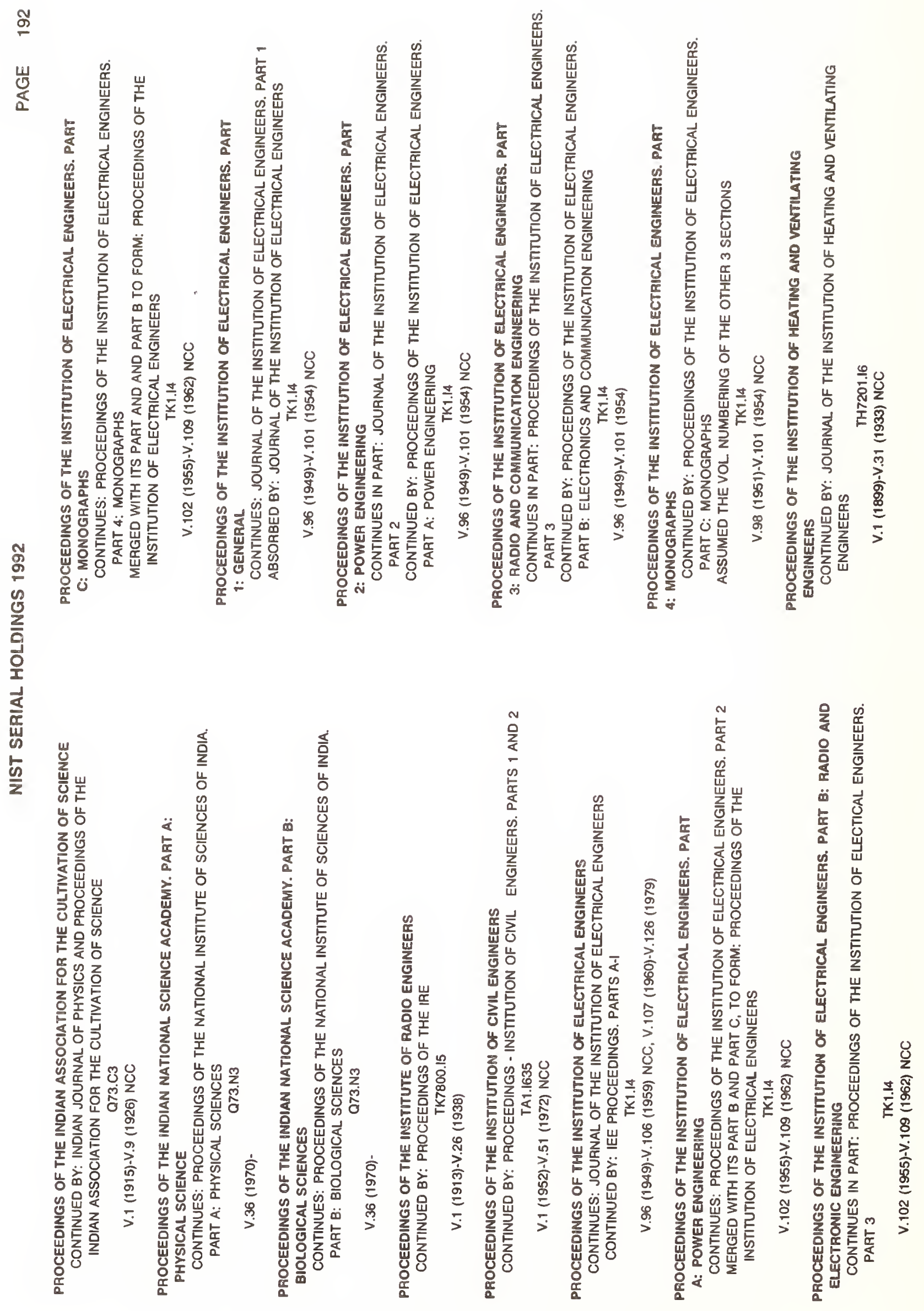


$\stackrel{8}{9}$
$\stackrel{0}{0}$
$\frac{0}{2}$
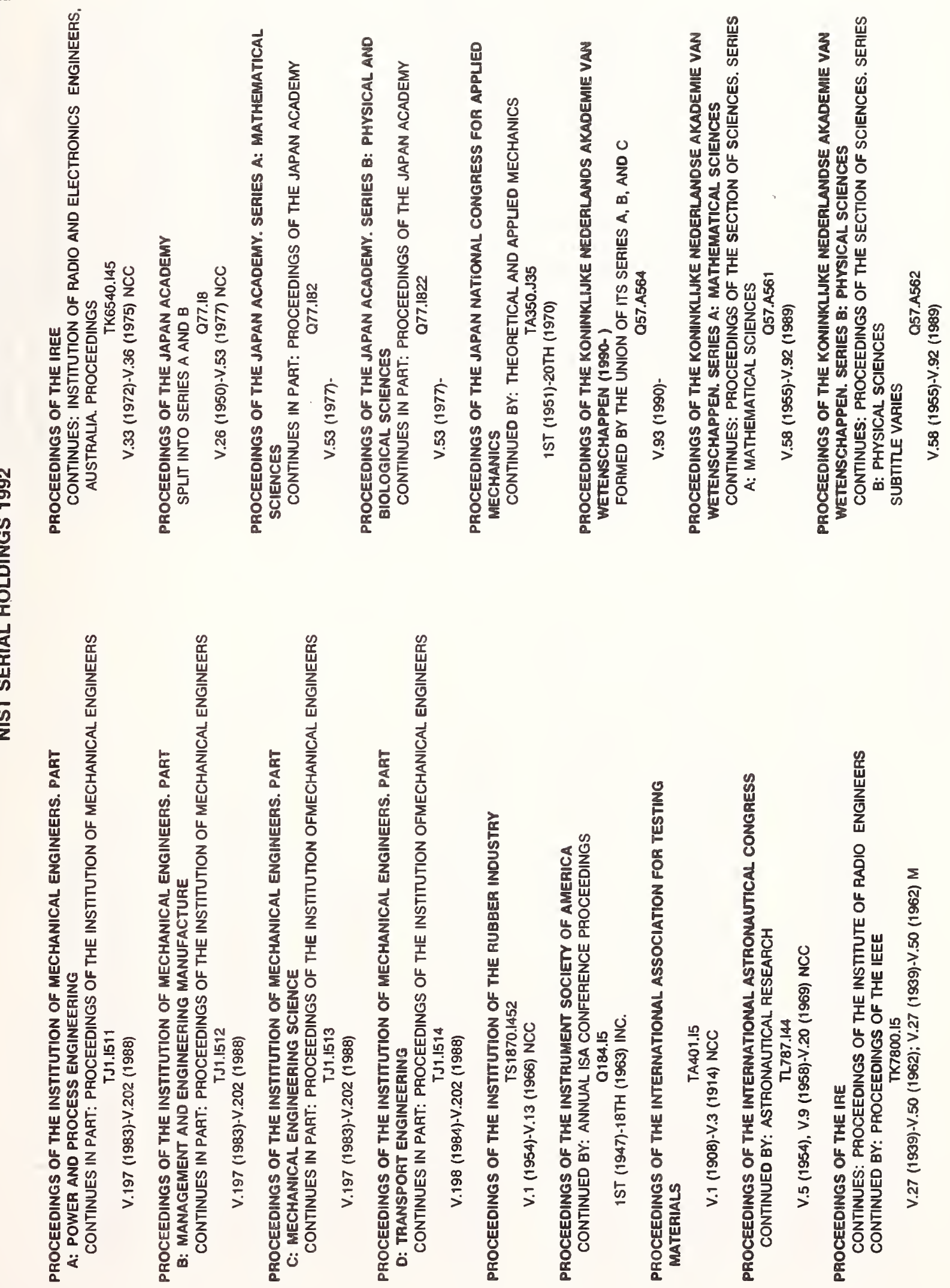
吉
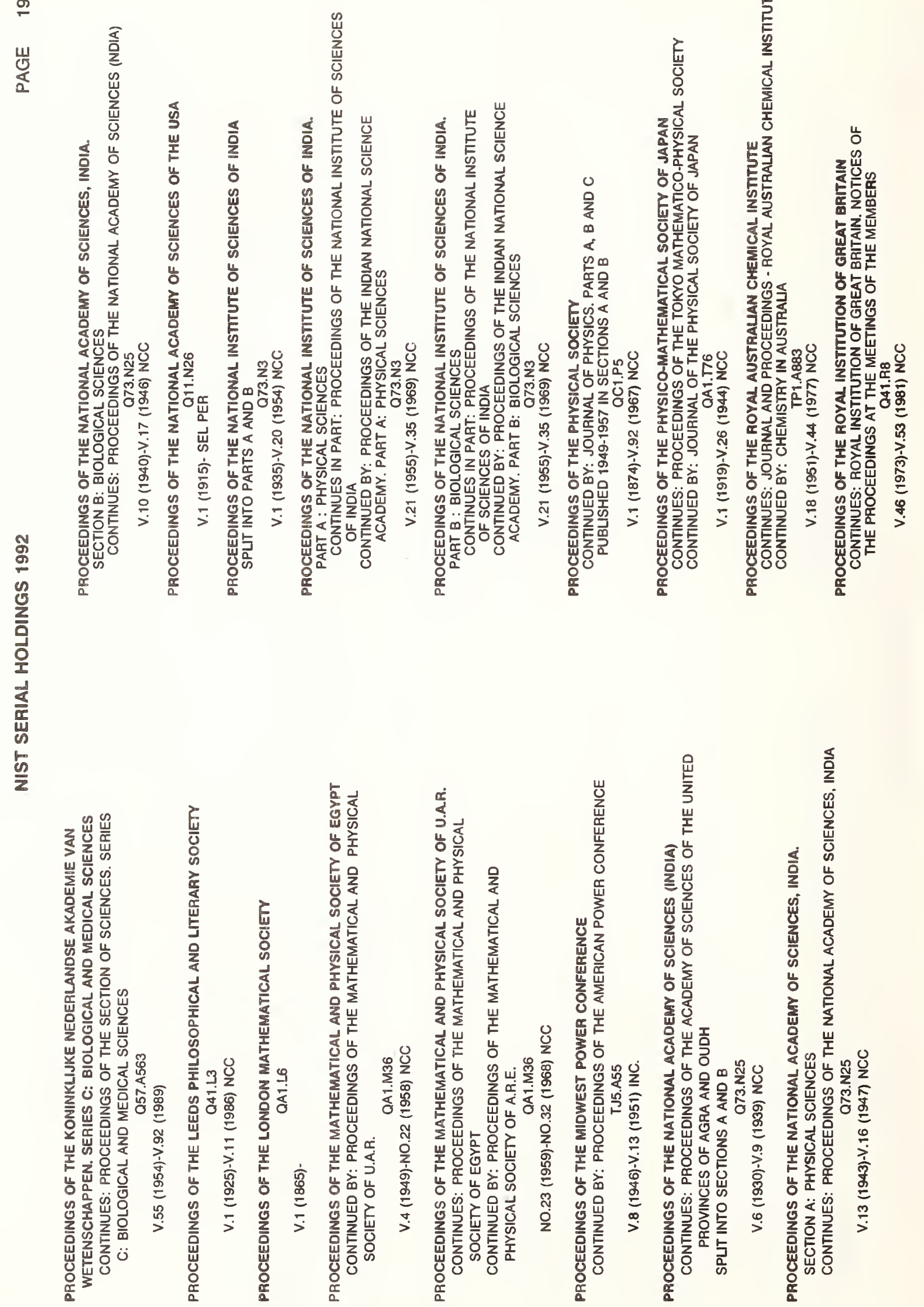

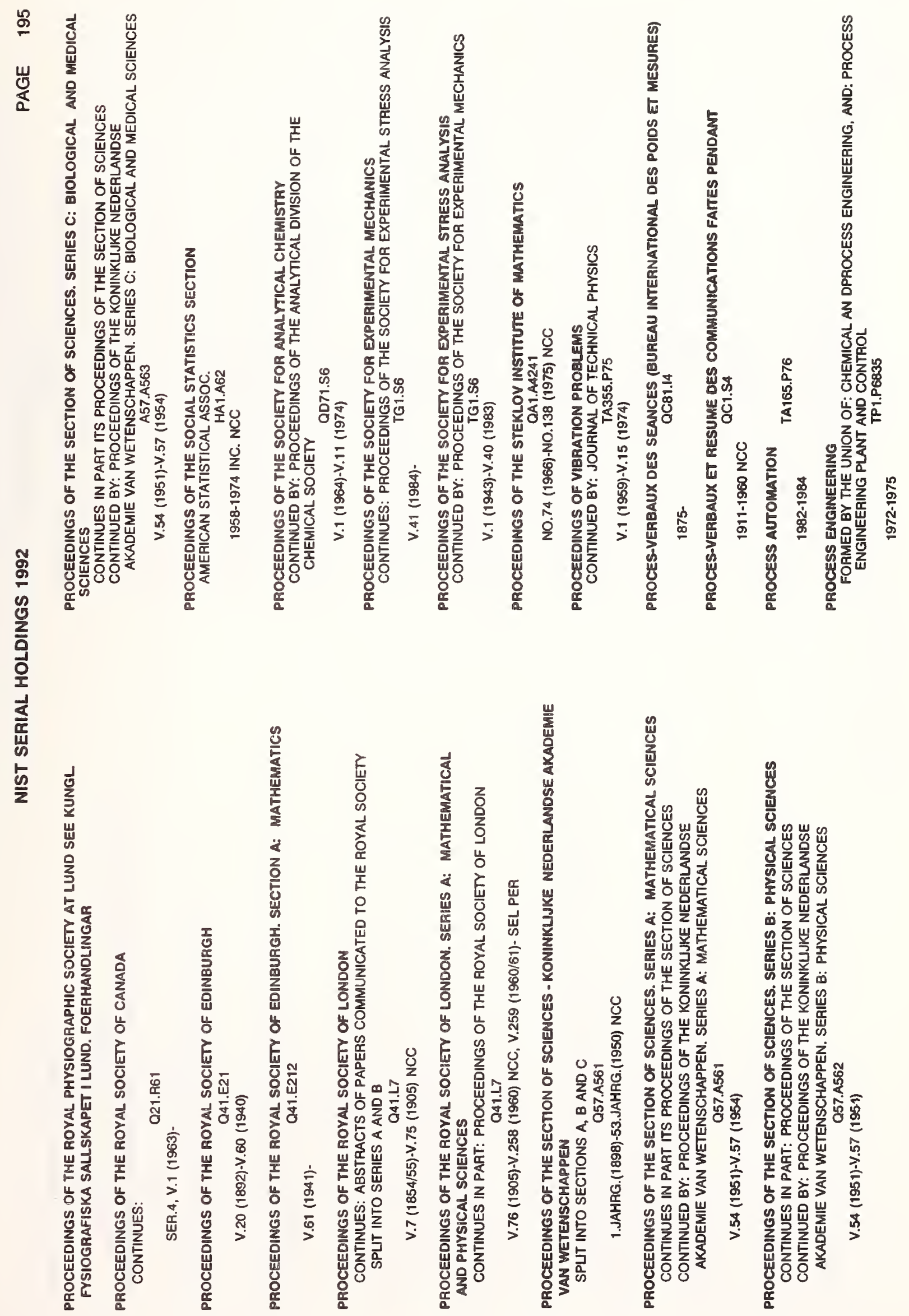


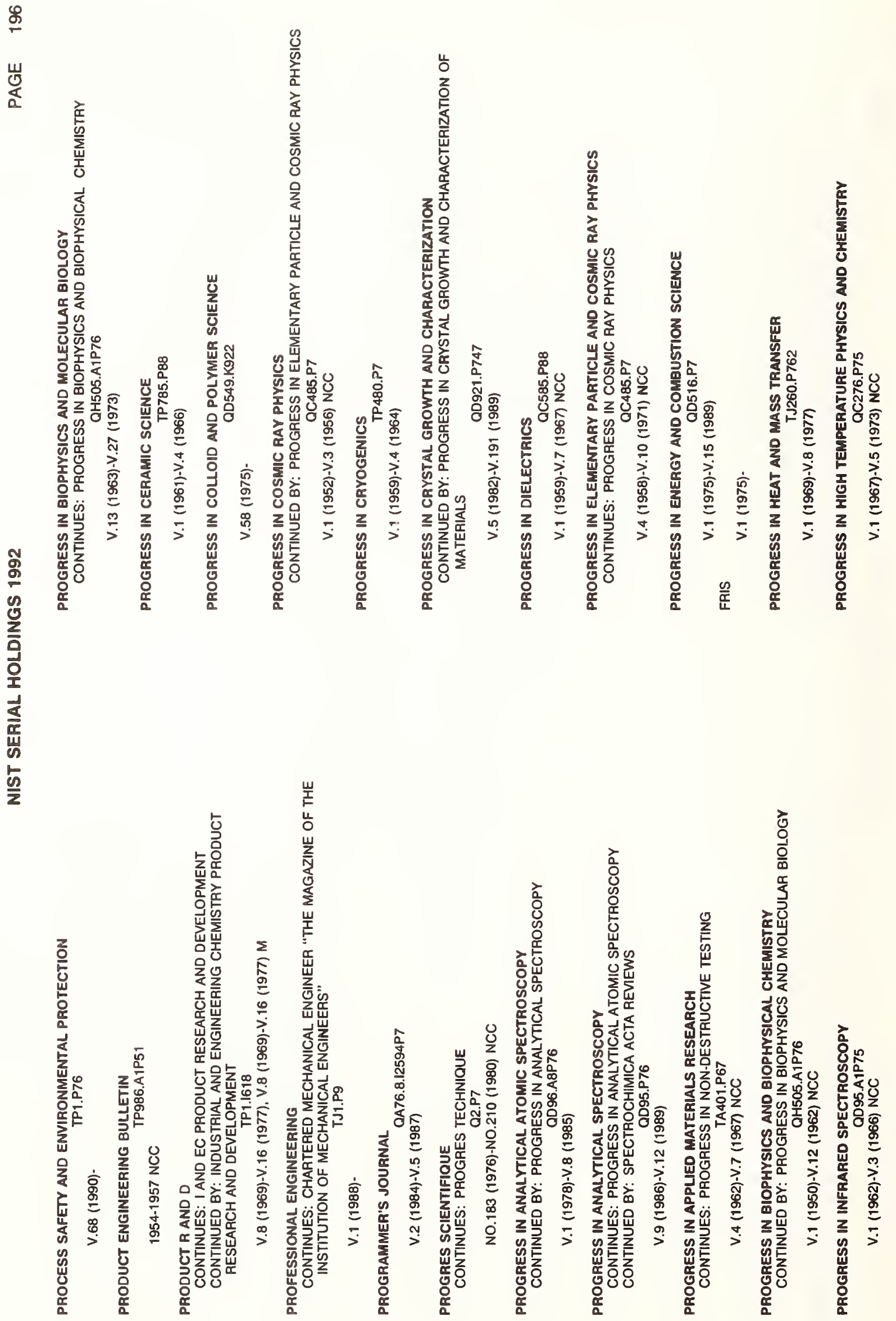



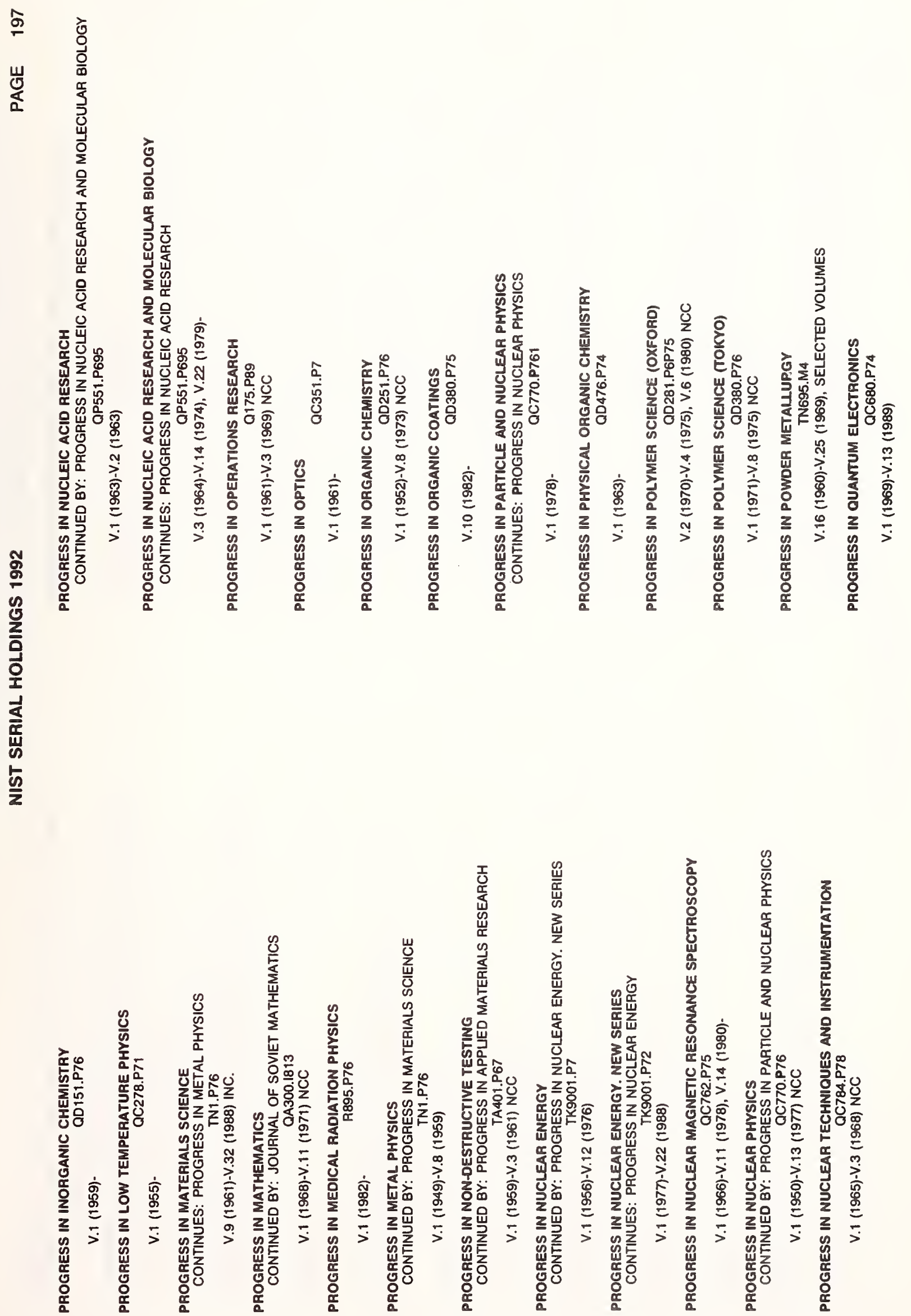
$\stackrel{\infty}{\circ}$

㟧

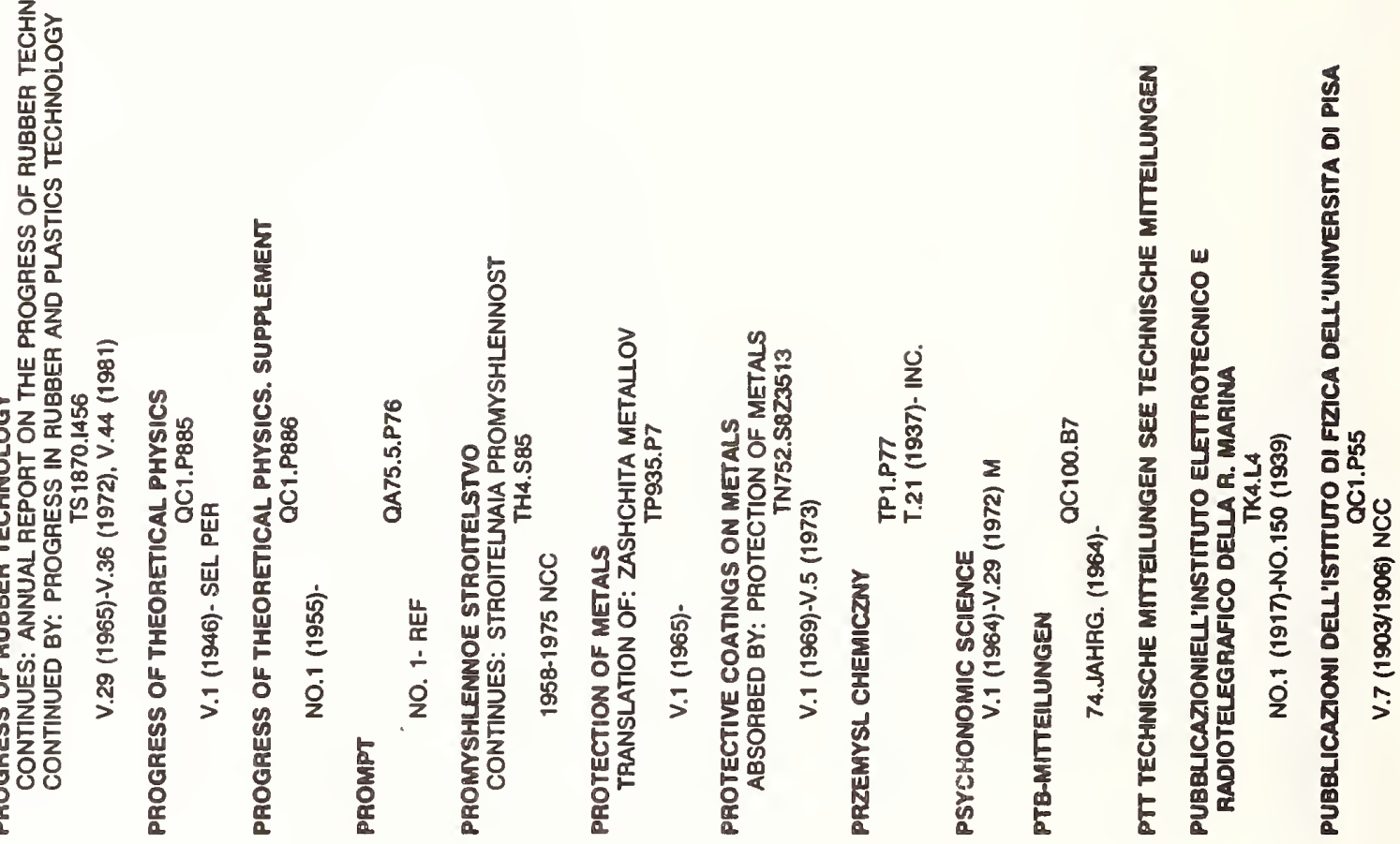

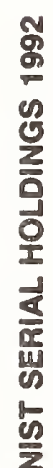

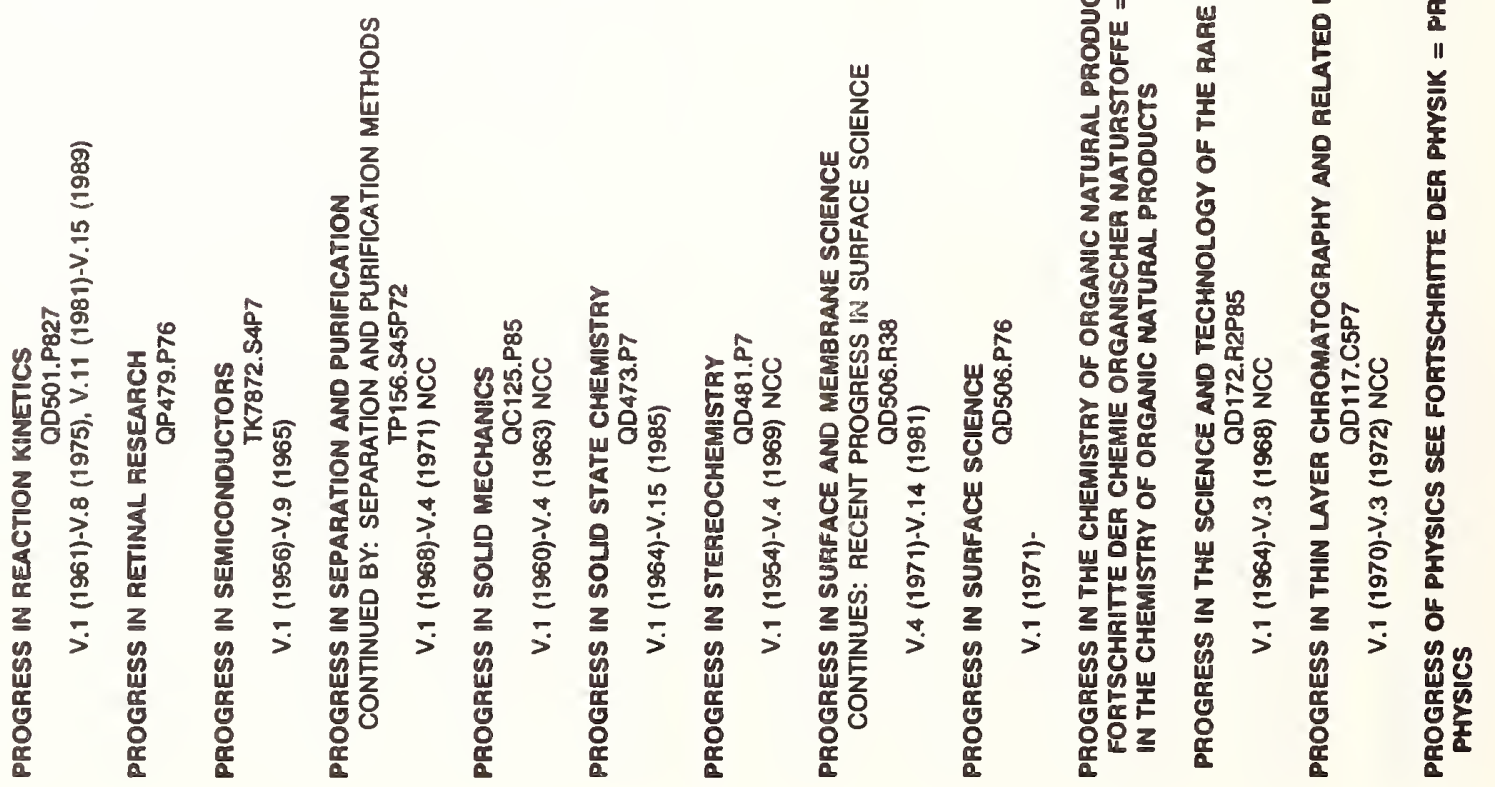


8

啶

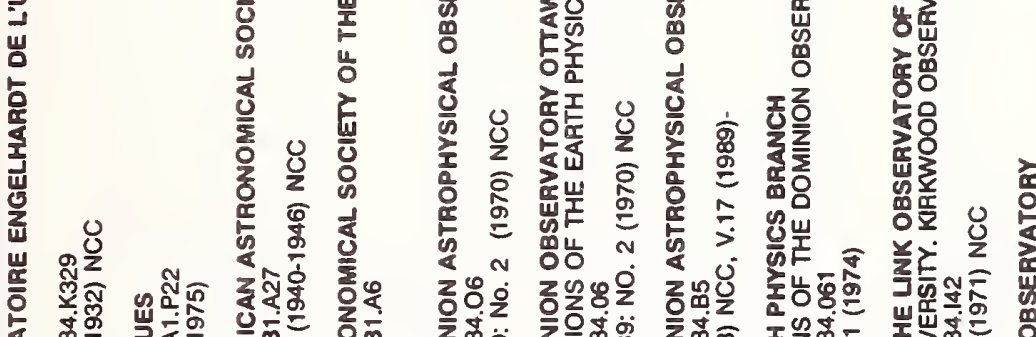

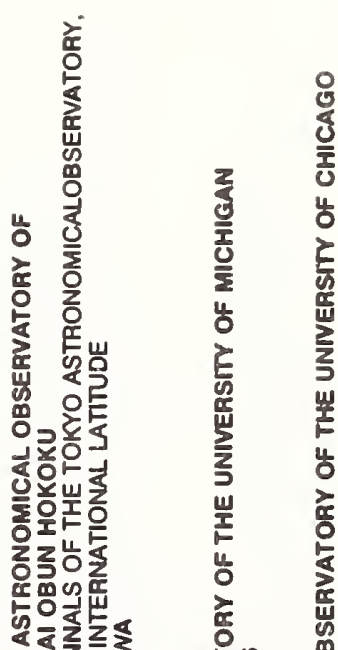

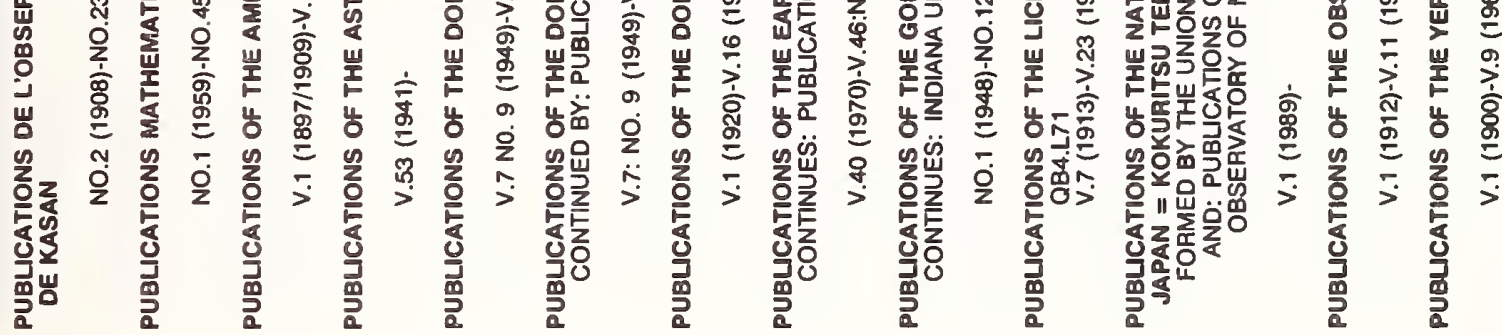

올

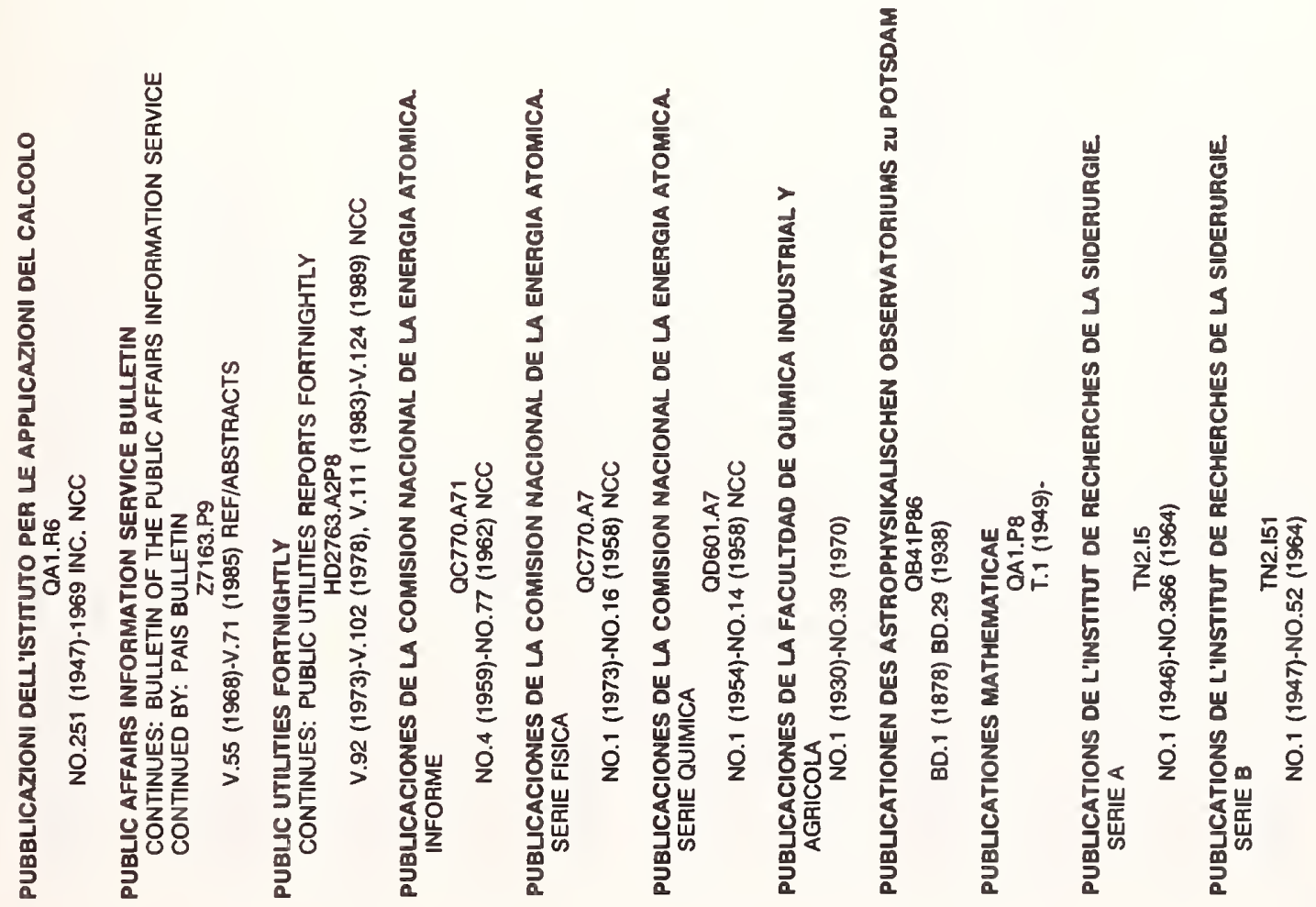


\&

삠
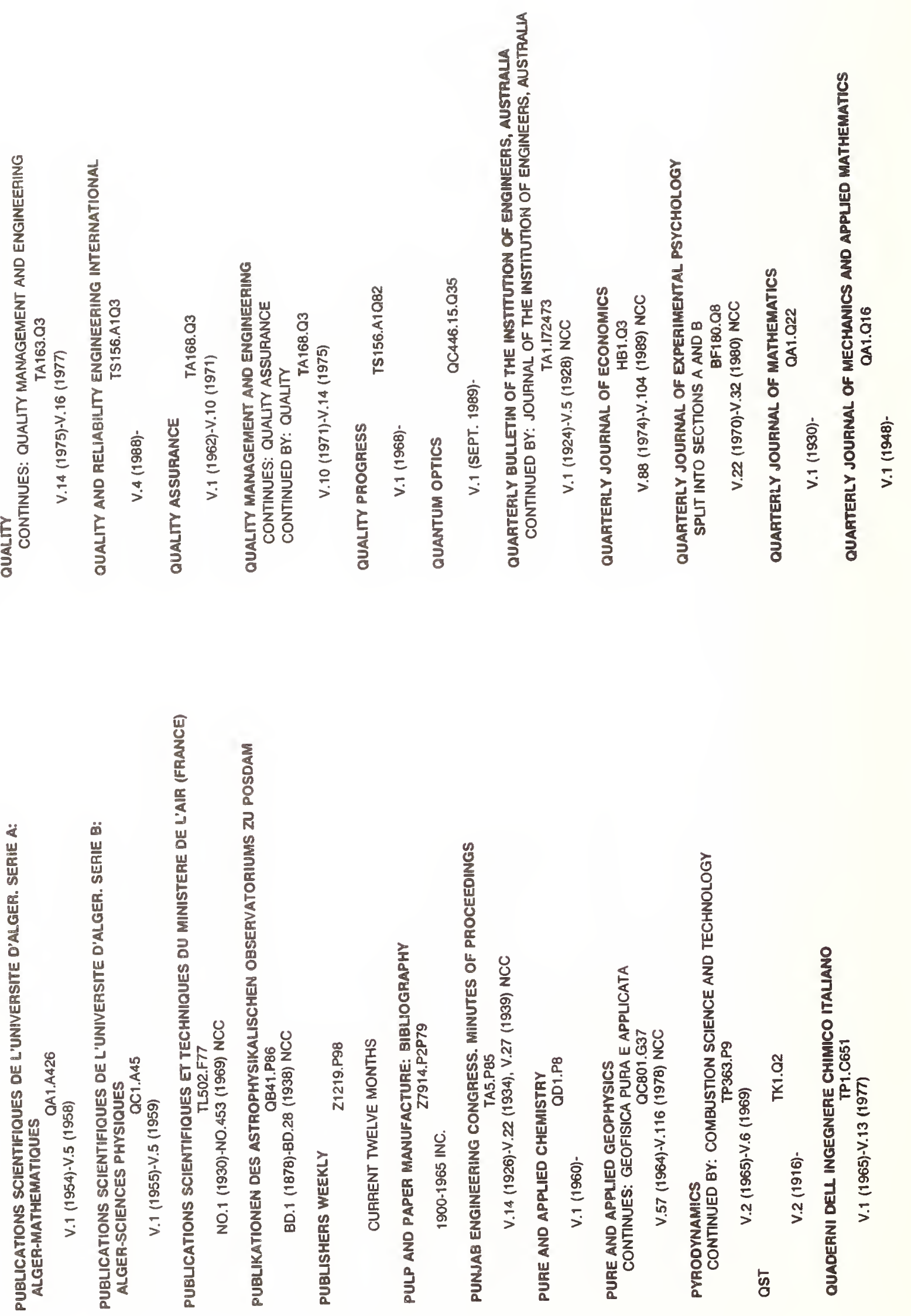
ธิ

뽕 
ํㅝㅁำ

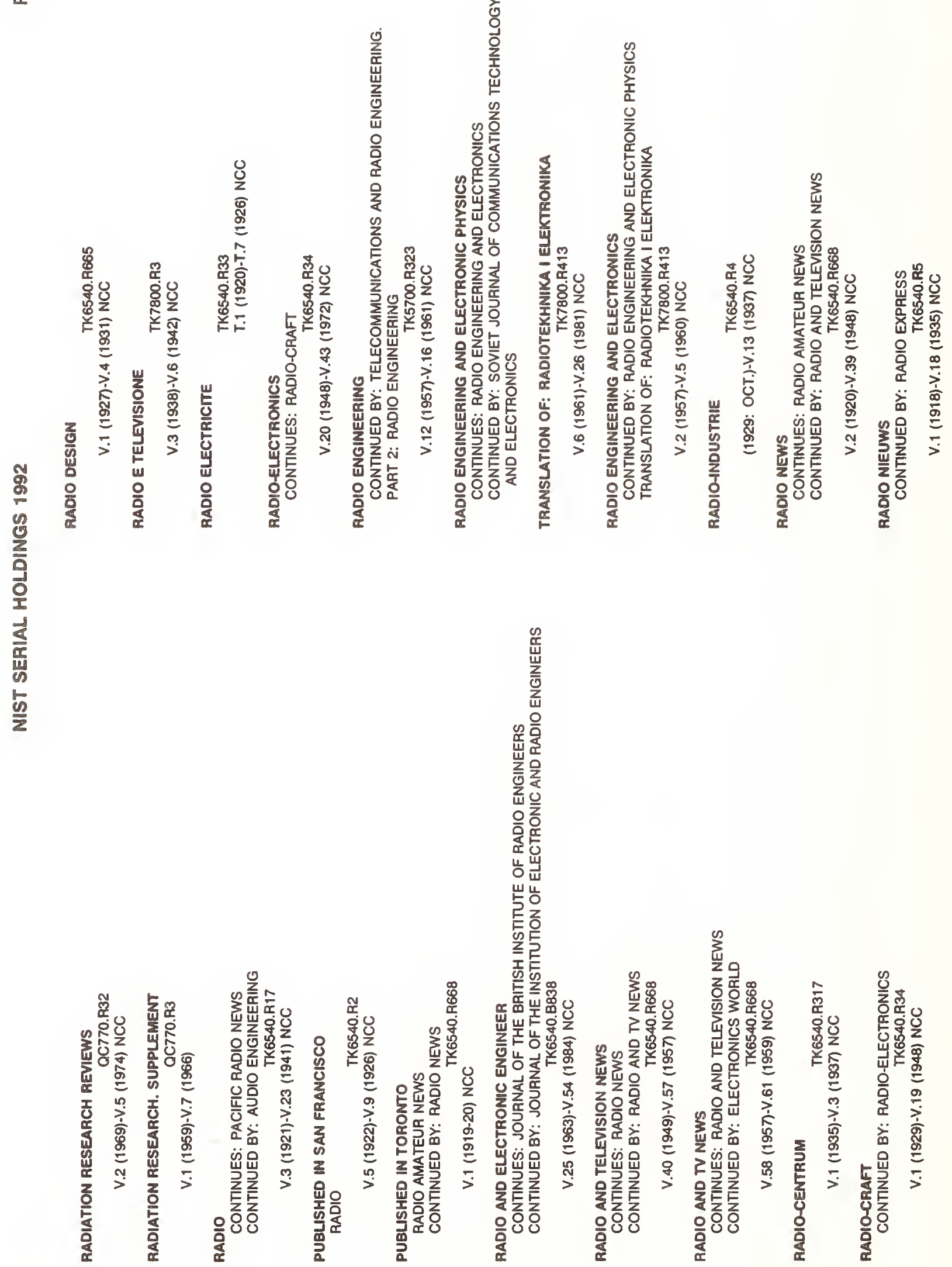




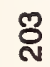

崖

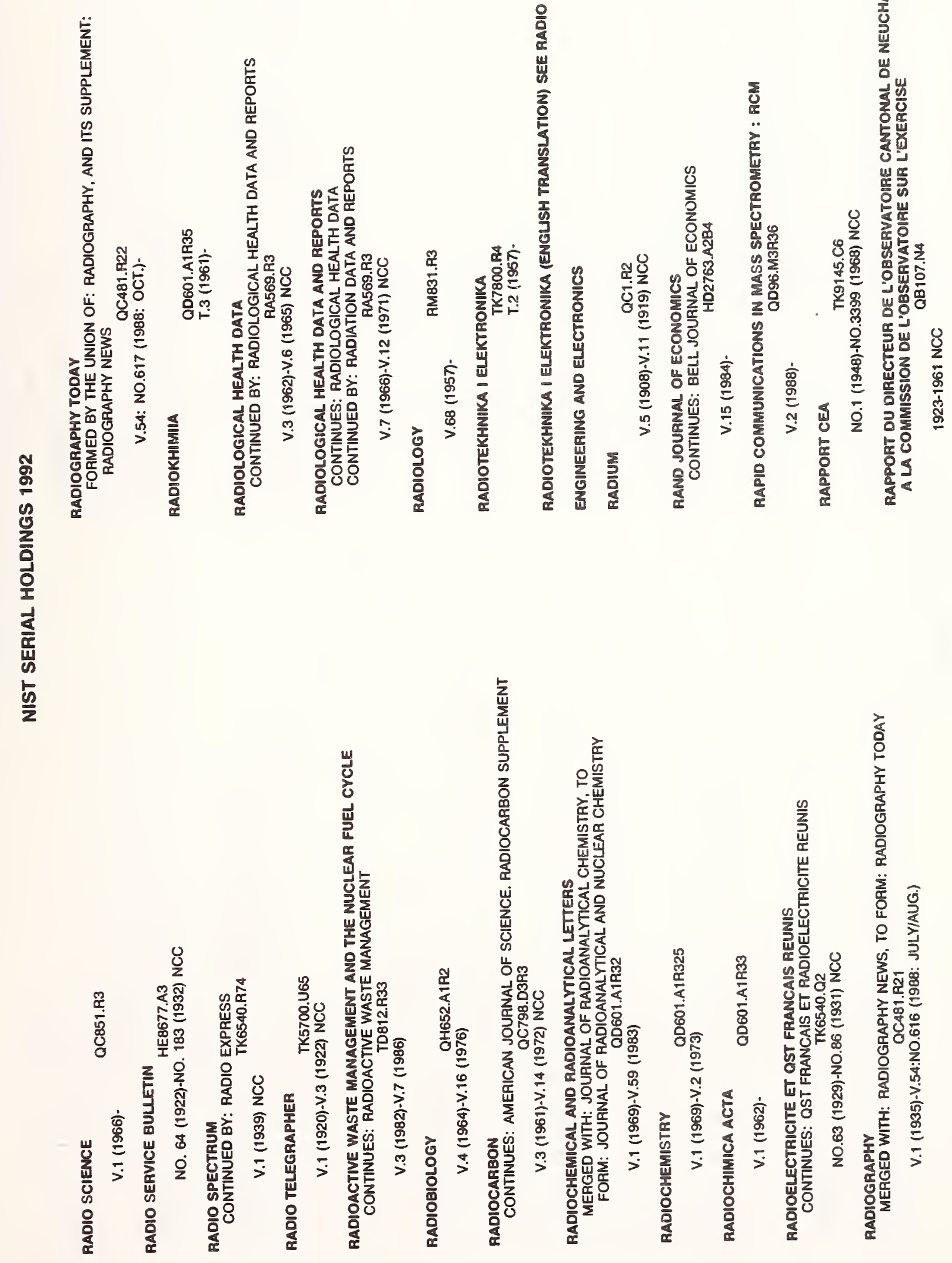


号

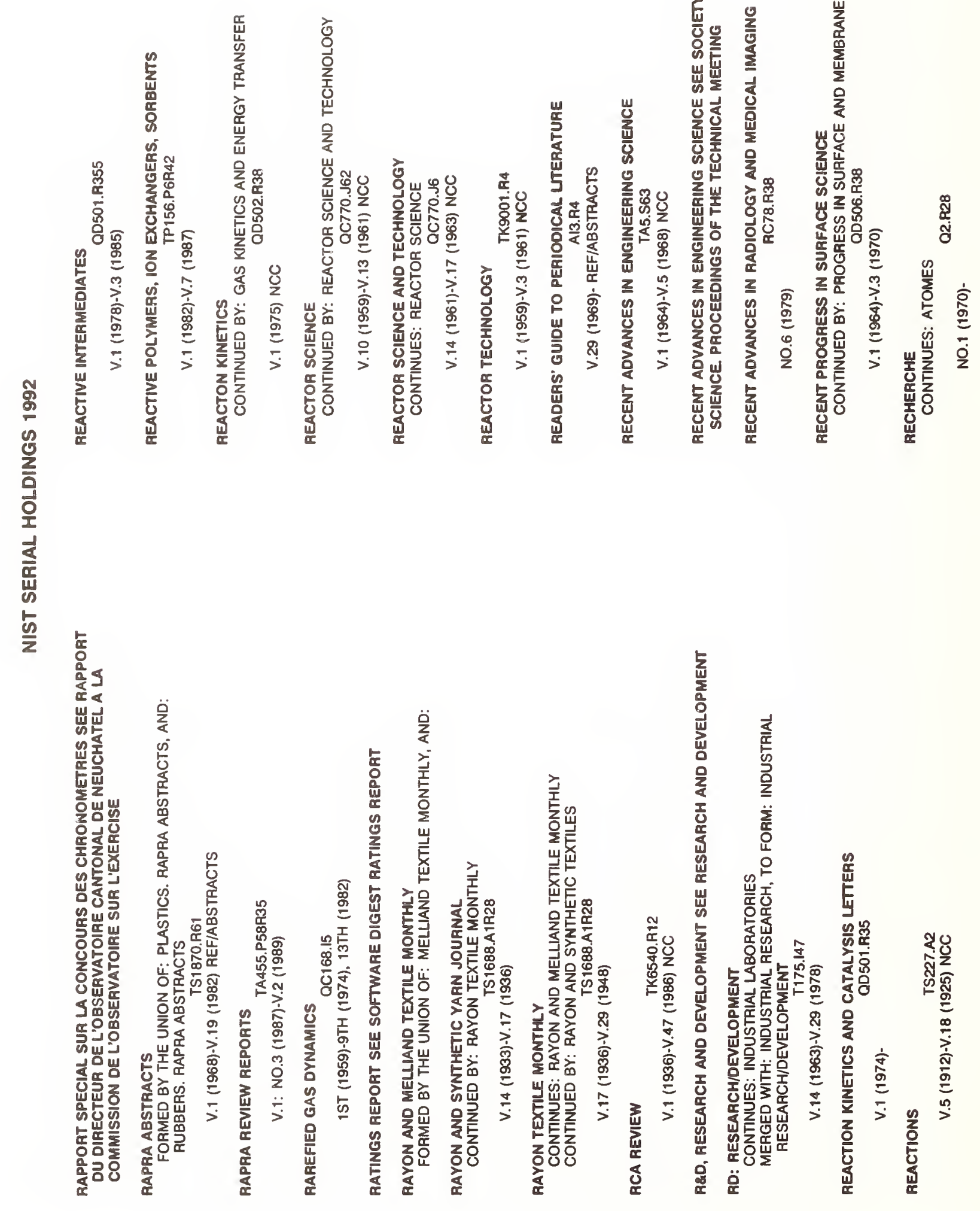




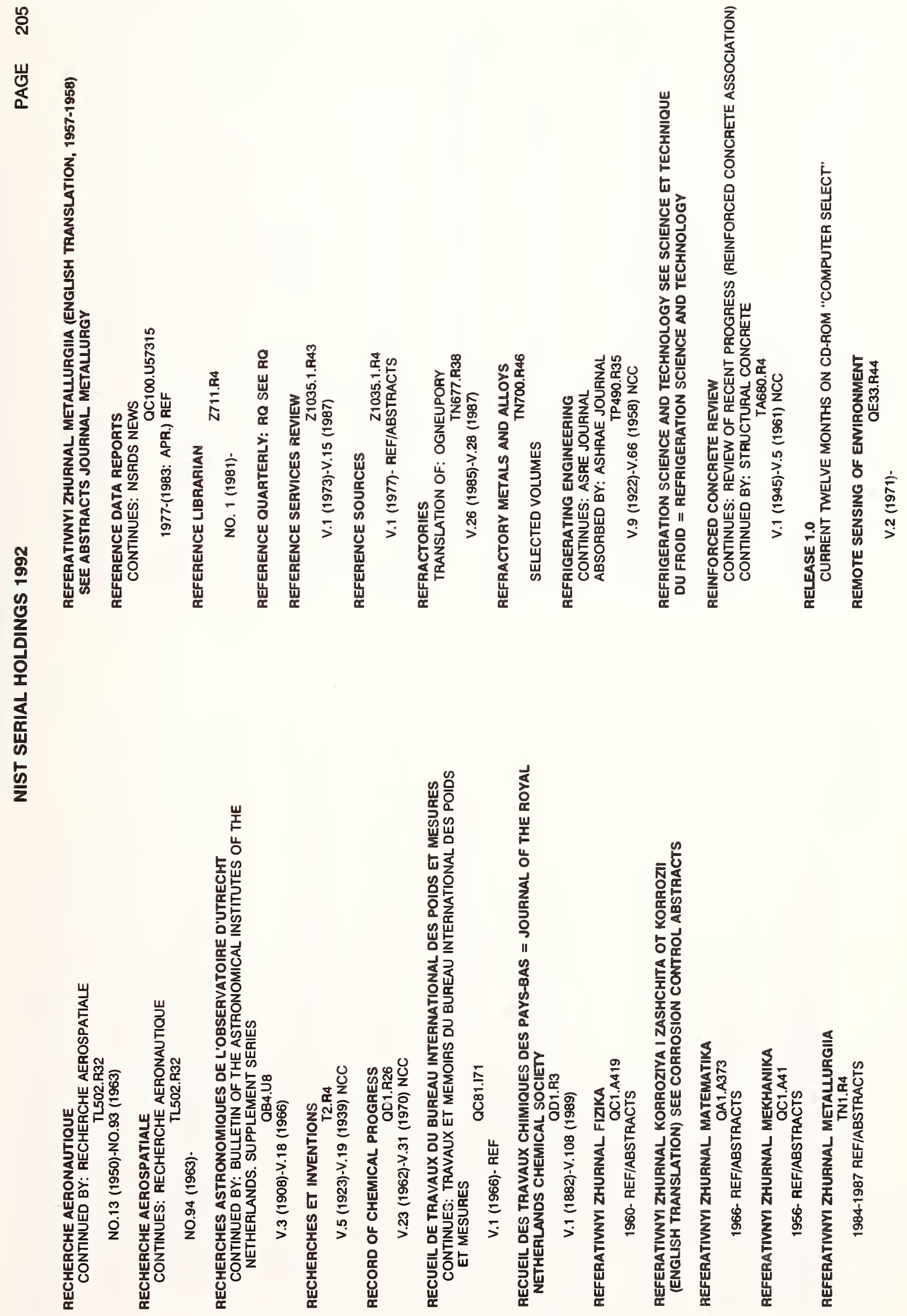




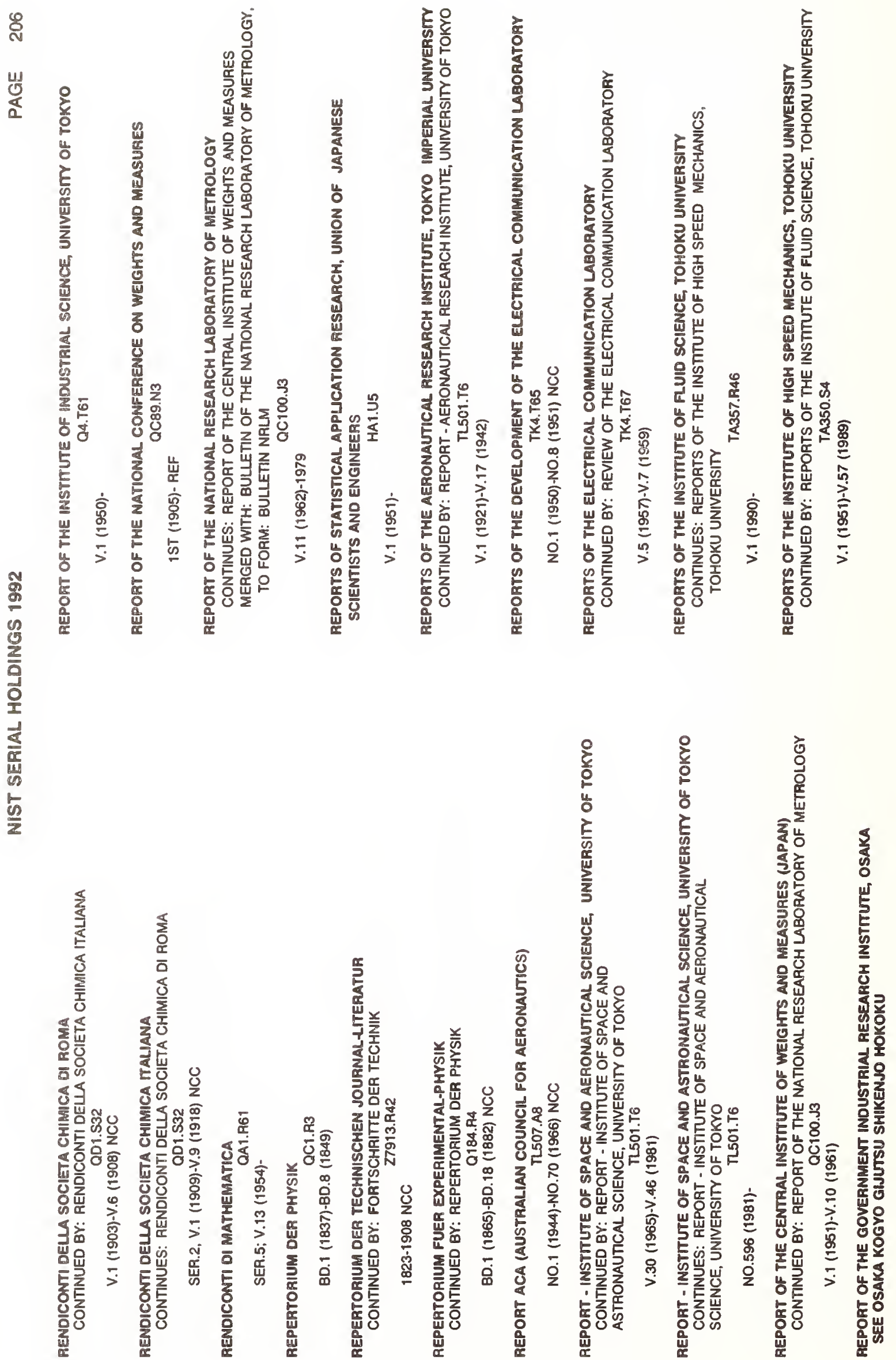




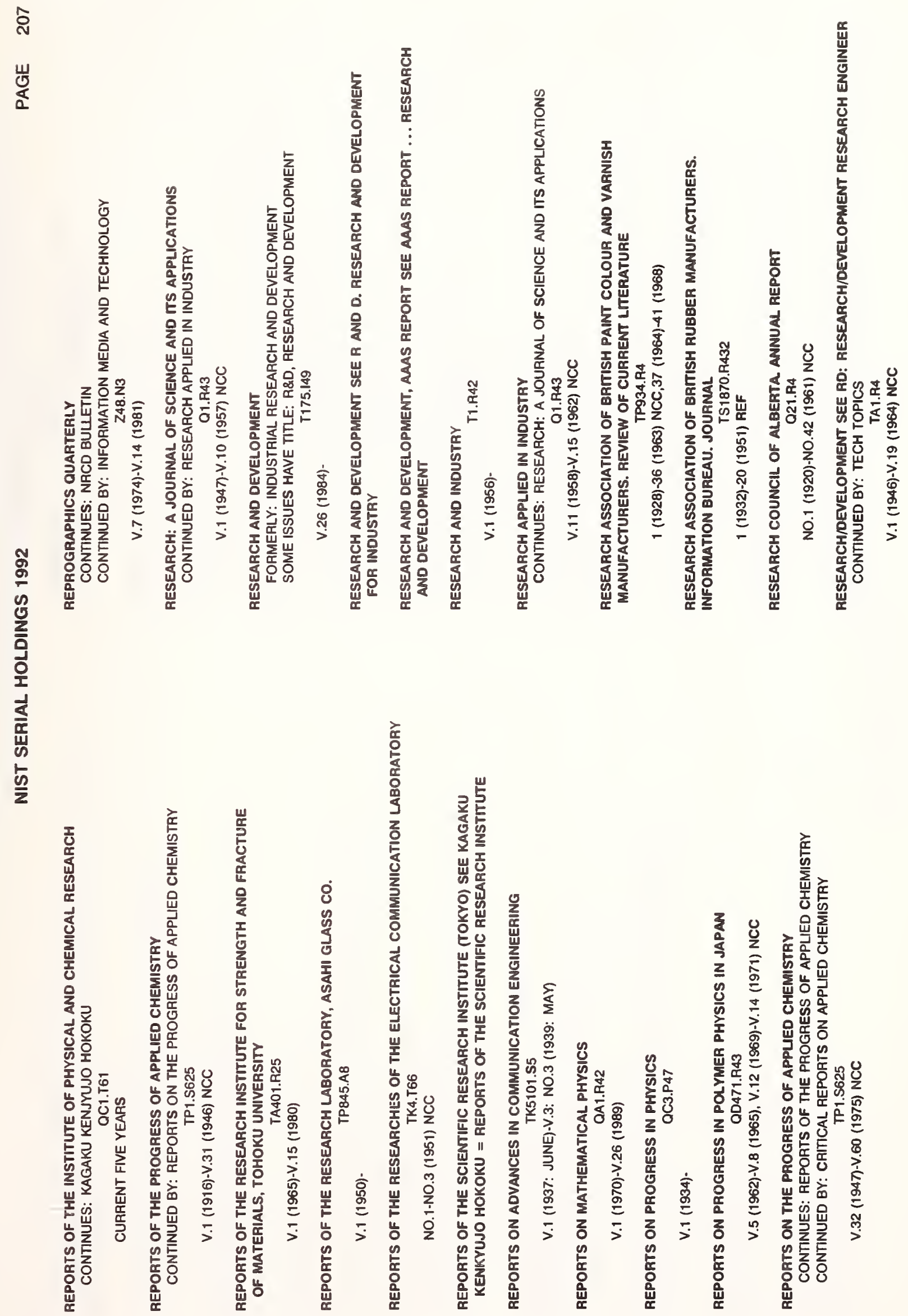


용

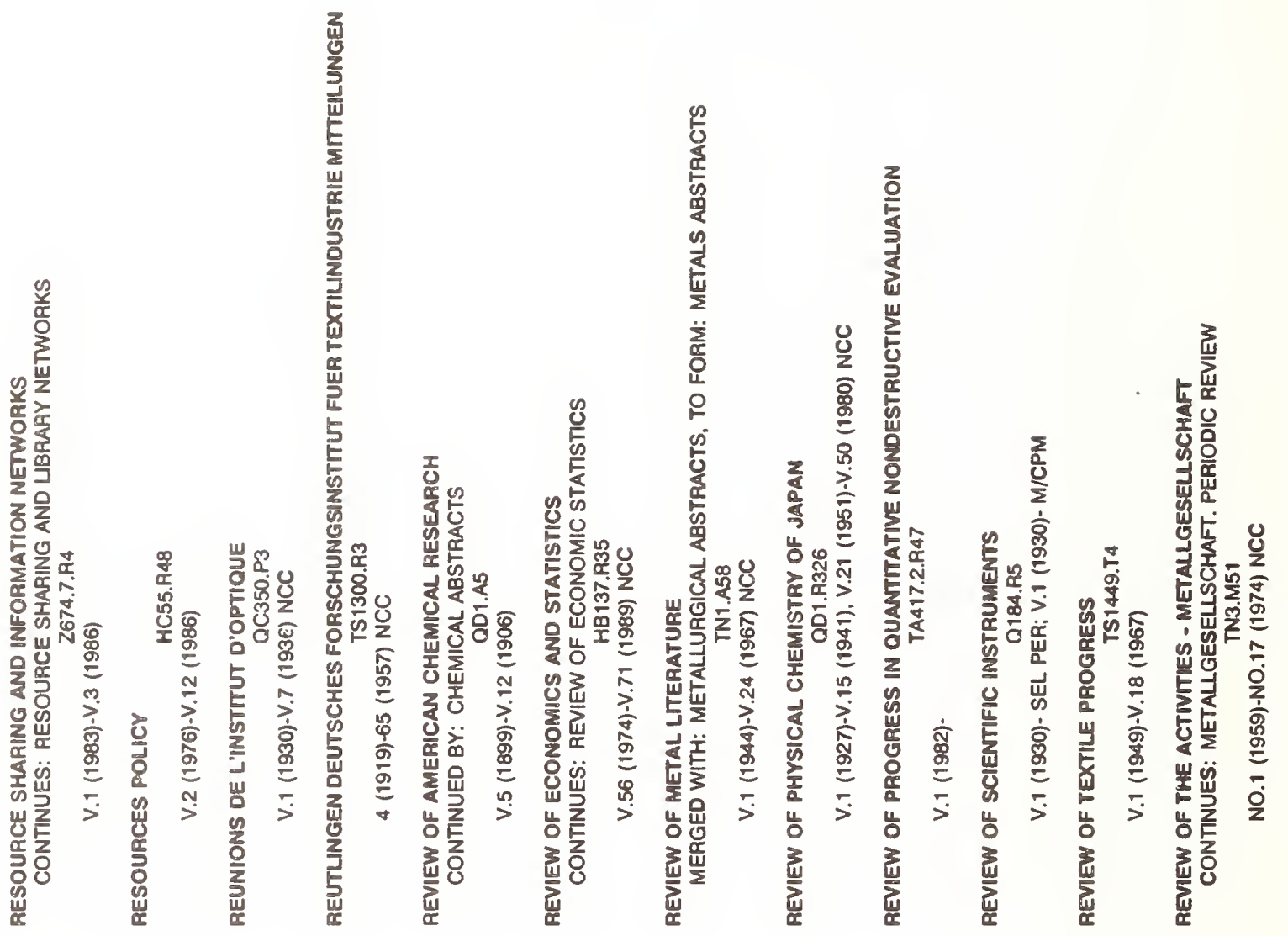

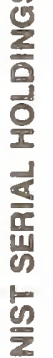

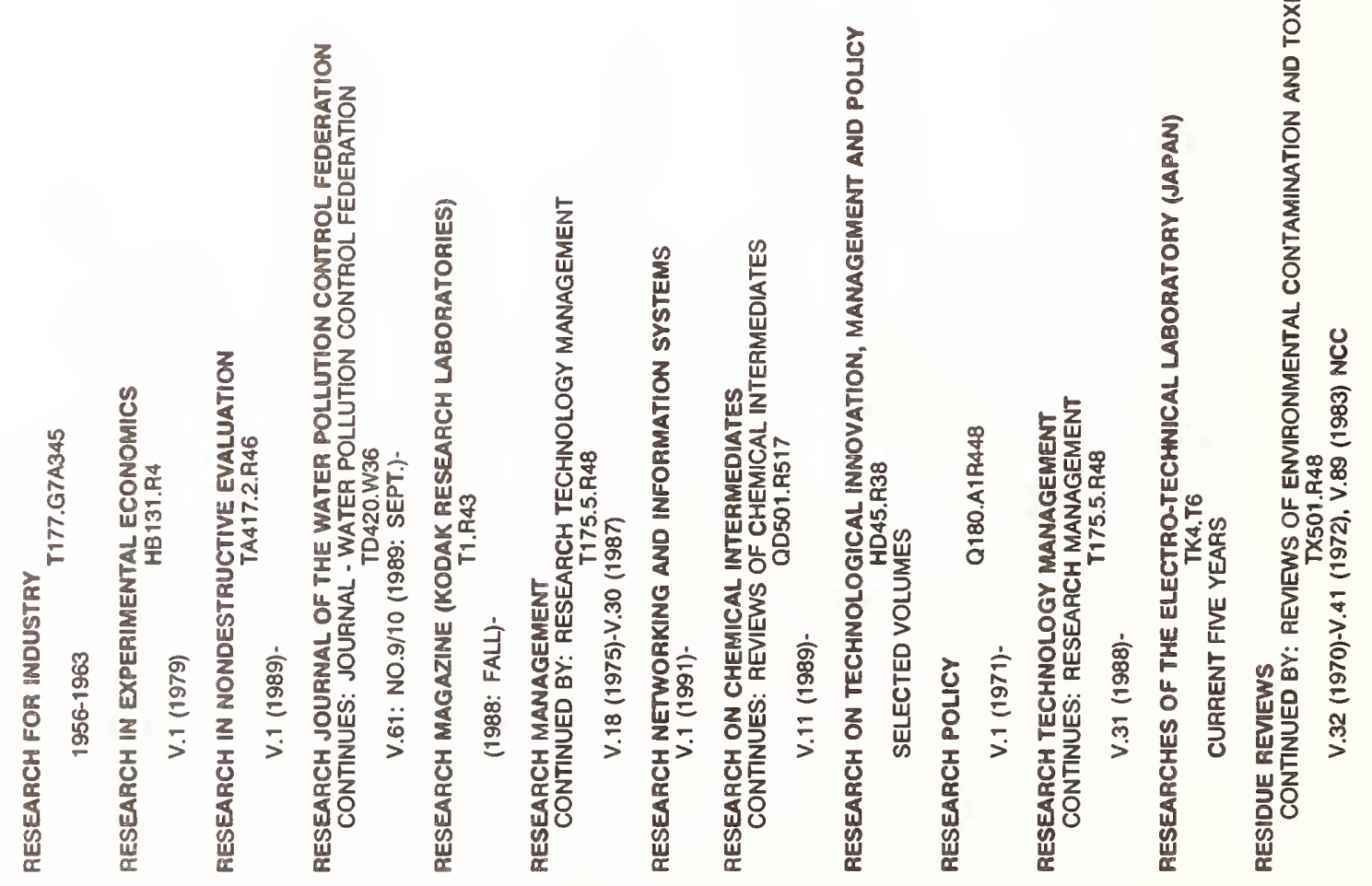


용

容

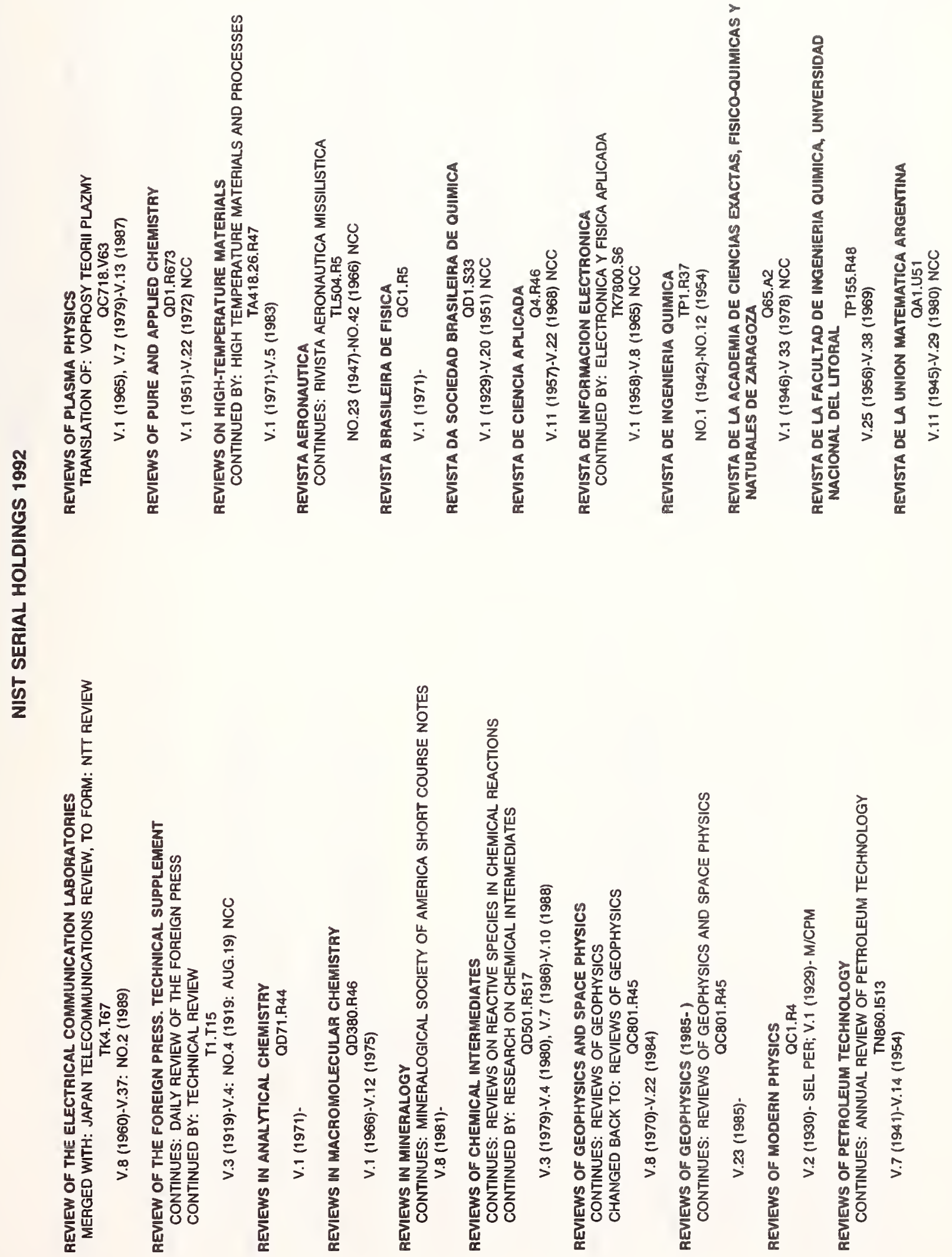




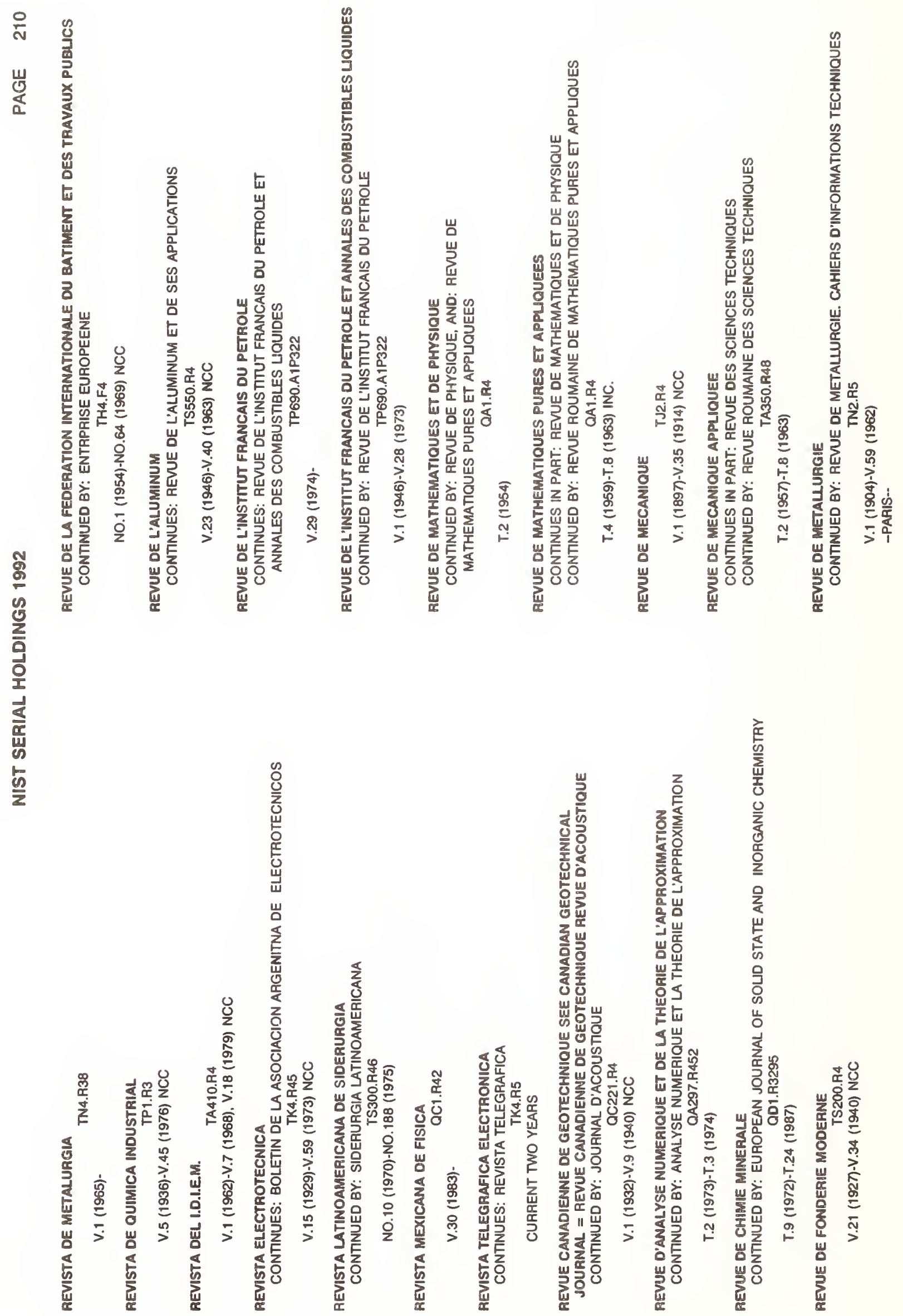




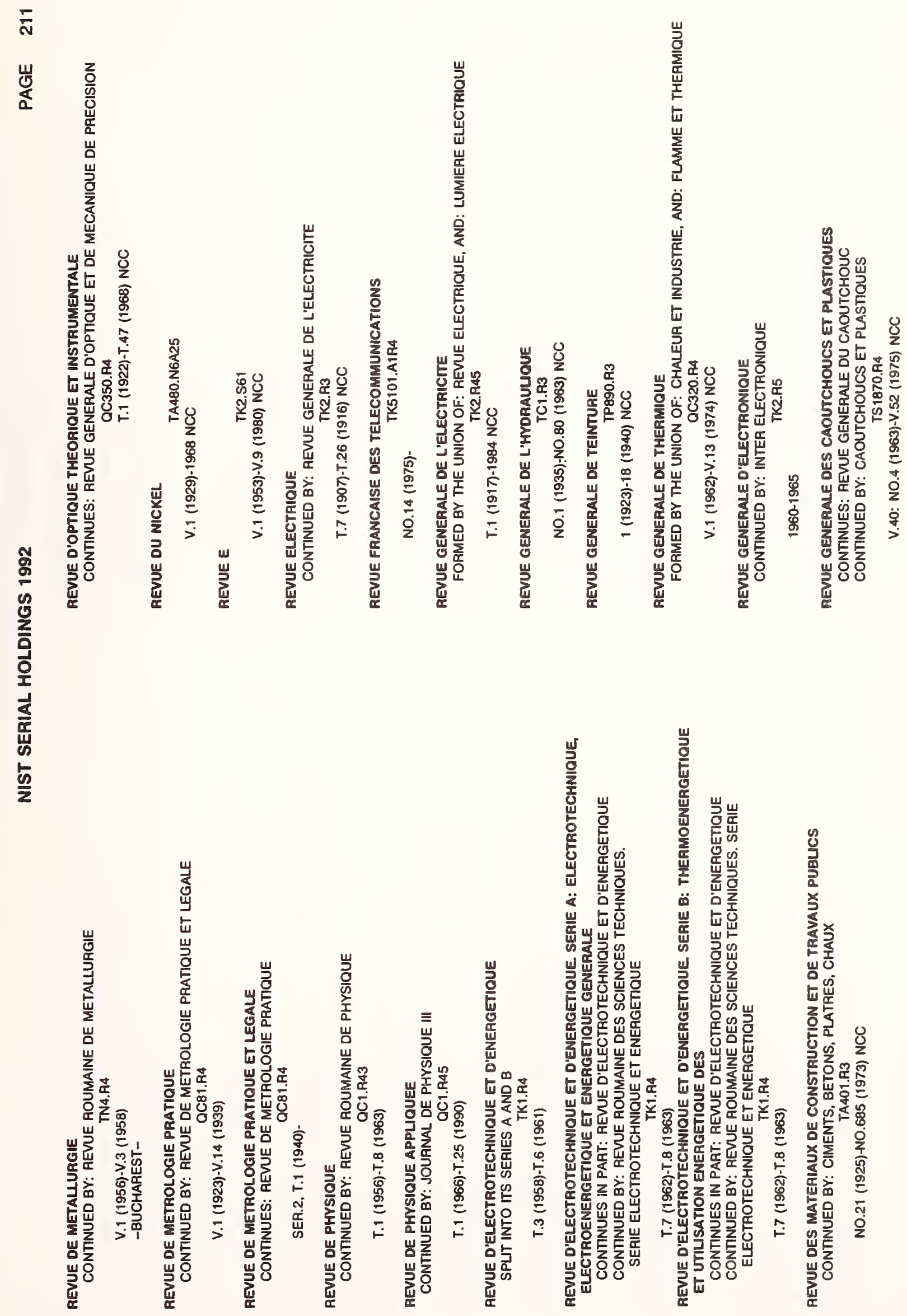




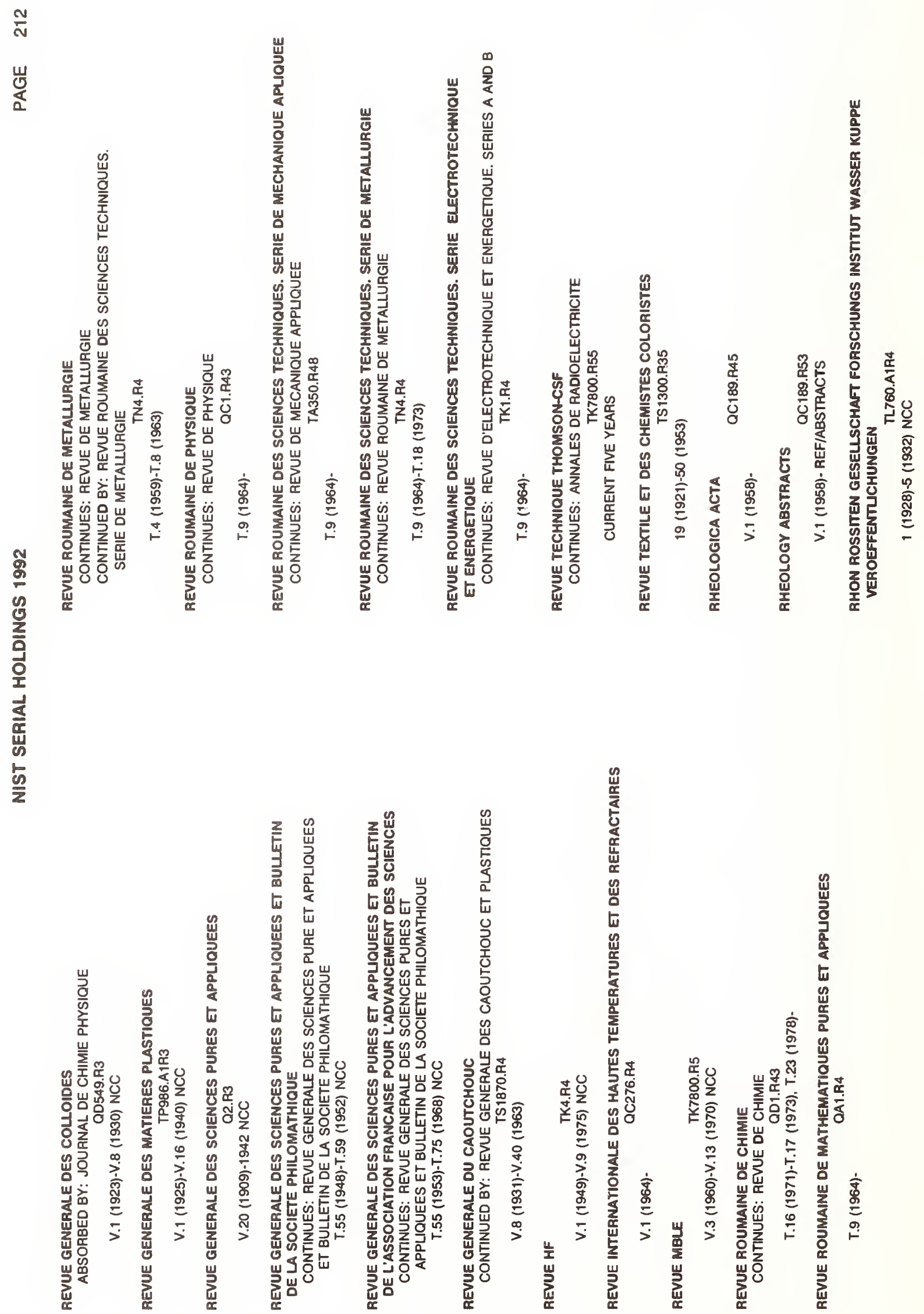




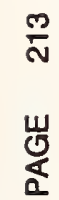
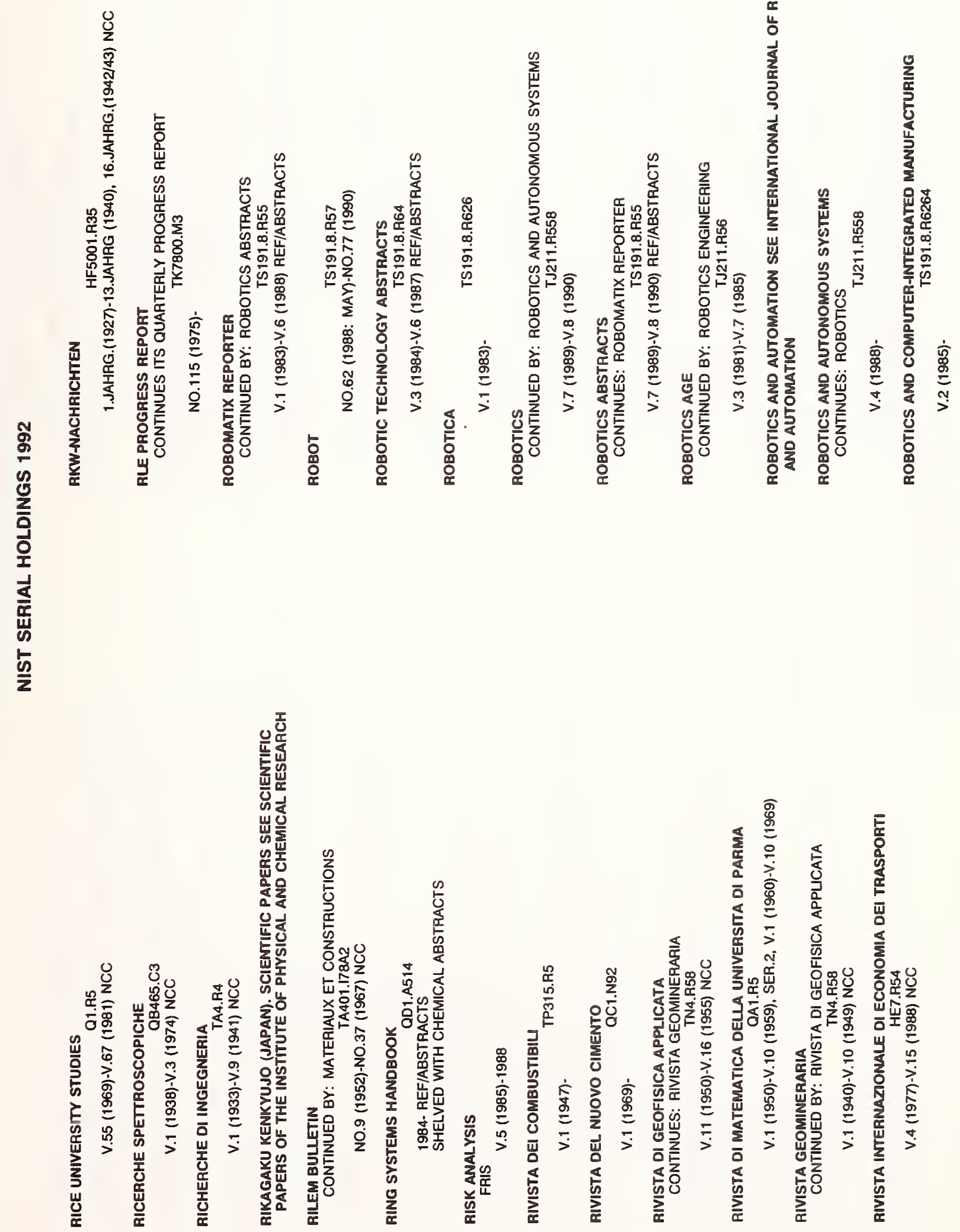
$\frac{5}{N}$

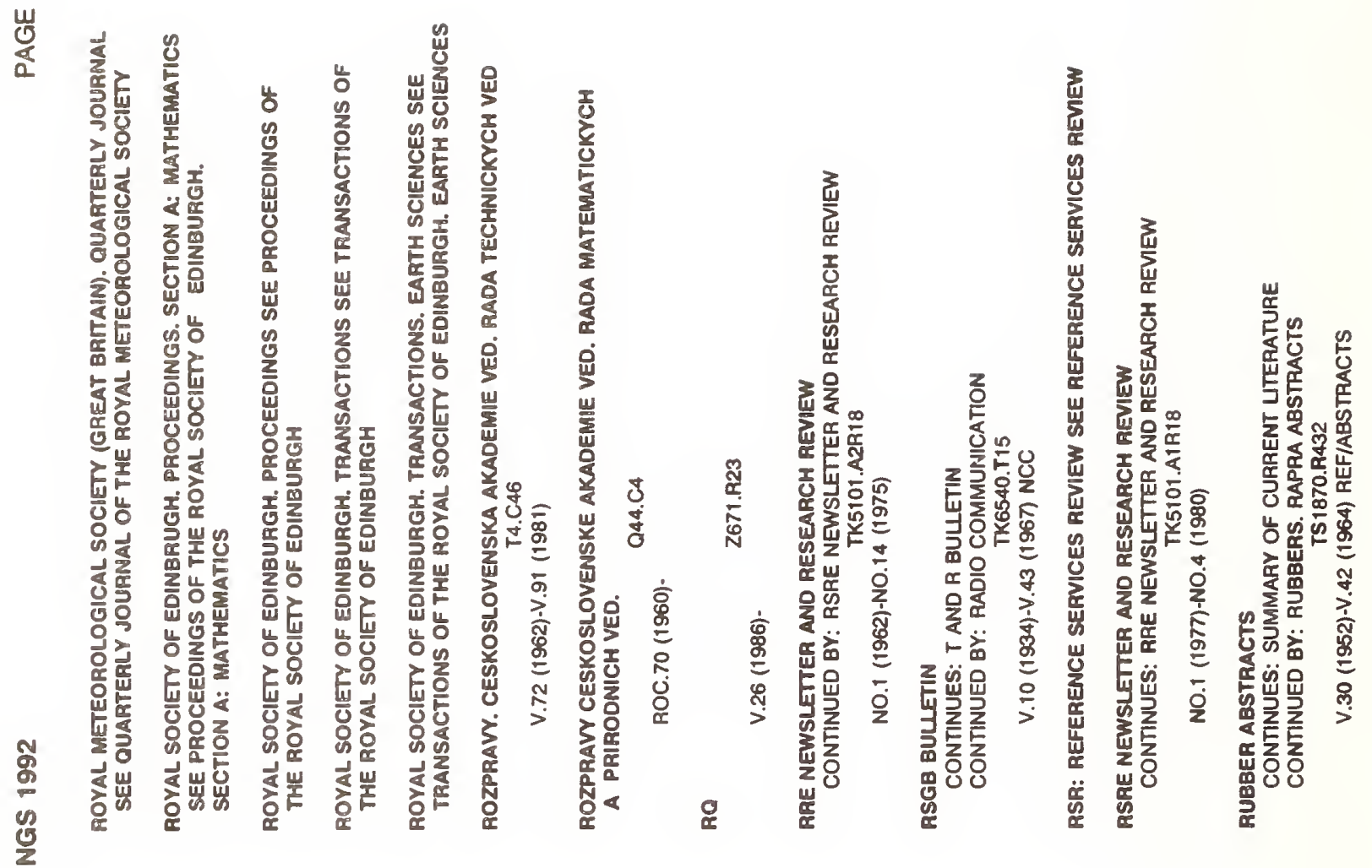


$\stackrel{n}{N}$

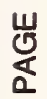
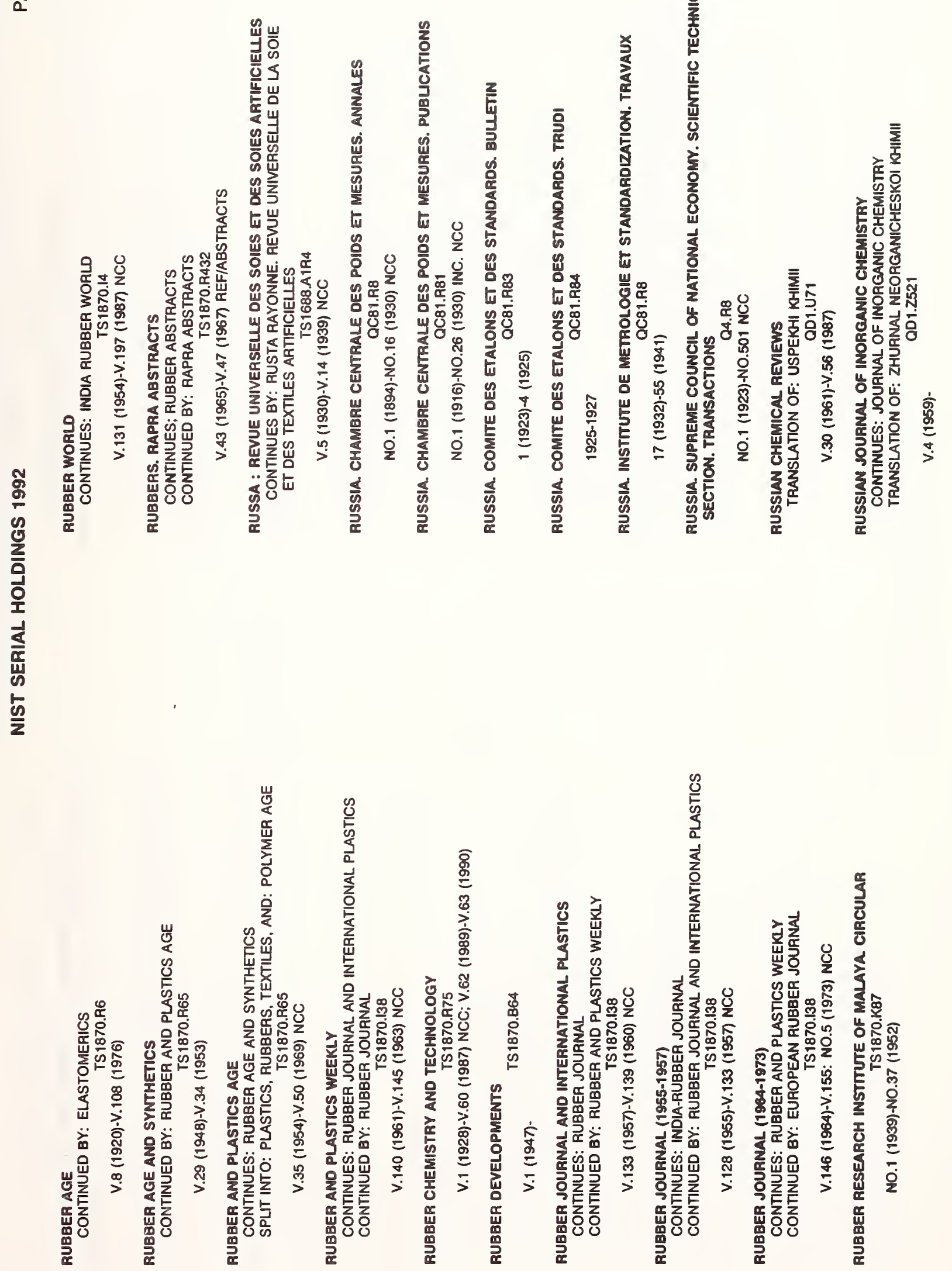


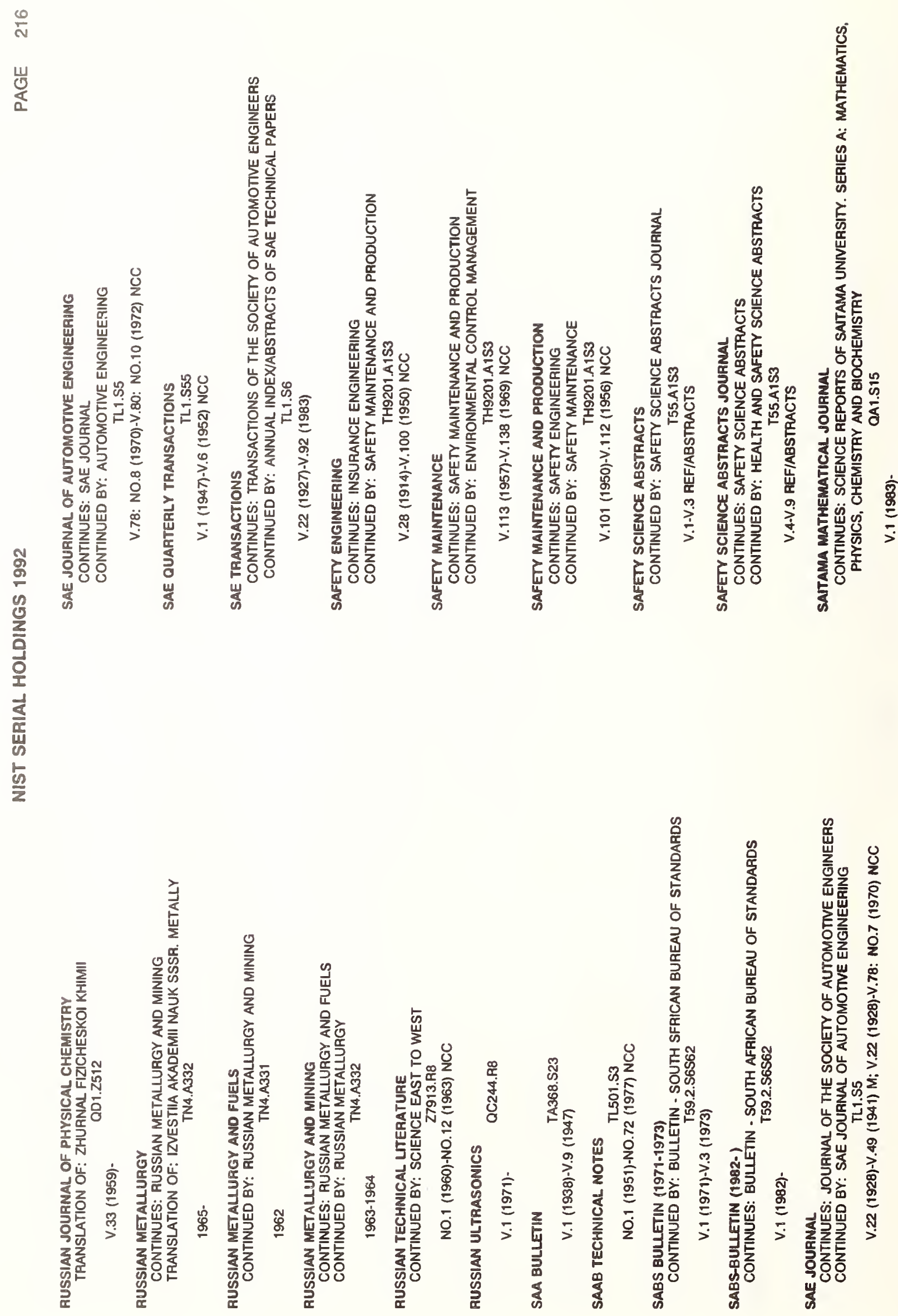




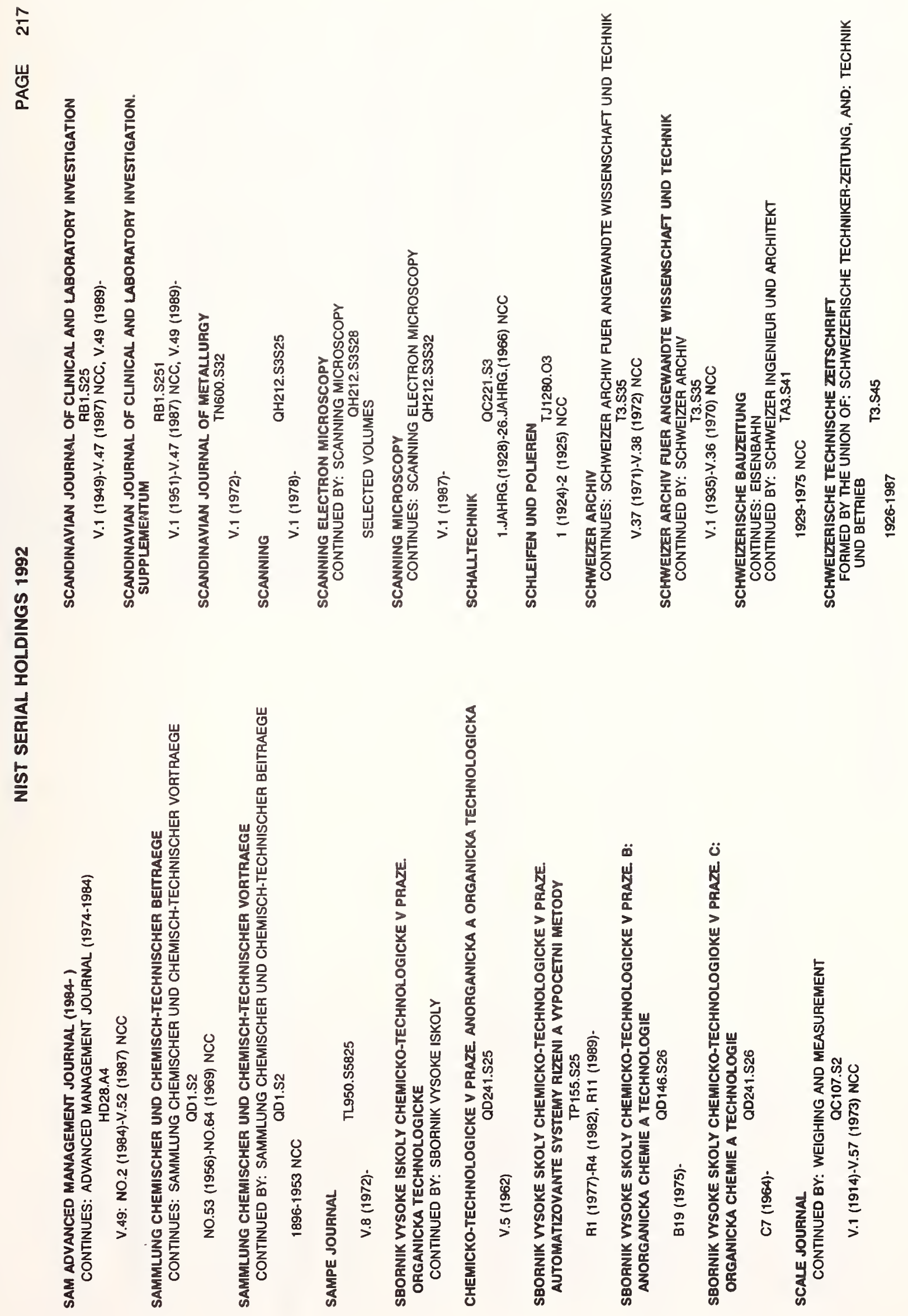


$\frac{\infty}{N}$
$\frac{w}{\alpha}$
$\frac{0}{2}$
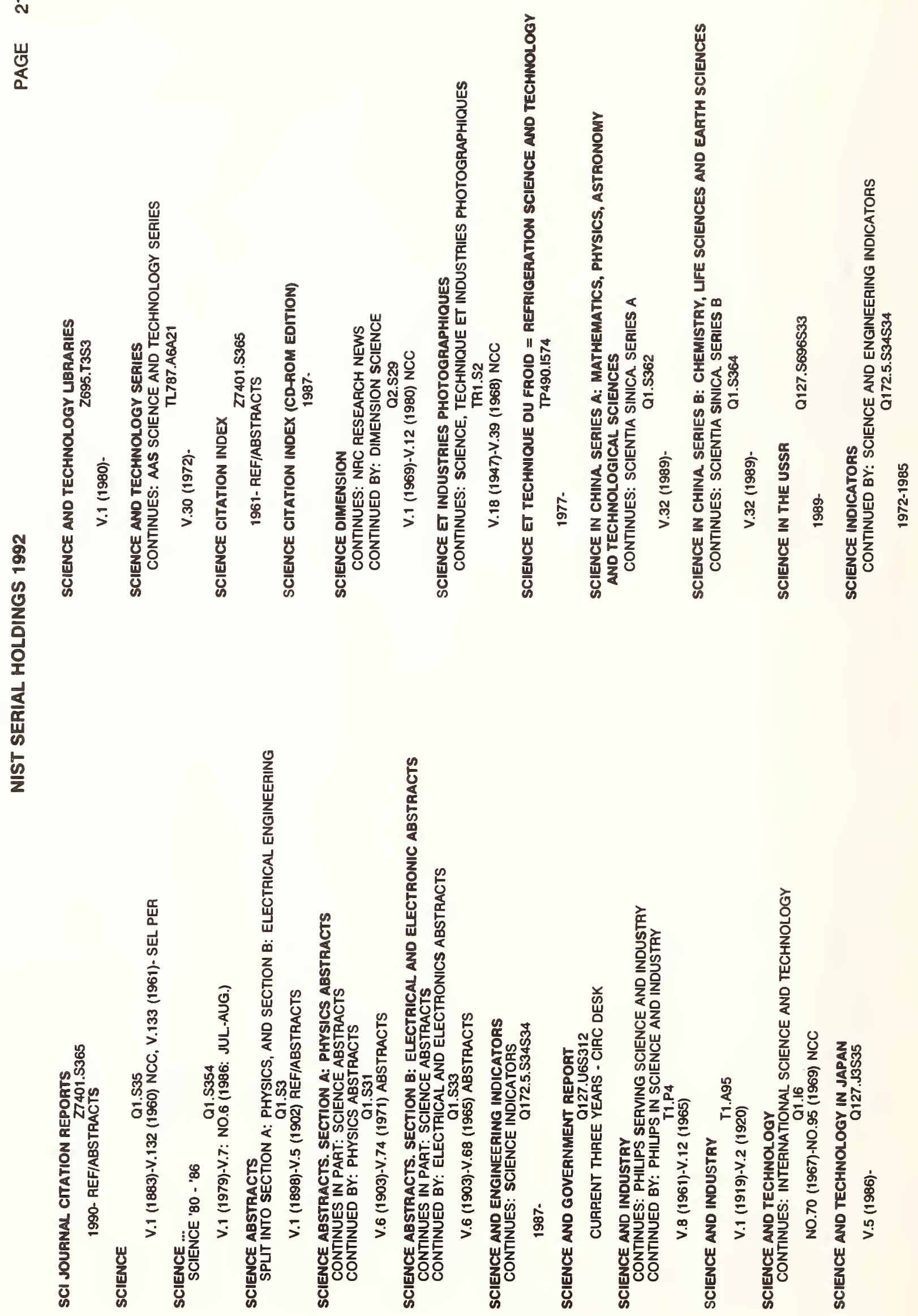


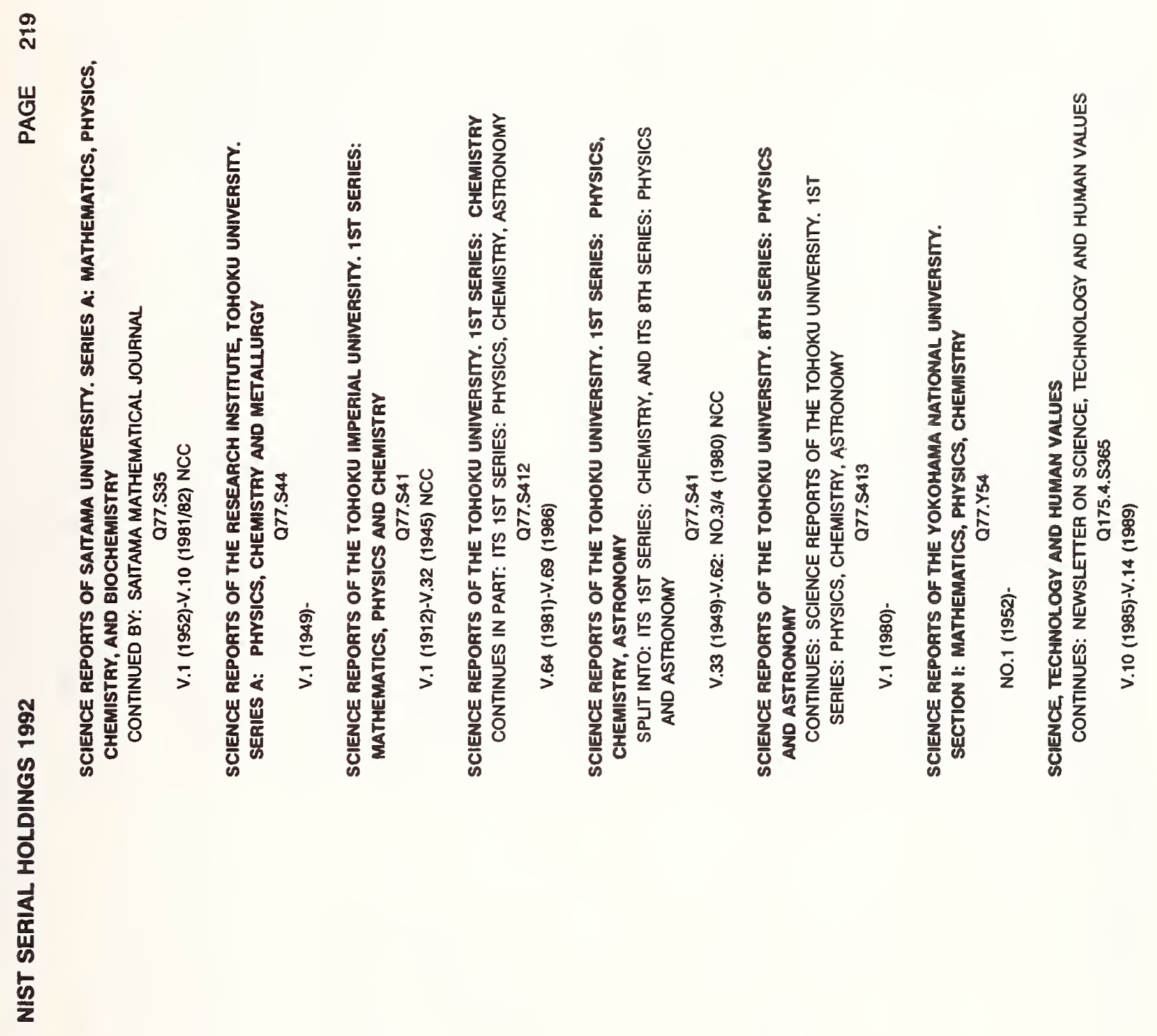

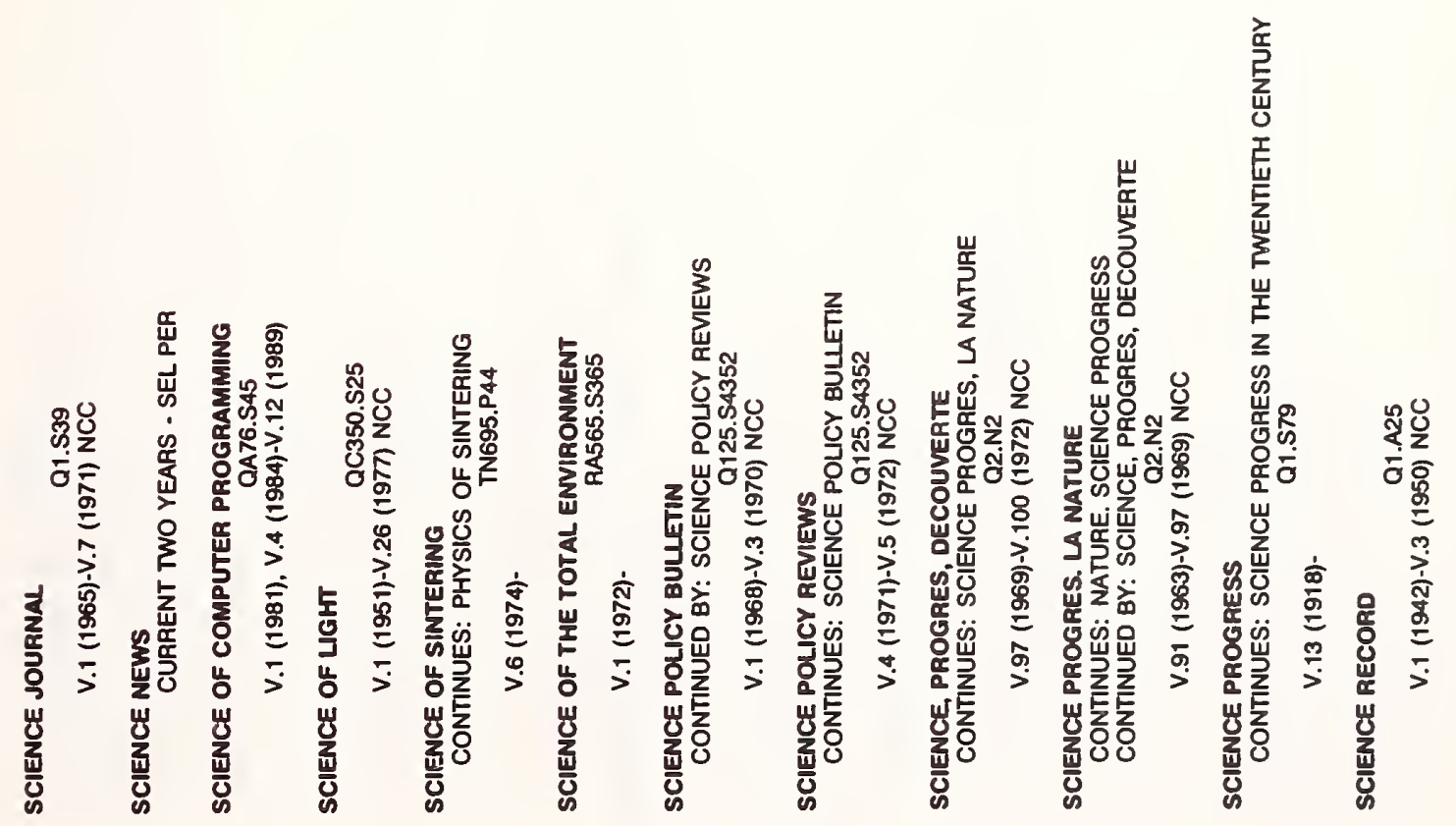




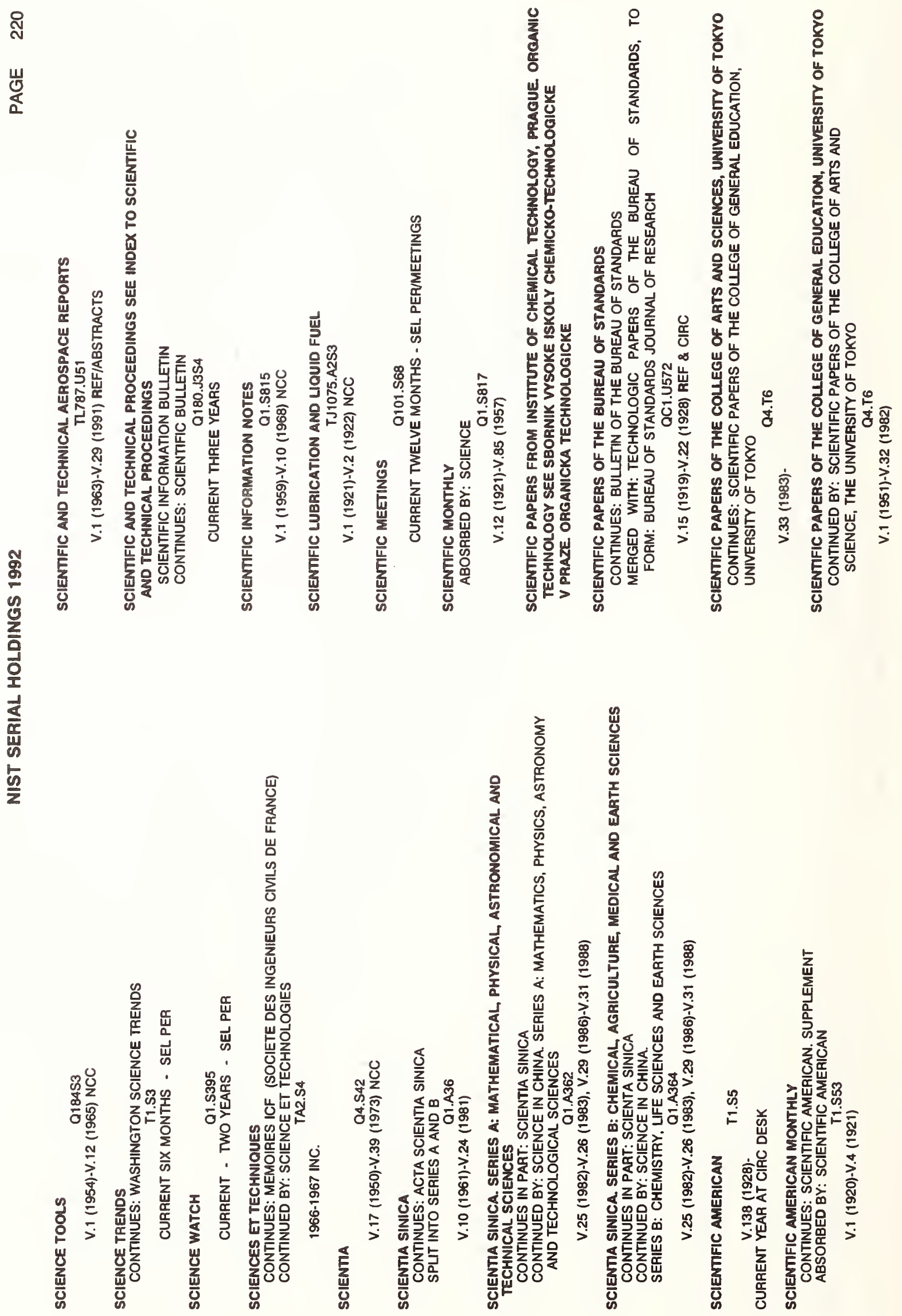


$\overline{\text { ง }}$

㠓

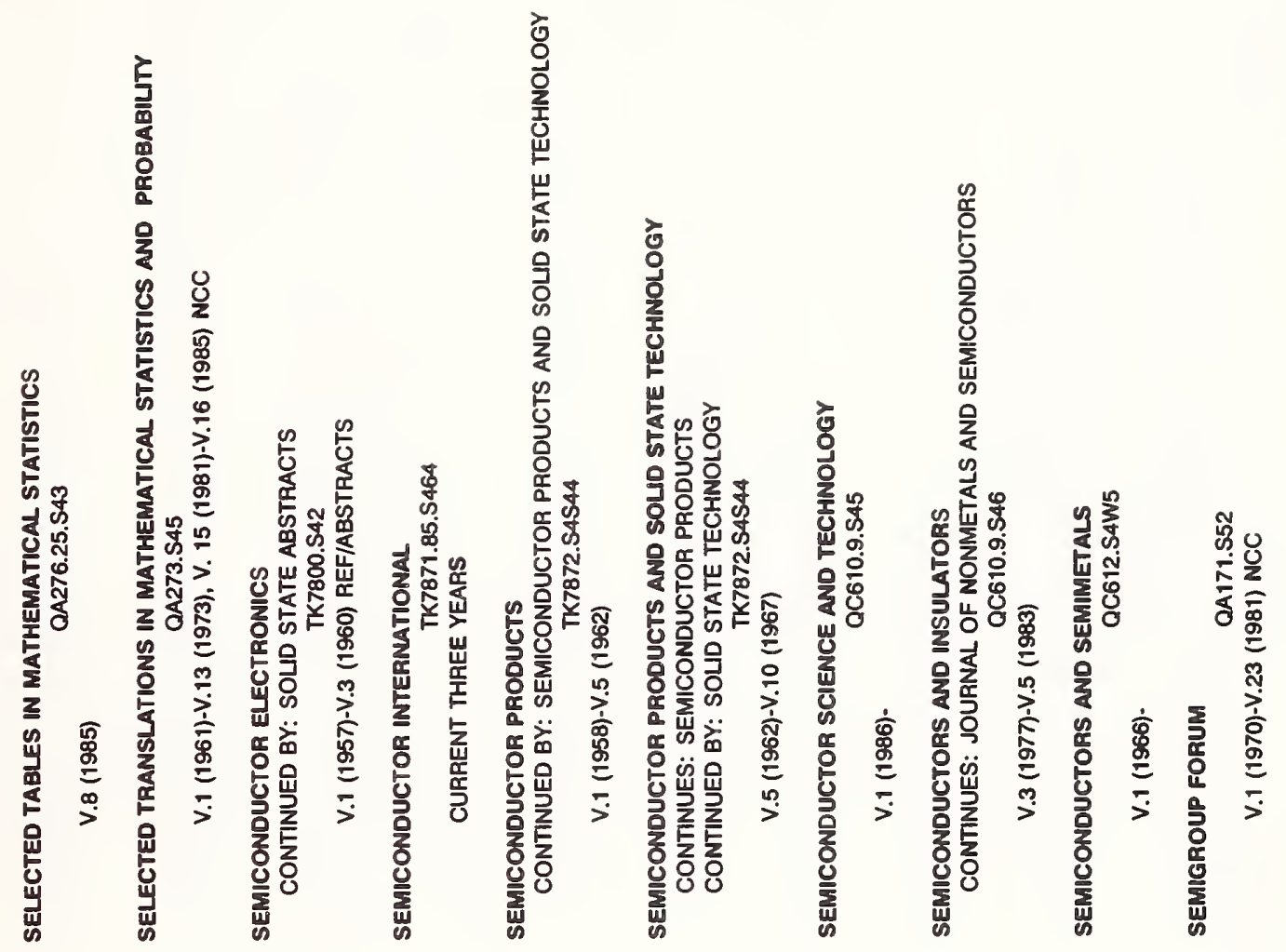

을

䊐

竧

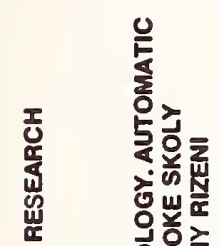

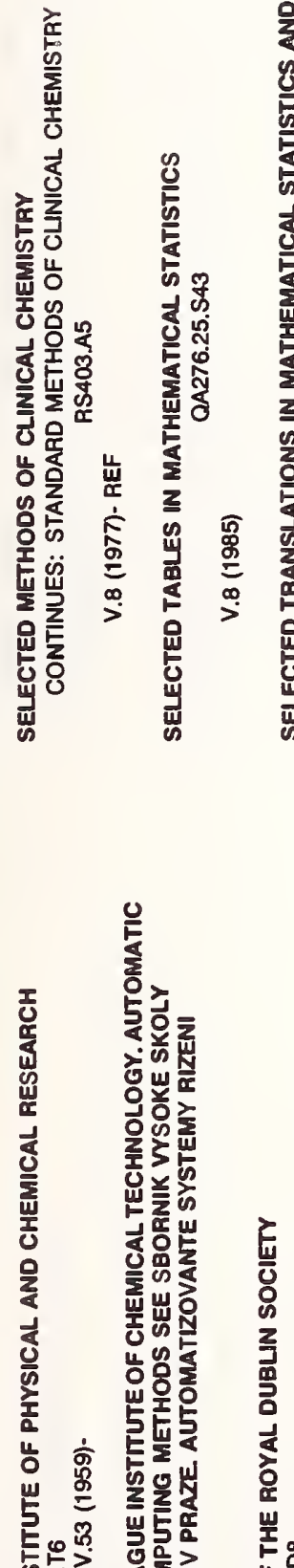

용

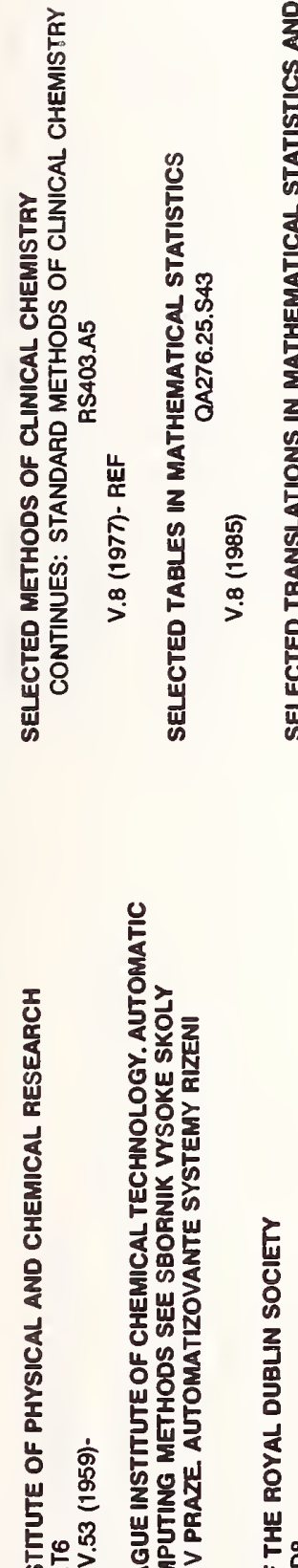

塎

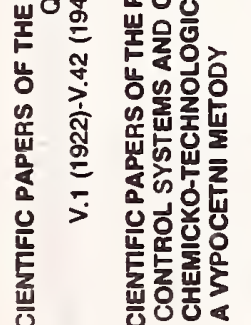

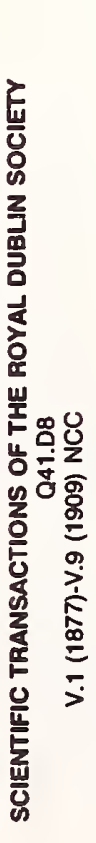

年

崖

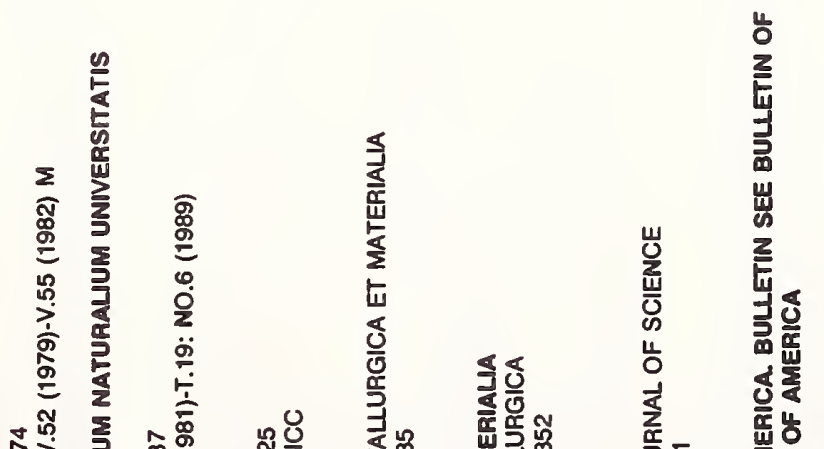

落

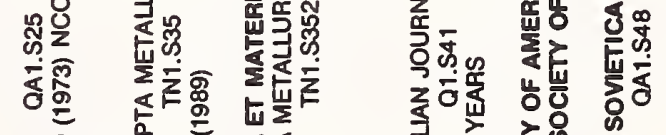




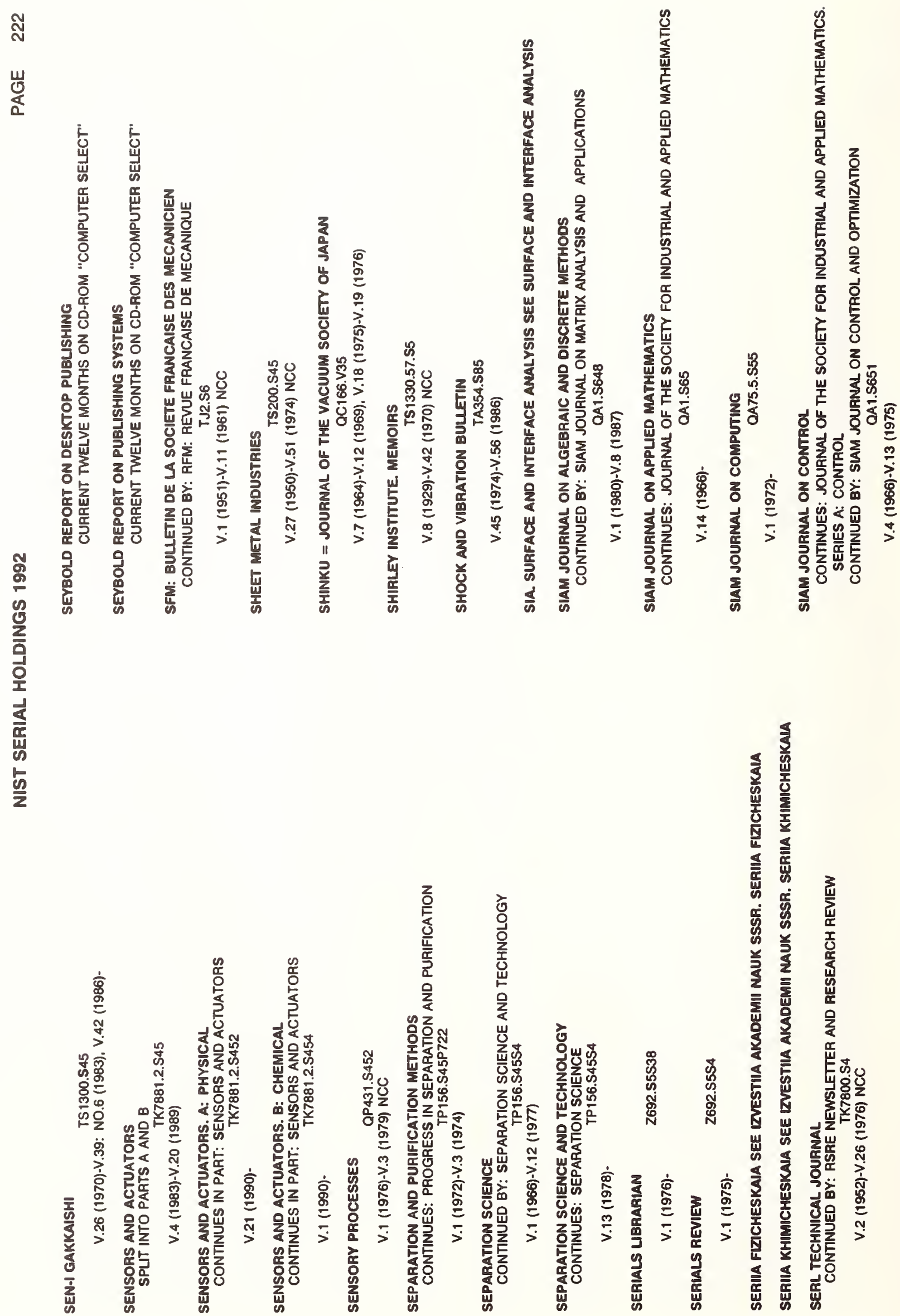


สู

岁
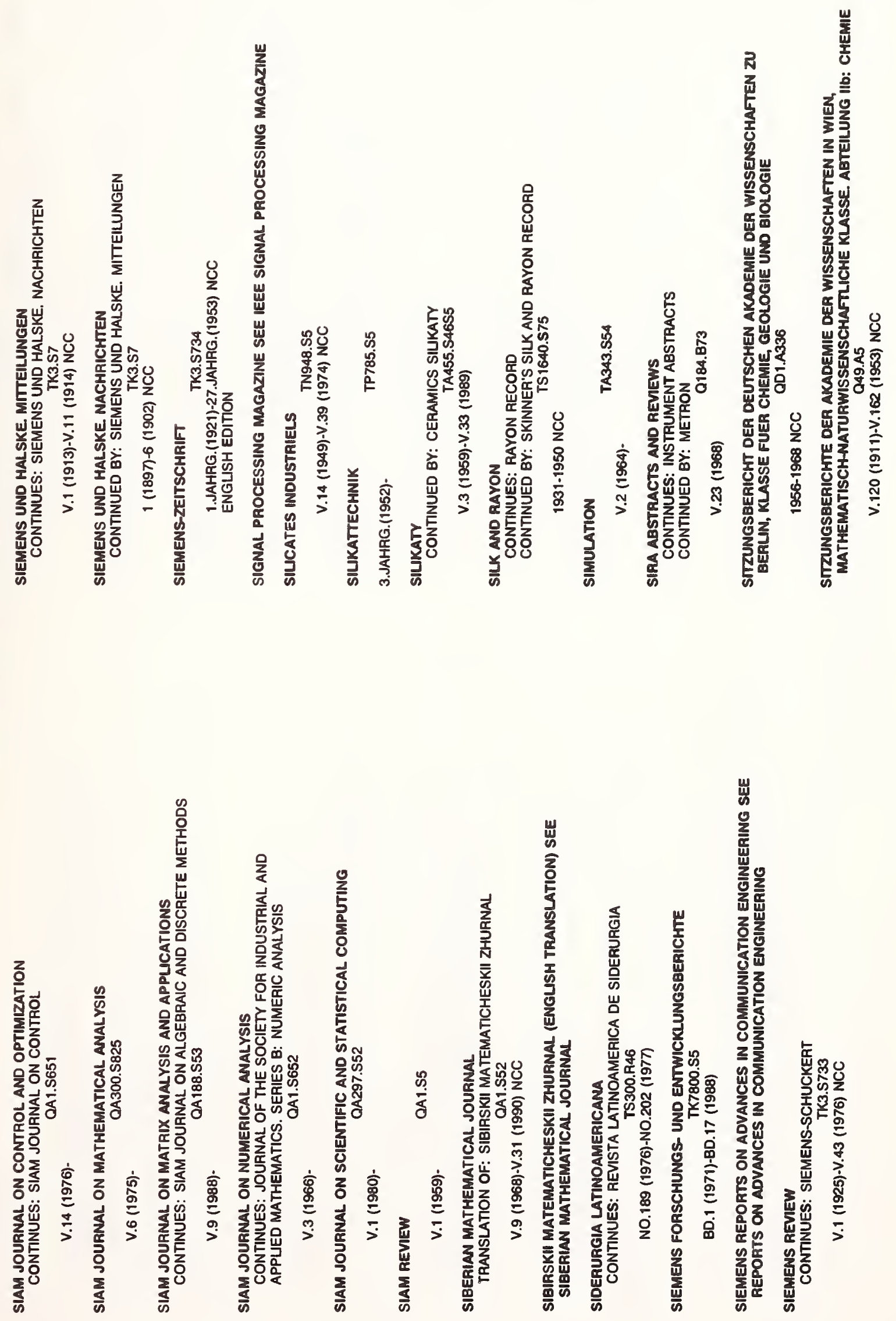


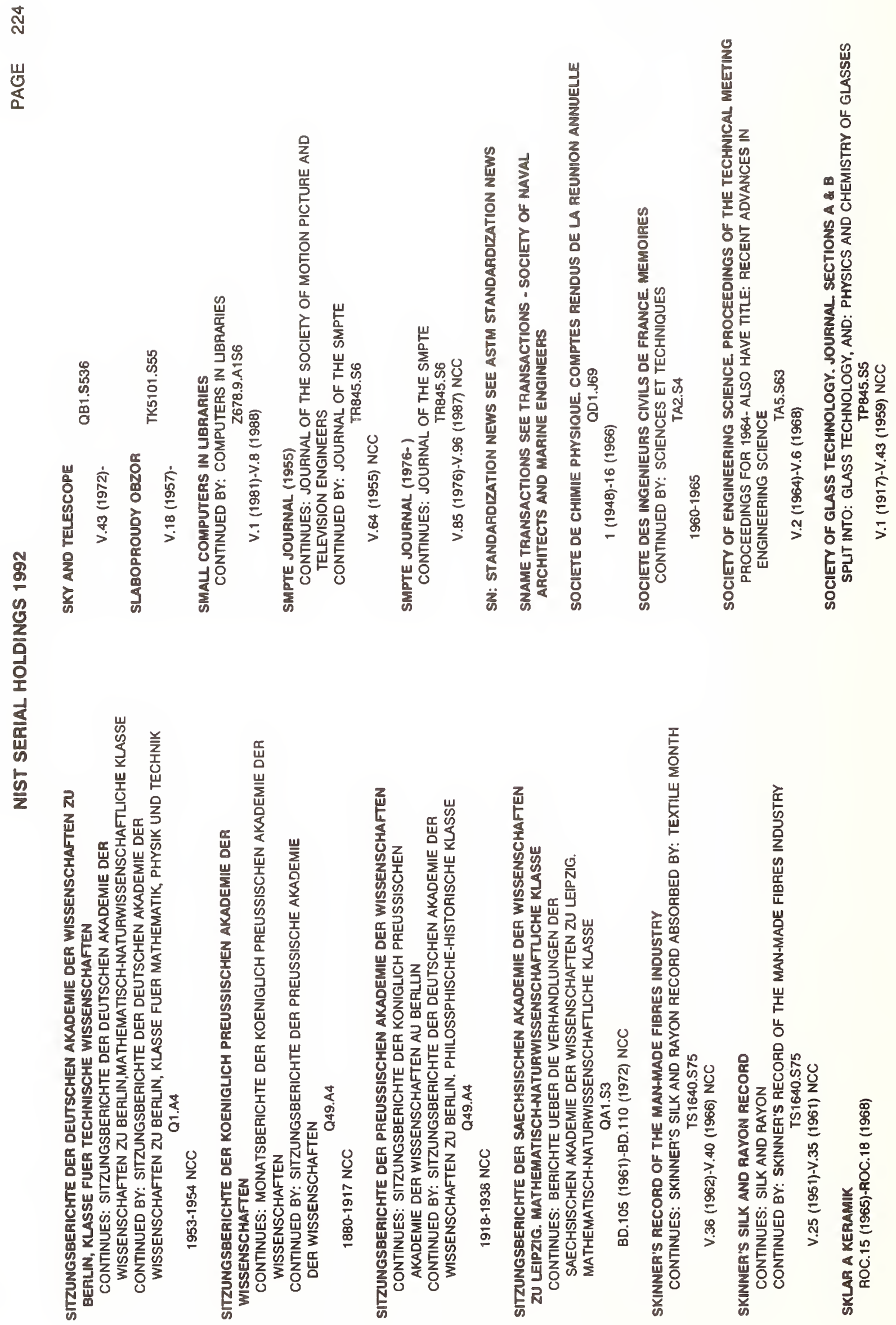


敢

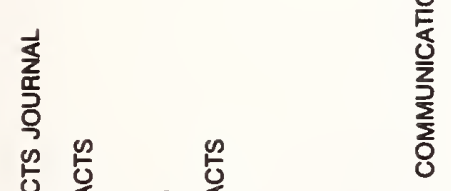

을

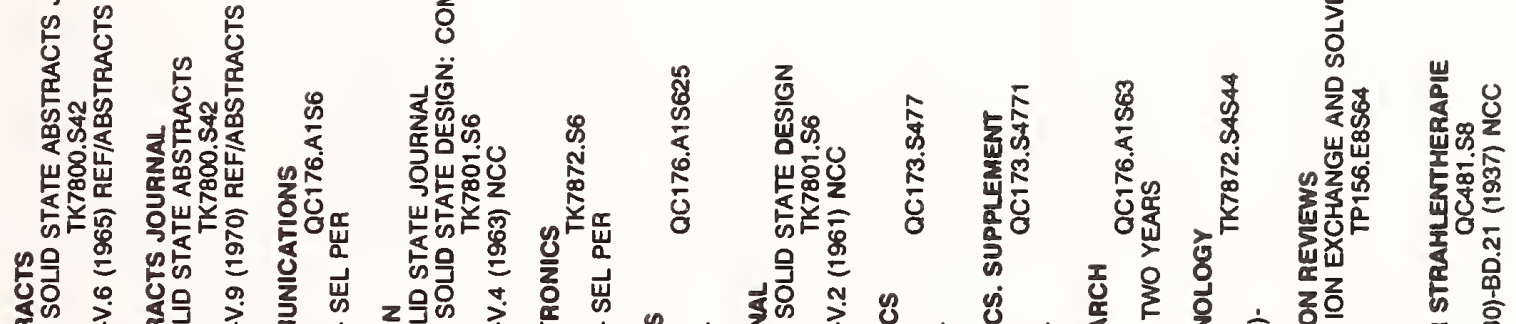

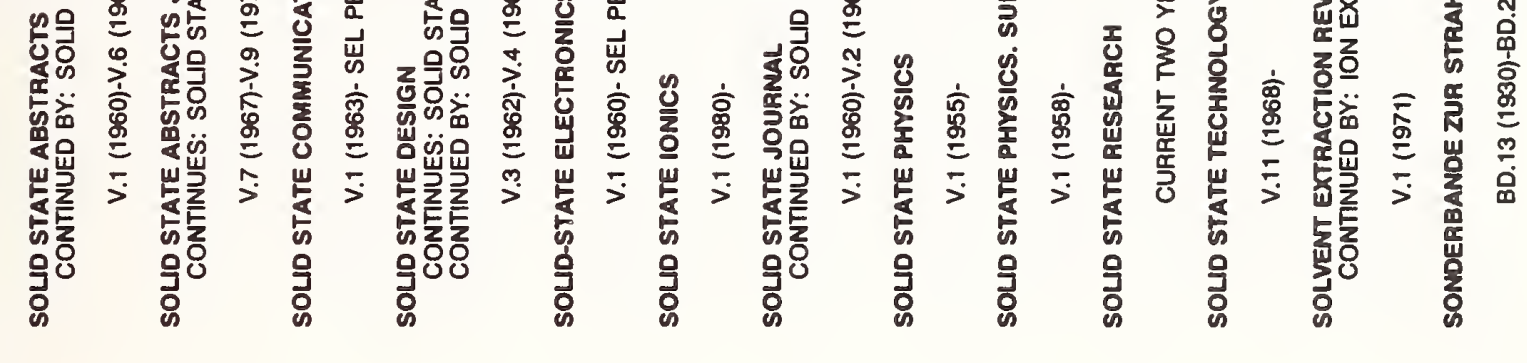

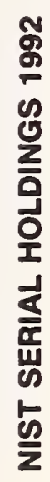

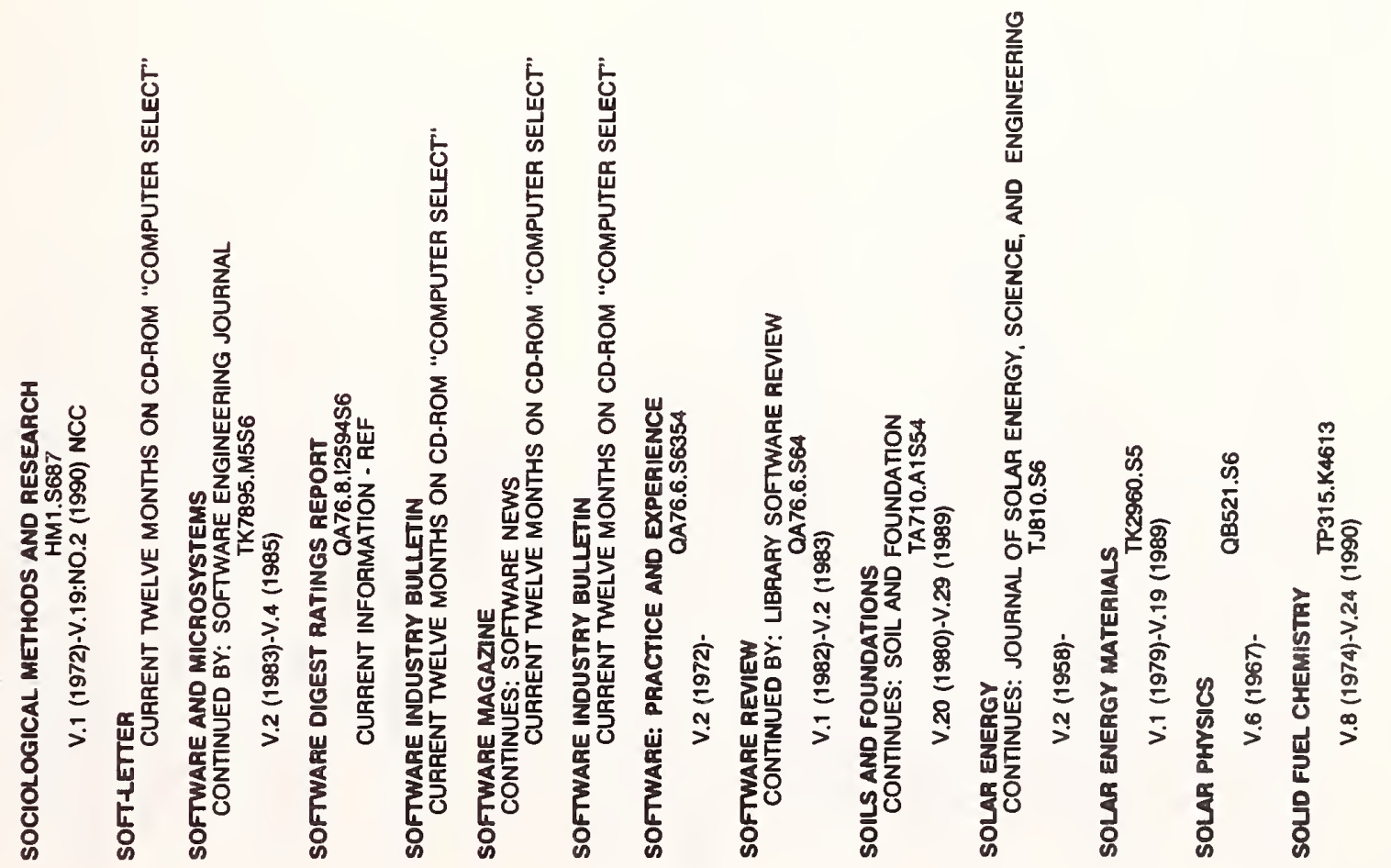


สํ

삠

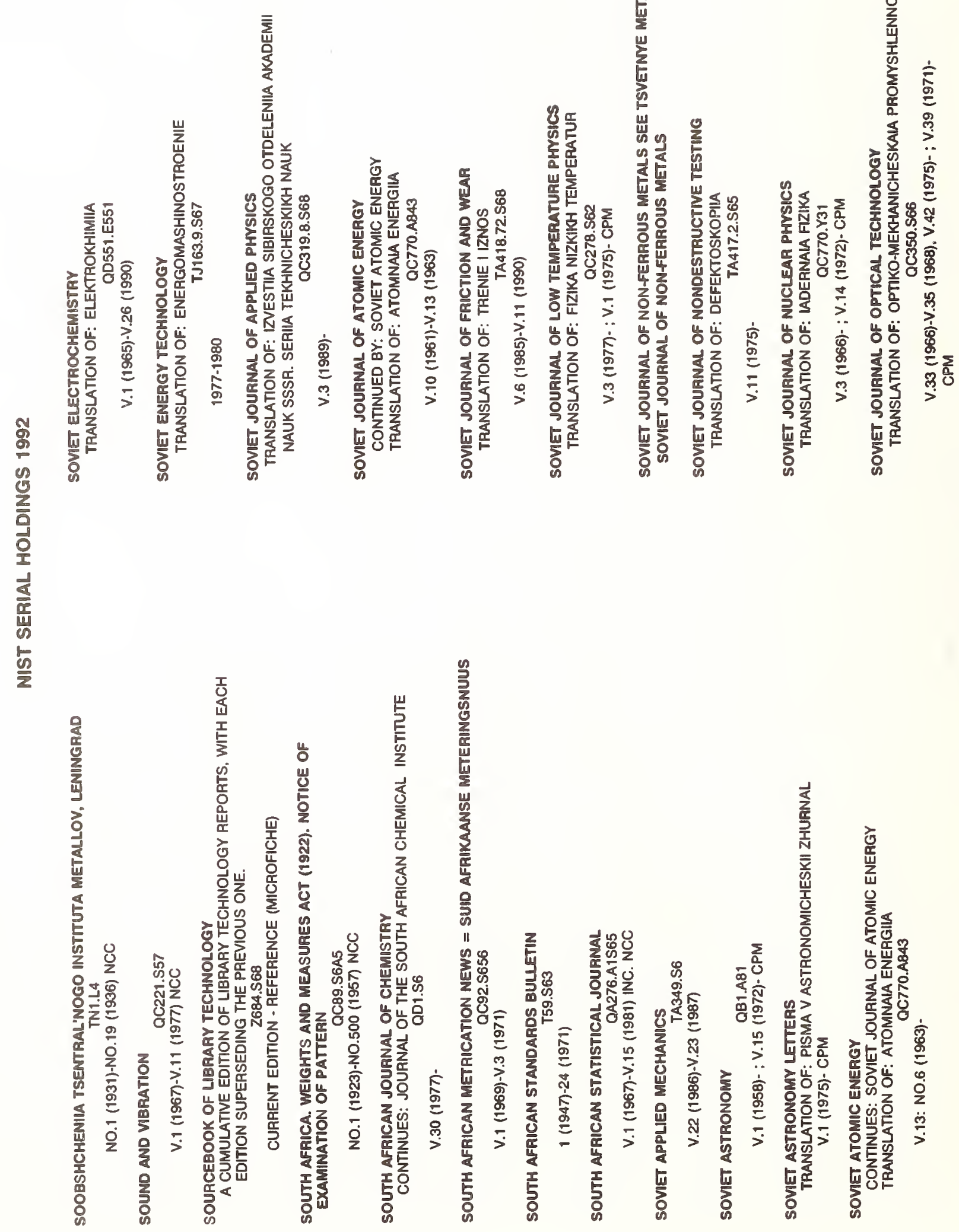


สิ

嵌

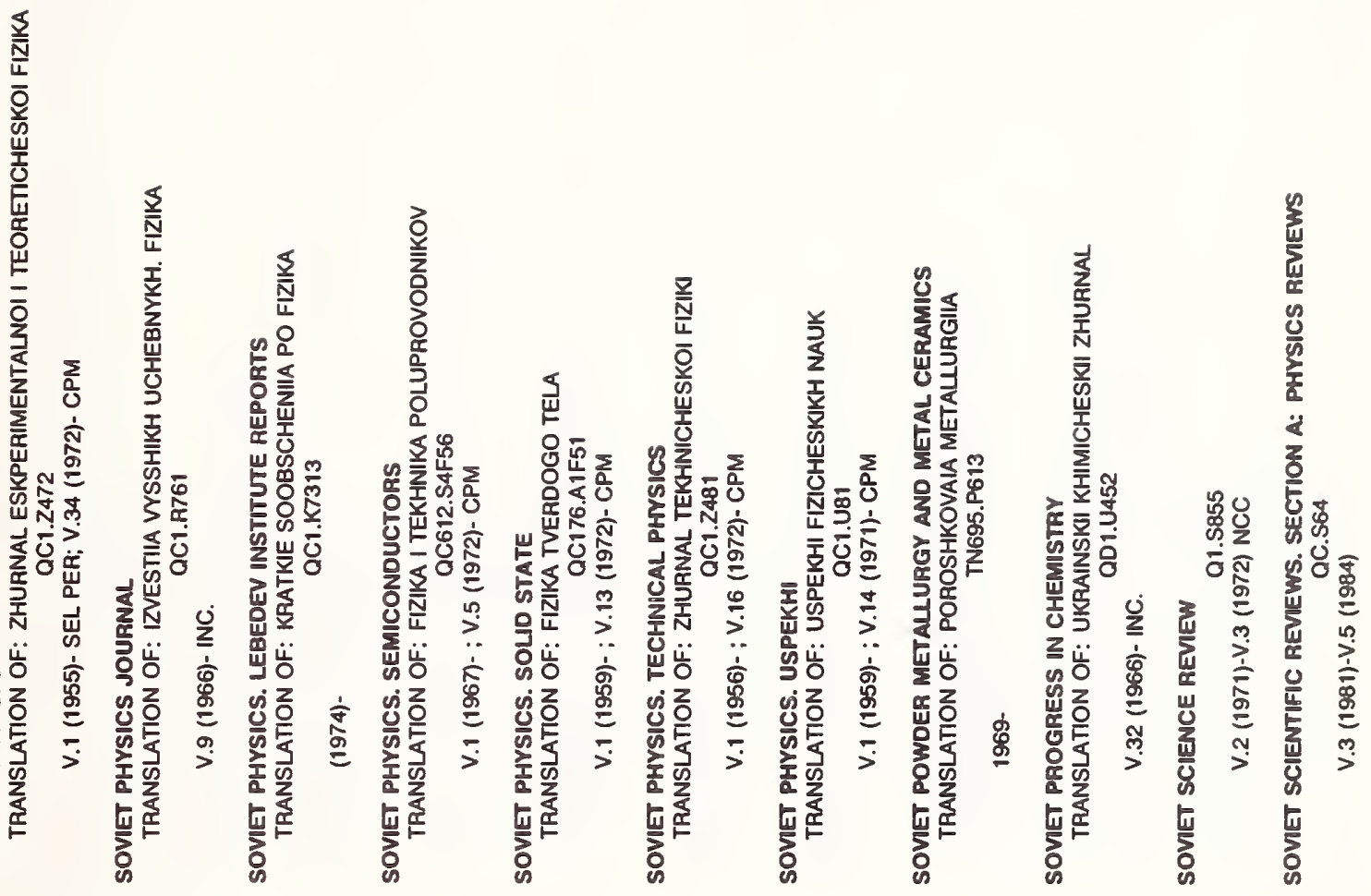

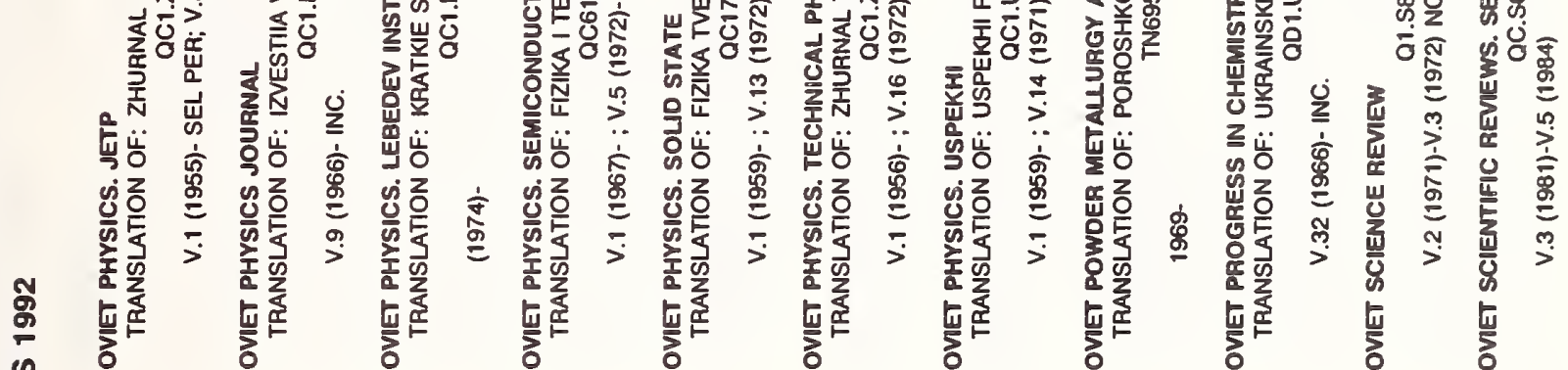

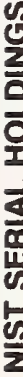

$\frac{5}{2}$

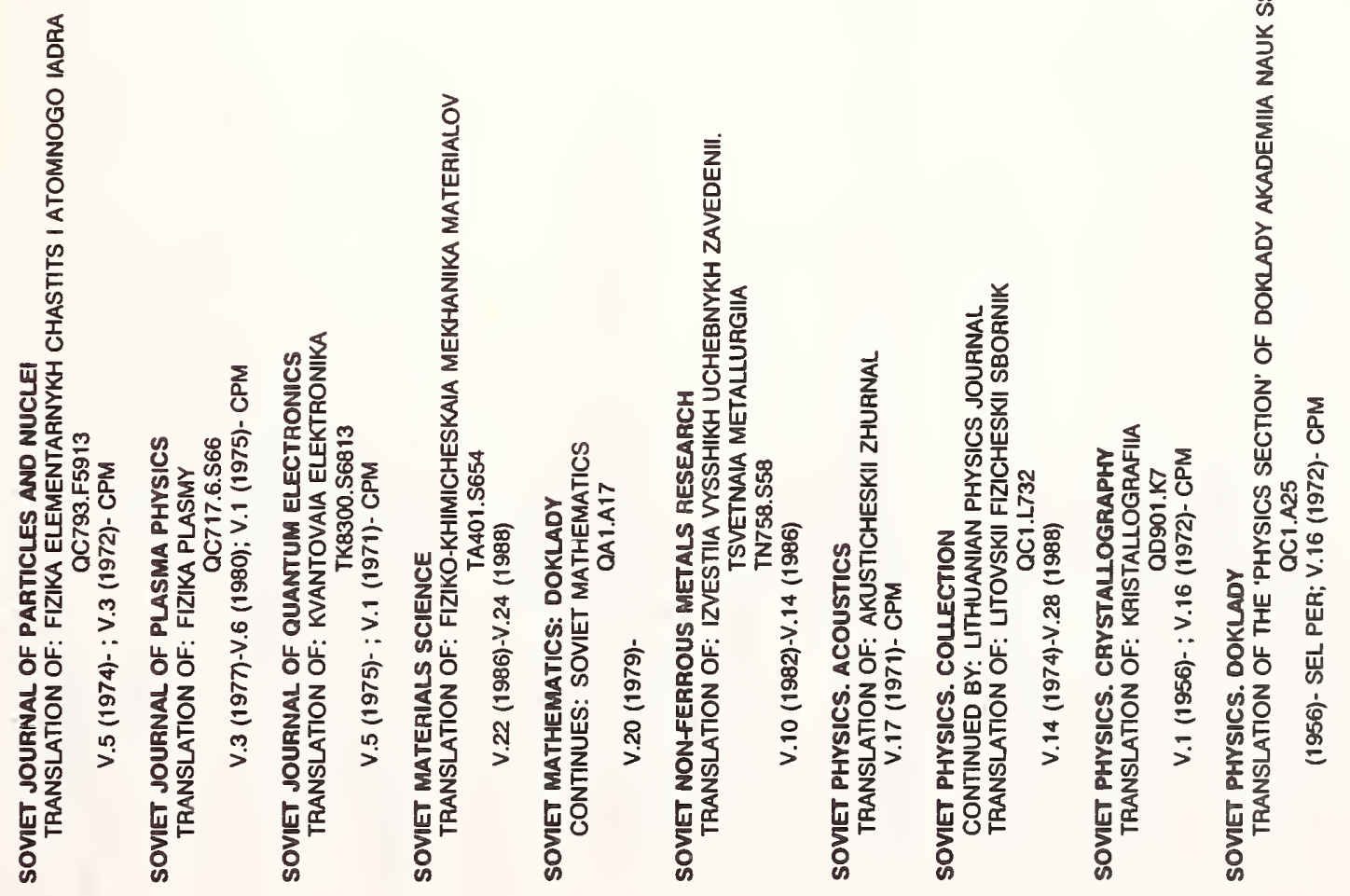




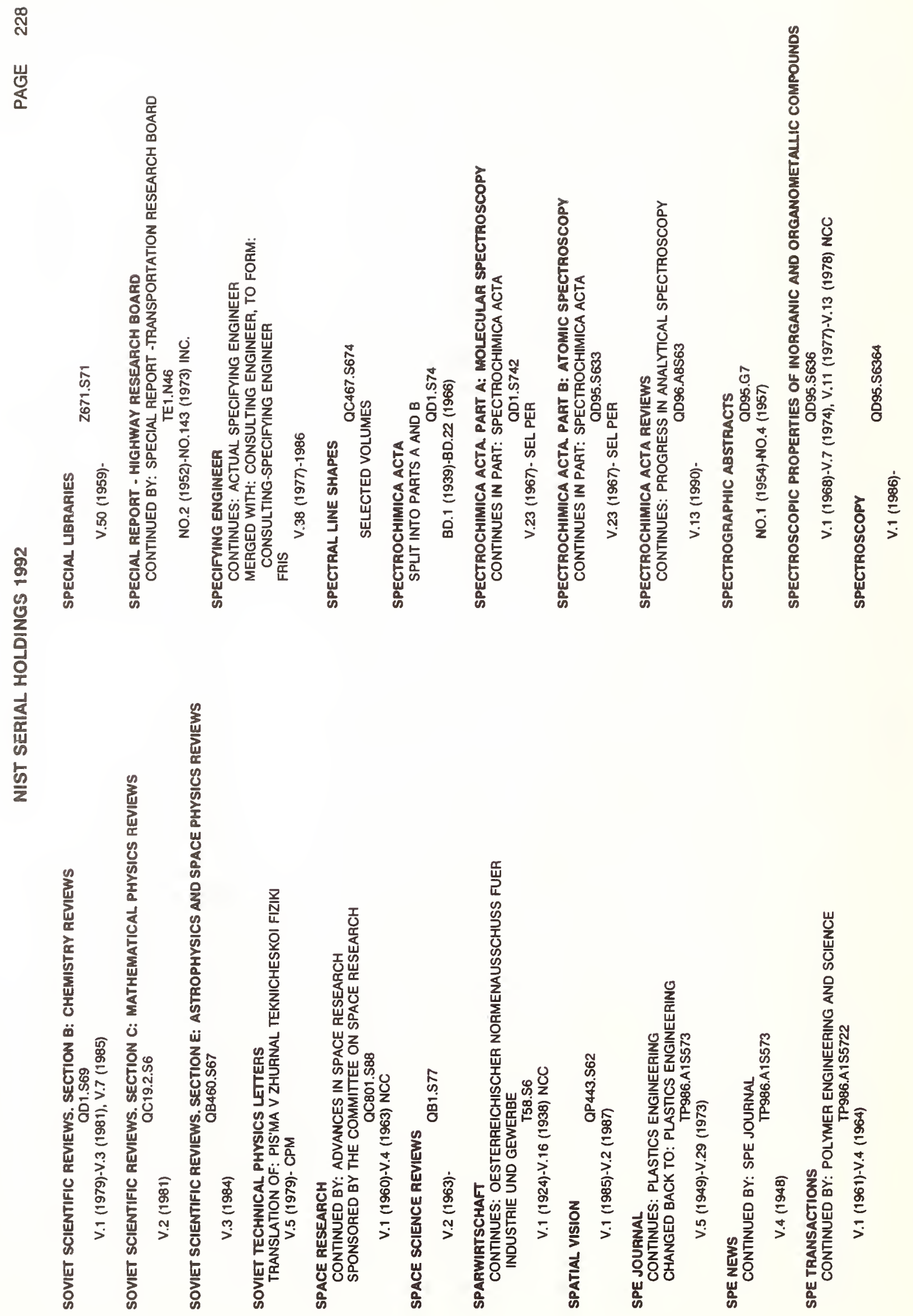


胥

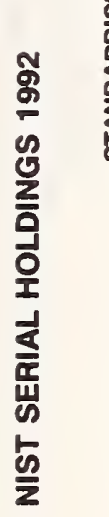
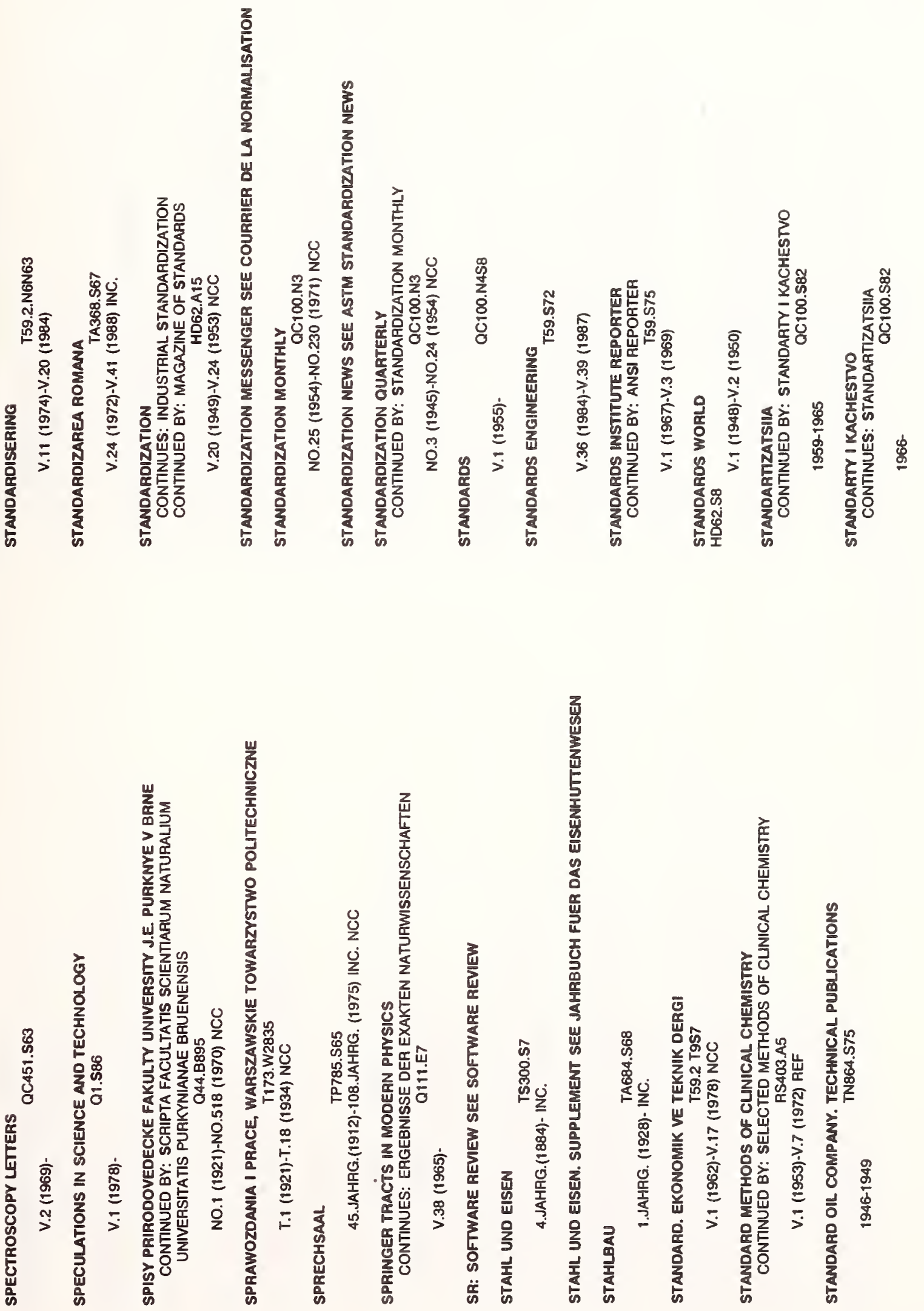

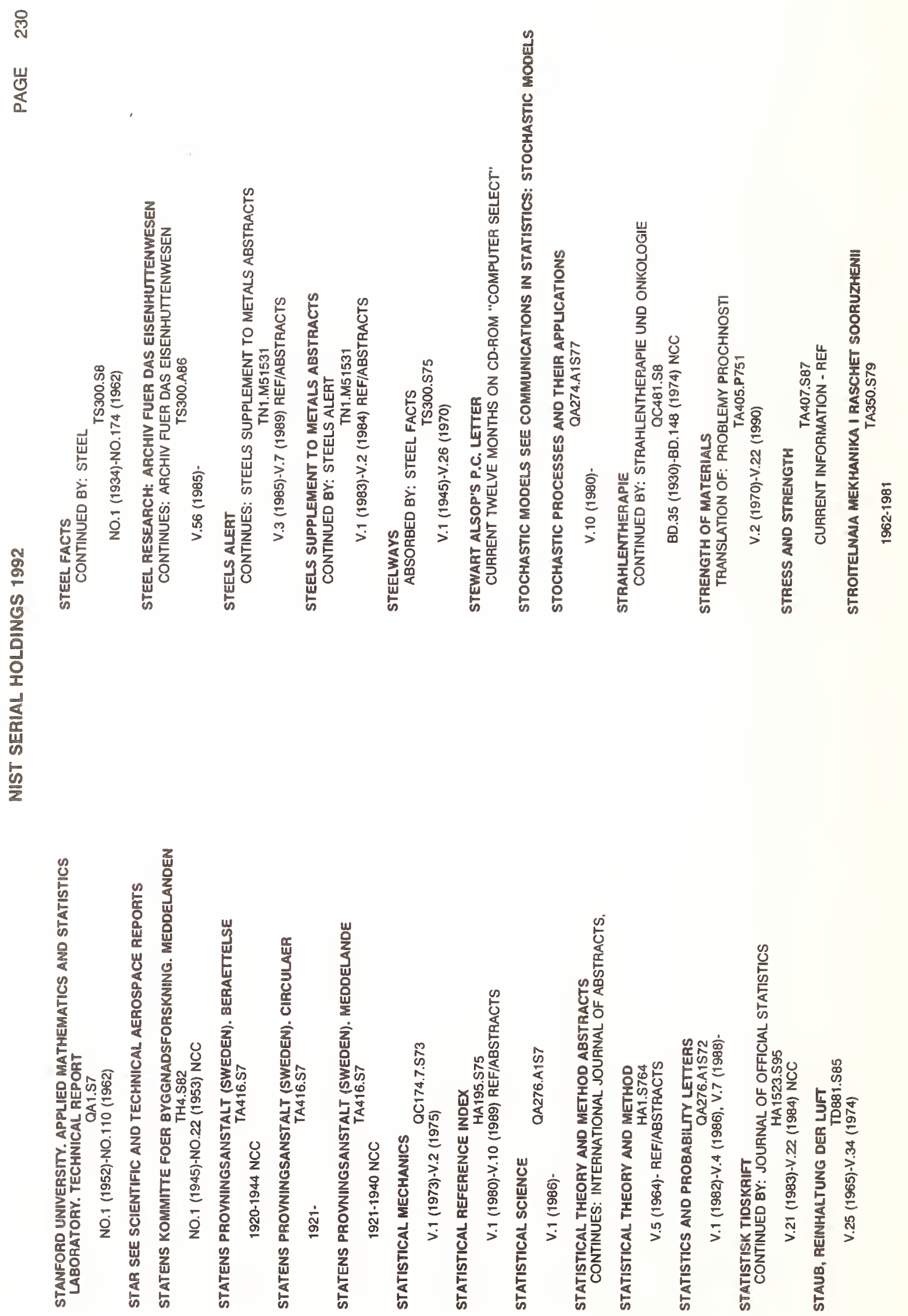
产

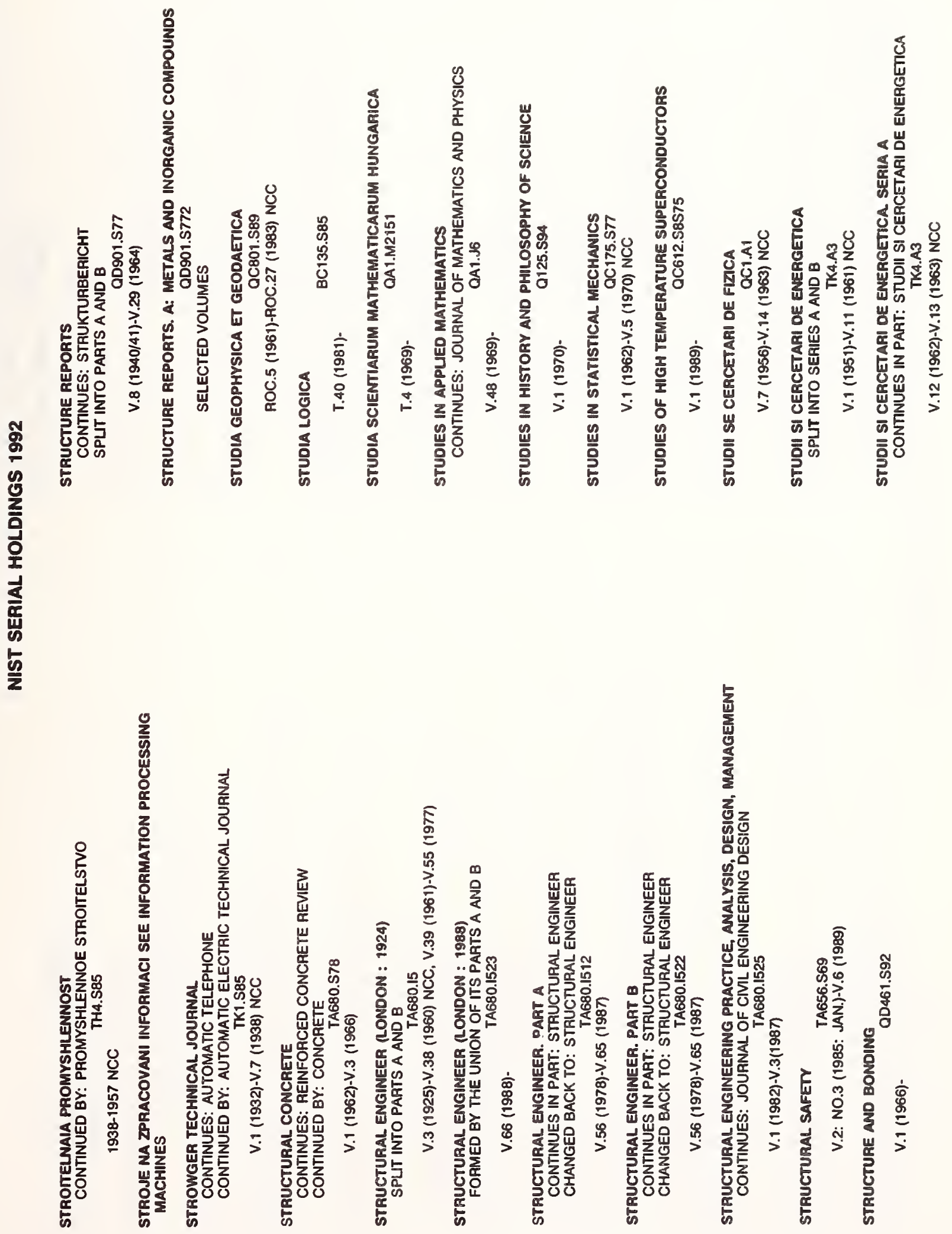


沉

嵌
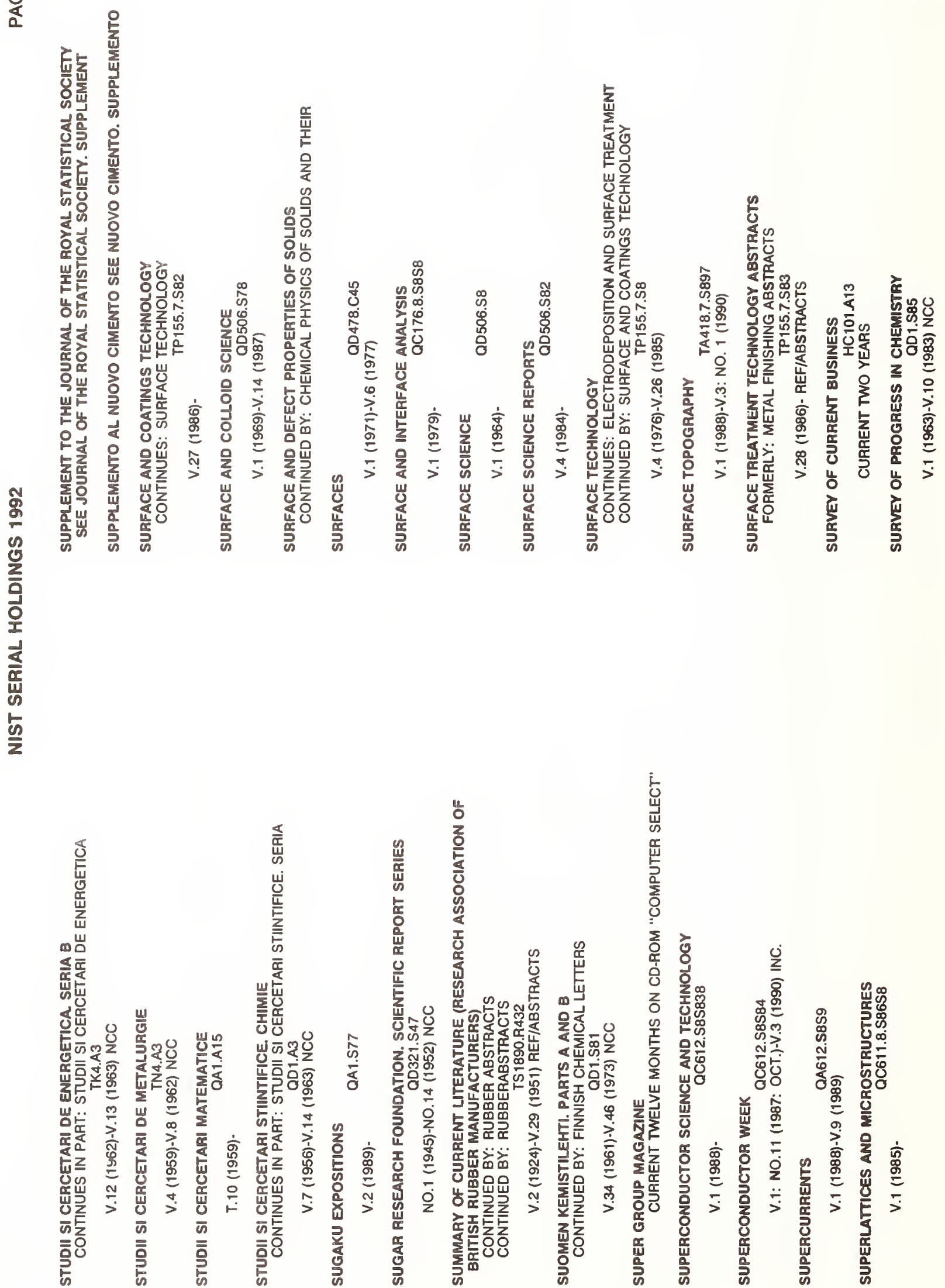


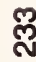

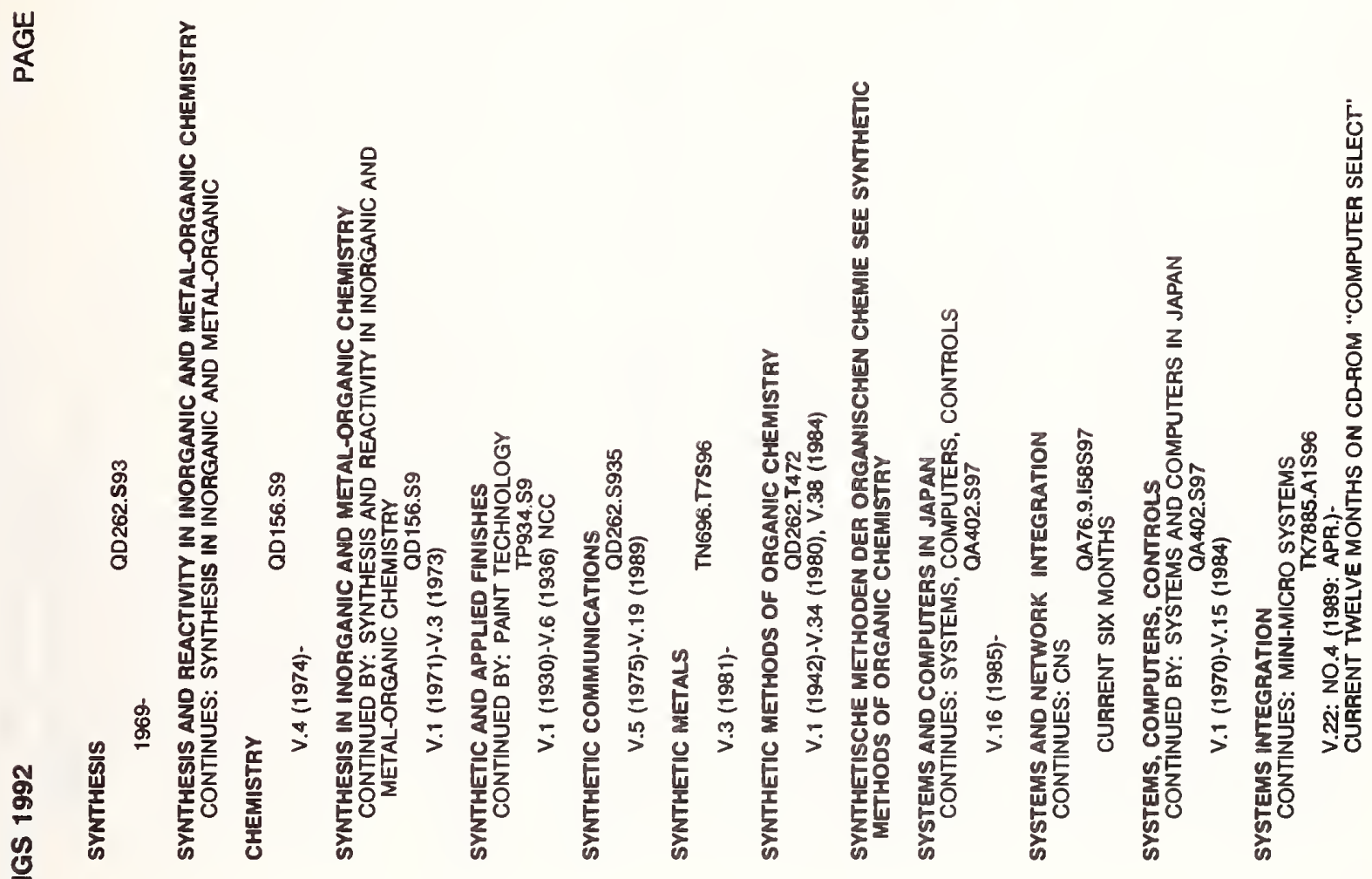

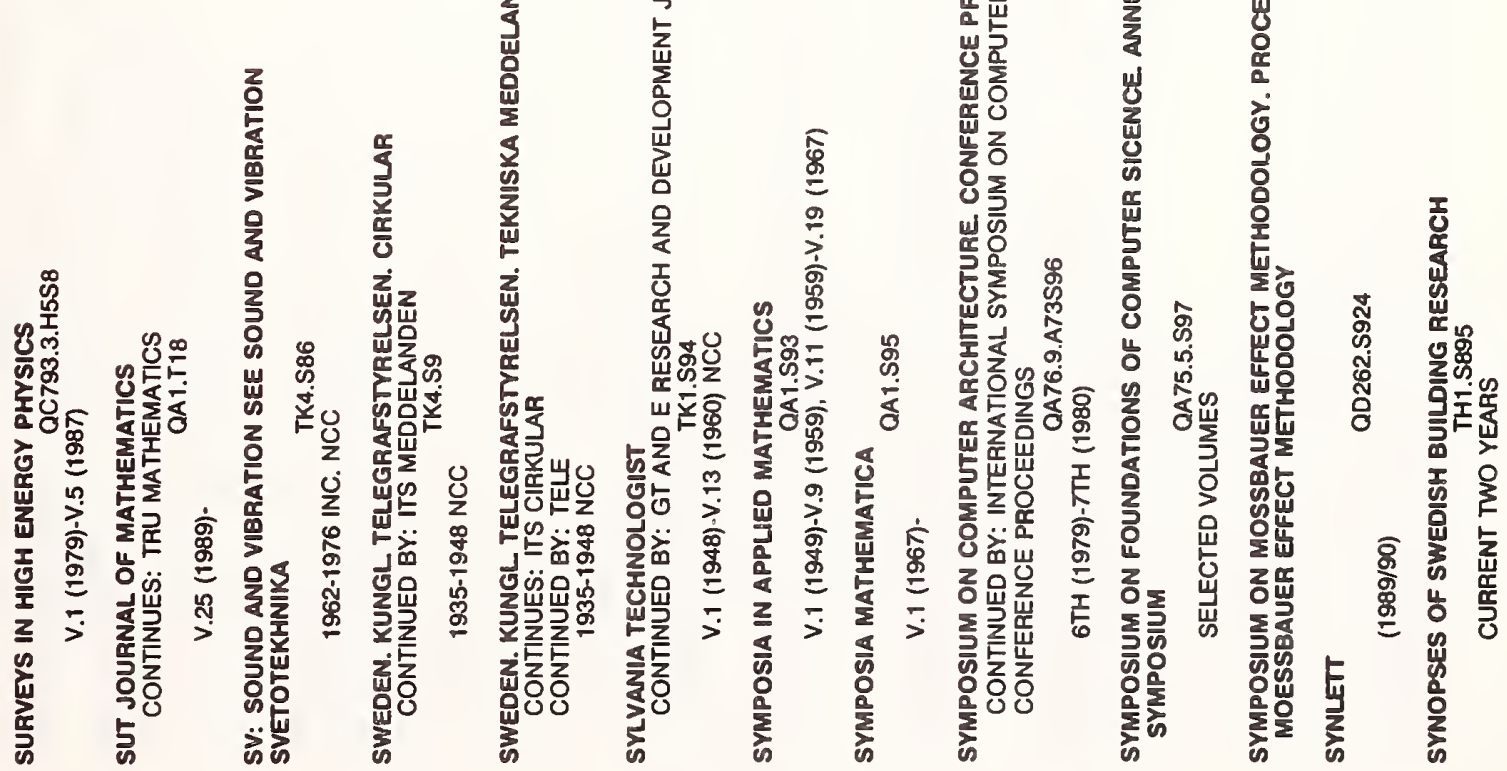


芯

峞

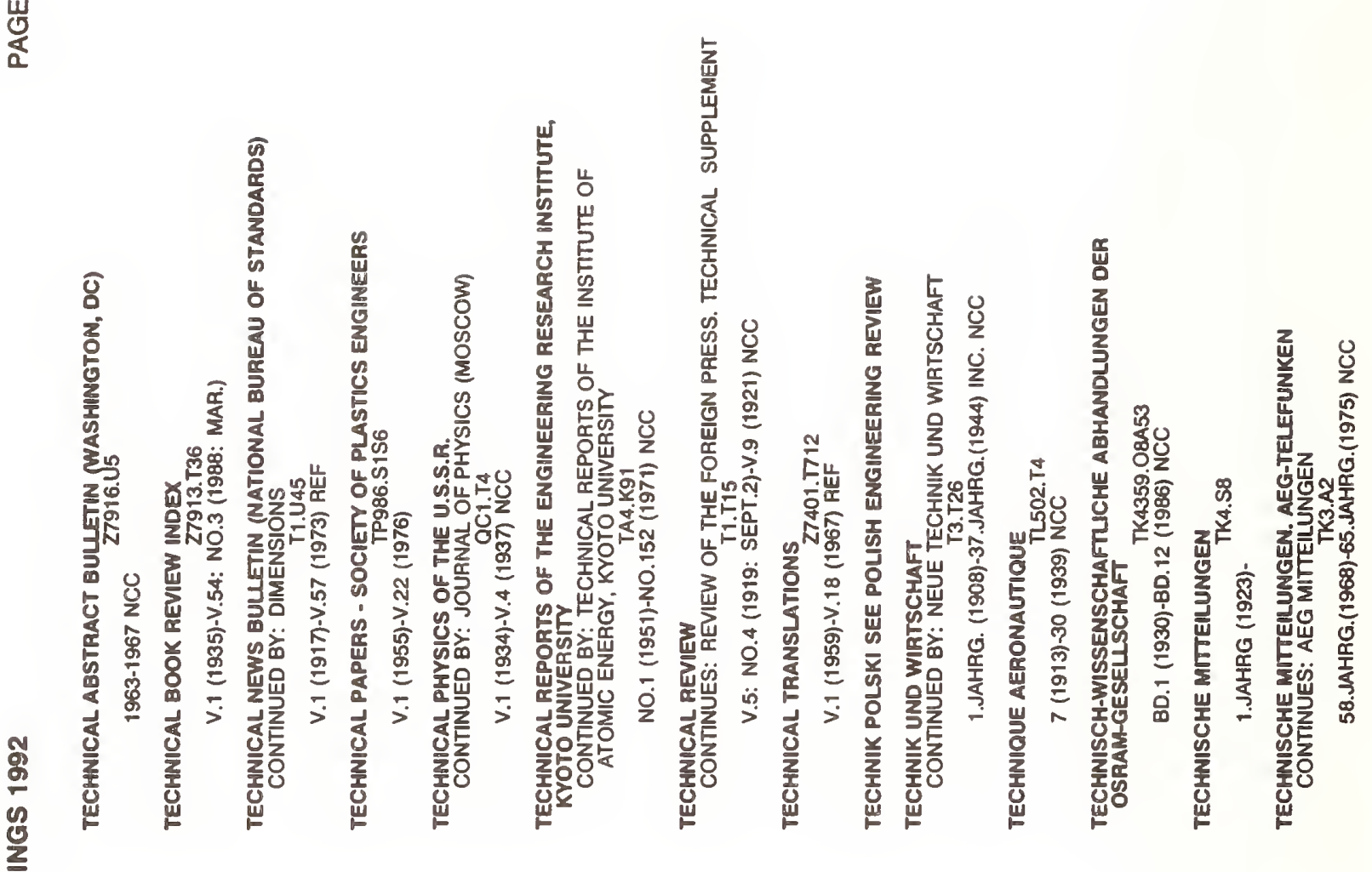


产

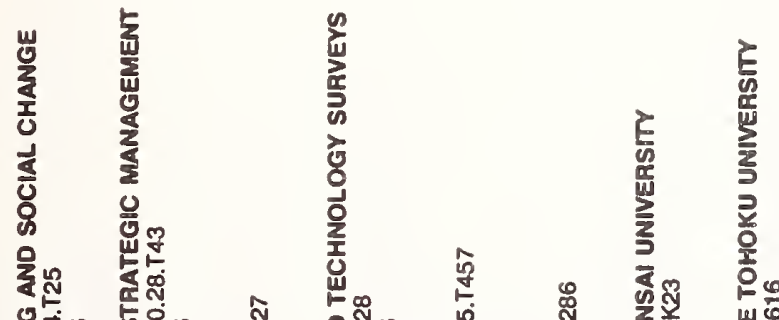

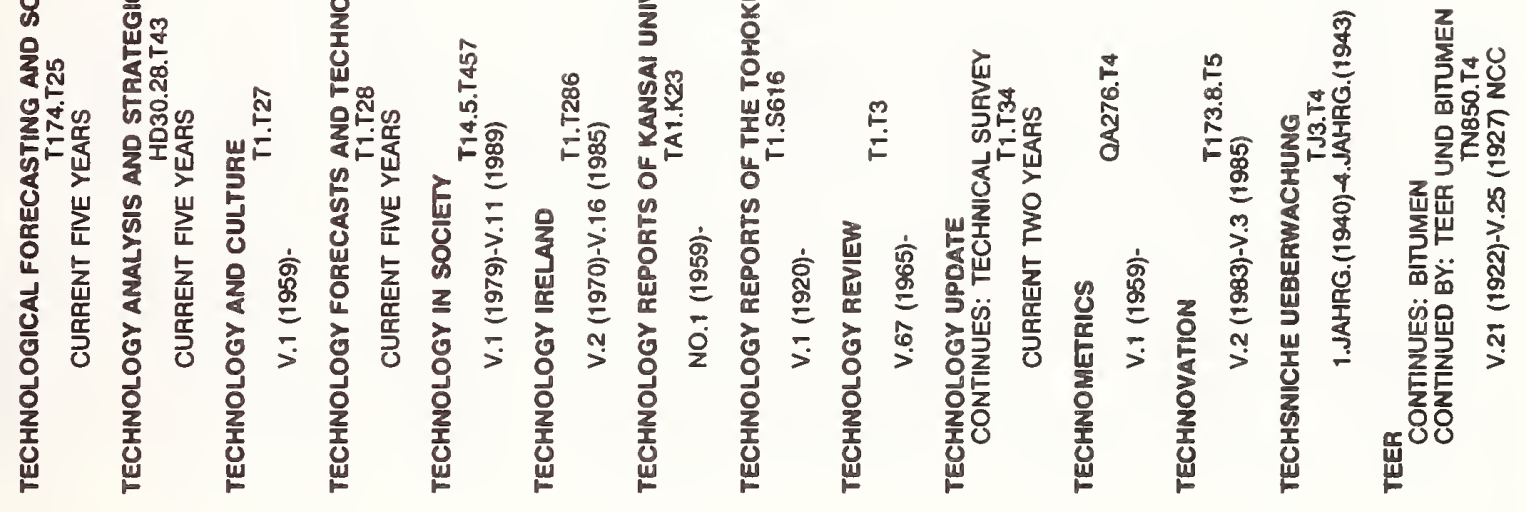

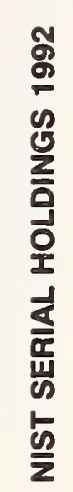

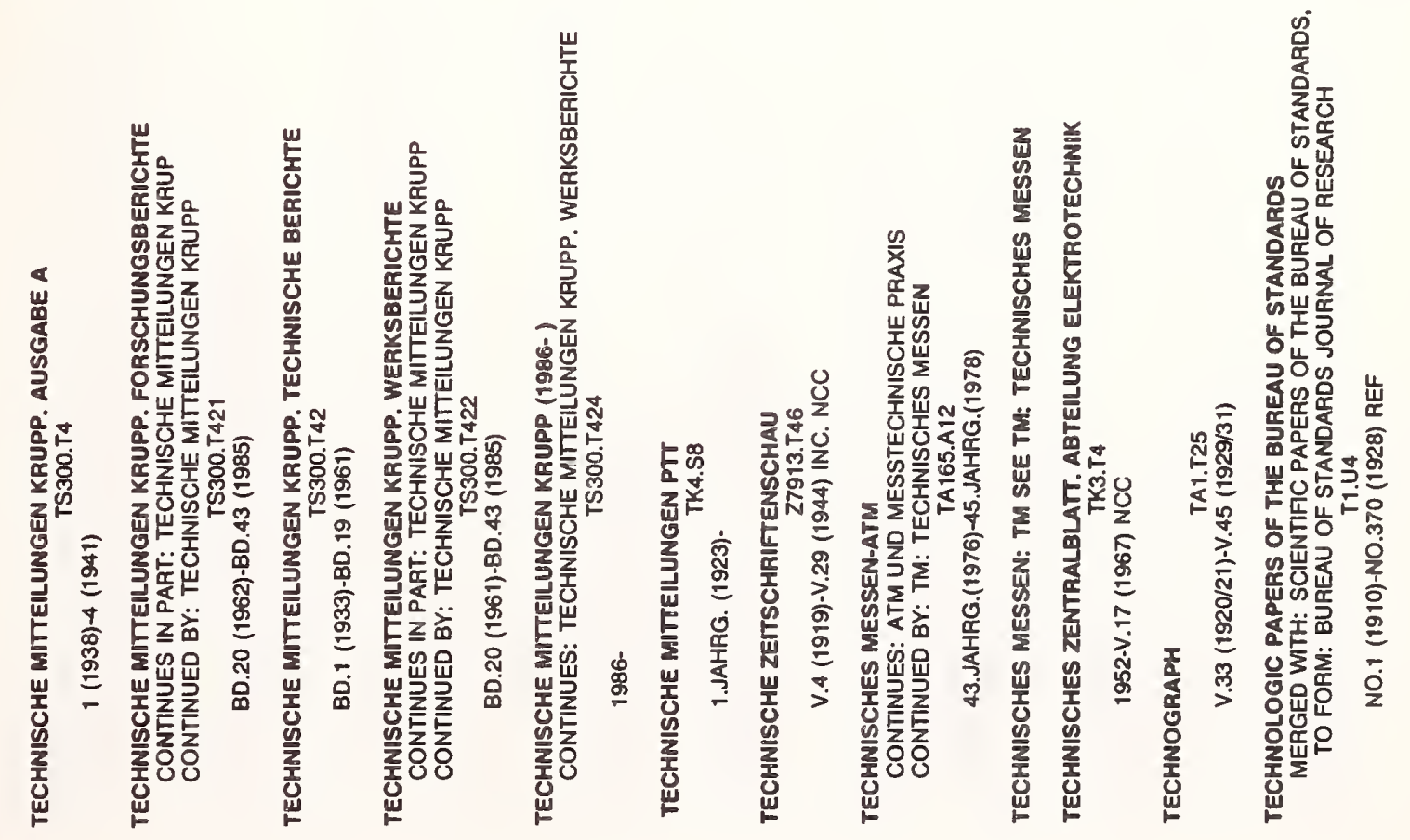




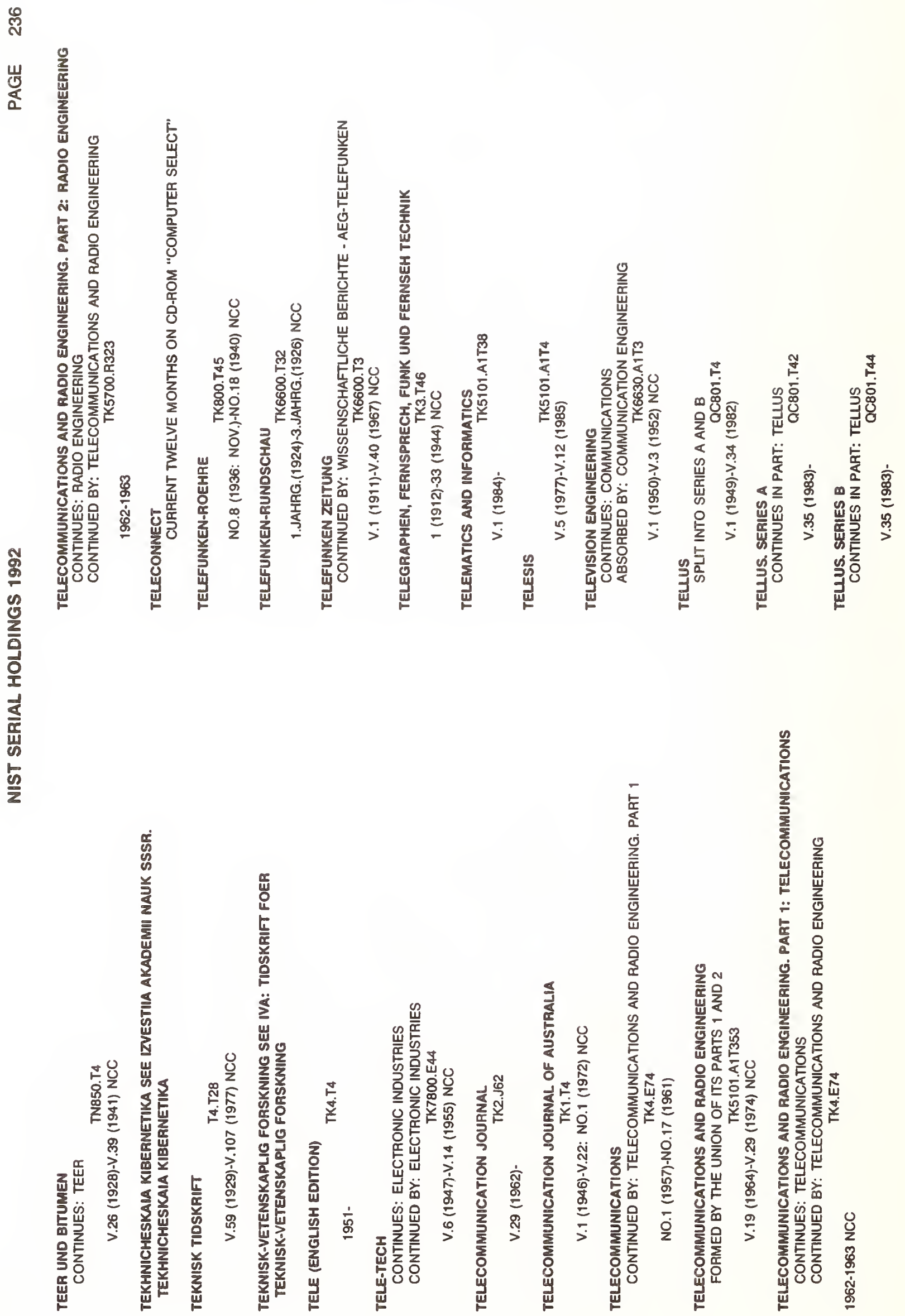




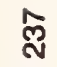

烹

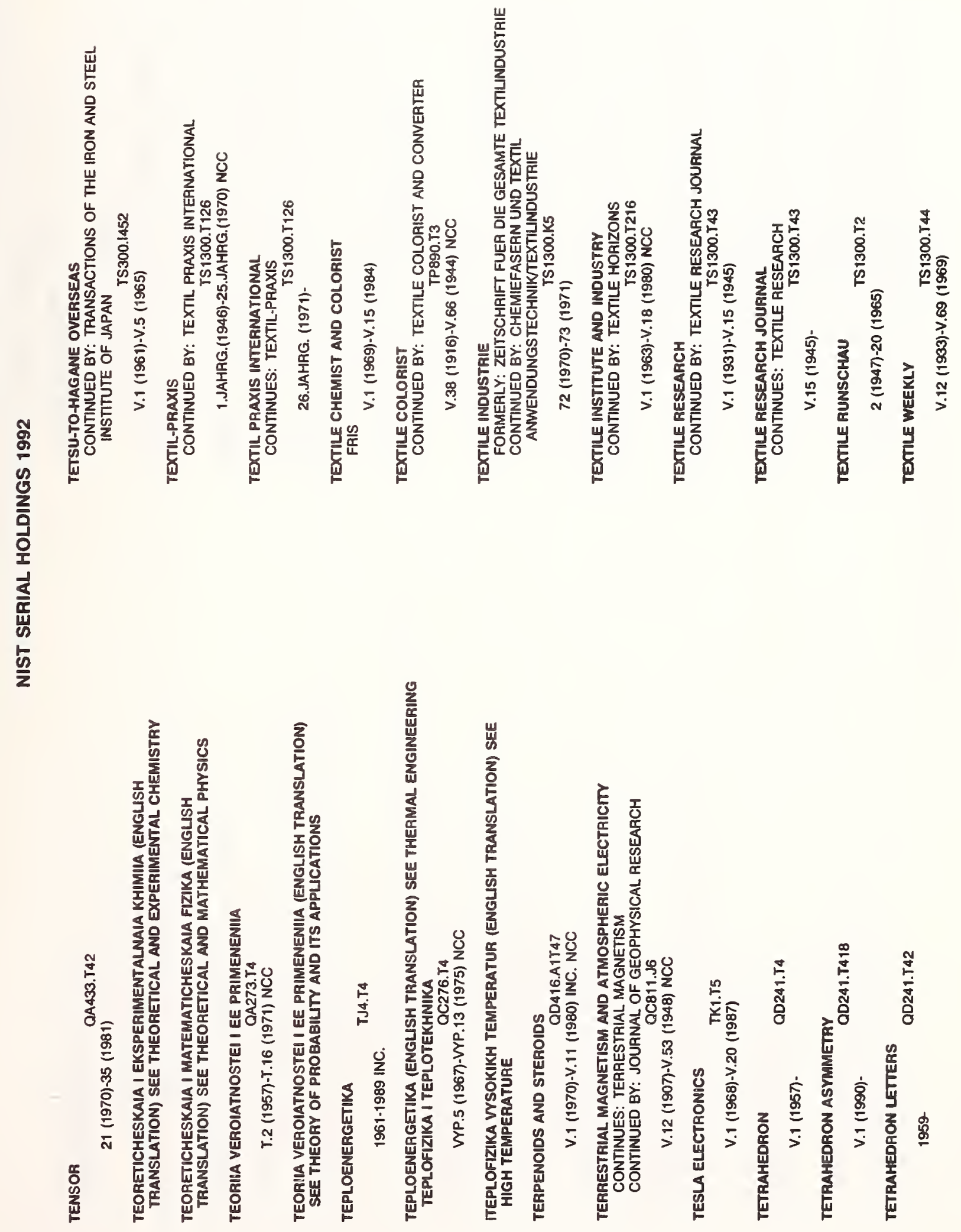




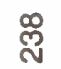

訔

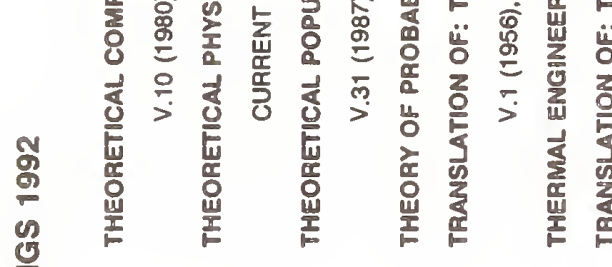

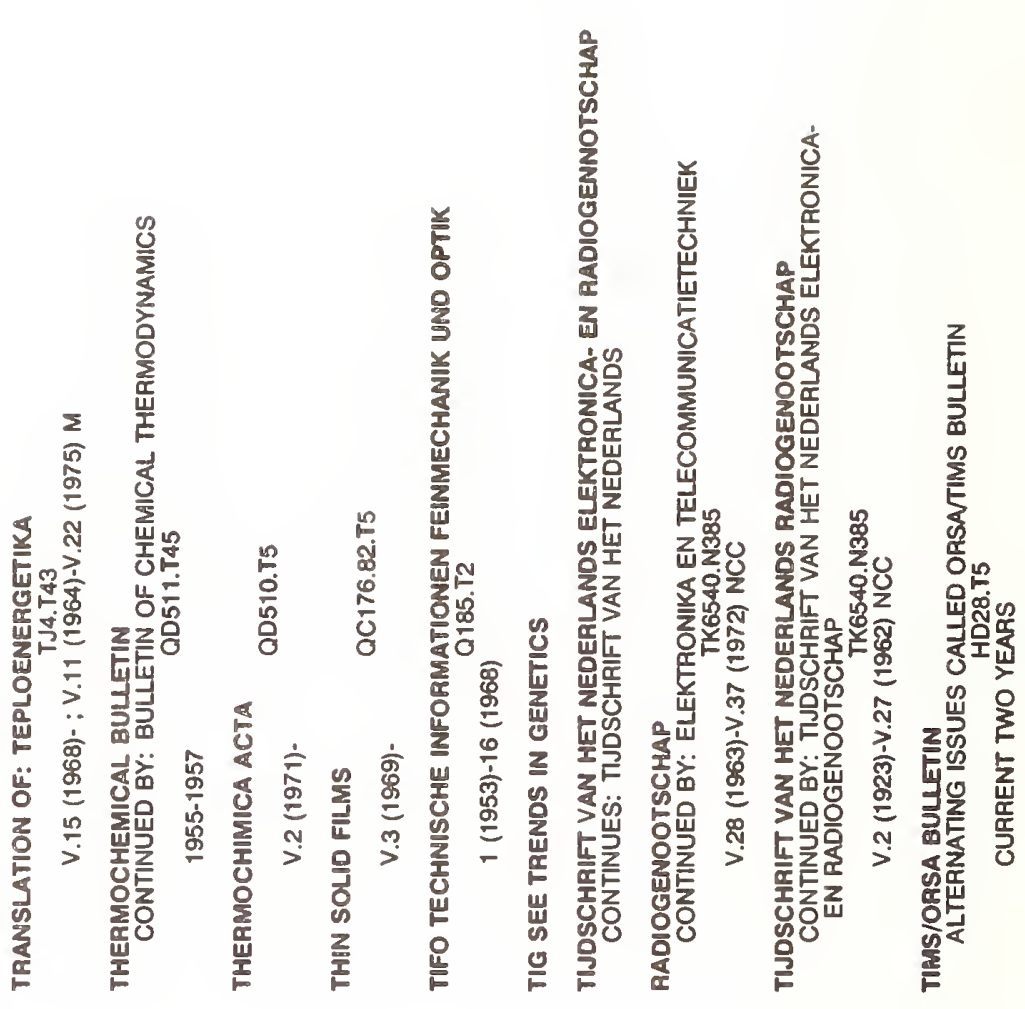

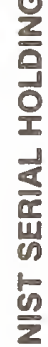

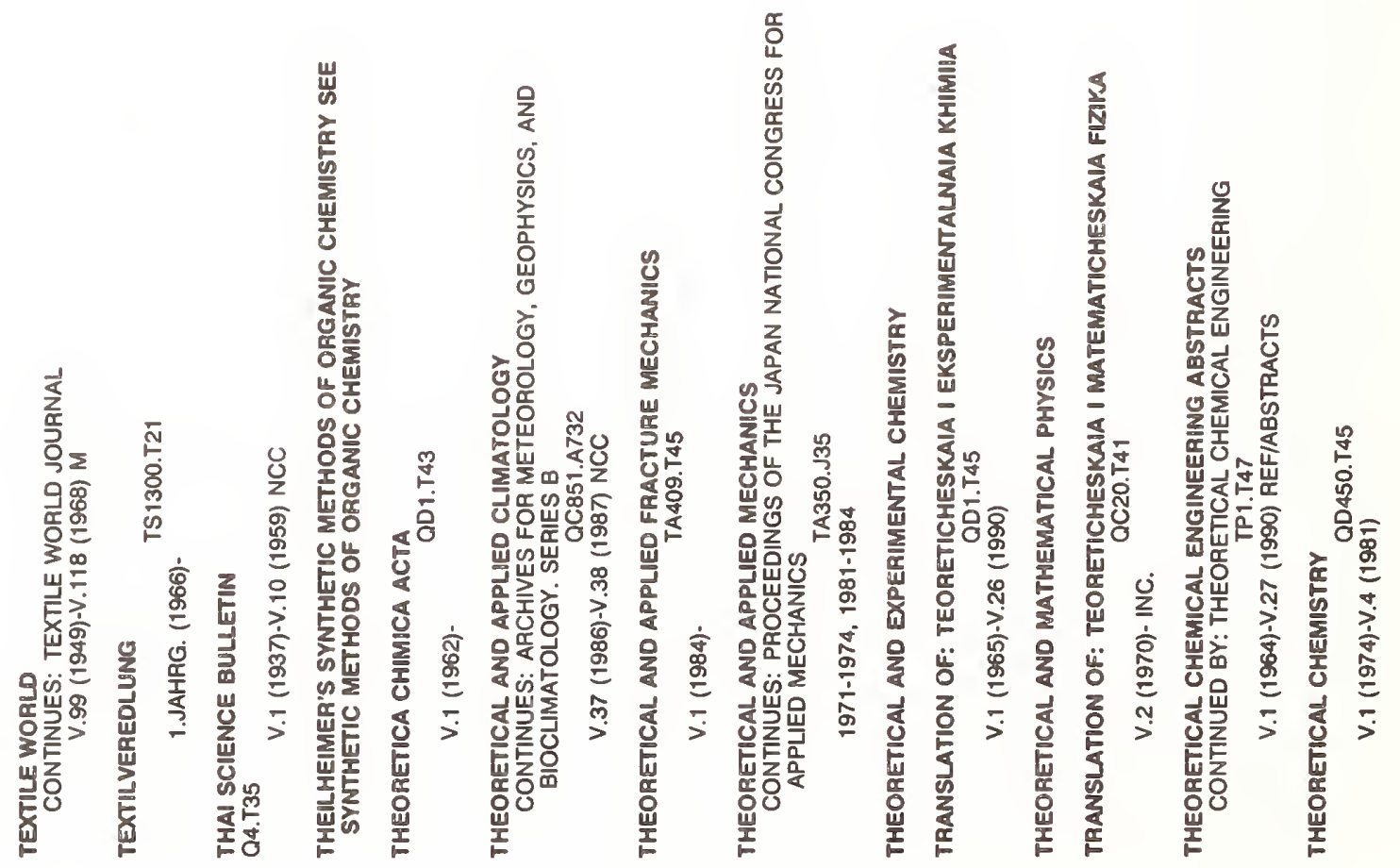


\%

容

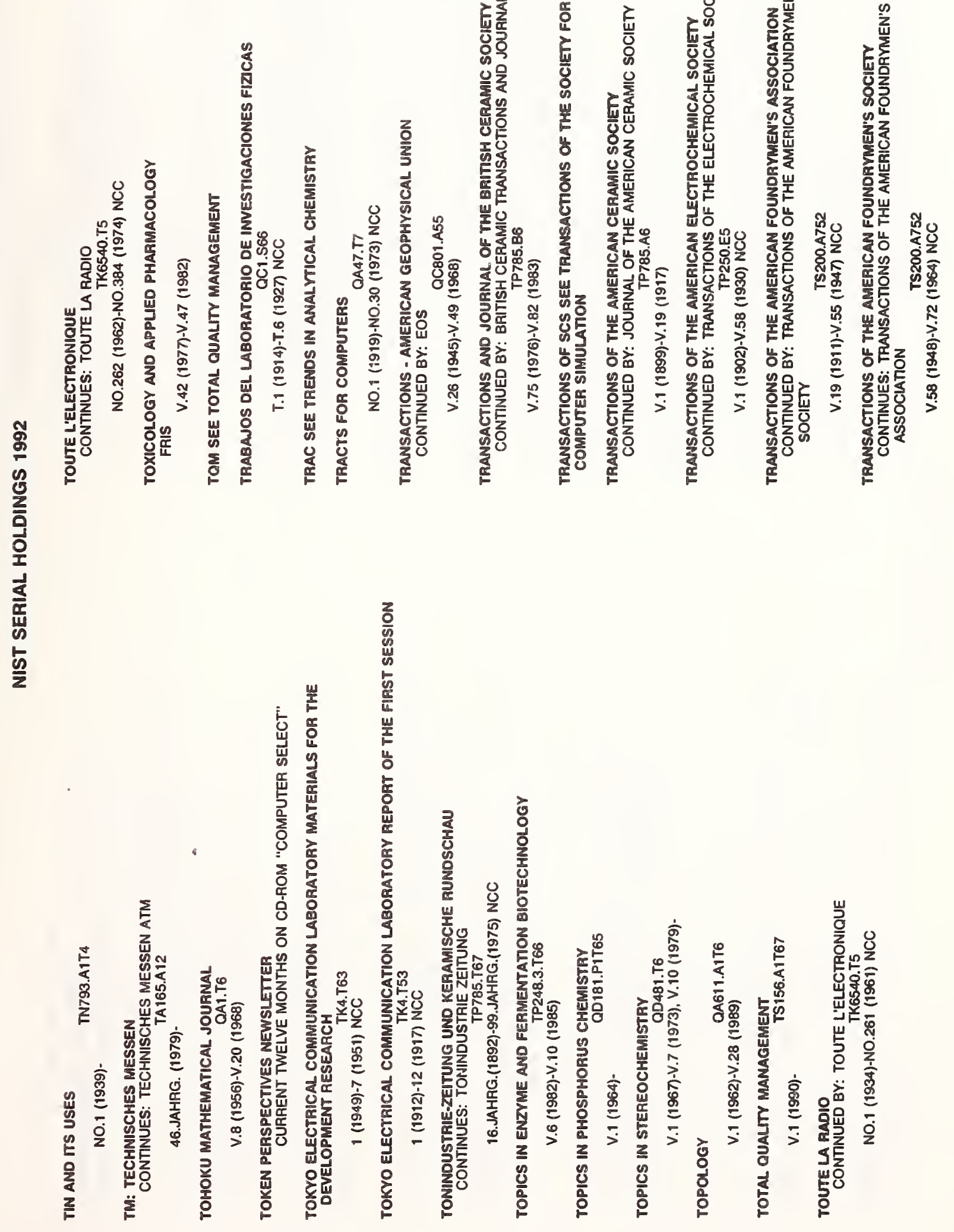




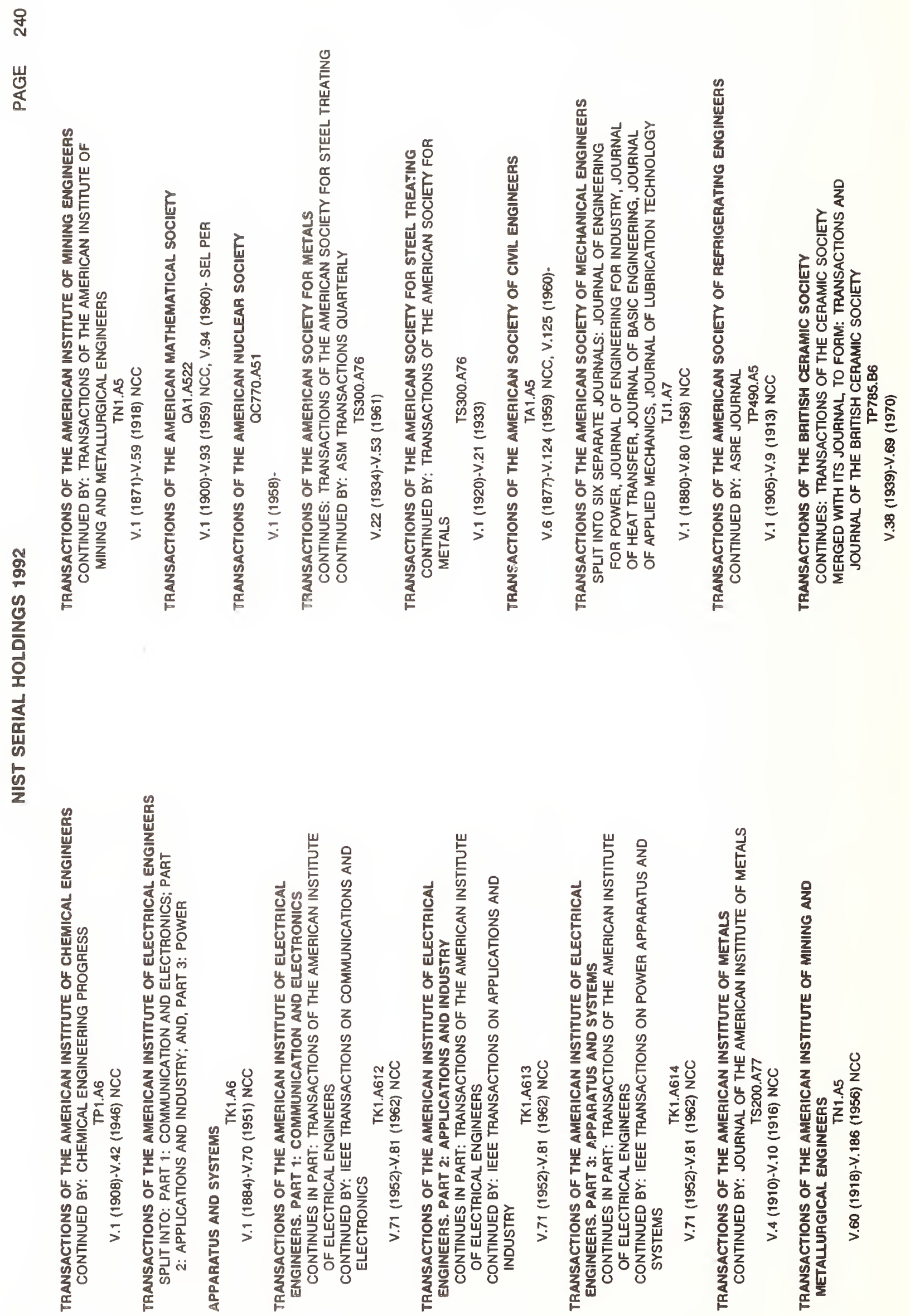



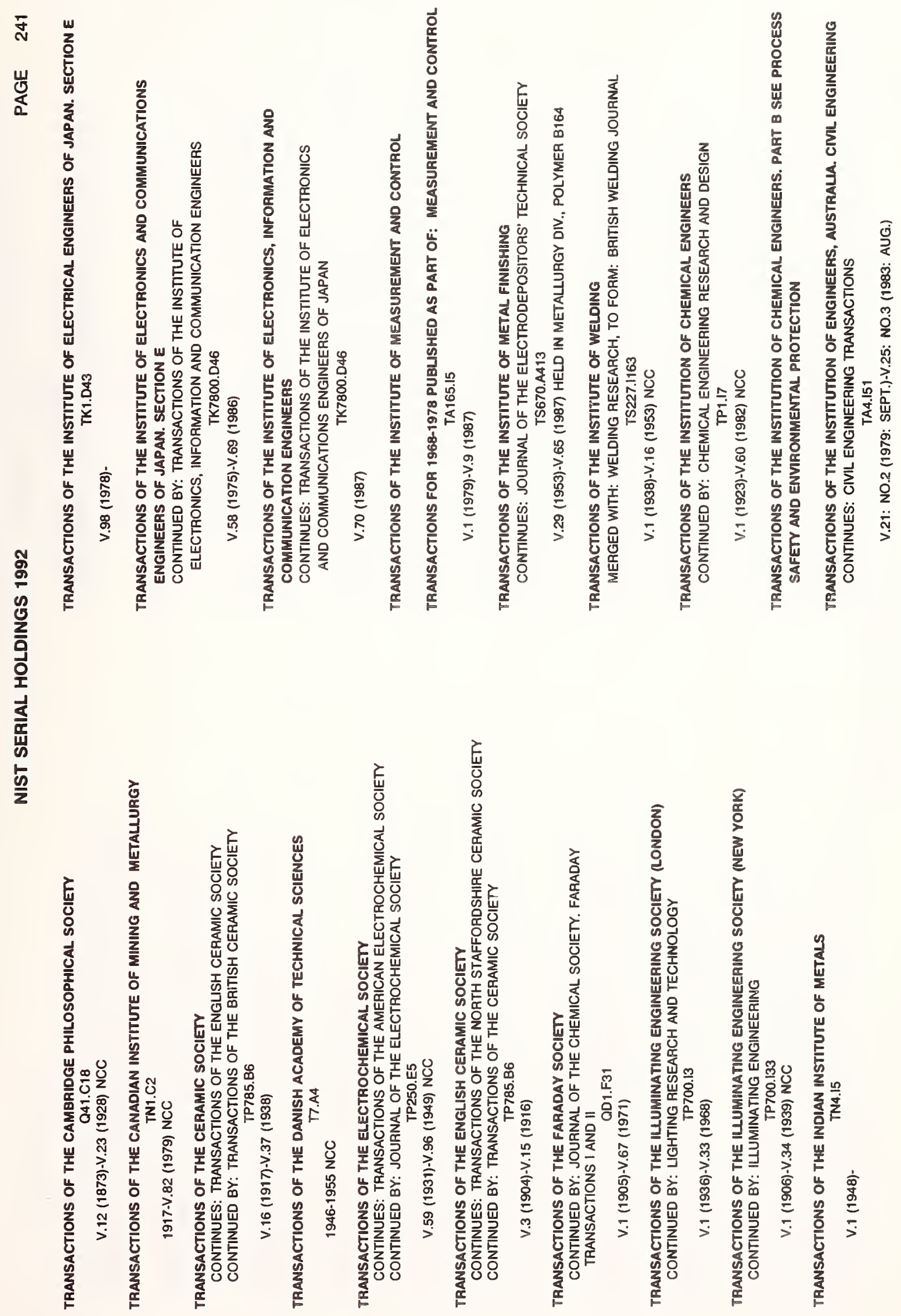


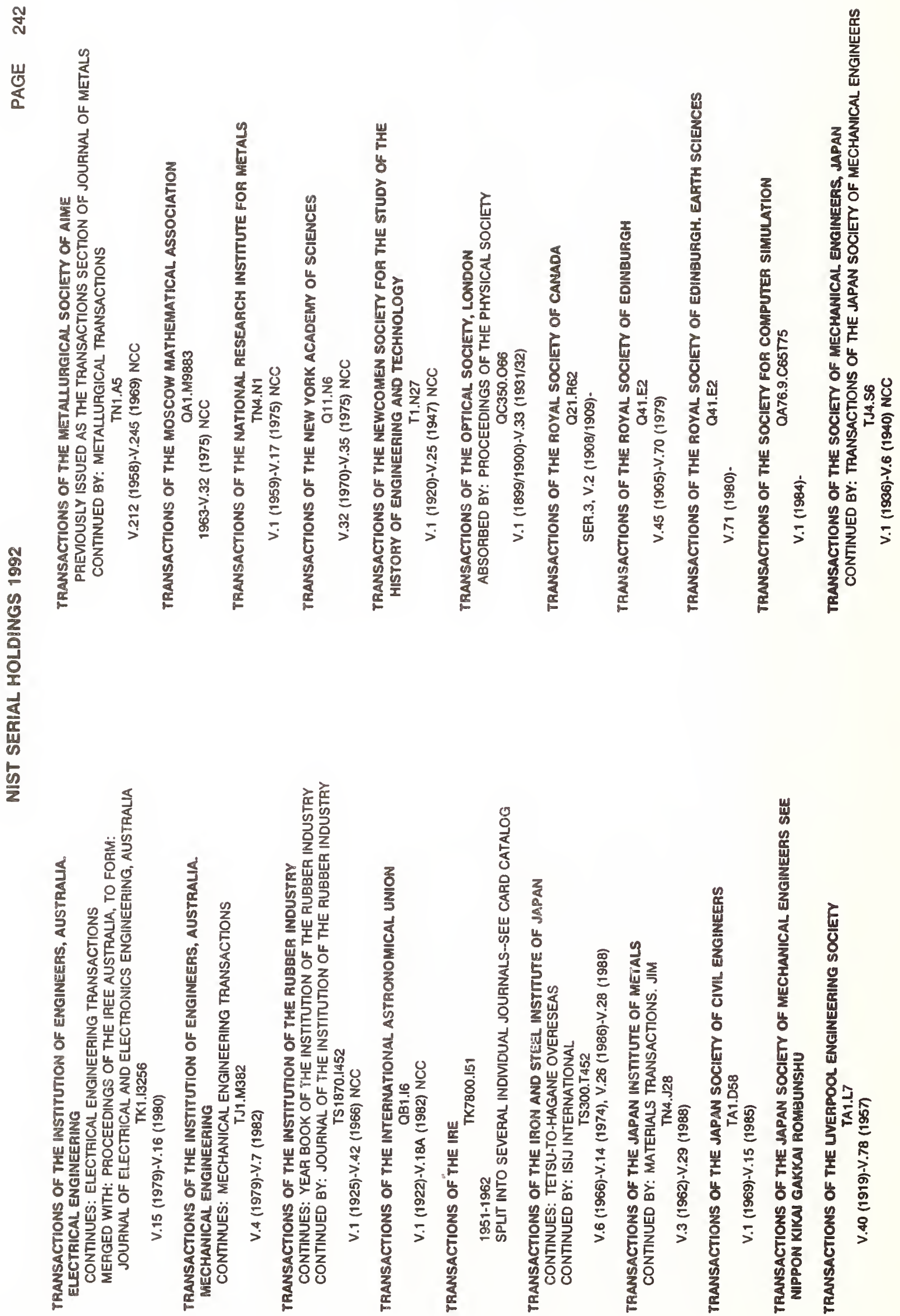




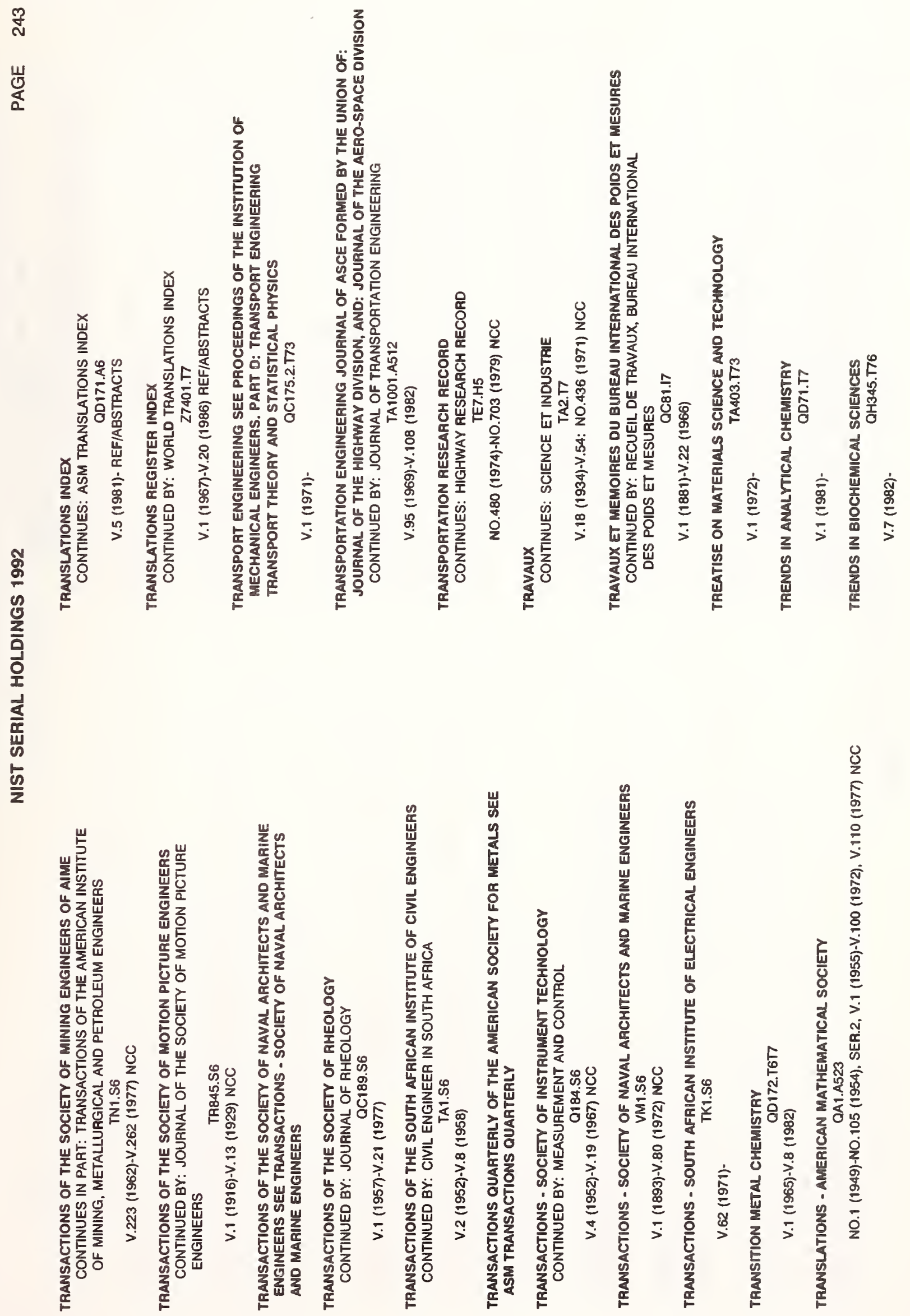




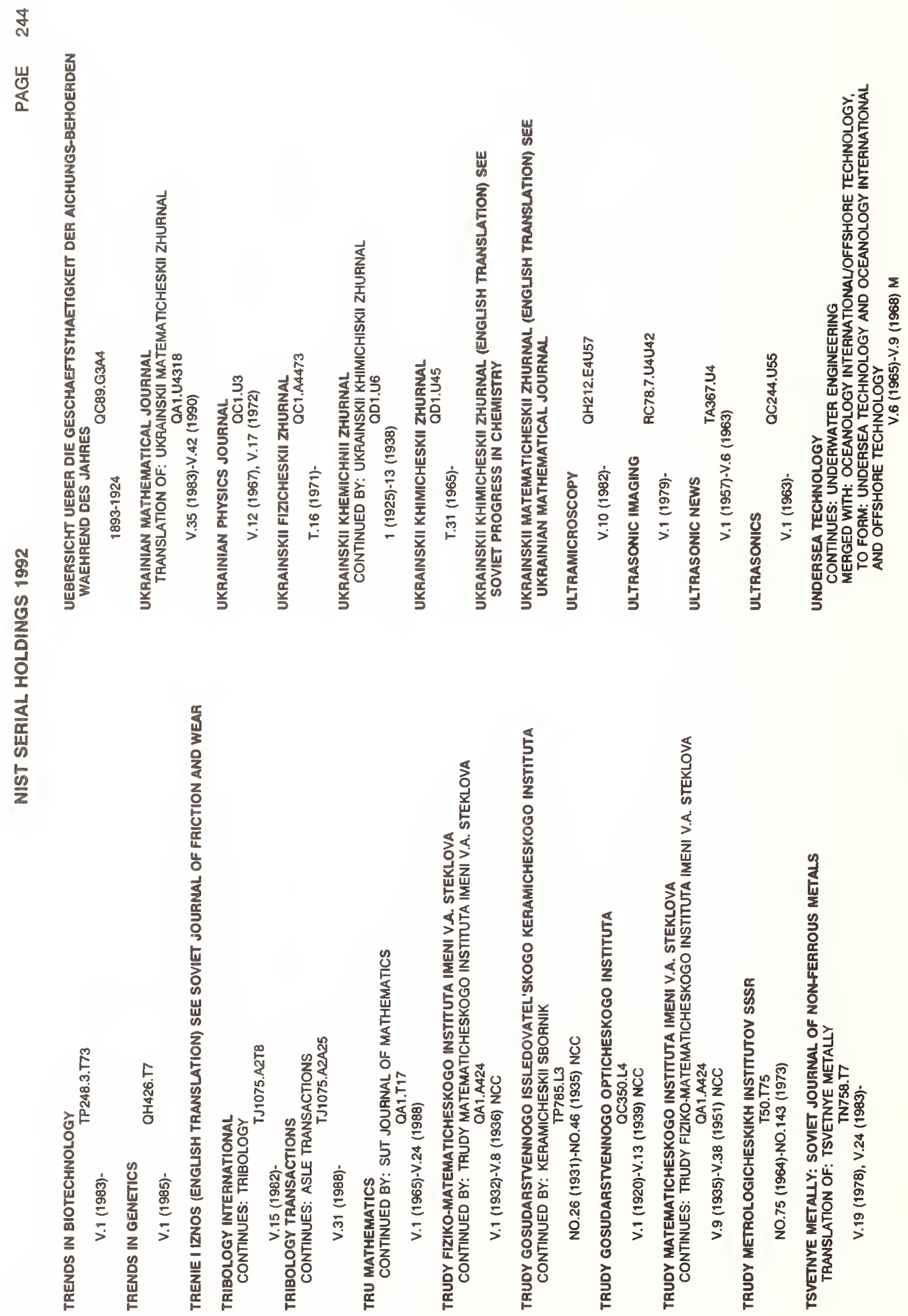




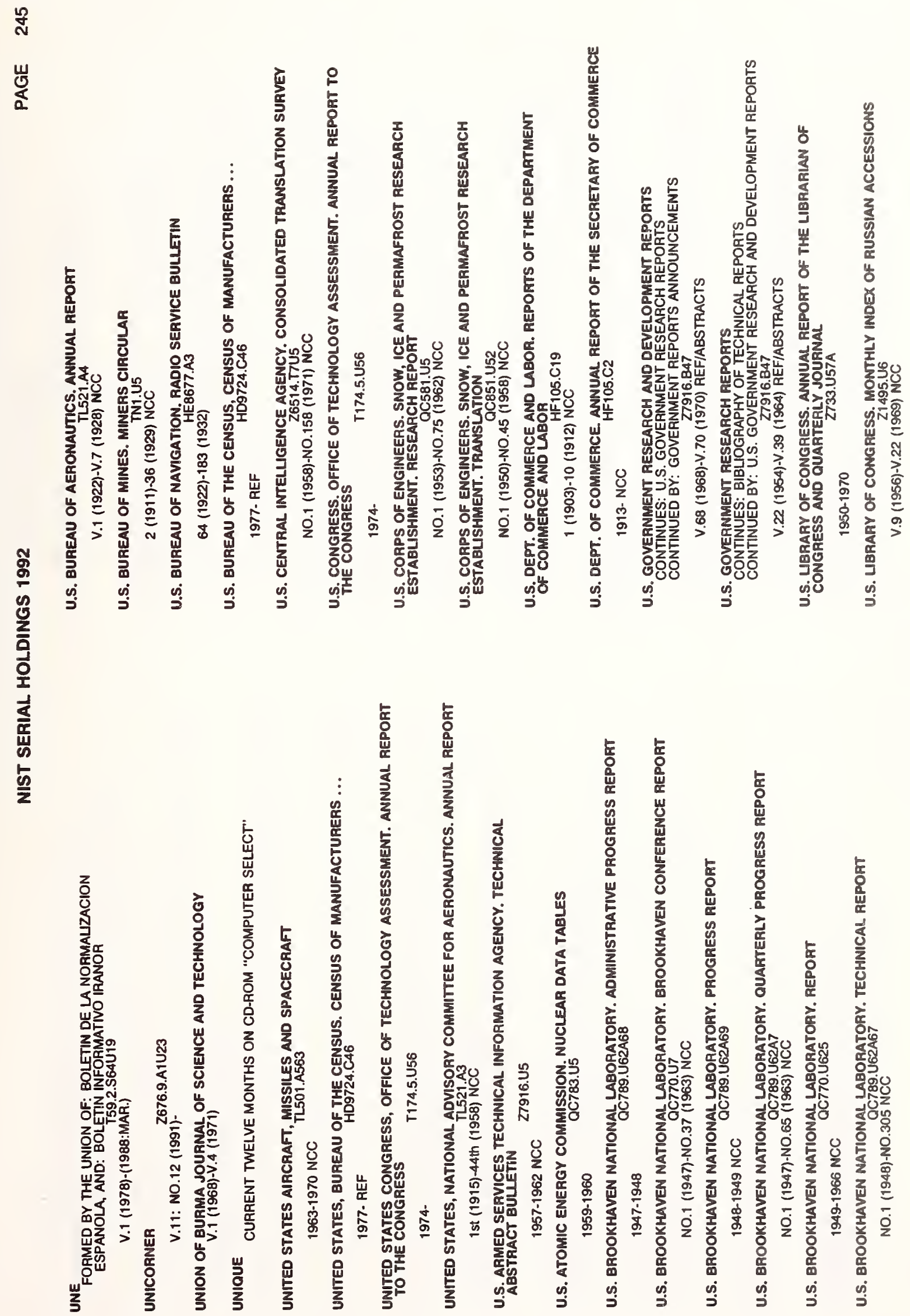




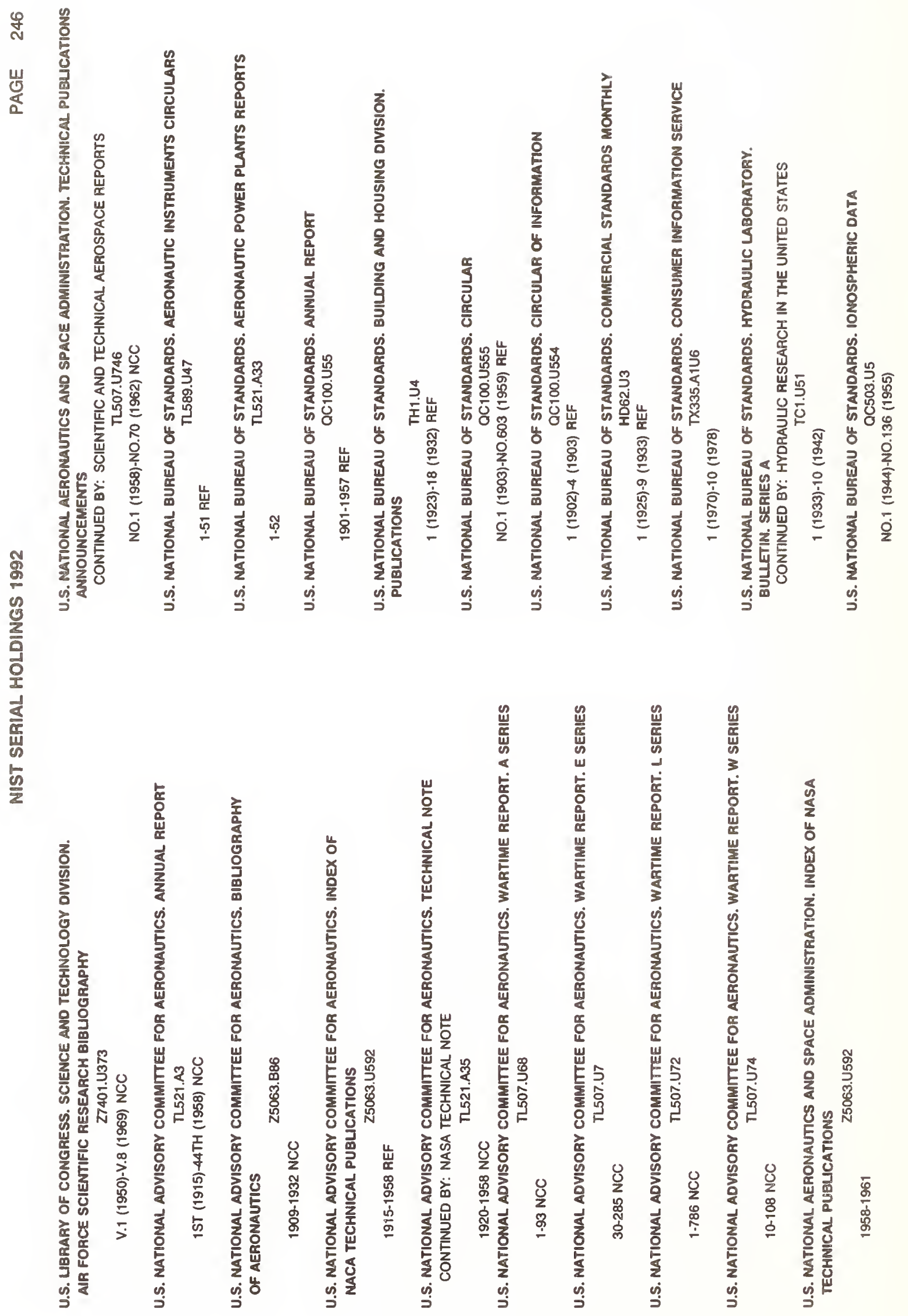




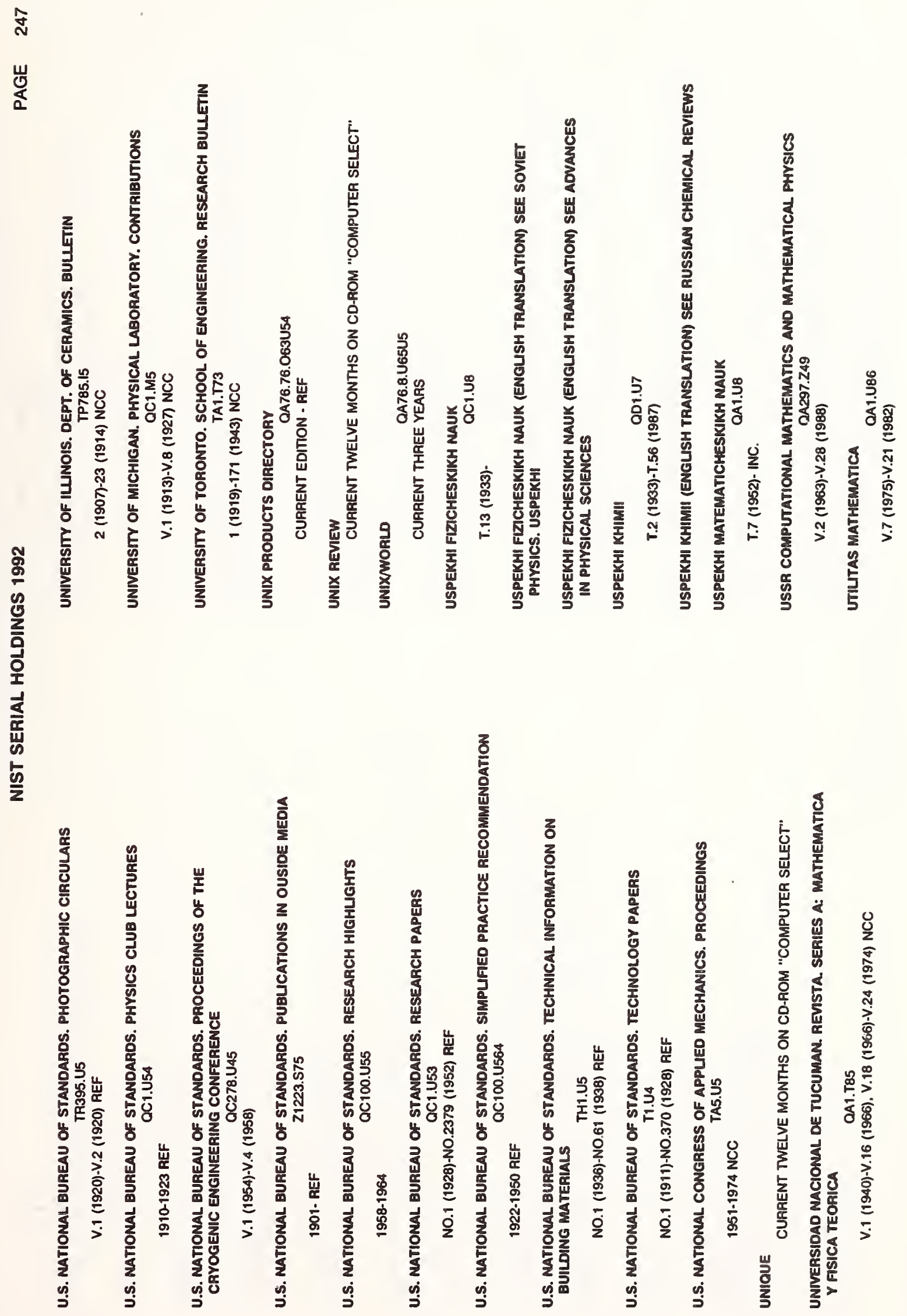




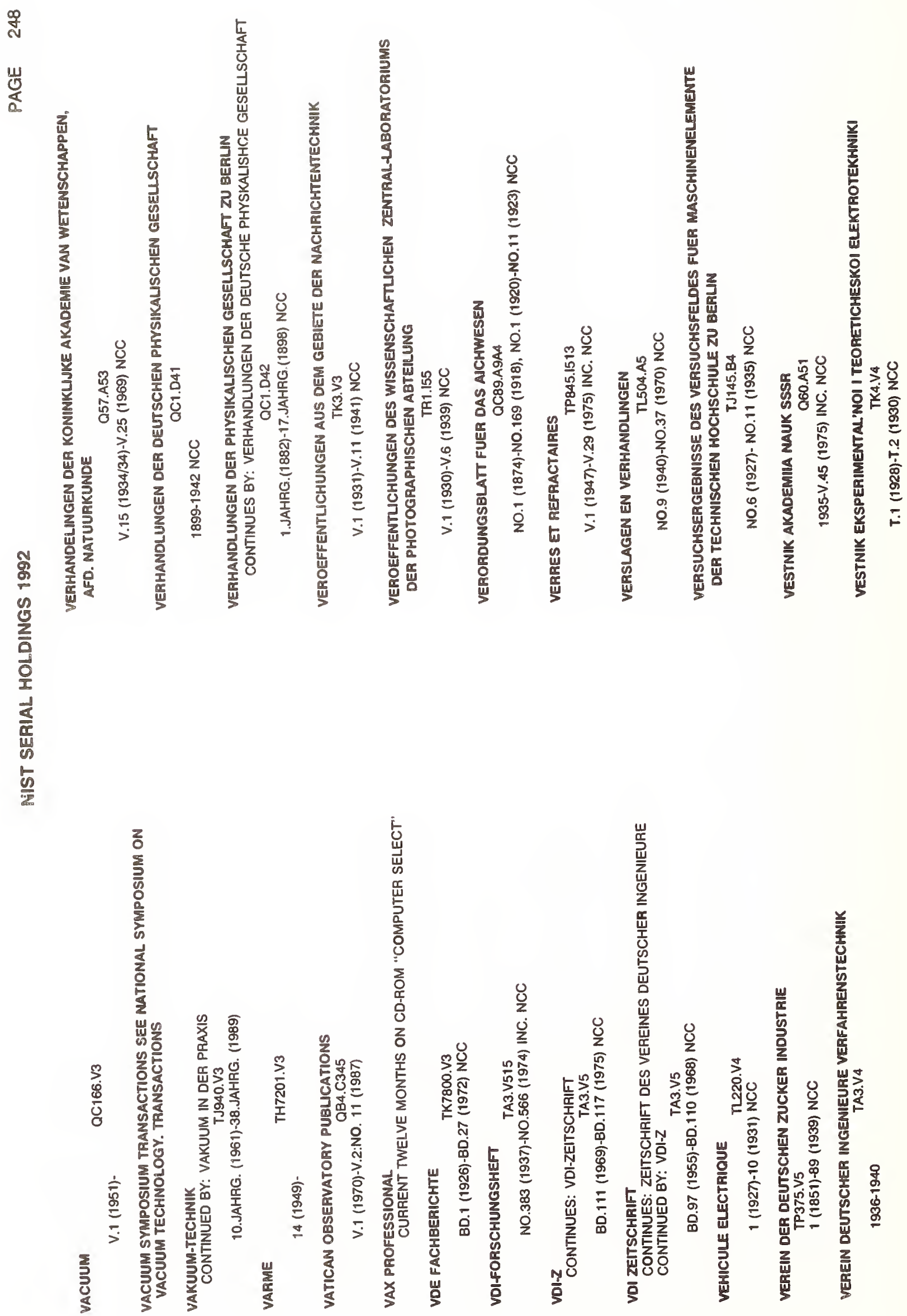




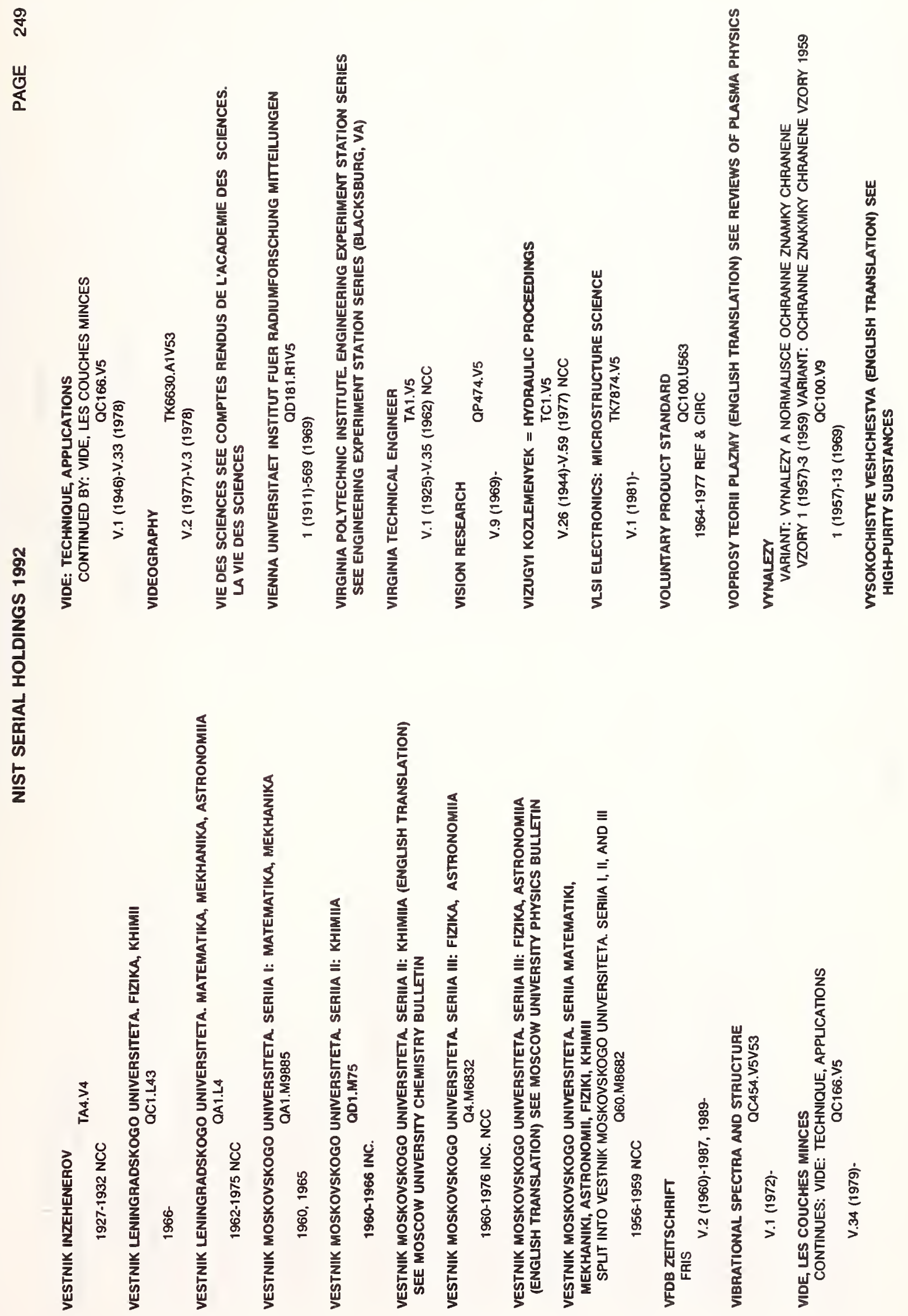


品

浐

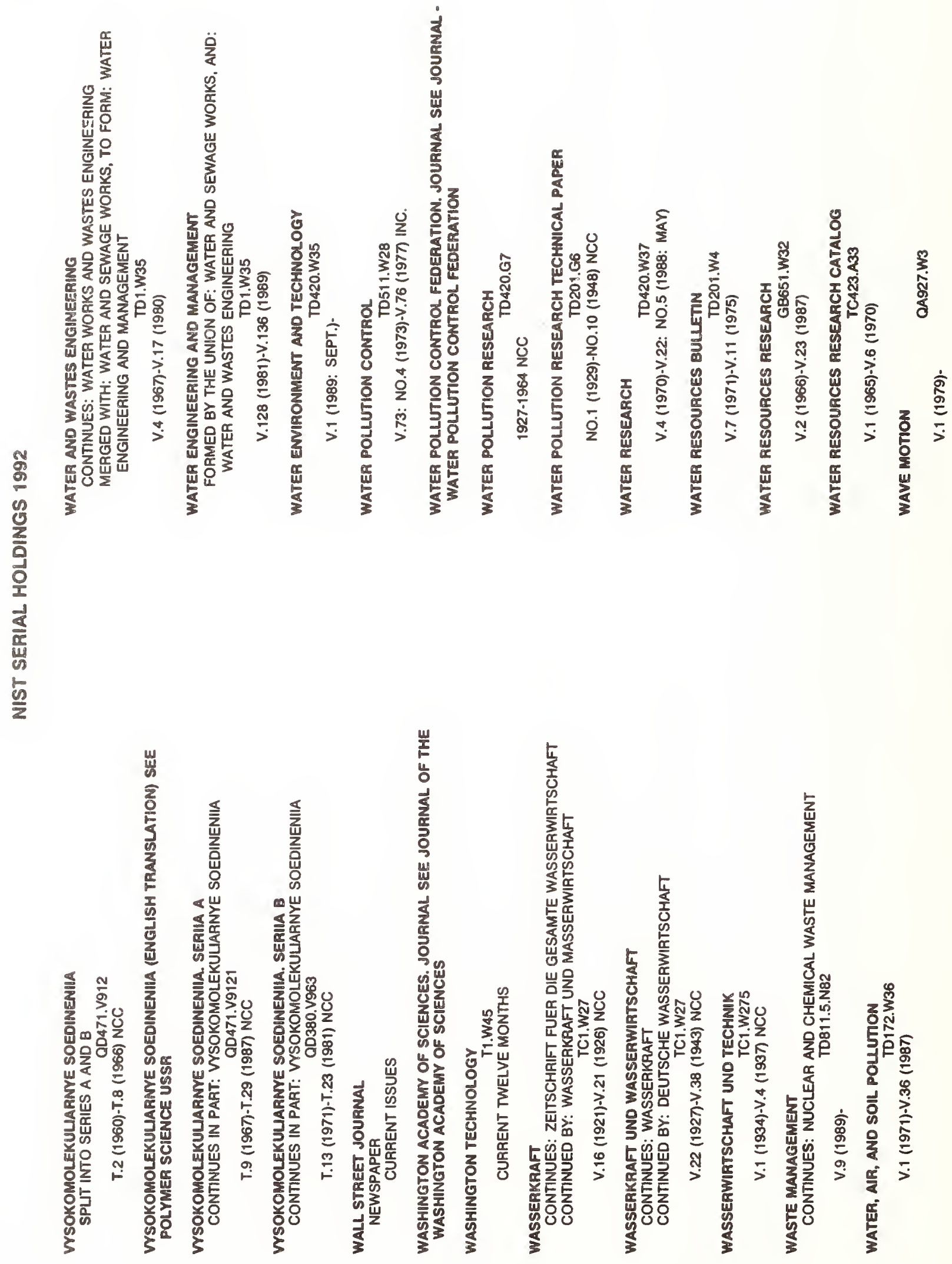


$\bar{\sigma}$
通
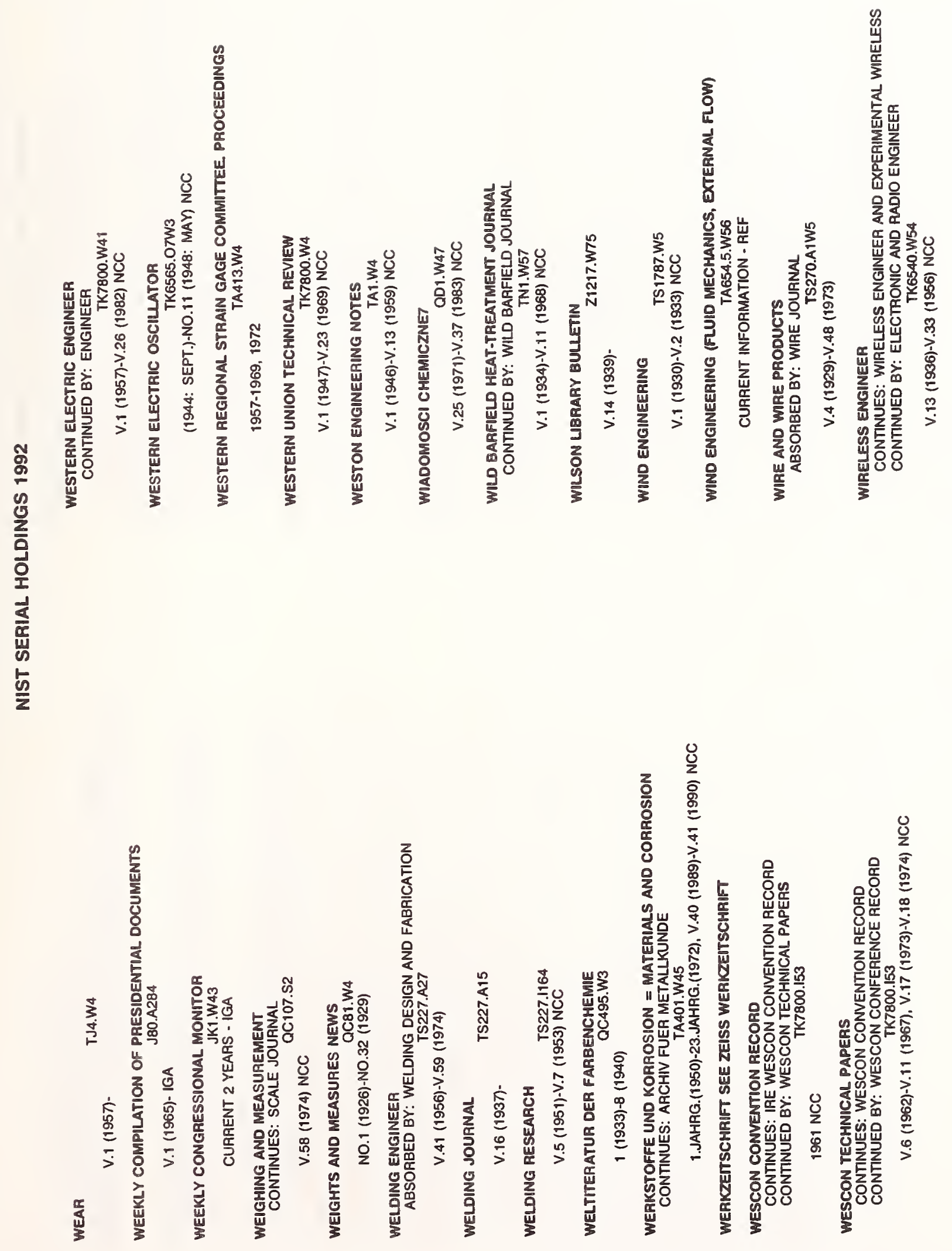
造

뿡
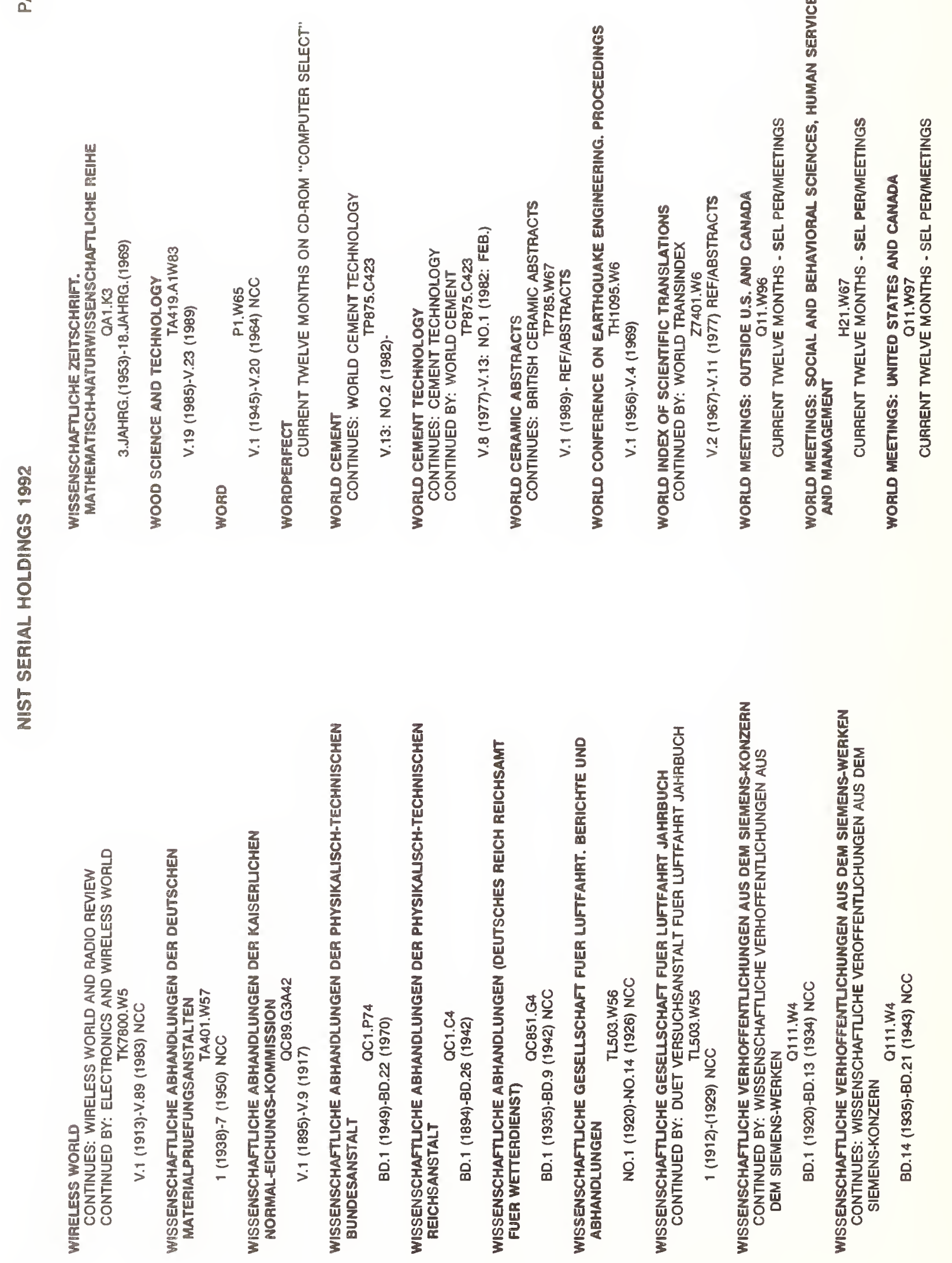

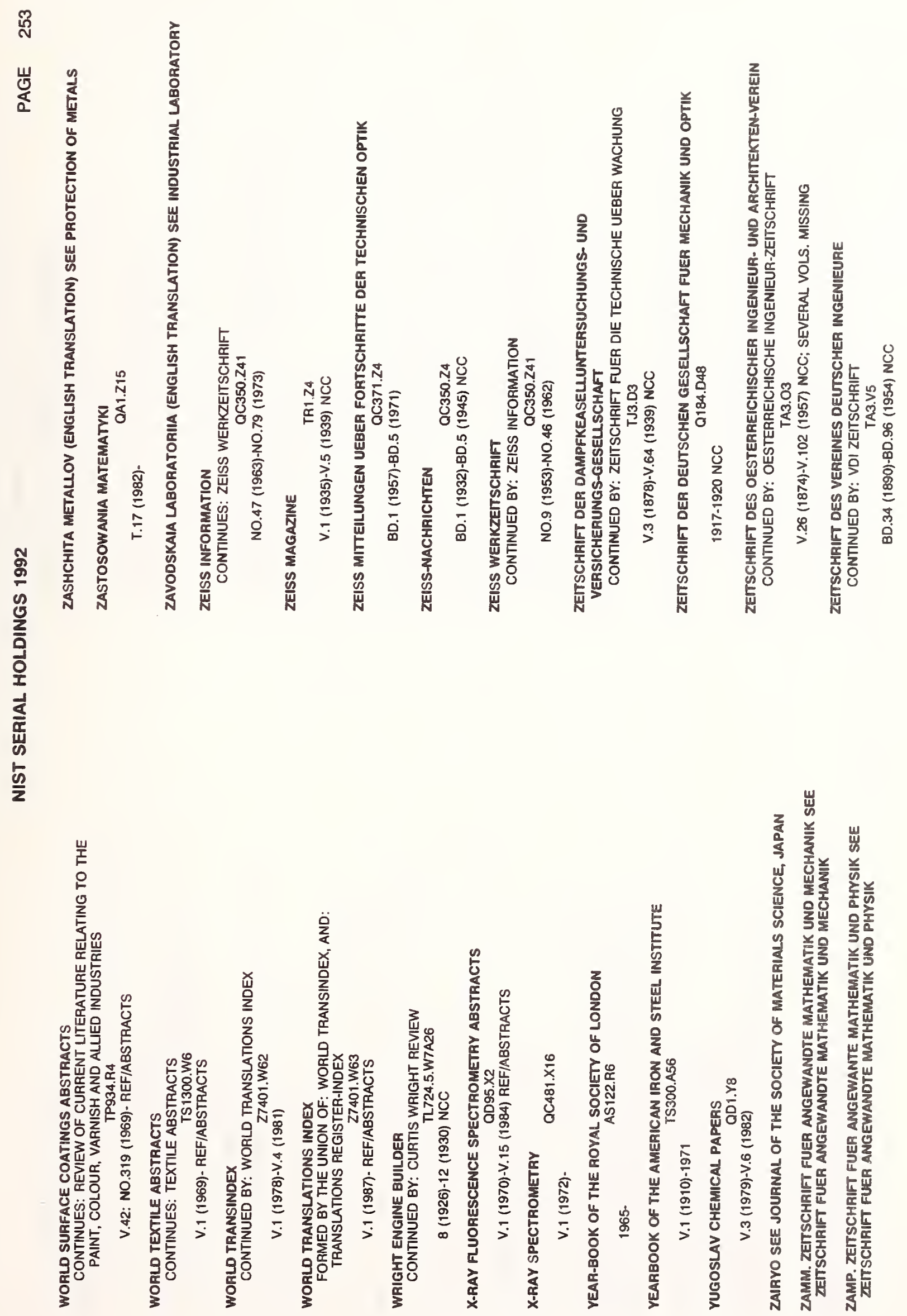
茶
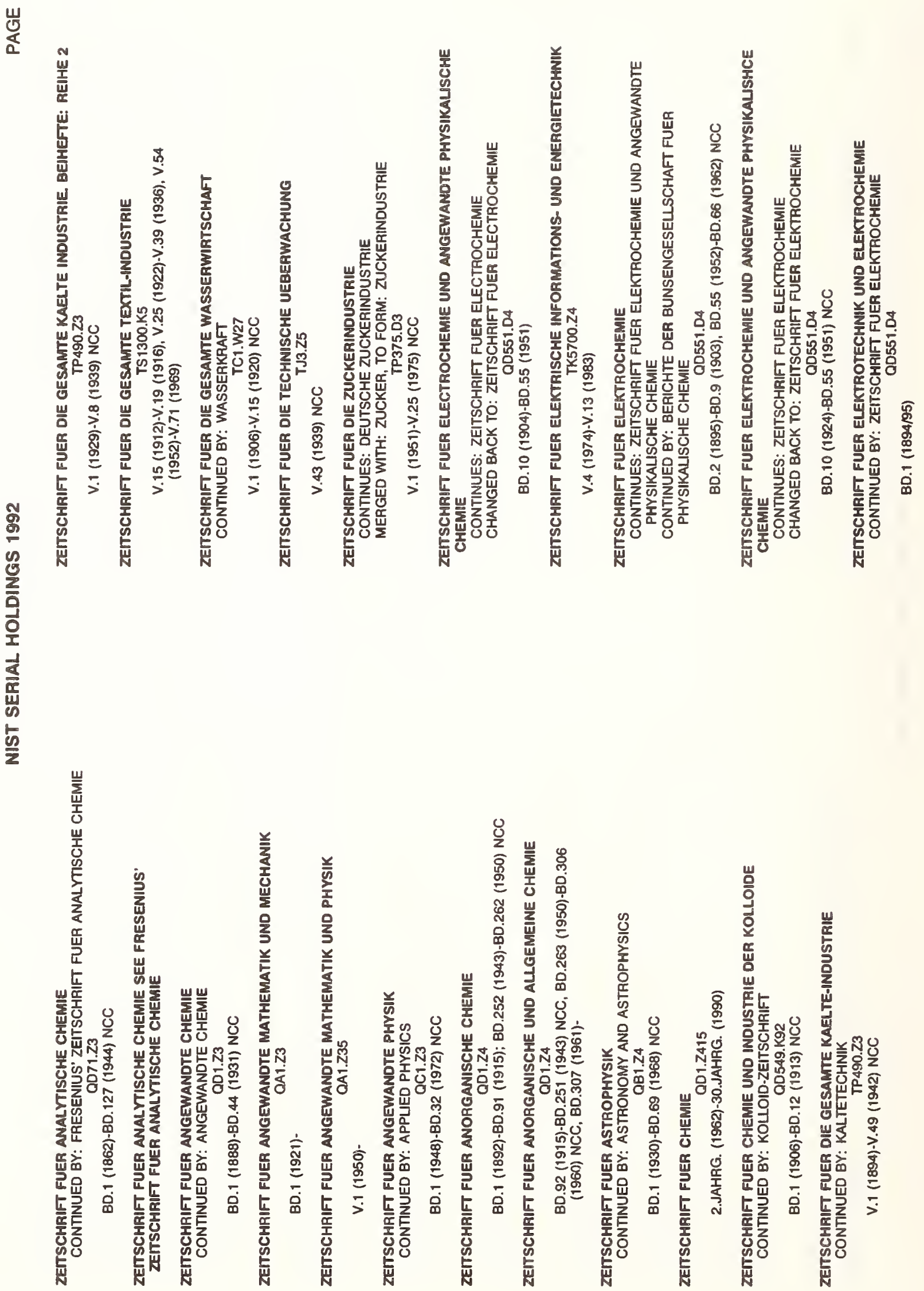


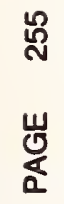

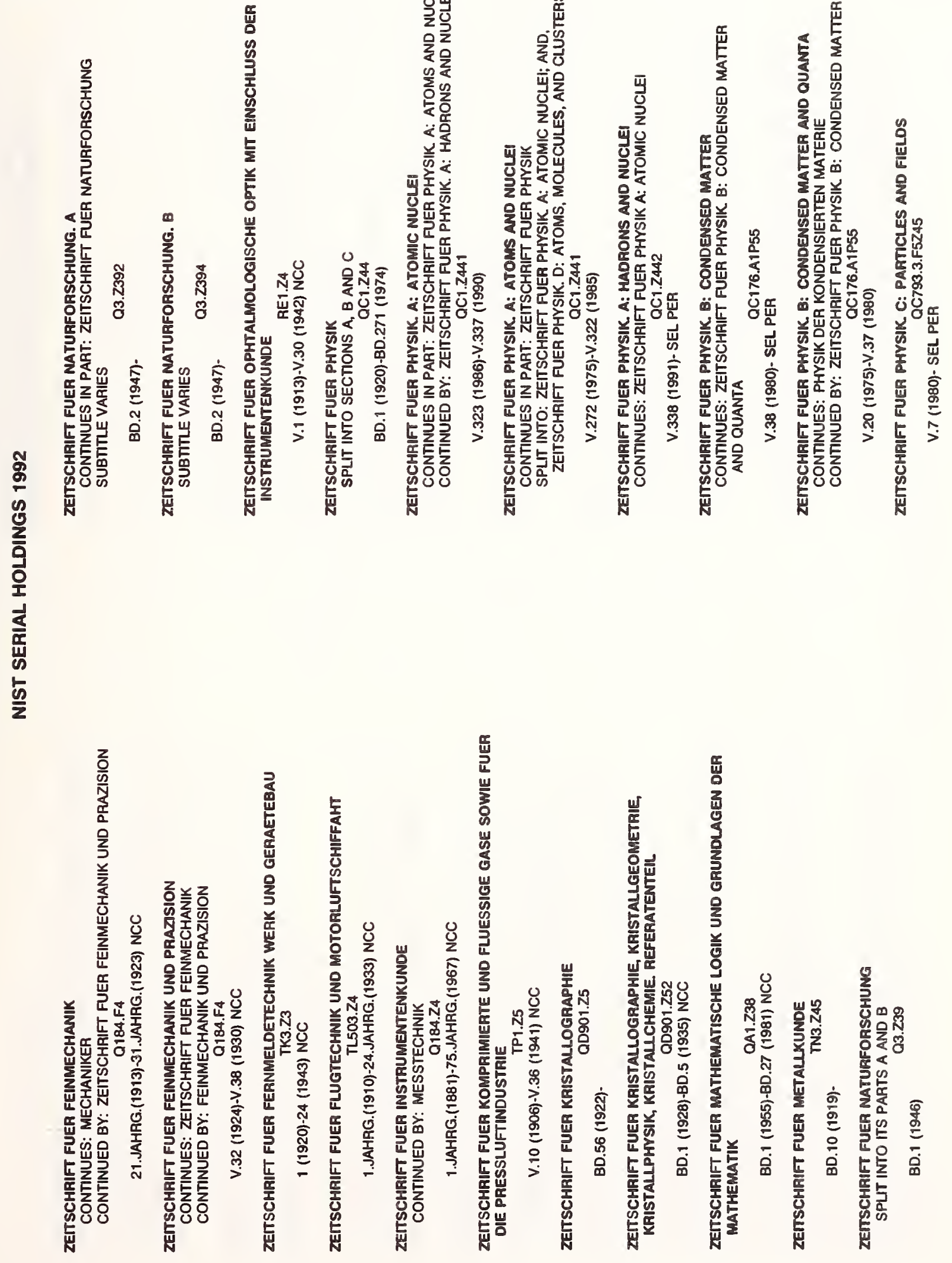




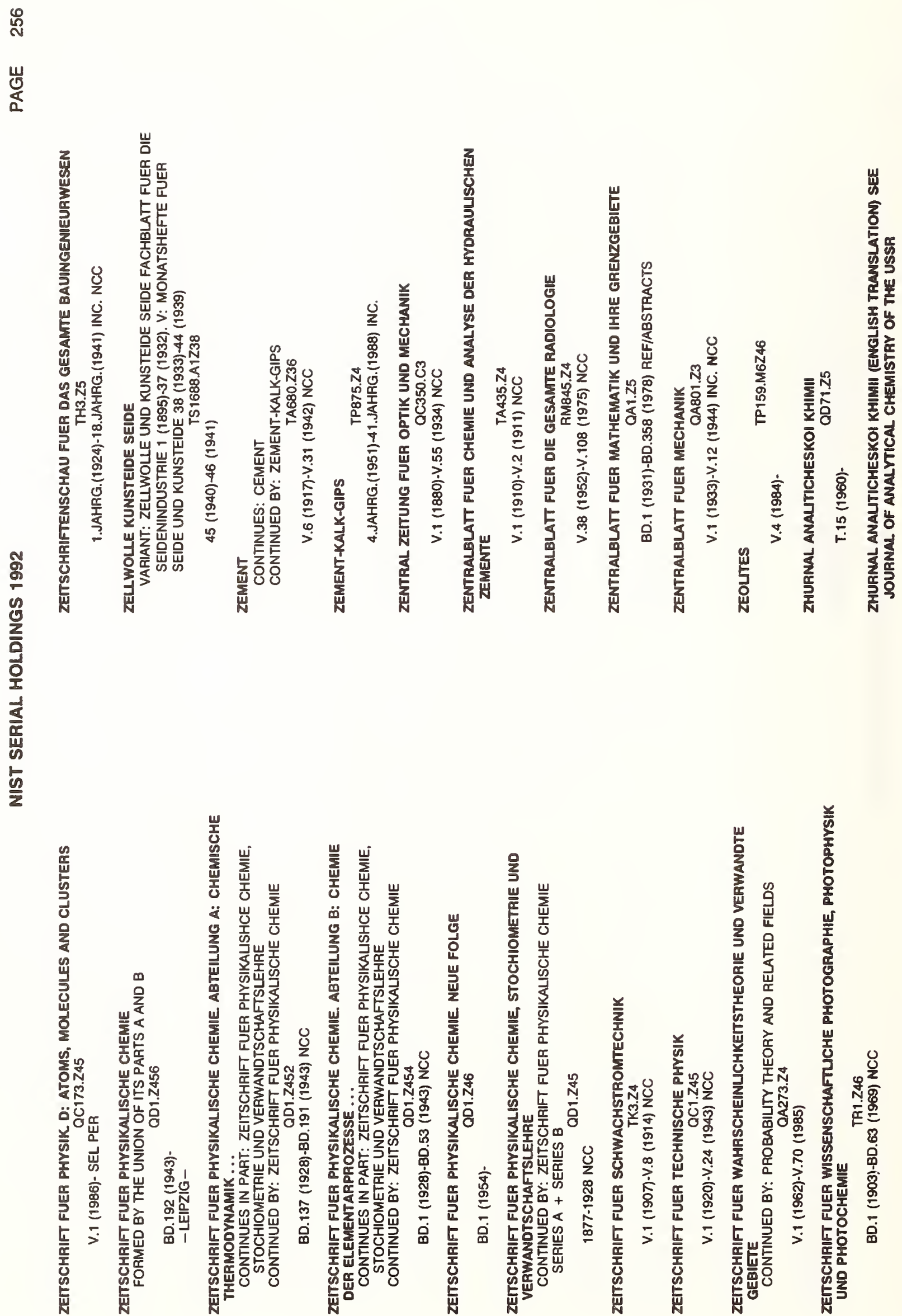


5

岩
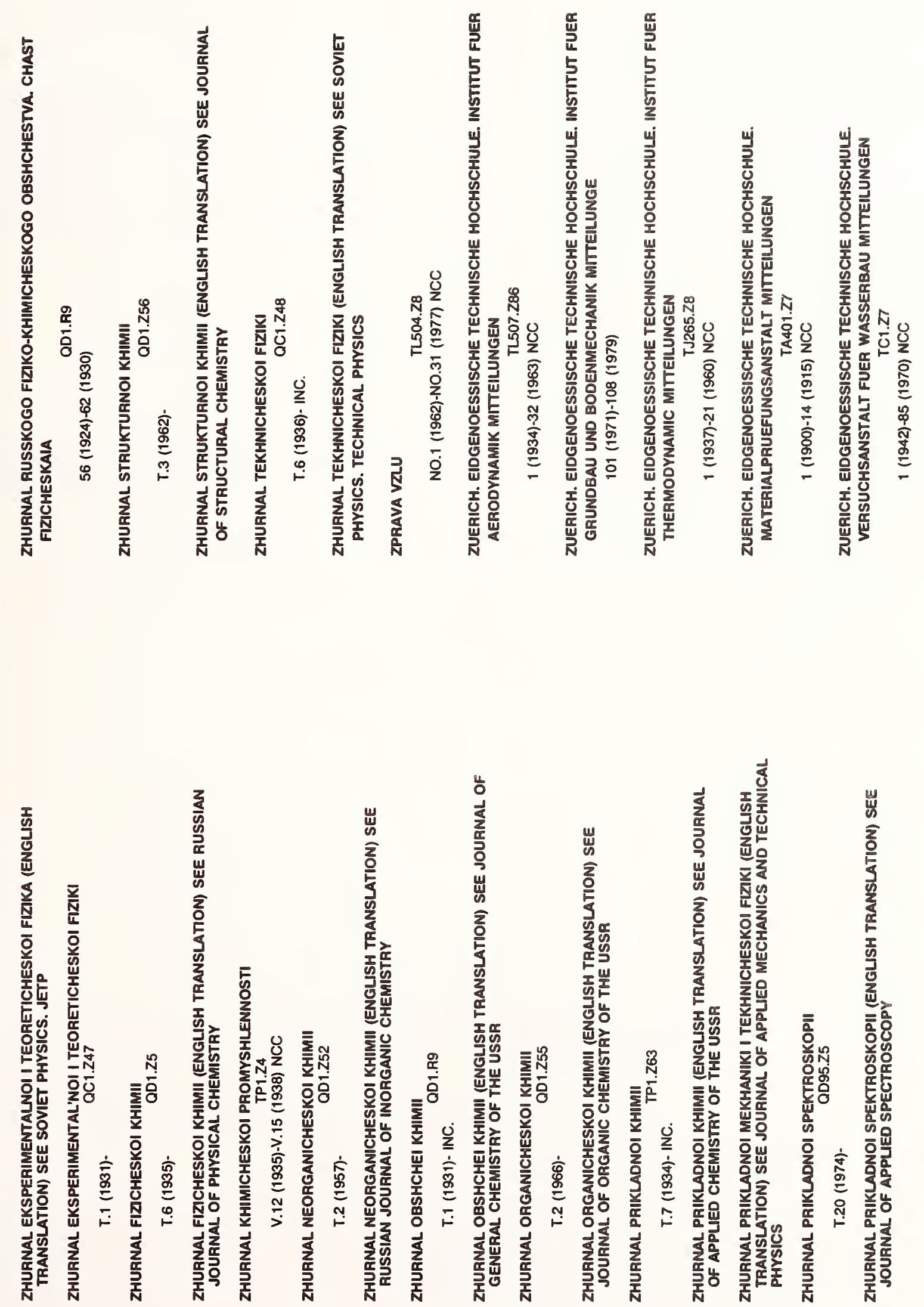
. 
1. PUBLICATION OR REPORT NUMBER

NATIONAL INSTITUTE OF STANDARDS AND TECHNOLOGY NIST/SP-777, 1992 EDITION

2. PERFORMING ORGANIZATION REPORT NUMBER

\section{BIBLIOGRAPHIC DATA SHEET}

3. PUBLICATION DATE

APRIL 1992

TITLEAND SUBTITLE

NIST Serial HoLdings 1992

AUTHOR(S)

Susan A. SANDERS, EDITOR

PERFORMING ORGANIZATION (IF JOINT OR OTHER THAN NIST, SEE INSTRUCTIONS)

U.S. DEPARTMENT OF COMMERCE

NATIONAL INSTITUTE OF STANDARDS AND TECHNOLOGY

GAITHERSBURG, MD 20899

7. CONTRACT/GRANT NUMBER

SPONSORING ORGANIZATION NAME AND COMPLETE ADDRESS (STREET, CITY, STATE, ZIP)

8. TYPE OF REPORT AND PERIOD COVERED FINAL

SAME AS ITEM \#6

SUPPLEMENTARY NOTES

Supersedes nist Special Publication 777, 1991 Edition

DOCUMENT DESCRIBES A COMPUTER PROGRAM; SF-185, FIPS SOFTWARE SUMMARY, IS ATTACHED.

- ABSTRACT (A 200-WORD OR LESS FACTUAL SUMMARY OF MOST SIGNIFICANT INFORMATION. IF DOCUMENT INCLUDES A SIGNIFICANT BIBLIOGRAPHY OR UTERATURE SURVEY, MENTION IT HERE.)

THIS PUBLICATION CONTAINS BIBLIOGRAPHIC INFORMATION ON APPROXIMATELY 5,000 TITLES HELD in the nist Research Information Center, representing CuRrent and noncurrent Journals, PERIODICALS, ANNUALS, MEMOIRS, PROCEEDINGS AND TRANSACTIONS.

KEY WORDS (6 TO 12 ENTRIES; ALPHABETICAL ORDER; CAPITALIZE ONLY PROPER NAMES; AND SEPARATE KEY WORDS BY SEMICOLONS)

ANNUAL REPORTS; JOURNALS; LIBRARY HOLDINGS; NIST PERIODICALS; NIST RESEARCH INFORMATION

CENTER; PROCEEDINGS; SERIALS; STANDARDS; TRANSACTIONS.

FOR OFFICIAL DISTRIBUTION, DO NOT RELEASE TO NATIONAL TECHNICAL INFORMATION SERVICE (NTIS).

ORDER FROM SUPERINTENDENT OF DOCUMENTS, U.S. GOVERNMENT PRINTING OFFICE, WASHINGTON, DC 20402.

ORDER FROM NATIONAL TECHNICAL INFORMATION SERVICE (NTIS), SPRINGFIELD, VA 22161.

14. NUMBER OF PRINTED PAGES

ECTRONIC FORM

S. G.P.0.: 1992-311-891:60463 


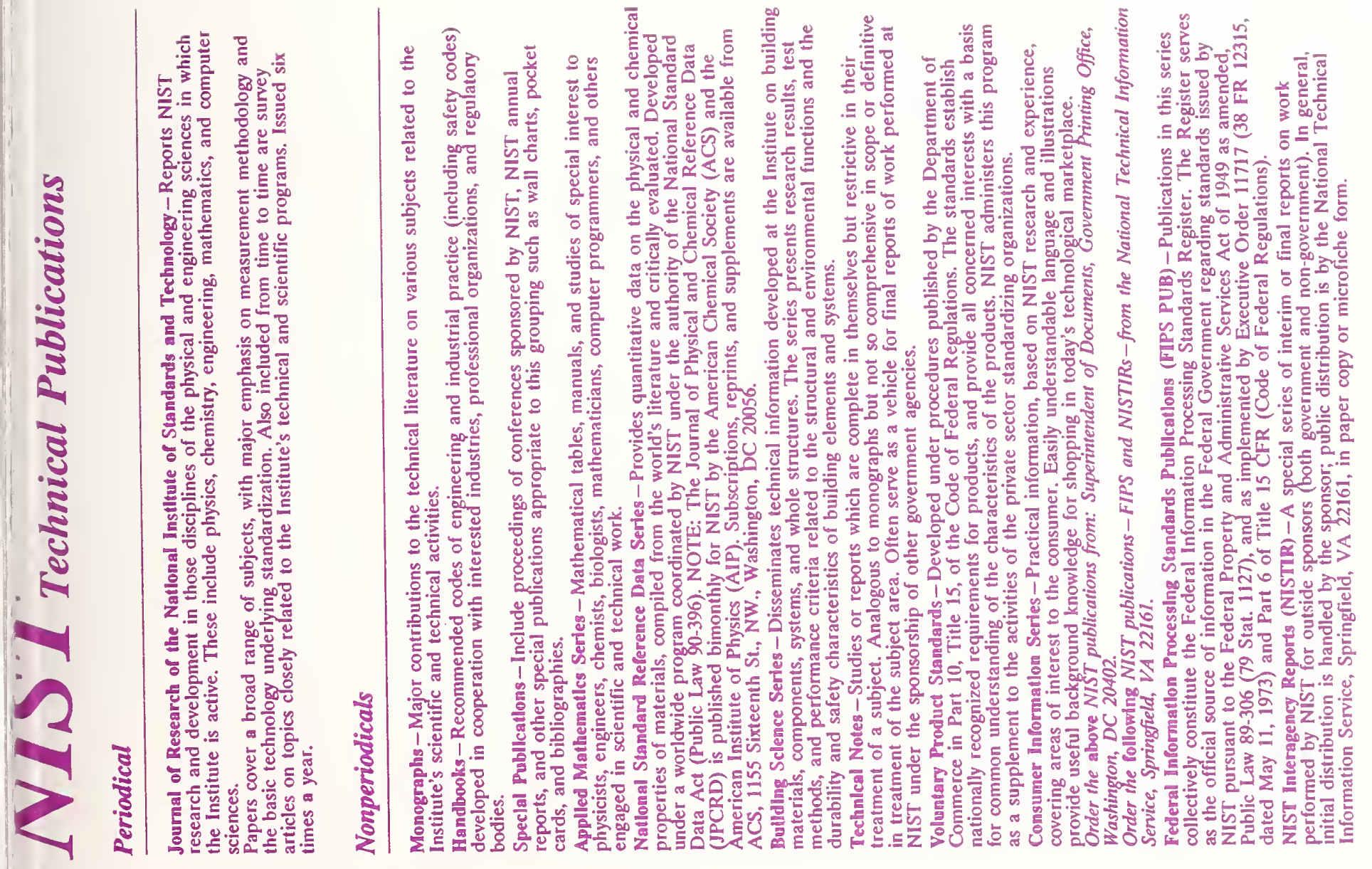


